\title{
Nouvelle-Calédonie
}

Archipel de corail

Claude E. Payri (dir.)

DOI : 10.4000/books.irdeditions.27797

Éditeur : IRD Éditions, Éditions Solaris

Année d'édition : 2018

Date de mise en ligne : 4 décembre 2019

Collection : Hors collection

ISBN électronique : 9782709926331

\section{Doneftition Qbooks}

http://books.openedition.org

\section{Édition imprimée}

ISBN : 9782709926324

Nombre de pages : 289

Ce document vous est offert par Institut Français de Recherche pour l'Exploitation de la Mer

\section{Bibliothèque
La Pérouse}

Référence électronique

PAYRI, Claude E. (dir.). Nouvelle-Calédonie : Archipel de corail. Nouvelle édition [en ligne]. Marseille : IRD Éditions, 2018 (généré le 06 janvier 2021). Disponible sur Internet : <http://books.openedition.org/ irdeditions/27797>. ISBN : 9782709926331 . DOI : https://doi.org/10.4000/books.irdeditions.27797.

(c) IRD Éditions, 2018

Conditions d'utilisation:

http://www.openedition.org/6540 
Nouvelle-Calédonie

Archipel de corail 



\section{Nouvelle-Calédonie Archipel de corail}

Sous la direction de Claude E. Payri

IRD Éditions

Institut de Recherche pour le développement, Marseille, 2018

Éditions Solaris 
Préparation éditoriale : Marie-Laure Portal

Conception maquette et mise en page : Pierre-Alain Pantz - Editions Solaris

Impression : Winson Press, Singapour

\section{Photos de couverture}

Page 1 de couverture (de haut en bas):

Baie d'Upi, lle des Pins. @ P.-A. Pantz

Biodiversité corallienne du récif Larégnère. @ IRD/S. Andréfouët

Page 4 de couverture (de gauche à droite) :

Chargement du filet à mikwaa sur une pirogue pontée, à Pwadèwia, baie de St-Joseph, île des Pins, 2017. @ M. Juncker

Fufs de poissons clown. ( $)$ G. Boussarie

Incubations de colonies coralliennes dans des enceintes. @ CNRS/E. Amice

Fou à pieds rouges (Sula sula) en vol. @ M. Juncker

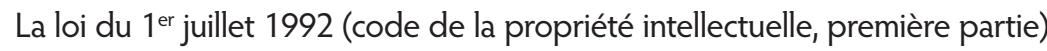
n'autorisant, aux termes des alinéas 2 et 3 de l'article L. 122-5, d'une part, que les « copies ou reproductions strictement réservées à l'usage du copiste et non destinées à une utilisation collective » et, d'autre part, que les analyses et les courtes citations dans le but d'exemple ou d'illustration, « toute représentation ou reproduction intégrale ou partielle faite sans le consentement de l'auteur ou de ses ayants droit ou ayants cause, est illicite » (alinéa $1^{\text {er }}$ de l'article L. 122-4).

Cette représentation ou reproduction, par quelque procédé que ce soit, constituerait donc une contrefaçon passible des peines prévues au titre Ill de la loi précitée.

\section{(c) IRD/SOLARIS 2018}

ISBN : 978-2-7099-2632-4

Cet ouvrage doit être référencé comme suit :

Payri, C.E. (dir.), 2018 - Nouvelle-Calédonie, archipel de corail.

IRD Editions/Solaris, Marseille/Nouméa, 288 p. 


\section{Remerciements}

Le comité de coordination scientifique, C.E. Payri, J. Aucan, B. Pelletier, C. Sabinot et E. Vidal, adresse ses plus vifs remerciements à tous les auteurs, qui se sont fortement mobilisés et qui ont contribué par leur enthousiasme à la réalisation de cet ouvrage. Nous tenons à remercier également Marie-Lise Sabrié, Thomas Mourier et Corinne Lavagne, de la Mission de la culture scientifique et technologique de l'IRD, ainsi que Frédéric Ménard, directeur du département Océan de l'IRD, pour leur soutien sans faille et leurs précieux conseils. Notre reconnaissance s'adresse également aux partenaires en charge de la gestion des récifs et des lagons de la Nouvelle-Calédonie pour leur contribution aux différents chapitres et leur investissement dans la gestion au quotidien de ce bien naturel et culturel. Enfin, pour leurs contributions bénévoles à cette aventure, notre reconnaissance va aux photographes et à l'artiste Noémie Sauve pour ses encres qui évoquent tout en finesse la vie sous-marine.

«Les extraits de dessins choisis pour illustrer les chapitres de cet ouvrage sont issus de ma résidence artistique à bord de Tara, expédition Tara Pacific (20162018) qui étudie les récifs coralliens et leur évolution face au changement climatique et aux pressions anthropiques.

Les dessins sont réalisés au crayon pour la partie 1 («Échanges et symbioses / photosynthèse et rayonnement nutritionnel des symbiodinium des coraux vers les autres animaux des récifs/ surproduction gélatineuse en partage »), partie 2 («Ce qui s'échange de l'air à l'eau de l'eau à l'air ») et partie 3 («Planche N et blanc, site Chesterfield»), au stylo bic pour la partie 5 (« Iconographies d'Échanges II Machines à Organismes »).

La partie 4 est quant à elle introduite par un extrait de lithographie en manière noire («Exosquelette de Tara dans les lueurs planctoniques sous la Voie Lactée »).

L'ensemble des travaux réalisés à l'issue de cette résidence sont visibles à I'adresse noemiesauve.blogspot.fr dans le chapitre TARA PACIFIC.»

Noémie Sauve 


\section{Sommaire}

Préface

Professeur Jean-Paul Moatti

Avant-propos

Édouard Hnawia

Introduction

La Nouvelle-Calédonie, terre de nickel, archipel de corail Claude E. Payri

\section{PARTIE 1}

Les récifs coralliens : une dynamique complexe dans un environnement changeant

Chapitre 1

Histoire contée par les récifs

Bernard Pelletier et Serge Andréfouët

\section{Chapitre 2 .}

Les habitats des récifs et lagons néo-calédoniens

Serge Andréfouët

Chapitre 3.

Les lagons vus par satellite

Cécile Dupouy, Jérôme Lefèvre, Guillaume Wattelez,

Chloé Martias, Rémi Andreoli et Didier Lille

\section{Chapitre 4.}

La valse des masses d'eau dans le lagon néo-calédonien Pascal Douillet, Jérôme Aucan, Jérôme Lefèvre, Romain Le Gendre, Térence Desclaux et Marion Drouzy
PARTIE 2 .

Les récifs coralliens, un réservoir de vie

Chapitre 5 ......

Les coraux de récifs de Nouvelle-Calédonie, un patrimoine diversifié et précieux

Francesca Benzoni

Chapitre 6.

Les récifs, fertilisés par les oiseaux marins?

Anne Lorrain, Fanny Houlbrèque, Francesca Benzoni,

Laura Tremblay-Boyer, Christophe Menkès, Claude E. Payri et Éric Vidal

Chapitre 7.

Les récifs en quête de diazotrophes

Valentine Meunier, Sophie Bonnet, Anne Lorrain, Mar Benavides, Mercedes Camps, Olivier Grosso et Fanny Houlbrèque

Chapitre 8.

Des eaux cristallines qui regorgent d'organismes microscopiques Sophie Bonnet, Renaud Fichez, Cécile Dupouy et Martine Rodier

Chapitre 9.

Histoire d'algues

Claude E. Payri, Laura Lagourgue, Lydiane Mattio, Julie Gaubert et Christophe Vieira

Chapitre 10

Les invertébrés marins de Nouvelle-Calédonie

Gustav Paulay

Chapitre 11

La biodiversité exceptionnelle des mollusques en Nouvelle-Calédonie Philippe Bouchet 
Chapitre 12

Les bénitiers, joyaux des récifs néo-calédoniens

Cécile Fauvelot, Philippe Borsa, Serge Andréfouët,

Josina Tiavouane, Simon van Wynsberge et Pascal Dumas

Chapitre 13

Les éponges, des microcosmes au cœur du récif

Sylvain Petek

\section{Chapitre 14}

Les poissons du Caillou se dévoilent

Michel Kulbicki, Laurent Vigliola, Laurent Wantiez et Gérard Mou-Tham

\section{Chapitre 15}

Larves et juvéniles de poissons : une survie précaire

Dominique Ponton, Laure Carassou et Philippe Borsa

\section{Chapitre 16}

La biodiversité fonctionnelle dans le lagon

Laurent Vigliola, Nicolas Guillemot, Laurent Wantiez et Michel Kulbicki

\section{Chapitre 17}

Les serpents marins des récifs coralliens de Nouvelle-Calédonie François Brischoux, Xavier Bonnet, Richard Shine et Claire Goiran

\section{Chapitre 18}

Les réseaux trophiques en milieux coralliens

Marine Julie Briand et Yves Letourneur

\section{Chapitre 19}

Le lagon, abri ou résidence des dauphins

Marc Oremus
Chapitre 20.. 135

Fragiles et menacés : les oiseaux marins de la mer de Corail Philippe Borsa et Éric Vidal

\section{Chapitre 21}

L'inventaire de la biodiversité récifale pour le partage des connaissances Éléonore Vandel, Sylvie Fiat, Jeanne de Mazières, Laurent Poncet et Pascale Joannot

\section{PARTIE 3}

Des récifs impactés mais résistants

\section{Chapitre 22.}

Les récifs et les pressions anthropiques, de la mine au lagon

Gilbert David

\section{Chapitre 23}

Les métaux et leurs impacts sur les coraux

Tom Biscéré, Anne Lorrain, Riccardo Rodolfo-Metalpa,

Richard Farman, Antoine Gilbert, Andy Wright et Fanny Houlbrèque

Chapitre 24... 155

Des super-coraux en Nouvelle-Calédonie résistent au changement climatique

Riccardo Rodolfo-Metalpa, Fanny Houlbrèque et Claude E. Payri

\section{Chapitre 25}

Le blanchissement corallien de 2016

Claude E. Payri, Francesca Benzoni, Laure. V. André et Fanny Houlbrèque

Chapitre 26. 167

La mobilité des îlots du lagon néo-calédonien : vulnérabilité ou résilience? Myriam Vendé-Leclerc et Manuel Garcin 
Chapitre 27

L'enjeu du « phénomène acanthaster » pour le Pacifique

Pascal Dumas et Mehdi Adjeroud

PARTIE 4 .

Paroles, pratiques et représentations autour des récifs

Chapitre 28

Trois millénaires au vent des récifs

Christophe Sand

\section{Chapitre 29}

Des récifs, une parole et des hommes

Emmanuel Tjibaou

\section{Chapitre 30}

Pêches identitaires, nourricières et commerciales dans les écosystèmes récifaux

Catherine Sabinot, Gilbert David, Matthieu Juncker, Séverine Bouard, Camille Fossier, Julie Mallet et Floriane Kombouare

\section{Chapitre 31}

Les récifs et leurs invertébrés, une manne durable pour les Calédoniens?

Pascal Dumas, Marc Léopold et Loïc Bourgine

\section{Chapitre 32}

Substances naturelles: des trésors cachés

Sylvain Petek

\section{Chapitre 33}

Le lagon, un patrimoine naturel et un espace de loisirs

Charles Gonson, Jocelyne Ferraris, Dominique Pelletier et Isabelle Jollit
PARTIE 5

.217

Des espèces sensibles dans un espace fragile

Gestion, protection et conservation

\section{Chapitre 34.}

Gérer des espèces emblématiques et des écosystèmes récifaux Catherine Sabinot et Éric Vidal

Chapitre 35 ..

Les bénitiers, une ressource à préserver

Cécile Fauvelot, Pascal Dumas et Josina Tiavouane

\section{Chapitre 36.}

Poissons rares ou endémiques,

des acteurs méconnus qu'il faut préserver

Michel Kulbicki, Philippe Borsa, Gérard Mou-Tham, Laurent Vigliola et Laurent Wantiez

\section{Chapitre 37}

Les requins aux abonnés absents

Laurent Vigliola,Jean-BaptisteJuhel, Laurent Wantiez et Michel Kulbicki

\section{Chapitre 38}

Les espèces emblématiques de poissons, porte-drapeaux de l'écologie participative?

Michel Kulbicki, Philippe Borsa, Gérard Mou-Tham, Laurent Vigliola et Laurent Wantiez

Chapitre 39.

Les tortues marines de Nouvelle-Calédonie

Tyffen Read et Richard Farman

\section{Chapitre 40}

Les oiseaux marins, sentinelles des eaux néo-calédoniennes Éric Vidal, Karen Bourgeois et Philippe Borsa 
Chapitre 41

Le dugong, sirène du lagon en danger

Christophe Cleguer et Claire Garrigue

\section{Chapitre 42}

Des savoirs locaux pour gérer et réglementer les récifs Catherine Sabinot, Estienne Rodary, Marlène Dégremont, Victor David et Gilbert David

\section{Chapitre 43}

Vers une gestion planifiée des réserves en Nouvelle-Calédonie Laurent Wantiez, Emmanuel Coutures, Maël Imirizaldu, Michel Kulbicki et Laurent Vigliola

\section{Chapitre 44} .259

Les défis d'une modélisation de l'écosystème corallien Morgan Mangeas, Antoine Wickel,Jean-Brice Herrenschmidt, Catherine Sabinot, Pierre-Yves Le Meur, Laurent Vigliola et Gilbert David
Chapitre 45 . .267

Droit applicable aux récifs coralliens de Nouvelle-Calédonie Victor David

\section{Chapitre 46}

Les récifs et lagons néo-calédoniens au patrimoine mondial de l'Unesco Myriam Marcon

Épilogue.

Didier Poidyaliwane

Glossaire

Sigles et acronymes

\section{Auteurs}





\section{Préface \\ Une impérieuse urgence}

Professeur Jean-Paul Moatti, président-directeur général de l'IRD

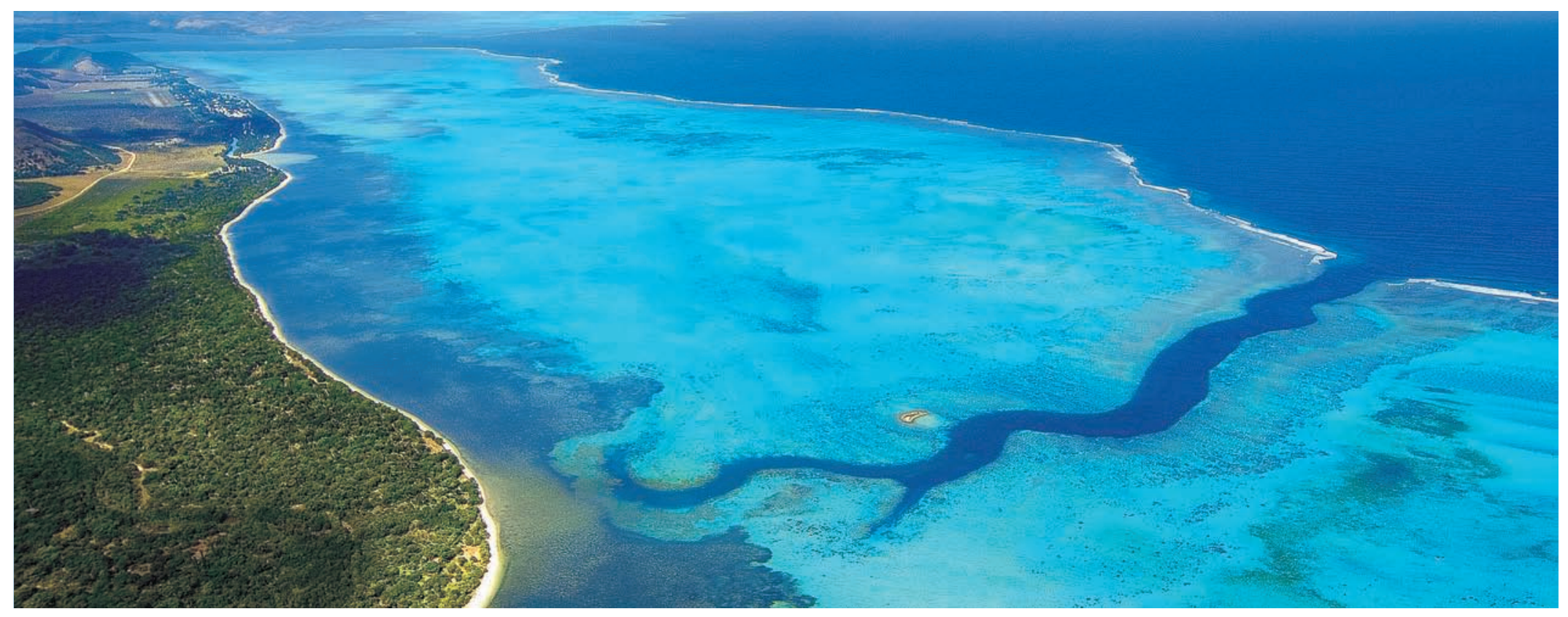

Vue du récif-barrière à Poé, sur la côte ouest de la Grande Terre. @ P.-A. Pantz

Exceptionnelle réserve de biodiversité marine, barrière protectrice du littoral face aux colères de l'océan, ressource économique clé et précieux patrimoine culturel pour de nombreuses populations insulaires et côtières, les récifs coralliens sont aujourd'hui l'un des écosystèmes les plus menacés de notre planète. Sous l'effet combiné du réchauffement climatique et de l'urbanisation accélérée des zones littorales, $20 \%$ des récifs coralliens dans le monde ont déjà été détruits sans espoir de retour, et $70 \%$ supplémentaires pourraient disparaître à court ou moyen terme. Préserver ces écosystèmes et mettre en place des modes de gestion durable de ces milieux vulnérables est bien une impérieuse urgence au cœur des Objectifs de développement durable (ODD) adoptés pour l'horizon 2030 par les Nations unies et la totalité de leurs Etats membres.

Abritant la deuxième plus grande barrière corallienne du monde après celle de l'Australie, la Nouvelle-Calédonie est en première ligne de ce défi international. Les recherches dédiées aux récifs et lagons de l'archipel néo-calédonien ont une longue tradition historique qui a commencé avec les expéditions du Capitaine Cook au XVIII ${ }^{\mathrm{e}}$ siècle. Elles se sont accélérées au cours du dernier demi-siècle en même temps que la communauté scientifique se mobilisait pour la préservation des récifs coralliens aux côtés de nombreux autres 
acteurs, ONG et institutions gestionnaires en charge de la protection et de la conservation de l'environnement et du patrimoine. Par sa présence de longue date dans la zone intertropicale et dans les territoires français d'outre-mer, plus particulièrement dans la zone Pacifique en Nouvelle-Calédonie et en Polynésie française, l'Institut de recherche pour le développement a vocation à s'engager résolument dans ce champ de recherches, qui appelle une approche interdisciplinaire combinant sciences biologiques, physiques, environnementales, humaines et sociales.

Associant une centaine d'experts issus d'organismes de recherche, d'universités et d'institutions en charge de la préservation de l'environnement et du patrimoine', tant néo-calédoniens que métropolitains, le présent ouvrage offre un état des connaissances les plus actuelles sur les récifs coralliens de Nouvelle-Calédonie. II permet d'appréhender l'extraordinaire diversité de ces récifs coralliens en lien avec l'histoire géologique et l'environnement marin, leur fonctionnement et les interactions entre la multitude d'organismes qui les composent ou qu'ils abritent. L'ouvrage met aussi en exergue comment, depuis 3000 ans, ces lagons et récifs offrent aux populations calédoniennes tout autant des ressources qu'un espace de vie et d'expression, occupant une place essentielle dans la culture Kanak. Enfin, les auteurs interrogent la capacité de résilience de cet écosystème face aux menaces induites par le réchauffement climatique et les autres changements environnementaux globaux et ils présentent différents dispositifs mis en place pour les préserver.

La publication de cet ouvrage tombe doublement à pic : 2018 a été déclarée « année internationale des récifs coralliens », en même temps qu'est célébré le dixième anniversaire de l'inscription par l'Unesco au patrimoine de l'humanité de $15000 \mathrm{~km}^{2}$ de récifs et lagons de Nouvelle-Calédonie. De surcroît, dans un contexte international où les mises en cause irrationnelles ou politiquement téléguidées de la science tendent à se multiplier, cet ouvrage illustre, de façon exemplaire, comment une recherche multidisciplinaire rigoureuse peut être mise au service d'une gestion durable d'un patrimoine naturel d'exception, non seulement pour les populations de NouvelleCalédonie et du Pacifique mais pour l'humanité toute entière.

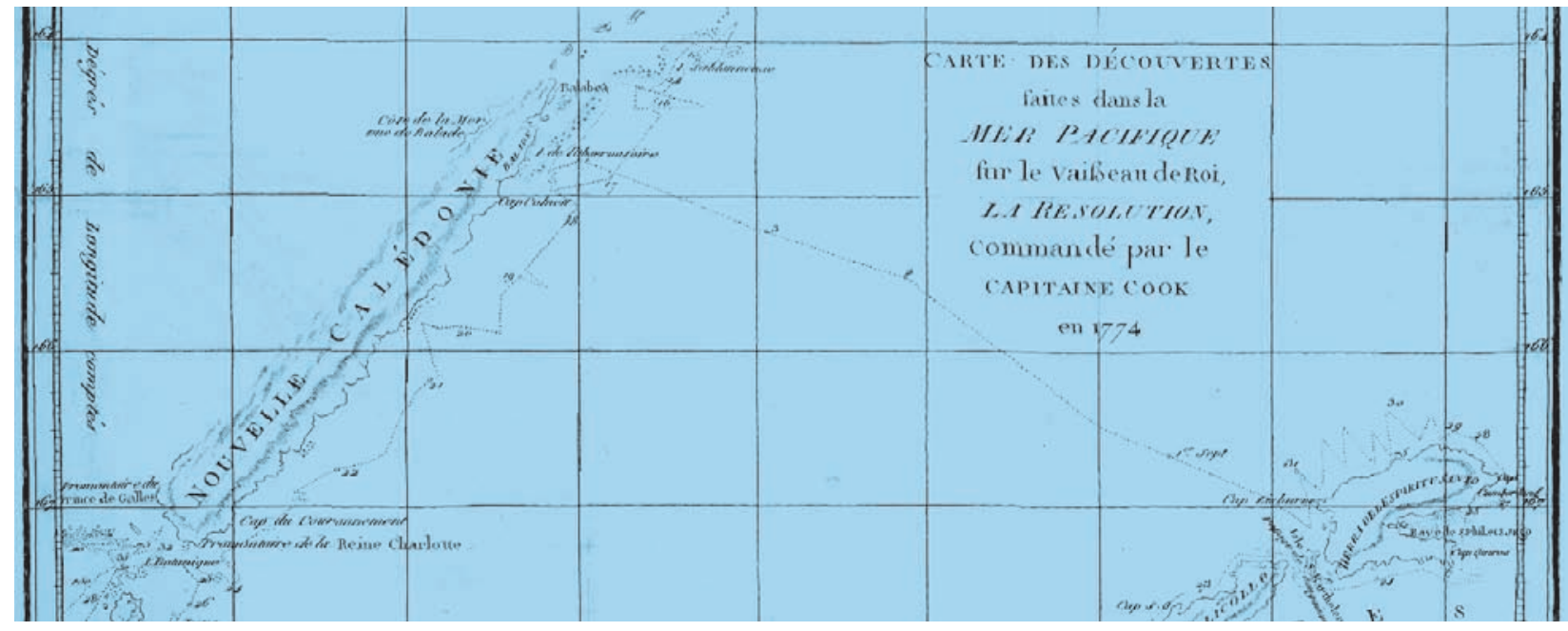

Carte de la Nouvelle-Calédonie, voyage du Capitaine Cook, 1774. @ Gallica/BNF

' L'Institut de recherche pour le développement (IRD), I'Université de la Nouvelle-Calédonie (UNC), l'Ifremer, Aquarium des lagons (ADL), le Service géologique de la Nouvelle-Calédonie (SGNC), l'Institut archéologique de Nouvelle-Calédonie et du Pacifique (IANCP), l'Agence de développement de la culture Kanak (ADCK), les services des 3 provinces en charge de la gestion des récifs et lagons, le Conservatoire d'Espaces Naturels de Nouvelle-Calédonie (CEN), la Direction des affaires maritimes de la Nouvelle-Calédonie en charge du Parc Naturel de la Mer de Corail (DAM). 


\section{Avant-propos \\ Lagons et récifs coralliens, socles d'une société et sources de bio-inspiration}

Edouard Hnawia, chimiste et ethnopharmacologue, représentant délégué de l'IRD en Nouvelle-Calédonie

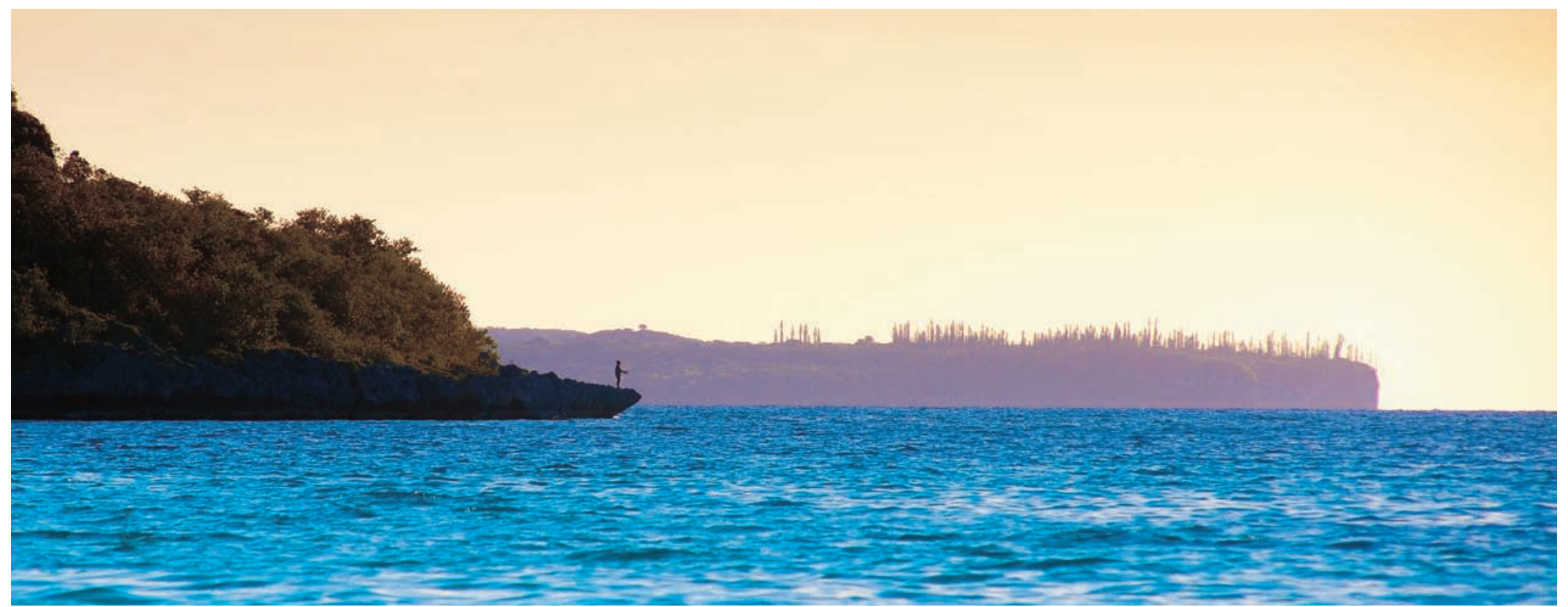

Baie du Sandal, Lifou. @ P.-A Pantz

Cet ouvrage sur les récifs et lagons calédoniens revêt une importance particulière pour moi à la fois en tant qu'enfant du pays et que chimiste et ethnopharmacologue. À la frontière de plusieurs champs disciplinaires, l'ethnopharmacologie étudie l'ensemble des matières d'origine végétale, animale ou minérale mobilisées par les sociétés traditionnelles pour vivre en harmonie avec leur environnement. Il est intéressant de remarquer qu'en Nouvelle-Calédonie, les recherches en pharmaco-chimie ont débuté sur les organismes des récifs et des lagons, et ce avant même les études de biodiversité. C'est la recherche de molécules d'intérêt pour de nouveaux médicaments qui a ensuite donné une impulsion particulière aux inventaires biologiques, grâce notamment à la curiosité, au dynamisme et à l'enthousiasme des plongeurs scientifiques de l'IRD (ex-Orstom).
Depuis plusieurs décennies désormais, la compréhension et la reconnaissance des liens que les sociétés humaines entretiennent avec le lagon, la description de la biodiversité marine et du fonctionnement des lagons occupent les chercheurs de l'Institut en partenariat avec des chercheurs des autres instituts de recherche et universités.

Bien avant eux, les habitants de Nouvelle-Calédonie, et plus particulièrement les Kanak, ont produit des savoirs liés aux récifs et lagons. Ces savoirs sont le socle de la vision d'une société qui met en liens la terre et la mer, les mondes visibles et invisibles, les Hommes et tout ce qui les entoure. Si le temps et les changements politiques, économiques et sociétaux plus ou moins brutaux ont conduit à gommer quelques pratiques anciennes, les récifs et lagons demeurent 


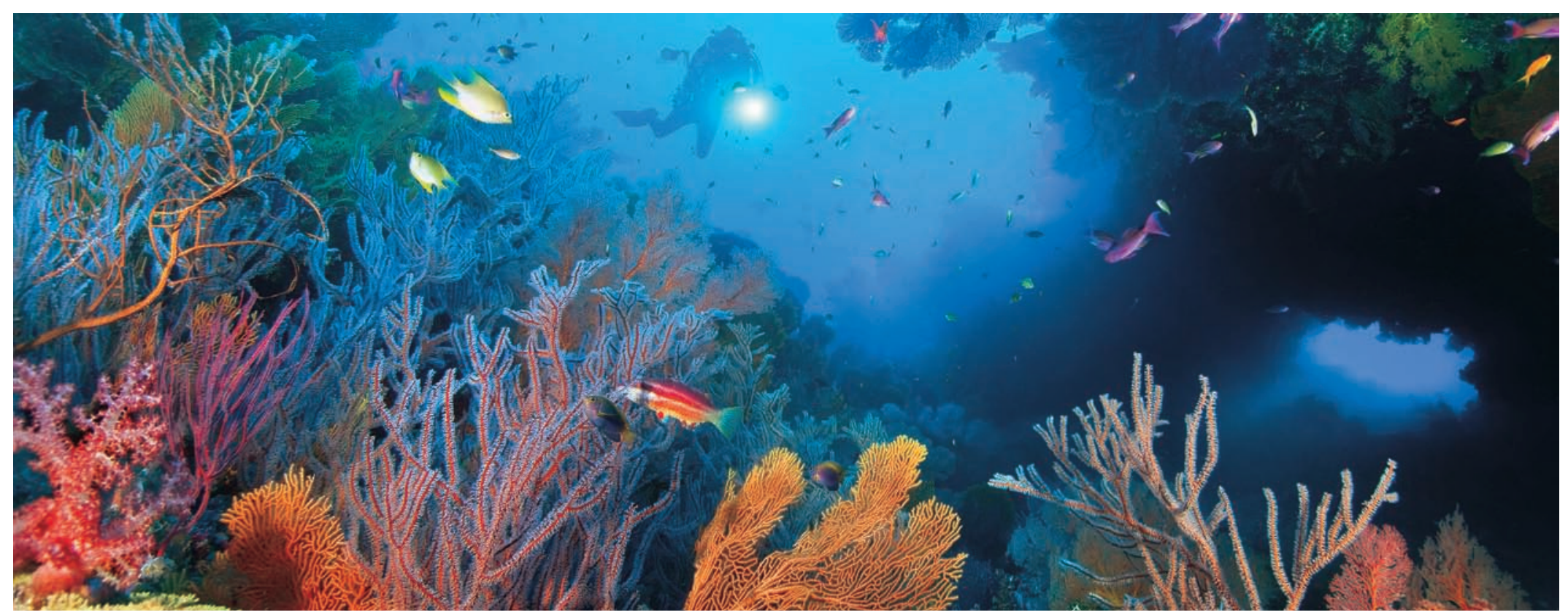

Communauté très diversifiée en gorgones, typique de la zone photique des récifs coralliens de Lifou. Profondeur : 20 m. Janvier 2008 ๑ Andromède Océanologie/ L. Ballesta

une source d'expression et de production de savoirs écologiques traditionnels. Des remèdes produits pour soigner les Hommes avec des plantes terrestres peuvent ainsi être informés par ce qui s'observe en mer. Un des récits m'ayant marqué à ce propos est celui d'un grand-père de mon clan. Il raconte comment il a été témoin d'un événement insolite au bord de la mer impliquant à la fois des espèces marines et terrestres, qui lui a permis de découvrir un remède contre les piqûres de rascasses et les brûlures de méduses.

La terre et la mer forment symboliquement comme physiquement un continuum. Et tout comme la terre, le lagon est avant tout dans l'esprit de beaucoup de Calédoniens un « garde-manger », un lieu où il est toujours possible de trouver de quoi alimenter sa famille. On compte aussi sur la faune associée aux récifs et aux lagons pour assurer le bon déroulement d'un événement coutumier, ou plus fréquemment pour bien recevoir ses hôtes. Une pollution du milieu peut en conséquence affecter l'organisation sociale. Nous l'avons vu cette année avec la pollution aux hydrocarbures provoquée par l'échouage du porte-conteneur le Kea Trader à Maré. Quelques semaines avant le déroulement de la fête de l'igname, moment essentiel qui rythme le cycle de la vie chez les Kanak, et qui doit être accompagné d'animaux marins de grande valeur, les pêcheurs ont craint de ne pouvoir accomplir leur devoir et de mettre alors en danger la tenue de la cérémonie. Quelques organismes sont également utilisés pour guider les hommes dans leurs travaux comme dans leurs décisions, pour « commander » la mer ou les poissons, ou encore pour les soigner. Prendre soin du lagon, c'est donc aussi prendre soin des Hommes.

Cet ouvrage, aux côté de la tradition orale qui véhicule nombre de récits et de légendes rappelant les liens du monde marin aux Hommes, se veut une pierre de plus pour perpétuer les savoirs et savoir-faire de tout un peuple qui s'appuie aujourd'hui sur l'oral comme sur l'écrit. Les chapitres qui suivent témoignent de l'intérêt que les scientifiques portent au lagon et aux Hommes qui en dépendent depuis près de 70 ans. Les résultats de leurs recherches contribuent à mieux connaitre pour mieux gérer ce patrimoine naturel et culturel hérité des Anciens et que nous souhaitons transmettre aux générations futures, avec l'espoir qu'ils y trouvent une source d'inspiration et qu'ils n'oublient pas de prendre le temps de l'observer. 


\section{Introduction \\ La Nouvelle-Calédonie, terre de nickel, archipel de corail}

Claude E. Payri

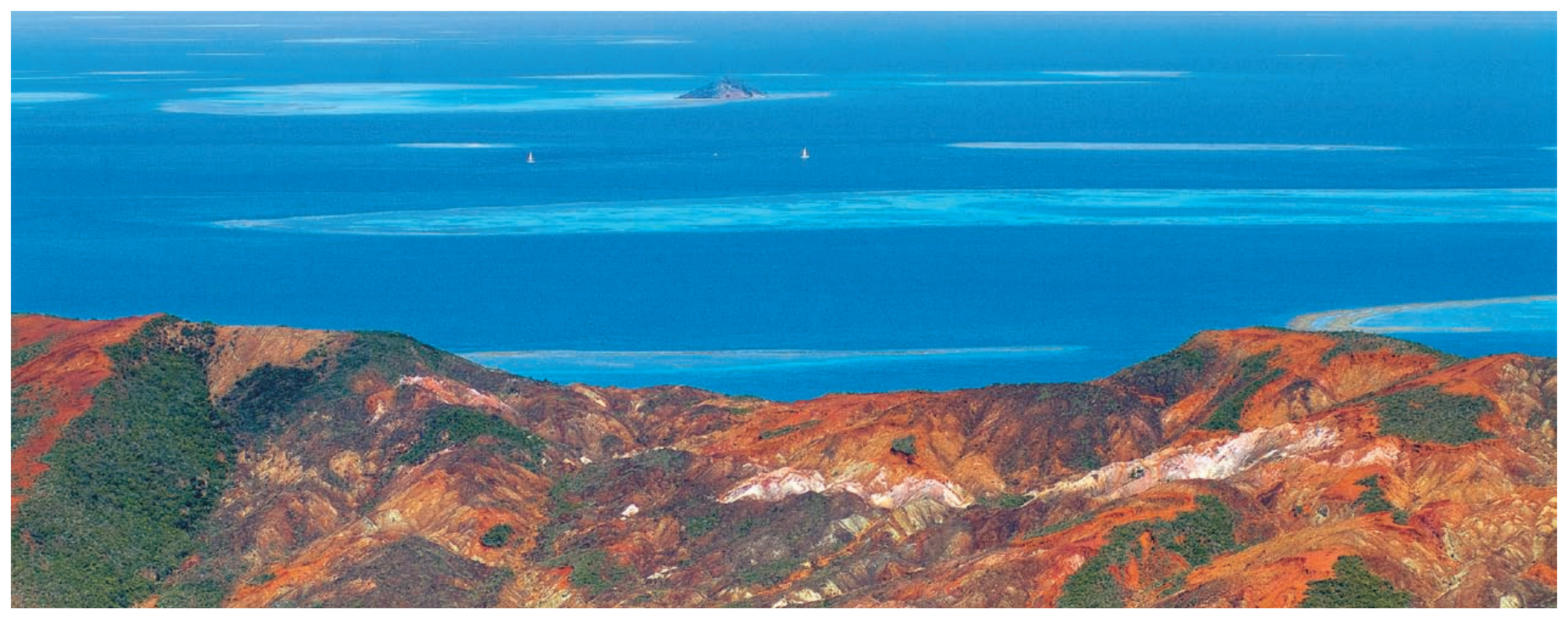

Ile Ouen. ๑ P.-A. Pantz

Les écosystèmes récifaux occupent une part importante du littoral de nombreux pays de la zone intertropicale. Certains de ces pays sont même exclusivement constitués d'îles coralliennes ou d'atolls, comme l'archipel des Maldives ou celui des Chagos dans l'océan Indien, et les îles Marshall, Kiribati, Tuvalu ou Tokelau dans l'océan Pacifique. Véritables remparts nourriciers, les récifs coralliens et les lagons qu'ils délimitent abritent un prodigieux concentré d'espèces. Hautement productifs, ils représentent la principale source de protéines pour des millions de personnes, tout en assurant la protection du littoral. Ils véhiculent dans l'imaginaire des Occidentaux la quiétude des eaux bleu turquoise des mers du Sud, la beauté des plages de sable blanc et la splendeur des poissons multicolores aux couleurs vives, attirant de très nombreux touristes.
Les récifs coralliens sont parmi les rares écosystèmes à croître et à se développer sur leur propre substrat. Ils sont bâtis par l'accumulation des squelettes calcaires des coraux qui sont ensuite consolidés par d'autres organismes comme les algues rouges calcaires. Ils abritent une multitude d'organismes qui expriment différentes formes de vie et constituent un réseau complexe de fonctions et d'interactions biologiques.

Leur maintien dans le temps et dans l'espace dépend alors étroitement de la capacité de ces organismes à vivre, à persister et à prospérer, permettant ainsi la croissance de l'édifice. Cette singularité leur confère une certaine fragilité, l'accroissement et l'extension des récifs étant en permanence contrebalancés par l'érosion physique et 
mécanique due aux tempêtes et aux cyclones, mais également par la bio-érosion due aux organismes qui perforent et érodent les squelettes calcaires, les réduisant à l'état de débris et de sable.

Les récifs sont vieux comme le monde. Mais par le passé ils étaient construits par d'autres organismes, qui se sont éteints, pour la plupart, au cours des grandes extinctions biologiques. Différents types de formations récifales se sont en quelque sorte enchaînés au fil des temps géologiques. Aux stromatolithes du Précambrien, constitués par des algues bleues ou cyanophycées, ont succédé durant près de 250 millions d'années des bryozoaires, des stromatopores, sorte d'éponges primitives, et des coraux primitifs disparus pour la plupart au cours de la grande extinction du Permien. Durant le Crétacé, les récifs étaient majoritairement construits par des rudistes, sorte de mollusques bivalves géants qui se sont éteints à leur tour, laissant la place aux coraux durs actuels. Après chacune de ces extinctions, il aura fallu des centaines de milliers, voire des millions d'années pour que de nouveaux récifs se reconstruisent. Ces récifs anciens, connus sur tous les continents, ont conservé visibles les traces d'une vie passée exubérante et d'une forte biodiversité.

Les récifs modernes tels qu'on les connaît aujourd'hui sont présents dans une centaine de pays. L'estimation de leur surface varie d'une étude à l'autre, en fonction des méthodes utilisées et des critères retenus pour en établir les limites. Ils occupent seulement $0,2 \%$ de la surface des océans mais concentrent la plus forte biodiversité marine. Nous connaissons 35000 à 60000 espèces associées aux récifs coralliens, mais leur nombre réel se situe probablement entre 1 et 9 millions. Cet écart s'explique par la méconnaissance de l'infiniment petit (bactéries, champignons, microalgues...) et des habitats peu accessibles (zones profondes, micro-habitats...). Cette biodiversité exceptionnelle n'est cependant pas répartie de manière homogène au sein des récifs de la planète. Ainsi, la zone Indo-Pacifique est dix fois plus riche que la zone de l'Atlantique Ouest, et on constate une décroissance progressive du nombre d'espèces lorsque l'on s'éloigne de la région du triangle de corail qui s'étend entre les Philippines, l'Indonésie et la Papouasie-NouvelleGuinée. À titre d'exemple, il existe environ 60 espèces de coraux dans les récifs de la zone de l'Atlantique Ouest, tandis que 500 à 600 espèces peuplent ceux de l'Indo-Pacifique. Le long des côtes ouest de l'Amérique du Sud et de l'Afrique, les récifs coralliens sont en revanche rares ou absents, en raison de l'apport important d'eaux douces déversées par les bassins de l'Amazone et du fleuve Congo.

Les plus grandes surfaces coralliennes se situent en Asie du SudEst et en Océanie. Les récifs et lagons de l'outre-mer français occupent $57557 \mathrm{~km}^{2}$ et arrivent en quatrième position après l'Indonésie, l'Australie et les Philippines. Les huit collectivités françaises d'outre-mer abritent ainsi près de $10 \%$ des récifs et $20 \%$ des atolls du monde.

Les lagons et récifs de la Nouvelle-Calédonie couvrent une superficie d'environ $40000 \mathrm{~km}^{2}$. La barrière récifale s'étire sur $1500 \mathrm{~km}$, ce qui en fait la première plus longue barrière continue et la seconde plus grande barrière au monde après la grande barrière de corail australienne.

Ces récifs ont été utilisés par l'homme dès son arrivée il y a 3000 ans, comme en témoignent les abondants restes d'os de poissons et de coquilles retrouvés dans les sites archéologiques de la NouvelleCalédonie. Les premières collections scientifiques datent de l'expédition du capitaine Cook en 1774 et l'installation des Européens en NouvelleCalédonie a ouvert la voie aux premières explorations naturalistes et aux premiers écrits sur le monde marin et les récifs coralliens de l'archipel. On doit d'ailleurs à Charles Darwin une des premières représentations cartographiques des récifs de la Nouvelle-Calédonie, réalisée avec une précision remarquable pour l'époque. Curieusement, la NouvelleCalédonie n'a pas été visitée par les grandes expéditions du XIX et du début du XXe siècle qui ont sillonné les océans à bord de L'Astrolabe, de L'Uranie ou de La Zélée.

Les missionnaires maristes et les naturalistes amateurs, comme Montrouzier, Balansa ou Vieillard, ont contribué entre 1850 et 1913 aux toutes premières collections naturalistes de la NouvelleCalédonie. Mais les études des lagons et des récifs ont débuté réellement après la Seconde Guerre mondiale, avec les premiers travaux en océanographie biologique auxquels sont désormais associés les noms de M. et Mme Catala, qui ont entrepris les premiers travaux en écologie marine avec l'étude exhaustive des communautés coralliennes des récifs de l'île aux Canards publiée en 1950. 
Depuis 70 ans, la recherche dédiée aux récifs et lagons de l'archipel néo-calédonien n'a cessé de se développer, mobilisant de nombreux acteurs - chercheurs de disciplines diverses (sciences de la nature, sciences humaines et sociales), mais aussi ONG et gestionnaires en charge de la protection et de la conservation de la nature et du patrimoine. Une abondante littérature, comprenant articles scientifiques, atlas, ouvrages collectifs, témoigne de l'attrait des chercheurs de tous horizons et de toutes disciplines pour les récifs et les lagons de la Nouvelle-Calédonie. Leur grande variété d'habitats et leur exceptionnelle biodiversité ont été reconnues par l'Unesco, qui a inscrit en 2008 une partie des récifs, lagons et écosystèmes associés sur la Liste du patrimoine mondial. Ce bien naturel à la valeur exceptionnelle fait partie depuis le 23 avril 2014 du Parc naturel de la mer de Corail, la plus grande aire marine protégée française.

Dans cet ouvrage, à travers le regard de plus de 100 chercheurs et acteurs en charge de la gestion de l'environnement ayant consacré une partie de leur temps à comprendre le rôle de ce fabuleux écosystème et de ses interactions avec les sociétés humaines, nous souhaitons partager notre étonnement devant une telle diversité de formes, de complexité d'interactions, mais aussi faire part de nos interrogations quant à la capacité de résistance de ces écosystèmes face aux changements globaux (activité humaine, élévation de la température, acidification des océans...). Nous souhaitons également montrer les liens que l'homme a développés avec cet écosystème, depuis son arrivée il y a 3000 ans jusqu'à aujourd'hui. Nous proposons de suivre divers chemins pour rendre compte des savoirs et pratiques d'hier et d'aujourd'hui et discuterons des normes actuelles choisies pour contribuer à la préservation de ce patrimoine naturel exceptionnel.

Au fil des pages, le lecteur fera d'abord plus ample connaissance avec la diversité des complexes récifo-lagonaires et de leurs habitats liée à l'histoire géologique et à l'environnement maritime de l'archipel (partie 1). Il découvrira ensuite que la biodiversité de cet écosystème rime paradoxalement avec richesse, rareté et singularité, que chaque espèce a sa place et que chaque fonction biologique compte (partie 2). L'ouvrage aborde ensuite les diverses menaces qui pèsent sur les récifs et les lagons, impactés par les changements globaux, et les différentes manières qu'ils ont d'y résister (partie 3). Les auteurs des sciences humaines et sociales nous amènent ensuite à porter un regard différent sur le lagon qui, dans la culture kanak, est aussi un monde invisible où la mémoire des ancêtres est omniprésente et qui, depuis 3000 ans, offre aux hommes et femmes néocalédoniens plus que des ressources, un espace de vie et d'expression (partie 4). Enfin, dans la dernière partie, nous présentons quelques enjeux de conservation autour d'espèces charismatiques et un aperçu des modes de gestion, de protection et de conservation mis en place par les services provinciaux et gouvernementaux de la NouvelleCalédonie en charge de la protection de l'environnement et de la gestion du milieu maritime (partie 5).

Nous espérons que le lecteur fera sienne la conviction des auteurs que gérer les récifs et les lagons ne peut se faire sans prise en compte des espèces et des espaces, mais également des différentes formes de savoirs, de pratiques et d'usages, et que seul le croisement entre recherche et enjeux de conservation permettra de maintenir en bon état, longtemps encore, ce bien patrimonial universel que sont les récifs et lagons de la Nouvelle-Calédonie.

\section{Références bibliographiques}

ANDRÉFOUËT S. et al., 2008 Atlas des récifs coralliens de France OutreMer, Centre IRD de Nouméa, $153 \mathrm{p}$.

CATALA R. 1950 Contribution à l'étude écologique des îlots coralliens du Pacifique Sud. Bulletin Biologique, 3 : 234-310.

KNOWLTON N., 2001 The futur of coral reefs. Proceedings of the National Academy of Sciences (USA), $98: 5419-5425$.

REAKA-KUDLA M. 1996 « The global biodiversity of coral reefs: a comparison with rain forests ». In Reaka-Kudla M. L., Wilson D. E. et Wilson E. O., éds, Biodiversity II: Understanding and Protecting our Biological Resources. Washington D.C., Joseph Henry Press, p. 83-108. 



\title{
Partie 1
}

\section{Les récifs coralliens : une dynamique complexe dans un environnement changeant}

\author{
Coordination : Bernard Pelletier
}

Les processus géologiques et les conditions environnementales contrôlent le développement des récifs coralliens. Marqueurs de l'interface terre-mer en domaine inter-tropical, et donc enregistreurs privilégiés du niveau relatif de la mer, les récifs nous renseignent à la fois sur la variation du niveau marin et sur les mouvements verticaux des terres. Ce sont aussi de merveilleuses archives du climat (température et salinité des eaux). Leur construction est aussi dépendante de leur exposition aux éléments (vent, houle, courant...), ainsi que de la qualité des eaux (rejets d'eaux douces, turdidité...). Un aperçu de la diversité des complexes récifo-lagonaires de la Nouvelle-Calédonie est proposé à travers plusieurs regards de géologues, d'océanographes physiciens et de biologistes. 



\section{Chapitre 1 \\ Histoire contée par les récifs}

Bernard Pelletier et Serge Andréfouët

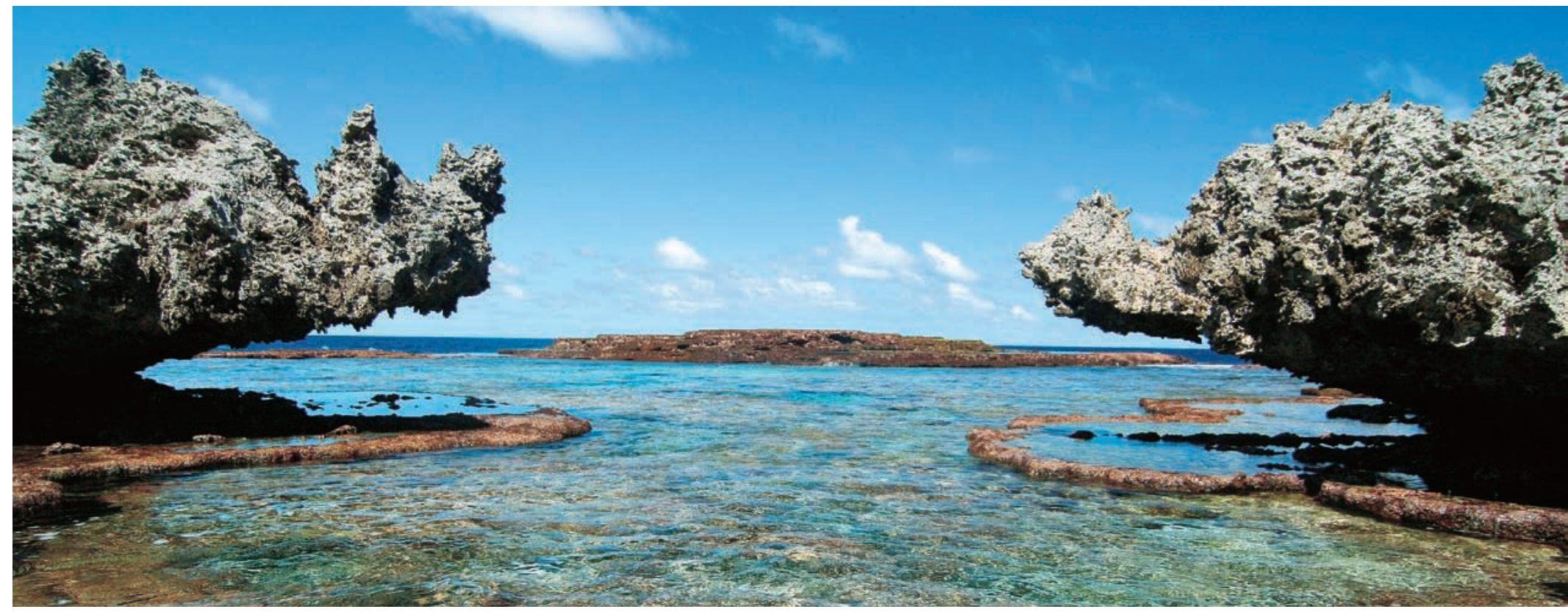

Platier récifal actuel surmonté d'un récif ancien, érodé à sa base (encoche) par le niveau marin actuel, Maré. @ IRD/S. Andréfouët

\section{Un large domaine océanique avec de nombreux bancs, atolls, îles et récifs associés}

La Nouvelle-Calédonie, nichée entre l'Australie et l'archipel du Vanuatu, juste au nord du tropique du Capricorne, est connue et fait rêver pour ses récifs vierges et ses magnifiques lagons. Avec 1,4 million de kilomètres carrés, la zone économique exclusive de la NouvelleCalédonie s'étend sur $1200 \mathrm{~km}$ du nord au sud $\left(15^{\circ} \mathrm{S}\right.$ à $\left.26^{\circ} \mathrm{S}\right)$ et sur $1800 \mathrm{~km}$ d'ouest en est $\left(157^{\circ} \mathrm{E}\right.$ à $\left.174^{\circ} \mathrm{E}\right)$. Elle héberge une multitude de récifs actuels associés à de nombreux bancs, atolls et îles, qui se répartissent sur cinq rides, principalement orientées nord-sud à nord- ouest sud-est, plus ou moins parallèles, en grande partie submergées et séparées par des bassins et fosses profondes (fig. 1).

Se succèdent d'ouest en est le grand complexe d'atolls de BellonaChesterfield-Bampton, qui termine au nord un alignement de guyots sur le bord nord-ouest de la ride de Lord Howe ; les bancs et récif Fairway et le banc de Lansdowne avec son récif Néréus, qui culmine à l'extrémité nord de la ride de Fairway ; la ride de NouvelleCalédonie, prolongement nord de la ride de Norfolk, le long de laquelle se succèdent du sud au nord, les bancs Antigonia et de la Torche, l'île des Pins, la Grande Terre (île principale, $400 \times 50$ km), l'archipel des Belep et les récifs d'Entrecasteaux et ses atolls au-delà 


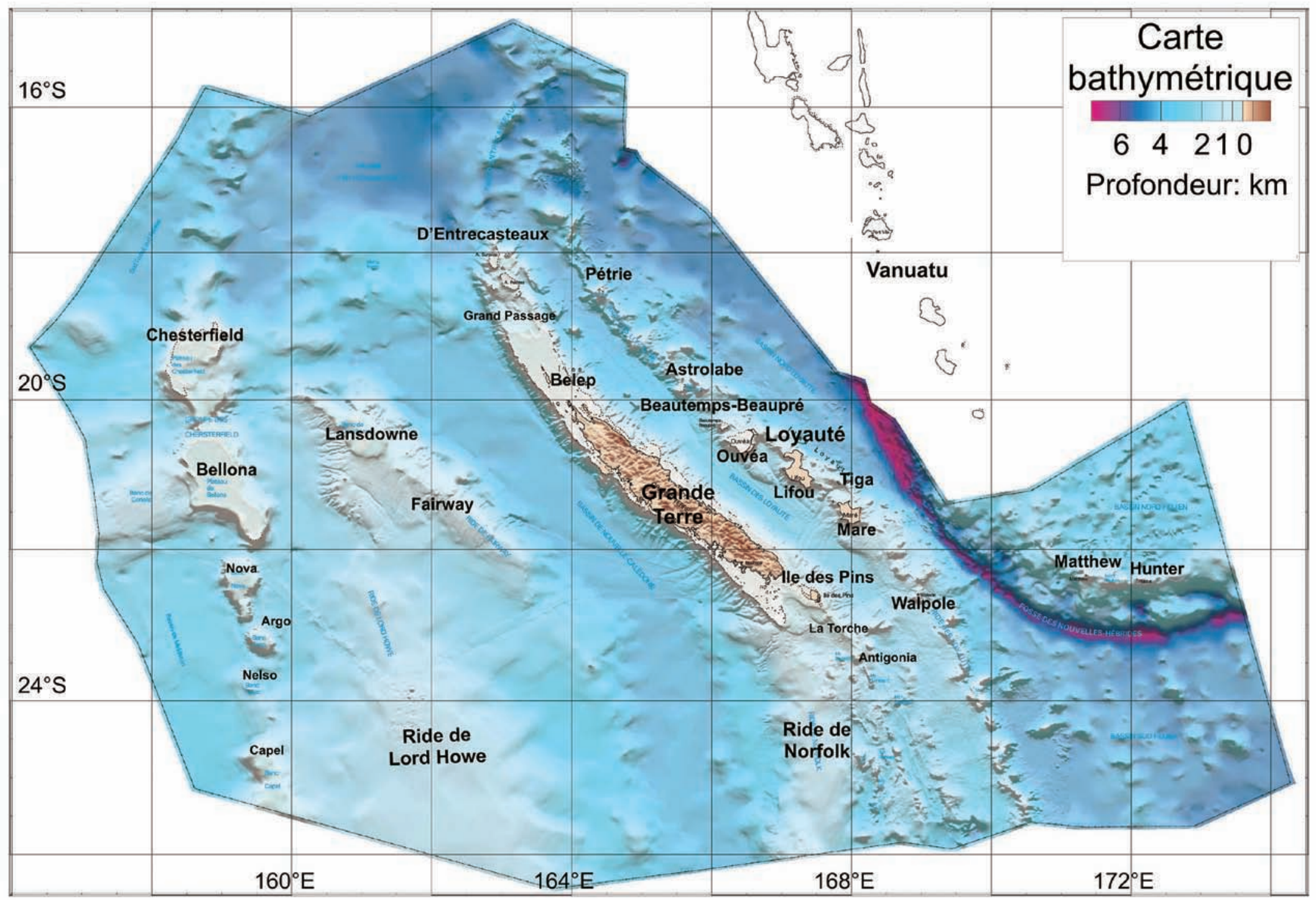

Figure 1 : La zone économique exclusive de la Nouvelle-Calédonie. Source : programme ZoNéCo, 1998 
du Grand Lagon Nord ; la ride des Loyauté le long de laquelle s'échelonnent du sud au nord l'île Walpole, le banc de l'Orne, le récif Durand, l'archipel des Loyauté avec ses îles principales Mare, Tiga, Lifou et Ouvéa, l'atoll de Beautemps-Beaupré et les récifs de l'Astrolabe et, plus au nord, celui de Pétrie ; enfin les îles de Matthew et Hunter qui pointent à l'extrême sud de l'arc du Vanuatu, au-delà de la profonde fosse du même nom.

\section{Le fruit d'une évolution géologique mouvementée}

L'évolution géologique ayant façonné le domaine océanique néocalédonien en une succession de rides (avec bancs et îles) et de bassins peut être divisée en quatre périodes (PELLETIER, 2007). Du Crétacé supérieur $(100 \mathrm{Ma})$ à l'Éocène inférieur $(50 \mathrm{Ma})$, la marge orientale du Gondwana (marge est australienne) est étirée, puis des bassins océaniques se sont ouverts, larguant vers l'est des lanières continentales dont celles des rides de Lord Howe et de NorfolkNouvelle-Calédonie. La période de l'Éocène moyen et supérieur (50-34 Ma) est marquée par un raccourcissement, de la convergence au sein de cette marge antérieurement dilacérée ; elle se termine par la mise en place, sur la ride de Norfolk-Nouvelle-Calédonie d'un des plus grands panneaux de lithosphère océanique affleurant au monde, la nappe des péridotites connue sur la Grande Terre (grand massif du sud et klippes le long de la côte nord-ouest), l'île des Pins et les îles Belep, qui, par altération météoritique ultérieure, donnera naissance à une des plus grandes réserves mondiales de nickel. D'importants mouvements verticaux de réajustement, une forte érosion et du volcanisme caractérisent la période Oligocène (34 Ma) à Miocène supérieur (12 Ma). Le début du Miocène supérieur est marqué par la naissance de la zone de subduction du Vanuatu, le long de laquelle la partie orientale du domaine, le bassin Est Loyauté, a largement disparu.

Actuellement, les rides et bassins entourant la Nouvelle-Calédonie sont portés par la plaque australienne qui plonge en subduction sous l'arc insulaire actif du Vanuatu. Le mouvement relatif de convergence, orienté est nord-est ouest sud-ouest, est particulièrement rapide, de $12 \mathrm{~cm} / \mathrm{an}$ au niveau des îles Loyauté (DUBOIS et al., 1977 ; PELLETIER et LOUAT, 1989). En s'approchant de la zone de subduction, la plaque plongeante se déforme ; elle se soulève puis s'effondre pour passer

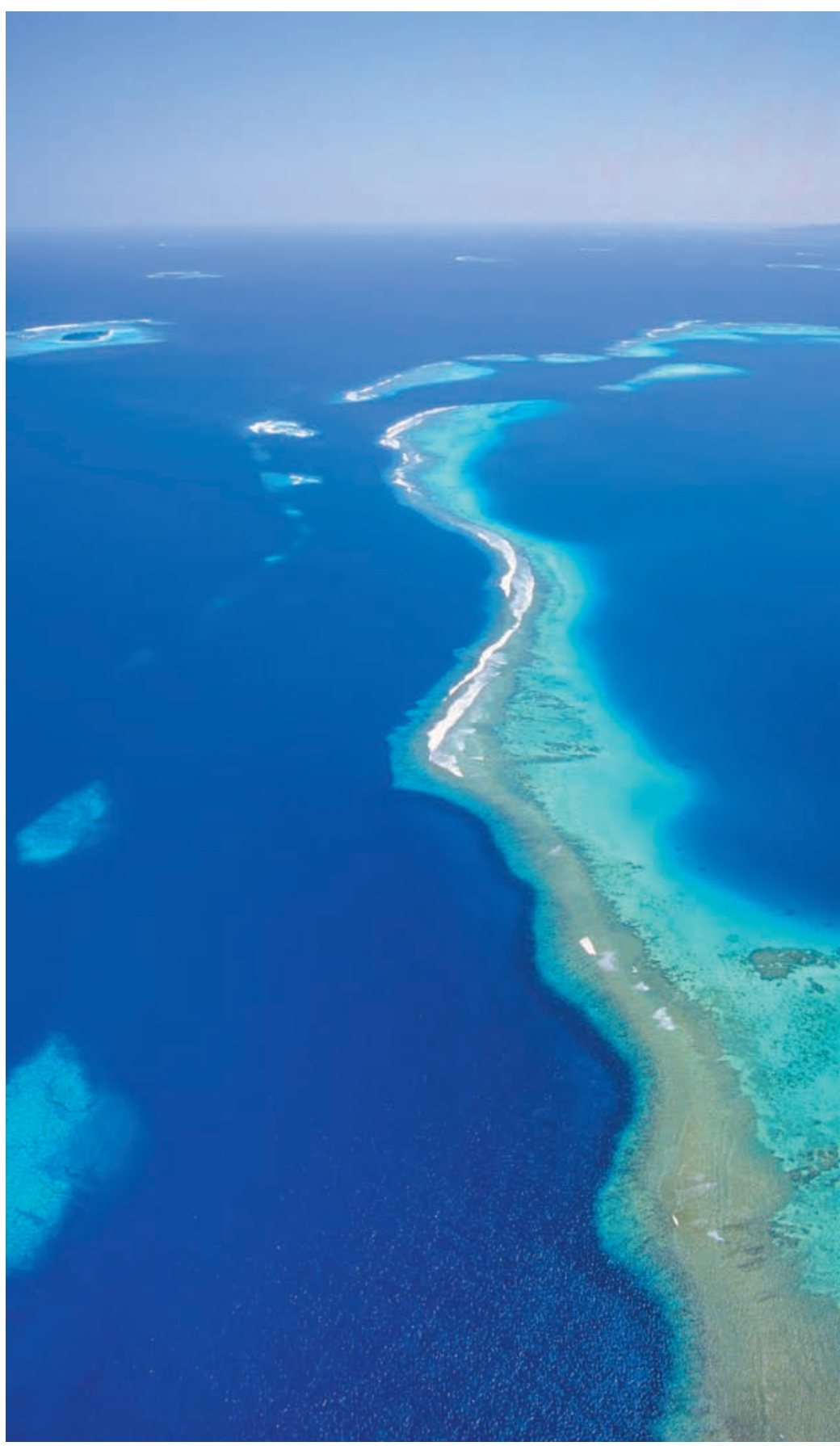

Récif-barrière complexe, grand Lagon Sud. ๑ P.-A. Pantz 


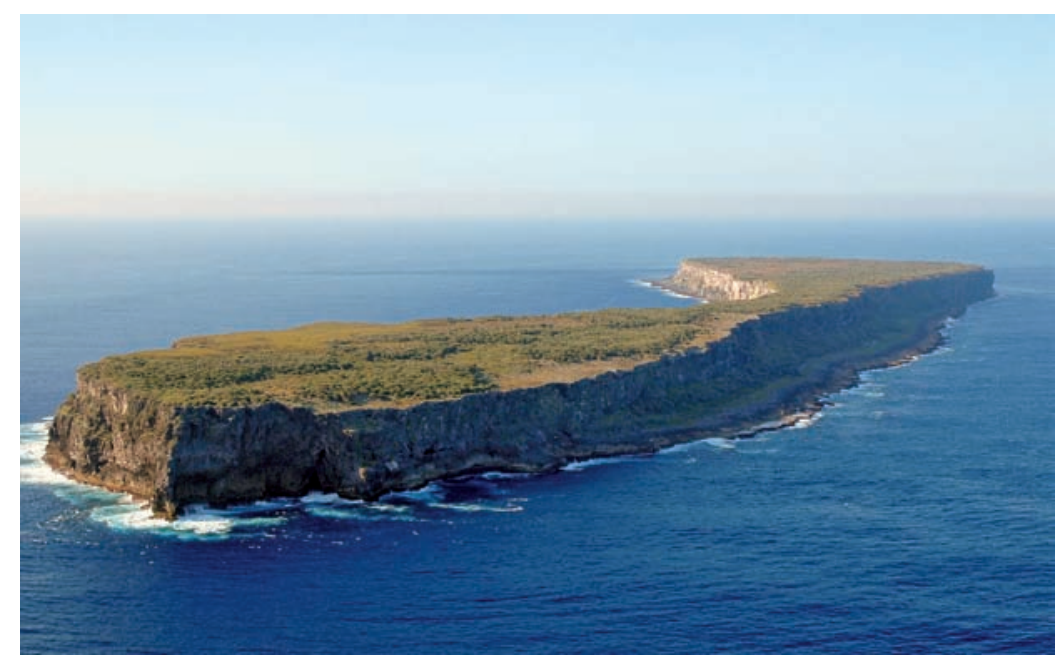

Récif soulevé, llot Walpole. @ IRD/P. Tirard

en subduction. Ce bombement lithosphérique avant subduction est notamment illustré par les formes et les différentes altitudes des îles Loyauté, constituées d'atolls soulevés et situés à différentes distances de la fosse (DUBOIS et al., 1974). L'atoll de Beautemps-Beaupré et celui d'Ouvéa, en partie exondé avec son grand lagon ouvert et basculé vers l'ouest et ses falaises atteignant une altitude $41 \mathrm{~m}$ sur la côte est, se soulèvent et émergent. Les anciens atolls de Lifou et de Maré, culminant respectivement à $104 \mathrm{~m}$ et $138 \mathrm{~m}$, se situent de part et d'autre du sommet du bombement. L'île de Walpole $(70 \mathrm{~m})$ a passé le sommet du bombement et entame sa subsidence. Vers $22^{\circ} \mathrm{S}$, la ride des Loyauté entre en subduction et vient percuter la terminaison sud de l'arc du Vanuatu, entraînant un découpage de la plaque supérieure le long d'une zone de fracture senestre et une diminution de la vitesse de convergence au sud du point d'impact (PELLETIER et LOUAT, 1989). La plaque ou plutôt microplaque portant les îles volcaniques actives de Matthew et Hunter est ainsi différente de celle qui porte les autres îles formant l'archipel néo-calédonien.

\section{Des récifs très variés}

Derrière Fidji et la Papouasie Nouvelle-Guinée, la NouvelleCalédonie monte sur le podium des pays de la planète ayant la plus grande diversité de type de récifs (fig. 2).
Des récifs d'Entrecasteaux à ceux de l'île des Pins, des récifs de Chesterfield-Bellona à ceux des îles Matthew et Hunter, les récifs néocalédoniens actuels couvrent environ $4500 \mathrm{~km}^{2}$ et constituent une mosaïque diversifiée de formes et structures résultant de l'histoire géologique de la région et des processus tectoniques qui continuent de nos jours à modeler le relief terrestre et sous-marin (ANDRÉFOUËT et al., 2009). Les conditions environnementales récentes, telles que la variation du niveau marin lors des dernières centaines de milliers d'années, et actuelles, plus locales et sur le court terme, comme l'exposition au vent, à la houle, aux rejets terrigènes et d'eaux douces ainsi qu'à la température, contrôlent aussi le développement géomorphologique des récifs. Outre ces processus physiques à l'échelle régionale et locale, les récifs néo-calédoniens sont aussi le fruit de nombreux processus biologiques à des échelles de temps plus courtes, comme la croissance corallienne.

\section{Des récifs-barrières, lagonaires et frangeants}

Les récifs autour de la Grande Terre sont les plus étudiés et aussi les plus diversifiés, avec notamment le complexe de récif-barrière continu le plus long de la planète. Ce dernier s'étire sur $1500 \mathrm{~km}$ (dont $1300 \mathrm{~km}$ de récif intertidal) et couvre environ $1750 \mathrm{~km}^{2}$. Entrecoupé de nombreuses passes relativement étroites et distantes de 1 à 70 km de la côte, il ceinture la Grande Terre (îles Belep et Balabio comprises) et son immense lagon, en offrant diverses configurations structurelles. Ainsi la partie sud de la côte orientale présente de larges portions de récifs ennoyés et parfois un double récif-barrière, alors que le nord de la côte orientale et la côte occidentale présentent des récifs-barrières de forme plus classique. La zone de Bourail se caractérise par un récif-barrière très proche de la terre et un lagon peu profond. Outre ces grands ensembles, il existe également des portions de barrière plus originales, comme au nord, où le récif s'incurve vers le lagon autour de l'île de Balabio, ou encore à l'extrême sud, dans la Corne Sud.

Le lagon autour de la Grande Terre couvre $16800 \mathrm{~km}^{2}$ et comprend de nombreux récifs peu profonds $\left(380 \mathrm{~km}^{2}\right)$, certains 
caractérisés par la présence d'îlots dont la création s'explique par la conjonction de relief récifal ancien et d'accumulation de débris carbonatés. Pouvant paraître superficiellement similaires au premier abord, les récifs de ces îlots présentent, du fait de ces différents processus de genèse, une grande diversité de formes et structures.

Les récifs frangeants, c'est-à-dire les récifs accolés à la masse terrestre principale, couvrent près de $400 \mathrm{~km}^{2}$ autour de la Grande Terre et se situent dans des endroits d'exposition très diversifiée : baies protégées et soumises à des apports terrigènes, côtes soumises aux alizés mais protégées de la houle du large et, enfin, côtes directement exposées à l'océan, comme au sud de la Grande Terre. Les différentes expositions se traduisent par des formations récifales très contrastées, plus ou moins développées.

\section{Des atolls}

La Nouvelle-Calédonie comprend plusieurs atolls. D'origine différente, les atolls des Chesterfield et Bellona, ceux des récifs d'Entrecasteaux et ceux des Loyauté offrent de vastes surfaces récifales et lagonaires (respectivement 2000 et $14000 \mathrm{~km}^{2}$ ), quasi équivalentes à celles qui entourent la Grande Terre.

L'énorme complexe formé par les deux atolls de Bellona et de Chesterfield-Bampton représente un tiers des surfaces récifales et lagonaires de l'ensemble de la zone économique de la NouvelleCalédonie. De forme dissymétrique avec un récif ennoyé à l'est et un profond lagon (40-60 m) parsemé de pinacles, ces atolls s'appuient sur cinq guyots qui sont les plus anciens volcans, d'âge possiblement Oligocène supérieur, issus du point chaud de Lord Howe.

À l'extrémité septentrionale de la ride de Nouvelle-Calédonie, les récifs d'Entrecasteaux, situés au-delà du Grand Passage, au nord du Grand Lagon Nord, se répartissent sur trois rides parallèles qui prolongent les structures de la Grande Terre et du Grand Lagon Nord. Ils comprennent les grands atolls et profonds lagons $(60 \mathrm{~m}) \mathrm{de}$ Huon et de la Surprise et l'atoll plus petit de Pelotas le long d'une ride centrale, l'atoll du Portail à l'ouest et ceux du récif Gilbert à l'est.
L'atoll d'Ouvéa $\left(850 \mathrm{~km}^{2}\right)$ et celui de Beautemps-Beaupré $\left(120 \mathrm{~km}^{2}\right)$, portés par la ride volcanique des Loyauté, présentent des lagons peu
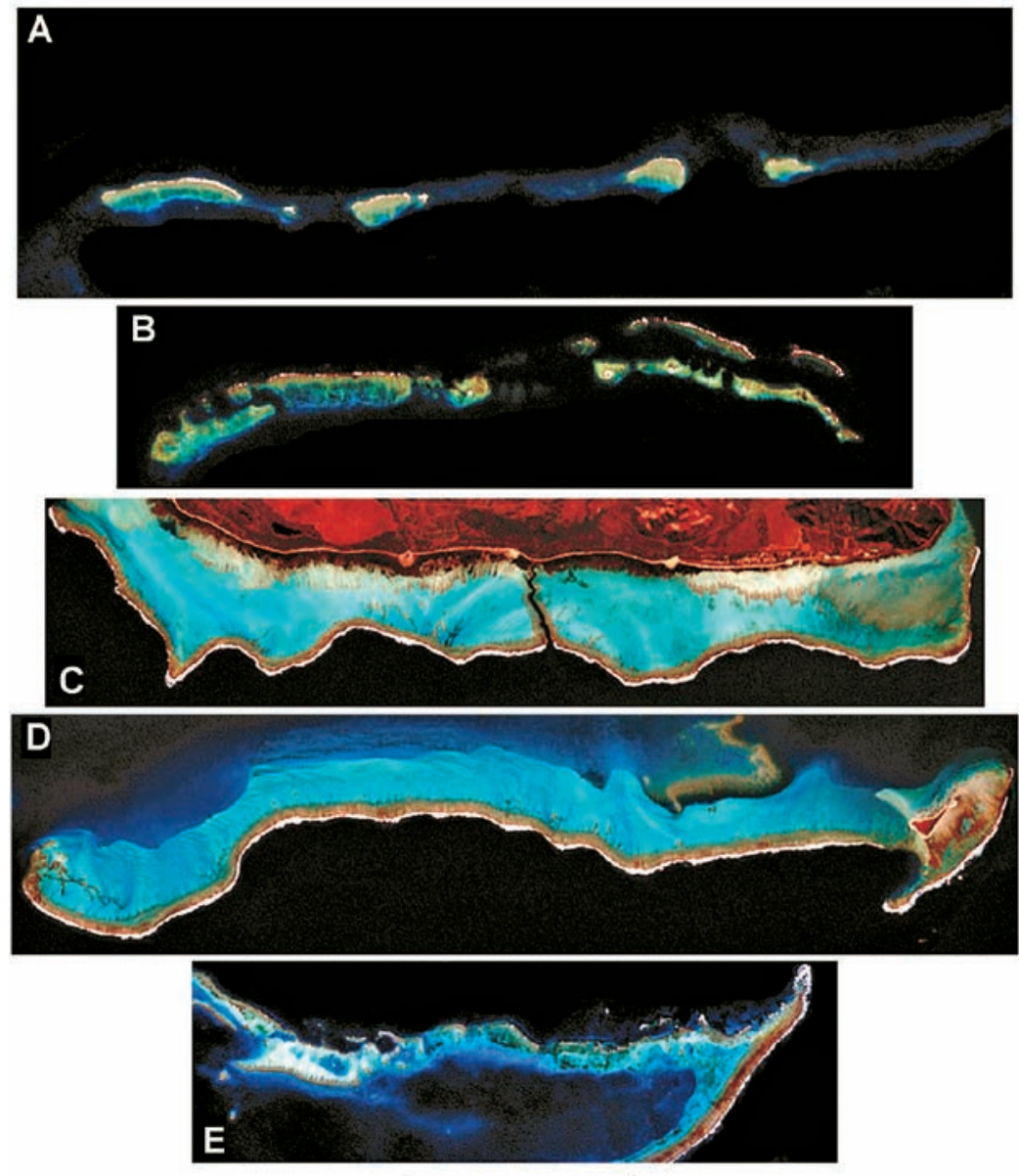

$5 \mathrm{~km}$

Figure 2 : Diversité des récifs-barrières de Nouvelle-Calédonie. Les images landsat (1999 2003) sont à la même échelle mais ont subi des rotations pour faciliter les comparaisons. Côte Est.

A : Récif-barrière extérieur, Canala, de larges portions de récif sont ennoyées ; $\mathrm{B}$ : Double récif-barrière extérieur, Poindimié, llot Bayes. Côte Ouest.

$C$ : Récif-barrière côtier, Poé;

$D$ : Récif-barrière extérieur, Grand Récif Extérieur - ilot Tenia, Boulouparis ;

$E$ : Récif-barrière imbriqué, Corne Sud.

Source : ANDRÉFOUËT et al., 2009 
profonds, ouverts vers l'ouest. Celui d'Ouvéa, bordé par les îles et récifs des Pléiades du nord et du sud, est caractérisé par un fond de lagon incliné en pente douce vers l'ouest et par l'île d'Ouvéa et ses hautes falaises à l'est. Contrairement aux autres atolls, ceux-ci sont en émergence.

\section{Quand les récifs nous renseignent sur les mouvements verticaux et les climats}

Le niveau marin est assez bien connu depuis les deux derniers millions d'années, avec une alternance de périodes chaudes de haut niveau marin (périodes interglaciaires, comme actuellement), favorables aux constructions coralliennes, et de périodes froides de bas niveau marin (période glaciaire). Depuis le dernier interglaciaire daté de 125000 ans, lors duquel le niveau marin était à $+6 \mathrm{~m}$ par rapport au niveau actuel, le niveau marin a descendu à $-120 \mathrm{~m}$ lors du dernier maximum glaciaire daté de $20-23000$ ans, puis a rapidement remonté pour être plus ou moins stable depuis 6000 ans. Le niveau de la mer étant connu et les récifs coralliens étant d'excellents marqueurs de celui-ci, l'analyse sédimentologique, la position et la datation des récifs anciens, construits lors des périodes interglaciaires et maintenant enfouis ou à l'affleurement, permettent donc de déduire les mouvements verticaux des îles.

Les mouvements verticaux récents (depuis le Pléistocène supérieur, il y a 125000 ans) et les zones en surrection ou en subsidence ont pu être ainsi décryptés et cartographiés à partir d'un échantillonnage systématique des formations récifales d'âge Pléistocène et Holocène, affleurant sur les bords des côtes ou atteints par très nombreux forages sur les récifs frangeants et barrières, notamment autour de la Grande Terre (CABIOCH et al., 1996) (fig.3).

L'analyse sédimentologique et stratigraphique des carottes forées apporte aussi de précieuses informations sur le processus de réinstallation des récifs coralliens lors de la dernière remontée postglaciaire du niveau marin. Les âges des plus vieux récifs holocènes autour de la Grande Terre ne dépassent pas 8200 ans, la température des eaux de surface était certainement trop froide (température inférieure d'au moins $4{ }^{\circ} \mathrm{C}$ à aujourd'hui) avant cette date pour permettre un développement significatif des récifs coralliens.

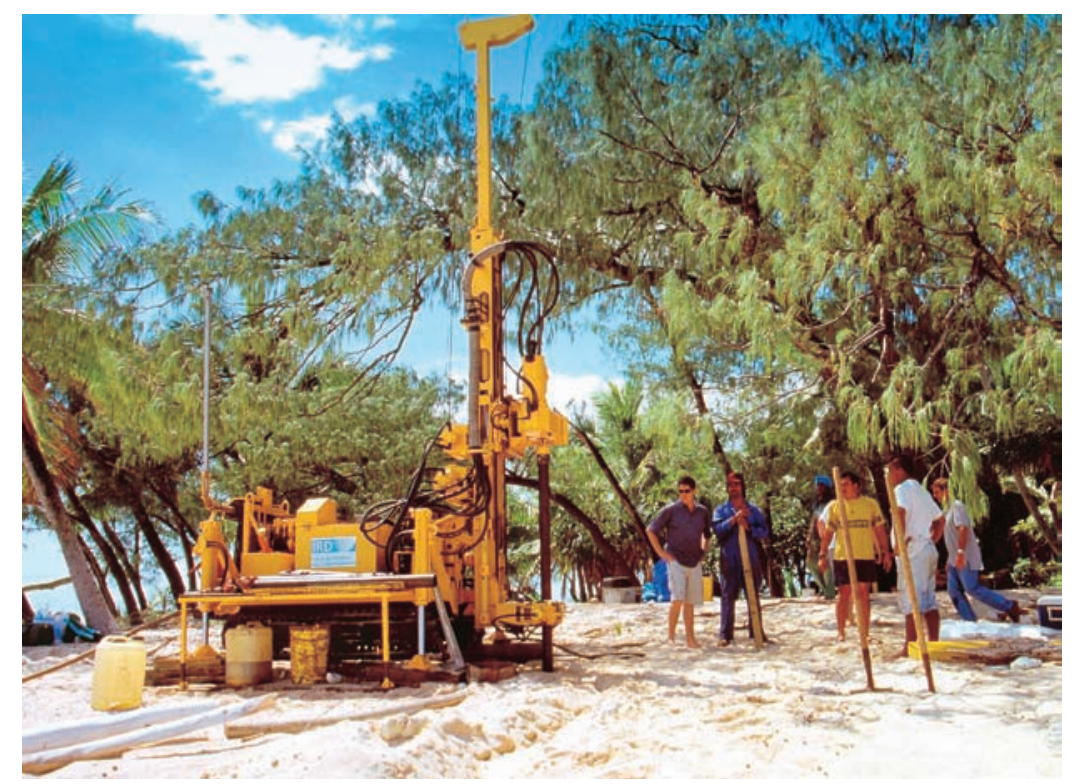

Forage du récif-barrière, îlot Bayes, côte est de la Grande Terre (2002). @ IRD/G. Cabioch

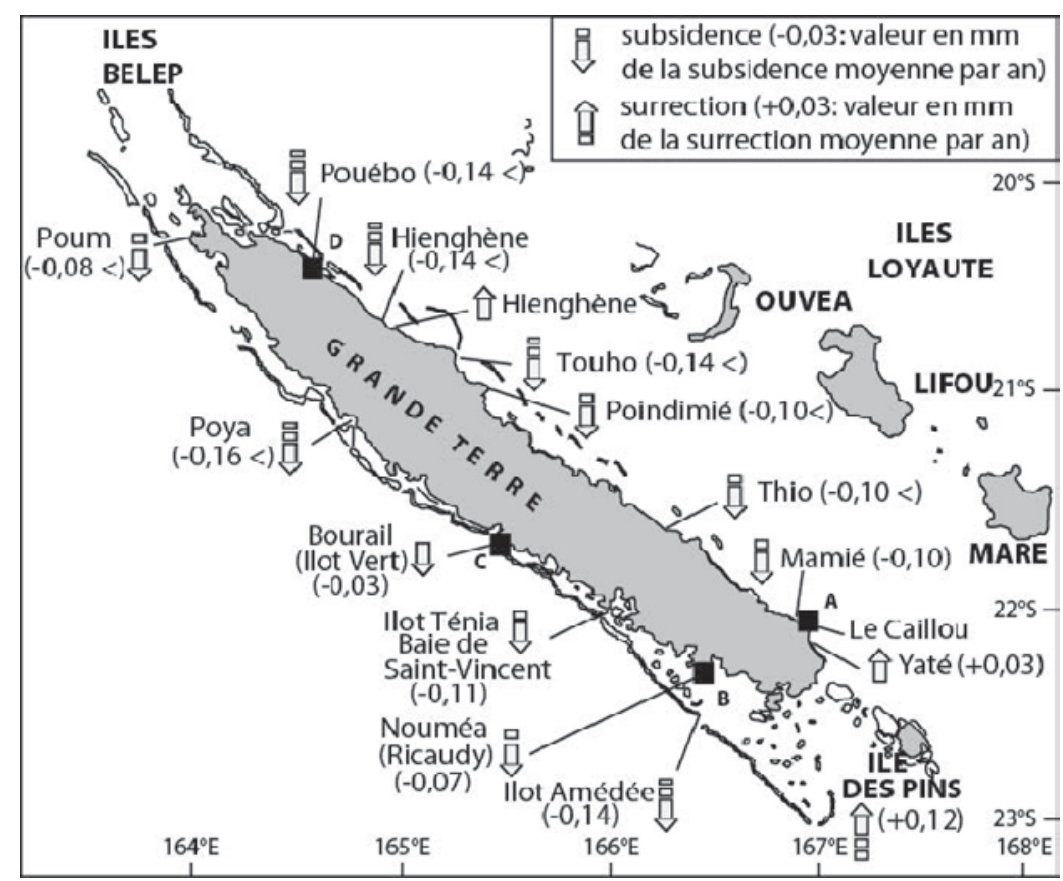

Figure 3 : Mouvements verticaux depuis 125000 ans autour de la Grande Terre. Source : Cabioch et al., 1996 


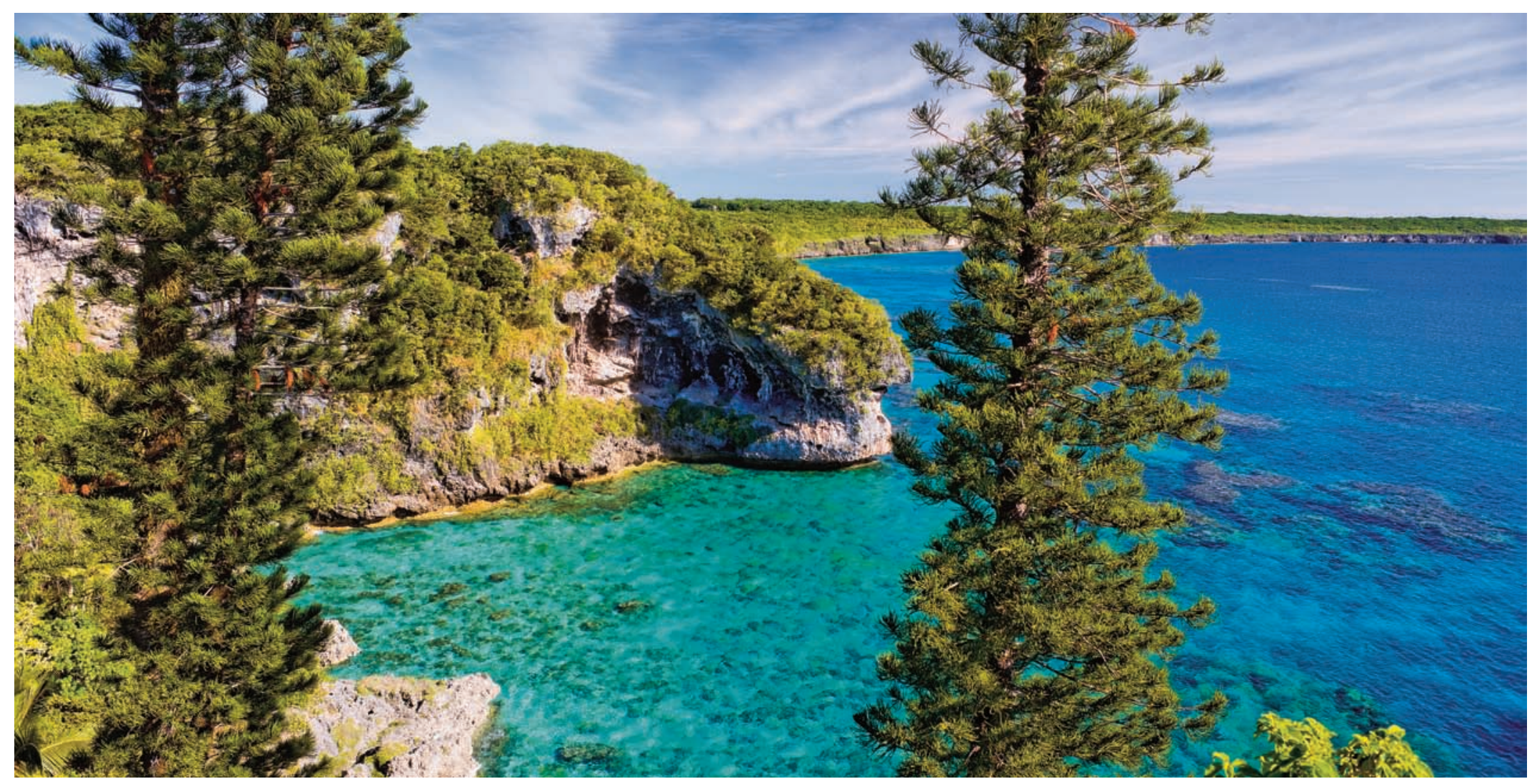

Terrasses récifales et falaises de calcaires récifaux avec encoches actuelle et ancienne, nord de Lifou, Joking. @ P.-A. Pantz

\section{Des zones en surrection avec des récifs et atolls anciens et soulevés}

Les anciens atolls d'âge Miocène moyen à Pléistocène des îles Loyauté, culminant de 40 à 140 m d'altitude, ont été fortement soulevés. À l'île des Pins, le complexe récifal attribué au haut niveau marin du dernier interglaciaire indique un soulèvement de $0,12 \mathrm{~mm} / \mathrm{an}$ depuis 125000 ans. Dans le sud-est de la Grande Terre, dans la région de Tara/Yaté, le récif frangeant construit à 125000 ans est aussi émergé. Il atteint une altitude maximum de $10 \mathrm{~m}$, ce qui indique une surrection de $0,03 \mathrm{~mm} / \mathrm{an}$, alors que dans cette même région le récif-barrière actuel se trouve profondément immergé, de 15 à $20 \mathrm{~m}$. L'ensemble des zones en surrection illustre le bombement lithosphérique de la plaque Australie avant sa subduction.

\section{Des zones en subsidence avec des récifs et atolls anciens, ennoyés et enfouis}

Des témoins du récif frangeant de 125000 ans affleurent également dans la région de Bourail, sur la côte ouest de l'île. Toutefois, leurs altitudes, de l'ordre de $2 \mathrm{~m}$, sont inférieures à celle admise pour ce haut niveau marin $(+6 \mathrm{~m})$, ce qui indique une légère subsidence de la région (-0,03 mm/an). Partout ailleurs autour de la Grande Terre, le récif frangeant de 125000 ans est sous le récif postglaciaire holocène ou immergé plus au large, indiquant une subsidence de 0,1 à plus de 0,16 mm/an, qui augmente vers le nord et le sud-ouest de part et d'autre d'une zone centrale relativement plus stable. Au niveau du récif-barrière, le platier établi à 125000 ans est surmonté par une formation holocène dont l'épaisseur dépend 
de la subsidence. Celle-ci croît nettement, en allant de la côte vers le large, comme, par exemple, dans le lagon de Nouméa ou au niveau du récif-barrière de Yaté. Le bâti néo-calédonien a donc subi, au cours des derniers 125000 ans, un double gauchissement, à la fois longitudinal et transversal, à la faveur de failles-flexures parallèles à l'île et de failles transverses qui la découpent en grands blocs.

Des taux de subsidence comparables ont été obtenus ou estimés depuis 125000 ans pour les atolls des récifs d'Entrecasteaux $(0,1 \mathrm{~mm} / \mathrm{an}$ à Huon) et des Chesterfield-Bellona (0,1 à 0,15 mm/an).

Les forages au niveau du récif-barrière ouest de la Grande Terre ont aussi permis de reconnaître des constructions récifales attribuées

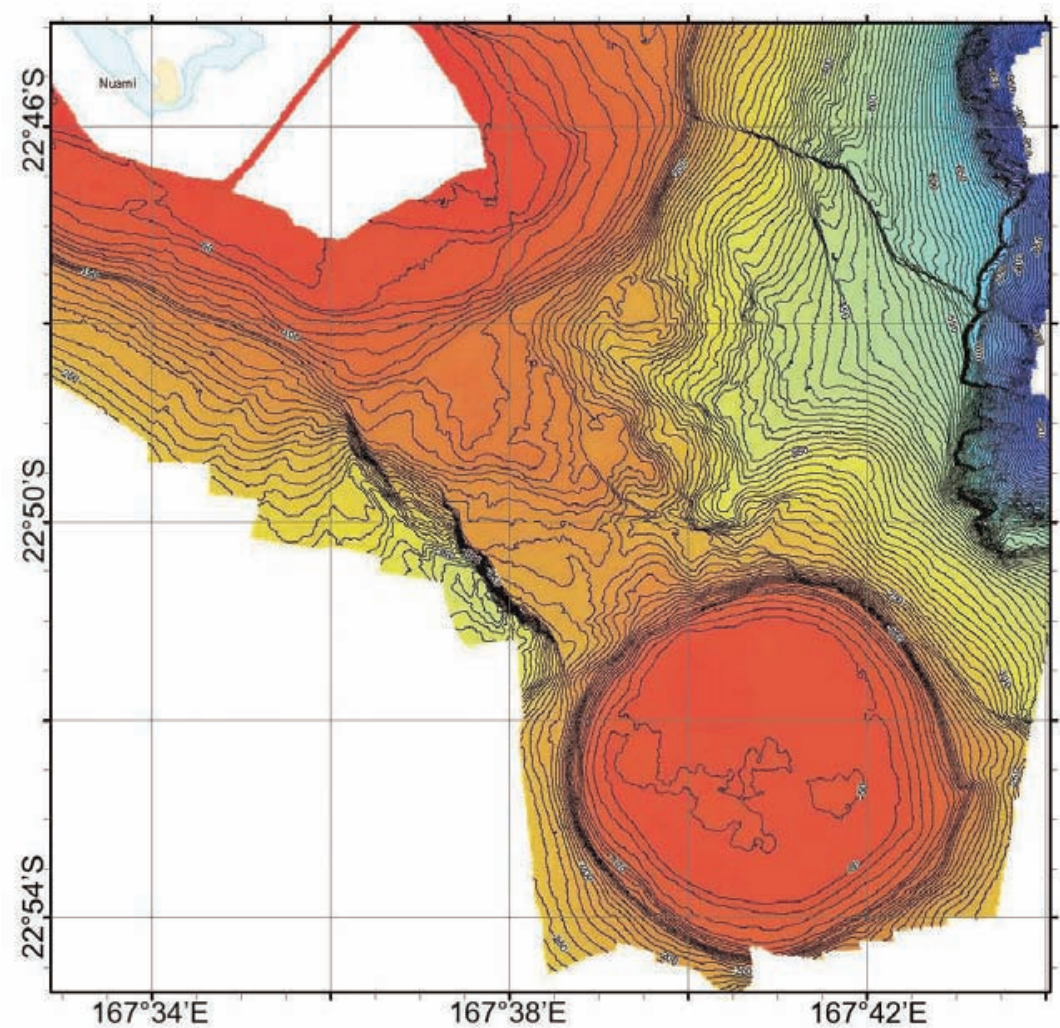

Figure 4 : Carte du banc de la Torche au sud de l'île des Pins. Isobathes tous les $10 \mathrm{~m}$. Source : IRD/B. Pelletier à des hauts niveaux marins antérieurs (lors du dernier million d'années). Par ailleurs l'analyse morphologique détaillée de l'ensemble des pentes externes du récif-barrière a révélé la présence de cinq terrasses marines entre - 20 et -120 m, interprétées comme la signature morphologique d'unités récifales développées au cours des derniers hauts niveaux marins. La distribution de la terrasse majeure, située entre -70 et $-85 \mathrm{~m}$ et interprétée comme le marqueur du haut niveau marin de 408000 ans, indique une segmentation en blocs basculés et des taux moyens de subsidence de 0,13 et $0,20 \mathrm{~mm} / \mathrm{an}$, comparables à ceux déduits depuis 125000 ans.

Enfin la subsidence est aussi indiquée par la présence d'atolls ennoyés (comme ceux du banc de la Torche (fig. 4) et Antigonia au sud de l'île des Pins) et de guyots sur la ride de Norfolk au sud de la Grande Terre, sur la ride des Loyauté et au sud du complexe de Bellona-Chesterfield (bancs Capel, Kelso, Argo et Nova fig. 1).

\section{Références bibliographiques}

ANDRÉFOUËT S. et al., 2009 A reappraisal of the diversity of geomorphological and genetic processes of New Caledonian coral reefs: a synthesis from optical remote sensing, coring and acoustic multibeam observations. Coral Reefs, $28: 691-707$.

CABIOCH G. et al., 1996 Contrôle climatique et tectonique de l'édification récifale en Nouvelle-Calédonie au cours du Quaternaire terminal. Bulletin Société Géologique de France, 167 : 729-742.

DUBOISJ., LAUNAY J., RÉCY J., 1974 Uplift movements in New Caledonia-Loyalty Islands area and their plate tectonics interpretation. Tectonophysics, 24 : 133-150. DUBOIS J. et al., 1977 New Hebrides trench: subduction rate from associated lithospheric bulge. Canadian Journal of Earth Sciences, 14:250-255.

PELLETIER B., 2007 « Geology of the New Caledonia region and its implications for the study of the New Caledonian biodiversity ». In : Payri C.E., Richer de Forges R., éd., Compendium of marine species from New Caledonia, IRD-Nouméa, Documents scientifiques et techniques, II (7), 2e éd. : 17-30.

PELLETIER B., LOUAT R., 1989 Mouvements relatifs des plaques dans le Sud-Ouest Pacifique. C.R. Acad. Sci. Paris, 308 (II) : 123-130. 


\section{Les habitats des récifs et lagons néo-calédoniens}

Serge Andréfouët

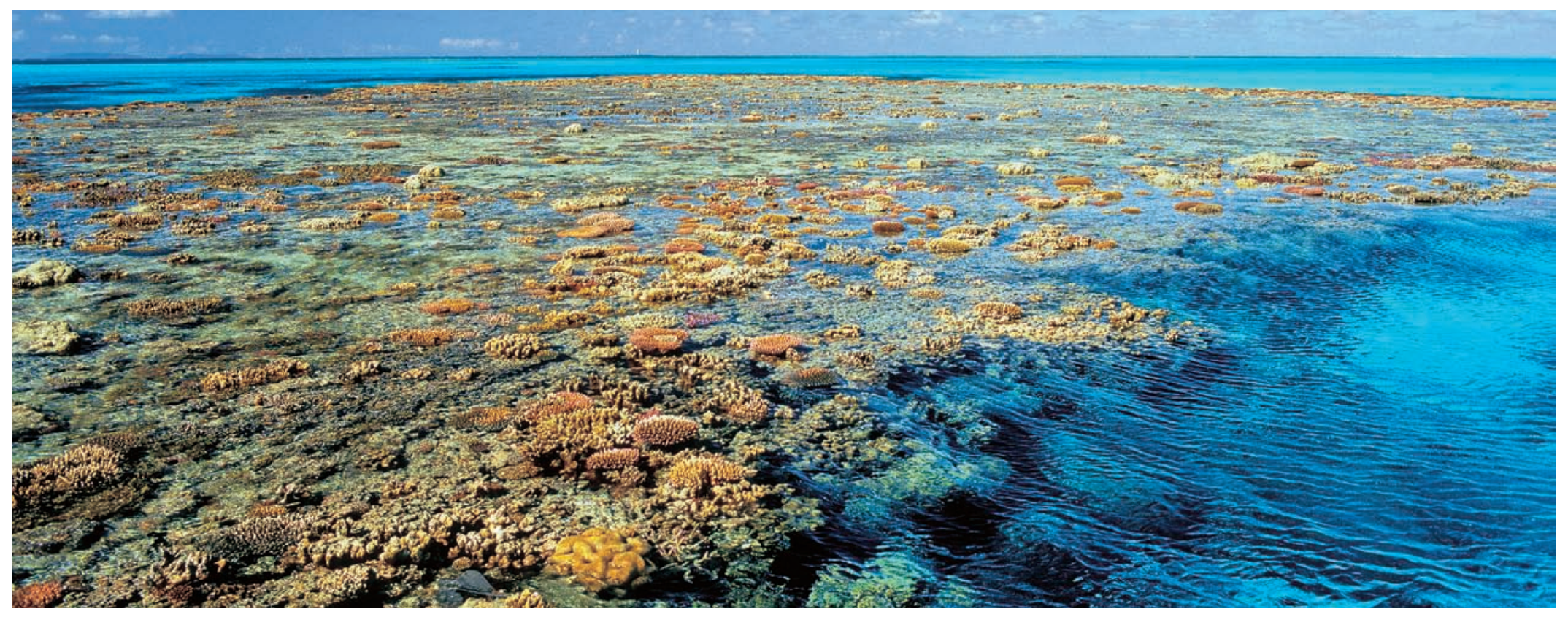

Récif Aboré qui s'étend au nord de la passe de Dumbéa, lagon sud-ouest. @ P.-A. Pantz

\section{De l'utilité de connaître les habitats}

La connaissance des types d'habitats présents dans une zone et leurs distributions spatiales (cartographie d'habitats) est nécessaire pour une bonne gestion, quelle que soit l'échelle de travail, pour un îlot, un récif, ou un ensemble de récifs. Cette connaissance permet d'estimer la vulnérabilité d'un site et offre une meilleure compréhension de l'effet des perturbations sur un récif. La caractérisation des habitats présents sur un site permet aussi $\mathrm{d}^{\prime}$ 'identifier son caractère remarquable. Enfin, la distribution des ressources sera souvent liée à celle des habitats.
Un habitat est défini ici comme une entité biologique et abiotique couvrant une centaine de mètres carrés au minimum. Cela correspond à la perception qu'aura un plongeur ou un apnéiste du récif ou du lagon dans lequel il évolue. On ne parle donc pas ici de microhabitats, comme l'intérieur d'une patate de corail ou d'une éponge.

\section{Typologie des habitats}

La Nouvelle-Calédonie présente une grande diversité d'habitats récifo-lagonaires. Pour comprendre cette diversité et la décrire, il est nécessaire d'établir une typologie d'habitats qui sert de référentiel. 
Exemples d'habitats des récifs et lagons calédoniens. A-D : quatre habitats coralliens.

A : Crête de récifs d'îlots dominés par des Acropora tabulaires de grande taille (lagon sud).

B : Platier infratidal à assemblage corallien mixte (Entrecasteaux).

$C$ : Platier à influence terrigène de récif d'îlot à Porites massifs formant des micro-atolls (Petit-Borendy).

D : Platier intertidal de récif-barrière dominé par des petits Acropora tabulaires (lagon sud)

E : Herbier mixte associé à une algueraie de Sargassopsis sur une terrasse sableuse de récif frangeant (Canala)

F : Platier infratidal à coraux mous Sarcophyton (Thio).

G : Lagon d'atoll sableux, ici pendant une agrégation de bernard-l'ermite (Entrecasteaux).

$\mathrm{H}$ : Lagon d'atoll à fond sableux et épave (Entrecasteaux).

C IRD/S.Andréfouët
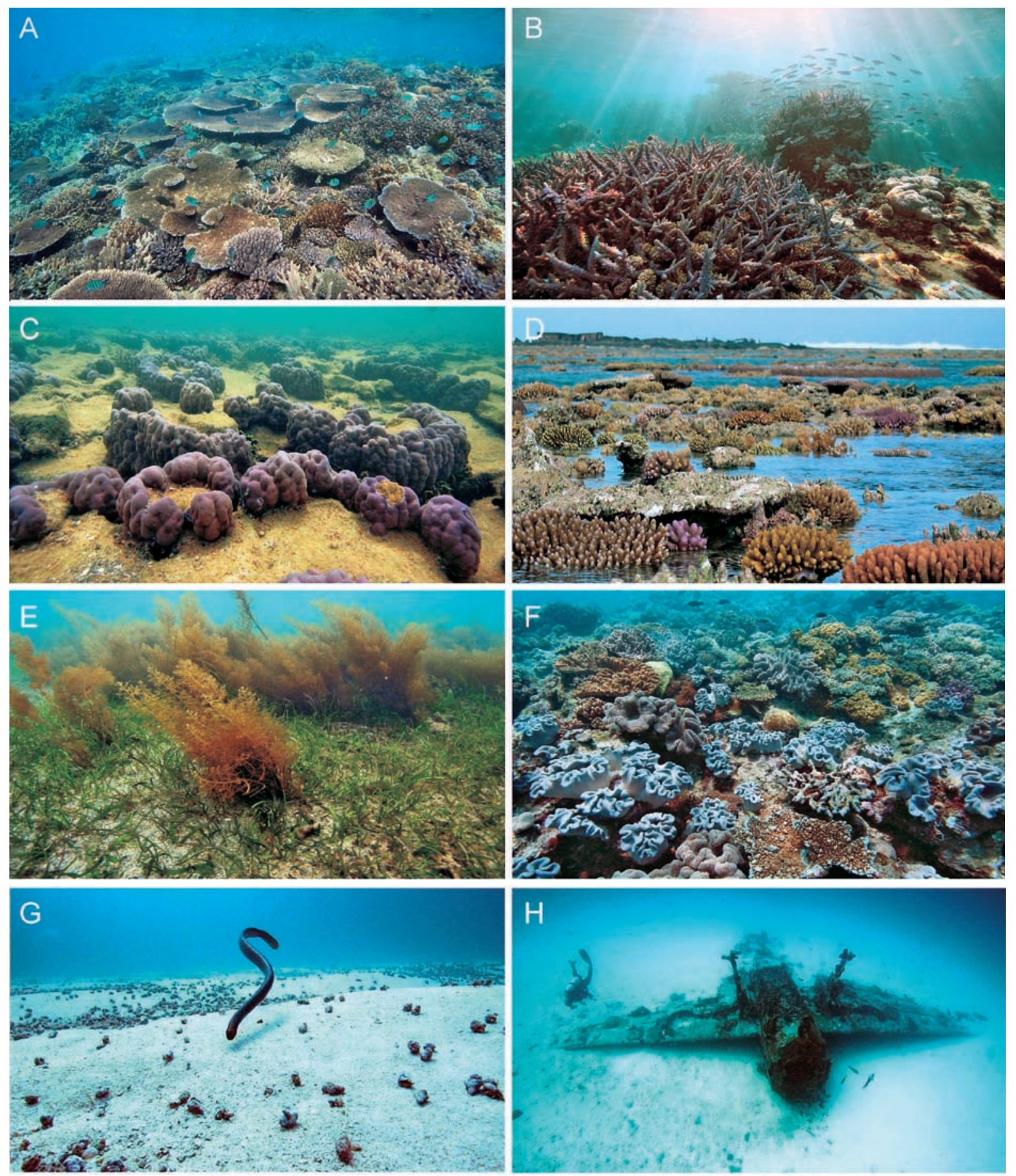


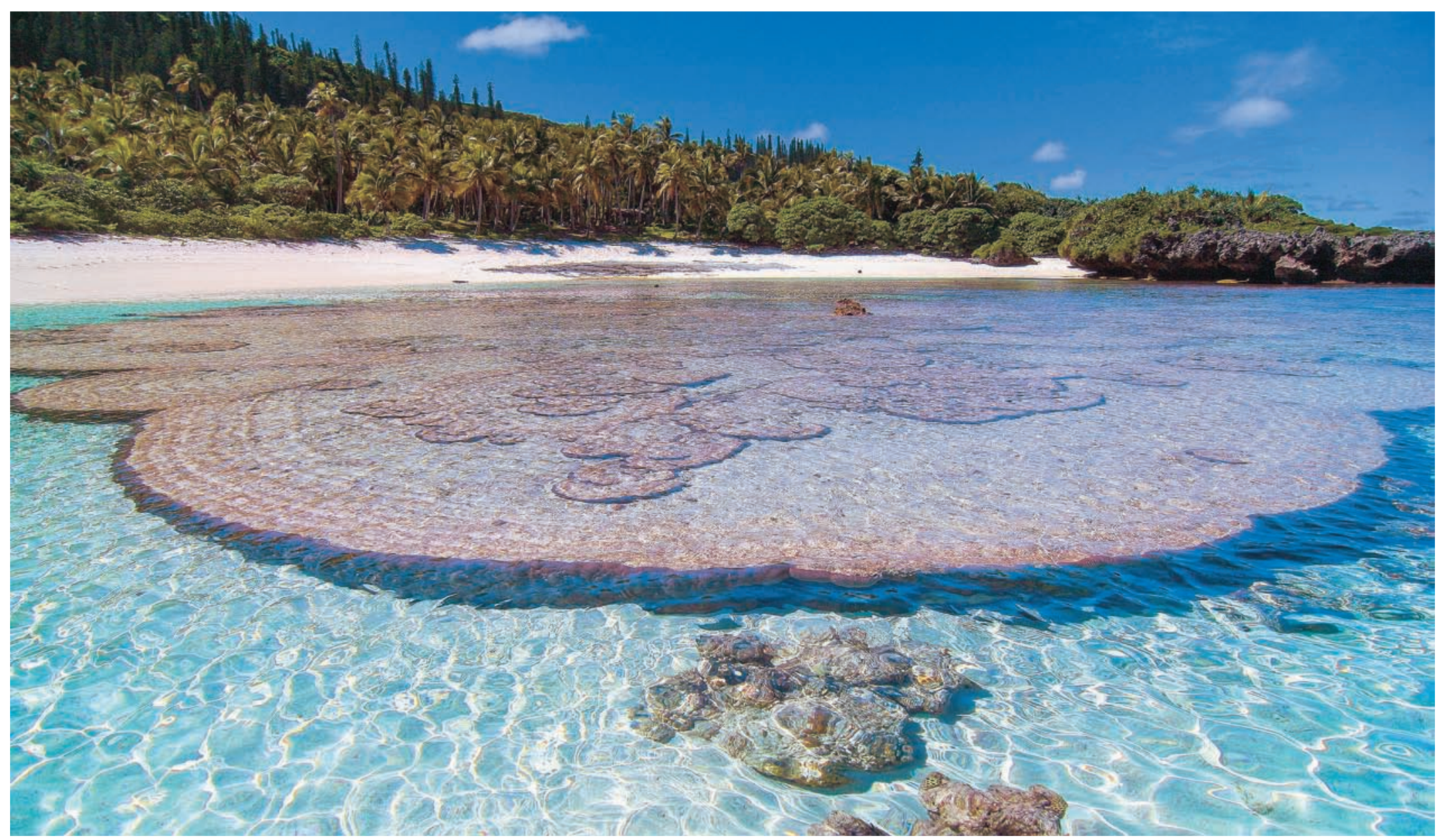

Micro-atolls de coraux massifs sur le platier récifal actuel au sud-est de Maré. Les rides visibles sur le pourtour du micro-atoll résultent de la variation du niveau marin. @ IRD/S.Andréfouët

Classiquement, une typologie d'habitat fait appel à plusieurs niveaux de description hiérarchisés qui incluent des informations sur la géomorphologie, l'architecture, la couverture benthique et les groupes taxonomiques.

L'intérêt de la description géomorphologique est de fournir une première indication sur l'environnement physique et les propriétés du récif étudié : genèse du récif, influence des apports terrigènes, distance à la côte, exposition aux houles, exposition aux vagues de vent, profondeur, etc. Ainsi, un « récif de baie » implique une zone enclavée, de faible énergie hydrodynamique, protégée, turbide, soumise à des apports terrigènes et d'eau douce. Cette description géomorphologique peut avoir plusieurs niveaux. Le premier niveau inclura par exemple les classes suivantes : récif-barrière, massif lagonaire, récif d'îlot, récif frangeant, massif océanique, récif de baie, atoll, banc. Chacune de ces catégories est mutuellement exclusive. Par exemple, l'appellation « récif frangeant » $d^{\prime}$ « atoll » n'a pas de sens.

Un deuxième niveau est décrit par les classes suivantes : platier, pente, crête, passe, terrasse, lagon, lagon enclavé, escarpement, 
chenal. Ces différentes catégories permettent de détailler la structure des unités du niveau précédent, en décomposant par exemple un « récif-barrière » en ses différents sous-composants, en allant de l'océan au lagon. Les différentes classes du premier ou du deuxième niveau citées ici sont loin d'être exhaustives, puisqu'il en existe plusieurs centaines. Toutefois, beaucoup sont rares et on présente ici les unités susceptibles d'être rencontrées fréquemment par le public (par exemple, « platier »).

Le troisième niveau de description d'un habitat est le niveau que l'on appellera de la « biocénose ». C'est le niveau que l'usage commun associe le plus souvent à la notion d'habitat. Ce troisième niveau, benthique, est ici décrit de manière générique par les classes suivantes : corallien, corail mou, corail mort, algueraie, herbier, sableux, détritique, autres. Le label de la classe est fonction des communautés, organismes et substrats dominants dans la biocénose : corail, algues ou sable par exemple. La classe « autres » inclut des habitats où des éponges, gorgones ou autres organismes sont bien présents mais plus rarement responsables de la structuration physique d'une biocénose comparativement aux coraux et algues, du moins en Nouvelle-Calédonie. Cette classe « autres » inclut aussi des biocénoses mixtes, assemblages de multiples éléments, mais sans dominance particulière. Elle comprend aussi des habitats artificiels, accidentels ou voulus (par exemple des épaves ou des remblais de scories d'origine minière). Chaque biocénose possède ensuite un certain nombre de caractères propres. La couverture benthique, l'architecture (forme de croissance, rugosité, taille des organismes) et les organismes dominants et associés sont les facteurs qui structurent le paysage sous-marin et donc correspondent à ce que le plongeur ou apnéiste verra en premier lieu. Par exemple, pour une biocénose corallienne, seront visibles le substrat, la couverture vivante (ou morte), les formes de croissance, les tailles des colonies et les genres dominants. Pour un herbier, seront perçus la densité de l'herbier, la hauteur de la canopée, le caractère mono-spécifique ou pluri-spécifique, la présence d'organismes associés (coraux, algues, éponges, organismes faisant des terriers). Pour une zone détritique, seront perçus l'origine des débris, la taille des débris, le degré de cimentation des débris, la présence d'organismes associés.
Enfin, l'information taxonomique est le niveau le plus fin et le plus difficile à renseigner compte tenu de l'expertise nécessaire. Faute de taxonomistes, l'information peut être simplifiée en ne travaillant par exemple qu'au niveau des familles, genres ou des morphotypes (coraux branchus, massifs, etc.) et non au niveau des espèces.

\section{Exemples d'habitats}

Pour conclure, un habitat est donc défini par trois clés principales. Chaque combinaison différente de ces variables fournit théoriquement un habitat différent. Une biocénose « algueraie » de « platier récifal » de « récif frangeant » n'est pas le même habitat qu'une biocénose « algueraie » de « terrasse » de « récif d'îlot ». Mais cela peut être bien sûr la même biocénose et offrir la même vue au plongeur ou apnéiste qui a le «nez dans son masque ». Le contexte géomorphologique fait partie de la notion de l'habitat, mais n'est pas forcément directement perceptible par le plongeur dans son champ de vision.

Des exemples d'habitats sont présentés sur l'illustration. Toutefois, ces huit habitats sont loin de représenter exhaustivement la diversité présente en Nouvelle-Calédonie. Une première compilation a permis de décrire 150 premiers habitats (ANDRÉFOUËT, 2014) à partir d'observations acquises au cours de diverses campagnes en mer effectuées de 2009 à 2013, notamment dans le Grand Lagon Nord, les lagons sud, sud-est et nord-ouest, la côte Est, l'île des Pins et les récifs de Cook et d'Entrecasteaux. Toutefois compte tenu des zones non encore visitées, notamment en profondeur, on estime que ces 150 habitats ne représentent que la moitié environ des configurations possibles que l'on pourrait trouver dans les récifs et lagons néo-calédoniens.

\section{Référence bibliographique}

ANDRÉFOUËT S., 2014 Fiches d'identification des habitats récifolagonaires de Nouvelle-Calédonie, Sciences de la Mer. Biologie Marine. Notes techniques IRD, Nouméa : 169 p. 


\section{Chapitre3 \\ Les lagons vus par satellite}

Cécile Dupouy, Jérôme Lefèvre, Guillaume Wattelez, Chloé Martias, Rémi Andreoli et Didier Lille

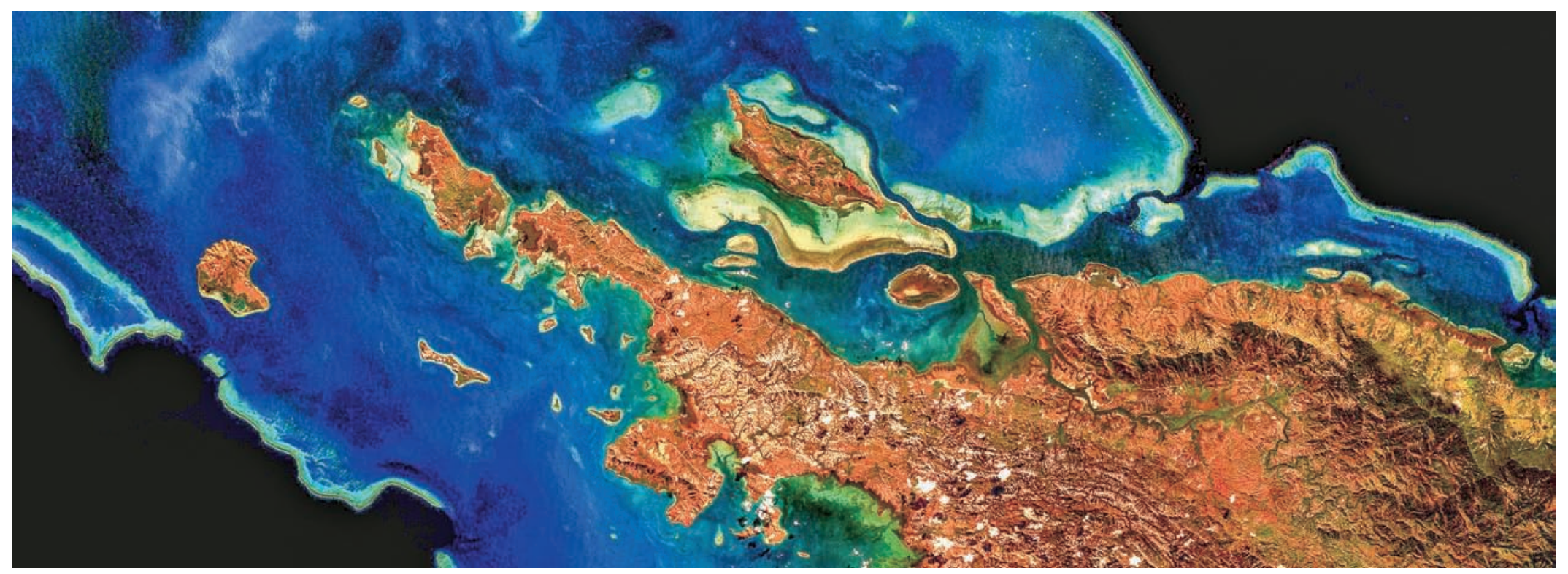

Nord de la Nouvelle-Calédonie. Récif des Français (à gauche), Récif de Balade (en haut à droite). Les récifs frangeants du nord et autour de l'île de Balabio sont visibles. (Image Landsat 7).

Nous utilisons principalement l'imagerie satellite pour répondre à différentes problématiques en rapport avec le milieu océanique. La Nouvelle-Calédonie est connue pour la richesse de sa biodiversité, en particulier pour son milieu marin. Cette richesse aquatique étant menacée par les nombreuses activités anthropiques et les événements climatiques extrêmes, il convient d'étudier leurs impacts sur ces écosystèmes. Pour ce faire, les scientifiques disposent de plusieurs indicateurs dits biogéochimiques, c'est-à-dire des indicateurs fournissant des renseignements à la fois sur les organismes vivants microscopiques contenant la chlorophylle, les éléments sédimentaires et terrestres et éventuellement des composés dissous dans l'eau.

Les barrières coralliennes se développent à la faveur de conditions favorables : température, degrés de salinité, oxygénation et apports en nourriture. Les coraux symbiotiques ont besoin d'eaux transparentes très claires permettant la photosynthèse de leurs zooxanthelles. Si les coraux de certaines baies sont parfois florissants, même en condition de grande turbidité, il est admis que trop de sédimentation nuit à leur croissance. Toutefois, les polypes assimilent aussi des organismes vivants, qui doivent eux-mêmes trouver leur source de nourriture.

Si les eaux du large baignant les récifs-barrières sont en général transparentes et peu riches, d'épisodiques enrichissements peuvent survenir et provoquer des blooms phytoplanctoniques, par apports nutritifs ou remontées d'eaux plus profondes. Ainsi, la construction des récifs-barrières résulte d'une « bonne santé » des coraux qui elle-même découle d'une « savante alchimie » entre différentes composantes de l'eau. 
Les images satellite nous enseignent que l'océan n'est pas toujours bleu. La sensibilité des capteurs est telle qu'une petite modification de couleur non perceptible pour nos yeux peut être détectée rapidement. Les satellites défilants balayent et « voient » d'un coup une largeur de champ considérable, de plusieurs centaines ou milliers de kilomètres, à des résolutions de $10 \mathrm{~m}$ à $250 \mathrm{~m}$ (par système de balayage ou par caméras CCD à $700 \mathrm{~km}$ de distance).

Comme chaque composante de l'eau (chlorophylle, turbidité et matière organique dissoute) a une couleur particulière, il est possible de déduire la concentration de chaque composante. Il est très utile de pouvoir différencier les différents apports minéraux (grosses particules sédimentant vite, comme les grains de sable ou des latérites fines) provenant des bassins-versants, le phytoplancton vert et riche en chlorophylle, et la partie dissoute. Cette dernière, absorbant fortement la lumière aux longueurs d'onde UV, a un rôle de parapluie solaire pour les coraux tropicaux et peut s'associer avec des polluants (pesticides) ou des métaux présents en faible concentration dans les eaux du lagon. Les données satellite de la couleur de l'eau permettent ainsi de décrire et de comprendre la dynamique de l'environnement des lagons et des récifs coralliens (turbidité, matière dissoute et chlorophylle).

\section{L'impact de la pluie sur la chlorophylle et la turbidité}

Lors de fortes dépressions tropicales ou après des périodes prolongées de pluie, la chlorophylle observée par satellite (quantité de phytoplancton) est multipliée par trois dans les lagons. Cet effet est visible jusqu'à $50 \mathrm{~km}$ des côtes (fig. 1, A et B). En utilisant un modèle physique-biogéochimique couplé à trois dimensions et en considérant l'interface entre l'océan et le lagon, le modèle reproduit l'augmentation de la chlorophylle à l'intérieur des passes du récif
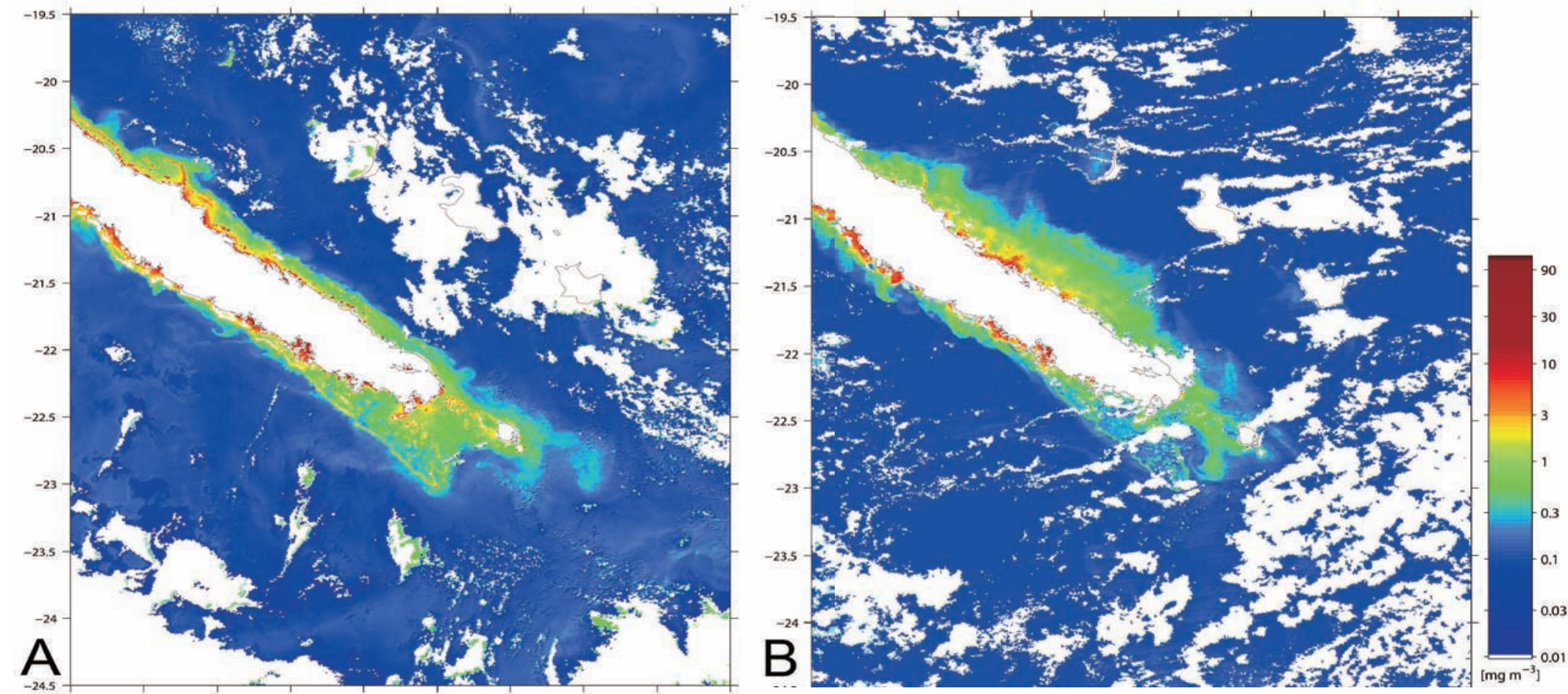

Figure 1 : Distribution de la chlorophylle (mg.m-3) estimée à partir d'images Modis, avant (A) et après (B) le fort épisode pluvieux de mars 2008. ๑ H. Murakami 


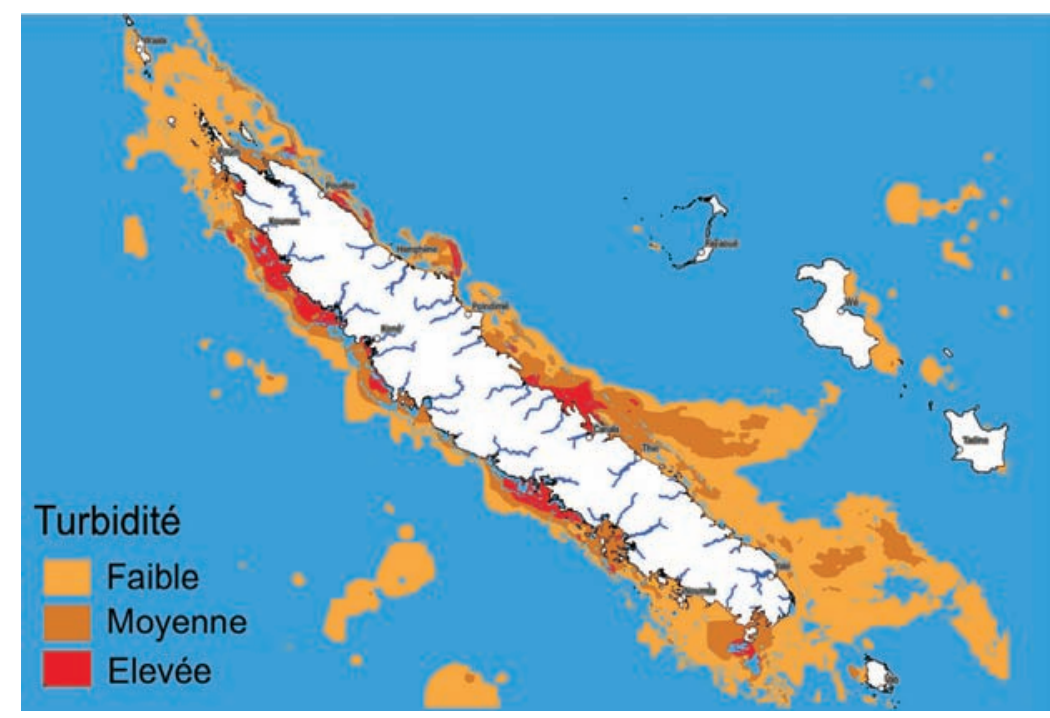

Figure 2: Turbidité (calculée) après la dépression Finna en décembre 2011. @ Bluecham SAS

(FUCHS et al., 2013). La modélisation biogéochimique peut alors être validée par les images satellite Modis de chlorophylle dans les lagons.

Lorsque le lagon est profond (plus de $20 \mathrm{~m}$ ), la turbidité est mesurable par télédétection, avec une validation issue des mesures in situ dans le lagon. Les panaches turbides détectés par les images Modis permettent de cartographier les impacts des bassins-versants. Ces panaches se développent et sont repris par la circulation océanique. La côte orientale est plus souvent impactée, en raison de la fréquence et de l'intensité des pluies et de la présence du grand massif du sud, de nature ultrabasique et latéritique (fig. 2).

À l'échelle du lagon sud-ouest, la chlorophylle observée par satellite indique que la concentration est plus faible dans les eaux baignant les récifs-barrières que sur la bande côtière. La transparence est donc plus forte sur les massifs de corail. Si on suit la chlorophylle au cours du temps à trois stations (fig. 3, A), une océanique au large de la passe de Dumbéa (OC1), une en milieu de lagon (M33) et une dans une baie (la baie de Dumbéa, GD10), on note que le pic de chlorophylle printanier se produit plus tardivement à l'extérieur de la barrière corallienne (OC1) que dans les eaux du milieu de lagon (M33) ou que dans la baie côtière (GD10) (fig. 3, B). Cependant, les eaux du large peuvent parfois être plus riches que celles de l'intérieur du lagon en raison de remontées d'eaux froides (NEVEUX et al., 2010).

Lorsque les eaux sont peu profondes, la couleur du fond influe trop sur le signal satellite. L'objectif est alors de détecter spécifiquement l'effet dû à la bathymétrie et à la couleur des fonds (MINGHELLI-ROMAN et DUPOUY, 2014). Les composantes de l'eau de mer sont alors accessibles seulement au prix de calculs plus compliqués (MURAKAMI et DUPOUY, 2013 ; WATTELEZ et al., 2016, 2017) comme dans le lagon sud-ouest proche de Nouméa, au niveau des zones d'arrière-récifs et de hauts-fonds (fig. 3A).
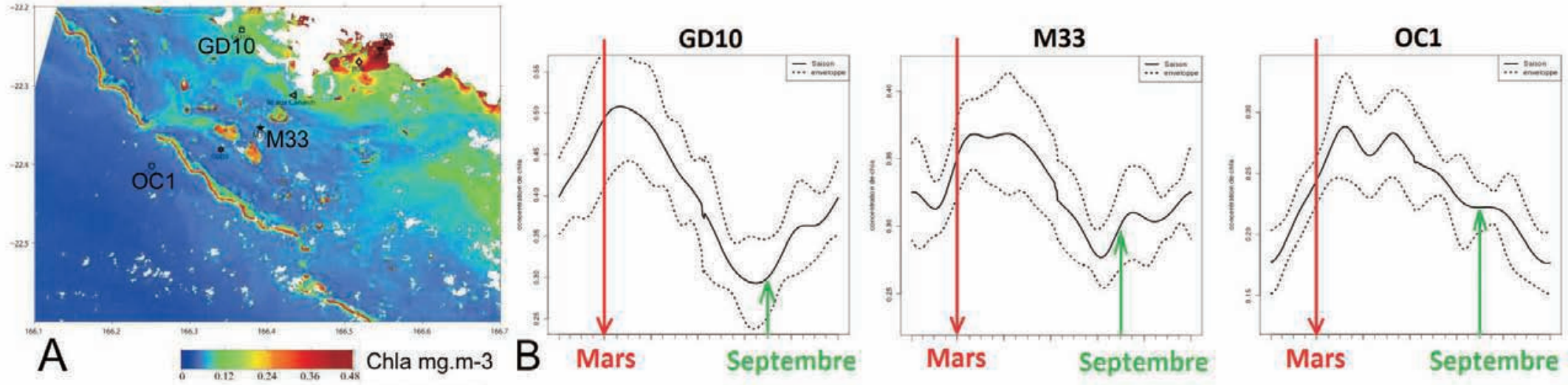

Figure 3: Chlorophylle dans le lagon de Nouméa. A: Chlorophylle estimée à partir d'image AVNIR à très haute résolution (20 mètres) après correction de la réflexion du fond (MURAKAMI et DUPOUY, 2013). B: Cycle saisonnier de la chlorophylle aux différentes stations (océanique OC1, lagonaire M33 et côtière GD10). Source : DUPOUY et al., 2011 


\section{Les efflorescences de cyanobactéries Trichodesmium}

La cyanobactérie filamenteuse Trichodesmium représente une part importante de la chlorophylle au large et à l'intérieur des lagons (DUPOUY et al., 2011). Ces efflorescences peuvent être observées sur des milliers de kilomètres au large de la Nouvelle-Calédonie et entrer par les passes dans les lagons. Elles sont très souvent visibles par satellite autour de la Nouvelle-Calédonie et forment des lignes parallèles au récif-barrière (fig. 4). Les mattes superficielles sont détectables grâce à un signal dans le proche infra-rouge et des anomalies de réflectance (DUPOUY et al., 2011).

\section{La matière organique dissoute colorée}

Dans les lagons, la quantité de matière dissoute colorée (MODC), qui protège les coraux des forts éclairements UV, est souvent liée aux apports des rivières, comme c'est souvent le cas sur la côte est de la
Nouvelle-Calédonie. Cette matière organique d'origine terrestre est transportée sur de longues distances dans le lagon en fonction des débits des rivières. Elle peut être associée avec les éléments métalliques, ce qui en fait un indice très important pour suivre l'environnement corallien. La matière organique dissoute est détectable par satellite. Le tryptophane, qui est aussi une partie de la matière dissoute, est produit par les massifs coralliens (MARTIAS et al., 2018), mais n'est accessible que par une analyse optique (spectro-fluorescence).

Les cartes de chlorophylle et de turbidité issues de données satellite peuvent être réalisées en continu et à l'avenir en temps quasi réel. Elles nous renseignent sur la composition de l'eau de mer, permettant ainsi une caractérisation précise et peu onéreuse de la qualité des eaux baignant les récifs et les massifs coralliens. Les images nous indiquent l'extension des panaches turbides et de chlorophylle. L'analyse des séries d'images depuis 1998 permet de suivre et d'expliquer l'impact des phénomènes climatiques (saisons, épisodes El Niño...) sur l'environnement des lagons et des récifs.
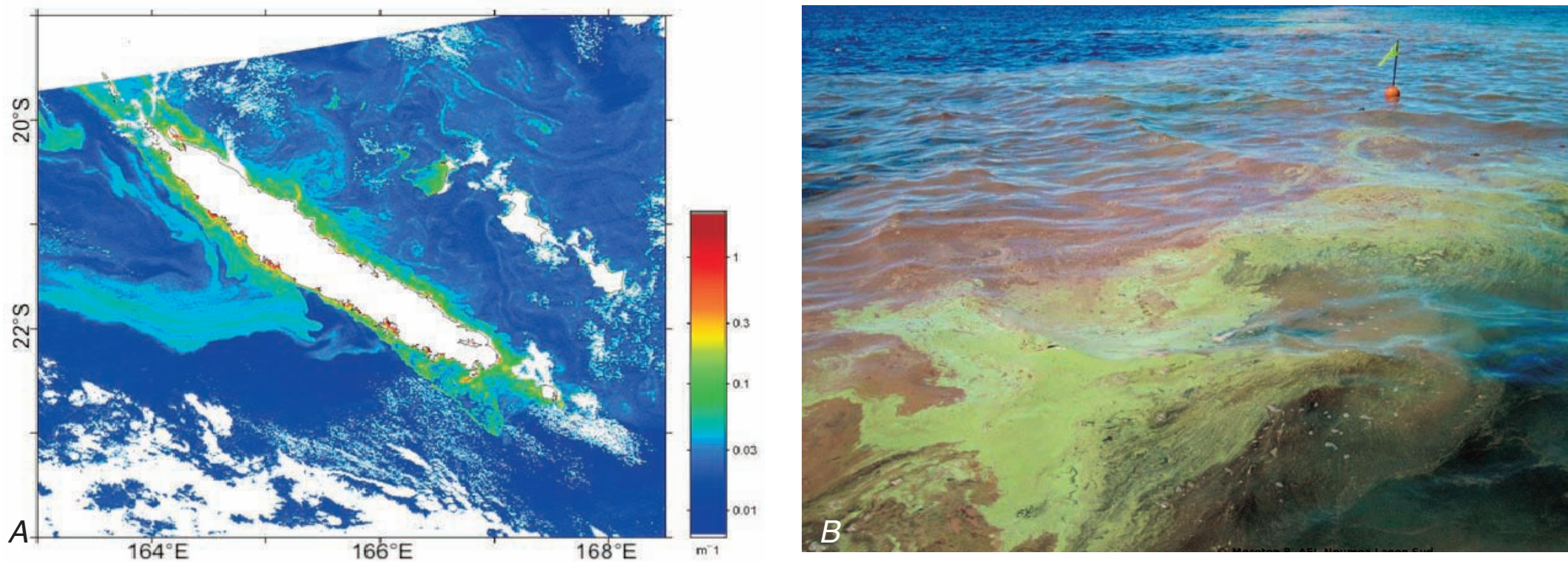

Figure 4 : Efflorescences de la cyanobactérie Trichodesmium. A : Autour de la Nouvelle-Calédonie en été, par temps calme (février 2010, image Modis).

$B$ : Les eaux roses sont fréquemment observées près des récifs-barrières (baie du Prony). ๑ A.E.L./ B. Moreton 


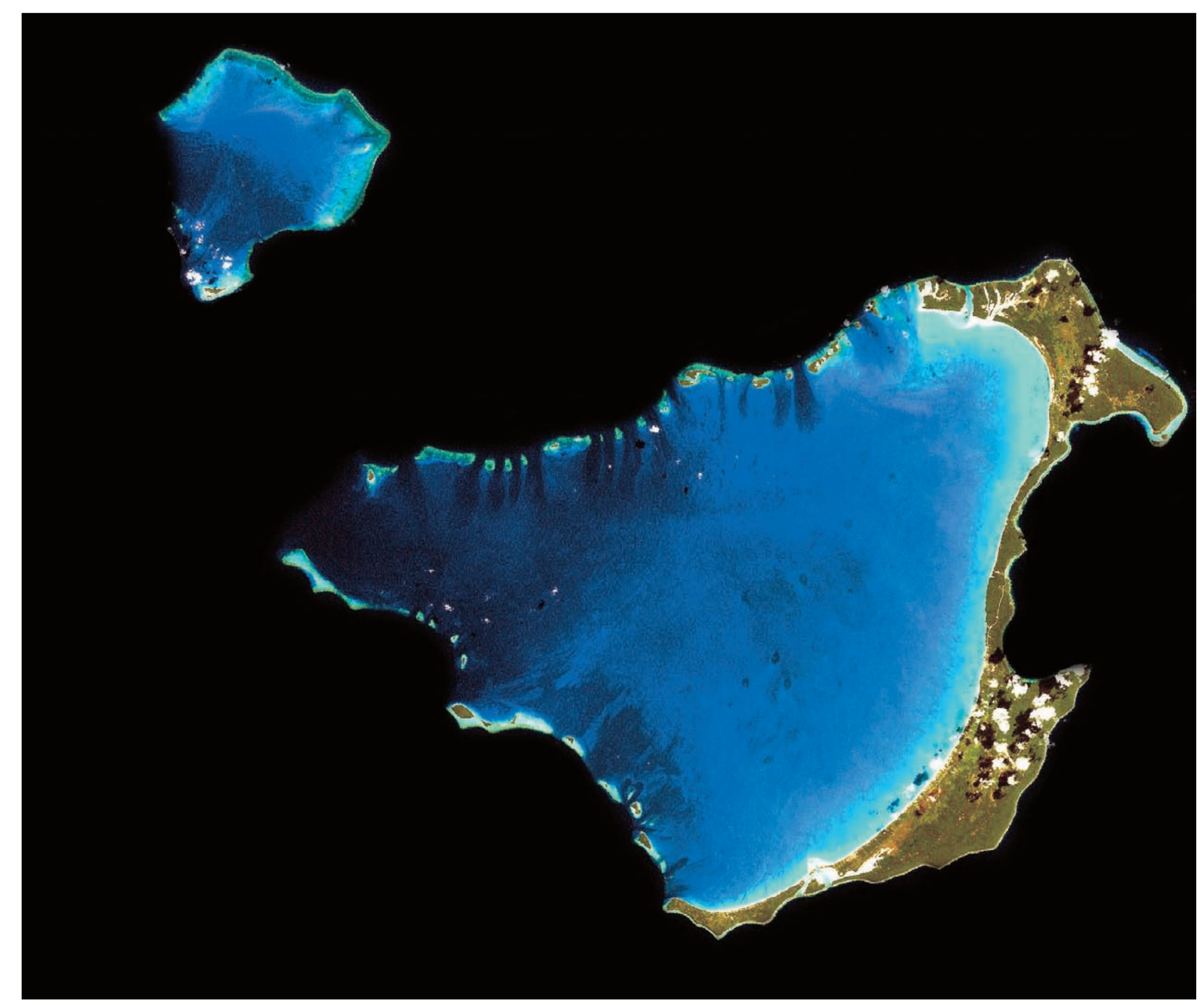




\section{Références bibliographiques}

DUPOUY C. et al., 2011 A new algorithm for detecting Trichodesmium surface blooms in the South Western Tropical Pacific. Biogeosciences, 8 : 1-17.

FUCHS R. et al., 2013 Modeling the ocean-lagoon interaction via upwelling processes on the South West of New Caledonia. Estuarine, Coastal and Shelf Science, $135: 5-17$.

MARTIAS C. et al., 2018 Characterization and sources of colored dissolved organic matter in a coral reef ecosystem subject to ultrama fi c erosion pressure (New Caledonia, Southwest Pacific). Science of Total Environment : 616-617, 438-452. doi : 10.1016/j.scitotenv.2017.10.261

MINGHELLI-ROMAN A., DUPOUY C., 2014 Seabed mapping in the lagoon of New Caledonia with MeRIS images. IEEE Journal of Selected Topics in Applied Earth Observations and Remote Sensing, 7 (6) : 2619-2629.
MURAKAMI H., DUPOUY C., 2013 Atmospheric correction and inherent optical property estimation in the southwest New Caledonia lagoon using AVNIR-2 high-resolution data. Applied Optics, 52 (2) : 182-198.

NEVEUX J. et al., 2010 Phytoplankton dynamics in the southern New Caledonian lagoon during a southeast trade winds event. Journal of marine systems, 82 : 230-244.

WATTELEZ G. et al., 2016 A statistical algorithm for estimating chlorophyll concentration in the Nouvelle-Calédonien lagoon. Remote Sens., 8 (1) : 45. WATTELEZ G. et al., 2017 Remotely sensed assessment of turbidity with Modis in the oligotrophic lagoon of Voh-Koné- Pouembout area. New Caledonia, Water, $9: 737$. 


\section{La valse des masses d'eau dans le lagon néo-calédonien}

Pascal Douillet, Jérôme Aucan, Jérôme Lefèvre, Romain Le Gendre, Térence Desclaux et Marion Drouzy

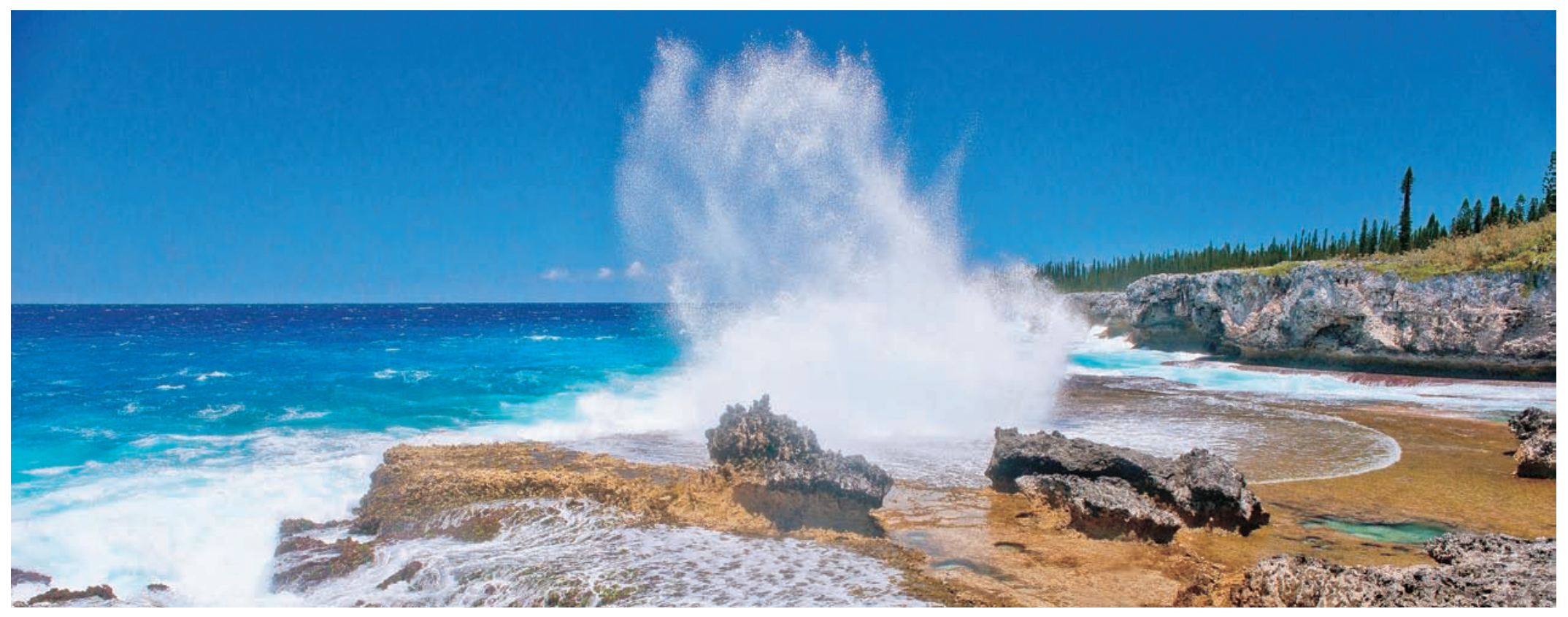

Vagues se brisant sur le platier récifal bordant le littoral, lle des Pins. @ P.-A. Pantz

La circulation lagonaire est le résultat du mouvement des masses d'eau déformé par la géomorphologie compliquée du lagon. Les grands courants et tourbillons océaniques (encadré 1) (CRAVATTE et al., 2015) et côtiers (MARCHESIELLO et al., 2010), la marée (OUILLON et al., 2010), le vent local (LEFEVRE et al., 2010) et la houle sont les principaux moteurs à l'origine de cette mise en mouvement. Bien que la marée imprime aux masses d'eau un mouvement alternatif qui nous est familier, les courants et propriétés des masses d'eau sont en réalité le résultat d'interactions non-linéaires complexes. Les modèles numériques ont permis de démontrer l'action déterminante de la marée et du vent sur la pulsation du lagon. Le renouvellement des masses d'eau, les propriétés et formes de la matière organique, le transport des larves sont par exemple contrôlés par ces deux moteurs.
Les effets de la houle océanique combinée à la houle levée par le vent local sur le lagon (la mer de vent) et dont la transmission de l'énergie est modulée par la marée, commencent à être étudiés par modélisation. Les modèles sont calibrés et validés à l'aide de précieuses observations mesurées par les océanographes et biologistes marins du centre IRD de Nouméa au cours de ces 20 dernières années. Les observations proviennent de dispositifs immergés (marégraphes, courantomètres, bouées dérivantes, houlomètres, capteurs de température et de salinité), de stations météorologiques automatiques et de campagnes de mesures des propriétés physico-chimiques des masses d'eau. Ces observations sont complétées par celles de MétéoFrance, de l'Ifremer et celles issues de données satellitaires (vent, houle, température, turbidité et distribution du phytoplancton en surface). 


\section{Encadré 1 \\ Les récifs calédoniens baignés par les courants}

Christophe Menkes

Le moteur principal de la circulation océanique dans la région du Pacifique sud est le courant sud équatorial (SEC) qui transporte vers l'ouest et redistribue les eaux des régions subtropicales vers l'Équateur et l'océan austral. La Nouvelle-Calédonie, comme tout archipel, constitue un obstacle au transport des eaux et génère des courants côtiers. Le courant sud équatorial se divise en deux branches en arrivant sur les rides des Loyauté et de NouvelleCalédonie (MARCHESIELLO et al., 2010 ; CRAVATTE et al., 2015). Une branche s'écoule vers l'ouest en contournant le sud de la Nouvelle-Calédonie pour former le jet sud calédonien (SCJ). Un faible courant variable, qui porte en général vers le sud-est, le courant du Vauban, longe la côte est de la Grande Terre. La branche principale du courant sud équatorial à l'est de la Nouvelle-Calédonie, appelée courant est calédonien (ECC), contourne la ride de Nouvelle-Calédonie par le nord et contribue au jet nord calédonien (NCJ), dans le Grand Passage et au nord des récifs d'Entrecasteaux. Ce courant continue vers l'ouest, passe $\mathrm{au}$ nord des îles Chesterfield et, en arrivant sur la côte est australienne, se divise en une branche nord et une branche sud, le courant est australien (EAC), se séparant à son tour en formant le contre-courant subtropical (STCC) qui reflue vers l'est au sud de la Nouvelle-Calédonie. Ce contre-courant alimente en partie le courant Alis (ACNC, Alis Current of New Caledonia) qui s'écoule vers le sud-est le long de la marge ouest de la Grande Terre. Par ailleurs, pendant la saison chaude, de novembre à avril, les alizés soufflant du sud-est créent une remontée des eaux vers la surface (upwelling) le long de la côte ouest de la Grande Terre (HENIN et CRESSWELL, 2005 ; MARCHESIELLO et al., 2010).

\section{Références bibliographiques}

CRAVATTE S. et al., 2015 Regional circulation around New Caledonia from two decades of observations. Journal of Marine Systems, 148 : 249-271. HÉNIN C., CRESSWELL G.R., 2005 Upwelling along the western barrier reef of New Caledonia. Marine and Freshwater Research, 56 : 1005-1010. MARCHESIELLO P. et al., 2010 Coastal upwelling, circulation and heat balance around New Caledonia's barrier reef. Marine and Pollution Bulletin, 61 : 432-448.
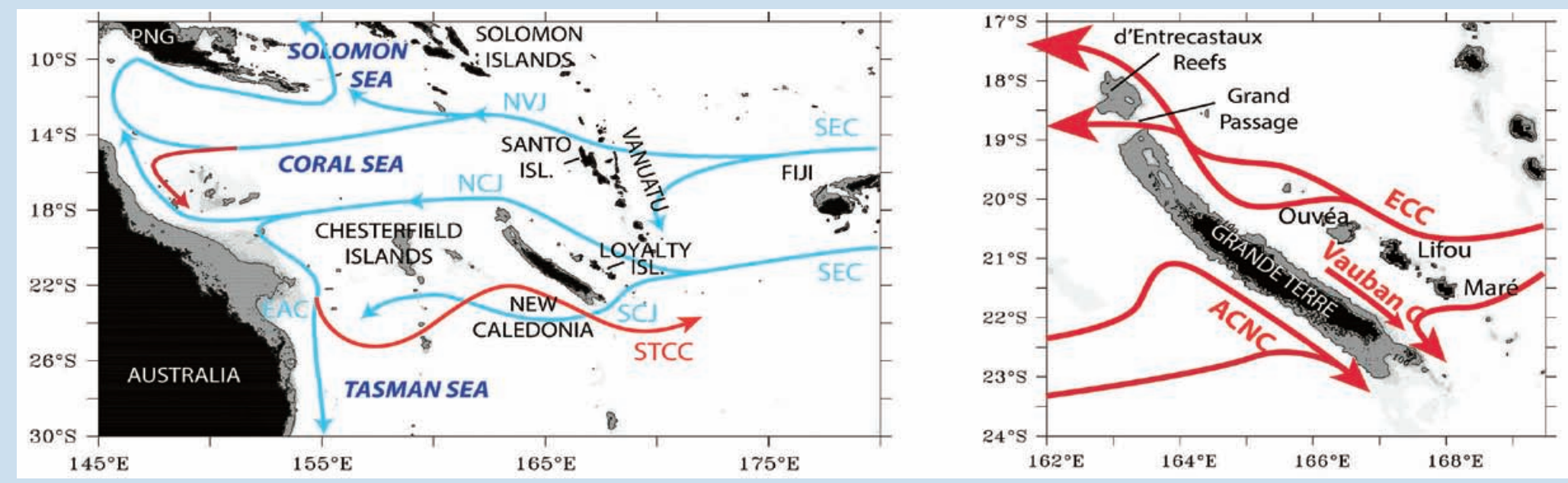

Circulation océanique autour de la Nouvelle-Calédonie. Source : CRAVATTE et al., 2015 


\section{Le va-et-vient dû aux planètes}

La marée dans les lagons est constituée par l'ensemble des ondes de marée résultant des attractions exercées par les astres situés à proximité de la Terre. Les courants de marée sont générés principalement par l'onde semi-diurne lunaire, engendrée par la force de la lune (onde M2) et, dans une moindre mesure, par l'onde semi-diurne solaire, engendrée par la force du soleil (onde S2) et l'onde diurne lunaire-solaire, engendrée par la force conjointe du soleil et de la lune (onde $K 1$ ). Les courants générés par l'onde $M 2$ (de l'ordre de $20 \mathrm{~cm} / \mathrm{s}$ ) sont trois fois plus forts que ceux induits par l'onde S2. Les courants liés à l'onde K1 sont 10 fois plus faibles, de l'ordre du centimètre par seconde, sauf dans les passes où ils peuvent atteindre $5 \mathrm{~cm} / \mathrm{s}$ (OUILLON et al., 2010).

L'amplitude et la phase des ondes $M 2$ et S2, qui représentent respectivement la variation du niveau de la mer et la direction de propagation des courants, sont illustrées par les fig. 2 et 3. L'onde M2 se propage d'est en ouest, perpendiculairement à la Grande Terre avec une propagation plus rapide au centre de celle-ci. Elle se propage au nord et au sud en la contournant. Elle pénètre dans le lagon sud-ouest principalement par le canal de la Havannah.

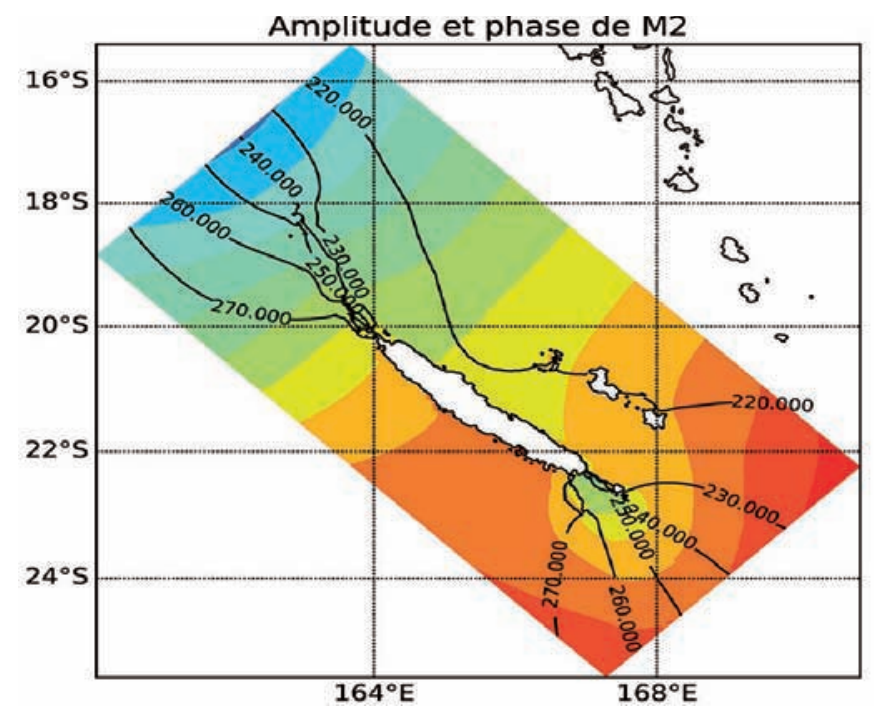

Figure 2 : Phase et amplitude (en mètres) de l'onde $M 2$.
L'amplitude de l'onde M2 est supérieure sur la côte Ouest mais croît de la même façon du nord au sud le long des deux côtes. Dans le lagon sud-ouest, l'amplitude de la marée diminue au niveau du canal de la Havannah puis recroît à l'intérieur du lagon. La propagation de l'onde S2 diffère entre les côtes Est et Ouest. La Grande Terre agit comme une frontière, en particulier le long d'une ligne entre la Grande Terre et l'île des Pins. La Grande Terre a le même effet sur l'amplitude de l'onde S2 que sur celle de M2. Dans le lagon sud-ouest, l'onde croît de la Corne Sud et du canal de la Havannah vers l'intérieur du lagon.

La marée génère un courant quasiment uniforme de la surface au fond. Les courants créés par ces ondes ont la même vitesse sur toute la colonne d'eau. Un exemple de champs de courants dans le canal de la Havannah au sud de la Grande Terre est donné à différentes périodes de la marée (encadré 2).

\section{Les vagues jouent aussi}

La Nouvelle-Calédonie est soumise à des vagues d'origine multiple, à cause de sa position au milieu du Pacifique sud-ouest et dans la zone inter-tropicale. Les tempêtes hivernales des deux hémisphères génèrent des houles longues qui peuvent traverser l'océan. Ainsi, les

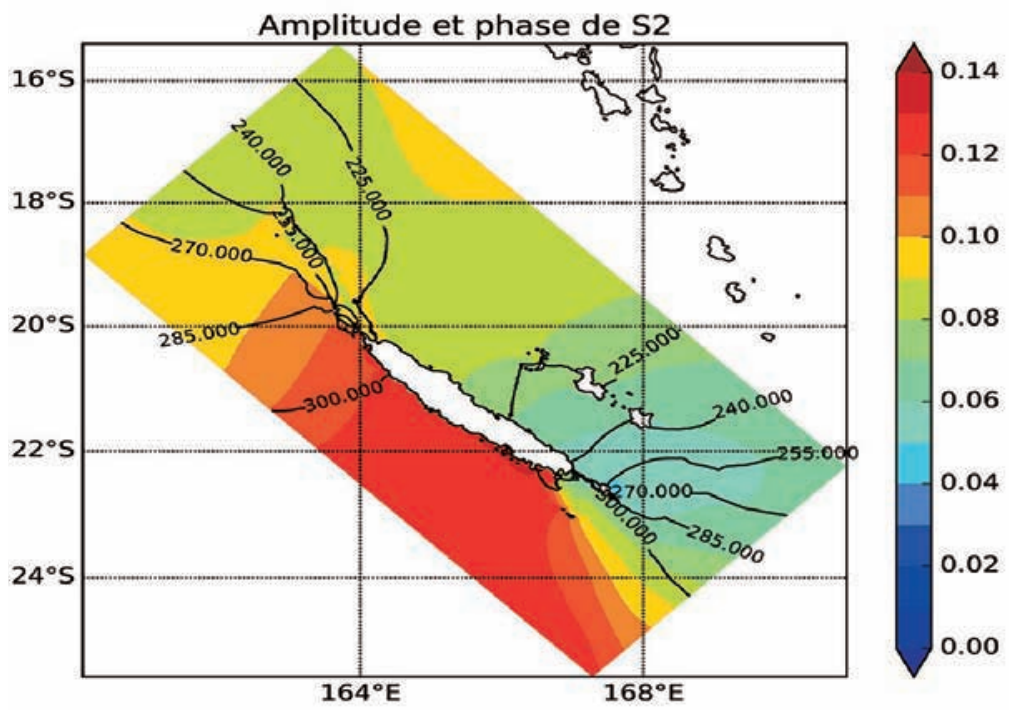

Figure 3 : Phase et amplitude de l'onde S2 
Encadré 2

\section{Va-et-vient dans le canal de la Havannah}

Les courants de marée dans le canal de la Havannah sont très forts. Ils suivent un rythme bien particulier en relation avec la hauteur de la marée. Lors de la basse mer, les courants sont sortants avec une force qui augmente en s'approchant de la passe (de l'ordre de $1 \mathrm{~m} / \mathrm{s}$ ). $4 \mathrm{~h}$ après la marée basse, les courants sont fortement rentrants dans le canal. Ils dépassent $1,5 \mathrm{~m} / \mathrm{s}$ et ils font entrer des masses d'eaux importantes au sud, dans la réserve Merlet. $1 \mathrm{~h}$ après

la haute mer, les courants sont toujours entrants au centre du canal et deux tourbillons se créent sur les côtés nord et sud du canal. C'est par les côtés que la renverse des courants débute. $3 \mathrm{~h}$ après, le courant est sortant avec un maximum en sortie de passe à plus de $1,5 \mathrm{~m} / \mathrm{s}$. En final, la marée crée un courant global, résiduel, entrant dans le lagon et dirigé vers le sud-ouest. Sa force est de l'ordre de quelques centimètres par seconde.
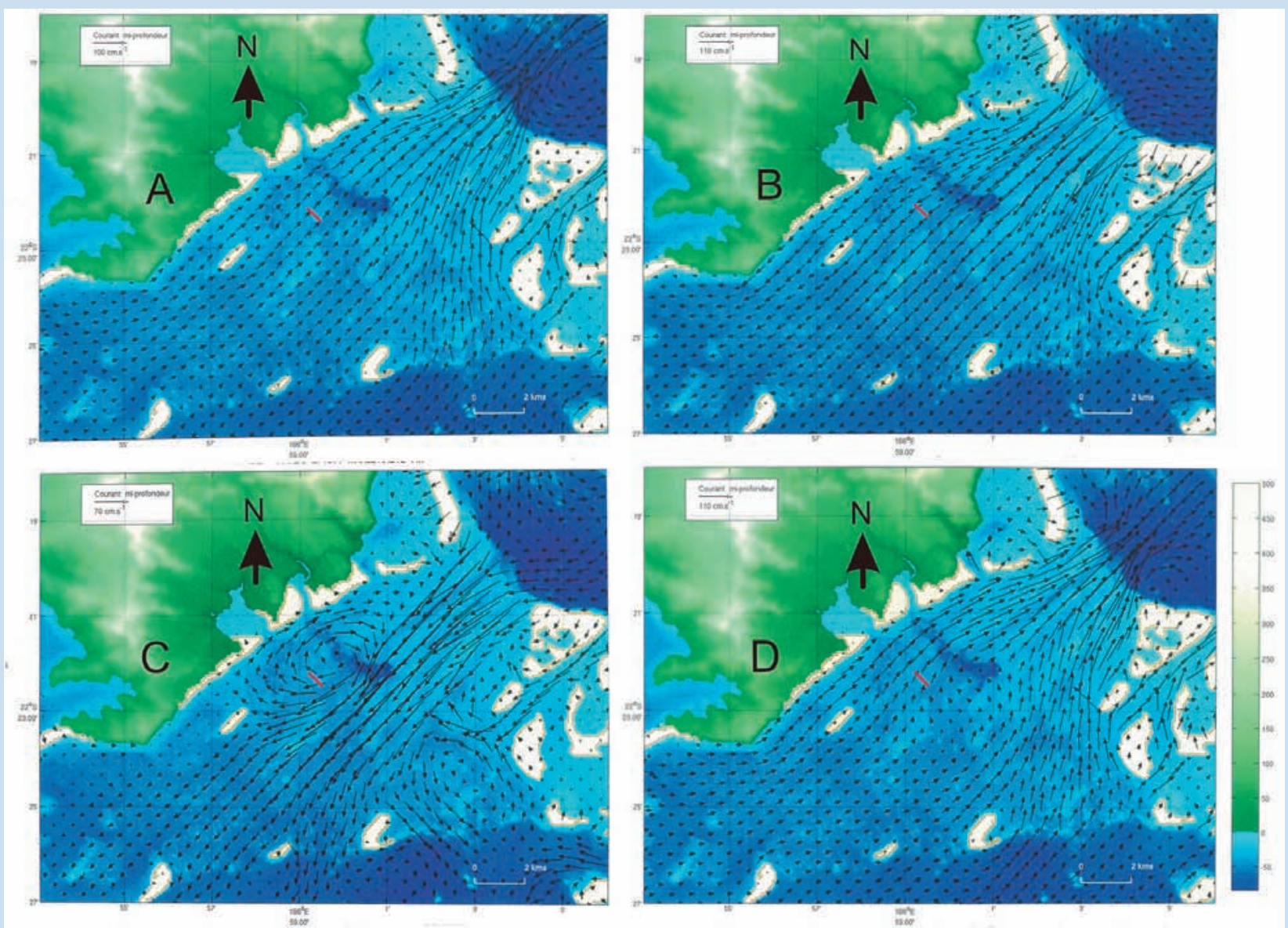

Courants de marée dans le canal de la Havannah. A : basse mer. B : basse mer $+4 \mathrm{~h} . \mathrm{C}:$ haute mer $+1 \mathrm{~h}$. D : haute mer $+4 \mathrm{~h}$. Source : IRD/P.Douillet 
récifs-barrières de la côte ouest de la Grande Terre sont impactés par des houles de sud-ouest qui sont générées par les tempêtes au large de l'Australie ou de la Nouvelle-Zélande et qui peuvent dépasser $4 \mathrm{~m}$ de hauteur. L'île d'Ouvéa, aux îles Loyauté, reçoit des houles de nord-ouest, plus petites, générées par les tempêtes au large du Japon. Tout autour de la Nouvelle-Calédonie, les alizés, vents dominants, produisent localement des vagues. Dans le Grand Lagon Sud-Ouest, cette «mer du vent » peut atteindre $2 \mathrm{~m}$. Enfin Les cyclones tropicaux peuvent générer des vagues extrêmes, supérieures à $10 \mathrm{~m}$. L'effet des vagues est donc multiple. Elles peuvent affecter la circulation de l'eau dans les lagons (encadré 3) et être responsables de l'évolution des plages et des îlots. En plus des courants engendrés par la marée et les vents tempétueux, le déferlement de la houle sur les édifices récifaux et les plages induit la formation d'une surcote de déferlement accompagnée de courants violents, notamment lors d'épisodes cycloniques.

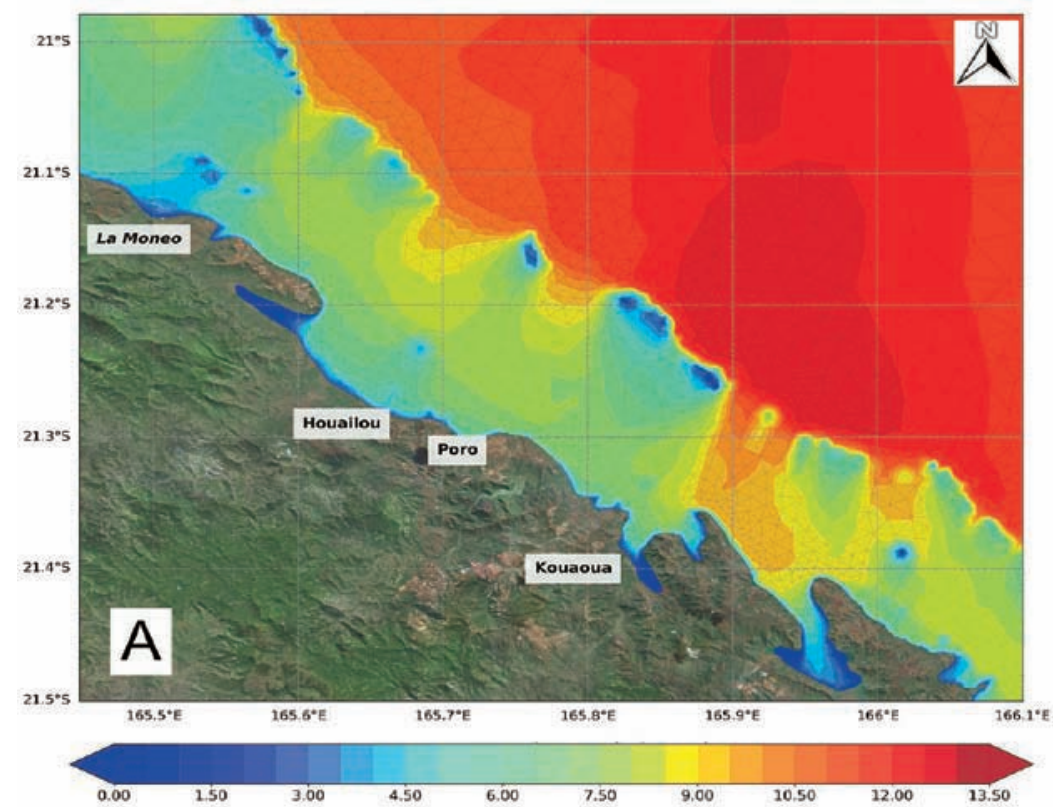

\section{Effet cyclonique}

Situés dans la bordure sud de la zone de convection du Pacifique sud, les lagons sont exposés à l'aléa cyclonique. Les obstacles récifaux (récifs-barrières et frangeants) et les mangroves procurent des services inestimables face aux menaces d'érosion et de submersion. Cependant, la résilience de ces écosystèmes à l'augmentation du niveau de la mer reste méconnue. La simulation de la houle cyclonique générée par le cyclone Cook lors de son arrivée sur Kouaoua détaille comment les édifices récifaux atténuent l'énergie transportée par la houle (fig. 4, A). Les littoraux jouissant d'une double protection (barrière et récifs intermédiaires, exemple embouchure de La Monéo) sont relativement préservés de la houle cyclonique (hauteur des vagues de $3 \mathrm{~m}$ contre $13 \mathrm{~m}$ au large), contrairement aux rivages situés en face des larges passes de Kouaoua et Canala, plus durement exposés (9 $\mathrm{m}$ à la côte contre $13 \mathrm{~m}$ au large). Cet exemple illustre

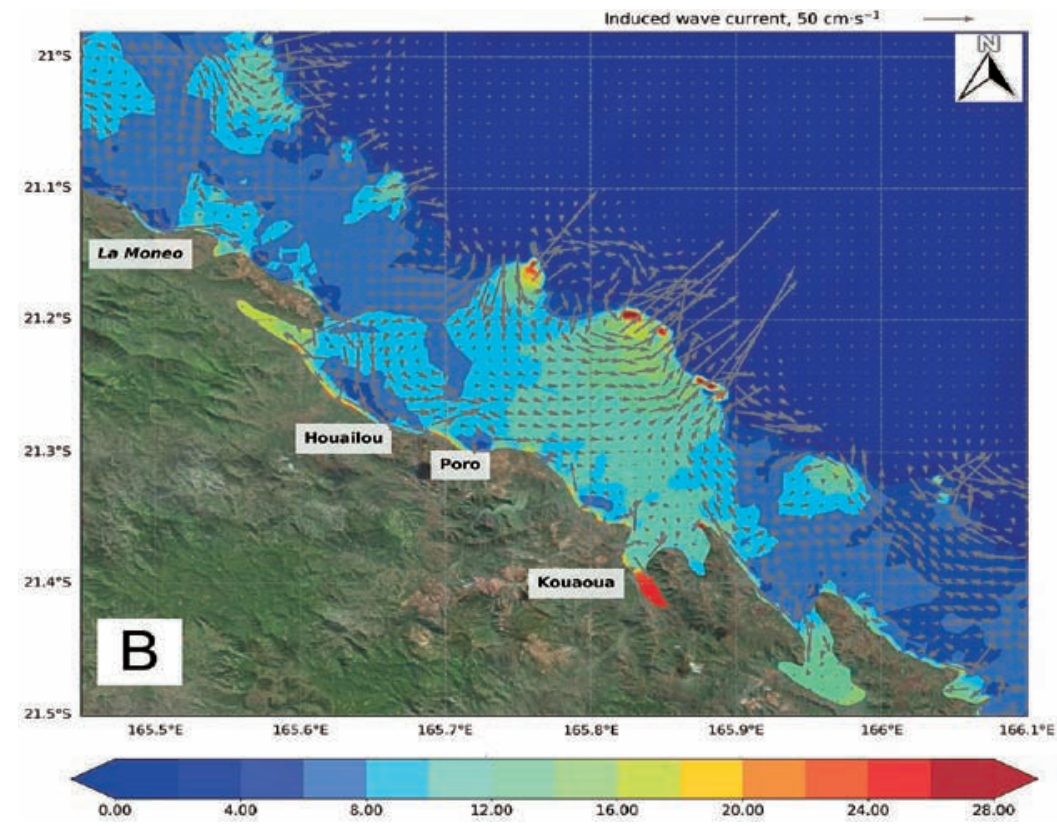

Figure 4 : Cyclone Cook à son paroxysme lors de son arrivée sur Kouaoua (côte est de la Grande Terre), le 9 avril 2017.

A : Hauteurs maximales (en mètres) de la houle simulée avec le modèle de houle SWAN, à $300 \mathrm{~m}$ de résolution.

B : Surcote de déferlement (en centimètres) et courants induits par le déferlement simulés moyennant une modélisation couplée vague-courant utilisant les modèles SWAN et FVCOM. Les données proviennent de Météo-France pour les vents cycloniques, du gouvernement de la Nouvelle-Calédonie (Direction des technologies et des services de l'information) pour la bathymétrie. Le modèle a été au préalable validé avec les observations de houle enregistrées à la passe de la Fourmi, Poindimié. Source : IRD/ J. Lefèvre 
comment une diversité de configuration récifale entraîne une diversité d'exposition au risque « submersion » sur de courtes distances. Les mouvements d'eau engendrés par la houle cyclonique sont à l'origine d'une redistribution spectaculaire des sables et débris coralliens. La simulation couplée vagues-courants permet de restituer l'action du déferlement prédit par le modèle de houle sur les quantités de mouvement simulées. Les surcotes et courants uniquement associés au processus de déferlement lié au cyclone Cook sont présentés sur la figure $4, B$ : sur le récif-barrière, une barre d'eau se forme entraînant une surcote de déferlement de $25 \mathrm{~cm}$, compensée par de puissants courants de retour portant vers le large, de 1 à $2 \mathrm{~m} / \mathrm{s}$. Dans la zone de déferlement proche des plages, on assiste à la formation de veines de courant parallèles au rivage, capables de charrier les sédiments arrachés à la côte. Dans les baies abritées de la houle cyclonique (par exemple, la baie étroite de Kouaoua), le déferlement à l'entrée de la baie agit contre les courants sortant. C'est le phénomène d'ensachage, entraînant une élévation supplémentaire du niveau moyen de 20 à $30 \mathrm{~cm}$.

\section{Le sens du vent et la dispersion des apports terrigènes}

Outre son rôle pour la formation des vagues, le vent agit aussi sur le transport et la dispersion des apports terrestres dans les eaux du lagon. Les écosystèmes coralliens sont exposés aux apports en nutriments, sédiments et polluants émanant de la terre et induisant des effets néfastes sur le corail. Toute altération anthropique du biotope terrestre (fertilisants, augmentation de l' « érodabilité » des sols, pesticides, contaminants) engendre des stress importants pouvant aller jusqu'à l'étouffement par la sédimentation. Les lagons néo-calédoniens ne font pas exception. Les rivières néocalédoniennes présentent un fonctionnement hydrologique caractéristique des îles tropicales hautes, à savoir une montée en charge rapide et intense.
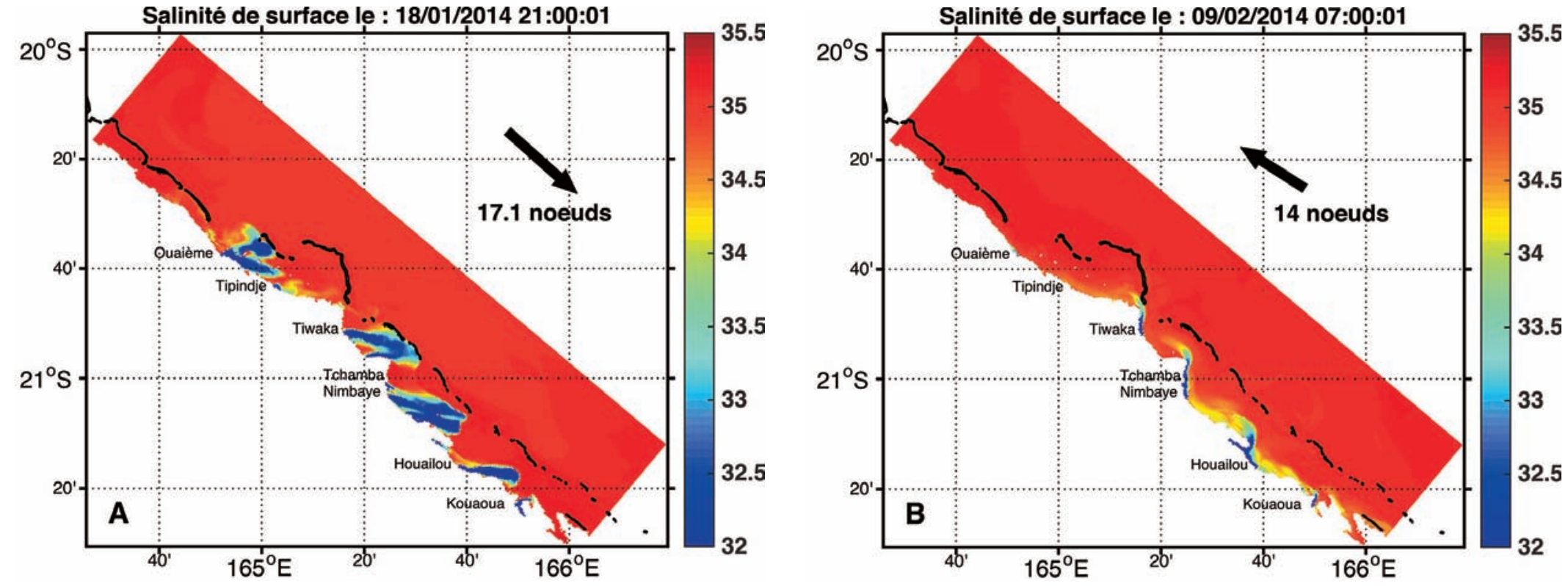

Figure 5 : Instantanés de distribution de la salinité de surface simulée par le modèle MARS3D (http://wwz.ifremer.fr/mars3d/), en unité PSU.

A : Pendant la dépression tropicale modérée June (janvier 2014) avec un vent de nord-ouest.

B : Suite à une crue début février 2014 en régime d'alizés. Seules les rivières les plus importantes ont été intégrées dans la modélisation. Source : Ifremer/R. Legendre 


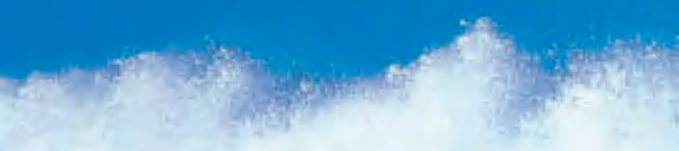

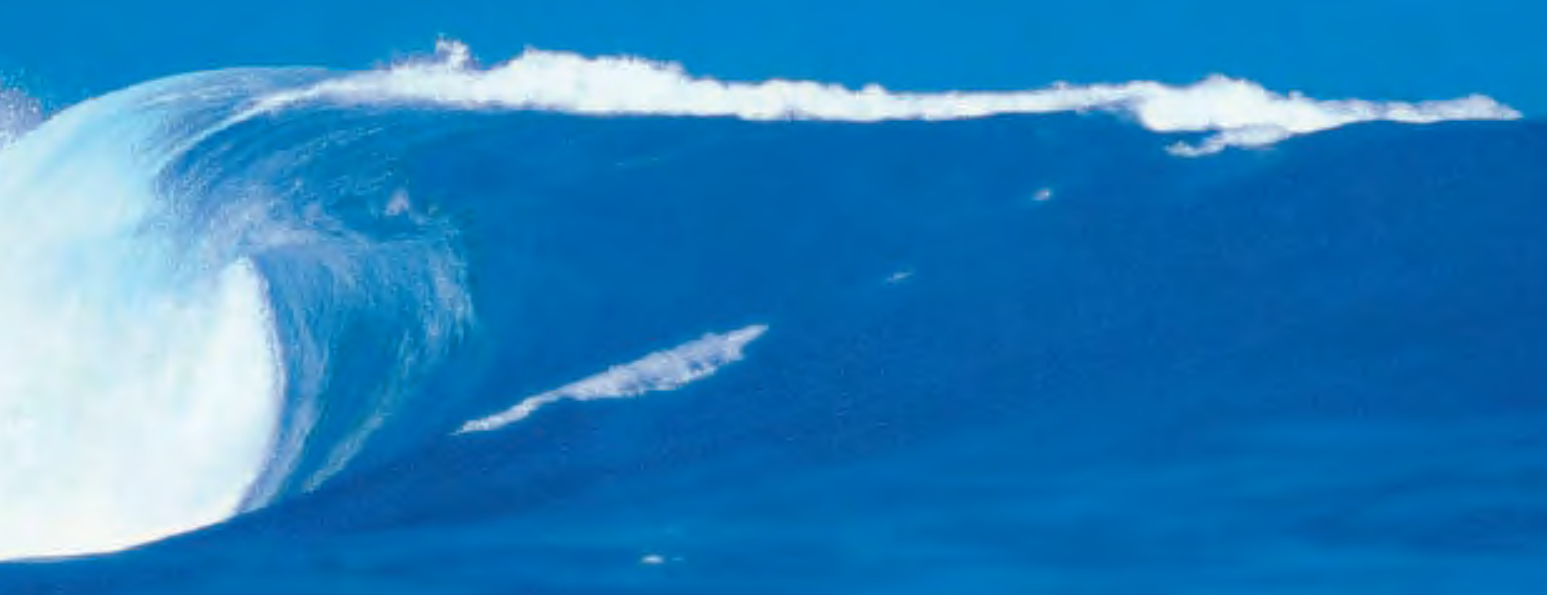

- 


\section{Encadré 3 \\ Influence de la houle sur la vidange du lagon}

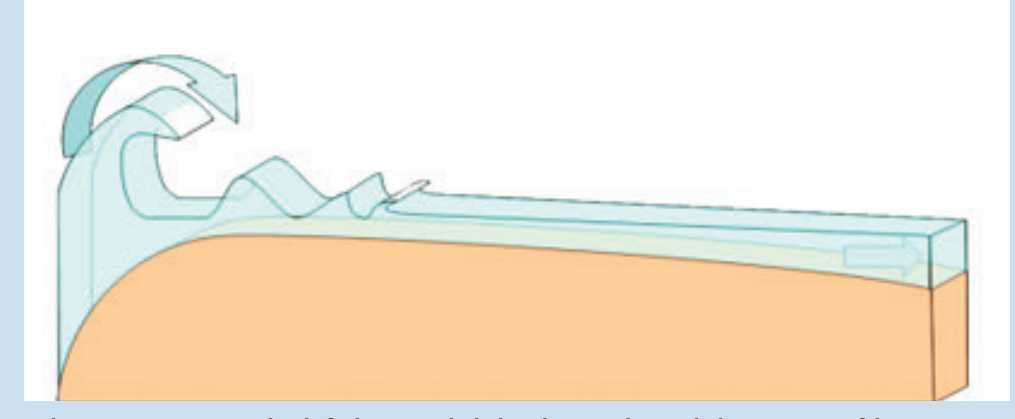

Schéma représentant le déferlement de la houle par-dessus la barrière récifale.

Le récif-barrière est plus haut sur la côte Ouest que sur la côte Est. Sur la côte Ouest, il affleure aux marées basses. Le déferlement de la houle du large agit sur le lagon comme une barrière physique empêchant la sortie des eaux du lagon par-dessus la barrière. Ce sont les eaux du large qui pénètrent ainsi dans le lagon. Ce flux est de l'ordre de $0,25 \mathrm{~m} / \mathrm{s}$ par mètre linéaire de barrière pour une houle moyenne (BONNETON et al., 2007) et influence les temps de résidence des eaux dans le lagon. Dans la partie nord du lagon sud-ouest, cette modification est particulièrement visible, les temps de résidence passe de 25 jours à moins d'un jour le long de la barrière avec l'ajout de la houle et a contrario augmente de la même proportion à la côte.

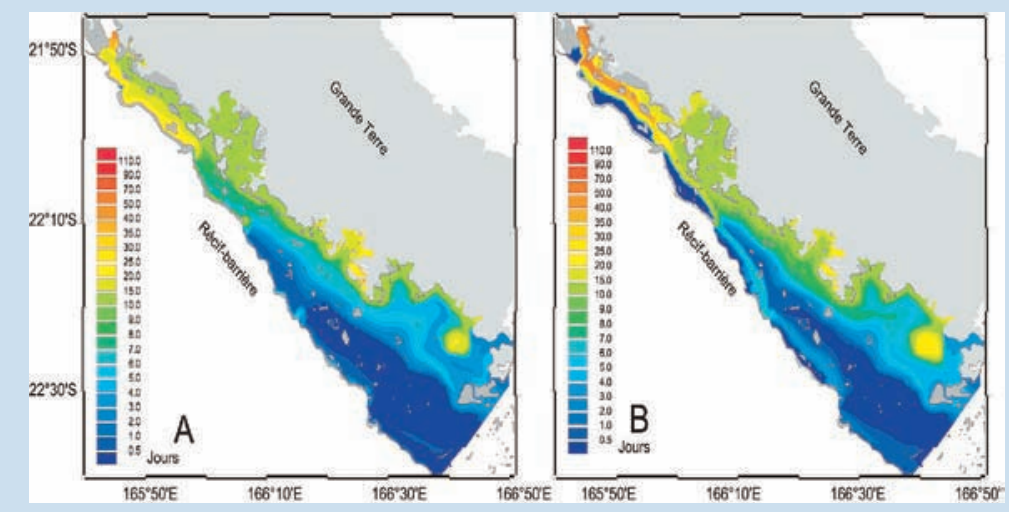

Temps de résidence dans le lagon sud-ouest. A : sans déferlement. $B$ : avec déferlement.
Les interactions atmosphériques avec la topographie locale induisent une disparité assez forte entre la côte est (plus arrosée) et la côte ouest de la Grande Terre (LEFEVRE et al., 2010). OUILLON et al. (2010), les facteurs influençant la variabilité basse fréquence de la salinité au sein des lagons sont en premier lieu le rythme saisonnier (saison sèche/humide), suivi des conséquences d'Enso (El NiñoSouthern Oscillation). À plus haute fréquence, les processus majeurs structurant la distribution de la salinité au sein des lagons sont les vents et les débits rencontrés. Les modèles hydrodynamiques permettent d'appréhender la distribution spatio-temporelle des panaches émanant des différents fleuves de la Grande Terre.

La figure 5 illustre l'extension spatiale des panaches sur la côte Est, simulés par modèle après deux épisodes pluvieux importants. Sur la côte Est, en situation de vents d'alizés de sud-est, les panaches sont rabattus vers le nord, le long de la côte, tandis qu'un vent de nord-ouest transporte les panaches vers l'est et le sud, vers le milieu océanique.

\section{Références bibliographiques}

BONNETON P. et al., 2007 Tidal modulation of wave-setup and waveinduced currents on the Aboré coral reef, New Caledonia. J. Coastal Research, Special Issue 50 : 762-766.

CRAVATTE S. et al., 2015 Regional circulation around New Caledonia from two decades of observations. Journal of Marine Systems, $148: 249-271$.

DOUILLET P. et al., 2013 « L'hydrodynamique du lagon sud-ouest ». In : Bonvallot J. (coord.), Gay J.-C. (coord.), Habert E. (coord.), Atlas de la Nouvelle-Calédonie, Marseille, Nouméa, IRD Éditions, Congrès de la Nouvelle-Calédonie : 41-44.

LEFÈVRE J. et al., 2010 Weather regimes and orographic circulation around New Caledonia. Marine Pollution Bulletin, Numéro spécial, New Caledonia tropical lagoons: an overview of multidisciplinary investigations, $61: 413-431$. MARCHESIELLO P.et al., 2010 Coastal upwelling, circulation and heat balance around New Caledonia's barrier reef. Marine pollution bulletin, 61 (7) : 432-480.

OUILLON S. et al., 2010 Circulation and suspended sediment transport in a coral reef lagoon: the southwest lagoon of New Caledonia. Marine Pollution Bulletin, 61 (7-12) : 269-296. 


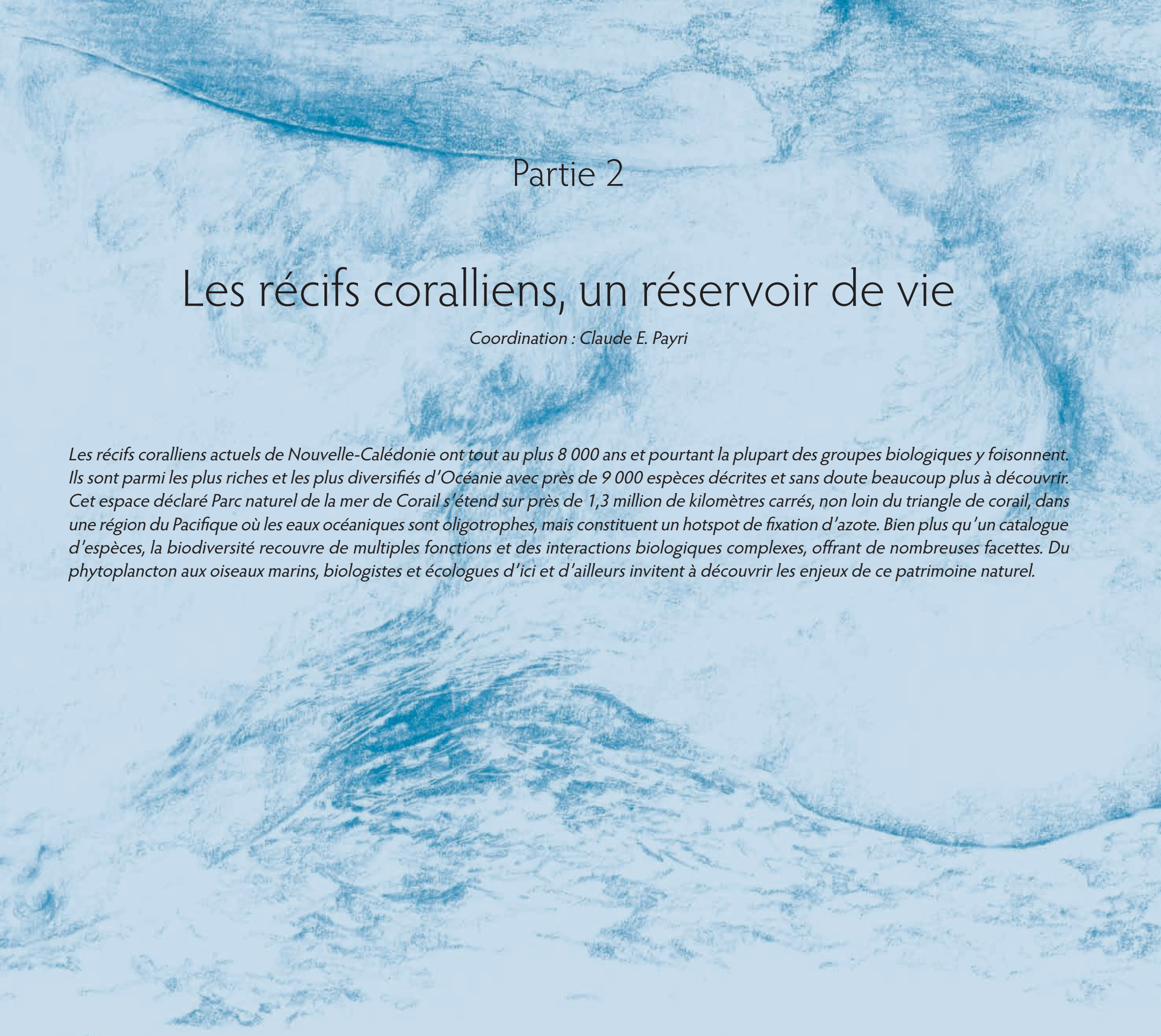





\section{Chapitre 5 \\ Les coraux de récifs de Nouvelle-Calédonie, un patrimoine diversifié et précieux}

Francesca Benzoni

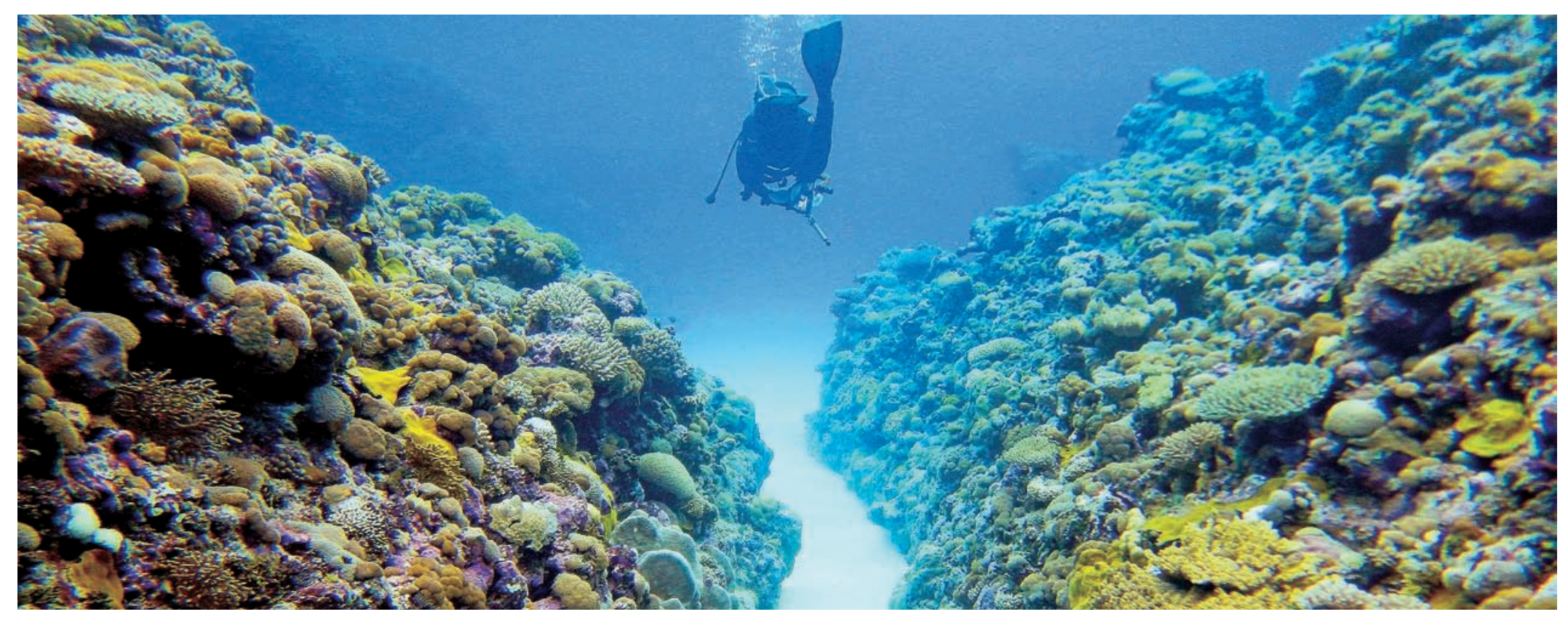

Entre des montagnes de coraux : un plongeur évolue dans un sillon entre deux éperons de récifs aux Chesterfield. @ IRD/F. Benzoni

Bien qu'ils ne ressemblent pas à des animaux, les coraux de récifs sont des invertébrés très anciens. Ils appartiennent à un groupe d'animaux exclusivement aquatiques appelés cnidaires, qui seraient apparus dans les océans il y a 600 millions d'années. Les cnidaires se présentent soit sous forme de méduse libre dérivant dans la colonne d'eau, soit sous forme de polype fixé sur le fond. Certaines espèces alternent entre les deux formes au cours de leur cycle de vie. Quelle que soit la forme, l'organisation est simple, constituée d'un corps mou et principalement composé d'eau, en forme de sac avec une bouche entourée d'une couronne de tentacules.

Les coraux durs passent toute leur vie, génération après génération, sous la forme d'un polype dont la forme est assez similaire à celle d'une anémone. Cependant, bien qu'ils soient des proches parents des anémones de mer colorées, leur organisation interne diffère, la plus visible étant la présence d'un solide squelette blanc constitué de carbonate de calcium (de composition similaire à celle du calcaire). À leur mort, le fait de laisser un squelette permet de garder une trace dans les archives fossiles.

Les premiers fossiles de coraux durs remontent à environ 240 millions d'années, mais grâce à l'étude de l'ADN des espèces vivantes, il a été possible de montrer que les coraux durs sont plus anciens et remonteraient au Paléozoïque il y a 425 millions d'années. C'est à peu près à cette même époque que les premières plantes ont commencé à coloniser la Terre. 


\section{Encadré 4 \\ Une première observation outre-mer de ponte corallienne}

Pascale Joannot

En 1986, selon nos collègues australiens, la ponte en masse des coraux avait lieu en général entre les $3^{\mathrm{e}}$ et $6^{\mathrm{e}}$ nuits après la première pleine lune d'été sous nos latitudes tropicales.

Ce phénomène n'avait encore jamais été observé dans les collectivités d'outre-mer. En Nouvelle-Calédonie, j'avais mobilisé, dès le lendemain de la pleine lune du lundi 13 novembre 1989, toute une équipe de scientifiques, plongeurs, journalistes, dont une partie observait en mer et l'autre à l'aquarium de Nouméa devenu une ruche nocturne où nos lampes de poche balayaient les bacs dans l'espoir de voir enfin la fameuse « nuit d'amour des coraux ». À la fin de la quatrième nuit de « planque », les coraux traités de tous les noms d'oiseaux ne faisaient plus recette et le samedi soir toute l'équipe avait déserté l'aquarium. Cependant ce soir du 18 novembre, les alizés, bien établis à cette époque, étaient tombés et j'eus l'intuition que les coraux pondraient.Je me rendis à l'aquarium

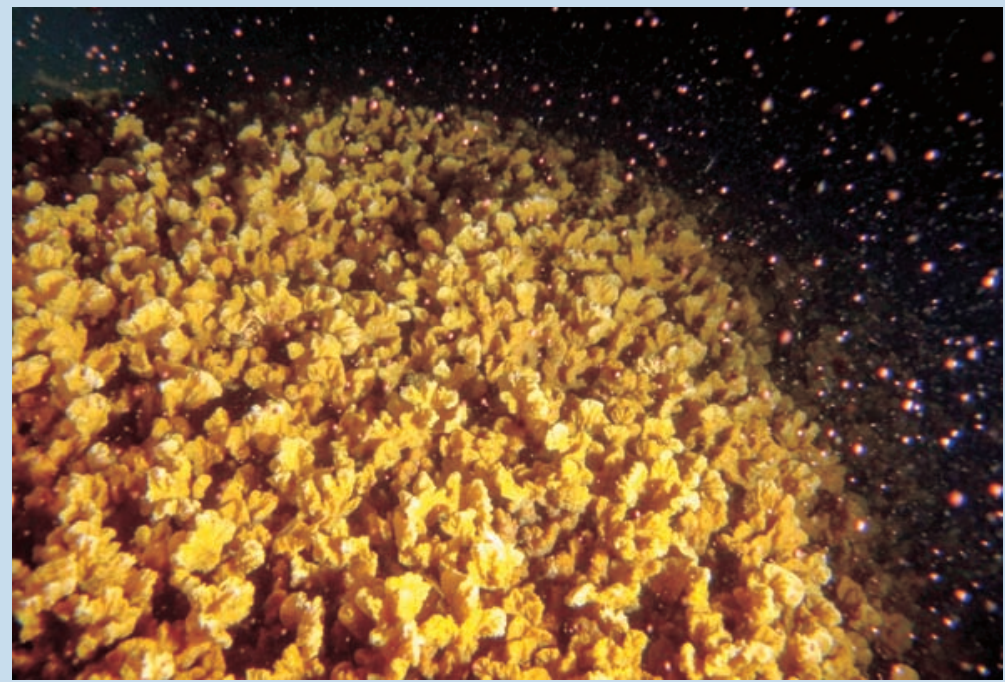

Ponte du corail Merulina scabricula survenue le 1er décembre 2015 dans le lagon de Nouméa. Les gamètes sont émis dans la colonne d'eau et remontent à la surface grâce au contenu riche en lipides. @ Biocénose/G. Lasne et dans le faisceau de ma lampe j'aperçus enfin le signal !

Des milliers de petites perles roses apparaissaient timidement à la surface des coraux, prêtes à s'aventurer au hasard des flots. Émerveillée, je pris quelques photos et appelai mes collègues pour partager ce magnifique spectacle.

Alain Gerbault ${ }^{\dagger}$, plongeur regretté de l'aquarium, plongea à la baie des Citrons et confirma que la ponte se déroulait également en mer. Claude Bretegnier, journaliste à RFO, filma la fumée de semence d'un corail solitaire ! Caractéristiques de la ponte du corail, les traînées roses aperçues le dimanche matin, confirmaient la ponte dans les lagons de la côte Ouest.

Ainsi, la Nouvelle-Calédonie est la première collectivité d'outremer où la ponte en masse du corail a été observée et décrite.

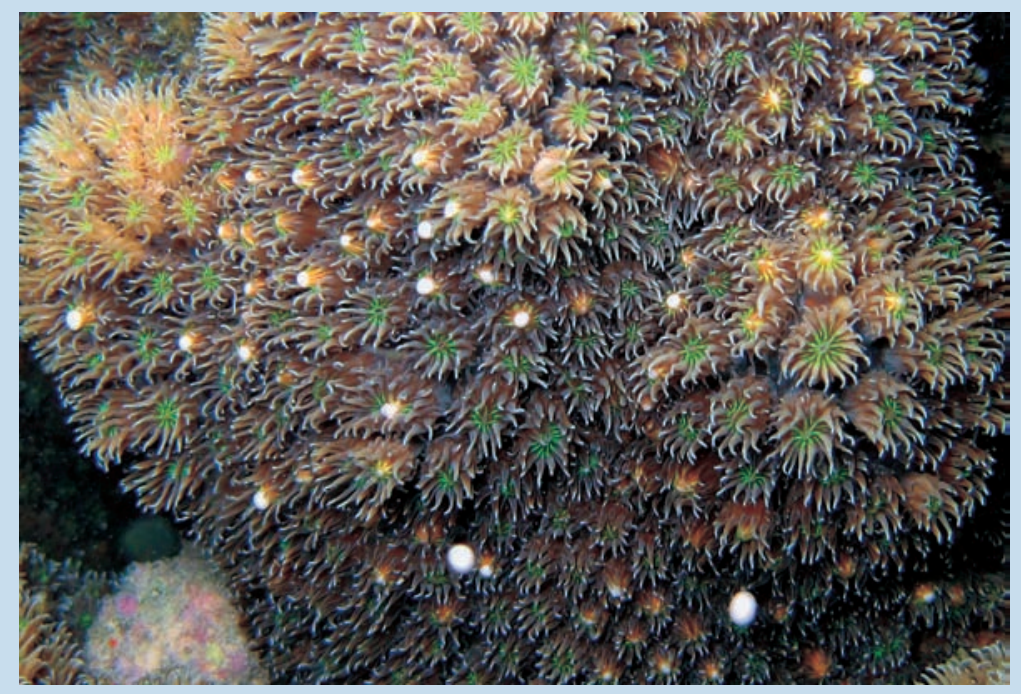

Ponte du corail Galaxea fascicularis survenue le 9 septembre 2009 dans le lagon de Nouméa. Les petites boules blanches qui s'échappent par la bouche des polypes sont les gamètes femelles qui vont se disperser dans la colonne d'eau où ils seront fécondés pour donner une larve. @ Biocénose/G.Lasne 


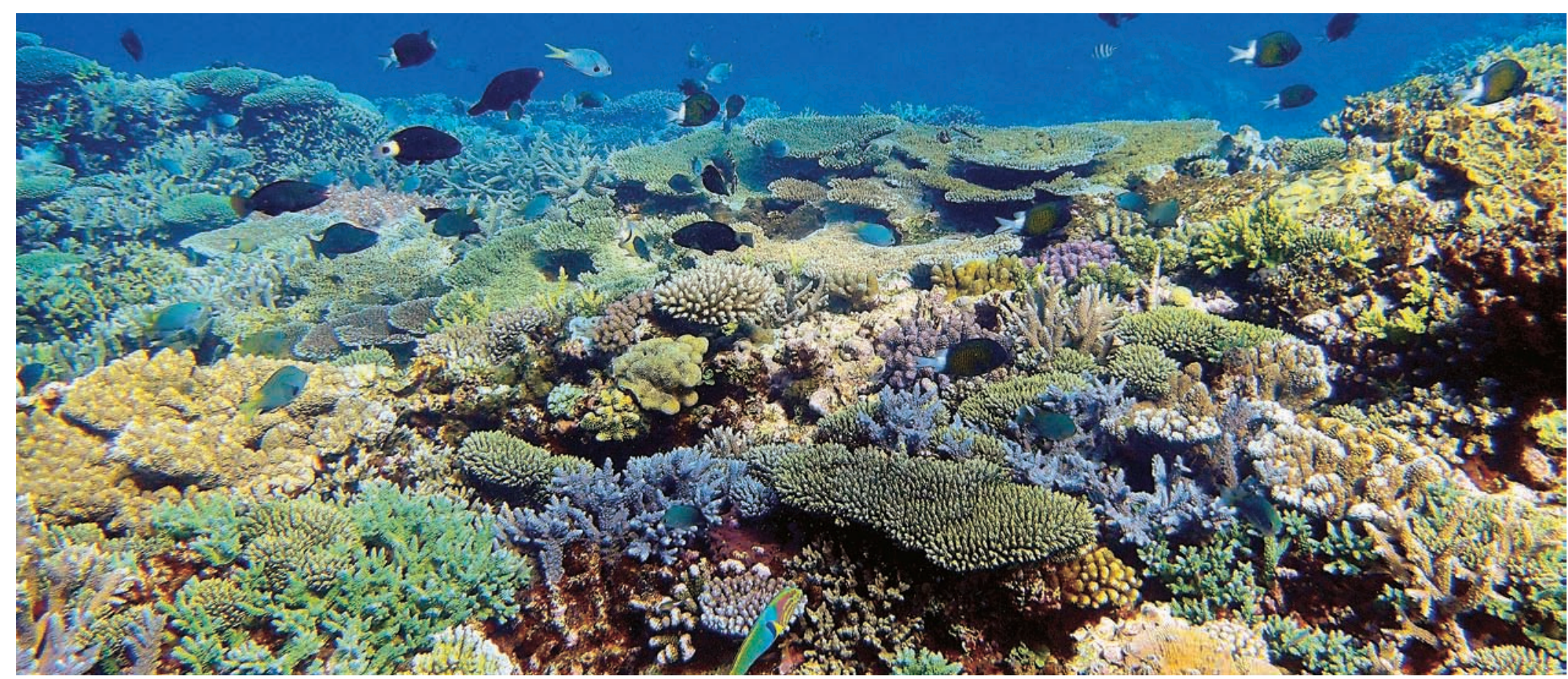

Assemblage de coraux à zooxanthelles dans un environnement bien éclairé formant une communauté à fort recouvrement corallien en bonne santé ; pente externe sur la côte ouest de la Grande Terre. (c) IRD/F. Benzoni

\section{L'évolution des coraux durs}

Fait intéressant, les premiers coraux durs ne ressemblaient en rien à ceux que l'on peut observer aujourd'hui sur un récif corallien : ils vivaient dans des eaux profondes, sombres et froides, et étaient relativement de petite taille. Au fil du temps, certains coraux durs sont remontés des profondeurs, se sont adaptés à la vie en eaux moins profondes et sont devenus de plus en plus coloniaux (ayant ainsi plusieurs polypes identiques) pour atteindre des tailles plus grandes. Une fois dans les eaux peu profondes et bien éclairées, les coraux durs ont établi une relation symbiotique avec des algues unicellulaires vivant dans leurs tissus, appelées zooxanthelles. Ce type $d$ 'association entre animaux marins et algues unicellulaires est assez commune dans nos océans, car elle est efficace et mène à une situation gagnant-gagnant pour les deux parties. L'algue acquiert une protection physique au sein de l'animal hôte, et celui-ci obtient de l'algue un apport énergétique car celle-ci réalise la photosynthèse et transforme ainsi l'énergie solaire en sucres. Cet apport énergétique supplémentaire permet au corail de produire plus efficacement son squelette calcaire et ainsi les coraux symbiotiques sont de meilleurs bâtisseurs de squelette. Cependant, du fait que les zooxanthelles ont besoin de lumière, le corail hôte est contraint de vivre dans des zones peu profondes et bien éclairées. Aujourd'hui, il existe environ 1400 espèces de coraux durs vivants, parmi lesquels environ la moitié est symbiotique et vit dans des eaux plus proches de la surface, et l'autre moitié est dépourvue de zooxanthelles et vit dans des eaux plus profondes jusqu'à $6000 \mathrm{~m}$ de profondeur. Les espèces zooxanthellées sont principalement concentrées dans la ceinture tropicale. Elles incluent de grands constructeurs de récifs, formant et entretenant l'un des écosystèmes les plus diversifiés, productifs et économiquement importants : les récifs coralliens. Bien que comparativement moins diversifiés en nombre d'espèces, les récifs coralliens profonds, formés par certaines espèces de coraux 
dépourvus de zooxanthelles, soutiennent un écosystème important et productif encore relativement mal connu. Les systèmes récifaux profonds et peu profonds sont précieux et économiquement importants, et sont actuellement soumis à un certain nombre de menaces locales et mondiales tels que le développement démographique et les usages croissant des ressources, le réchauffement des eaux qui a une conséquence directe sur la vitalité des coraux (blanchissement du corail, chap. 25) et l'acidification des océans. Une situation qui a conduit les scientifiques à définir et déclarer une crise mondiale des récifs coralliens.

\section{Des zones de concentration coralliennes}

Les espèces coralliennes des eaux peu profondes formant des récifs coralliens ne sont pas équitablement réparties sous les tropiques: les faunes coralliennes de l'Atlantique et de l'IndoPacifique sont très différentes, la seconde étant plus riche et plus diversifiée. Dans la région Indo-Pacifique, un hot spot de diversité des coraux durs a été décrit dans la zone qui englobe à peu près les Philippines, la Papouasie-Nouvelle-Guinée, l'Indonésie et la Malaisie et que l'on nomme le «triangle de corail ». On y trouve la plus forte concentration de coraux durs avec jusqu'à 500 espèces. Ce hot spot de biodiversité concerne non seulement les coraux, mais également plusieurs autres invertébrés et poissons ainsi que les plantes marines. Plusieurs facteurs ont contribué à travers le temps à cette concentration de la diversité de la vie marine. Il s'agit, entre autres, des variations au cours du temps géologique du niveau de la mer, de l'hétérogénéité élevée actuelle des habitats avec un gradient marqué des côtes vers le large, d'apport de nutriments, de salinité, d'hydrodynamisme et de turbidité. En dehors du triangle, la diversité tend à s'estomper progressivement pour atteindre ses valeurs les plus basses dans le Pacifique est. La Nouvelle-Calédonie se situe non loin au sud des limites du triangle de corail, à l'extrémité orientale de la mer de Corail. La proximité de ce haut lieu de diversité marine peu profonde explique en partie la richesse et la variété des écosystèmes marins et des récifs coralliens néo-calédoniens qui sont intégrés dans la plus grande aire marine protégée française créée à ce jour, le parc naturel de la mer de Corail, dont une partie est inscrite sur la Liste du patrimoine mondial de l'Unesco (encadré 5).

\section{Une géomorphologie très propice aux habitats récifaux}

Un autre facteur important qui a conduit à la diversité des récifs coralliens de Nouvelle-Calédonie et des coraux récifaux est la remarquable hétérogénéité géomorphologique de l'île qui fournit une grande variété d'habitats récifaux abritant de multiples espèces de faune et de flore marines. Ces habitats incluent des baies et des sites lagonaires, dans lesquels le benthos récifal est soumis à des fortes charges en sédiments terrigènes, conduisant à des assemblages d'espèces, des répartitions et des morphologies inhabituelles (par exemple dans la baie du Prony et au banc Gail) (encadré 6).

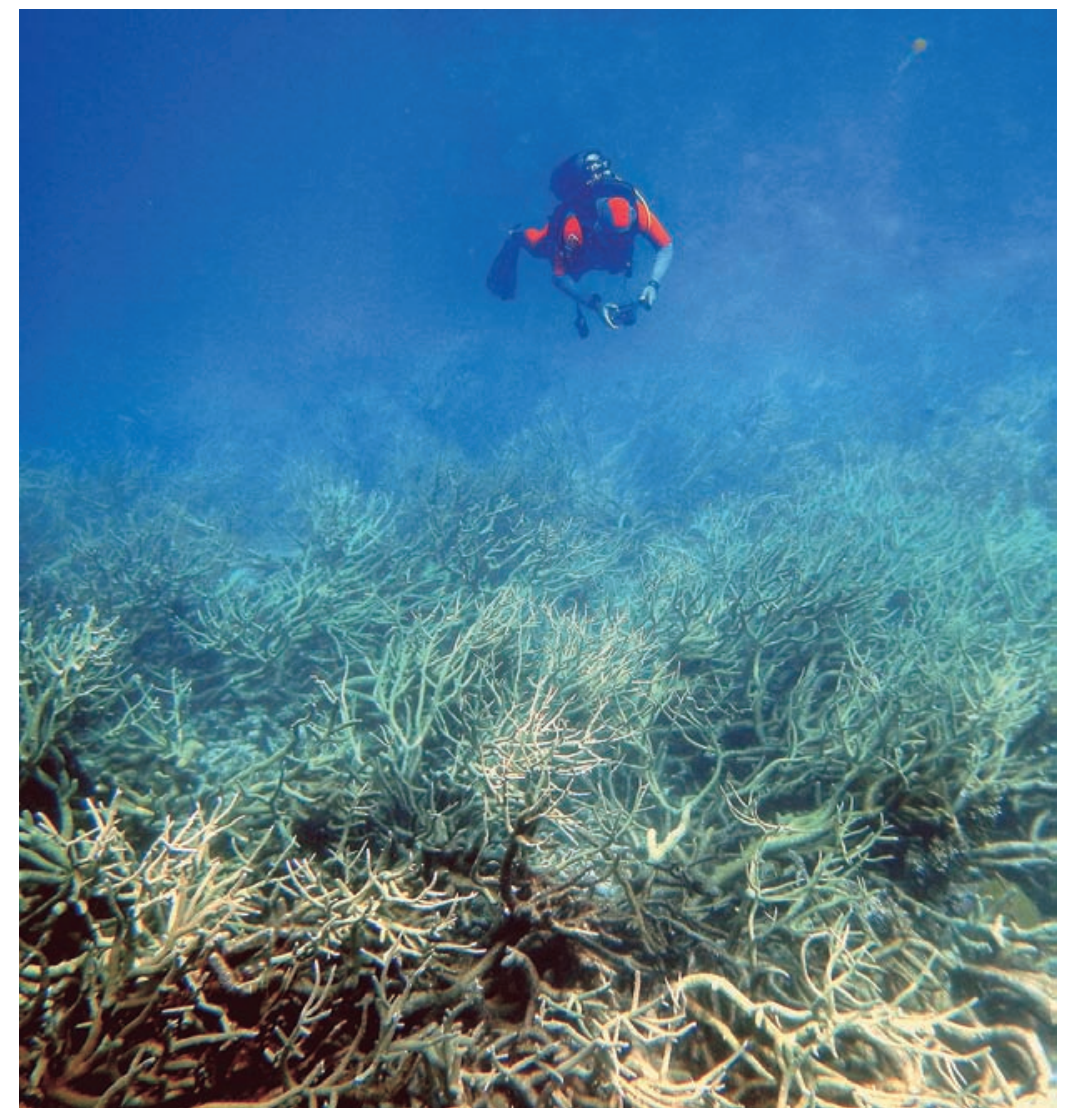

Planant sur le fragile jardin de d'Acropora branchu dans le lagon intérieur des récifs d'Entrecasteaux, lieu de ponte pour les poissons (faible diversité en espèces de coraux durs et haute fonction écologique). ( ) IRD/F. Benzoni 


\section{Encadré 5}

\section{Le parc naturel de la mer de Corail : un foisonnement d'espèces}

Marie-Hélène Merlini et Julie-Anne Kerandel

Les scientifiques sont unanimes. Lors des plongées effectuées sur les récifs des îles éloignées à l'occasion d'inventaires de la biodiversité, la surprise est de taille. Sous leurs yeux, des poissons plus gros, des poissons peu craintifs, beaucoup de prédateurs : des carangues, des loches au comportement surprenant de curiosité. Laurent Wantiez, maître de conférences en écologie marine à l'université de Nouvelle-Calédonie, est formel : « Pratiquement à chaque plongée, vous allez voir entre un et dix requins, des bancs de perroquets à bosse, des grosses carangues, des thons à dents de chien [...]. Toutes ces espèces sont en abondance dans ces récifs (Campagne Bioreef 2016)».

\section{Continuer à accroître les connaissances}

Pour évaluer avec précision la richesse biologique des récifs coralliens du parc naturel, des campagnes scientifiques dédiées sont organisées depuis 2006. Objectif : réaliser un comptage des espèces à partir d'un tracé défini au préalable. En l'état actuel des connaissances sur de nombreux groupes d'espèces dans les zones étudiées (Chesterfield, Entrecasteaux, Astrolabe), on peut d'ores et déjà indiquer qu'il existe sur les récifs d'Entrecasteaux et de l'Astrolabe une grande richesse en poissons, dont des requins en bonne santé. Les récifs des Chesterfield, eux, renferment une ressource remarquable en algues, coraux, échinodermes (animaux marins tels que les oursins, les étoiles de mer, les holothuries), poissons de récif (perroquets, loches, poissons-papillons...), requins serpents de mer...

Les récifs coralliens, ou écosystèmes récifo-lagonaires, abritent $25 \%$ des espèces marines connues par l'homme (MC ALLISTER, 1995 ; BURKE et al., 2012), et donc jouent un rôle majeur pour de nombreuses espèces. Du fait de leur isolement, les récifs du parc naturel de la mer de Corail peuvent présenter des spécificités.
Par exemple, certains organismes ne se dispersent peu, voire pas du tout, favorisant ainsi l'apparition de nouvelles espèces encore méconnues. La connectivité entre les récifs du parc et les pays voisins, indispensable au bon fonctionnement des écosystèmes, attire également l'attention des scientifiques. La biodiversité du parc naturel est bien loin d'avoir livré tous ses secrets.

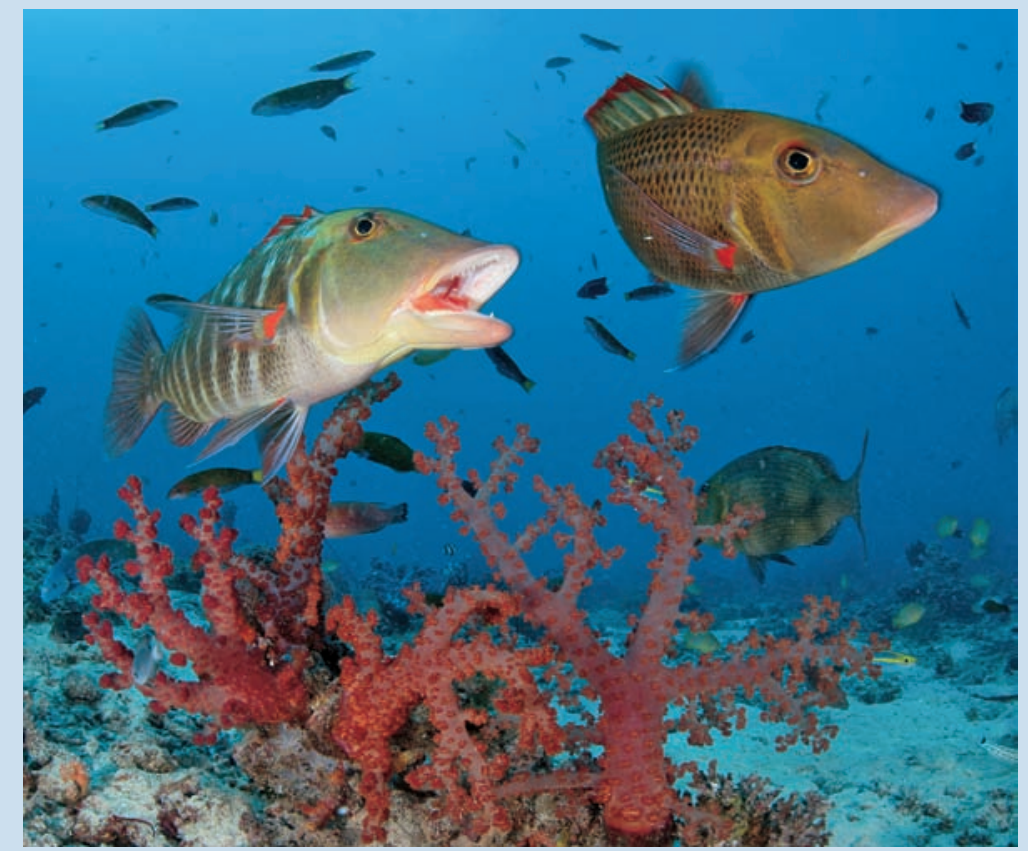

Lethrinus miniatus ou gueule rouge n'est pas craintif et peut se montrer agressif en mordant tout ce qui bouge. $\odot$ M. Juncker

\section{Références bibliographiques}

BURKE et al., 2012 Récifs coralliens en péril. Revisité : synthèse à l'intention des décideurs. World resources institute, Washington D.C., 45 p. MC ALLISTER, 1995 Status of the World Ocean and its Biodiversity. Sea Wind, $9: 1-72$. 


\section{Les champions de la boue}

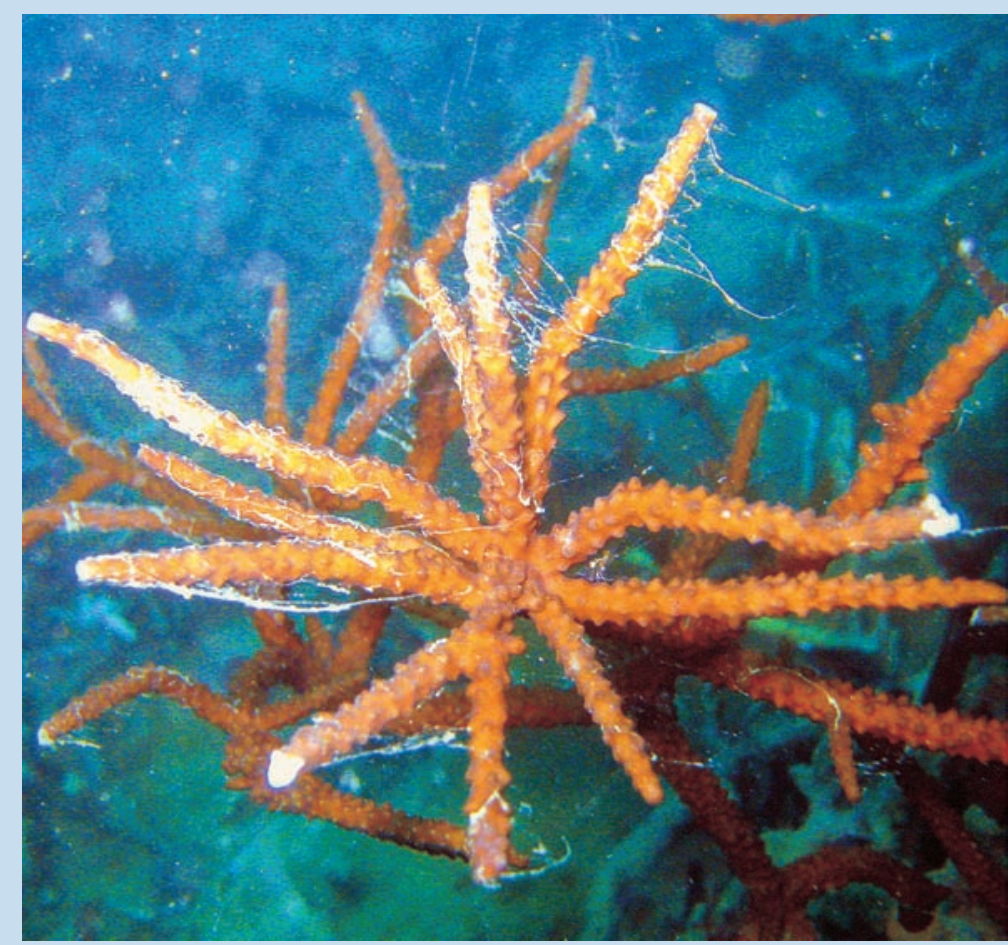

Acropora tortuosa produisant du mucus qui piège les sédiments (banc des Japonais). (c) IRD/F. Benzoni

Les coraux de récifs vivent et se développent généralement dans des eaux claires et bien éclairées. En effet, des expériences ont démontré qu'un excès de sédiments peut se déposer sur le polype du corail et l'obstruer jusqu'à sa mort. En effet, se débarrasser des sédiments n'est pas une tâche facile pour un organisme qui vit attaché au substrat. Par conséquent, on pourrait s'attendre à ce que les environnements turbides constituent des habitats moins attrayants pour les coraux.

Le long du littoral de la Grande Terre se trouvent de nombreuses baies protégées du mouvement des vagues où le fond est constitué de sédiments fins, souvent vaseux. Certains d'entre eux

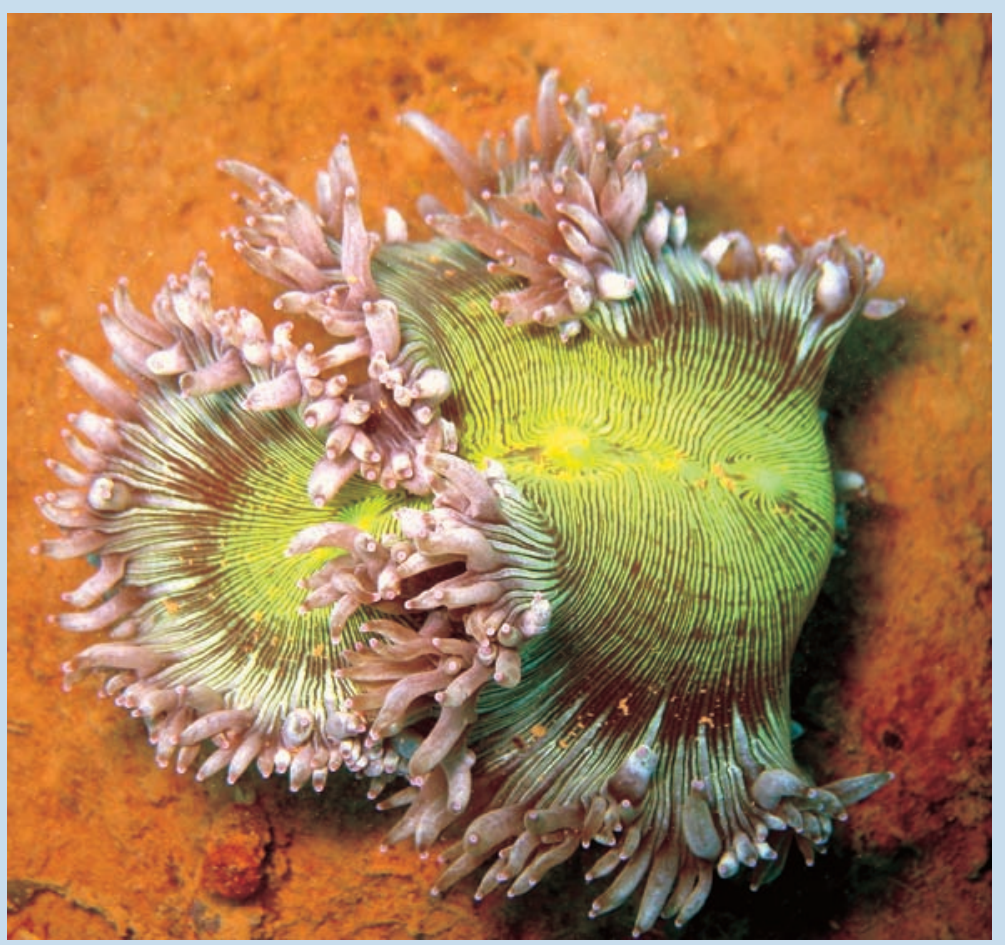

Catalaphyllia jardinei, qui étale ses polypes mous et colorés, pouvant atteindre jusqu'à 2/3 du volume du squelette (banc Gail). ๑ IRD/F. Benzoni

sont chargés en terre rouge provenant des sols naturellement érodés et délavés, d'autres ont une charge terrigène accrue par les activités humaines directes ou indirectes. Une communauté de coraux très spéciale vit dans ces habitats, comprenant des espèces qui y vivent presque exclusivement, comme l'espèce de corail endémique de Nouvelle-Calédonie, Cantharellus noumeae. Comment font ces coraux ? Ils maîtrisent deux stratégies qui, habilement combinées, leur permettent de s'épanouir dans la boue. La première nécessite la production de mucus. Très efficace, le mucus visqueux abondamment produit par ces coraux est leur précieux allié. Une fois le sédiment piégé dans le mucus, le corail s'en débarrasse par le mouvement de ses tentacules. 


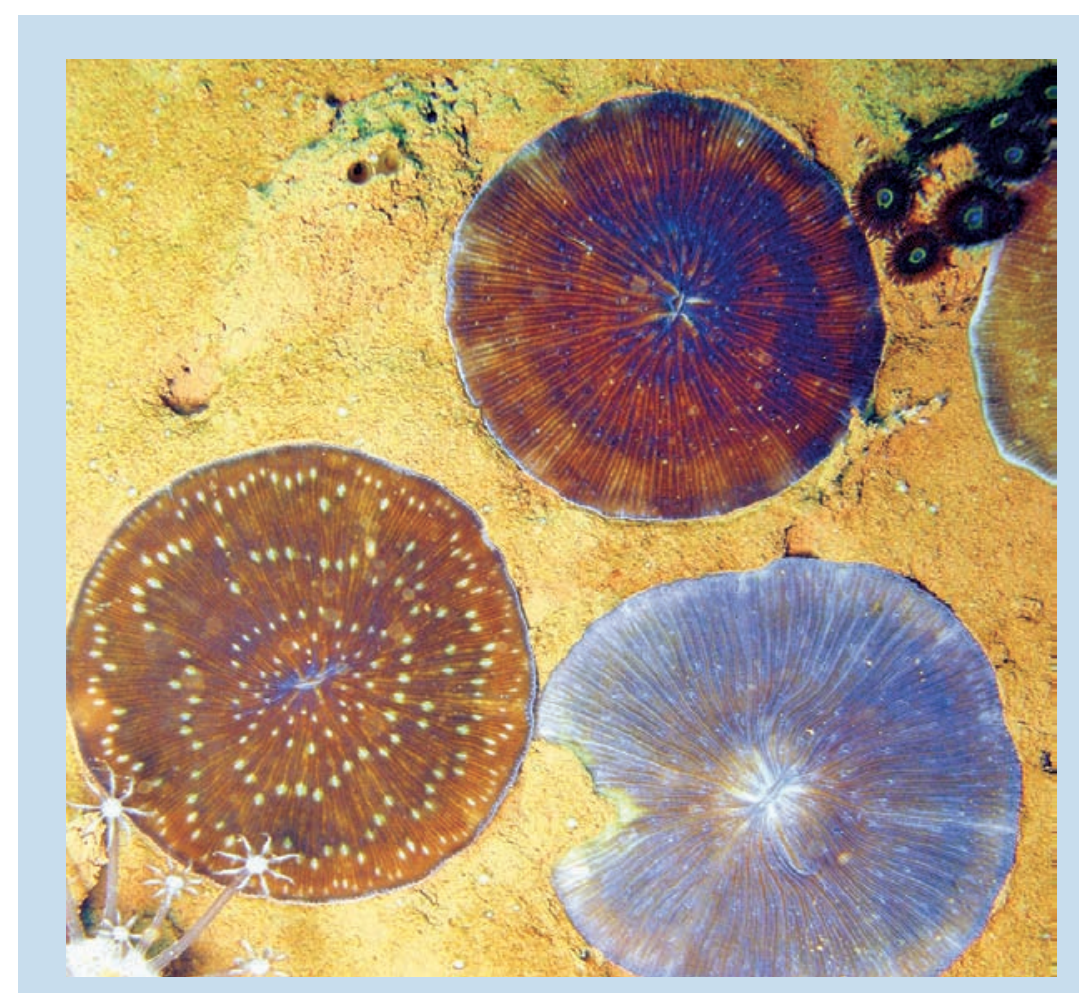

A $35 \mathrm{~m}$ de profondeur, les eaux calmes et obscures de la baie du Prony cachent une communauté très colorée de coraux affectionant les sédiments et adaptés à la vie de ces conditions extrêmes. @ IRD/F. Benzoni

La deuxième option consiste à étaler le polype afin que le sédiment se dépose sur les parties du corps souples et capables de changer de forme du polype, ce qui permet au corail d'évacuer le sédiment par les mouvements de l'animal ou de l'eau. Beaucoup de ces coraux ressemblent de ce fait à des fleurs colorées qui fleurissent sur les sédiments. La présence de coraux sur les fonds meubles implique celle d'un grand nombre d'animaux associés au corail

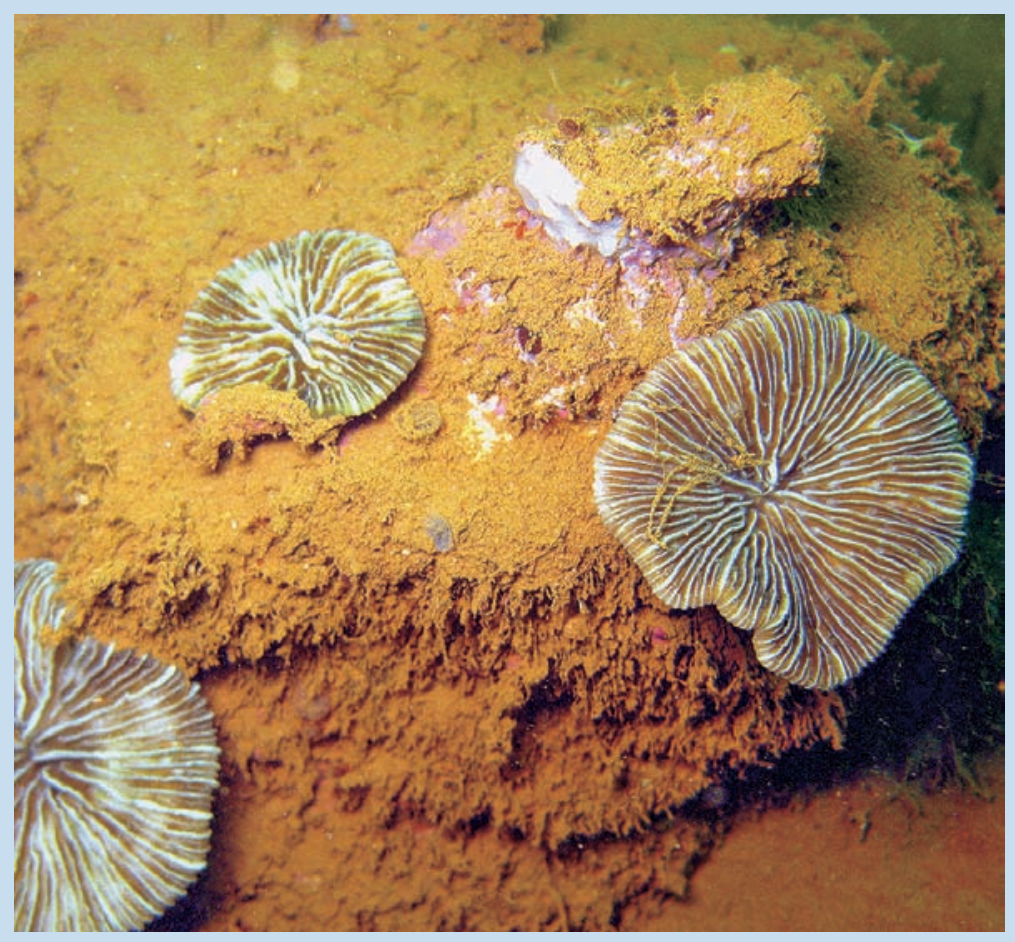

Le corail endémique Cantharellus noumeae est trouvé exclusivement dans les environnements de vase autour de la Grande Terre (Port-Boisé). @ IRD/F. Benzoni

qui, autrement, ne s'y trouveraient pas : en somme, ils entretiennent une communauté inattendue et très diversifiée. Les agrégations de coraux à fond meuble de Grande Terre comme celles de la baie du Prony ou du banc Gail, sont rarement observées ailleurs dans le monde et sont répertoriées parmi les particularités de la Nouvelle-Calédonie.
En ce qui concerne le milieu profond, la Nouvelle-Calédonie est actuellement considérée comme le point chaud mondial pour la diversité des coraux d'eau profonde. L'étude des coraux durs de Nouvelle-Calédonie a débuté au début des années 1900, et a d'abord concerné les coraux profonds. Ceux-ci ont été échantillonnés au cours de plusieurs campagnes océanographiques dans les années 1970 et 1980 (Bathus 3-4, Musorstom 5, 7-9) entre 80 et 1434 m de fond par dragage et chalutage. L'étude des collections impressionnantes hébergées au MNHN (Muséum national d'histoire naturelle) a été récemment finalisée par des spécialistes. Ces études ont révélé une biodiversité sans précédent dans les écosystèmes profonds de Nouvelle-Calédonie, laquelle est plus élevée que dans le triangle d'or avec jusqu'à 170 espèces identifiées incluant des espèces nouvelles pour la science ( $M$. Kitahara, comm. pers.). 
5 


\section{Merveilleux coraux fluorescents \\ Pascale Joannot}

C'est en Nouvelle-Calédonie, au banc Gail, à proximité de la rivière des pirogues, sur un fond de vase remarquable mais difficile d'accès qu'en 1958 les premiers coraux fluorescents ont été récoltés par $35 \mathrm{~m}$ de profondeur, par les plongeurs Michel Laubreaux et René Gail, disparu en plongée.

Le Dr Catala, fondateur du premier aquarium de Nouméa, les soumit aux ultraviolets et découvrit la fluorescence des coraux allant du vert foncé au jaune lumineux en passant par toute une série de rouges et d'orangés.

Il est à noter que l'on trouve aussi des coraux fluorescents en surface et qu'une même espèce peut présenter des fluorescences différentes. Les granulations constituant le support des pigments responsables des propriétés fluorescentes sont situées dans la chair de l'animal. Ces pigments appartiennent aux groupes des flavines, urobilines et ptérines (PELOUX, 1960). Le squelette calcaire de l'animal ne produit aucune fluorescence. J'ai pu constater qu'une exposition répétée des coraux aux UV provoque leur blanchissement qui se résorbe en un mois lorsqu'ils sont remis en lumière naturelle.

En 1996, une mer très calme, des températures et l'ensoleillement élevés ont provoqué dans les lagons néo-calédoniens et à l'aquarium de Nouméa un important blanchissement des coraux se manifestant par le changement rapide ou graduel (selon les colonies) de la couleur naturelle en couleur fluorescente pastel blanche, rose, jaune ou bleu. Alors que les coraux de l'aquarium blanchissaient, certains résistaient et « brunissaient ». Une colonie d'Echinopora, présentait une pigmentation plus intense alors que chaque année, en période estivale, elle blanchissait avant de retrouver ses couleurs brunes dès le rafraîchissement de l'eau.

Ces observations permettent de s'interroger sur le rôle des pigments responsables (flavoprotéines) de l'émission des couleurs fluorescentes et sur le rôle de masque ou écran aux UV que pourraient jouer les zooxanthelles symbiotiques du corail.

\section{Référence bibliographique}

PELOUX Y, 1960 : Etude. Histologique des coraux fluorescents de profondeur. Compte rendu, de l'Académie des Sciences, 250 : 1129-1130.

Tapis de Trachyphyllia geoffroyi aux diverses couleurs fluorescentes pastel à l'aquarium des lagons. (c) P.A. Pantz 
Concernant les coraux peu profonds, bien que certains spécialistes aient déployé des efforts remarquables pour les identifier, comprendre leur répartition et leur rôle écologique, l'étude des vastes zones récifales du territoire étaient relativement rares jusqu'à la dernière décennie et principalement focalisée sur la région sud ouest de la Grande Terre (région de Nouméa), et ce, pour des raisons logistiques. Depuis 2005, l'IRD de Nouméa a mené plusieurs campagnes scientifiques à bord du navire de recherche Alis avec pour objectif principal d'explorer et de documenter la diversité des récifs coralliens de Nouvelle-Calédonie, en particulier sur deux principaux organismes récifaux fondamentaux pour la construction et le fonctionnement de ces écosystèmes : macroalgues et coraux durs. L'occurrence et la distribution de ces organismes ont été documentées par des spécialistes lors de plongées en scaphandre autonome jusqu'à la limite de la zone mésophotique et le matériel collecté est étudié selon une approche traditionnelle basée sur l'examen de la morphologie des organismes (formes, tailles, etc..) et selon une approche génétique.

Au total, plus de $350 \mathrm{~h}$ d'observations sous-marines ont été réalisées par différents spécialistes, et nous avons aujourd'hui une meilleure compréhension de la diversité et de la répartition des coraux durs sur le territoire, y compris dans les zones reculées comme les Chesterfield et Bellona au milieu de la mer de Corail, au niveau des récifs d'Entrecasteaux, des îles Loyauté et de l'île des Pins. Bien que les collections de référence soient encore à l'étude, les résultats obtenus jusqu'à présent ont conduit à une estimation plus réaliste des espèces de coraux durs et à la description d'espèces jusque-là méconnues. Compte tenu des changements considérables dans la manière $d$ 'identifier et de classifier les espèces au cours de la dernière décennie, l'estimation actuelle de la diversité des espèces basée sur des spécimens existants et/ou des illustrations in situ atteint un total de 390 espèces. Dans l'ensemble, en tenant compte des coraux peu profonds et profonds, la Nouvelle-Calédonie hébergerait un imposant tiers des espèces de coraux durs actuels.

Au-delà du simple nombre total d'espèces, il est intéressant de noter que, sur la base de l'exploration de ces différentes zones, nous pouvons dire aujourd' hui que chaque région et groupe d'îles de la

\section{Encadré 8}

\section{La relève assurée ?} Un fort recrutement des coraux dans le lagon sud-ouest de Nouvelle-Calédonie

Mehdi Adjeroud et Christophe Peignon

Le recrutement, qui se définit comme l'intégration des jeunes individus dans les populations adultes, est une étape cruciale dans la vie des coraux. II influence la répartition spatiale des peuplements adultes, mais aussi leur variabilité temporelle. Après le passage de perturbations importantes, comme les cyclones, les événements de blanchissement des coraux ou les pullulations de prédateurs comme les acanthasters, qui engendrent de fortes mortalités chez les adultes, la recolonisation des récifs se fait essentiellement via le recrutement. Durant leur première année de vie, les recrues ne font que quelques millimètres de diamètre. Ces recrues vont vite grandir, mais n'atteindront le stade adulte et ne seront capables de se reproduire sexuellement qu'au bout de 4 ans en moyenne.

Afin de mieux comprendre comment se structurent et se maintiennent les coraux de Nouvelle-Calédonie, une étude sur le recrutement a été mise en place en 2011. Des plaques de terre cuite ont été disposées sur 14 stations, couvrant les principaux habitats du lagon sud-ouest. Ces plaques ont été laissées pendant 5 mois (octobre à mars) pour permettre aux recrues de se fixer. Ces plaques sont ensuite ramenées au laboratoire pour y être examinées au microscope. À ce stade, les caractères morphologiques, sur lesquels se base l'identification des espèces, ne sont pas suffisamment développés et seules quelques familles de recrues peuvent être distinguées. 

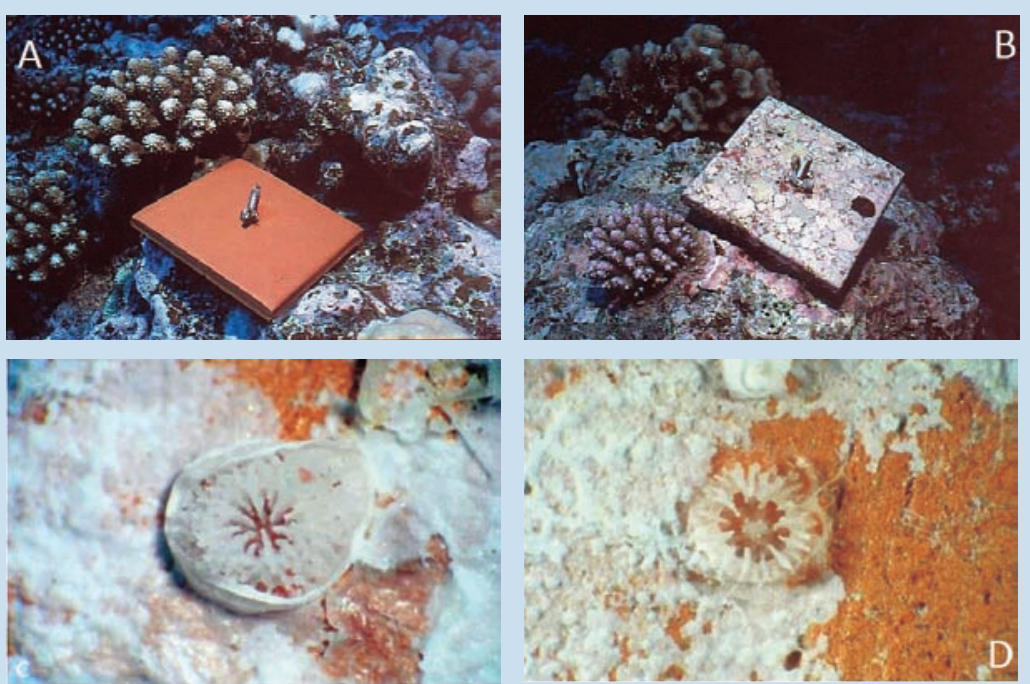

Plaques de terre cuite utilisées pour étudier le recrutement des coraux.

A : Plaque nouvellement installée.

$B$ : Après 5 mois sur le récif, la plaque est colonisée par des algues calcaires encroûtantes et par des coraux invisibles à l'œil nu.

Photographies au microscope de recrues des deux familles les plus abondantes en Nouvelle-Calédonie.

C : Acroporidae. D : Pocilloporidae. @ M. Adjeroud

Les résultats des trois premières années montrent que le recrutement des coraux est très variable dans l'espace et dans le temps. Comparativement à d'autres récifs du Pacifique, l'abondance des recrues est souvent élevée, avec un pic important sur certaines stations des récifs frangeants et îlots lagonaires en 2013-2014.

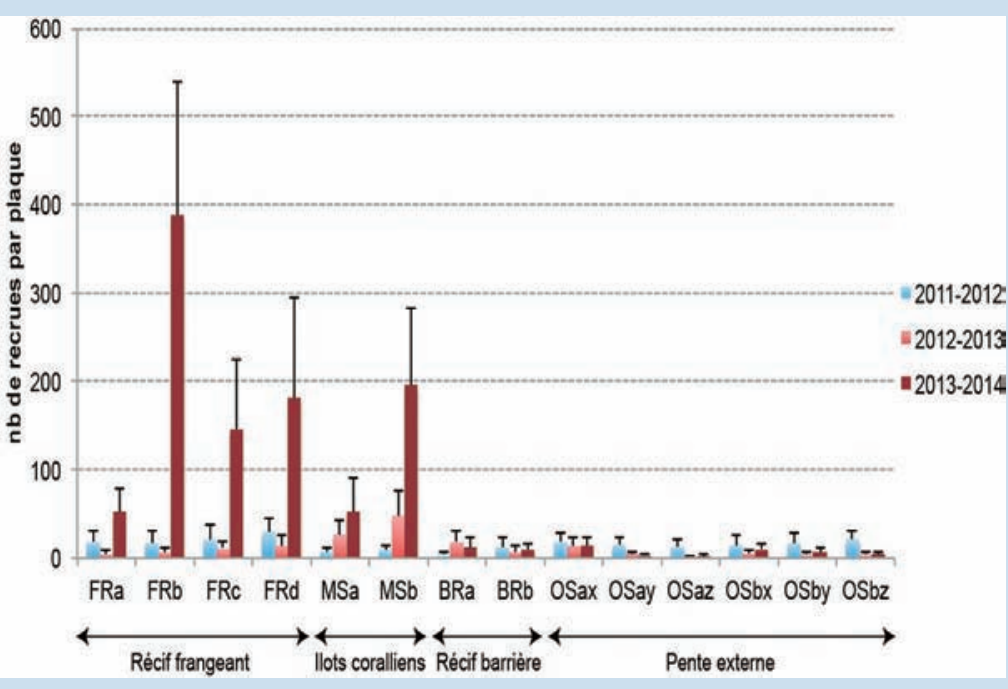

Variabilité spatiale et temporelle de l'abondance des recrues (toutes familles confondues) des coraux enregistrée dans 14 stations d'étude des quatre principaux habitats récifaux du lagon sud-ouest de Nouvelle-Calédonie. Source : M. Adjeroud

Ces taux de recrutement sont mêmes supérieurs à ceux obtenus sur la Grande Barrière en Australie. Ces résultats, plutôt encourageants, suggèrent une forte capacité de recolonisation et de résilience des récifs de Nouvelle-Calédonie.
ZEE (Zone économique exclusive) de Nouvelle-Calédonie se caractérisent par des assemblages uniques de coraux et d'habitats coralliens. Certains sont caractérisés par des communautés abondantes constituées de quelques espèces dominantes, comme les sites lagonaires des récifs reculés de Chesterfield ou d'Entrecasteaux, d'autres sont composés de petites espèces cavernicoles dissimulées à la limite de la zone mésophotique. Globalement, la diversité unique de la faune récifale corallienne de Nouvelle-Calédonie ne réside pas seulement dans le nombre d'espèces, mais dans la variété de leurs associations pour composer des paysages récifaux remarquablement différents, soutenant différents organismes associés et écosystèmes productifs. Ce patrimoine est de grande valeur et mérite non seulement les mesures de conservation actuellement en place, mais également un suivi scientifique continu de son état de santé. 



\section{Chapitre 6 \\ Les récifs, fertilisés par les oiseaux marins?}

Anne Lorrain, Fanny Houlbrèque, Francesca Benzoni, Laura Tremblay-Boyer, Christophe Menkès, Claude E. Payri et Éric Vidal

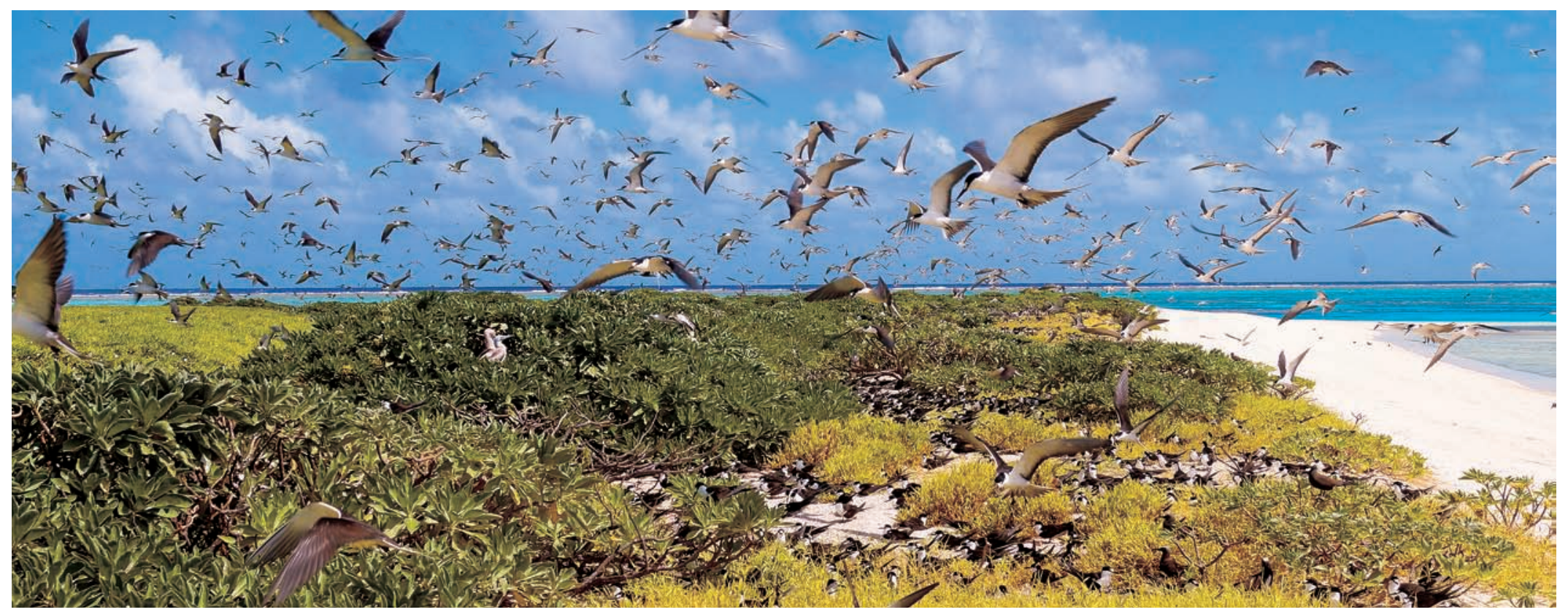

Îles Chesterfield : les sternes fuligineuses nichent en colonies nombreuses. @ IRD/E. Vidal

Les coraux bâtisseurs de récifs offrent un habitat à des dizaines de milliers d'espèces de poissons, crustacés, mollusques, créant un univers foisonnant de vie au milieu de vastes déserts océaniques. Certains oiseaux marins parcourent de larges zones océaniques pour se nourrir et reviennent ensuite à terre pour se reproduire sur des îlots bordés de récifs coralliens. Des recherches récentes ont permis de montrer des interactions insoupçonnées entre ces oiseaux marins et les coraux constructeurs de récifs, ces derniers se nourriraient en partie de l'azote issu des excréments des oiseaux marins (LORRAIN et al., 2017).

Les oiseaux marins nichent en effet sur les îlots pendants quelques mois de l'année, entrânant l'accumulation d'énormes quantités d'excréments, connus sous le nom de guano. Ce guano est reconnu comme une source importante d'azote et de phosphates et est utilisé depuis de nombreuses années comme engrais naturel. Ces déjections d'oiseaux marins venus nicher sur les côtes fertiliseraient ainsi les écosystèmes terrestres, mais enrichiraient aussi localement l'écosystème corallien. Des recherches utilisant des marqueurs isotopiques permettent de tracer l'entrée de l'azote issu du guano dans les chaînes alimentaires marines. L'analyse d'échantillons d'eau et de coraux a ainsi montré la présence d'azote issu du guano dans les eaux des lagons, mais aussi dans les tissus des coraux vivant à proximité des îlots. L'azote du guano peut arriver en mer par lessivage des stocks accumulés sur les îlots, par percolation via des résurgences d'eau douce en mer, ou via le dépôt direct de fientes lors des trajets effectués par les oiseaux au-dessus du lagon pour aller se nourrir (fig. 1). À propos des mécanismes permettant aux coraux 


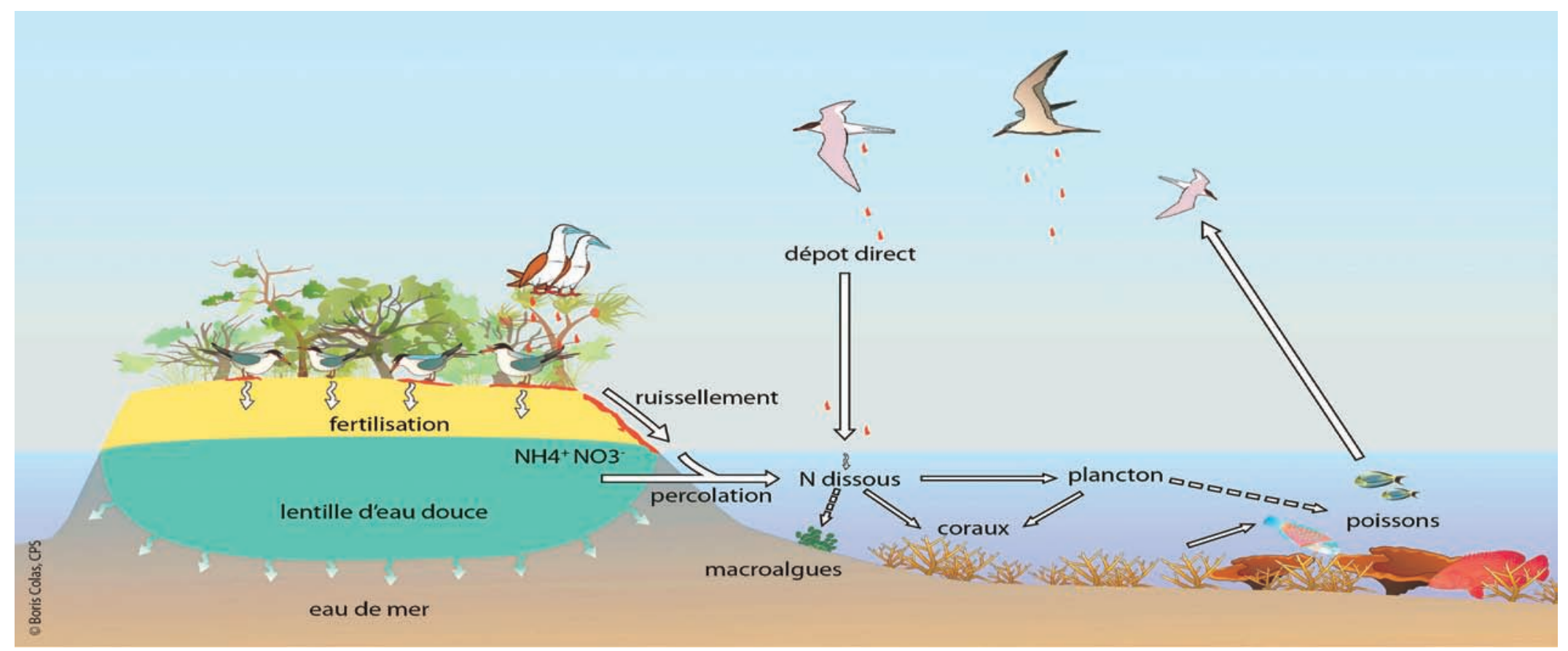

Figure 1 : Diagramme schématique de l'entrée d'azote provenant du guano dans l'écosystème corallien. Source : LORRAIN et al., 2017, modifié.

d'assimiler l'azote issu du guano, plusieurs hypothèses existent, voire coexistent. L'azote peut être utilisé par du plancton, à son tour ingéré par les coraux ou il peut être directement capté sous forme dissoute par les coraux et les zooxanthelles qu'ils renferment (microalgues vivant en symbiose avec les coraux).

Si l'azote issu du guano est assimilé par les coraux situés à proximité de grandes colonies aviaires, reste à savoir s'il est ingéré par d'autres maillons de l'écosystème et comment cette contribution affecte la santé de l'écosystème. Plusieurs études récentes ont mis en évidence qu'un apport en nutriments, selon sa forme (nitrate, ammonium, urée), la durée d'exposition et l'apport simultané ou non d'autres nutriments (comme les phosphates) pouvait avoir un impact positif ou négatif sur la résistance des coraux aux changements climatiques. Cet apport en azote (et phosphates) via le guano pourrait donc soit permettre aux coraux de mieux résister au réchauffement des eaux, soit au contraire entraîner un déséquilibre de leur métabolisme et rendre par exemple leurs squelettes plus fragiles. Des recherches supplémentaires sont nécessaires pour évaluer précisément son impact. Les apports d'azote sont généralement d'origine humaine via les eaux usées de grandes villes ou l'utilisation d'engrais pour l'agriculture et l'étude de l'impact de l'azote provenant du guano constitue une originalité par rapport aux études antérieures travaillant sur les apports de nutriments. Les îlots éloignés offrent ainsi un terrain de jeu particulièrement intéressant, loin de toute présence humaine.

Les coraux et les oiseaux marins sont deux communautés particulièrement menacées par les changements climatiques et anthropiques, et la découverte du rôle des oiseaux sur les écosystèmes coralliens via leurs excréments suggère que leur gestion doit probablement se faire en synergie.

\section{Référence bibliographique}

LORRAIN A. et al., 2017 Seabirds supply nitrogen to reef-building corals on remote Pacific islets. Scientific Report, $7: 3721$. 


\section{Chapitre 7 \\ Les récifs en quête de diazotrophes}

Valentine Meunier, Sophie Bonnet, Anne Lorrain, Mar Benavides, Mercedes Camps, Olivier Grosso et Fanny Houlbrèque

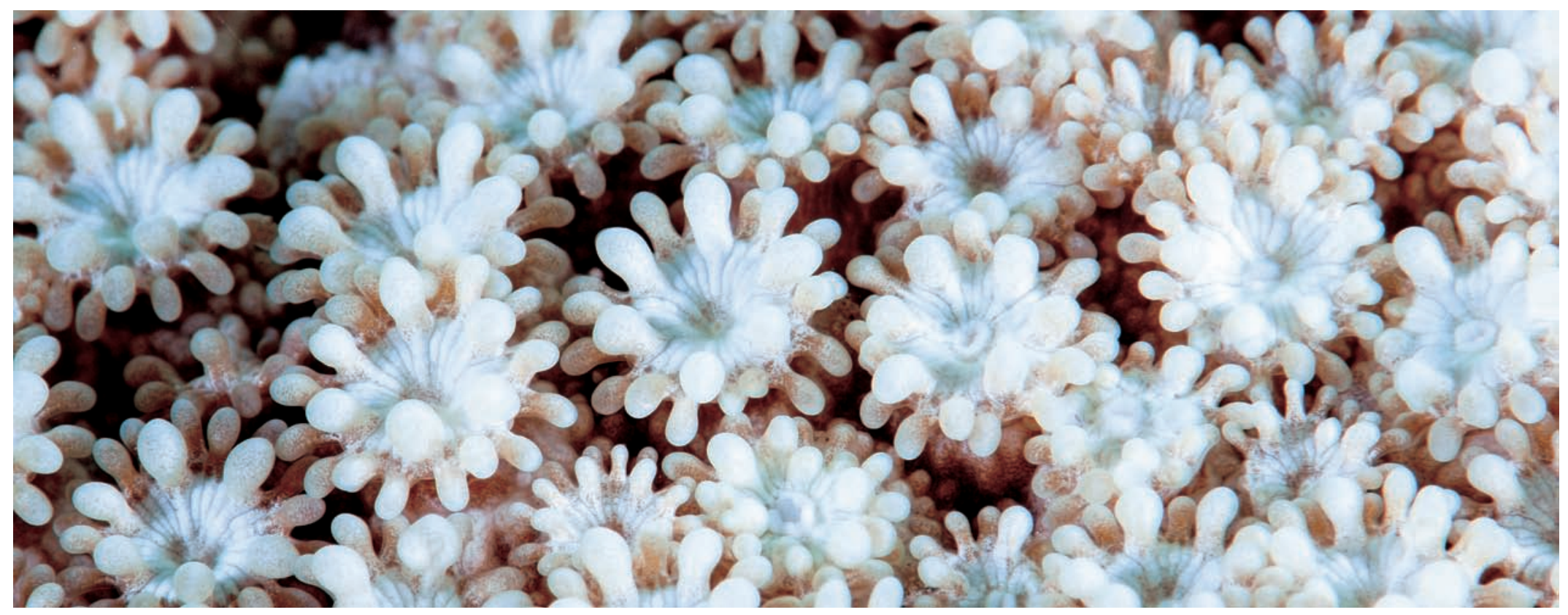

Polypes de corail déployés en quête de nourriture. @ G. Boussarie

\section{Le corail, ce prédateur vorace}

Les récifs coralliens représentent un véritable puits de diversité et constituent des réserves écologiques majeures. Bien qu'ils se développent dans des eaux oligotrophes, c'est-à-dire pauvres en éléments nutritifs, ils sont considérés comme l'un des écosystèmes les plus productifs de la planète. Une telle réussite évolutive est en grande partie expliquée par l'association entre les coraux et des microalgues symbiotiques présentes au sein de leurs tissus, les Symbiodinium, qui transfèrent au corail la majeure partie du carbone photosynthétisé. Mais, pour combler totalement leurs besoins en nutriments et en énergie, les coraux ont la capacité d'utiliser un deuxième mode de nutrition. En effet, la plupart sont de redoutables prédateurs capables de se nourrir sur une large gamme de proies (nutrition hétérotrophe) (HOULBREQUE et FERRIER-PAGES, 2009). Leur régime alimentaire inclut des particules sédimentaires, de la matière organique dissoute et du plancton présent dans la colonne d'eau. Le corail utilise plusieurs procédés pour capturer ses proies, par exemple la décharge de filaments urticants (les nématocystes) qui injectent une substance toxique paralysante, la production de mucus pouvant piéger des proies de très petite taille ou la capture par leurs tentacules permettant de ramener directement le butin dans la cavité buccale. 


\section{De l'azote à tout prix !}

L'azote est un élément indispensable au bon développement des coraux. Il est nécessaire notamment à la synthèse de leurs protéines, molécules présentes chez tous les êtres vivants. Pour combler ses besoins journaliers en azote, le corail utilise différents mécanismes (fig. 1) : il abrite dans ses tissus des bactéries et cyanobactéries capables de fixer le diazote atmosphérique $\left(\mathrm{N}_{2}\right)$, il peut assimiler des composés azotés dissous (organiques et inorganiques) dans l'eau de mer environnante avec l'aide de ses Symbiodinium. Il obtient également de l'azote par les proies et les particules qu'il ingère.

L'océan Pacifique sud-ouest est reconnu pour être un « hotspot » de la fixation d'azote atmosphérique. Autour des archipels mélanésiens et notamment en Nouvelle-Calédonie, les taux de fixation d'azote sont parmi les plus élevés au monde (BONNET et al., 2017). En effet, de fortes abondances de bactéries et cyanobactéries planctoniques fixatrices d'azote y sont présentes. Ces organismes, aussi appelés « diazotrophes », ont la capacité de fixer le diazote atmosphérique $\mathrm{N}_{2}$ dissous dans la couche de surface de l'océan et de le réduire en ammonium pour satisfaire leurs besoins azotés. Une partie de cet azote est relarguée dans le milieu environnant et transférée aux autres organismes du plancton n'ayant pas cette

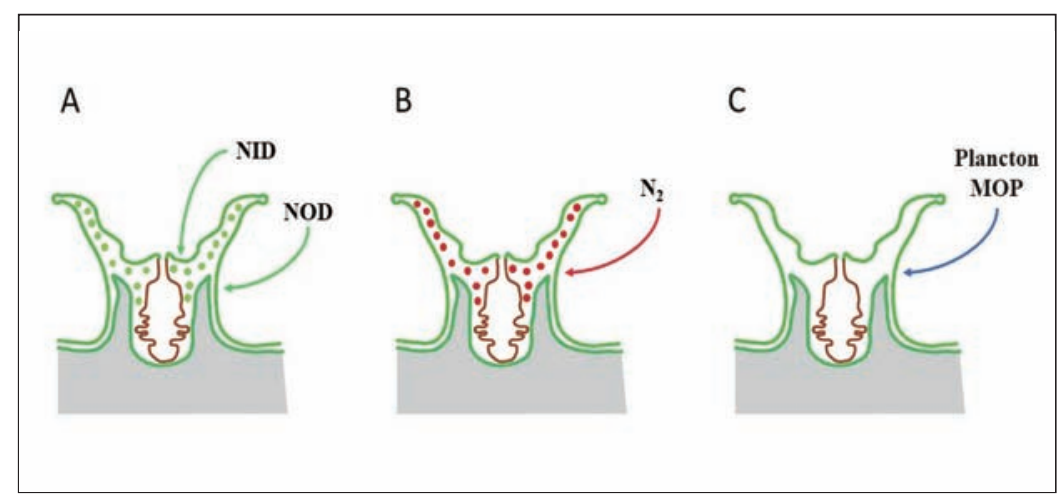

Figure 1 : Principales stratégies de prélèvement de l'azote pour les coraux.

A : Sous forme dissoute inorganique ou organique (NID ou NOD) par le tissu corallien et les Symbiodinium (représentés par les points verts).

B : Sous forme de diazote par les bactéries et cyanobactéries présentes à l'intérieur des tissus (représentés par les points rouges).

$\mathrm{C}$ : Sous forme de matière organique particulaire (MOP) et de plancton par le corail. capacité (BONNET et al., 2016). Ainsi, la fixation d'azote soutient en période estivale la quasi-totalité de la production nouvelle planctonique dans le lagon néo-calédonien (BERTHELOT et al., 2015). Il a été montré également qu'une part importante du plancton est rapidement exportée vers le fond du lagon, profitant potentiellement aux organismes fixés tels que les coraux.

\section{Des diazotrophes pour un corail}

Les coraux étant de très importants prédateurs de plancton, les organismes fixateurs d'azote ou le plancton ayant bénéficié de la fixation d'azote pourraient ainsi constituer une source de nourriture pour les coraux au travers de leur nutrition hétérotrophe. Cependant, le rôle de la fixation d'azote planctonique dans la nutrition des coraux a été jusque-là peu exploré. Une équipe de chercheurs de l'IRD de Nouméa s'est intéressée au cheminement de l'azote depuis l'atmosphère, assimilé par le plancton, lui-même ingéré par le corail.

L'azote naturel présent dans l'atmosphère terrestre correspond essentiellement à l'isotope ${ }^{14} \mathrm{~N}$. Ainsi en réalisant des marquages isotopiques avec un autre isotope, le ${ }^{15} \mathrm{~N}$, cela permet de suivre le cheminement de l'azote depuis l'atmosphère jusque dans les organismes du plancton et enfin potentiellement dans les coraux. Dans nos expériences, des boutures de corail appartenant à l'espèce Stylophora pistillata, très commune et abondante dans le lagon néocalédonien, ont été incubées pendant $12 \mathrm{~h}$ en présence d'eau de mer et de plancton marqué au ${ }^{15} \mathrm{~N}_{2}$. La concentration en plancton a été quantifiée avant et après incubation pour déterminer les taux d'ingestion par les coraux.

Des analyses ont été réalisées afin de connaître la composition isotopique exacte du tissu corallien et de ses symbiontes. Cela a permis de mettre en évidence un enrichissement significatif en ${ }^{15} \mathrm{~N}$ à l'intérieur même des Symbiodinium, ce qui signifie que l'azote en provenance de la diazotrophie est assimilé et directement alloué et stocké au sein des symbiontes. L'absorption de diazotrophes planctoniques ou de plancton issu de la diazotrophie apporterait six fois plus d'azote que ce qu'apporte quotidiennement l'ingestion de plancton de petite taille. 


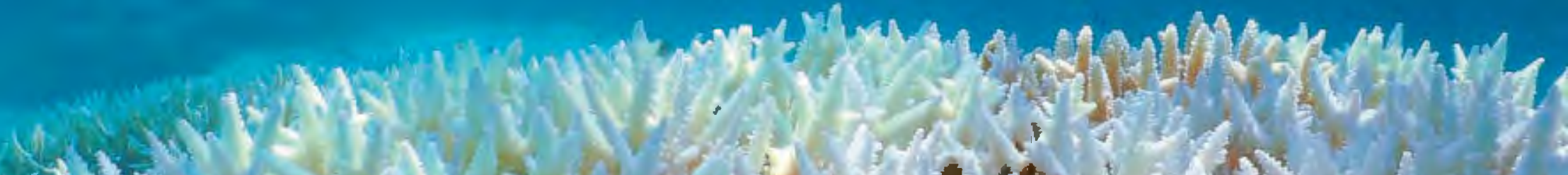

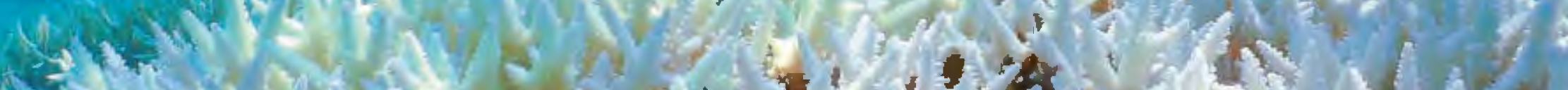

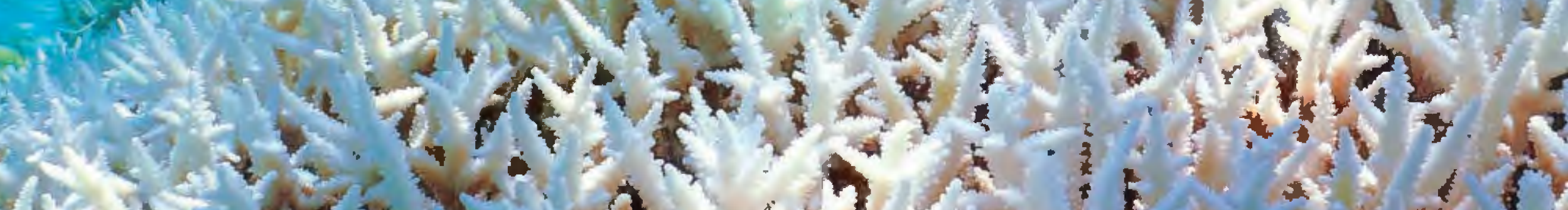

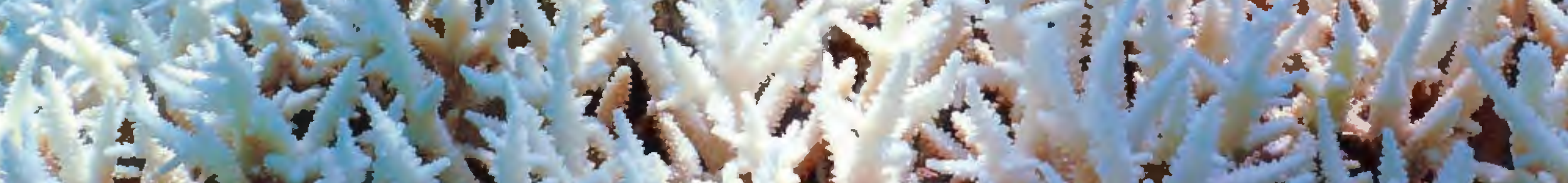

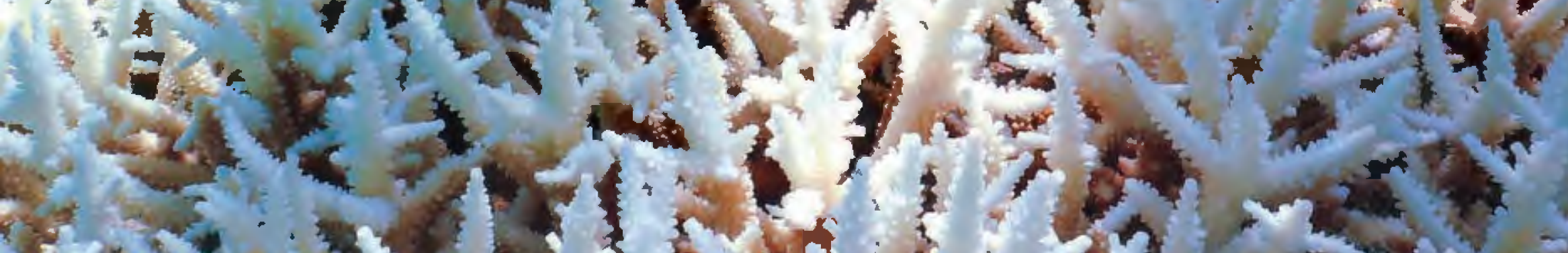

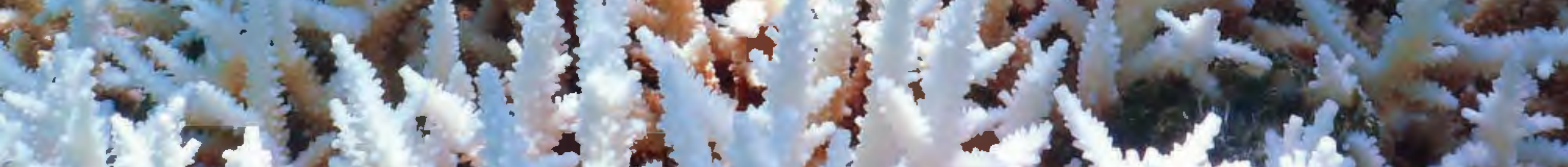
$34 \times 2 x ?$ 2 $=x$

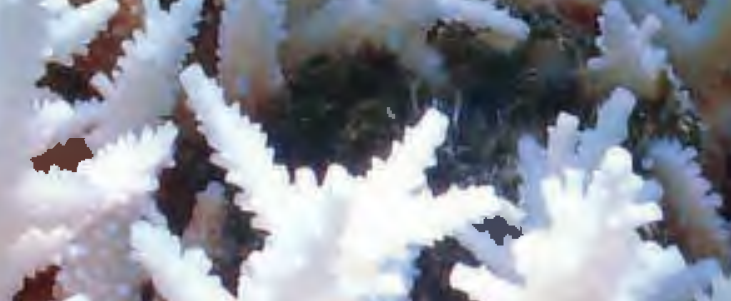


La forte abondance et l'activité de diazotrophes dans le lagon de Nouvelle-Calédonie suggèrent donc que ces organismes représentent une source d'azote importante pour les coraux tropicaux (BENAVIDES et al., 2016). Cependant, les voies de transfert de l'azote issu de la diazotrophie au sein du corail ainsi que son utilisation préférentielle par les symbiontes restent un mystère et des expériences complémentaires s'avèrent indispensables.

\section{L'azote à la rescousse !}

Depuis ces trente dernières années, les phénomènes de blanchissement corallien ne cessent de se répéter à des fréquences de plus en plus élevées à travers le monde. Épargnés jusqu'alors, les récifs néo-calédoniens frangeants et intermédiaires ont été fortement impactés en février 2016 par un épisode de blanchissement massif, touchant également l'ensemble des récifs mondiaux (chap. 25). Lorsque les coraux sont blanchis, ils sont dépourvus de leurs Symbiodinium. Ils perdent leur coloration et ne bénéficient plus de leur source d'énergie principale. Dans ce contexte, de nombreux travaux ont permis de démontrer qu'en cas de stress environnemental, tel que l'augmentation de la température de l'eau de mer, les coraux étaient capables d'augmenter leur nutrition sur le plancton et la matière organique (PALARDY et al., 2008). Ce constat soulève donc l'hypothèse que les coraux pourraient tirer profit de la présence de plancton diazotrophe pour combler leurs besoins en azote lors d'un événement de blanchissement. Des expériences préliminaires ont montré la capacité de Stylophora pistillata à augmenter sa consommation de plancton diazotrophe ou bien d'incorporer davantage les composés issus de ces diazotrophes, pendant un épisode de blanchissement. Les coraux blanchis pourraient compenser le manque d'énergie et d'azote lié à la perte de ses symbiontes. Reste à savoir si cet apport en azote permet d'augmenter, sur le long terme, la résilience des coraux après un événement de blanchissement.

\section{Références bibliographiques}

BONNET S. et al., 2016 Diazotroph derived nitrogen supports diatoms growth in the South West Pacific: a quantitative study using nanoSIMS. Limnology and Oceanography. doi : 10.1002/lno.10300.

BONNET S. et al., 2017 Hot spot of $\mathrm{N}_{2}$ fixation in the western tropical South Pacific pleads for a spatial decoupling between $\mathrm{N}_{2}$ fixation and denitrification. Proceedings of the National Academy of Sciences of the United States of America., 114 (14) : E2800-E2801.

BENAVIDES M. et al., 2016 Diazotrophs : a non-negligible source of nitrogen for the tropical coral Stylophora pistillata. Journal of Experimental Biology, 219 (17) : 2608-2612.

BERTHELOT H. et al., 2015 Dinitrogen fixation and dissolved organic nitrogen fueled primary production and particulate export during the Vahine mesocosm experiment (New Caledonia lagoon). Biogeosciences, 12 : 4099-4112.

HOULBREQUE F., FERRIER-PAGES C., 2009 Heterotrophy in tropical Scleractinian corals. Biological Reviews. 84 : 1-17.

PALARDY J. E., RODRIGUES L. J., GROTTOLI A. G., 2008 The importance of zooplankton to the daily metabolic carbon requirements of healthy and bleached corals at two depths. Journal of Experimental Marine Biology Ecology, 367 : 180-188. 


\title{
Des eaux cristallines qui regorgent d'organismes microscopiques
}

\author{
Sophie Bonnet, Renaud Fichez, Cécile Dupouy et Martine Rodier
}

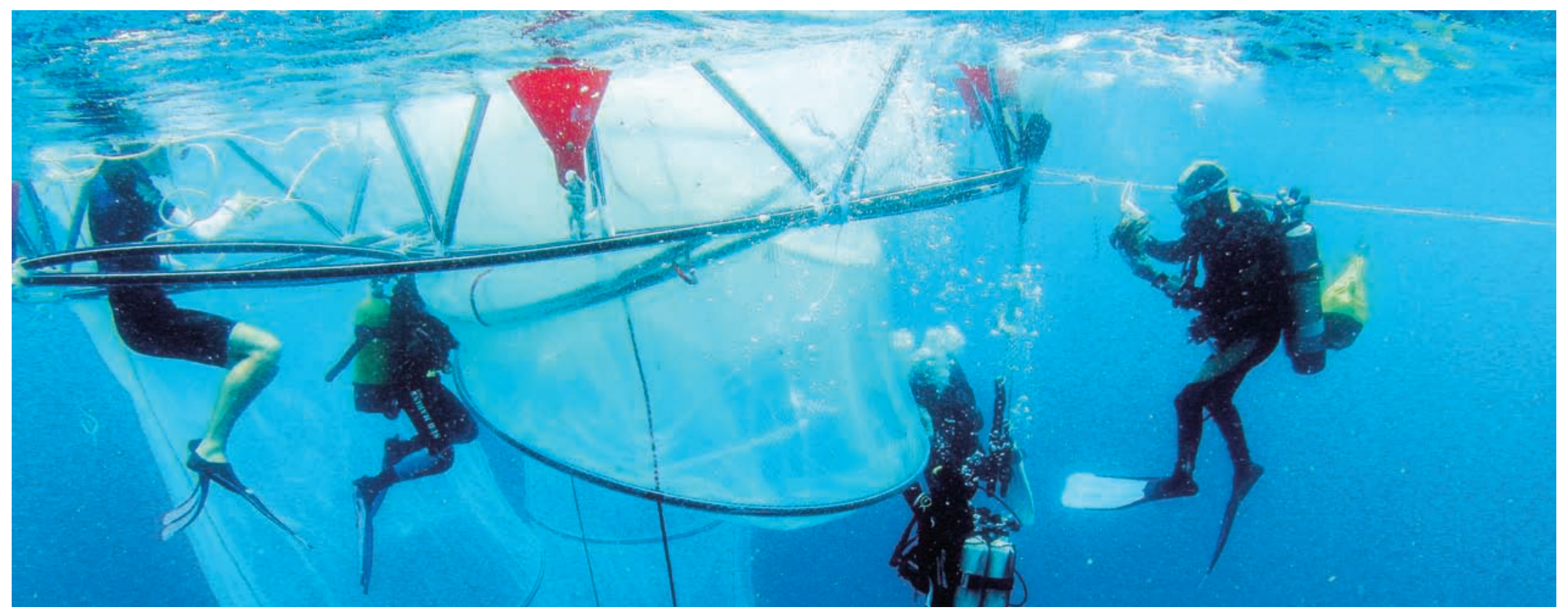

Mésocosmes déployés dans le cadre du projet Vahine en Nouvelle-Calédonie. @ IRD/J.-M. Boré et IRD/E. Folcher

Les récifs coralliens et les lagons de Nouvelle-Calédonie baignent principalement dans des eaux aux allures cristallines. Cette clarté de l'eau, ou oligotrophie (eau faiblement nourrie, du grec « oligo », peu, « trophein », nourrir), provient des très faibles concentrations en éléments nutritifs des eaux de la province océanique qui entourent la Nouvelle-Calédonie et qui pénètrent dans le lagon sous l'action des courants de marée ou du déferlement par-dessus le récif. Les programmes de recherche conduits sur le lagon ont permis d'identifier deux grands facteurs structurants qui expliquent, à eux seuls, l'essentiel de la variabilité spatiale des caractéristiques des eaux (FICHEZ et al., 2010) : un gradient d'enrichissement trophique et un gradient de salinité qui manifestent clairement que les eaux du lagon font l'objet d'une lutte d'influence permanente entre les apports de l'océan et ceux de la terre. Si l'enrichissement trophique au voisinage de la côte peut-être imputable à des facteurs naturels liés en particulier au temps de renouvellement élevé des eaux dans les zones les plus abritées, certains sites s'écartent résolument de ce schéma d'organisation général, révélant des conditions d'enrichissement anormales principalement attribuables aux rejets en eaux usées au voisinage des zones urbanisées. Par ailleurs les variations saisonnières et interannuelles de température et salinité sont amplifiées sur la côte ; les baies jouent ainsi un rôle de caisse de résonance dans le fonctionnement physique du lagon, avec des répercussions tant dans la répartition des espèces que dans la vulnérabilité des milieux. 
Si les récifs coralliens et les lagons de Nouvelle-Calédonie baignent principalement dans des eaux aux allures cristallines, chacune des gouttes d'eau qui composent le lagon regorge de millions d'organismes microscopiques qui constituent le plancton (du grec « phyton », plante et « planktos », qui dérive au gré des courants) et qui se sont remarquablement adaptés à l'environnement très spécifique qui les accueille et les transporte au gré des courants.

Méconnus car invisibles à l'œil nu, ces micro-organismes en suspension dans l'eau de mer sont composés en majorité de bactéries, de microalgues (aussi appelées « phytoplancton »), et de plancton animal (aussi appelé «zooplancton »). À l'instar des végétaux terrestres, le phytoplancton est composé d'organismes photosynthétiques pourvus de chlorophylle grâce à laquelle il peut capter l'énergie solaire. La lumière du soleil, le dioxyde de carbone $\left(\mathrm{CO}_{2}\right)$ et les sels minéraux dissous dans l'eau (l'azote, le phosphore, les micronutriments) suffisent au phytoplancton pour croître et se développer. Le phytoplancton joue un rôle clé à plusieurs titres. D'abord, il est à la base de la chaîne alimentaire marine. Ensuite, en réalisant la photosynthèse, il produit de l'oxygène. À l'échelle globale, on estime que le phytoplancton produit plus de la moitié de l'oxygène sur Terre, alors qu'il ne représente que $1 \%$ de la biomasse d'organismes photosynthétiques (la majeure partie étant constituée par les végétaux terrestres). Enfin, il intervient dans la régulation du climat : il effectue la photosynthèse et utilise ainsi le $\mathrm{CO}_{2}$ atmosphérique. À sa mort, une partie sédimente vers le fond des océans, permettant de séquestrer durablement le $\mathrm{CO}_{2}$ au travers d'un processus appelé « la pompe biologique à carbone ». Dans les lagons, ces organismes phytoplanctoniques qui sédimentent contribuent à nourrir les organismes fixés sur le fond tels que les coraux (chap. 7).

Le sud-ouest du Pacifique - incluant la Nouvelle-Calédonie et l'ensemble des archipels allant de l'Australie à Tonga - présente une singularité : il est le siège des plus fortes abondances de microalgues fixatrices d'azote de l'océan mondial (BONNET et al., 2017) (fig. 1). Ces microalgues aussi appelées « diazotrophes » ont un avantage compétitif dans ces déserts : elles sont capables de s'affranchir des éléments minéraux azotés qui font défaut car elles ont la capacité d'utiliser l'azote de l'air (une ressource inépuisable) en réalisant la fixation d'azote. Ainsi ce processus permet de fertiliser les eaux de surface en azote tel un engrais naturel, et ainsi de soutenir la vie dans ces déserts.

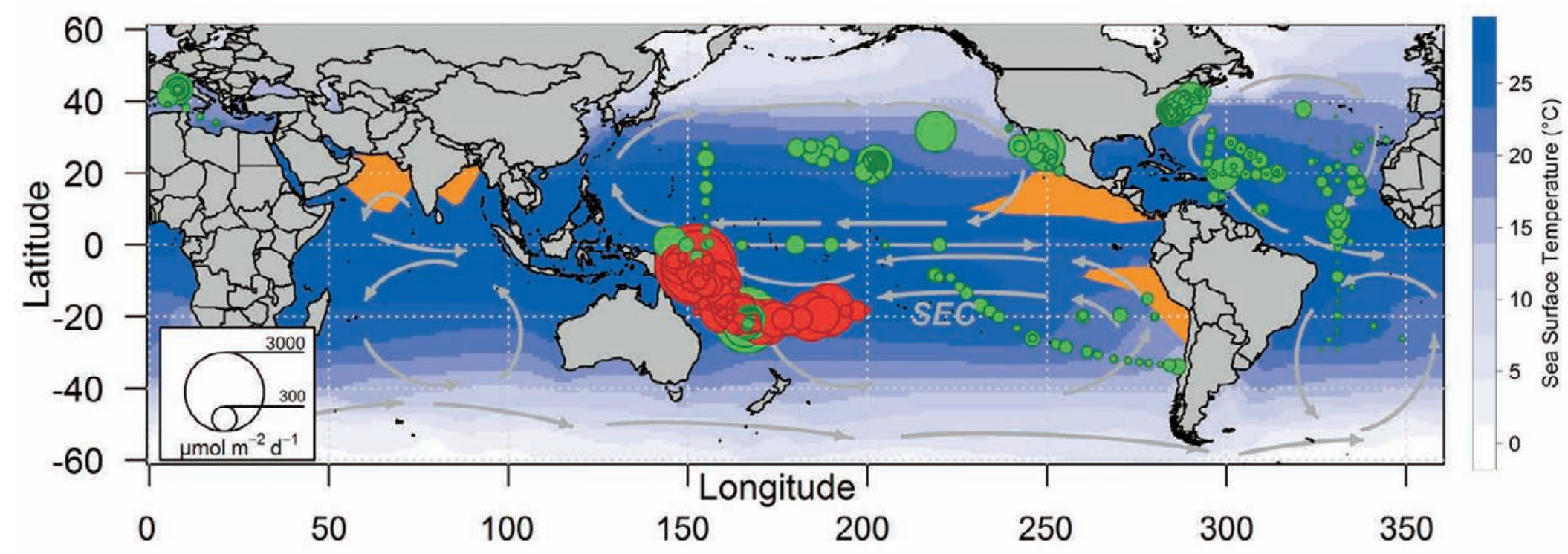

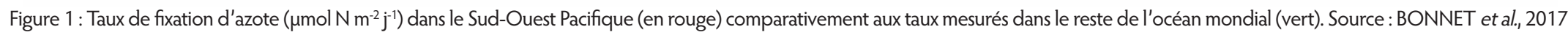


Les cyanobactéries filamenteuses appelées Trichodesmium sont des organismes présents toute l'année dans les eaux tropicales. Associées en faisceaux et s'accumulant à la surface sous forme de poussière dorée, elles sont très souvent observées par les navires sillonnant la région et sont notées comme « eaux colorées » sur les plus anciennes cartes marines. Les échantillons prélevés par la Marine nationale jusqu'au Vanuatu, Fidji et Tonga révèlent une grande diversité d'espèces qu'on retrouve autour en Nouvelle-Calédonie. Ces 98 échantillons de surface ont servi à calibrer un algorithme de détection automatique (DUPOUY et al., 2011). Les efflorescences vues par satellite peuvent en effet couvrir des milliers de kilomètres carrés. En assumant une distribution homogène des Trichodesmium sur la surface couverte $\left(90000 \mathrm{~km}^{2}\right)$ et un taux de fixation d'azote moyen, la quantité d'azote fixée par le développement massif de diazotrophes (bloom) pendant 10 jours est estimée entre 0,02 à 1,17 × 109 $\mathrm{g}$ d'azote (DUPOUY et al., 1988).

Dans les lagons néo-calédoniens, la croissance des Trichodesmium est forte en été et les blooms d'environ une semaine se produisent à la faveur de faibles vents et d'enrichissements en sels nutritifs sur la côte Ouest, en baie de Sainte-Marie où domine T. erythraeum, ou sur la côte Est, en baie de Ouinné, où domine l'espèce océanique $T$. thiebautii (RODIER et LE BORGNE, 2010).

Pour étudier en détail le rôle de ces organismes sur le fonctionnement de l'écosystème lagonaire néo-calédonien, une équipe de chercheurs pilotée par l'IRD a déployé pendant un mois dans le lagon de Nouvelle-Calédonie des «mésocosmes », sortes de tubes à essai géants (50 $000 \mathrm{l}$ ) qui permettent d'étudier les premiers maillons de la chaîne alimentaire marine. L'objectif était d'étudier « à qui profite la fertilisation par les microalgues diazotrophes » ? Les résultats principaux issus de ce projet montrent que la quasi-totalité de la production biologique nouvelle dans la colonne d'eau du lagon néo-calédonien est soutenue par l'activité de ces microalgues diazotrophes en période estivale. Le bloom dans les mésocosmes a augmenté la productivité du système d'un facteur 2 et l'export de carbone d'un facteur 5 (BERTHELOT et al., 2015). Le devenir de la fixation d'azote dans l'écosystème dépendait des organismes en présence.
Lorsque les diazotrophes vivant en symbiose avec d'autres microalgues n'ayant pas la capacité de fixer le diazote (les diatomées) dominaient la communauté, l'azote issu de la diazotrophie (NDD) était exporté (directement) (BERTHELOT et al., 2015) ; aucun transfert ne se produisait vers les premiers maillons de la chaîne alimentaire planctonique (phytoplancton/bactéries), mais celui-ci était transféré au plancton animal (ou zooplancton) par broutage direct (HUNT et al., 2016). Lorsque les diazotrophes libres et unicellulaires (UCYN, Cyanobacterium) dominaient, environ $20 \%$ du NDD était rapidement $(24 \mathrm{~h})$ transféré au plancton non diazotrophe (BONNET et al. 2016) et au zooplancton dont la nutrition azotée était soutenue à $35 \%$ par la fixation d'azote (HUNT et al., 2016), soit directement (par broutage), soit indirectement par broutage du plancton qui s'était développé sur le NDD. L'efficacité du système à exporter du carbone par rapport à la production primaire (e-ratio) était plus élevée lorsque les UCYN dominaient. Cet export était à la fois direct, par la chute des petites cellules d'UCYN (5,7 $\pm 0,8 \mu \mathrm{m})$ agrégées en grosses particules $(100-500 \mu \mathrm{m})$ ayant des taux de chute élevés, et indirect, c'est-à-dire lié à la chute de plancton non diazotrophe s'étant développé à partir du NDD (BONNET et al., 2016). In fine, 60 \% de la production exportée était soutenue par la diazotrophie.

Les résultats acquis dans le cadre de Vahine (Variability of Vertical and Trophic Transfer of Diazotroph-derived Nitrogen in the South West Pacific) ont permis d'obtenir les premières données quantitatives sur le devenir de la fixation d'azote dans l'écosystème marin et de réaliser des typologies par type d'organisme dominant. Elles ont été intégrées dans un modèle autorisant les simulations numériques pour réaliser des prévisions sur l'évolution de la productivité du lagon et des eaux environnantes (GIMENEZ et al., 2016). De nombreuses études montrent que la diazotrophie devrait augmenter dans l'océan du futur plus chaud, plus acide et plus stratifié, ce qui renforce l'intérêt de ces prévisions. 


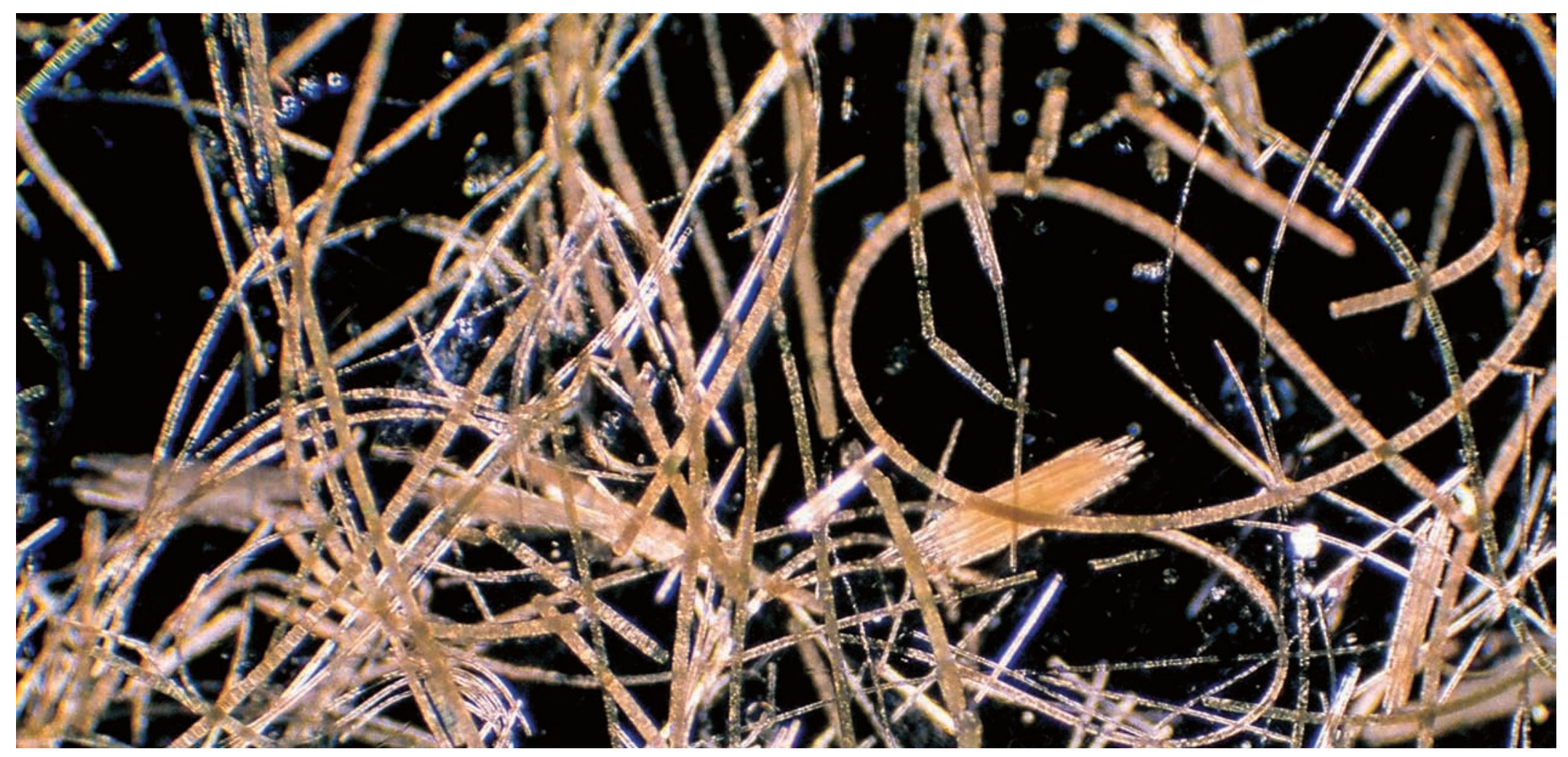

Trichodesmium vue au microscope. @ IRD/G.Dirberg et C. Dupouy

\section{Références bibliographiques}

Biogeochemical and biological response to a diazotroph bloom in a lownutrient, low-chlorophyll ecosystem : results from the Vahine mesocosms experiment. Biogeosciences :

https://www.biogeosciences.net/special_issue193.html

BERTHELOT H. et al., 2015 Dinitrogen fixation and dissolved organic nitrogen fueled primary production and particulate export during the Vahine mesocosm experiment (New Caledonia lagoon). Biogeosciences, 12: 4099-4112.

BONNET S.et al., 2016 Dynamics of $\mathrm{N}_{2}$ fixation and fate of diazotroph-derived nitrogen in a low nutrient low chlorophyll ecosystem: results from the Vahine mesocosm experiment (New Caledonia). Biogeosciences, 13 : 2653-2673. BONNET S. et al., $2017 \mathrm{~A}$ hot spot of $\mathrm{N}_{2}$ fixation in the western tropical South Pacific pleads for a spatial decoupling between $\mathrm{N}_{2}$ fixation and denitrification. PNAS. doi : 10.1073/pnas.1619514114, 2017.

DUPOUY C., PETIT M., DANDONNEAU Y., 1988 Satellite detected cyanobacteria bloom in the southwestern tropical Pacific. Implication for nitrogen fixation. International Journal of Remote Sensing, 8 (3) : 389-396. DUPOUY C. et al., $2011 \mathrm{~A}$ new algorithm for detecting Trichodesmium surface blooms in the South Western Tropical Pacific. Biogeosciences, 8 : 1 17. doi : $10.5194 / \mathrm{bg}-8-1-2011$.

FICHEZ R. et al., 2010 Biogeochemical typology and temporal variability of lagoon waters in a coral reef ecosystem subject to terrigeneous and anthropogenic inputs (New Caledonia). Marine Pollution Bulletin, 61 : 309-322. GIMENEZ A. et al., 2016 Biogeochemical fluxes and fate of diazotroph derived nitrogen in the food web after a phosphate enrichment: Modeling of the Vahine mesocosms experiment. Biogeosciences, 13 : 5103-5120.

HUNT B.P.V. et al., 2016 Contribution and pathways of diazotroph derived nitrogen to zooplankton during the Vahine mesocosm experiment in the oligotrophic New Caledonia lagoon. Biogeosciences, 13 : 3131-3145.

RODIER M., LE BORGNE R., 2010 Population and trophic dynamics of Trichodesmium thiebautii in the SE lagoon of New Caledonia. Comparison with T. erythraeum in the SW lagoon. Marine Pollution Bulletin, 61 : 349-359. 


\section{Chapitre 9 \\ Histoire d'algues}

Claude E. Payri, Laura Lagourgue, Lydiane Mattio, Julie Gaubert et Christophe Vieira

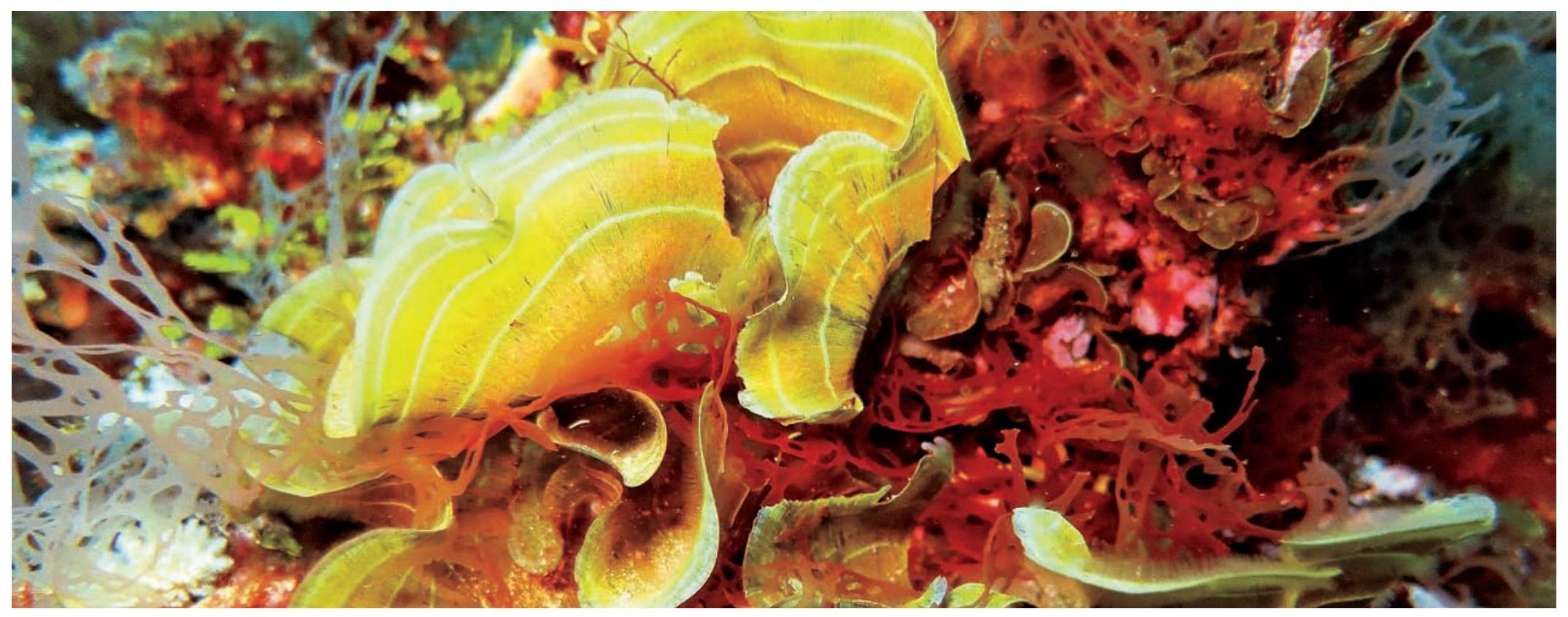

Assemblage typique d'algues dans le Lagon Sud. Canal Woodin, 2015. Au centre Stypopodium lame brune iridescente, mêlée à la délicate dentelle rouge du Kallymenia. @ IRD/ C.E Payri

\section{Les algues, de drôles d'organismes}

Les algues des récifs coralliens regroupent un ensemble hétérogène d'organismes tous capables de faire la photosynthèse, mais que l'histoire évolutive a fait diverger en plusieurs grandes lignées indépendantes. Bien qu'il n'ait aucune signification taxonomique, le terme « algue » est utilisé par commodité pour évoquer des végétaux marins aux formes et aux couleurs diverses incluant des microalgues unicellulaires de quelques microns ou des macroalgues généralement pluricellulaires et pouvant atteindre plusieurs dizaines de centimètres de long (encadré 9).

\section{Algues nourricières, algues protectrices}

Les macroalgues jouent un rôle important dans l'écologie des récifs coralliens. Comme tous les organismes photosynthètiques, elles participent activement à la production primaire.

Elles sont la principale source de nourriture pour une grande variété d'herbivores vivant dans les récifs et les lagons (poissons, crustacés, mollusques) et sont la base même du réseau trophique de l'écosystème corallien. Les plus consommées sont les formes filamenteuses qui tapissent les coraux morts et forment un feutrage algal abritant lui-même 
Encadré 9

\section{Les microalgues}
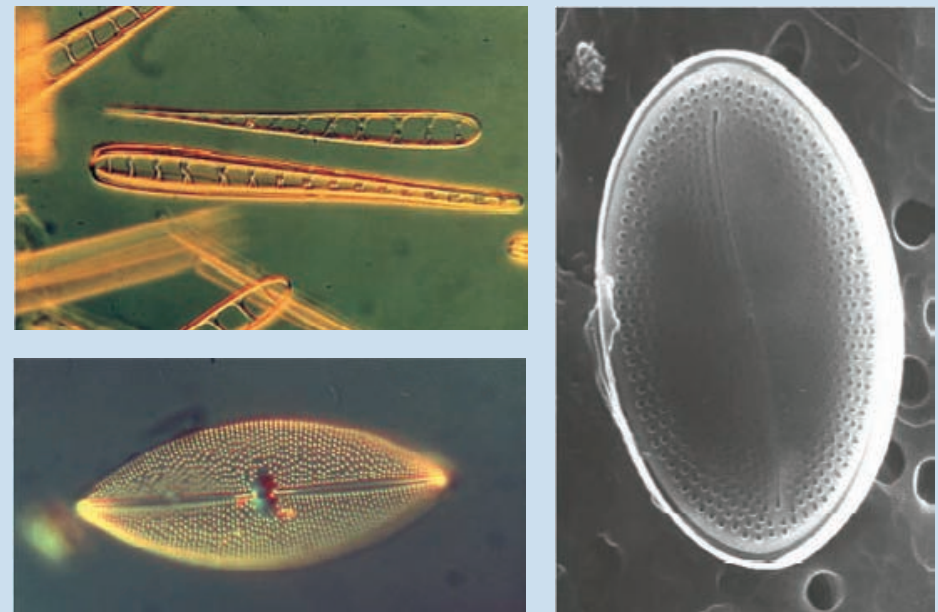

Diatomées benthiques A : Climacosphenia moniligera $(250 \mu \mathrm{m})$.

B : Navicula granulata $(90 \mu \mathrm{m})$. C : Cocconeis sp. (40-50 $\mu \mathrm{m})$.

A, B : @ M. Ricard ; C :@ CRIOBE/B. Delesalle

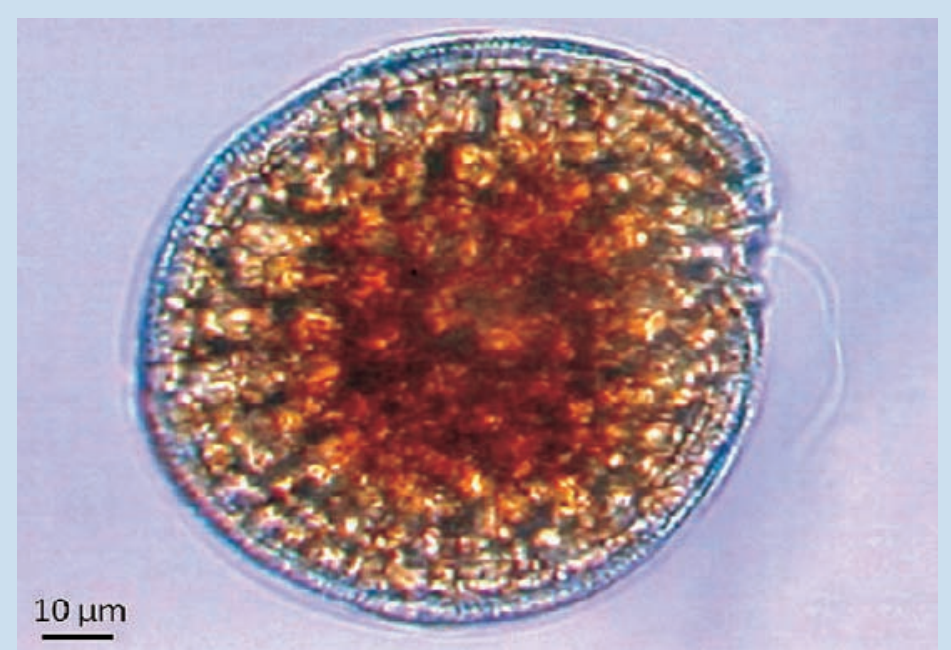

Cellule de Gambiersdiscus issue de culture. Cette microalgue se développe sur d'autres supports, dont les macroalgues. Lorsque ces dernières sont broutées, les herbivores prélèvent en même temps les Gambierdiscus. Ces microalgues contiennent des toxines (ciguatoxines) qui s'accumulent le long de la chaine alimentaire et provoquent une maladie appelée la ciguatera.

c) Institut Louis Malardé/M. Chinain

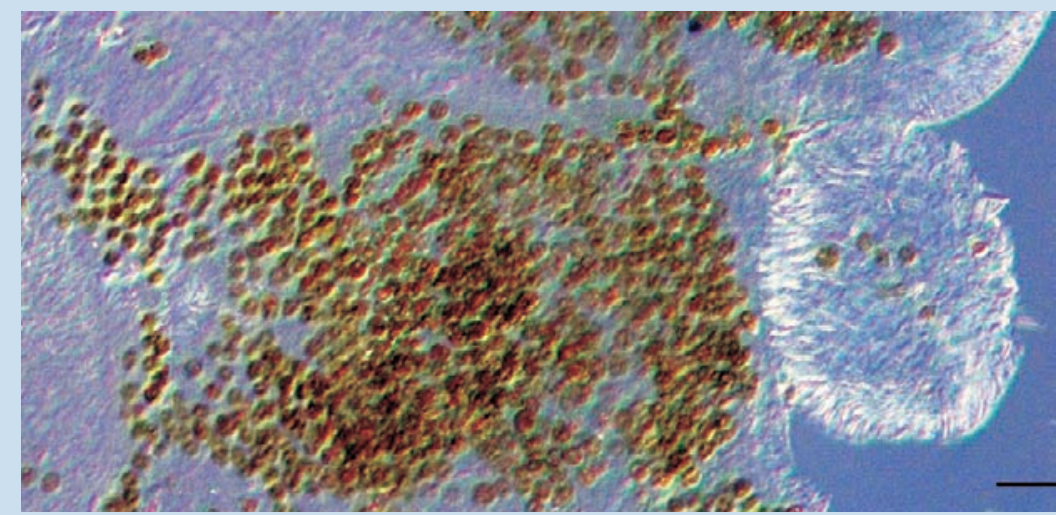

Vue microscopique de zooxanthelles (Symbiodinium) dans un polype du corail branchu Pocillopora damicornis. Échelle : $40 \mu \mathrm{m}$. @ CNRS/V. Berteaux-Lecellier

Les formes unicellulaires microscopiques, ou microalgues, vivent généralement libres dans la colonne d'eau et constituent le phytoplancton. Toutefois plusieurs d'entre elles, comme certaines diatomées, doivent se fixer à un support pour se développer et forment les premières étapes du phénomène de « fouling ».

D'autres ont fait alliance avec des animaux et les plus célèbres sont les zooxanthelles que l'on trouve en symbiose dans les polypes des coraux bâtisseurs de récifs ou encore dans le manteau des bénitiers. Les zooxanthelles ou Symbiodinium sont des dinoflagellés, comme Gamberdiscus, une autre microalgue bien connue dans les régions coralliennes causant la ciguatera, intoxication alimentaire provoquée par la consommation de poissons des récifs et des grands prédateurs (barracudas, requins.). Alors que Symbiodinium s'abrite dans les tissus de l'animal hôte, Gambierdiscus se développe, lui, à la surface des coraux morts ou de grandes algues. 
une petite faune mobile très riche (le « algal turf » des Anglo-Saxons) et dont raffolent les poissons «peigneurs ». Les formes plus coriaces comme les Turbinaria ou les Sargasses sont rarement broutées, tout comme les algues calcaires que seuls les poissons-perroquets ou certains mollusques sont capables de racler grâce à leur dentition puissante laissant des empreintes bien spécifiques. Les plus grandes d'entre elles, comme les grandes algues brunes (sargasses), forment une canopée sous laquelle trouvent refuge de très nombreux invertébrés et poissons qui y séjournent tout ou partie de leur vie (encadré 10).

De même, les algues rouges calcaires et massives jouent un rôle essentiel dans la construction et la consolidation des structures récifales. Elles en assurent le maintien et, sans leur activité de cimentation, la seule matrice corallienne ne serait pas assez solide pour résister aux assauts des vagues et aux événements majeurs tels que cyclones et tsunamis. Dans les sites les plus exposés sur les récifsbarrières et sur les pentes externes du récif, elles remplacent les coraux moins adaptés à un fort hydrodynamisme, et forment un glacis compact de couleur rose-beige ou des amas arrondis en forme de cerveau ou dressés telles des chandelles comme dans les atolls des Chesterfield ou des récifs d'Entrecasteaux.

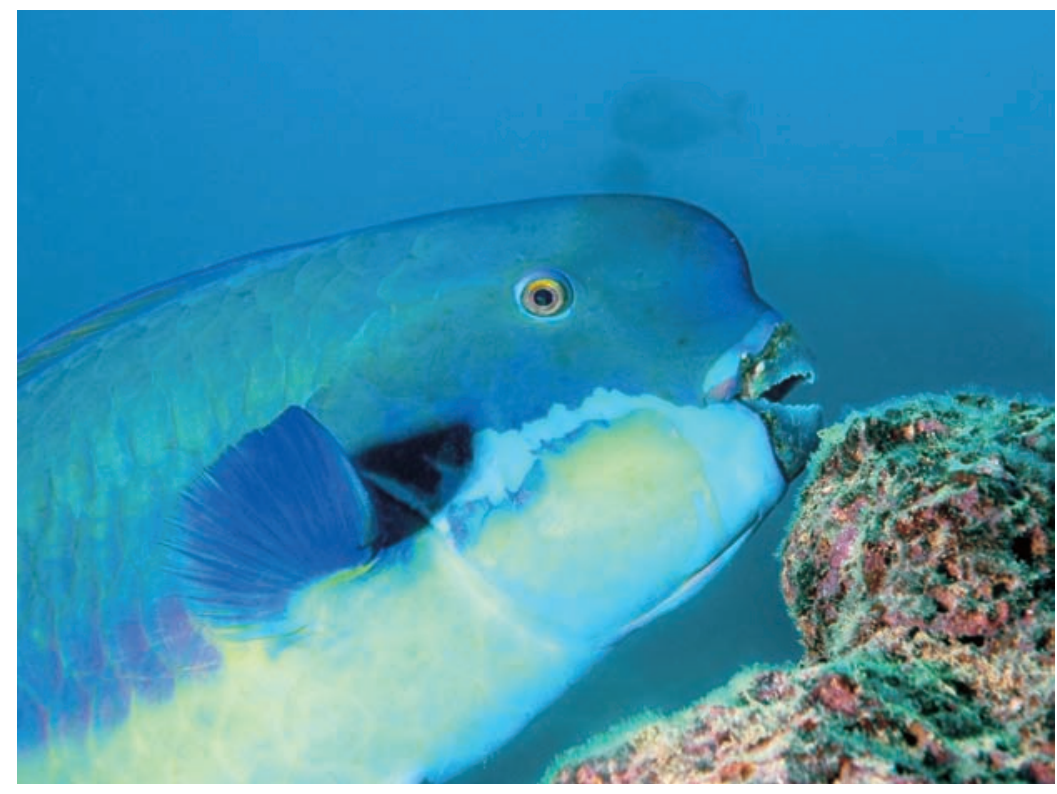

Actions de broutage par des poissons perroquets. @ M. Juncker
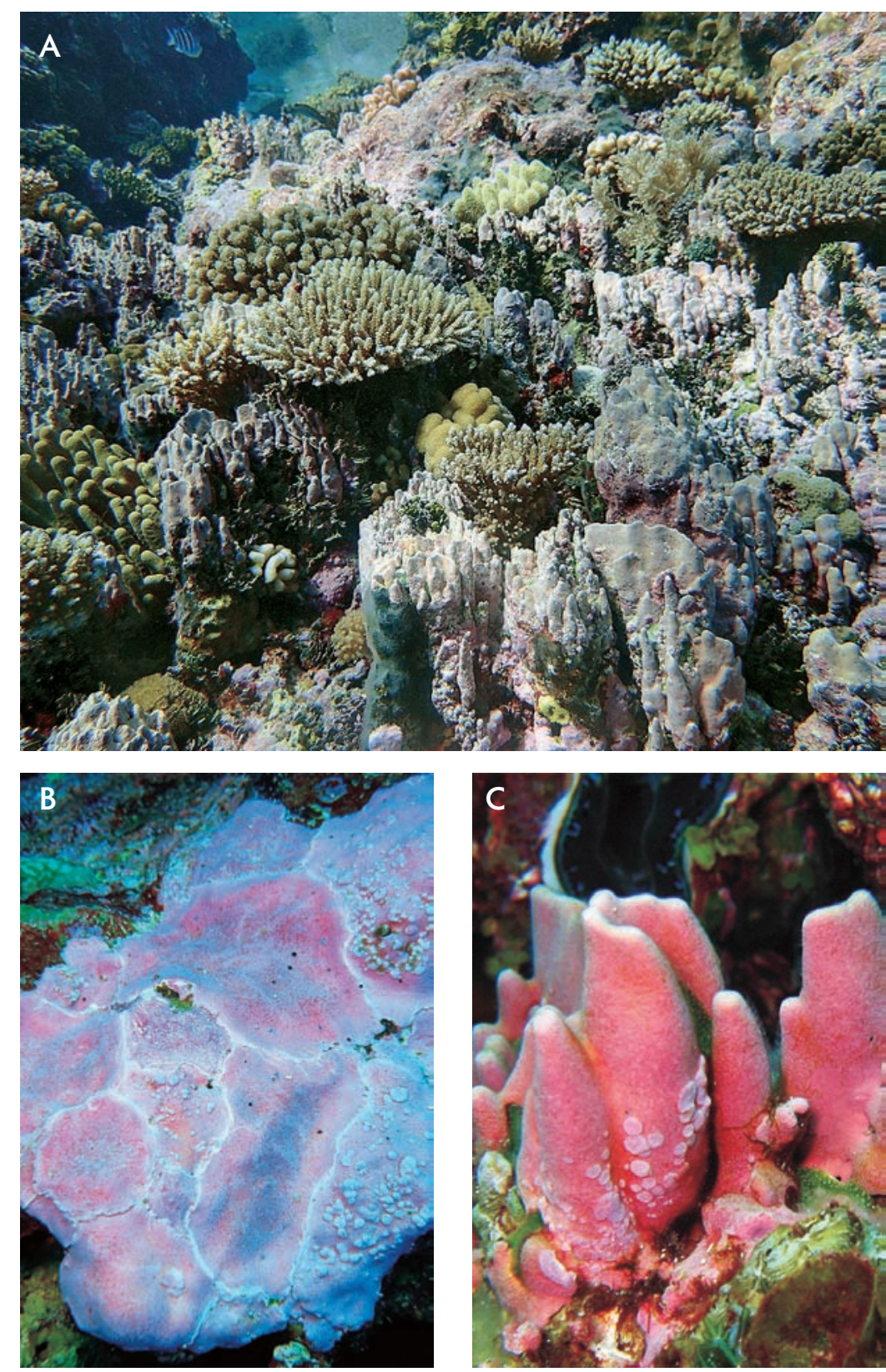

A: Les algues rouges calcaires (corallines) dominent dans les zones exposées des pentes externes où elles édifient des constructions imposantes, comme aux îles Chesterfield. @IRD/ G. Lasne $B$ : Formes encroûtantes massives qui assurent la cimentation du substrat.

$C$ : Formes en « chandelle » de Porolithon.

(c) IRD/C. E. Payri 


\section{Macroalgues, un cabinet de curiosités}

Entre corps mous ou masses pierreuses, l'architecture et les couleurs de ces organismes peuvent être déconcertantes. Rouges, vertes ou brunes, les macroalgues des récifs et lagons offrent toutes les formes imaginables depuis celles rappelant des feuilles de plantes terrestres à des formes ramifiées plumeuses, filiformes, articulées ou à des formes à peine reconnaissables tant elles adhèrent au substrat. Ces espèces adhérentes, voire encroûtantes, qu'elles soient brunes comme Lobophora obscura, sont nombreuses à colorer les débris coralliens, redonnant aux substrats inertes une seconde vie. Certaines

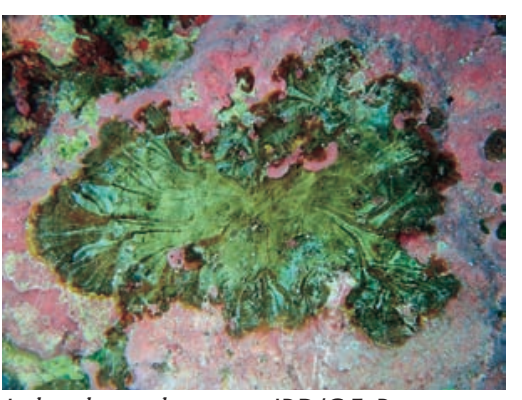

Lobophora obscura. ( IRD/C.E. Payri

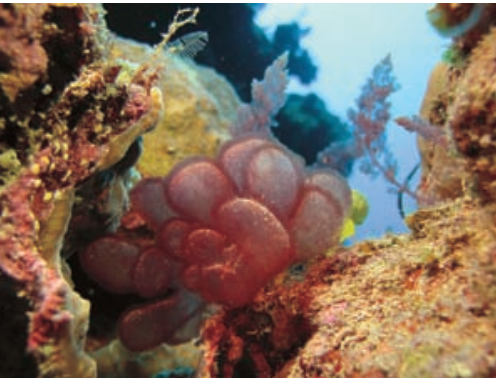

Gibsmithia complexe hawaiensis. @ IRD/C.E. Payri

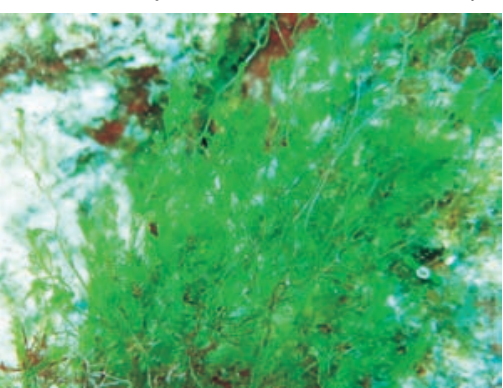

Cladophora sp. @ IRD/C.E. Payri

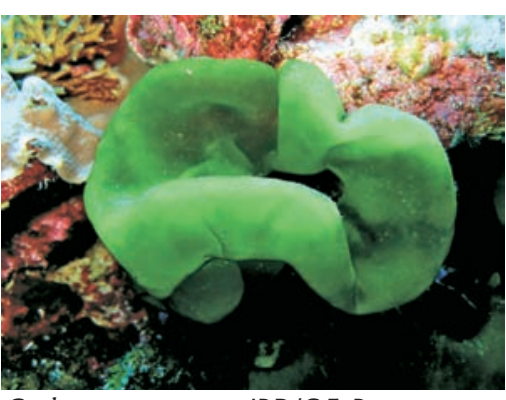

Codium saccatum. @ IRD/C.E. Payri

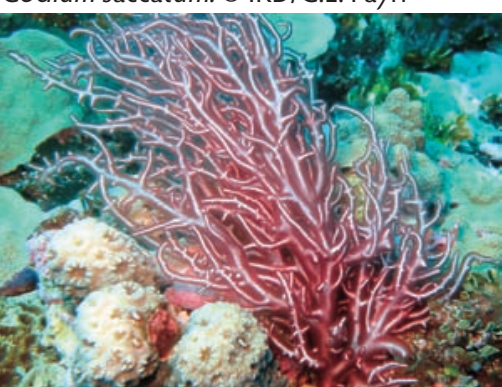

Trichogloea requinerii @ IRD/C.E. Payri

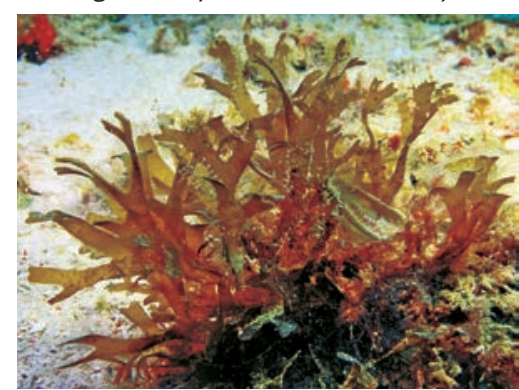

Dictyota sp. ( IRD/J.-L. Menou méritent un détour car on pourrait $s^{\prime} y$ méprendre. Les formes en béret kaki des Codium saccatum ne sont pas moins étranges que les billes de l'espèce voisine Codium globosum ou les jeunes individus d'Halimeda cylindracea qui étalent leurs segments telle une main tendue. Ces trois exemples ont en commun d'être composés d'une cellule unique tubulaire géante contenant de multiples noyaux, et ramifiée pour former le corps de l'algue (encadré 11). Plus insolites ces algues rouges d'aspect gélatineux et duveteux, tantôt globuleuses comme Gibsmithia, tantôt ramifiées ou Trichogloea, qui résistent au courant de la mer, mais qui se disloquent au contact de la main qui cherche à les cueillir.

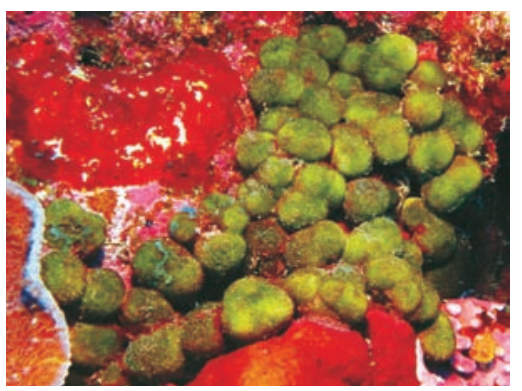

Codium globosum. ( ) IRD/C.E. Payri

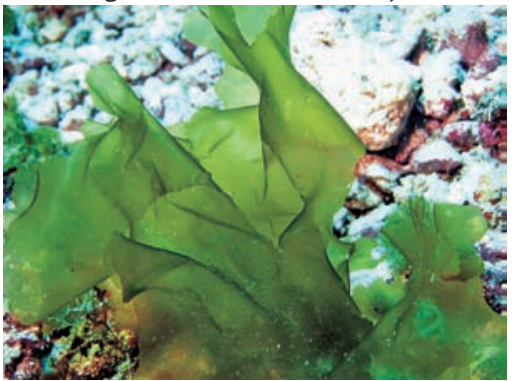

Umbraulva sp. @ IRD/C. Geoffray

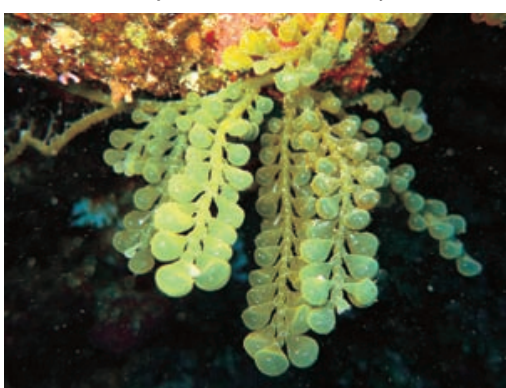

Caulerpa cactoides. @ IRD/C. Geoffray

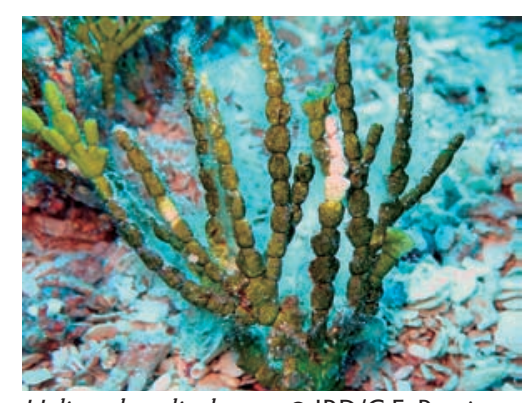
Halimeda cylindracea. @ IRD/C.E. Payri

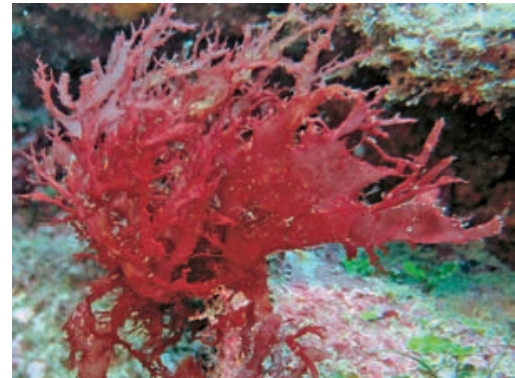

Halymenia sp. () IRD/C.E. Payri

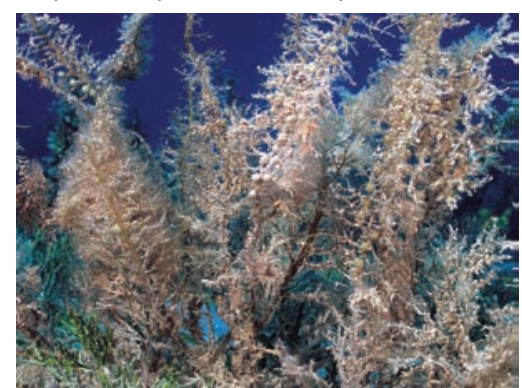

Sargassopsis decurrens. @ IRD/J.-L. Menou 


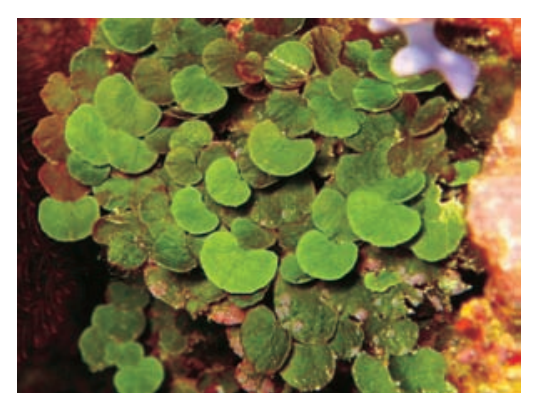

Halimeda complexe minima. @ IRD/C.E. Payri

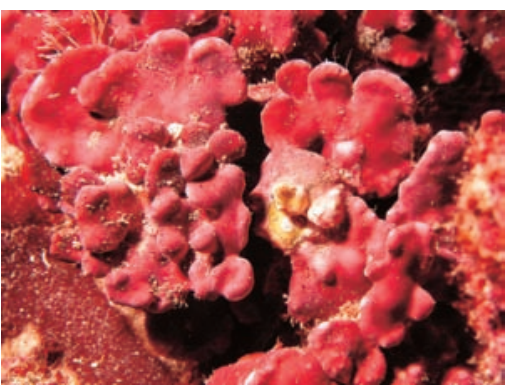

Lithophyllum proliferum. @ IRD/C.E. Payri

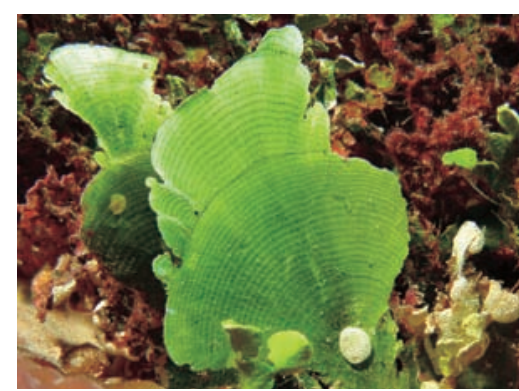

Udotea geppiorum. @ IRD/J.-L.Menou

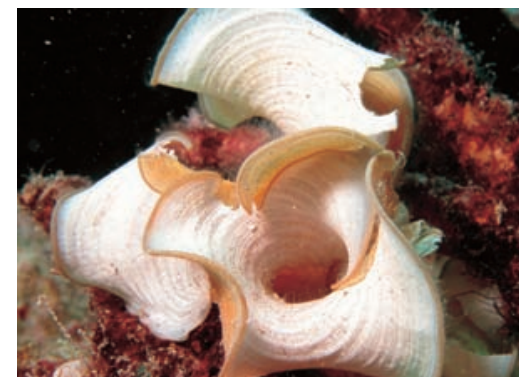

Padina complexe melemele. @ IRD/C. Geoffray

Plus classiques, les frondes en lames foliacées minces (Umbraulva) ou épaisses et digitées (Halymenia), ou filamenteuses (Cladophora), avec des structures ramifiées simples (Dictyota)à plus complexes (Caulerpa), voire hautement spécialisées, mimant feuilles et tiges comme chez les Sargassum.

Si la majeure partie d'entre elles sont des « algues molles », c'està-dire dépourvues de structure rigide, plusieurs groupes ont la capacité de former une trame calcaire par précipitation du carbonate de calcium de l'eau de mer dans les parois internes des cellules comme chez certaines algues rouges qui forment les Corallinales avec plus de 100 genres différents, ou algues vertes aux records plus modestes avec une vingtaine de genres, dont Halimeda, Udotea, Neomeris... Chez les algues brunes, seul de genre Padina précipite à la surface des frondes un fin dépôt de calcaire.

Enfin encore plus déroutant, ces nodules pierreux, formes singulières rondes ou branchues, construites par des algues rouges calcaires à partir d'un débris corallien (nucléus) autour duquel l'algue va se développer en couches concentriques sous l'action d'un courant modéré. Ces nodules libres appelés rhodolithes, lie de vin ou rose, tapissent les cuvettes des platiers ou forment les champs de maërl dans les fonds de lagons balayés par des courants modérés.

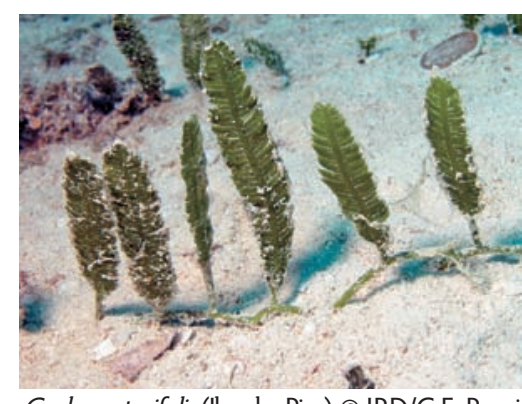

Caulerpa taxifolia(lles des Pins). @ IRD/C.E. Payri

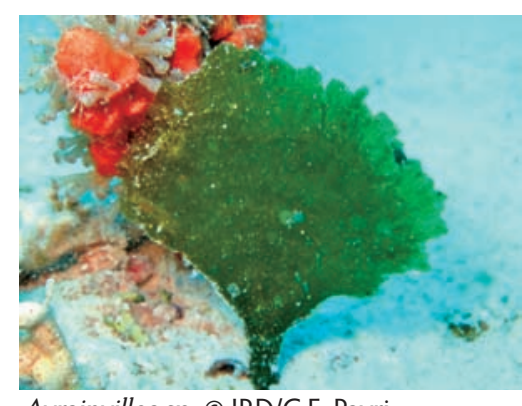

Avrainvillea sp. (๐) IRD/C.E. Payri

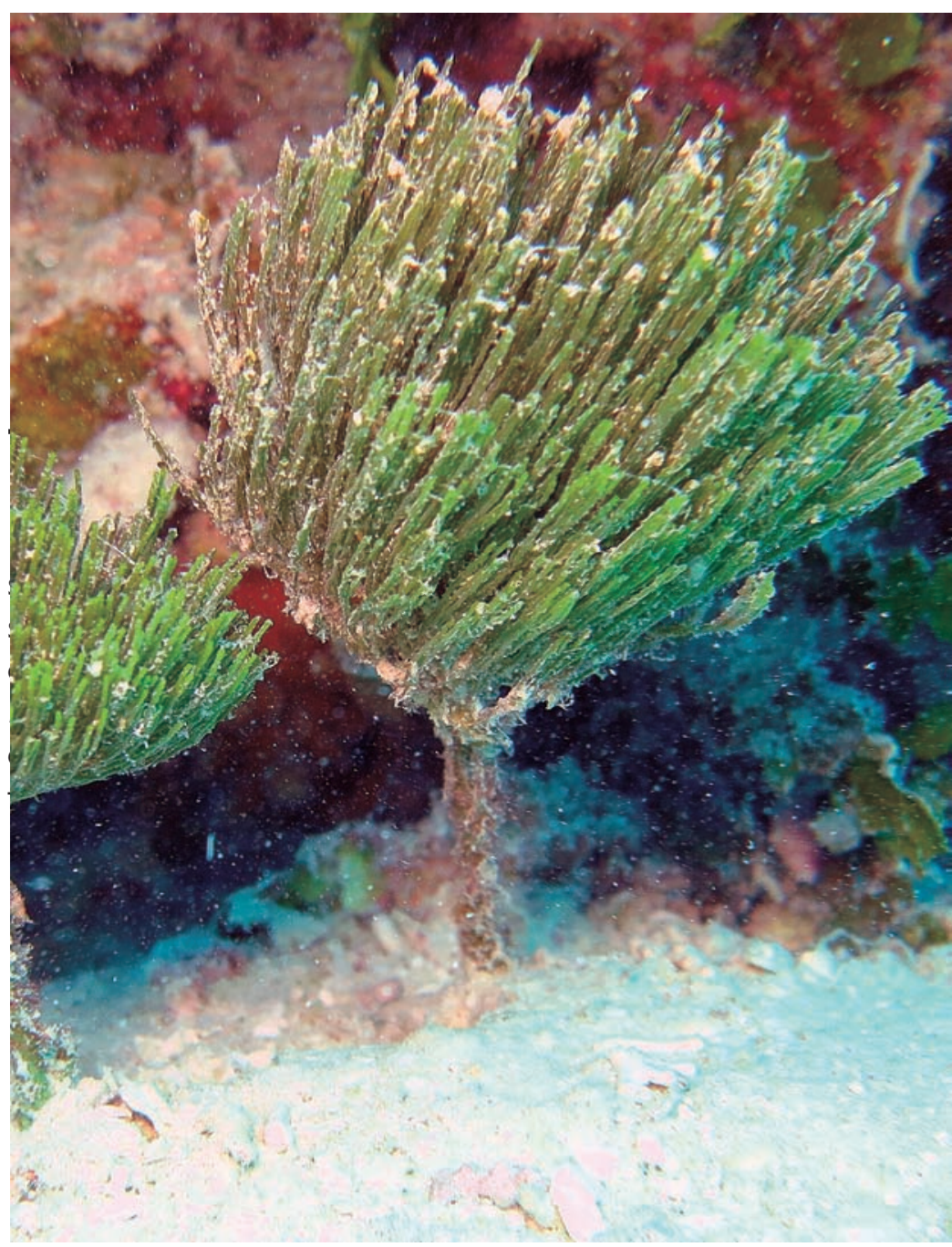

Penicillus sp nov. @ IRD/C.E. Payri 


\section{Encadré 10}

\section{Les sargasses, un maquis au fond du lagon}

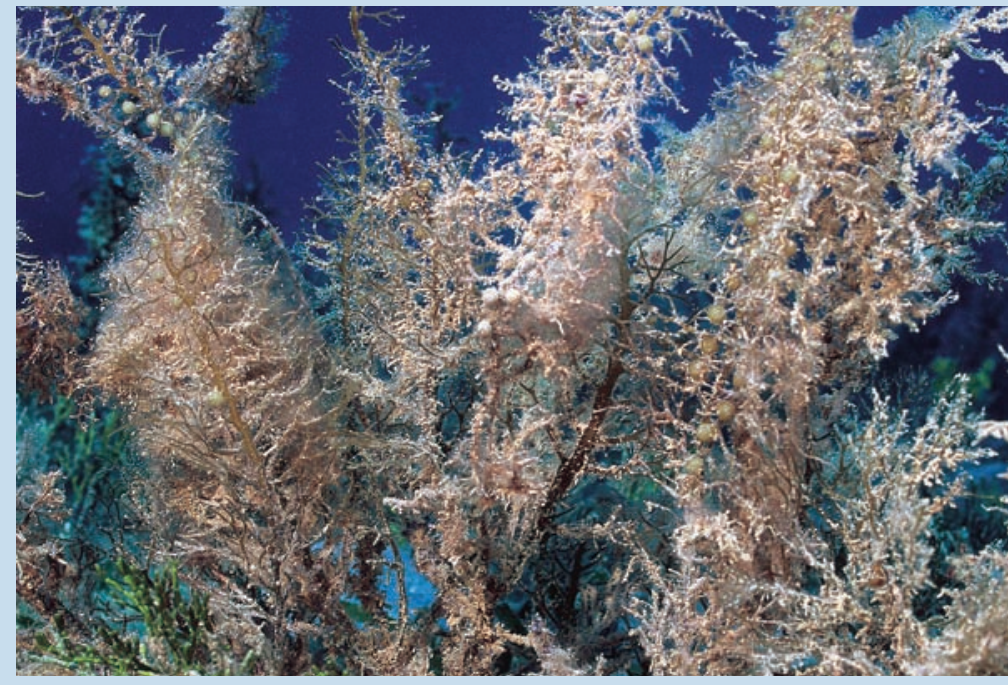

Sargassopsis decurrens appartient à la famille des Sargassaceae. Cette espèce se reconnait facilement grâce à sa morphologie particuliere en arrête de poisson ou sapin de noël. Les vésicules aérifères (boules de noël) des sargasses leur permettent de se tenir dressées et de flotter lorsque qu'un des axes se détache (tempêtes, senescence) (c) IRD/C. Geoffray

Les espèces de la famille des sargasses (Sargassaceae) structurent un des habitats benthiques majeurs du lagon néo-calédonien à l'instar des forêts de grandes algues brunes des régions tempérées (fucales et laminaires). Leur canopée peut atteindre une hauteur d'1 à 2 m, formant ainsi un véritable maquis sous-marin qui joue un rôle essentiel dans le cycle biologique de nombreuses espèces d'animaux en leur apportant substrat, nourriture et refuge contre les prédateurs ou des conditions environnementales difficiles. Les algueraies de sargasses du lagon abritent ainsi une grande diversité d'invertébrés (amphipodes, polychètes, mollusques...) et jouent un rôle essentiel de nurseries pour de nombreuses espèces de poissons. Les sargasses sont très diversifiées morphologiquement. Certaines ressemblent à une branche de houx brune (par exemple Sargassum ilicifolium) alors

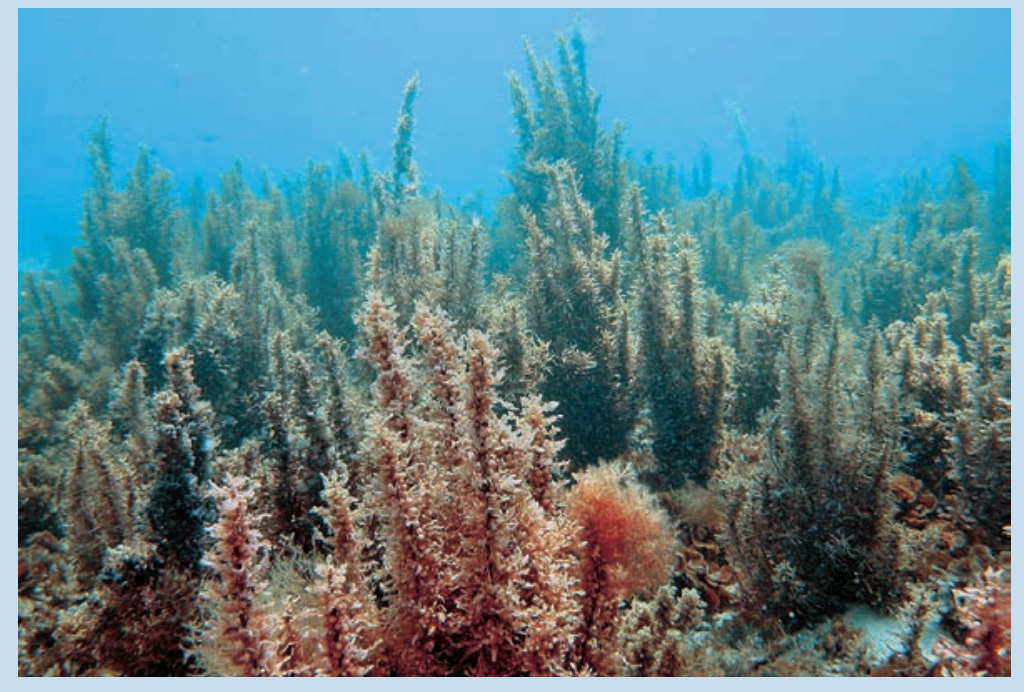

Champs de sargasses dans le lagon sud. Sargassum spinuligerum y est l'espèce la plus abondante et peut atteindre 1,5 a 2 mètres de haut. Cette véritable forêt sous-marine est un habitat essentiel pour de nombreuses autres espèces d'algues, poissons, invertébrés et mollusques. @ IRD/C. Geoffray

que d'autres font penser à un sapin de noël aplatit voire même à une arête de poisson (par exemple Sargassopsis decurrens) ! Elles se trouvent dans des habitats très diversifiés depuis la zone intertidale côtière jusqu'au récif-barrière. Elles forment des populations denses ou éparses sur les platiers côtiers, sur les platiers frangeants d'îlots, sur les fonds de lagon jusqu'à $30 \mathrm{~m}$ de profondeur, et sur le récif-barrière jusqu'à plus de $50 \mathrm{~m}$ de fond ($56 \mathrm{~m}$ dans le cas de $S$. turbinarioides à l'île des Pins). Elles se développent sur tous types de substrats durs : des fonds rocheux plus ou moins ensablés (par exemple $S$. polyphyllum) ou envasés, des fonds détritiques (par exemple $S$. polycycstum), dans les anfractuosités des récifs et sur les enrochements artificiels (par exemple $S$. aquifolium). 


\section{Encadré 11}

\section{Les unicellulaires, « siphonées » ces algues !}

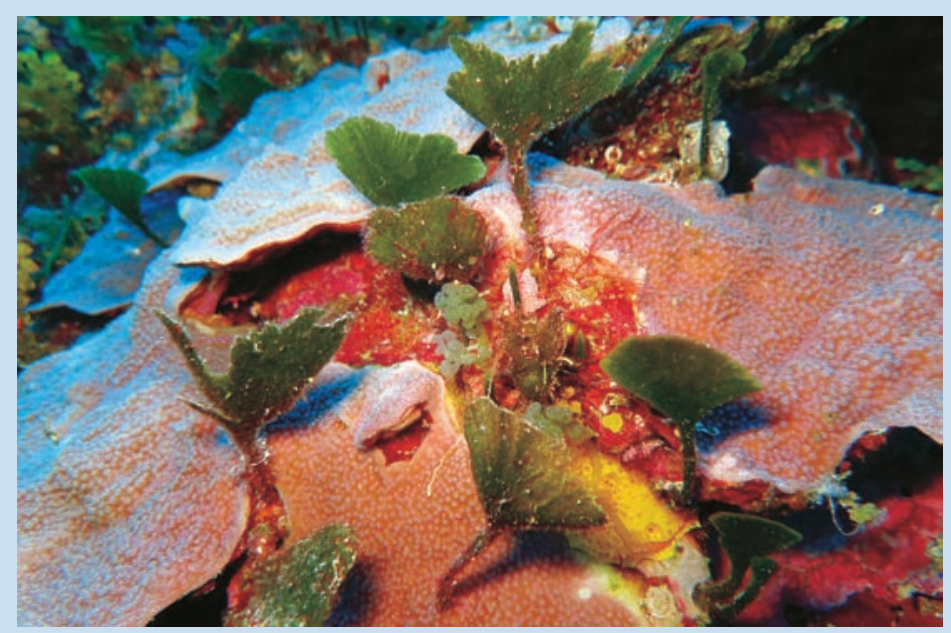

Avrainvillea sp nov. (c) IRD/C.E. Payri

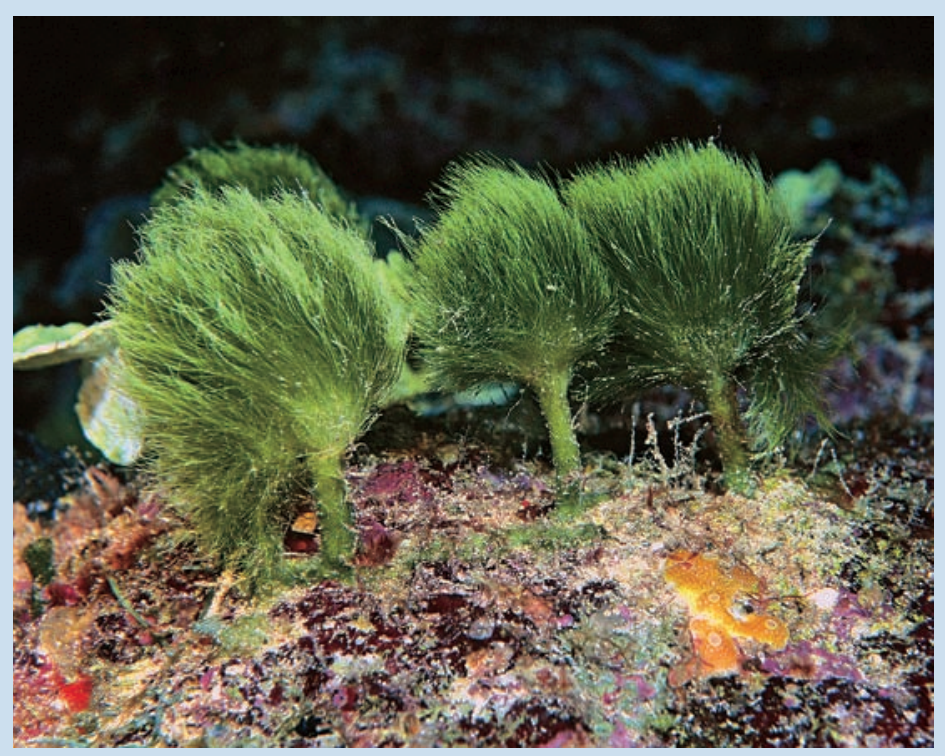

Rhipilia penicilloides. @ IRD/C.E. Payri

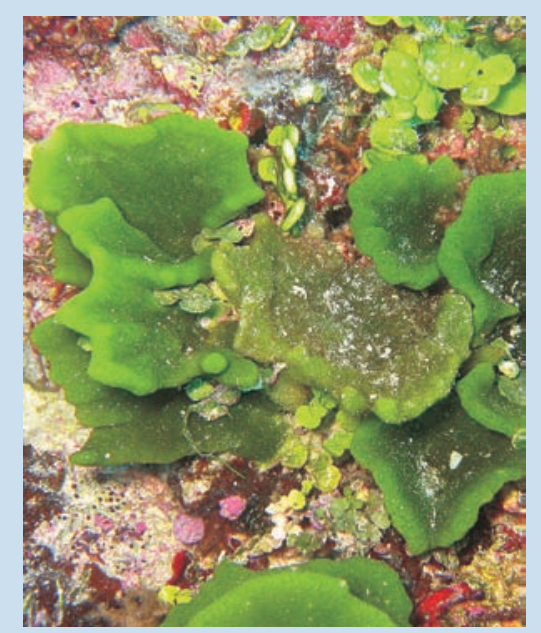

Rhipilia sp nov. @ IRD/C.E. Payri

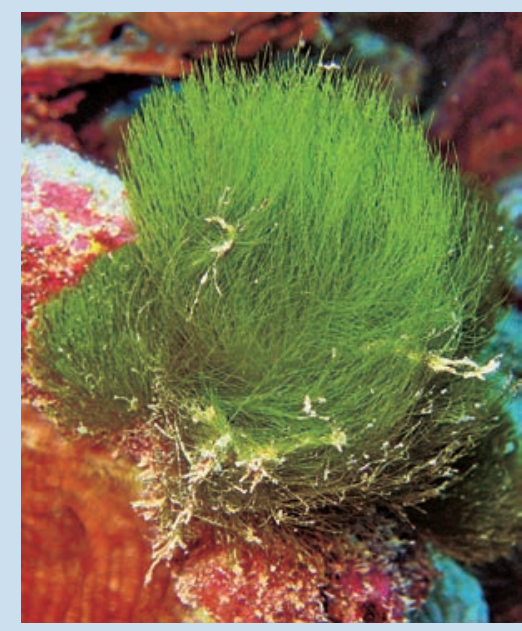

Chlorodesmis sp. @ IRD/C.E. Payri

Qui aurait pu penser que les algues ci-contre ne sont en réalité qu'une seule et même cellule ? C'est pourtant ce qui caractérise les espèces appartenant à l'ordre des Bryopsidales. Malgré cette structure simple, leur diversité morphologique est incroyable, avec des spécimens pouvant mesurer plus de $10 \mathrm{~cm}$ de haut, et pouvant former des thalles très différents d'une famille à une autre, avec des parties si bien différenciées (rhizoïdes, stipe et lame comparables aux racines, tige et feuilles des plantes) que l'on ne pourrait croire qu'il s'agit d'un organisme unicellulaire. Ces algues sont pourtant constituées d'une seule cellule, plurinucléée et tubulaire que l'on nomme siphon, qui se ramifie ensuite en plusieurs branches partageant toujours le même cytoplasme. Et c'est l'agencement et l'organisation de ces siphons (pouvant s'entremêler, être parfaitement alignés voire coalescer ou encore rester libres), si différents d'une espèce à une autre, qui entraînent cette si grande diversité morphologique visible à l'œil nu. 
En Nouvelle-Calédonie, toutes les macroalgues sont des organismes benthiques, c'est-à-dire qui se développent en étant fixés à un support, ce dernier pouvant être un grain de sable.

On ne connaît à ce jour que deux espèces de macroalgues qui se développent sans jamais être fixées. Il s'agit de deux espèces de sargasses de la mer du même nom, située dans l'Atlantique nord. Ces algues pélagiques forment des radeaux de très grandes étendues. Depuis quelques années les îles des Caraibes et les côtes du Brésil et d'Afrique de l'Ouest connaissent des échouages massifs de ces sargasses pélagiques sans que l'on ait pu à ce jour clarifier leur origine et expliquer ce phénomène récent.

Dans les lagons, il est fréquent de voir après une forte houle, flotter des sargasses ou d'autres espèces qui, après avoir été détachées de leur substrat, dérivent au gré des courants avant de s'échouer sur le rivage ou de disparaître dans les profondeurs.

\section{Un monde de couleur}

Les macroalgues sont communément désignées par leur couleur : on parle d'algues rouges, vertes et brunes, et même bleues ces dernières étant des bactéries (cyanobactéries) qui ne seront pas traitées ici. Pour faire simple, les trois grandes catégories de couleur renvoient aux trois grandes divisions, rhodophytes (algues rouges) et chlorophytes (algues vertes), qui forment deux branches divergentes mais appartenant à la même « lignée verte », et les phéophytes de la « lignée brune », bien distincte de la précédente. Trois types de pigments, chlorophylles (pigments verts), caroténoïdes (pigments orange et jaunes) et phycobilines (pigments rouges et bleus) suffisent à donner aux algues toutes les couleurs en fonction de leur concentration, semant parfois la confusion. Des algues rouges peuvent apparaître marron, tandis que des algues brunes peuvent prendre des couleurs verdâtres... Mais les combinaisons pigmentaires ne sont pas les seuls critères sur lesquels se basent la taxonomie ; les différents produits de la photosynthèse, les parois cellulaires, la forme et le nombre de flagelles chez les unicellulaires ou les organes de reproduction et les organites qui composent la cellule comme les plastes sont autant d'éléments pris en considération.

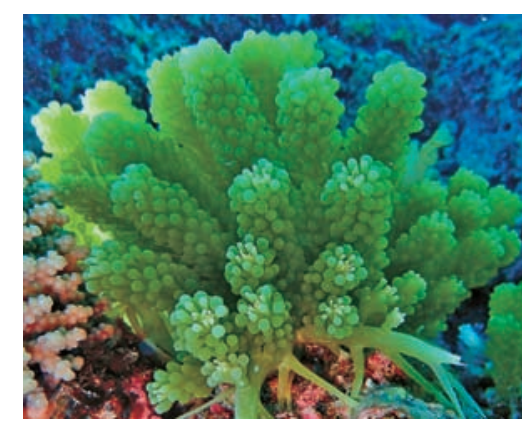

Caulerpa chemnitzia. @ IRD/C.E. Payri

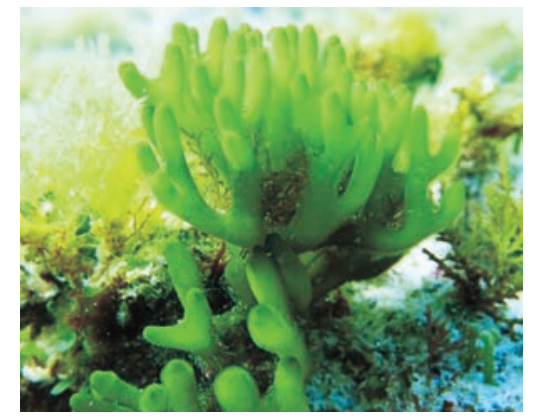

Codium taylorii. @ IRD/C.E. Payri

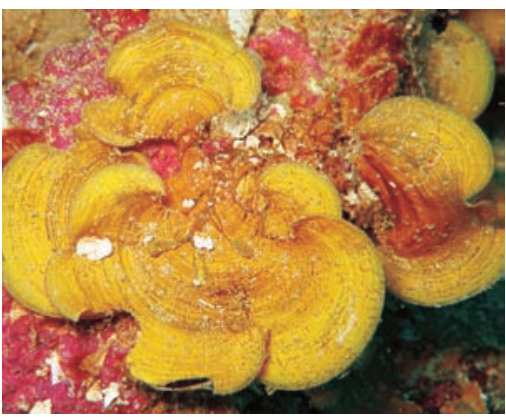

Padina melemele. @ IRD/C.E. Payri

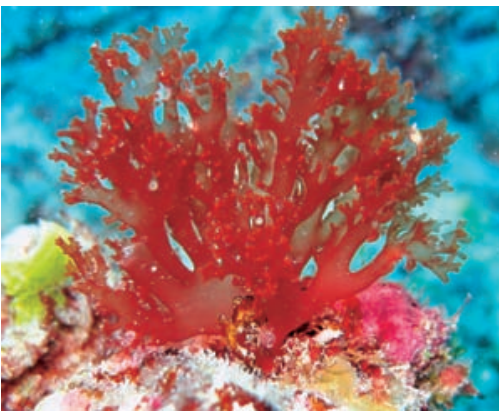

Platoma sp. @ IRD/C.E. Payri

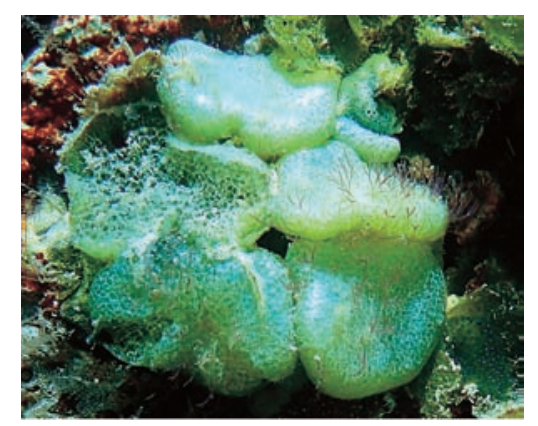

Dictyosphaeria cavernosa. @ IRD/G. Lasne

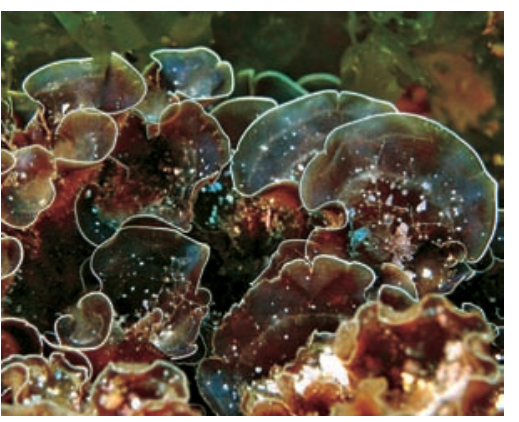

Distromium didymotrix. @ IRD/C.E. Payri

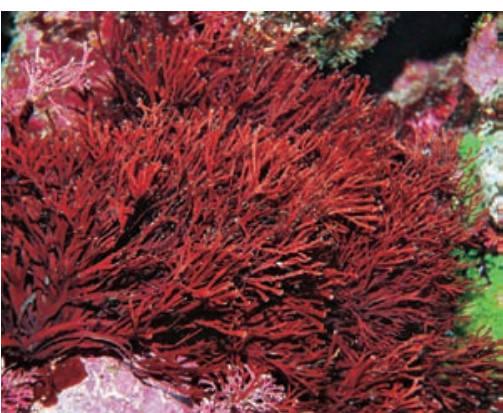

Melanthalia vieillardii. @ IRD/C.E. Payri

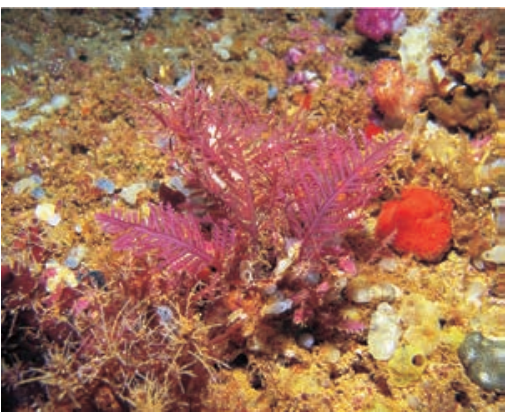

Callophycus serratus. @ IRD/C.E. Payri 


\section{Elles sont partout...}

Depuis les forêts de mangroves où, sur les racines des palétuviers, se niche la petite algue rouge Bostrychia, en passant par les herbiers littoraux, où prolifèrent de nombreuses espèces d'algues brunes comme les Padina, d'algues rouges comme les Dichotomaria et d'algues vertes dont les Caulerpes aux frondes digitées (par exemple Caulerpa cupressoides), plumeuses (par exemple Caulerpa sertularioides ou C. taxifolia), ou en grappe de raisin (par exemple Caulerpa racemosa et C. chemintzia).

En s'enfonçant vers les fonds lagonaires, on découvre sur les sables gris plusieurs espèces d'algues vertes, où se mêlent des Halimeda reconnaissables à leurs petits segments calcaires, des Udotées en forme d'éventail calcaire d'un vert tendre et des Avrainvillea vert foncé, dont la fronde dépourvue de calcaire à un toucher de velours, toutes plantées dans les sédiments par un pivot de rhizoïdes compacts. Les fonds rocheux sont généralement occupés par les algueraies à sargasses dont les petits flotteurs portent vers la surface les longues frondes qui abritent sous la canopée d'autres espèces d'algues brunes (Lobophora, Dictyopteris, Hormophysa...) pour former un écosystème particulièrement productif. Dans les récifs intermédiaires et les récifs-barrières les macroalgues molles se font plus discrètes bien qu'elles soient encore très nombreuses. C'est le domaine des algues vertes Rhipilia et Chlorodesmis, qui forment des pompons d'un vert intense au sommet des colonies coralliennes, ou encore des Halimeda qui s'étalent en longues draperies le long des parois des coraux massifs ou se dissimulent au contraire dans les interstices des coraux avec des espèces étranges, comme Valonia ventricosa (grosses billes vertes) ou Dictyosphaeria cavernosa (formant des cupules très compactes). Dans ces zones les moindres substrats durs sont cimentés par des encroûtements d'algues rouges qui consolident l'édifice. Après la barrière de corail débute la pente externe le long de laquelle vont se répartir les algues en fonction de la profondeur et du mouvement des eaux pour former des communautés jusqu'à plus de $100 \mathrm{~m}$ de profondeur. Quelle que soit leur couleur, elles sont toutes bien accrochées aux substrats durs ; les espèces aux frondes dressées se balancent dans le mouvement incessant de l'eau comme la plupart des algues rouges, telles que Gibsmithia, Dudresnaya, Predaea, Platoma et autres Liagoraceae... d'autres au contraire étalent sur le substrat des lames arrondies fines d'un brun doré caractéristique des algues brunes de l'ordre des Dictyotales (Distromium, Lobophora, Homeostrichus...); les algues vertes sont majoritairement des Halimeda et des Codium, ces derniers étant tantôt ramifiés et dressés, tantôt adhérant fortement aux coraux. De nombreuses espèces se logent sous les surplombs ou tapissent les parois des excavations : il s'agit de nombreux Peyssonnelia, certains encroûtants, d'autres formant de grandes lames arrondies d'un rouge très sombre. On les distingue aisément des algues calcaires qui encroûtent les moindres surfaces, offrant une mosaique de couleurs chaudes dans cet univers relativement sombre. À ces grandes formes imposantes d'algues rouges, s'opposent de petites espèces vertes graciles de quelques millimètres de haut et dont la diversité est inversement proportionnelle à la taille, c'est le monde des genres calcifiés (Rhipidosiphon) ou non (Rhipiliopsis, Rhipiliella), et dont bon nombre reste encore à décrire. Les macroalgues sont partout, vivant même à l'intérieur des squelettes de coraux et autres substrats carbonatés, formant que ce l'on appelle des « endolithes ». Par leur action perforante, ces algues provoquent une véritable carie superficielle de la roche et contribuent avec les autres organismes perforant tels que bivalves, éponges et vers, à façonner la morphologie récifale.

Bien qu'elles soient tributaires de la lumière, les macroalgues colonisent également la zone mésophotique, cette partie du récif audelà de $70 \mathrm{~m}$ de profondeur et jusqu'à $125 \mathrm{~m}$ que quelques plongeurs expérimentés ont prospecté équipés de recycleurs alimentés par des mélanges de gaz adaptés. Les algues de cette zone sont presque toutes de nouvelles espèces de brunes Distromium, de rouges Delisea, Phacelocarpus et de vertes Halimeda.

\section{Combien d'algues néo-calédoniennes ?}

Il y aurait entre 7000 et 15000 espèces de macroalgues dans le monde. En Nouvelle-Calédonie les premières estimations portent ce nombre à 443 espèces dans le compendium publié en 2007. 


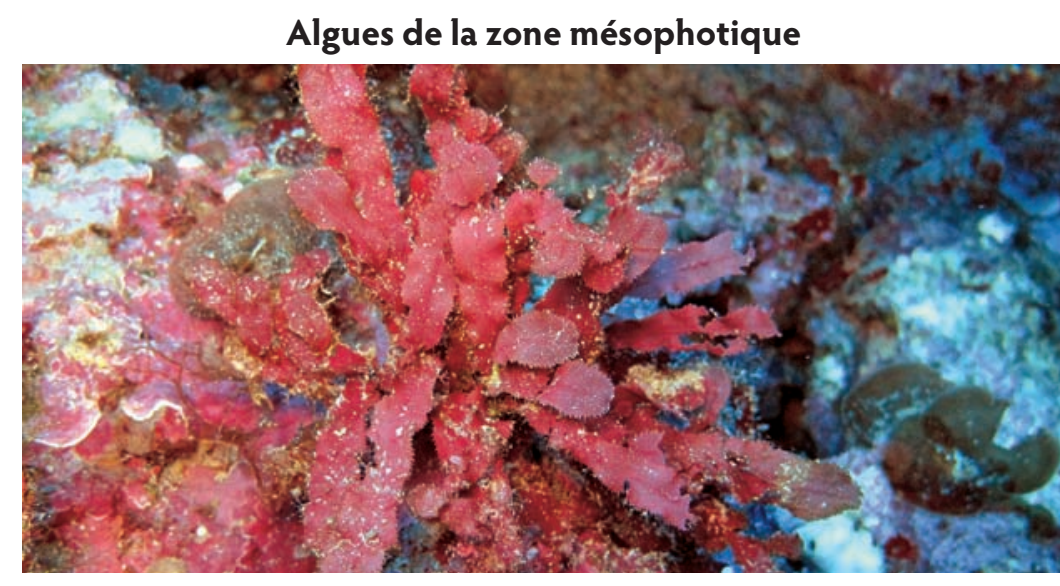

Phacelocarpus neurymenioides (-80 m de profondeur). @ IRDJ.-L. Menou

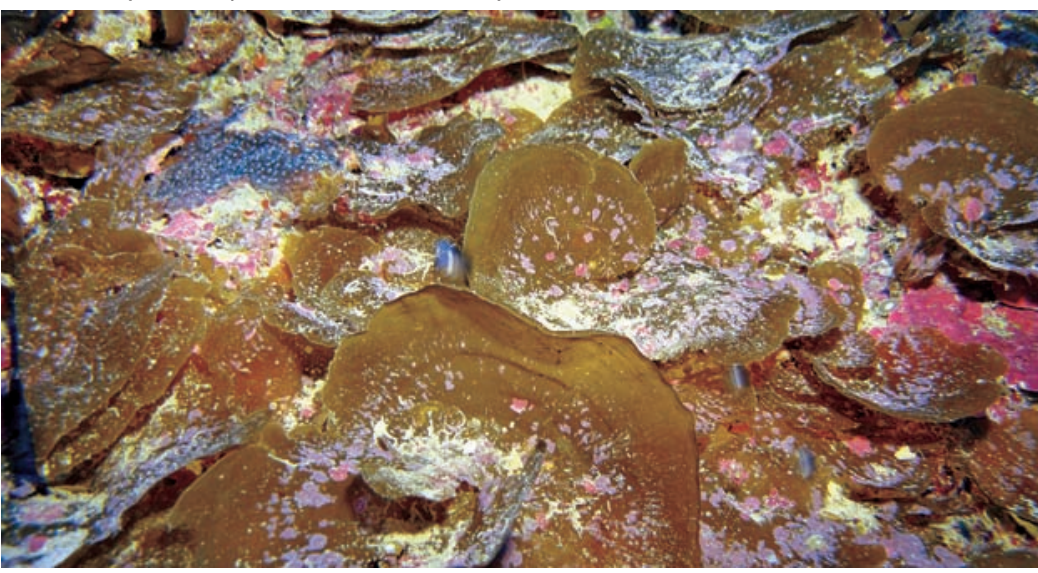

Distromium sp. (-85 m de profondeur). @ Biocénose/G. Lasne

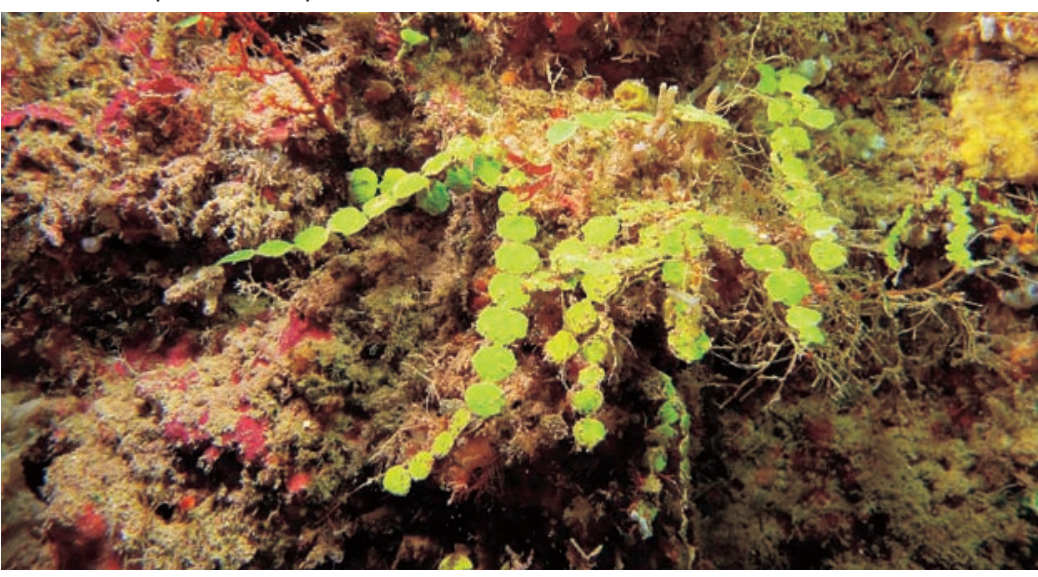

Halimeda complexe minima (-100 m de profondeur). @ IRD/J.-L. Menou
Cependant, cette estimation est très préliminaire car basée sur des collections limitées et des observations essentiellement morphologiques. Ce nombre ne cesse d'augmenter avec les nouvelles campagnes de collecte, des prospections répétées entre 40 et $60 \mathrm{~m}$ de profondeur et la généralisation des analyses génétiques. Il est probable que ce nombre atteigne, voire dépasse, le millier d'espèces. Il serait prétentieux de penser que l'inventaire des macroalgues de NouvelleCalédonie est achevé car, en dépit de l'effort de prospection développé dans tout l'archipel au cours des 15 dernières années, tous les sites n'ont pas été inventoriés de manière comparable et la grande région du lagon sud-ouest demeure à ce jour la mieux connue. Si la macroflore marine est de mieux en mieux étudiée, un grand nombre d'espèces nécessite toutefois d'être nommées selon le code de nomenclature botanique (c'est-à-dire un nom de genre suivi d'un nom d'espèce). En effet, la généralisation des analyses ADN et de l'outil barcoding a multiplié le nombre de taxon à une cadence très supérieure au temps nécessaire pour décrire les espèces. À titre d'exemple, le genre Lobophora (algue brune), recensé en Nouvelle-Calédonie par deux espèces jusqu'en 2007, en compte aujourd' hui près de 30 , dont 10 sont nouvelles pour la science (encadré 12). À l'échelle mondiale le genre compte plus de 100 espèces, dont seulement une trentaine est décrite et nommée ; les autres sont répertoriées par des séquences ADN reliées à des spécimens. Cet état de fait pourrait être généralisé à l'ensemble des groupes étudiés confortant l'idée selon laquelle le nombre total d'espèces ne sera jamais connu ! Néanmoins, nous sommes capables de décrire des communautés d'espèces en fonction des grands types d'habitats ou de leurs affinités biogéographiques. $\AA$ À titre indicatif les quelques centaines d'espèces répertoriées à ce jour représentent 63 familles et 185 genres répartis de manière inégale entre les trois grandes divisions. Les algues rouges totalisent plus de la moitié des espèces ; viennent ensuite les algues vertes avec une très forte dominance des Bryopsidales et enfin les algues brunes, qui représentent moins d'un cinquième des espèces, mais constituent les plus grandes biomasses. Neuf familles totalisent plus de la moitié des espèces, tandis que de nombreuses autres affichent un petit nombre de représentants. De même, un grand nombre d'espèces sont relativement rares. Cette rareté biologique et écologique signalée pour les poissons, les mollusques et autres invertébrés semble être une règle. De même, le taux d'endémisme chez les algues est inférieur à $3 \%$ comme pour la majorité des autres groupes biologiques. 


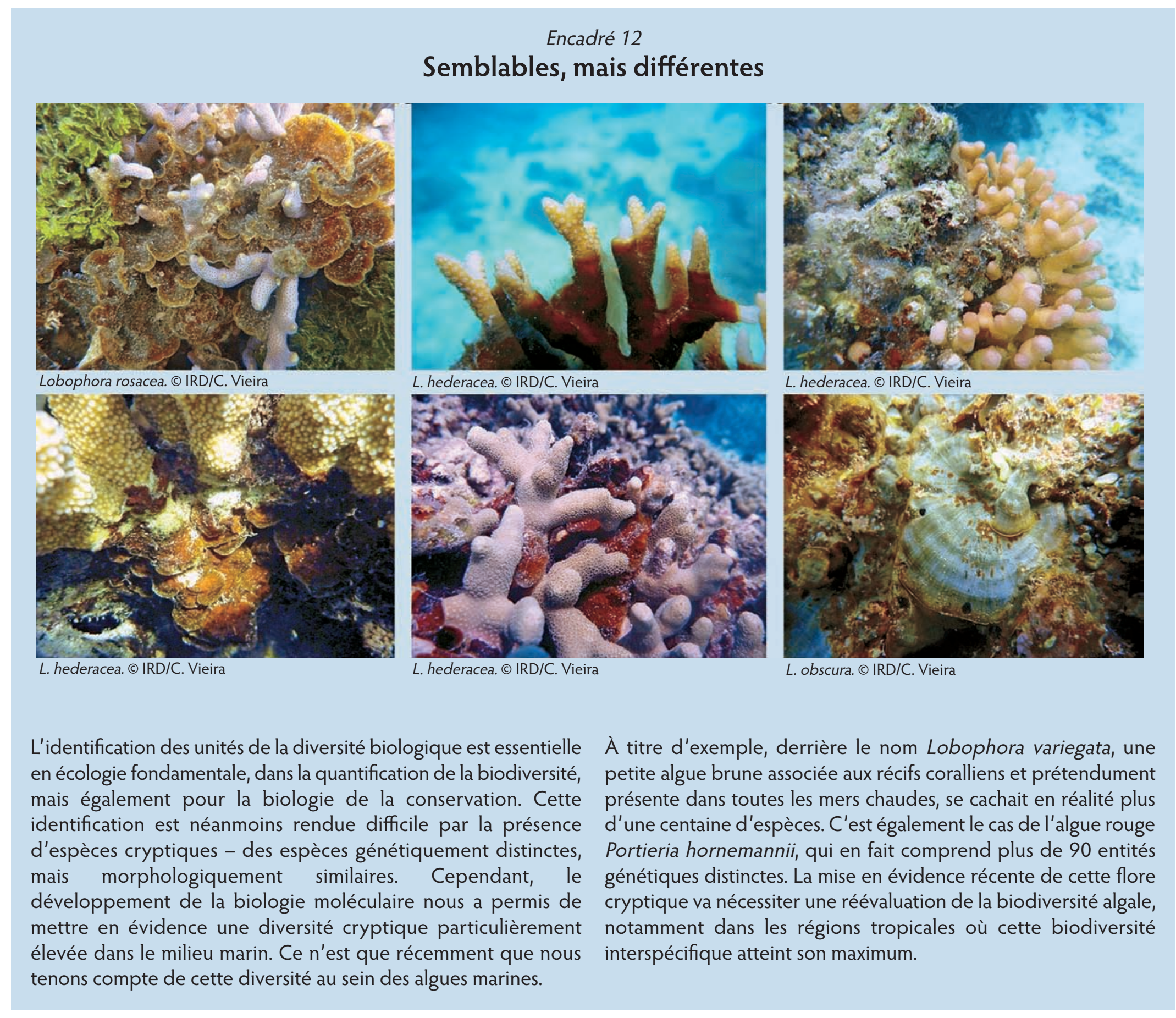




\section{Quand l'histoire géologique et la géographie décident de la diversité}

La flore marine néo-calédonienne est particulièrement riche, avec un nombre d'espèces aussi important qu'en Méditerranée pour une surface bien plus faible. Plusieurs raisons à cela. Tout d'abord la proximité du triangle de corail (Philippine, Indonésie, Papouasie Nouvelle-Guinée), zone qui concentre la plus forte biodiversité marine au monde, une diversité d'habitats exceptionnelle avec plus de 150 unités géomorphologiques et enfin un contexte océanographique et climatique qui offre un gradient tropical - subtempéré, voire tempéré, du nord au sud, avec une région sud-ouest influencée par des remontées d'eaux froides (upwelling) alors que les eaux qui baignent la côte Est enregistrent quelques degrés centigrades de plus. Ainsi, les algues des îles Loyauté partagent moins de $25 \%$ de leurs espèces avec le reste de l'archipel et montrent une très forte affinité avec les flores du Vanuatu, des Salomon et de la Papouasie Nouvelle-Guinée. A contrario, le Grand Lagon Sud qui englobe l'île des Pins et la Corne Sud abrite des espèces observées à Lord Howe (Australie) et sur les côtes ouest de l'Australie, et caractéristiques des récifs coralliens sub-tempérés.

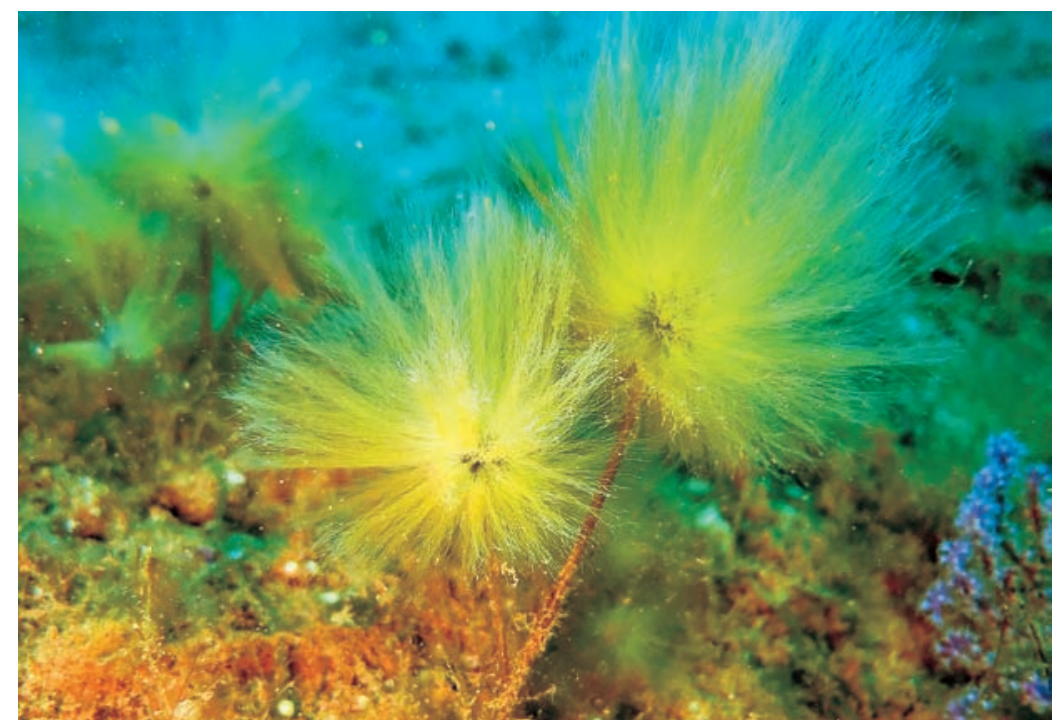

Bellotia simplex décrite de la Baie de Saint Vincent, côte ouest de la Grande Terre. Canal Woodin, 2015. @ IRD/J.-L. Menou
Certains genres, comme Melanthalia, une grande algue rouge, ont une répartition restreinte au sud de la Nouvelle-Calédonie, de l'Australie et au nord de la Nouvelle-Zélande. Cet endémisme subrégional est interprété comme un vestige du Gondwana. Chaque grande région de l'archipel néo-calédonien possède quelques taxons caractéristiques que l'on ne trouve que là. Le genre Penicillus, une algue verte à l'allure de pinceau, n'a été observé que dans les fonds sableux des atolls des Chesterfield; alors qu'Apjonhia, une algue verte en forme de sapin, n'est présente qu'à l'île des Pins. L'ordre des Sporochnales (Bellotia, Nereia) souligne la ressemblance des flores marines néo-calédoniennes et australiennes. Ce sont des algues brunes très élégantes aux extrémités en forme de petits pompons et au toucher gluant, très diversifiées en genres et en espèces que l'on trouve dans les fonds de baies riches en sédiments terrigènes. Et puis il y a tout un florilège d'espèces en commun avec l'archipel des Ryukyu au sud du Japon ; la plupart de ces espèces, qui affectionnent les petits fonds au Japon, se développent plus profondément $(30 \mathrm{~m})$ en Nouvelle-Calédonie en raison de la température plus fraîche en profondeur. Le plus bel exemple est celui de Padina stipitata du banc Gail au sud de la Grande Terre, dont les séquences $A D N$ sont strictement les mêmes que celles des spécimens de la localité type au Japon.

Les données taxonomiques sont trop fragmentaires à l'échelle du bassin du Pacifique pour pouvoir tirer des conclusions sur la limite des aires de répartition géographique des espèces d'algues. Toutefois, les connaissances acquises grâce à l'étude phylogénique moléculaire de certains groupes montrent que la flore marine néo-calédonienne appartient à la région du Pacifique sud-ouest, qui englobe la mer de Corail à l'ouest et l'arc mélanésien qui s'étire depuis les îles Salomons jusqu'aux îles Fidji à l'est et qu'elle partage aussi une part de sa biodiversité avec les autres régions du bassin du Pacifique.

Pour expliquer son exceptionnelle biodiversité, il faut remonter le temps, jusqu'aux périodes de régression du niveau de la mer, au cours desquelles l'archipel néo-calédonien a probablement été une zone de refuge tout comme le triangle de corail et où se sont accumulées au fil du temps de nombreuses espèces liées aux récifs coralliens. 


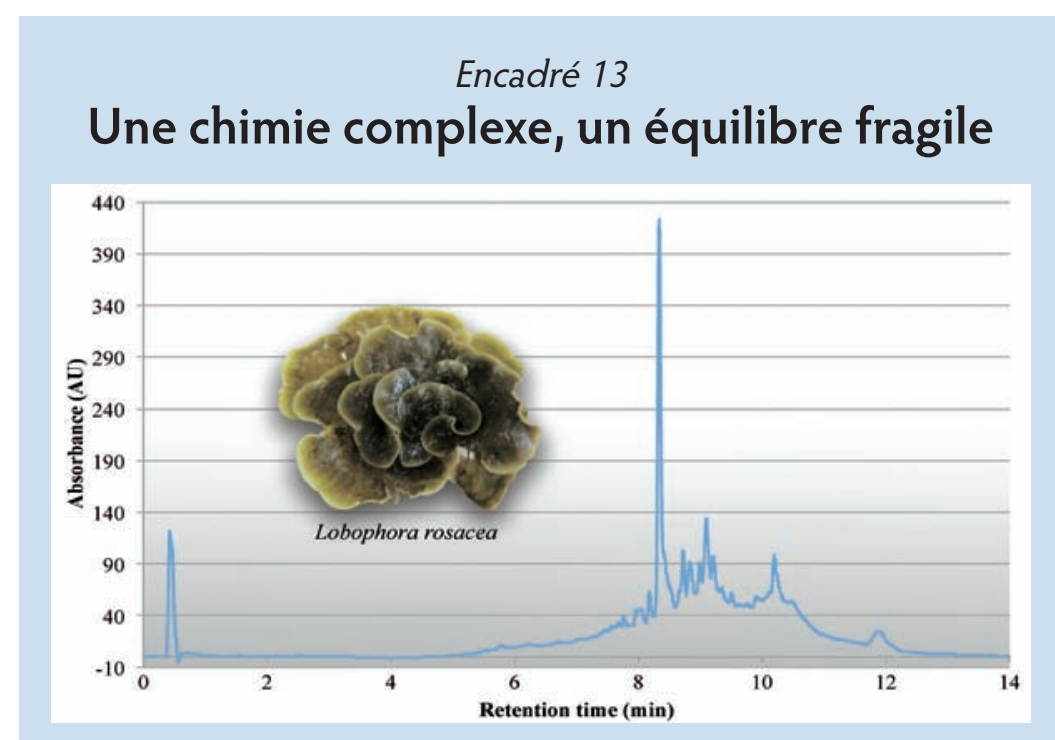

Profil métabolomique de l'algue brune Lobophora rosacea, communément présente dans le lagon de Nouvelle-Calédonie souvent associée aux coraux branchus.

Au sein des écosystèmes coralliens, les interactions sont largement médiatisées chimiquement, notamment entre les organismes benthiques. Les animaux marins utilisent des signaux chimiques par exemple dans la régulation des comportements sociaux et de reproduction, ou encore dans la reconnaissance des aliments. Afin d'éviter, de minimiser ou de tolérer les dommages causés par des herbivores, les algues ont développé plusieurs types d'adaptation réduisant leur attrait, et les défenses chimiques sont une des stratégies les plus employées par les algues tropicales. L'arsenal chimique dont elles disposent agit non seulement comme barrière chimique face à de multiples agresseurs (herbivores, bactéries, épiphytes, pathogènes), mais peut également s'avérer une « arme » redoutable dans la compétition pour l'espace avec d'autres organismes benthiques comme les coraux, notamment suite à des perturbations fragilisant ces écosystèmes. Comme pour les coraux, les interactions chimiques jouent un rôle important dans la reproduction et le recrutement des algues. Mais nous n'avons pour le moment qu'exploré la partie visible de l'iceberg, et avons encore énormément à découvrir sur les fonctions biologiques et écologiques des composés chimiques des algues marines.

\section{Bonnes ou mauvaises algues?}

Les macroalgues sont souvent, à tort, associées à des dégradations du milieu. Comme indiqué plus haut elles sont un maillon indispensable du système au point qu'il serait plus exact de qualifier ces écosystèmes de récifs algo-coralliens. Toutefois, la prolifération anormale de certaines communautés algales peut signer un déséquilibre écologique, notamment quand les algues prennent le dessus des coraux vivants. Les algues sont-elles alors la cause ou le résultat de la disparition des coraux ? Cette question revêt un enjeu majeur au moment où la communauté internationale alerte sur la régression des surfaces coralliennes dans le contexte des changements globaux. Les changements de communauté décrits dans de nombreuses régions du monde semblent pour le moment épargner globalement l'écosystème corallien néo-calédonien, mais pour combien de temps encore ? L'accroissement des activités humaines sur les littoraux est une réalité et, si les récifs coralliens de NouvelleCalédonie jouissent encore d'un état de santé bon, voire excellent, pour la majorité d'entre eux, les régions péri-urbaines montrent quelques stigmates de dégradation, avec notamment des interactions biologiques entre les algues et les coraux au détriment de ces derniers. Les algues ont des capacités de croissance et de reproduction bien supérieures à celles des coraux ; aussi, lorsque pour diverses raisons les colonies coralliennes meurent, elles offrent de nouvelles surfaces colonisables par les algues. Le blanchissement corallien, les maladies des coraux, l'étouffement des polypes coralliens par les apports de particules terrigènes sont autant d'agents causant la mort des coraux. Si les conditions environnementales du milieu ont changé au point de favoriser la croissance des algues et limiter de fait le recrutement corallien, alors les proliférations d'algues molles peuvent être associées à la dégradation du récif (encadré 13).

Il n'y a pas de bonnes ou de mauvaises algues; elles ont toutes un rôle et une fonction dans l'écosystème corallien. Comme tous les autres organismes, elles ont développé au cours de leur propre histoire évolutive des traits biologiques fonctionnels qui leur permettent de se maintenir dans leur milieu. Les algues sont un réservoir inestimable de substances bioactives, dont il n'est pas facile de déterminer les mécanismes d'action sur leur environnement, mais 
dont on sait grâce à l'écologie chimique qu'elles sont des voies de communication régissant les interactions biologiques. De nombreuses Dictyotales produisent des polyphénols qui éloignent les prédateurs, d'autres entrainent la mort des polypes coralliens comme cela fut mis en évidence chez Lobophora hederacea en Nouvelle-Calédonie. Si certaines algues rouges calcaires sont connues pour tuer les coraux avec lesquels elles entrent en compétition pour l'occupation de l'espace, comme dans le cas du Pneophyllum conicum, d'autres du même groupe Titanoderma jouent un rôle important dans la fixation des jeunes larves de coraux. Les mécanismes mis en jeu sont mal connus et la production de molécules attractives n'est pas exclue.

\section{Les algues, source d'inspiration}

Avec un millier d'espèces, voire plus, les algues des lagons et récifs néo-calédoniens offrent un terrain fertile pour de nombreuses recherches. Depuis les premiers travaux des missionnaires et des naturalistes amateurs de la fin du XIX ${ }^{\mathrm{e}}$ siècle, les connaissances se sont accumulées. Au fil des disciplines et des approches méthodologiques, différentes facettes de cette diversité ont été révélées. Aux travaux de taxonomie indispensables pour connaître ce que l'on cherche à protéger, d'autres approches à l'interface des disciplines ont levé un coin du voile sur les questions qui se posent autour du devenir de ces communautés dans le contexte des changements globaux. Comprendre leur histoire évolutive, analyser les interactions biologiques entre les espèces de macroalgues et les autres organismes des récifs, mais aussi rechercher des molécules d'intérêt pour l'homme dans ce réservoir de molécules complexes produites par les algues pour grandir, se défendre et se reproduire, voilà le champ de recherche qui s'ouvre aux phycologues (encadré14).

\section{Encadré 14 \\ Spécialités et étymologie}

Les scientifiques qui étudient les algues sont appelés des «phycologues » et non des «algologues » qui de leur côté étudient la douleur ! En français, le terme « algue » est issu du latin «algae» alors que les termes «algologue» et «phycologue » sont issus du grec ancien : « algos » (douleur), que l'on retrouve aussi par exemple dans le terme « antalgique », «phycos » (algues) et «logos » (étude), que l'on retrouve par exemple dans «musicologue ».

\section{Références bibliographiques}

DIJOUX L. et al., 2012 Diversity of Halimeda (Bryopsidales, Chlorophyta) in New Caledonia: a Combined Morphological and Molecular Study. Journal of Phycology, 48 (6) : 1465-1481.

MATTIO L., PAYRI C.E., 2009 Taxonomic revision of Sargassum species (fucales, phaeophyceae) from New Caledonia based on morphological and molecular analyses. Journal of Phycology, 45 (6) : 1374-1388.

PAYRI C. E., 2007 « Revised checklist of marine algae (Chlorophyta, Rhodophyta and Ochrophyta) and seagrasses (Marine Angiosperma) of New Caledonia ». In : Payri C.E., Richer de Forges R., éd., Compendium of marine species from New Caledonia, IRD-Nouméa, Documents scientifiques et techniques, II (7), $2^{\mathrm{e}}$ éd. : 95-112.

VIEIRA C. et al., 2014 Toward an inordinate fondness for stars, beetles and Lobophora? Species diversity of the genus Lobophora (Dictyotales, Phaeophyceae) in New Caledonia, Journal of Phycology, 50 (6) : 1101-1119. 


\section{Chapitre 10 \\ Les invertébrés marins de Nouvelle-Calédonie}

Gustav Paulay

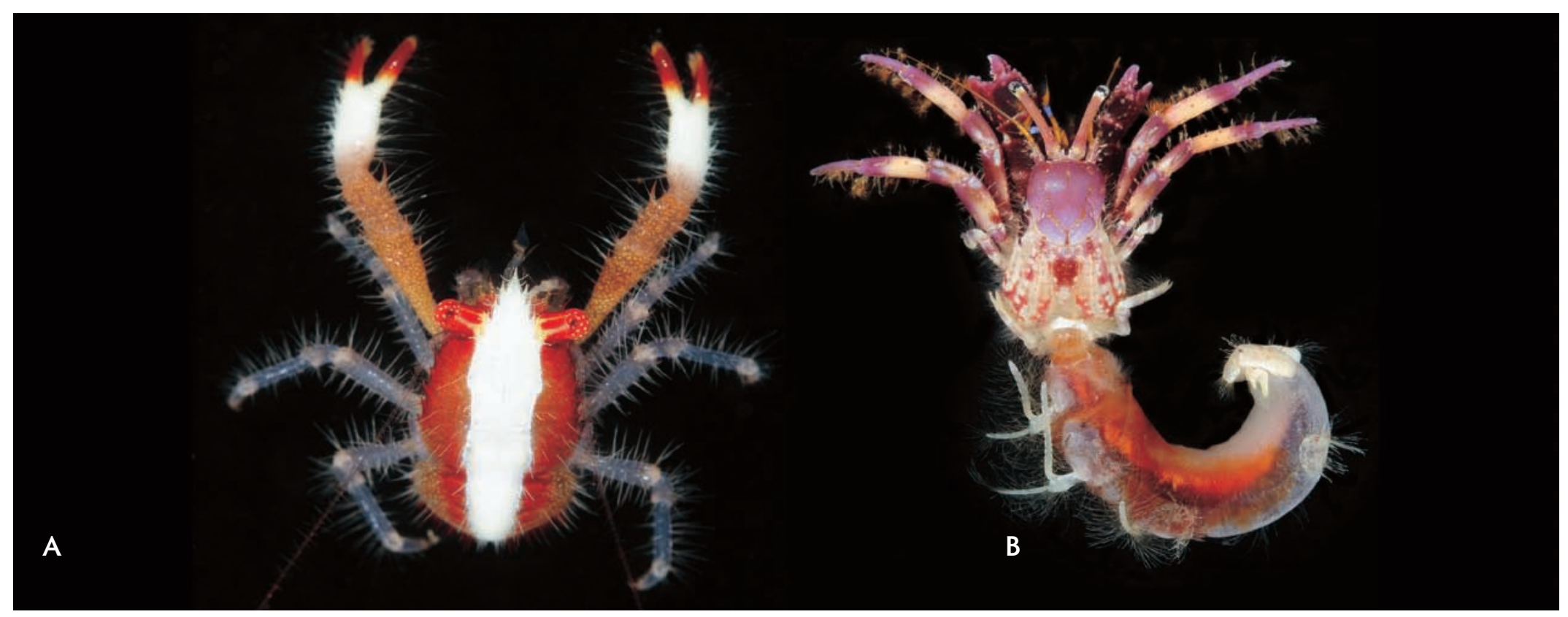

A : Galathea n. sp., une espèce nouvelle de Galathée de Nouvelle-Calédonie. B : Calcinus spicatus, une espèce endémique subtropicale méridionale ; l'espèce s'étend de la NouvelleGalles du sud aux îles Gambier. @ G. Paulay

\section{Une biodiversité insoupçonnée}

La faune marine de Nouvelle-Calédonie est l'une des plus étudiées et des plus diversifiées du Pacifique, avec plus de 9000 espèces recensées dans la littérature. Cependant, une grande partie des recherches scientifiques se sont concentrées sur les eaux profondes, tandis que les organismes récifaux ont été moins étudiés.

Des études faunistiques et taxinomiques ciblées démontrent néanmoins que les récifs néo-calédoniens sont parmi les plus riches
d'Océanie. Par exemple, alors que seules quatre espèces de langoustines du genre Galathea avaient été recensées en NouvelleCalédonie, une étude publiée en 2015 a porté ce chiffre à 34 espèces, dépassant ainsi toute autre région du monde. Bien que la plus grande diversité du genre se situe dans les zones récifales, la moitié des espèces néo-calédoniennes proviennent des eaux profondes, suggérant qu'il reste encore beaucoup à documenter, comme démontré par la description récente d'une nouvelle espèce. La faune récifale néo-calédonienne est également remarquable par ses diverses relations biogéographiques et son endémisme significatif. 


\section{Une richesse exceptionnelle en habitats}

Les récifs abritent la plus grande biodiversité marine grâce à leur complexité structurelle offrant divers micro-habitats où loge une variété déconcertante d'organismes. Les récifs sont avant tout complexes à l'échelle microscopique - une seule tête de corail peut héberger des centaines d'espèces animales. Cette complexité est encore accrue dans les grands systèmes récifaux et à diverses échelles où se crée une mosaïque d'environnements selon l'exposition, la profondeur, la distance à la côte et aux eaux océaniques, etc. La diversité des habitats et des espèces augmente donc rapidement avec la taille et la complexité des récifs.

Avec la deuxième plus longue barrière de corail au monde, la Nouvelle-Calédonie fait partie des grands hotspots de la diversité marine. Les récifs de l'archipel s'étendent des eaux tropicales aux eaux subtropicales, et des récifs océaniques aux baies envasées sous l'influence des apports terrigènes. La géologie complexe de la Grande Terre crée des habitats uniques et inhabituels qui abritent une vie marine saisissante. Les baies envasées abritent des coraux fluorescents qui flottent littéralement sur la vase (encadrés 6 et 7), les coraux mous et les éponges s'ancrent dans les sédiments, tandis que les cauris sont déformés et plus foncés (mélaniques), probablement en raison de l'impact des métaux lourds lessivés des roches ultramafiques. À l'opposé, les récifs autour des îles calcaires comme Maré et les récifs océaniques d'Entrecasteaux sont à l'extrémité océanique du spectre récifal. La diversité des habitats récifaux y est plus grande que n'importe où ailleurs en Océanie, à l'exception de la Nouvelle-Guinée.

\section{Le lien entre biodiversité et latitude}

En plus de la taille et de la diversité des habitats, la géographie et l'âge des paysages sous-marins sont des facteurs importants de diversité biologique. Ainsi, on observe un changement net de la diversité dans le Pacifique selon la latitude et la longitude. La diversité à l'échelle mondiale culmine dans la région indo-malaise du Pacifique ouest, alors qu'elle diminue vers l'est à travers le Pacifique. La Nouvelle-Calédonie se situe proche de ce centre de diversité mondiale.
La relation inverse entre la diversité et la latitude est le schéma biogéographique le plus frappant sur Terre. Les tropiques abritent la plus grande diversité, mais la plupart des espèces tropicales se répartissent largement entre les tropiques du Cancer et du Capricorne et il y a peu de différenciations dans la diversité au sein de cette zone. Autour des tropiques, une faune supplémentaire, subtropicale, fait son apparition, et de nombreuses espèces sont restreintes à une étroite ceinture latitudinale. La Nouvelle-Calédonie est au carrefour de ces deux grands biomes, enrichie par des espèces de ces deux régions. Elle abrite une faune tropicale indo-pacifique, ainsi que des espèces qui vivent exclusivement dans une bande étroite allant de l'Australie subtropicale jusqu'à Pitcairn et à l'île de Pâques. Une partie de cette faune subtropicale a une distribution anti-tropicale, mettant ainsi en évidence des liens intéressants avec le nord-ouest du Pacifique et le biote régional japonais.

\section{La biodiversité cachée}

La diversité tend à s'accumuler avec le temps - les jeunes écosystèmes ne sont pas aussi riches que les anciens. La NouvelleCalédonie est le seul microcontinent tropical en Océanie, un fragment de Gondwana plus ancien que les îles océaniques du Pacifique. Alors que l'île a subi une submersion et qu'elle a émergé depuis l'Oligocène, les habitats peu profonds ont probablement persisté dans la région depuis le Mésozoïque. L'impact de l'âge sur la diversité et l'endémisme du biome terrestre de NouvelleCalédonie est très connu. La présence de nombreuses lignées anciennes endémiques suggère que l'âge géologique joue un rôle important comme cela a été particulièrement bien démontré pour le biome des eaux profondes. Le grand système de barrière récifale lui-même est un produit du temps et contraste avec la diversité plus limitée des récifs et des habitats entourant les jeunes îles volcaniques du Vanuatu voisin.

L'endémisme marin reste peu exploré autour des récifs néocalédoniens. Il y a des espèces endémiques très évidentes, comme I'holothurie Holothuria altaturricula, mais dans l'ensemble le niveau d'endémisme est modeste (environ $5 \%$ dans les holothuries en eaux 
peu profondes). Toutefois, la révolution de la taxonomie moléculaire a montré que de nombreuses espèces que l'on croyait répandues sont en réalité des complexes de formes endémiques qui ont échappé aux taxonomistes précédents. Par exemple, les travaux génétiques ont montré que le gastéropode Astralium « rhodostoma » en NouvelleCalédonie, correspond à deux espèces, toutes deux endémiques.

La symbiose est une source majeure de diversité dans tous les écosystèmes, et en particulier sur les récifs. Les hôtes sont divers, avec l'abondance des grandes éponges, des cnidaires, des échinodermes et des bâtisseurs de tubes comme les polychètes

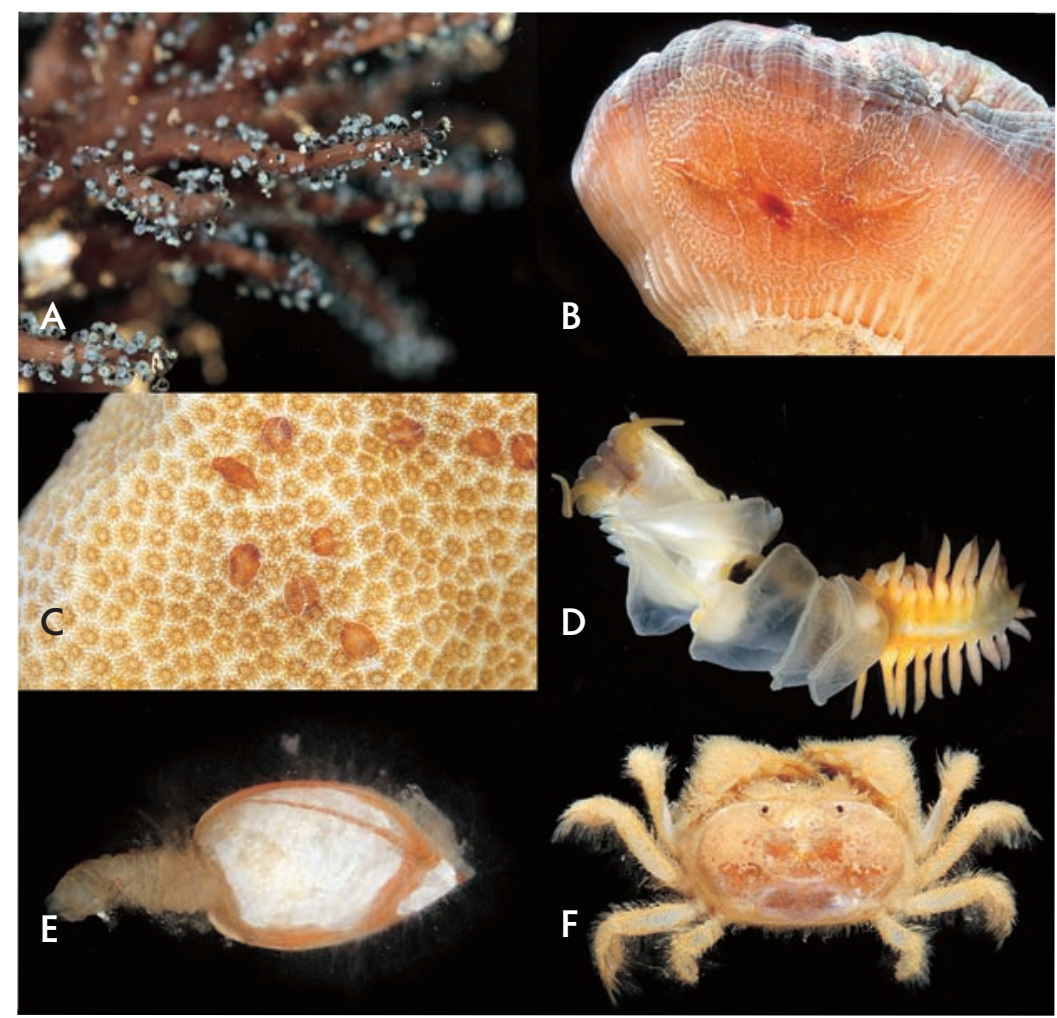

Symbiontes inhabituels.

A : Loxosomella $n$. sp., un entoprocte sur une éponge.

B : Le cténophore benthique Coeloplana n. sp. symbiotique sur le corail Trachyphyllia geoffroyi.

C: L'acoèle Waminoa? sur Porites.

D : Le polychète Chaetopterus luteus à l'extérieur de son tube.

E : Dianajonesia sp., un pousse-pied symbiotique sur Nautilus macromphalus.

F : Tetrias fischerii, un crabe (pea crab) symbiotique avec Chaetopterus. @ G. Paulay chaetoptères. Certains des taxons les plus diversifiés de NouvelleCalédonie sont symbiotiques, tels que les crabes galathoïdes, les gastéropodes eulimidés et les palourdes galeommatoïdienne. Les symbiotes comprennent également des groupes animaux inhabituels tels que les Aceola (vers plats), les cténophores et les Entoprocta. Le genre polychète Chaetopterus est plus abondant et diversifié en Nouvelle-Calédonie que partout ailleurs dans les tropiques. L'un de ses symbiotes, Tetrias fischerii, a été décrit à partir d'un spécimen provenant de Nouméa et connu jusqu'à présent uniquement à partir d'un seul holotype sec, pourtant il s'agit d'un des crabes les plus communs autour de Nouméa.

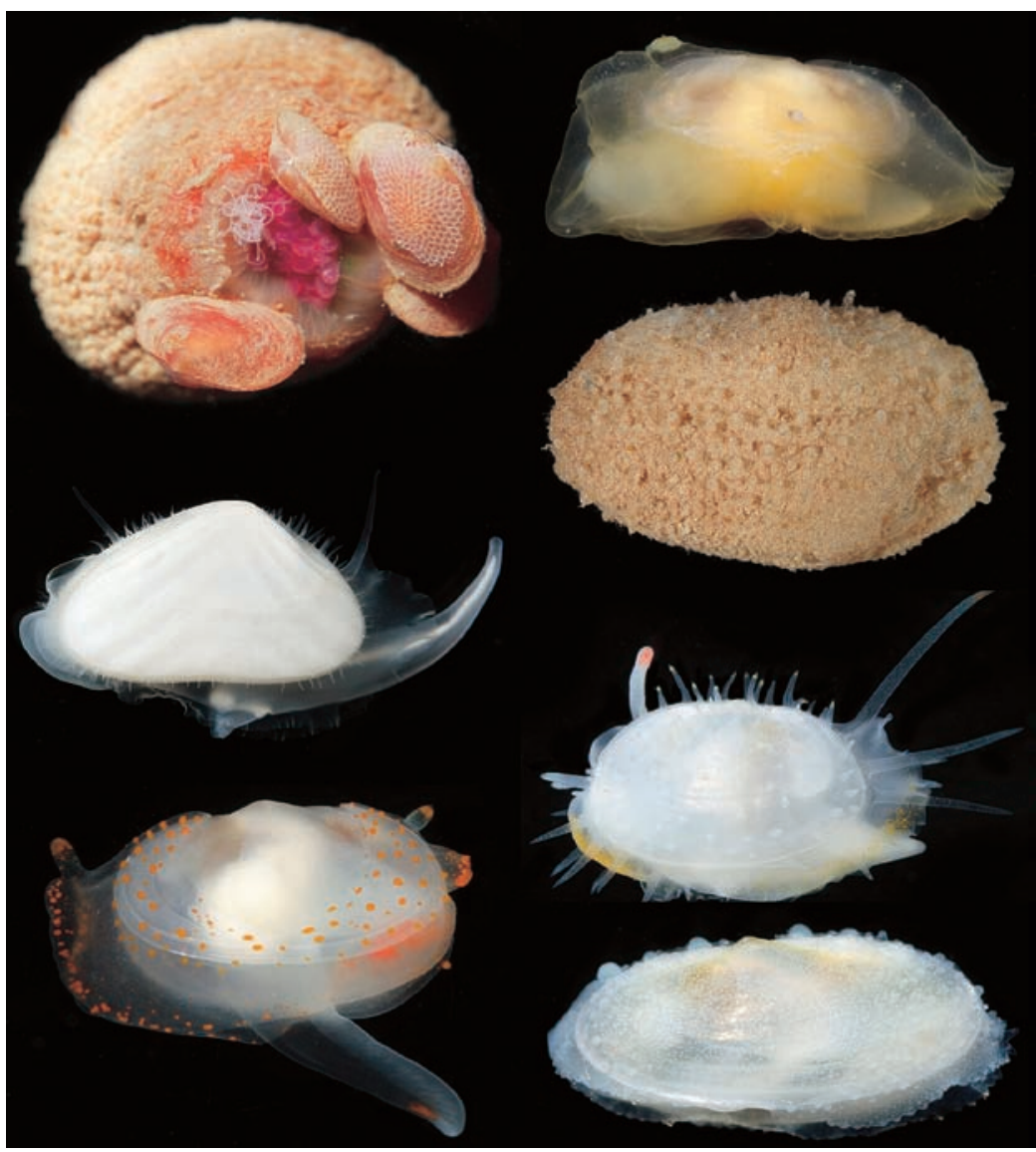

Exemples de la faune bivalve galeommatoïdienne très riche de Nouvelle-Calédonie. Ces petites palourdes, typiquement symbiotiques, constituent le groupe de bivalves le plus diversifié de Nouvelle-Calédonie. (c) G. Paulay 



\section{Chapitre 11 \\ La biodiversité exceptionnelle des mollusques en Nouvelle-Calédonie}

Philippe Bouchet

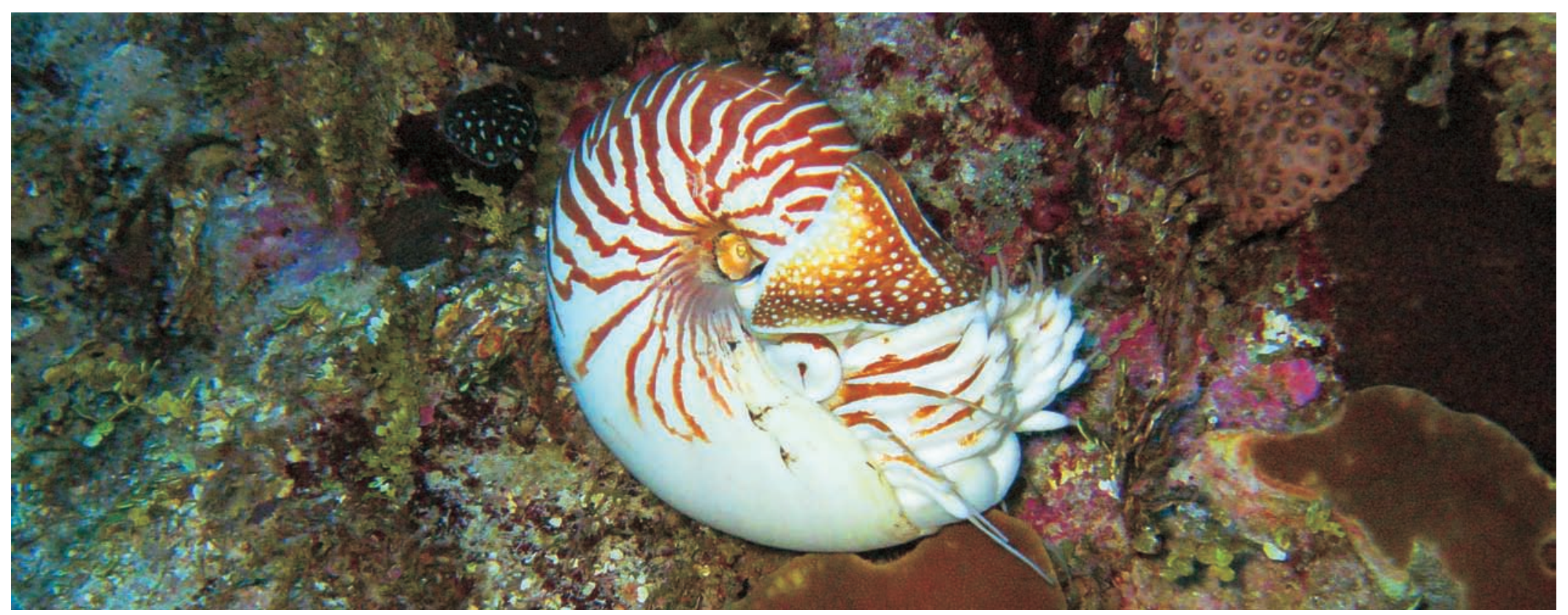

Endémique de Nouvelle-Calédonie, le nautile Nautilus macromphalus appartient à un groupe de céphalopodes que l'on qualifie souvent de « fossiles vivants », représentés dans la nature actuelle par cinq espèces. Les animaux vivent en eau profonde et remontent la nuit le long de la pente externe du récif-barrière, Chesterfield, 2015. ๑ IRD/C.E Payri

On compare souvent les récifs coralliens aux forêts tropicales : ce sont les deux grands écosystèmes de la planète les plus riches en espèces. Numériquement, ces espèces sont pour l'essentiel des invertébrés. À ce jour ce ne sont pas moins de 9000 espèces d'invertébrés qui ont été inventoriées dans les écosystèmes marins côtiers de NouvelleCalédonie. Cette exceptionnelle biodiversité peut être abordée à travers quelques mots-clés : richesse, rareté, singularité et endémisme.

\section{Richesse de la biodiversité}

À l'exception des coraux, ce sont sans aucun doute les mollusques et les crustacés décapodes qui ont donné lieu aux études les plus soutenues en matière d'inventaire de la biodiversité récifale et lagonaire en Nouvelle-Calédonie. Au-delà des mollusques et des crustacés décapodes, les échinodermes, les gorgones, les ascidies et les spongiaires ont été la cible de recherches menées dans les lagons de Nouvelle-Calédonie dans le cadre de programmes de chimie des substances naturelles conduits dans les années 1975 à 2000. Enfin, le compartiment « parasite » a fait l'objet d'une étude monumentale - mais encore très parcellaire -, en particulier sur les helminthes (monogènes) des mérous et des loches (Serranidae).

Quatre sites en particulier - Koumac et Nouméa, sur la côte Ouest ; Touho, sur la côte Est ; et Lifou, aux îles Loyauté - ont fait l'objet d'un échantillonnage intensif des mollusques, mettant en œuvre des moyens 
de collecte (suceuse, panier de brossage) performants pour la petite faune cryptique, suivis d'un effort de tri considérable. À titre d'exemple - qui est devenu un modèle en matière de macro-écologie -, 2738 morpho-espèces de mollusques ont été documentées au terme d'un inventaire représentant 400 journées-personnes sur 29500 ha à Koumac, établissant le « record du monde » du nombre d'espèces d'un site marin côtier tropical. Pour autant, ce chiffre reflète davantage l'effort d'échantillonnage et de tri qu'une exceptionnelle richesse intrinsèque : les mêmes méthodes appliquées à d'autres sites au Vanuatu, en Papouasie Nouvelle-Guinée et aux Philippines conduisent à des chiffres comparables, sinon supérieurs. La plupart de ces espèces sont petites ou très petites : à peine $10 \%$ ont une taille adulte supérieure ou égale à $40 \mathrm{~mm}$ (les « coquillages »), alors qu'un tiers mesure moins de $4 \mathrm{~mm}$ dans leur plus grande dimension.

\section{De nombreuses espèces rares}

L'étude conduite à Koumac démontre une très grande hétérogénéité spatiale, puisque $32 \%$ des espèces n'ont été trouvées que dans une seule des 42 stations échantillonnées. Elle démontre aussi le poids des espèces rares : $20 \%$ des espèces sont représentées par des singletons (spécimens uniques), et $48 \%$ par cinq spécimens ou moins. Les projections des estimateurs de biodiversité suggèrent en fait que le nombre réel d'espèces présentes sur le site de Koumac est de l'ordre de 3500 à 4000.

Ces chiffres phénoménaux s'expliquent par l'extrême diversité au sein des familles spécialisées : commensaux, associés et parasites. Alors que les livres de « coquillages » illustrent mitres, strombes, térèbres et cônes, ceux-ci comptent au final pour moins de 10 \% de la diversité des mollusques récifaux, dont les gros bataillons sont en fait constitués d'Eulimidae (parasites d'échinodermes), Triphoridae et Cerithiopsidae (mangeurs de démosponges), Pyramidellidae (ectoparasites d'autres invertébrés) et turridés (chasseurs de polychètes).
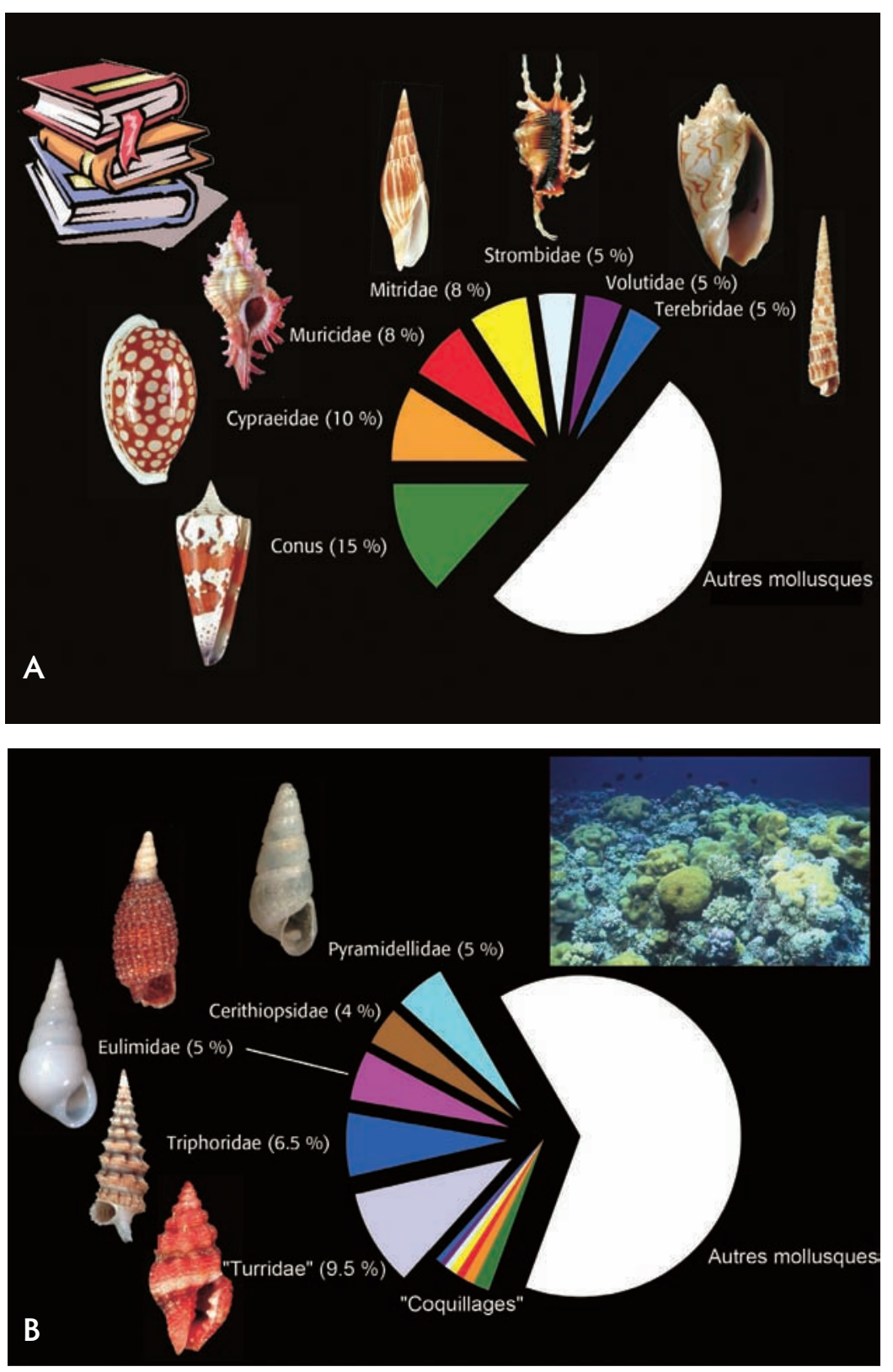

On assimile souvent les mollusques aux « coquillages ».

A : De très nombreux ouvrages donnent une représentation biaisée de leur diversité, composée de cônes, porcelaines, mitres et strombes.

$B$ : En réalité, la diversité des mollusques se situe principalement dans les familles de microgastéropodes - commensaux, associés et parasites. @ P. Bouchet 


\section{Singularité des écosystèmes selon les côtes}

La Nouvelle-Calédonie s'étend sur cinq degrés de latitude. La Grande Terre présente un contraste saisissant entre une côte au vent, avec des petits fleuves torrentueux charriant des sédiments terrigènes, et une barrière récifale très discontinue fermant un lagon profond ; et une côte sous le vent, avec des fleuves de faible débit, et une barrière récifale coupée de peu de passes, fermant un lagon peu profond. Les îles Loyauté, les récifs Bellona et Chesterfield n'ont ni lagon (à l'exception notable d'Ouvéa), ni barrière récifale, ni rivières. Il s'ensuit des différences relativement considérables entre les deux côtes de la Grande Terre et celles des îles et récifs détachés, qui se reflètent dans la composition faunistique de leurs écosystèmes côtiers.

Ainsi, $21 \%$ seulement des espèces sont partagées par les trois sites de Koumac, Touho et Lifou, et $52 \%$ des espèces sont présentes seulement sur un seul des trois sites. De ce fait, à la grande richesse locale des récifs de Nouvelle-Calédonie se superpose une grande disparité géographique.

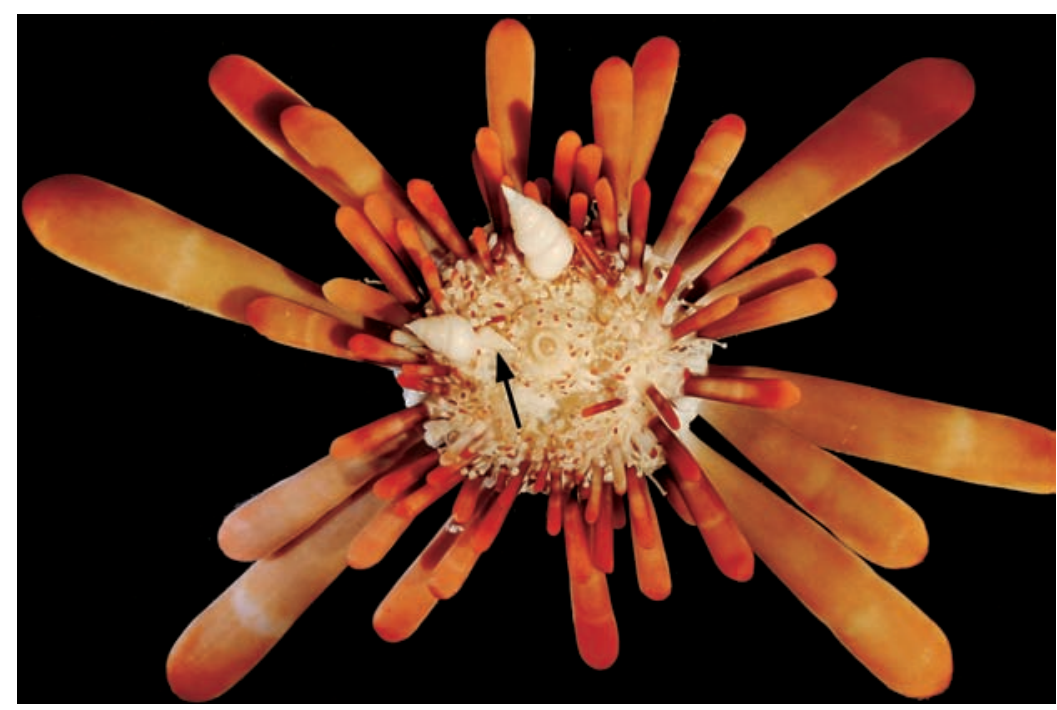

Les représentants de la famille des Eulimidae sont tous des parasites - temporaires ou permanents, externes ou internes - d'échinodermes. Toutes les classes sont parasitées. Ici une espèce du genre Echineulima sur un oursin du genre Heterocentrotus. Noter le dimorphisme sexuel - le mâle (flèche) est distinctement plus petit que la femelle. @ W. Rudman

\section{Un faible niveau d'endémisme}

La Nouvelle-Calédonie - tout comme les îles hautes de Polynésie française, d'ailleurs - est célèbre pour le très haut niveau d'endémisme de sa faune et de sa flore terrestres : de 40 à $100 \%$ selon les taxons. Le niveau d'endémisme des invertébrés marins côtiers est, par comparaison, extrêmement faible: sans aucun doute moins de $5 \%$, et peut-être même seulement 2 à $3 \%$. Certes, l'intensité des recherches conduites en Nouvelle-Calédonie fait qu'un nombre important d'espèces n'est connu que de Nouvelle-Calédonie, mais cet endémisme apparent cache la qualité insuffisante des inventaires conduits dans les archipels et récifs voisins. Ainsi, A. Cecalupo et I. Perugia viennent de décrire 64 nouvelles espèces de gastéropodes Cerithiopsidae de Nouvelle-Calédonie (encadré 15); il serait trompeur de considérer ces 64 espèces comme endémiques, en l'absence d'études comparables aux Salomons ou sur la Grande Barrière australienne. Si l'on s'en tient aux espèces dont la répartition est significativement restreinte à la Nouvelle-Calédonie, il y a malgré tout de véritables endémiques, et même des micro-endémiques.

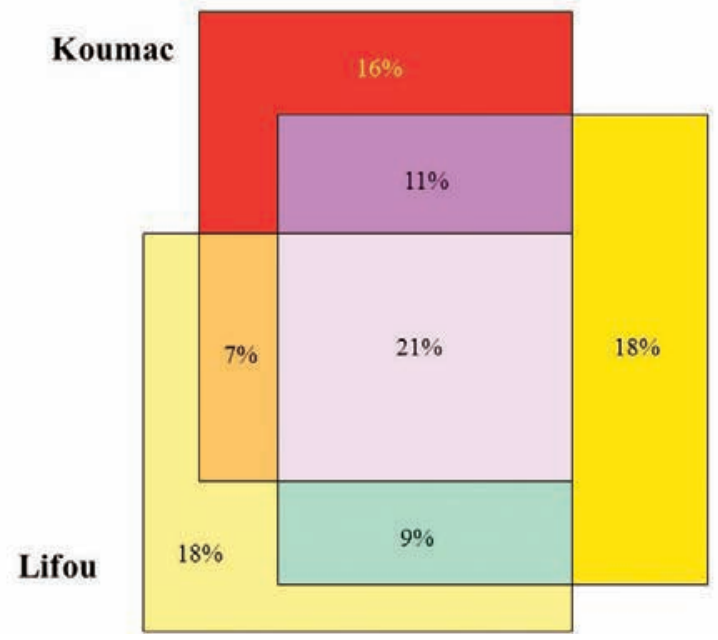

Touho

Ne pas mettre tous ses oeufs dans le même panier ! C'est l'enseignement tiré de la comparaison de trois sites échantillonnés de manière très approfondie, à Koumac (côte Ouest), Touho (côte Est) et Lifou (îles Loyauté). Sur 1711 espèces de mollusques appartenant à 17 familles, seules $21 \%$ sont présentes sur les trois sites, tandis que $52 \%$ sont présentes sur un seul site. La notion de « site représentatif » n'est pas fondée scientifiquement - ce qui est évidemment lourd de conséquences en termes de stratégie d'aires protégées. @ P. Bouchet 
Ainsi la volute Cymbiola rossiniana (« volute de l'île des Pins ») a une répartition limitée à l'extrême sud des récifs de NouvelleCalédonie, de l'île des Pins au secteur de Nouméa ; de même, Cymbiola deshayesiana a une répartition limitée au lagon nord et Cymbiolacca thatcheri et Lyria grangei sont des endémiques des Chesterfield au milieu de la mer de Corail. Les volutes sont caractérisées par un développement larvaire intracapsulaire, sans phase de dispersion planctonique, ce qui explique que quatre des cinq espèces de volutes de Nouvelle-Calédonie soient endémiques avec des distributions (très) restreintes. Si l'on examine d'autres groupes de gastéropodes bien inventoriés, 13 des 150 espèces (soit $8,5 \%$ ) de Muricidae recensés de Nouvelle-Calédonie dans la tranche 0-100 m peuvent être considérés comme endémiques. Par contre, deux seulement des 93 espèces de cônes (gastéropodes Conidae) et aucune des 69 espèces de porcelaines (gastéropodes Cypraeidae) recensées de Nouvelle-Calédonie n'est endémique. Il faut cependant pondérer ce faible niveau d'endémisme par le fait que la quasi-totalité des espèces récifales de Nouvelle-Calédonie - et d'ailleurs - sont définies par une approche strictement morphologique, et il est probable que des espèces aujourd'hui
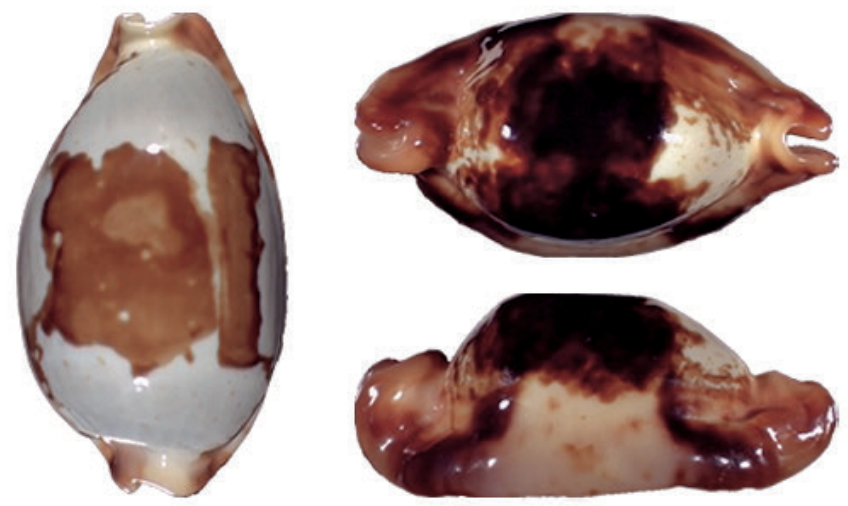

Particulièrement recherchées des collectionneurs, les porcelaines niger et rostrées sont emblématiques des coquillages de Nouvelle-Calédonie. Le phénomène de nigérisation et rostration n'affecte, à des degrés divers, que certains individus, et uniquement dans le lagon sud de la Grande Terre. Il a été suggéré que le nickel, ou encore les températures hivernales, pouvaient être responsables du phénomène, qui n'a pas vraiment fait l'objet d'études scientifiques. À droite, spécimen niger et rostré, à gauche spécimen «normal » de Bistolida stolida. ( ) F. Lorenz réputées être des espèces à grande répartition se révéleront, après séquençage, être des complexes d'espèces dont certaines à répartition plus restreinte, voire endémiques.

Au terme de 40 ans de recherches continues sur la faune et la flore marines de Nouvelle-Calédonie, le verre de l'inventaire et de la description des espèces est à moitié plein, et l'archipel attire les scientifiques du monde entier pour la richesse et l'intégrité de ses écosystèmes lagonaires et récifaux: un kilomètre carré d'écosystèmes lagonaires et récifaux en Nouvelle-Calédonie renferme plus d'espèces que toute la Méditerranée! Mais le verre est aussi à moitié vide : le nombre réel d'espèces présent en Nouvelle-Calédonie est probablement 5 à 10 fois supérieur aux 9000 espèces d'invertébrés inventoriées, et il reste beaucoup à faire pour mieux comprendre cet incroyable empilement d'espèces.

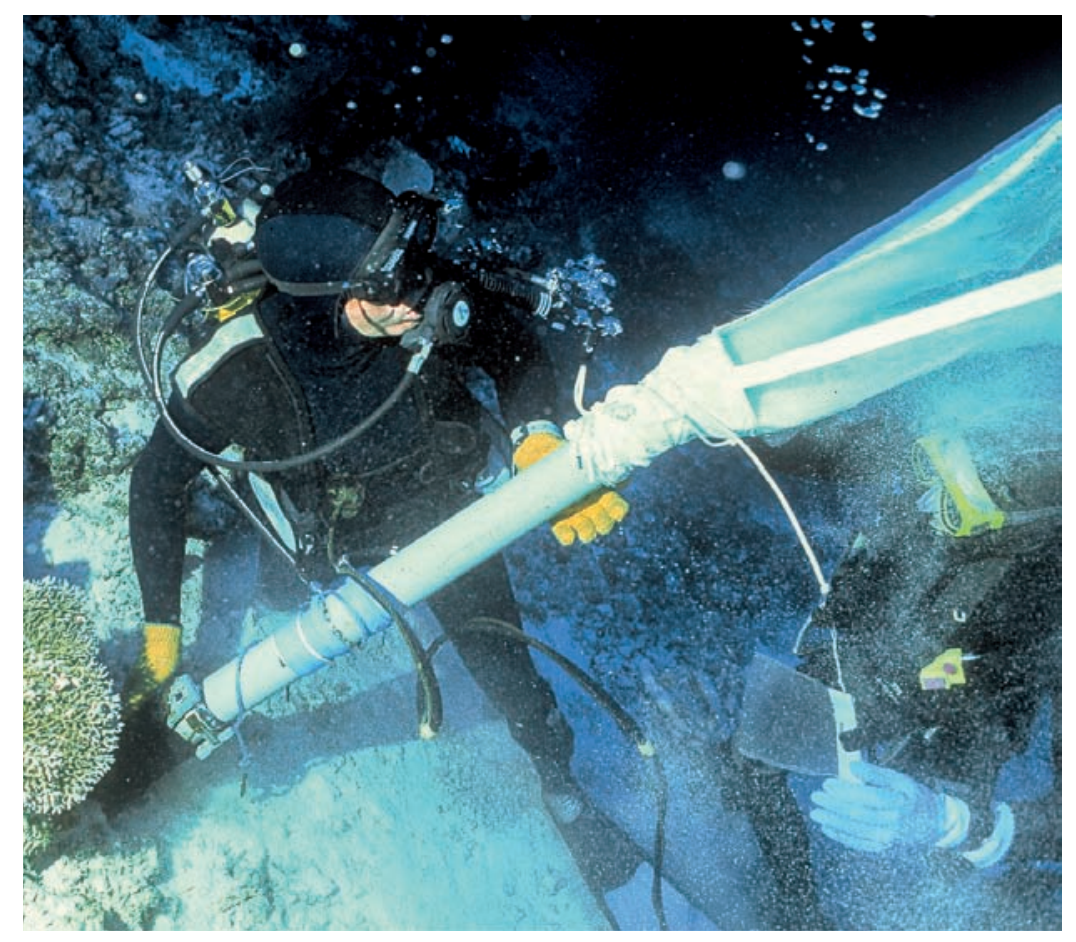

Suceuse et panier de brossage : deux outils non conventionnels, mais redoutablement efficaces d'échantillonnage du petit benthos en plongée, sur fonds durs comme sur fonds meubles. $\odot \mathrm{DR}$ 


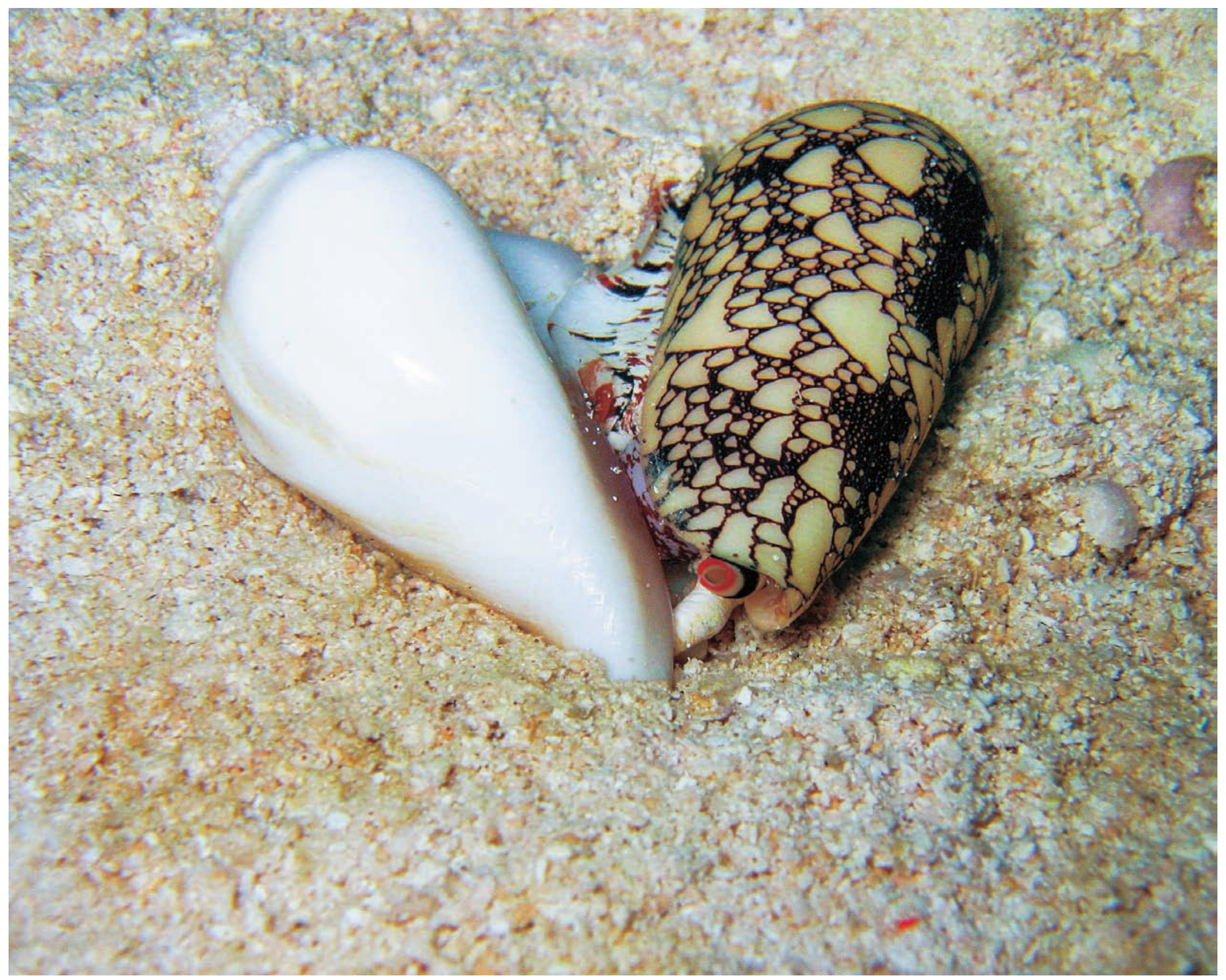

Le cône omaria (Conus omaria) est un prédateur carnivore (à droite) qui se nourrit strictement de mollusques avec une préférence pour les strombes (à gauche). ll projette sur sa proie un dard relié à une glande remplie d'un venin très puissant. Le cône avale ensuite sa proie par une trompe ou proboscis de grande taille et il la digérera lentement grâce aux enzymes qu'il sécrète. Chesterfield, $-15 \mathrm{~m}$, juillet 2008. @ IRD/J.L. Menou 


\section{Encadré 15}

\section{Le rôle des amateurs}

En biologie marine comme en entomologie ou en botanique, les amateurs jouent un rôle essentiel dans l'inventaire et la description de la biodiversité. Certains groupes ont davantage la faveur des amateurs que d'autres. Certes, les mollusques concentrent à eux seuls une part importante de l'expertise taxonomique non académique, mais nous vivons une époque où les gens sont globalement plus diplômés, ont davantage de loisirs, et - grâce à Internet - plus facilement accès à la littérature scientifique ; l'utilisation d'outils tels que la microscopie électronique à balayage s'est également démocratisée ; il n'y a finalement que les
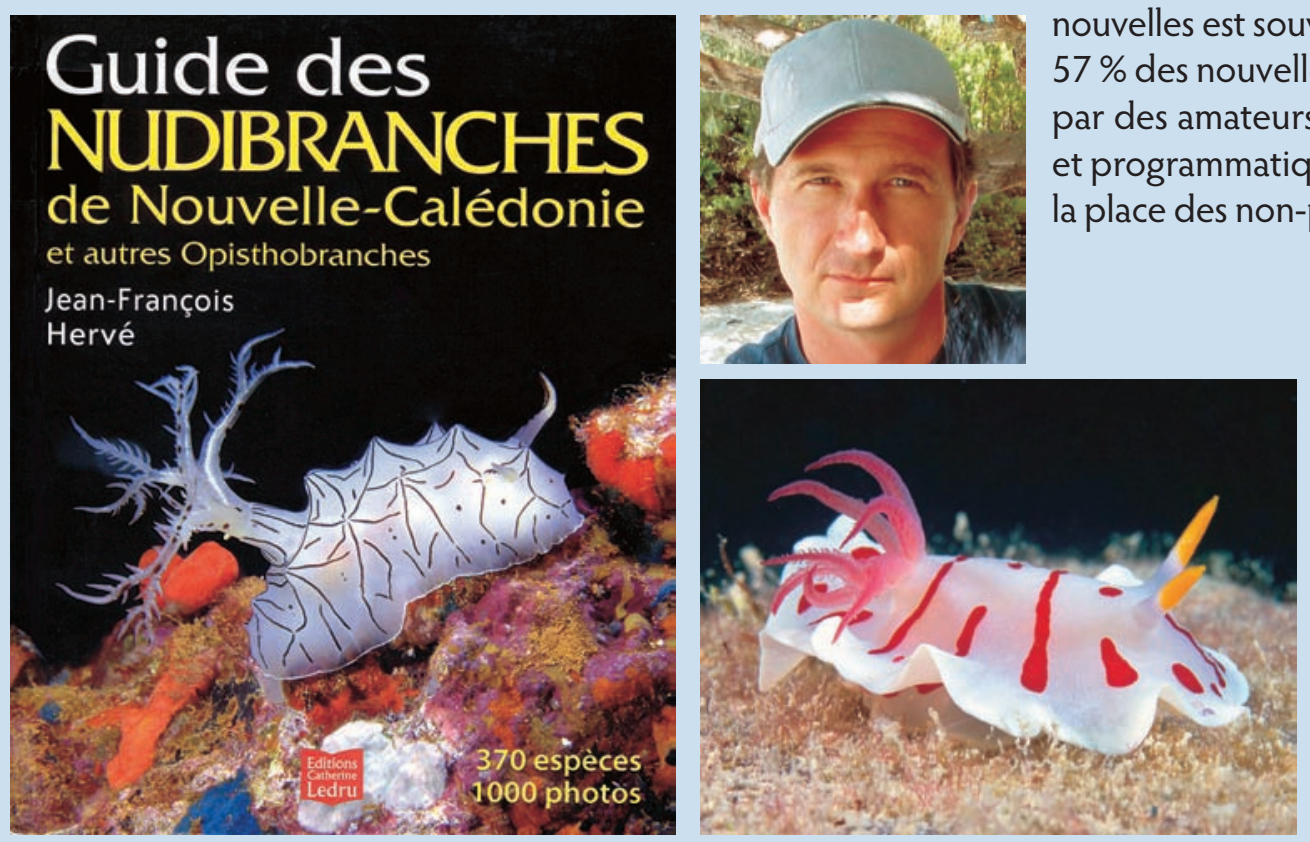

Les nudibranches sont un des sujets favoris des plongeurs, dont certains deviennent des experts sur le groupe. L'auteur du Guide des Nudibranches de Nouvelle-Calédonie est médecin à Nouméa ; avant lui - et avant l'ère de la plongée -, Jean Risbec avait, dans les années 1930, été professeur de mathématiques au lycée Lapérouse. Verconia catalai, décrit de Nouvelle-Calédonie - mais non endémique -, a été nommé en l'honneur de René Catala, le fondateur de l'aquarium de Nouméa. @ J.-F. Hervé. techniques moléculaires qui restent hors du champ des amateurs. Conséquence de tout ce qui précède : des vocations de taxonomistes amateurs éclosent dans tous les compartiments de la biodiversité : mollusques, bien sûr, crustacés, échinodermes, mais aussi bryozoaires ou hydraires. Un malacologue amateur n'est pas un « collectionneur de coquillages », même si beaucoup sont venus à la malacologie par ce canal. Comme un professionnel académique, un amateur crée des connaissances nouvelles et publie ses résultats dans des revues spécialisées. Comme un professionnel académique, un taxonomiste amateur est souvent spécialisé dans l'étude d'une famille, et la description d'espèces nouvelles est souvent le moteur de sa passion : entre 2000 et 2015, $\%$ des nouvelles espèces de mollusques marins ont été décrites par des amateurs. Si l'on considère le faible soutien institutionnel et programmatique à l'inventaire de la biodiversité, il est clair que la place des non-professionnels doit être reconnue et encouragée.
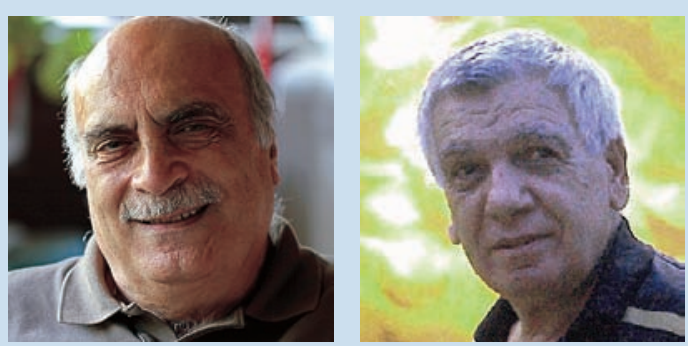

La malacologie (étude des mollusques) bénéficie de l'appui d'une communauté d'amateurs de haut niveau qui, comme les professionnels, publient sur des sujets pointus. Dans leur vie active, Alberto Cecalupo et Ivan Perugia étaient respectivement concessionnaire automobile et ingénieur en génie climatique. Dans leur vie de retraités malacologues amateurs, ils sont les grands spécialistes des Cerithiopsidae une famille de microgastéropodes mangeurs d'éponges. Ils ont publié en 2017 une monographie régionale des espèces de Nouvelle-Calédonie, comprenant la description de pas moins de 64 espèces nouvelles pour la science. (c) A. Cecalupo et I. Perugia. 


\section{Chapitre 12 \\ Les bénitiers, joyaux des récifs néo-calédoniens}

Cécile Fauvelot, Philippe Borsa, Serge Andréfouët, Josina Tiavouane, Simon van Wynsberge et Pascal Dumas

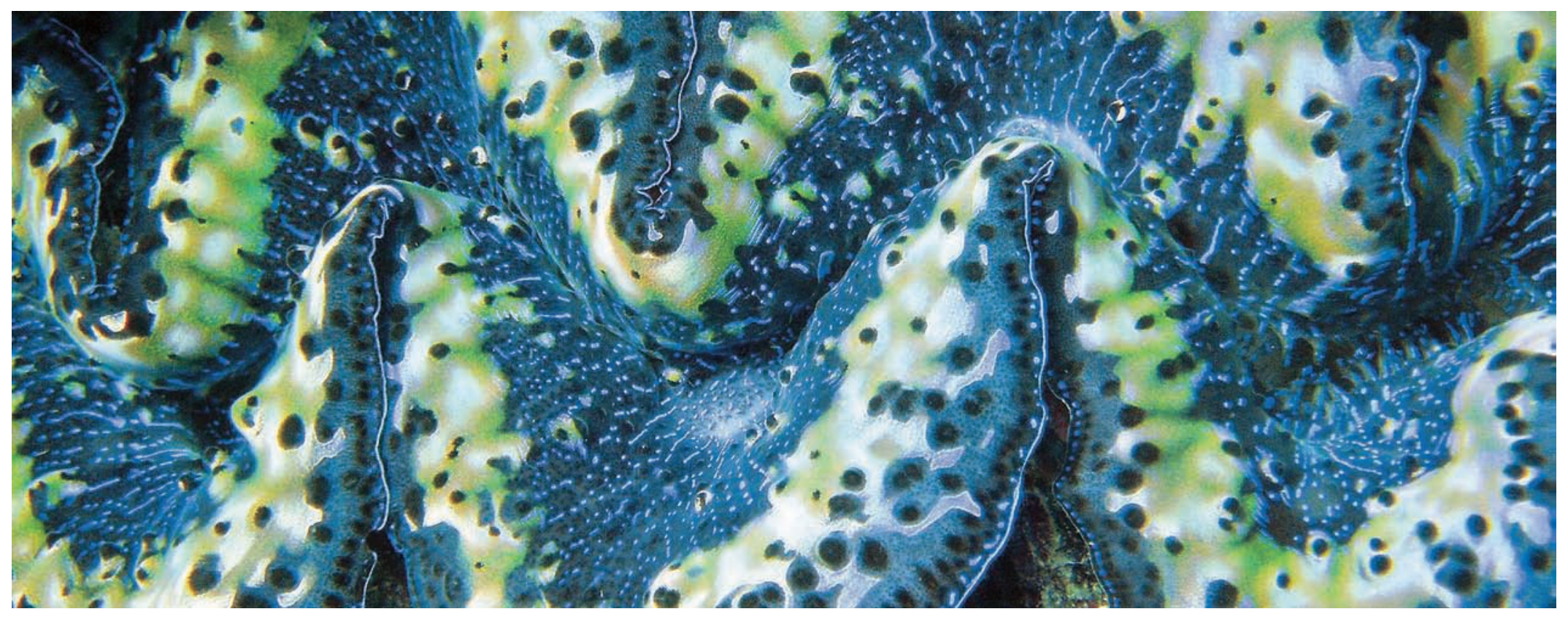

Le manteau des bénitiers héberge des microalgues qui leur donnent ces couleurs chatoyantes. Tridacna maxima $\odot$ IRD/S. Andréfouët

\section{Des « coquillages » imposants mais encore mal connus}

Les bénitiers sont des mollusques marins de la classe des bivalves² tout comme les huitres, moules, palourdes etc. - habitant les eaux côtières chaudes de la zone Indo-Pacifique. On les trouve préférentiellement dans les faibles profondeurs des lagons et sur les pentes externes des récifs-barrières - jusqu'à $30 \mathrm{~m}$ de profondeur selon l'espèce - où ils participent à la construction des récifs coralliens et constituent un substrat physique pour de nombreux organismes récifaux. Exploités depuis des millénaires pour leur chair et leur coquille, ils ont une grande importance économique, vivrière et patrimoniale pour de nombreuses communautés de la zone Indo-Pacifique.

Sur une douzaine d'espèces actuellement décrites, sept appartenant à deux genres distincts sont présentes en NouvelleCalédonie : Tridacna maxima, T. crocea, T. squamosa, T. derasa et T. mbalavuana, T. noae et Hippopus hippopus. Leur densité et leur distribution varient largement d'une espèce à une autre, en fonction de leurs caractéristiques écologiques, mais aussi en raison des pressions de pêche ciblée sur certaines espèces ou certains récifs.

${ }^{2}$ Mollusques dont le corps est protégé par une coquille calcaire en deux parties plus ou moins symétriques. 
Tridacna maxima, d'une longueur maximale de $35 \mathrm{~cm}$, est l'espèce la plus commune. Sa densité est, en moyenne, d'une centaine d'individus par hectare de récif. De par sa taille relativement petite et son encastrement dans le récif, c'est une espèce qui n'est pas ou est très peu pêchée. Tridacna crocea (longueur maximale, $15 \mathrm{~cm}$ ) a une densité moyenne proche de celle de T. maxima.

En réalité, cette valeur moyenne cache une distribution spatiale très hétérogène, les individus étant souvent observés en fortes agrégations sur des zones particulières du récif. De petite taille et profondément encastrée dans les coraux, donc difficilement accessible, cette espèce n'est pas pêchée en Nouvelle-Calédonie mais elle l'est ailleurs, par exemple au Vanuatu. De taille plus imposante (longueur maximale, $42 \mathrm{~cm}$ ) et plus facile à prélever que les deux précédentes, Tridacna squamosa est recherchée par les pêcheurs. La densité observée est relativement faible, de l'ordre d'une dizaine d'individus par hectare de récif.

Encore plus gros, Tridacna derasa (longueur maximale, $60 \mathrm{~cm}$ ) est désormais rare en Nouvelle-Calédonie (environ deux individus par hectare) : sa grande taille ainsi que l'absence de fixation au substrat en font une espèce prisée par les pêcheurs. C'est aussi le cas du bénitier « rouleur » Hippopus hippopus (longueur maximale, $50 \mathrm{~cm}$ ), dont les individus sont faciles à prélever car ils ne sont pas fixés et vivent principalement sur les substrats sablo-détritiques peu profonds. Les très faibles densités observées (inférieures à un individu par hectare) sont la conséquence d'une surpêche sur l'ensemble du territoire.

À ces cinq espèces s'ajoutent deux autres espèces récemment recensées en Nouvelle-Calédonie, dont les distributions sont limitées au nord-est de la Grande Terre et aux îles Loyauté : T. noae (longueur maximale, $30 \mathrm{~cm}$ ), qui est une espèce relativement rare, récemment distinguée de $T$. maxima par la génétique; et T.mbalavuana (longueur maximale, $56 \mathrm{~cm}$ ) qui est l'espèce la plus rare de Nouvelle-Calédonie, avec seulement quelques individus isolés recensés à ce jour. Enfin, une espèce autrefois présente en NouvelleCalédonie, T. gigas, n'y est plus observée qu'à l'état fossile ou sub-fossile : elle y est considérée comme éteinte.

\section{Importance écologique des bénitiers}

Comme les coraux, les bénitiers abritent des algues unicellulaires symbiotiques appelées zooxanthelles, qui produisent par photosynthèse une partie de l'énergie nécessaire à leur croissance, leur reproduction et leur survie. Les couleurs chatoyantes du manteau des bénitiers s'expliquent par la présence de ces algues. Cette symbiose peut être perturbée dans des conditions de stress environnemental, conduisant, comme dans le cas des coraux, à des blanchissements massifs et à la mort des organismes. Au stade adulte, les bénitiers filtrent également l'eau de mer dont ils consomment les particules et micro-organismes. La symbiose avec les zooxanthelles leur apporte les produits de la photosynthèse (glucose, oligosaccharides et acides aminés) et complète les apports nutritifs résultant de la filtration de l'eau de mer. Ainsi, les bénitiers participent à l'épuration de l'eau en absorbant le plancton, les sédiments et les polluants. Ils sont ainsi souvent considérés comme de bons indicateurs de la qualité de l'eau et de la santé des milieux coralliens. De plus, les bénitiers participent au cycle du carbone à travers l'absorption du carbone inorganique dissous et la respiration, et grâce à la photosynthèse effectuée par les zooxanthelles symbiotiques.

Les bénitiers ont un cycle de vie en deux phases, avec une phase adulte benthique (les adultes sont généralement fixés au substrat à l'aide de leur byssus ou simplement posés sur le fond) et une phase larvaire pélagique. Les bénitiers ont un mode de reproduction hermaphrodite, où chaque individu adulte possède à la fois des gonades mâle et femelle. Les gamètes mâles sont libérés en premier, suivis environ $30 \mathrm{mn}$ plus tard par les gamètes femelles, ce qui limite la possibilité d'autofécondation. La fécondation a lieu en pleine eau dans les heures qui suivent la libération des gamètes, et les embryons se transforment en larves au bout de $24 \mathrm{~h}$. Ces larves sont appelées trochophores puis véligères selon le stade de développement. Lorsqu'apparaît une ébauche de pied, elles deviennent des pédivéligères qui se fixent sur le substrat une quinzaine de jours après la fécondation, pour se métamorphoser en juvéniles. Cette phase larvaire assure la connectivité des populations (encadré 16). Certains bénitiers peuvent vivre plusieurs dizaines d'années. 


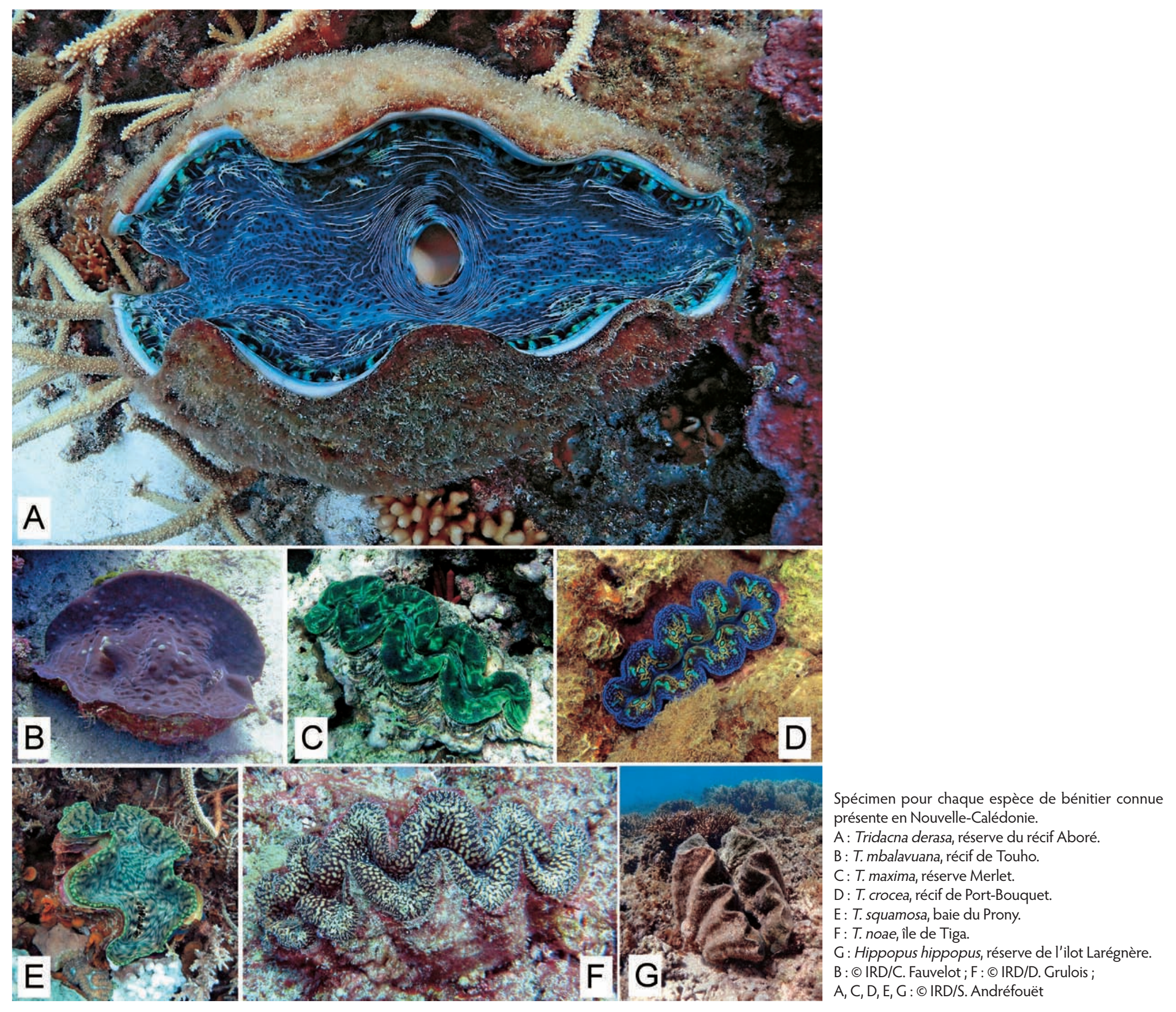




\section{Des espèces emblématiques menacées par la surpêche}

Dans le Pacifique, l'utilisation et la consommation des bénitiers ont débuté peu après $l$ 'installation des premières populations humaines comme en témoignent les nombreux artefacts retrouvés tout au long de leur aire de répartition. Objets de prestige, plus durables que le bois, ils ont constitué une monnaie d'échange prisée et continuent à jouer un rôle important dans les pratiques culturelles de la plupart des îles du Pacifique. Leur chair - y compris le muscle adducteur, les gonades et le manteau - est une source de protéines traditionnellement vivrière, cette pêche a progressivement évolué vers une exploitation de type commercial, entraînant notamment l'extinction locale des grands bénitiers dans les zones les plus peuplées du Pacifique sud-ouest. La vulnérabilité des bénitiers face à la surexploitation par la pêche, associée à une dynamique des populations incertaine (croissance lente et recrutement erratique), a causé le déclin de la plupart des espèces.

Quatre des 12 espèces connues sont considérées comme « vulnérables » dans la liste rouge des espèces menacées établie par I'Union internationale pour la conservation de la nature (IUCN). Trois sont estimées comme étant à « faible risque et dépendantes de la conservation ». Une seule espèce, $T$. crocea, reste placée dans la catégorie « faible risque/moins concernée ». Les quatre autres espèces n'ont pas encore fait l'objet d'une évaluation par l'IUCN. Tous les bénitiers sont inscrits à l'annexe Il de Convention régulant le commerce international des espèces sauvages menacées d'extinction (CITES, Convention internationale sur le commerce des espèces menacées), c'est-à-dire «non nécessairement menacées d'extinction, mais dont le commerce international doit être contrôlé afin d'éviter une exploitation incompatible avec la survie des espèces » et dont «le commerce international ne peut avoir lieu sans l'octroi d'un permis ».

Les bénitiers sont également des animaux d'aquarium recherchés à la fois pour leurs couleurs (les plus colorés étant T. maxima, T noae, $T$. crocea et $T$. derasa) et leur rôle dans l'épuration de l'eau des aquariums d'agrément. Ils sont ainsi listés parmi les 10 invertébrés marins les plus prisés par les aquariophiles.
La pêche des bénitiers est une activité traditionnellement très répandue en Nouvelle-Calédonie. Au moins deux espèces (Hippopus hippopus et Tridacna derasa) sont couramment exploitées à des fins vivrières ou commerciales. Elles sont consommées directement, ou bien vendues sur les marchés et parfois échangées dans le cadre de pratiques coutumières. Avec en moyenne $4 \mathrm{t}$ de chair déclarées annuellement dans les années 2000 les données de la pêche professionnelle montrent une exploitation relativement soutenue pour alimenter le marché local de la chair. Cette estimation est certainement très en deçà de la réalité si l'on considère l'absence de données quantitatives sur la pêche vivrière et plaisancière. Parallèlement à ce marché, les données CITES liées au suivi des exportations depuis la Nouvelle-Calédonie montrent que l'exportation de coquilles de bénitiers reste importante (plus de 19000 coquilles entre 1994 et 2003, pour la plupart H. hippopus et $T$. maxima), bien qu'en déclin ces dernières années. De fait, l'augmentation de la pression de pêche en lien avec le développement démographique du territoire soulève de vives inquiétudes quant à l'état de la ressource, avec des populations de bénitiers présentant localement des signes évidents de surexploitation (densités réduites, faibles tailles des individus) notamment dans les zones du lagon les plus fréquentées. De ce fait, plusieurs mesures de conservation ont été mises en place en Nouvelle-Calédonie pour tenter d'enrayer le phénomène (chap. 35).

La pollution et l'urbanisation du littoral ont aussi un impact sur les populations de bénitiers, de même que la prédation, les maladies (virus) et le réchauffement climatique : perte des zooxanthelles (blanchissement) liée à l'augmentation de la température de l'eau, modification de la croissance liée à l'acidification des océans, et augmentation de la mortalité des juvéniles sous l'effet combiné du réchauffement et de l'acidification des océans. Les adultes et juvéniles sont des proies pour de nombreux prédateurs : le manteau, les gamètes, les œufs et les larves sont mangés par les tortues, les poulpes, certains poissons (balistes et labres) et certains gastéropodes (familles des pyramidellidés et des ranellidés). Des éponges perforantes peuvent fragiliser l'animal en creusant des petits trous dans les valves. Enfin, les vers plats du genre Stylochus peuvent se glisser entre les valves pour ensuite dévorer les tissus. 


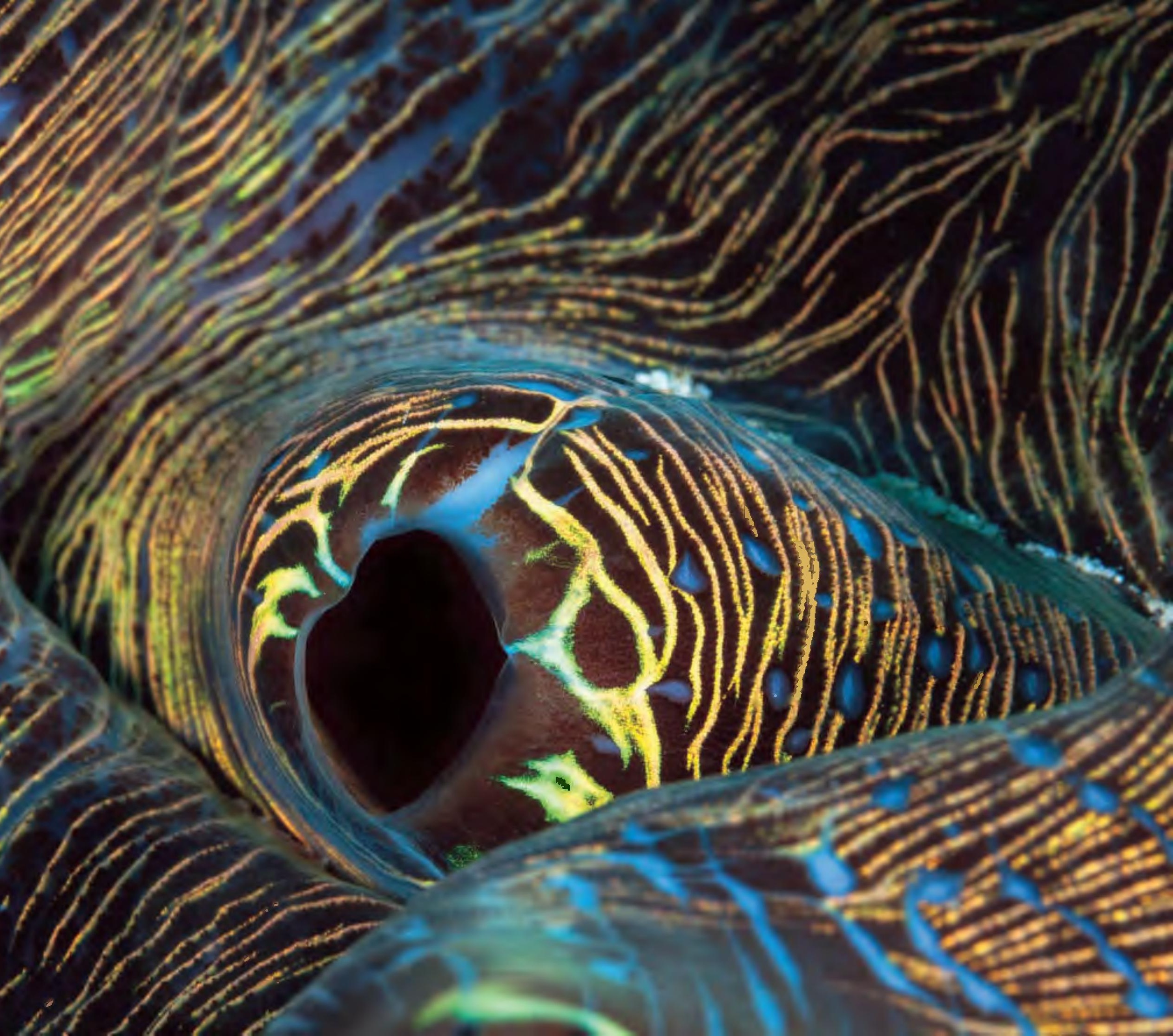




\section{Encadré 16 \\ Connectivité des populations de bénitiers}

La connectivité des populations fait référence au flux d'individus entre sites et, pour les espèces marines fixées telles que les bénitiers, elle correspond à un flux de larves échangées entre récifs. En Nouvelle-Calédonie, nos études ont montré que les populations de bénitiers Tridacna maxima et Hippopus hippopus n'étaient pas génétiquement homogènes à l'échelle de l'archipel, indiquant une connectivité limitée entre certains récifs. Ainsi, pour H. hippopus, il semble y avoir peu d'échanges de larves entre les récifs d'Entrecasteaux et le reste des populations échantillonnées en Nouvelle-Calédonie, et en moindre mesure, entre les îles Loyauté et la Grande Terre. Pour Tridacna maxima, une plus grande connectivité est observée et nos études ont montré que celle-ci dépendait principalement de la distance géographique entre récifs. Cependant, pour toutes les espèces de bénitiers, il semble que très peu de larves proviennent de récifs extérieurs à la Nouvelle-Calédonie et on ne peut donc compter sur un approvisionnement allochtone pour repeupler nos récifs.

\section{Références bibliographiques}

BORSA P. et al., 2015 Distribution of Noah's giant clam, Tridacna noae. Marine Biodiversity, 45 : 339-344.

DUMAS P. et al., 2011 Les bénitiers de Nouvelle-Calédonie : statut des populations, impact de l'exploitation et connectivité. Rapport final d'opération, Zoneco, 86 p. FAUVELOT C. et al., 2016 BeN-Co : Connectivité des bénitiers en NouvelleCalédonie. Rapport final d'opération, Zoneco, $58 \mathrm{p}$.

NEO M.L. etal., 2017 Giant clams (Bivalvia, Cardiidae, Tridacninae): A comprehensive update of species and their distribution, current threats and conservation status. Oceanography and Marine Biology: An Annual Review, 55 : 85-388.

TIAVOUANEJ., FAUVELOT C., 2017 First record of the Devil Clam, Tridacna mbalavuana Ladd 1934, in New Caledonia. Marine Biodiversity, 47 : 781-782. VAN WYNSBERGE S. et al., 2017 Considering reefscape configuration and composition in biophysical models advance seascape genetics. Plos One 12 : e0178239 |DOI 10.1371/journal. pone.0178239

WABNITZ C. et al., 2003 From ocean to aquarium: The global trade in marine ornamental species. Cambridge, UK: UNEP WCMC, 64 p. 


\section{Les éponges, des microcosmes au cœur du récif}

Sylvain Petek

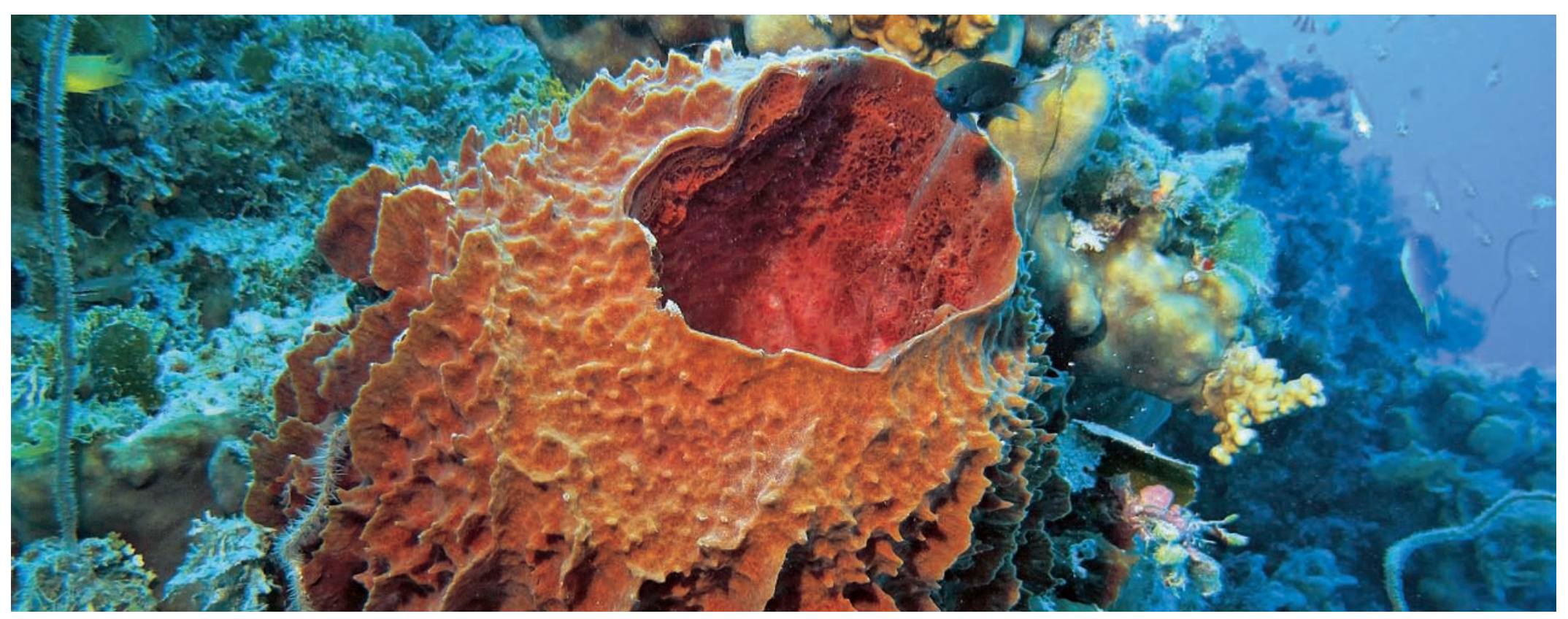

Éponge tonneau Xetospongia sp., pente externe, lles Chesterfield @ IRD/J.-L. Menou

La plupart des plongeurs ou des randonneurs palmés sont déjà passés devant ces animaux apparemment simples aux couleurs chatoyantes, sans forcément savoir de quoi il s'agissait. Mise à part l'éponge de bain, issue d'espèces dont on n'utilise que le squelette, ces organismes demeurent relativement méconnus du grand public.

Ces invertébrés sous toutes les latitudes, de la surface jusqu'à plus de $3000 \mathrm{~m}$ de profondeur, sont parmi les animaux les plus anciens et les plus primitifs encore vivants sur Terre. Les plus vieux fossiles datent du Cambrien, il y a 540 millions d'années.
Leur anatomie est particulièrement simple, contrairement à la majorité des animaux, elles ne comportent pas de tube digestif, pas de bouche ni d'anus, ni d'organes ou de tissus spécialisés. Elles absorbent l'oxygène, les nutriments et micro-organismes présents dans le milieu ambiant via des pores en filtrant l'eau environnante. Elles sont ainsi capables de filtrer plusieurs centaines de litres d'eau par jour. Ces organismes sont généralement fixés sur un substrat et pour la plupart incapables de se mouvoir. D' une espèce à l'autre, elles offrent une très grande variété de couleurs, de textures, de consistances, leurs formes variant en fonction de l'exposition au courant. 


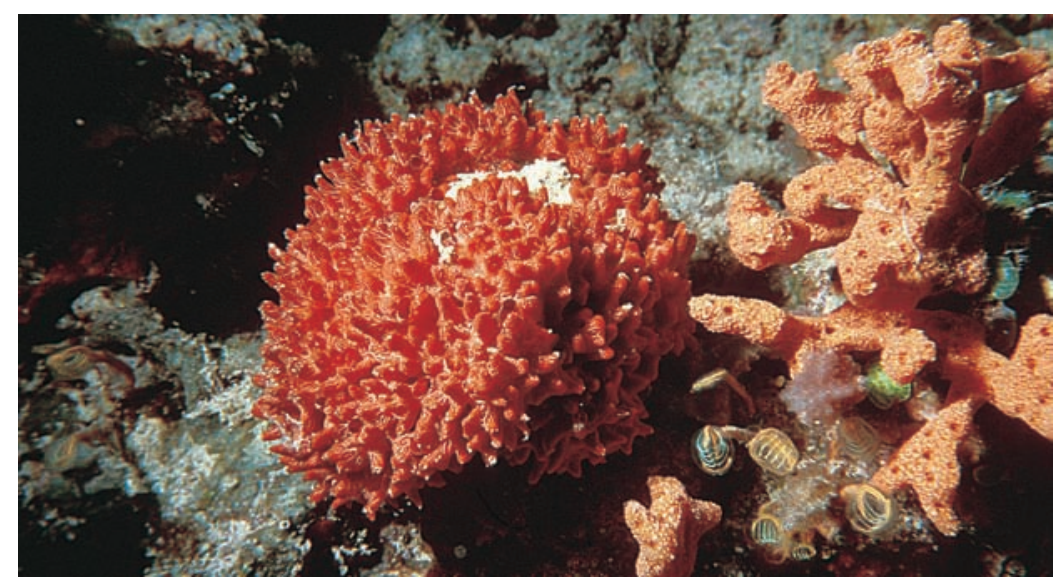

Clathria (Thalysias) hirsuta. HOOPER et LÉVI, 1993. @ IRD/G. Bargibant

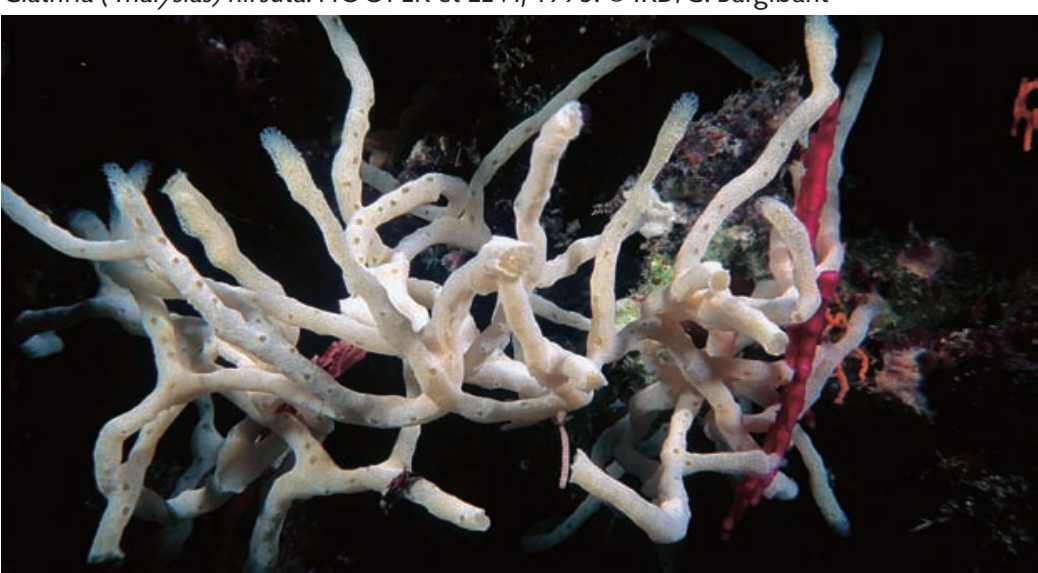

Leiosella ramosa. BERGQUIST, 1995. @ IRD/J. L. Menou

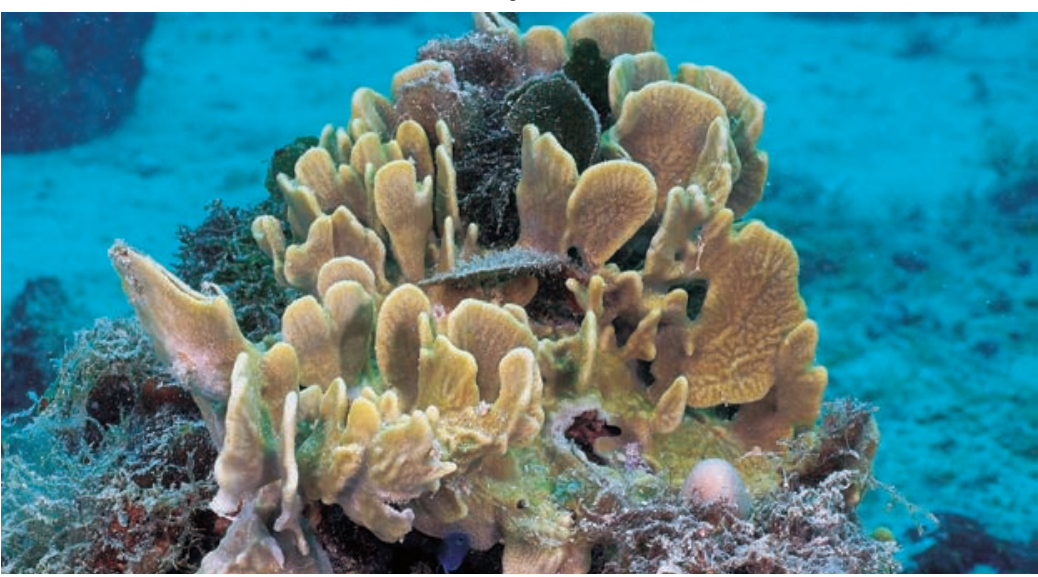

Lamellodysidea herbacea. KELLER, 1889. ๑ IRD/E. Folcher
Les éponges sont par ailleurs un petit écosystème à elles seules, un microcosme, hébergeant de nombreux micro-organismes, pour certains symbiotiques, pouvant représenter jusqu'à $50 \%$ de la masse de l'éponge. Les plus massives abritent également dans leurs anfractuosités toute une variété de mollusques, de crustacés et d'échinodermes.

Suivant l'espèce, leurs rôles au niveau des récifs, peuvent être très différents. Certaines participent à l'érosion, en perforant les structures coralliennes, alors que d'autres contribuent à la chaîne alimentaire. Capables d'absorber $99 \%$ des bactéries environnantes et les matières organiques en suspension, leurs rejets azotés contribuent à la croissance des algues sur le récif. Par ailleurs, certaines espèces sont consommées par les tortues, des poissons, des nudibranches et des étoiles de mer.

En Nouvelle-Calédonie, ce sont quelque 300 espèces qui ont pu être recensées et identifiées, des lagons aux pentes externes de la barrière récifale, mais on estime qu'il y en aurait plus de 600. La plupart n'ayant jamais été décrites par ailleurs, ce qui porterait leur taux d'endémisme à $71 \%$.

\section{Références bibliographiques}

BERGQUIST, 1995 Dictyoceratida, Dendroceratida and Verongida from the New Caledonia Lagoon (Porifera: Demospongiae). Memoirs of the Queensland Museum, 38 (1): 1-51.

HOOPER et LÉVI, 1993 Poecilosclerida (Porifera: Demospongiae) from the New Caledonia Lagoon. Invertebrate Taxonomy, 7 (5): 1221-1302.

HOOPER J.N.A., VAN SOEST R.W.M. (éd.), 2002 Systema Porifera: A guide to the Classification of Sponges. New York, Kluwer Academic/Plenum Publishers, $1707 \mathrm{p}$.

KELLER, 1889 Die Spongienfauna des rothen Meeres (I. Hälfte). Zeitschrift für wisssenschaftliche Zoologie, 48 : 311-405, pl. XX-XXV.

LEVI, 1983 Pseudaxinyssa cantharella n.sp. Démosponge Axinellidae du lagon de Nouméa (Nouvelle-Calédonie). Bulletin du Muséum national d'Histoire naturelle, $(4$, A) 5 (3) : 719-722.

LEVI C. (éd.) et al., 1998 Sponges of the New Caledonian lagoon. Paris, Orstom, $214 \mathrm{p}$.

VAN SOEST R.W.M. et al., 2017 World Porifera database : http://www.marinespecies.org/porifera (consulté le 28/08/2017). 


\section{Chapitre 14 \\ Les poissons du Caillou se dévoilent}

Michel Kulbicki, Laurent Vigliola, Laurent Wantiez et Gérard Mou-Tham

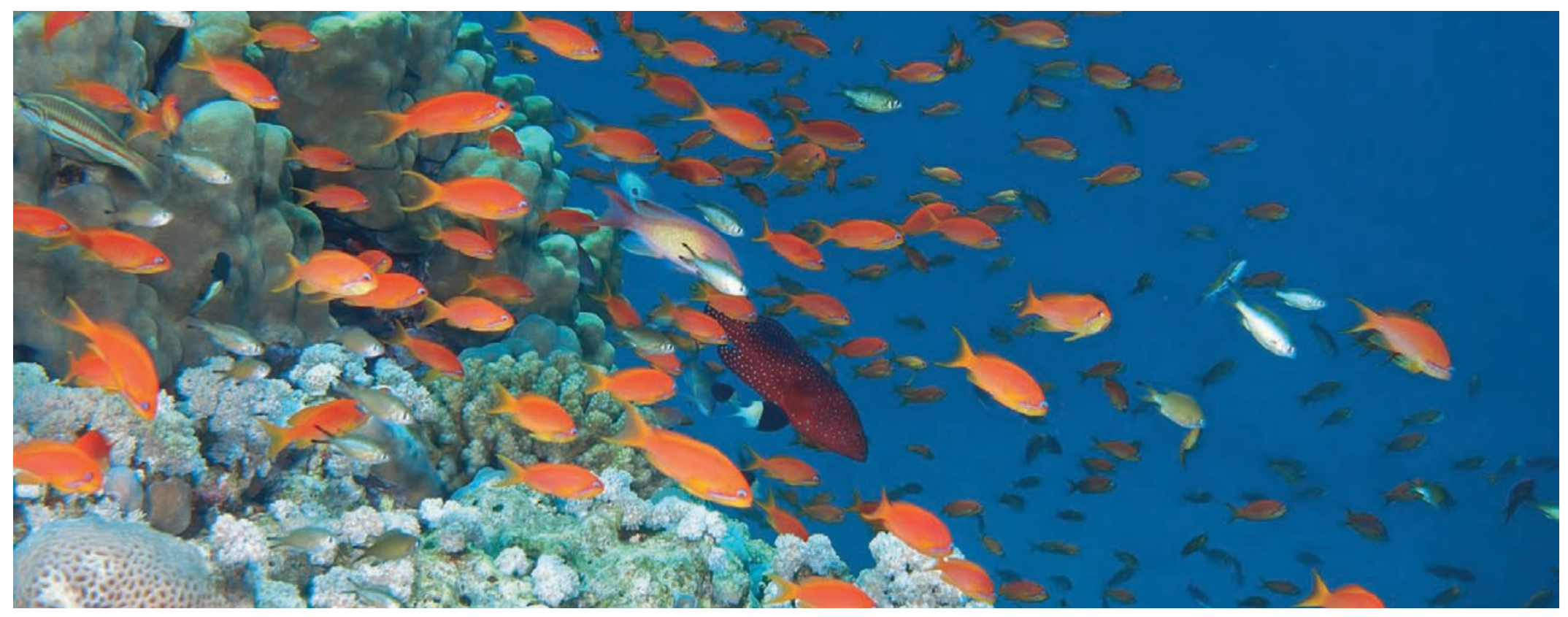

La diversité en poisson est maximale sur les récifs riches en habitat, jusqu'à plus de 300 espèces à l'hectare. @ R.- F. Myers

\section{Combien de poissons dans les lagons ?}

Les poissons de récif sont les vertébrés les plus diversifiés de la planète. En Nouvelle-Calédonie ces organismes comptent un nombre exceptionnel d'espèces (KULBICKI et al., 2013 ; LABOUTE et GRANDPERRIN, 2016). Néanmoins, nous n'en connaissons pas le nombre exact car il est difficile de comptabiliser toutes les espèces d'un récif. En effet, beaucoup d'espèces sont très difficiles à capturer, soit parce qu'elles vivent dans la matrice récifale, soit parce qu'elles vivent en profondeur, soit parce qu'elles ont un comportement qui les rend peu accessibles. De plus, une fois capturées ou photographiées il est parfois difficile d'identifier une espèce avec certitude, notamment quand il existe nombre d'espèces qui lui ressemblent. Pour finir l'inventaire des espèces est très hétérogène. Si les alentours de Nouméa ou Ouvéa, ont été bien prospectés, la province Nord, Maré, Tiga, la Côte oubliée ou l'île des Pins, ainsi que la plupart des récifs éloignés (Astrolabe, Pétrie, Durand, Surprises...) ont fait l'objet d'études moins systématiques. Il existe cependant de nombreux relevés visuels en plongée ainsi que des inventaires faunistiques ponctuels dont le bilan permet de régulièrement compléter la diversité des poissons de la Nouvelle-Calédonie.

Le dernier bilan date de 2011 (FRICKE et al., 2011). Il rapporte 1740 espèces de poissons récifaux sur un total de 2343 poissons marins pour 
la Nouvelle-Calédonie. Depuis, les connaissances ont évolué et le nombre d'espèces récifales est d'environ 1800 . Le nombre total ne sera probablement jamais connu mais il ne devrait vraisemblablement pas dépasser les 2000 espèces. À titre comparatif, sur l'ensemble de l'Europe, du nord de la Norvège jusqu'au sud-est de la Méditerranée, il n'y a que 900 espèces connues sur le plateau continental (moins de $100 \mathrm{~m}$ de profondeur) pour une superficie environ 30 fois supérieure à celle des lagons et récifs de Nouvelle-Calédonie. Cette diversité extraordinaire observée en Nouvelle-Calédonie est directement liée à la proximité $\mathrm{du}$ « triangle de corail » délimité par l'Indonésie, les Philippines et la mer de Chine, où se situe le maximum de diversité dans les océans Indiens et Pacifique, avec des zones dépassant localement les 2500 espèces (fig. 1).
À mesure que l'on s'éloigne de ce triangle de corail, la diversité diminue, que ce soit vers l'est, car les îles sont de plus en plus petites et isolées, soit en augmentant de latitude, car la température de l'eau se refroidit. Ainsi, à Tahiti, le nombre d'espèces de poissons récifaux n'est que de 740, à l'île de Pâques il n'est plus que de 148 et à Norfolk, qui représente la limite sud de la faune tropicale, il n'y a plus que 304 espèces.

\section{Le fruit de l'histoire et de la géographie}

La raison profonde de la grande diversité des poissons de récifs de la Nouvelle-Calédonie est avant tout historique. La NouvelleCalédonie fait partie de la province « sud-ouest Pacifique » (KULBICKI

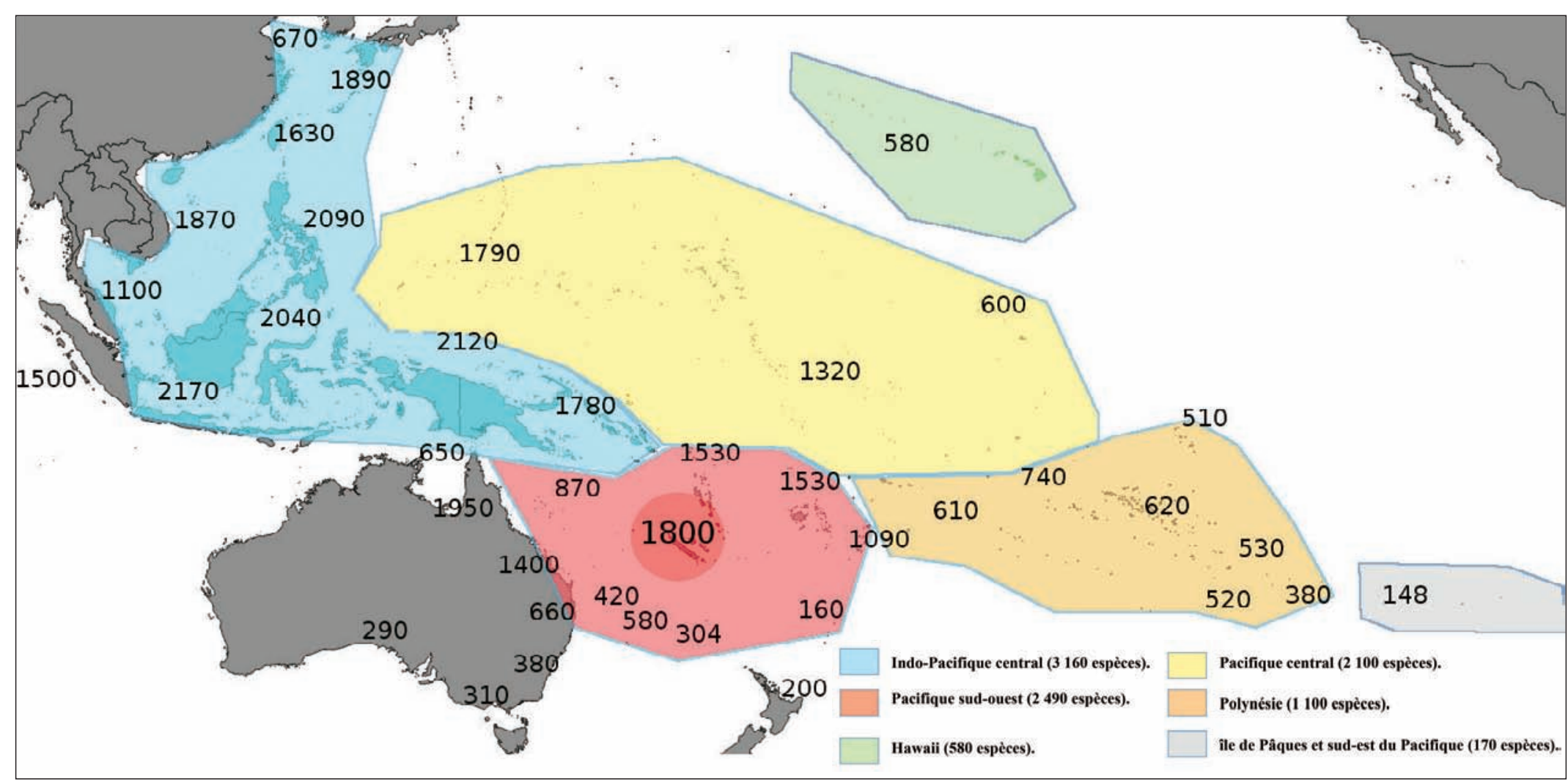

Figure 1 : Répartition du nombre d'espèces de poissons récifaux par zones biogéographiques dans le Pacifique tropical. La Nouvelle-Calédonie est symbolisée par un rond rouge. Source : KULBICKI et al., 2013a 
et al., 2013), qui englobe le sud de la mer de Corail, le sud de la Grande Barrière de Corail, Norfolk, Lord Howe, les récifs d'Elisabeth et Middleton. La province Sud-Ouest est voisine de la région IndoPacifique central, qui inclut le «triangle de corail ». Le nombre d'espèces très élevé dans cette région ( 3160 espèces) et cette province (2 490 espèces) est attribué à l'histoire évolutive de ces zones. La température et la salinité de l'eau de mer ont beaucoup varié au cours des âges géologiques. Le résultat a été de grandes variations du niveau marin et des couvertures coralliennes. Durant les épisodes glaciaires du Quaternaire, les eaux étaient très basses et il n'y avait que peu de régions où les coraux subsistaient. Ces régions étaient donc des refuges pour la faune de zones où les coraux avaient disparu. La région Indo-Pacifique central comprenait des surfaces importantes de tels refuges, la Nouvelle-Calédonie étant l'un d'entre eux, sauf au cours des périodes les plus froides.

C'est ainsi que, depuis le fond des âges, le territoire a pu accumuler une faune marine dont la diversité est exceptionnelle mais largement partagée avec les régions voisines qui ont eu une histoire évolutive très similaire. La faune des poissons de récif de Nouvelle-Calédonie comporte ainsi une majorité d'espèces se retrouvant à l'ouest (Grande

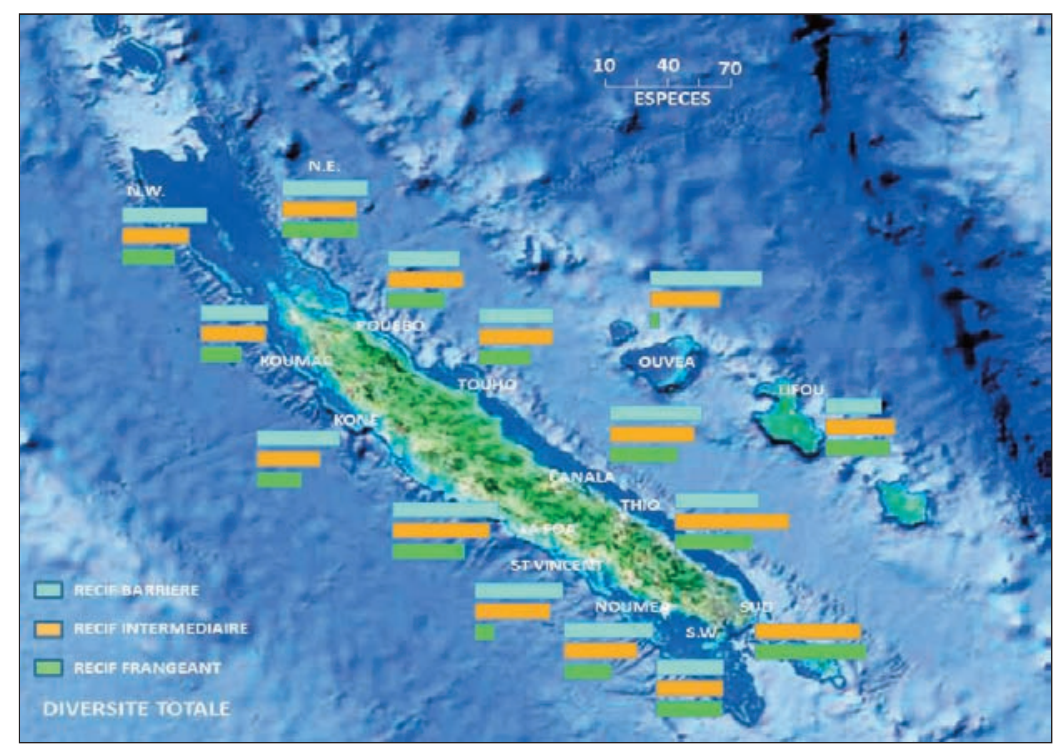

Figure 2: Nombre d'espèces de poissons récifaux pour une surface de $250 \mathrm{~m}^{2}$ en fonction du type de récif. Source : KULBICKI et al., 2013a
Barrière de Corail) (environ $60 \%$ ), une proportion moindre (30\%) provenant de l'arc mélanésien formé par la Papouasie, Salomon et Vanuatu, et peu d'espèces provenant du sud (rides de Norfolk et des Loyautés) (10\%). En conséquence, l'endémisme (chap. 36) est faible pour les poissons de Nouvelle-Calédonie, comprenant, suivant les modes d'estimation, entre 1,8\% et 3,8\% d'espèces uniques au Caillou.

Les facteurs géographiques ont également contribué à la richesse des lagons néo-calédoniens. Il a par exemple été démontré que, dans les pays de l'Indo-Pacifique, le nombre d'espèces était proportionnel aux surfaces de récifs disponibles, à la taille des îles et à leur degré d'isolement. Plus une île est petite, isolée et avec peu de récifs, moins elle aura d'espèces. Ainsi la Grande Terre, grâce à sa grande taille et ses vastes surfaces récifales et lagonaires, compte plus de 1400 espèces de poissons récifaux, alors que les lles Loyauté, plus petites, n'en comptent qu'environ 800 malgré la grande proximité de ces deux ensembles géographiques. De manière analogue, les Chesterfield, très isolés et virtuellement sans terre émergée, ne comptent que 800 espèces récifales malgré de vastes surfaces récifales immergées. De la même façon, la Polynésie, qui est constituée de petites îles éloignées ne comprend au total que 900 espèces récifales, ce qui est à mettre en relation avec les surfaces des terres émergées (4 $200 \mathrm{~km}^{2}$ contre $18700 \mathrm{~km}^{2}$ en NouvelleCalédonie) et l'éloignement du triangle de corail.

La température de l'eau est également un facteur important qui intervient sur le nombre d'espèces, les récifs ayant des eaux chaudes supportant davantage d'espèces. Ce gradient de température agit sur de grandes distances, mais il est déjà perceptible au niveau de la Grande Terre, des études ayant montré que le nombre d'espèces sur un récif était plus élevé dans le nord de la Grande Terre que dans le sud. Néanmoins, la richesse spécifique et la composition des peuplements de poissons de récif varient au sein de la NouvelleCalédonie, surtout selon le type d'habitat récifal (fig. 2).

En règle générale le nombre d'espèces augmente de la côte jusqu'au récif-barrière. Ce gradient est plus accentué dans les zones où les récifs frangeants sont sous forte influence terrigène, par exemple quand ils se situent dans de grandes baies, Ouvéa, 
représentant une exception avec très peu d'apports terrestres, le peu d'espèces littorales s'y expliquant par une quasi-absence de récifs sur le littoral. Les premières études basées sur l'observation des poissons en plongée sur des surfaces restreintes $\left(250 \mathrm{~m}^{2}\right)$ ne montraient pas de gradient marqué dans le nombre moyen d'espèces par échantillon sur des axes nord-sud ou est-ouest. Des études plus récentes mettent cependant en évidence des différences notables entre les extrémités sud (île des Pins; Walpole) et nord (Grand Lagon Nord). Par ailleurs, la composition spécifique varie davantage d'un échantillon à un autre dans le nord que dans le sud, et sur la Grande Terre comparée aux lles Loyauté. Autrement dit, le nombre d'espèces par unité de surface ne change que modérément : en revanche la variabilité de leur composition change fortement.

\section{Carte d'identité des habitants du lagon}

Les 1800 espèces de poissons récifaux de Nouvelle-Calédonie se distribuent en 125 familles. L'importance de ces familles est très inégale, avec 10 familles regroupant $51 \%$ des espèces et 20 familles en rassemblant les deux tiers. Beaucoup de familles ne sont représentées que par une espèce ( 30 familles) ou au plus cinq espèces ( 63 familles). Les familles les mieux représentées sont les gobies (190 espèces), suivies des labres (129 espèces), les poissons demoiselles (Pomacentridae, 109 espèces) et les poissons soldats (Apogonidae, 87 espèces). Un examen des traits de vie des espèces récifales montre que plus de $50 \%$ des espèces font moins de $15 \mathrm{~cm}$ de taille maximale et seulement $9 \%$ dépassent $80 \mathrm{~cm}$ de

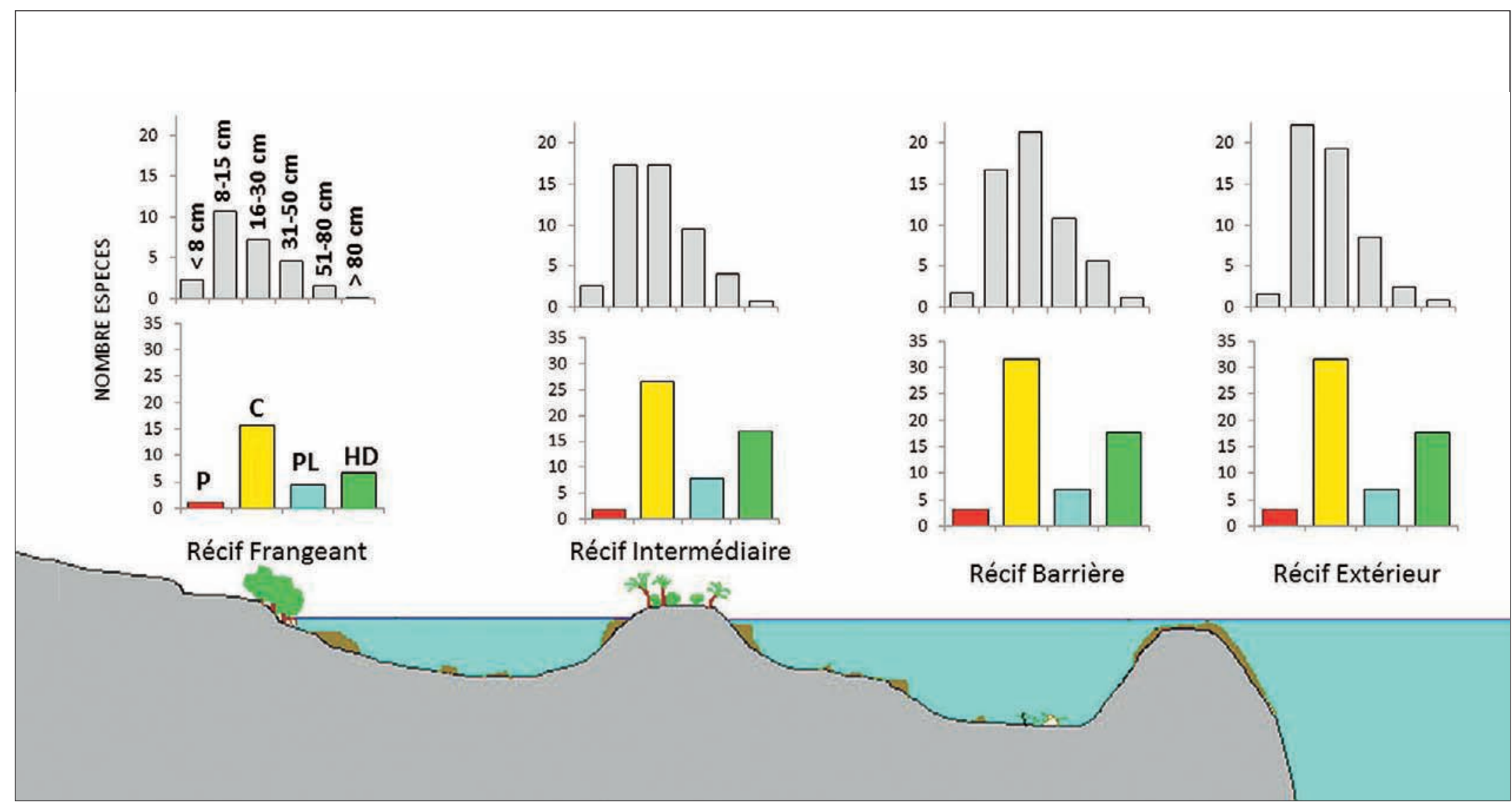

Figure 3 : Distribution de la taille et du régime alimentaire des poissons de la côte à l'océan. P: piscivore. C: carnivore. PL: planctonophage. HD : herbivore. Source : KULBICKI et al., 2013b 
taille maximale. Ce type de distribution se retrouve dans l'ensemble du Pacifique tropical. La distribution des tailles des espèces est en grande partie liée au nombre d'espèces. Plus la richesse spécifique est grande, plus la proportion de petites espèces augmente. Un corollaire est que, de façon générale, l'abondance des poissons est également plus importante quand le nombre d'espèces est élevé. Ainsi la proportion d'espèces de grande taille sera plus grande en Polynésie ou encore dans le sud de la Grande Barrière de Corail qu'en Nouvelle-Calédonie. Ceci a des implications importantes en gestion. En effet, les petites espèces sont en général moins vulnérables que les grandes, ce qui confère une plus grande stabilité et résistance aux peuplements en Nouvelle-Calédonie (chap. 38). Les régimes alimentaires des poissons de récifs sont dominés par les espèces consommant des invertébrés mobiles (40\% des espèces). Les trois catégories suivantes sont les mangeurs de plancton (19\%), les piscivores (15\%) et les omnivores (13\%). Les herbivores ne représentent que $7 \%$ des espèces et les poissons corallivores, 3,5\%. Ces proportions sont assez semblables à ce qui existe dans les provinces biogéographiques proches de la Nouvelle-Calédonie. En revanche la proportion des piscivores augmente vers les régions plus froides ou à mesure que l'on s'éloigne vers des îles petites et isolées, avec en corollaire moins de planctonophages et d'omnivores et plus d'espèces moins spécialisées dans leur habitat. II est probable que ceci est d'une part lié à la distribution de taille des espèces (plus les espèces sont grandes et plus elles tendent à avoir des niveaux trophiques élevés) et d'autre part à la proportion d'espèces généralistes qui est d'autant plus grande que les poissons sont de grande taille et qu'il y a peu d'espèces.

La distribution des traits de vie des poissons varie également en fonction des habitats, notamment entre les habitats côtiers et ceux du large (fig. 3). Par exemple, la proportion des espèces de petite taille est plus grande sur les récifs côtiers et, inversement, la proportion de grandes espèces est plus grande sur les récifs océaniques. En termes de régime alimentaire il est important de noter l'augmentation des herbivores et des planctonophages à mesure que l'influence océanique augmente. Ces différences semblent liées à la stabilité des conditions environnementales. En effet, sur la côte, l'apport de nutriments par le ruissellement augmente la production primaire et donc le niveau de ressources primaires disponibles par rapport aux récifs océaniques.

Cette différence ne se traduit cependant pas par davantage d'espèces, au contraire. À l'opposé, les récifs côtiers sont soumis à des variations très importantes de salinité, de turbidité et d'apports de sédiments pouvant considérablement gêner les espèces sédentaires qui sont les plus nombreuses sur ces récifs. Par ailleurs, les espèces côtières ont des durées de vie larvaire et des aires géographiques plus restreintes que pour les espèces des récifs océaniques. La plupart des espèces de poissons de récif se dispersent via des larves pélagiques qui peuvent rester plusieurs semaines dans le domaine océanique.

Plus ce séjour (durée de vie larvaire) est long et plus les espèces peuvent coloniser des récifs éloignés. À noter que les espèces à longue durée larvaire tendent à être des espèces généralistes (habitat et/ou alimentation) et que la proportion d'espèces généralistes augmente de la côte vers le large. Tout ceci montre que les zones abritées ont accès à un renouvellement plus local de leurs populations et qu'en conséquence il est probable que ces populations seront plus fragiles à des changements importants de l'environnement.

\section{Références bibliographiques}

FRICKE R., KULBICKI M., WANTIEZ L., 2011 Checklist of the fishes of New Caledonia. Stuttgarter Beiträge zur Naturkunde A, nouvelle série, 4:341-463. KULBICKI M. et al., 2013a Global biogeography of reef fishes: a hierarchical quantitative delineation of regions. Plos One, 8 (12) : e81847, doi 10.1371/journal.pone.0081847.

KULBICKI M., VIGLIOLA L., WANTIEZ L., 2013b « Les poissons côtiers ». In : Bonvallot J. (coord.), Gay J.-C. (coord.), Habert E. (coord.), Atlas de la Nouvelle-Calédonie, Marseille, Nouméa, IRD Éditions, Congrès de la Nouvelle-Calédonie, PI. 18.

LABOUTE P., GRANDPERRIN R., 2016 Guide des poissons de NouvelleCalédonie. Nouméa : Édition Catherine Ledru, 695 p. 



\section{Chapitre 15 \\ Larves et juvéniles de poissons : une survie précaire}

Dominique Ponton, Laure Carassou et Philippe Borsa

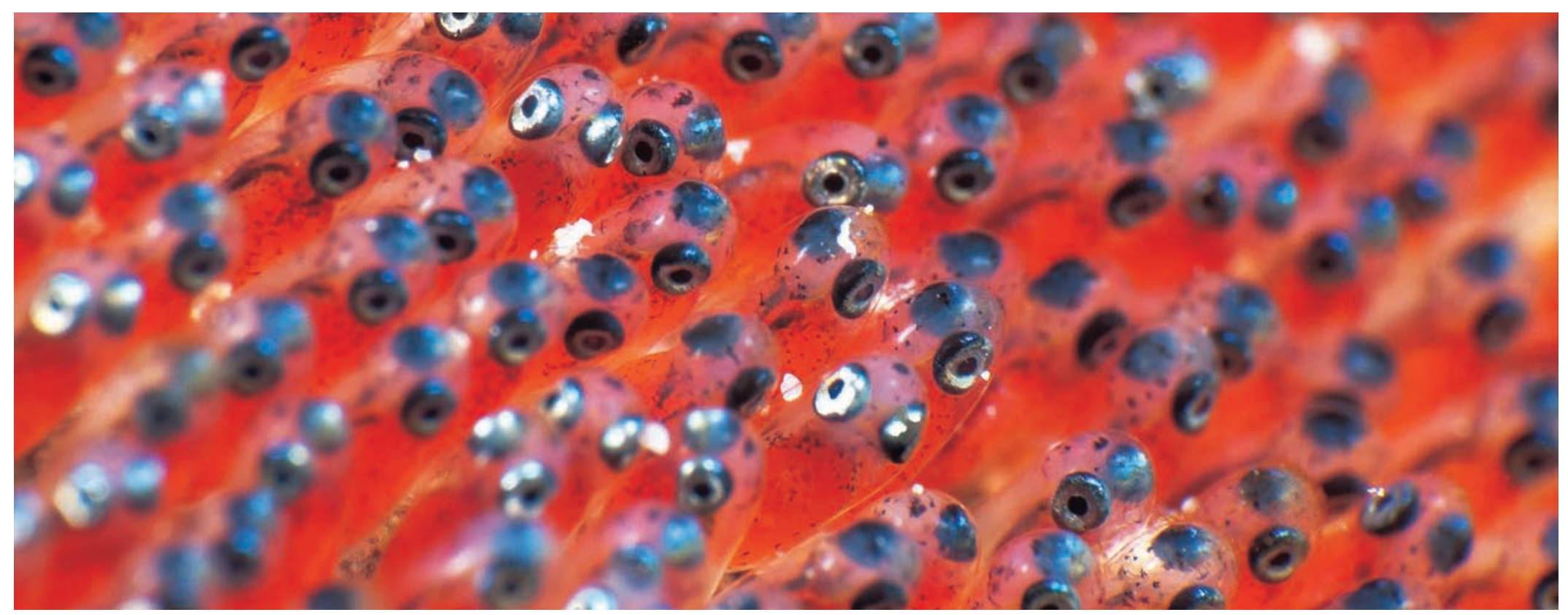

Eufs de poissons clown. La réserve vitelline est très colorée et les yeux des larves sont bien visibles. ๑ G. Boussarie

\section{Pourquoi étudier les premiers stades de vie des poissons?}

Beaucoup d'espèces de poissons récifaux présentent un cycle de vie en deux parties qui se distinguent par l'occupation d'habitats contrastés: une partie dite «phase larvaire », qui se déroule en pleine eau, suivie par une «phase benthique », où la larve, une fois installée à proximité du récif ou du fond du lagon, se transforme en un juvénile qui, s'il survit, grandira jusqu'à devenir un poisson adulte. Bien qu'il existe peu de données précises dans la littérature, il est généralement admis que, pour la grande majorité des espèces, la survie des poissons durant la phase larvaire est très faible : probablement moins de $1 \%$ des larves échappent à la prédation ou aux maladies. Il en résulte que, sur une ponte de plusieurs milliers à plusieurs centaines de milliers d'œufs, peu d'individus finissent par s'installer sur le fond pour y grandir. Les juvéniles subissent à leur tour une forte mortalité dans les tout premiers jours qui suivent leur installation. Ce niveau de mortalité n'a été que très rarement évalué et ceci, pour très peu d'espèces, mais il atteindrait plusieurs dizaines de pourcent par jour : une hécatombe. En résumé, un jeune poisson « moyen » a toutes les chances de périr. Seule une très faible proportion des juvéniles atteint le stade adulte.

Un tel « goulet d'étranglement » démographique signifie que les facteurs qui influencent la survie des larves et juvéniles expliquent en grande partie les variations d'abondance des adultes. Comme 
suggéré il y a plus d'un siècle par le chercheur norvégien Johan Hjort, un des pionniers des études sur l'écologie des larves de poissons: « le principal problème qui caractérise les sciences halieutiques est la description et la compréhension de la nature des fluctuations naturelles des stocks » (HJORT, 1914). Cette remarque, émise pour les espèces tempérées, reste valable pour les poissons tropicaux, même si, chez ces derniers, les études sur les stades larvaires sont encore peu nombreuses. Sous les tropiques, et en milieu corallien en particulier, les travaux sur les larves et juvéniles de poissons concernent essentiellement la phase de transition dite d'installation, juste avant, pendant, et juste après que les larves s'installent sur le fond. En Nouvelle-Calédonie, les travaux de notre équipe ont ainsi porté sur l'identification des facteurs de l'environnement, des zones et des périodes favorables à la survie des larves de poissons pendant la période précédant leur installation (CARASSOU, 2008). Nous nous sommes aussi intéressés à la croissance des juvéniles, pendant et peu après leur installation sur le fond (MELLIN, 2007). Nous avons pu démontrer que la croissance des juvéniles de différentes espèces, laquelle conditionne grandement leur survie, était influencée par les conditions de croissance au stade larvaire, ainsi que par le moment et le lieu où les larves s'installent. Il existe donc un lien étroit entre les processus larvaires et juvéniles. Ces jeunes stades de vie restent néanmoins difficiles à étudier compte tenu des difficultés d'identification des différentes espèces, très diverses en NouvelleCalédonie (plus de 1500 espèces recensées à ce jour). Nous avons ainsi été amenés à mettre au point des méthodes pour l'identification des larves et juvéniles des poissons récifaux en Nouvelle-Calédonie.

\section{Comment les capturer?}

Les petites larves de quelques millimètres sont généralement capturées à l'aide de filets à mailles très fines qui sont tractés derrière un bateau ou plus rarement poussés devant ou sur les côtés. La capture des larves de plus grande taille requiert des filets plus gros, généralement de plusieurs mètres de côté, essentiellement pour la raison que ces larves, plus rapides, ont une meilleure capacité d'évitement. Les individus en fin de phase larvaire peuvent également être capturés à l'aide de filets fixes lorsqu'ils passent avec les vagues par-dessus la crête récifale. Les larves de certaines espèces sont attirées par la lumière : celles-ci peuvent donc être capturées à l'aide de pièges lumineux. Au moment de leur installation sur le fond, les jeunes juvéniles peuvent aussi être capturés dans des récifs artificiels mis à leur disposition. Les juvéniles plus âgés peuvent être capturés dans les herbiers en utilisant une senne de fond tirée par des plongeurs, ou dans les colonies de coraux dans lesquelles ils s'abritent, en utilisant un anesthésique, généralement de l'essence de clou de girofle.

\section{Comment identifier les larves et juvéniles de poissons récifaux?}

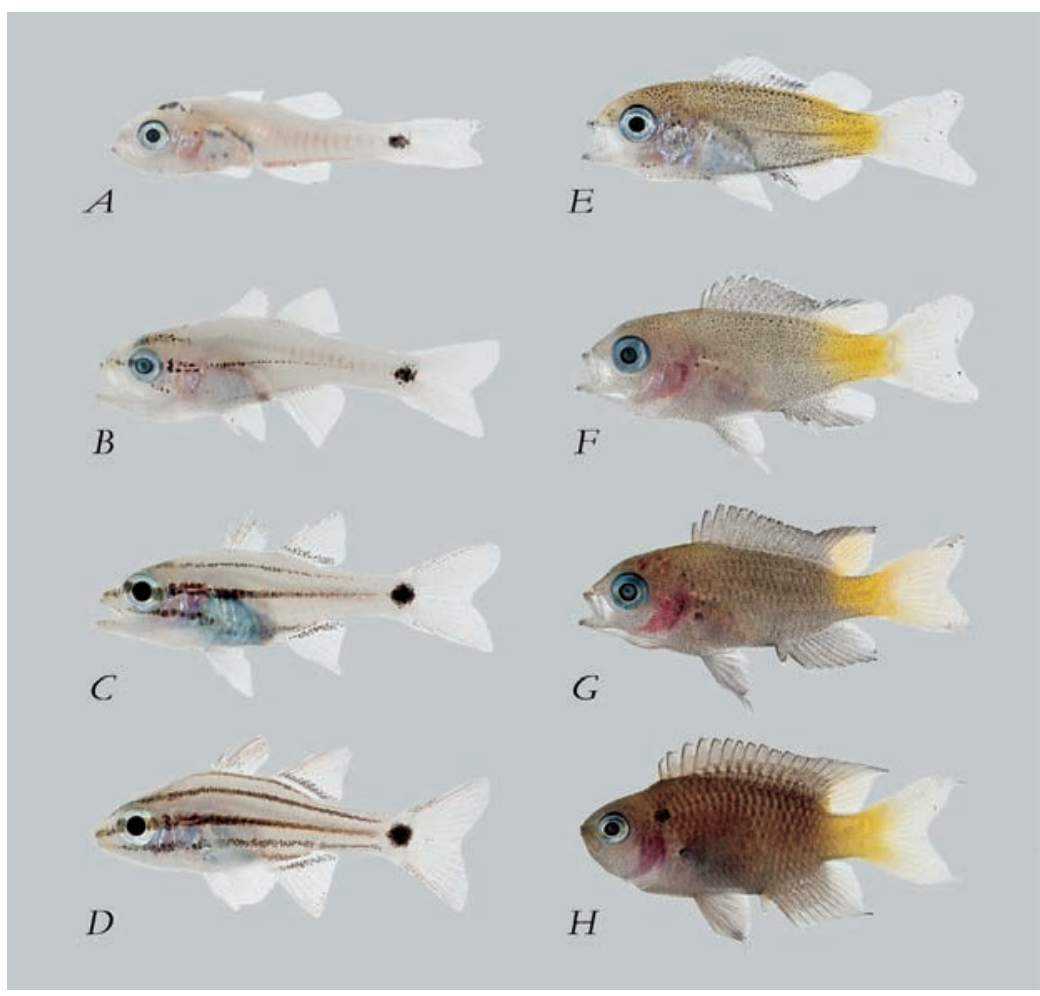

Séries de développement chez deux poissons.

Un poisson-cardinal finalement identifié comme Ostorhinchus doederleini.

$A$ : à la capture. $B$ : après sept jours d'élevage en aquarium.

$C$ : après 22 jours d'élevage. $D$ : après 51 jours d'élevage.

Un poisson-demoiselle finalement identifié comme Neopomacentrus violascens.

$E$ : à la capture. $F$ : après 7 jours d'élevage en aquarium.

$G$ : après 15 jours. $\mathrm{H}$ : après 91 jours. @ IRD/D. Ponton 
En milieu récifal, les larves et même les juvéniles de la plupart des espèces ont des formes et des couleurs très différentes de celles des adultes, et sont rarement décrits dans les ouvrages d'identification des poissons. De ce fait, les difficultés rencontrées pour identifier larves et juvéniles des poissons ont considérablement freiné les travaux à ce sujet. Il existe des guides d'identification des larves, mais soit ceux-ci couvrent des zones géographiques très étendues et sont de ce fait relativement peu précis - ne permettant pas de descendre au détail des espèces et se limitant à la description des familles -, soit ils ne concernent que quelques espèces capturées en un endroit donné.

Les guides les plus précis sont obtenus par la photographie ou le dessin de larves ou juvéniles capturés en milieu naturel puis mis en élevage jusqu'à ce qu'ils ressemblent à de petits adultes et puissent être alors identifiés d'après leur morphologie. Cette méthode d'identification à l'espèce est longue et coûteuse : elle ne peut donc pas être utilisée en routine dans les laboratoires. De ce fait, une approche alternative et de plus en plus répandue consiste en l'utilisation des marqueurs génétiques, comme les barcodes ADN (fig. 1).
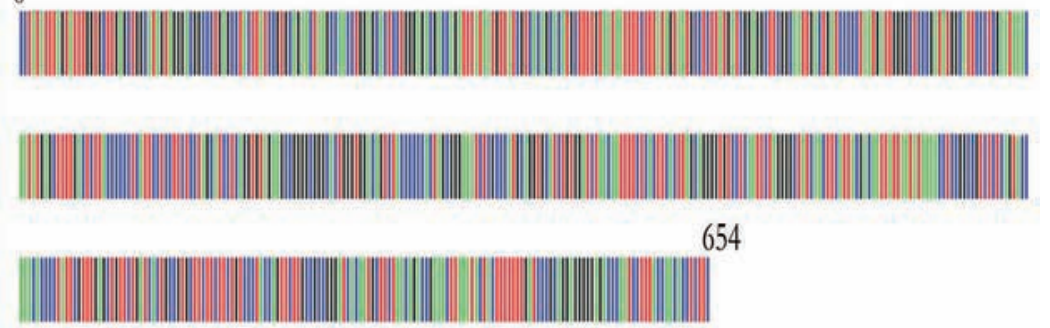

Figure 1: Barcode ADN de poisson, ici un bec-de-cane malabar Lethrinus olivaceus, tel que représenté dans la base de données internationale Bold. Les quatre nucléotides constitutifs de l'ADN $(A, C, G, T)$ sont codés par quatre couleurs différentes. La longueur du barcode est ici 654 nucléotides. BOLD (http://v4.boldsystems.org/)

Le barcode ADN le plus souvent utilisé chez les poissons est la séquence nucléotidique d'un fragment de l'ADN mitochondrial, qui correspond au gène d'une enzyme du métabolisme respiratoire, la cytochrome-oxydase 1. Le barcode ADN de la larve est comparé à une base de données de barcodes ADN de référence, obtenue à partir d'une collection d'individus adultes identifiés par des experts. À chaque espèce correspond généralement un barcode unique, à quelques mutations près du fait de la variabilité naturelle entre individus d'une même espèce. Ainsi, dans une majorité de cas, il est possible d'identifier la larve à l'espèce à partir de son seul barcode ADN. Toutefois, il existe des exceptions. Par exemple, certaines espèces proches sont susceptibles de partager le même barcode ADN à la suite d'événements d'hybridation plus ou moins récents qui ont permis aux mitochondries d'une espèce de coloniser l'autre espèce.

\section{Les larves et juvéniles de poissons de Nouvelle-Calédonie}

Les larves et les juvéniles de poissons récifaux montrent toute une palette de couleurs et ont des formes parfois extravagantes. Comme nous l'avons vu, il est difficile de les identifier à l'espèce à partir de leur seule morphologie externe. Ceci est particulièrement vrai pour les bossus et becs-de-cane ou Lethrinidae (individus 28 à 32) et les picots ou Siganidae (individus 63 et 64) chez qui la forme du corps et les patrons de tâches et de couleurs sont très semblables d'une espèce à l'autre.

\section{Des variations temporelles claires et des variations interannuelles mal comprises}

Comprendre quelles larves sont présentes en pleine eau à quel moment est important pour anticiper les variations de l'abondance des juvéniles de poissons dans les milieux récifaux, en fonction, par exemple, du contexte climatique global ou des pressions locales exercées par les populations humaines. Pour ce faire, il est important de connaître les périodes de l'année pendant lesquelles les larves de différentes espèces viennent coloniser les milieux lagonaires. En Nouvelle-Calédonie, des études à l'aide de pièges lumineux posés dans des baies proches de Nouméa suggèrent que la diversité des larves est la plus élevée durant l'été austral, de septembre à décembre (fig. $2, A$ ). Certaines familles de larves ont toutefois des préférences différentes (fig. 2, B). Ces études n'ont pu être réalisées que sur une période de 18 mois entre 2002 et 2003. Elles ne peuvent être généralisées sachant que les patrons saisonniers peuvent varier d'une année à l'autre, selon les conditions climatiques par exemple. Étendre l'effort d'échantillonnage sur plusieurs années est malheureusement difficile car fort coûteux. 


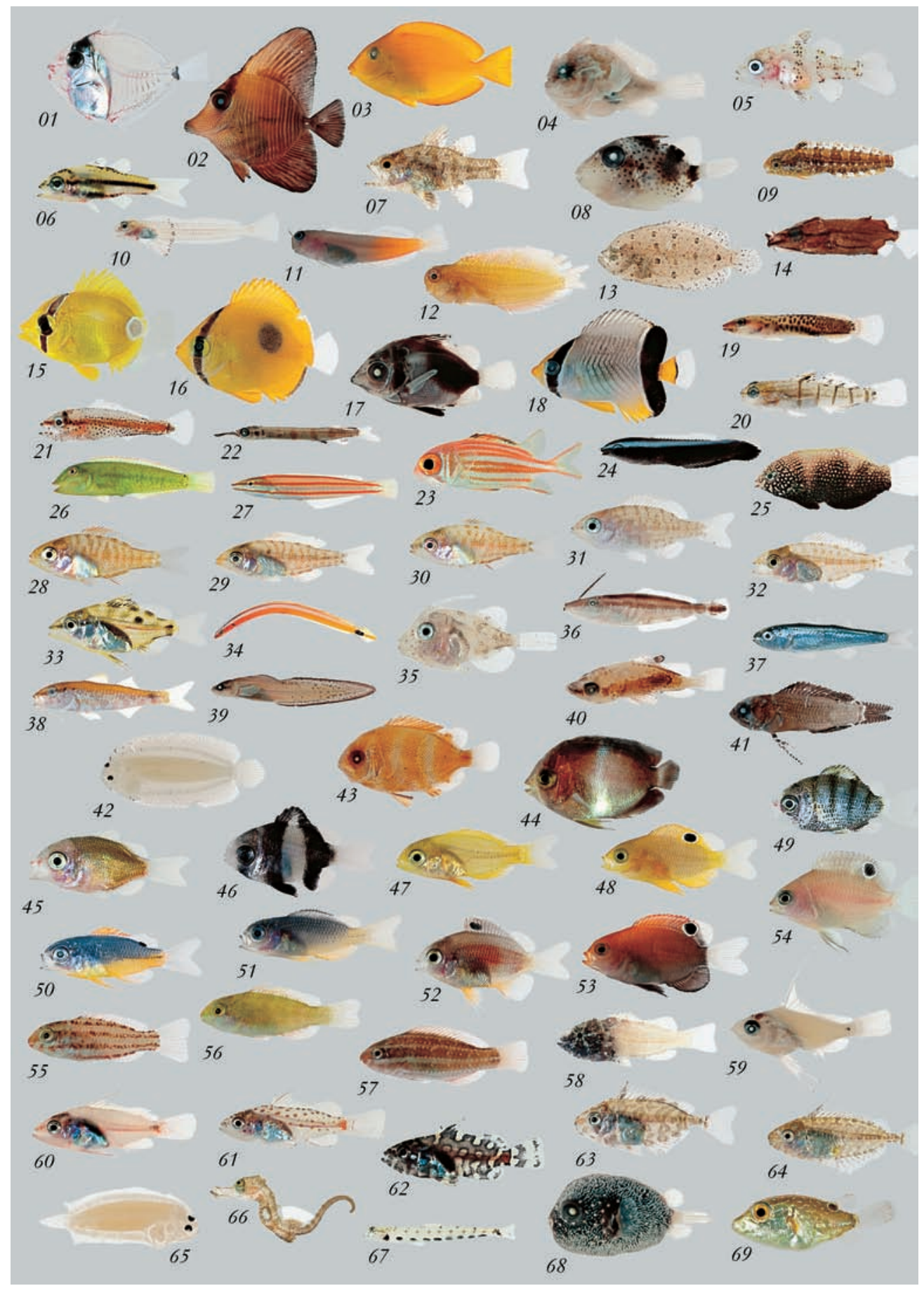

Quelques exemples de la diversité de formes et couleurs que l'on peut observer chez les larves et juvéniles de poissons récifaux de Nouvelle-Calédonie.

01 à 03 : Acanthuridae.

04 : Antennariidae.

05 à 07 : Apogonidae.

08 : Balistidae.

09 à 12 : Blenniidae

13 : Bothidae.

14 : Centriscidae.

15 à 18 : Chaetodontidae.

19: Gobiesocidae.

20 : Gobiidae.

21: Haemulidae.

22 : Hemiramphidae.

23 : Holocentridae.

24 à 27 : Labridae.

28 à 32 : Lethrinidae.

33 : Lutjanidae.

34 : Microdesmidae.

35 et 36 : Monacanthidae.

37 et 38 : Mullidae.

39 : Ophidiidae.

40 : Platycephalidae.

41 : Plesiopidae.

42 : Poecilopsettidae.

43 et 44 : Pomacanthidae.

45 à 54 : Pomacentridae.

55 à 57 : Scaridae.

58 : Scorpeanidae.

59 à 62 : Serranidae.

63 et 64 : Siganidae.

65 : Soleidae.

66 : Syngnathidae.

67: Synodontidae.

68 et 69 : Tetraodontidae.

(c) IRD/D. Ponton 


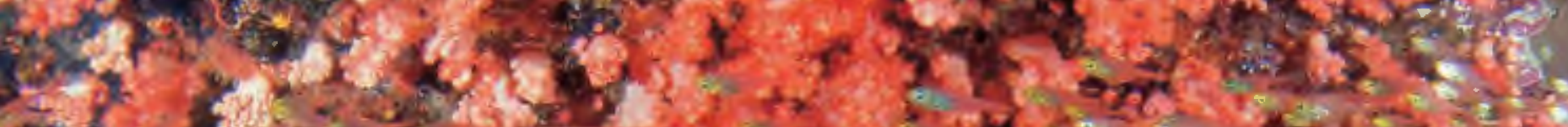

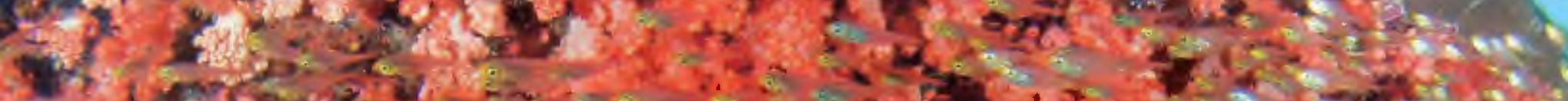

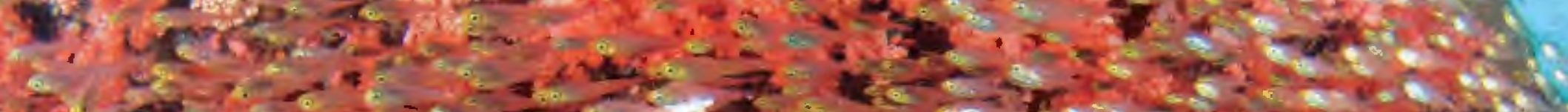

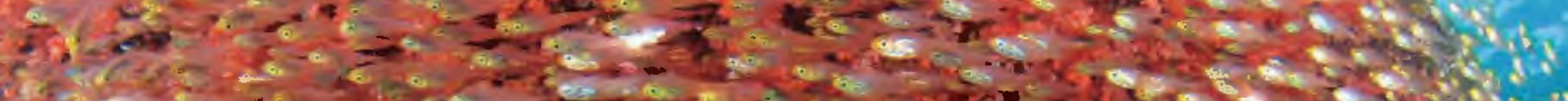

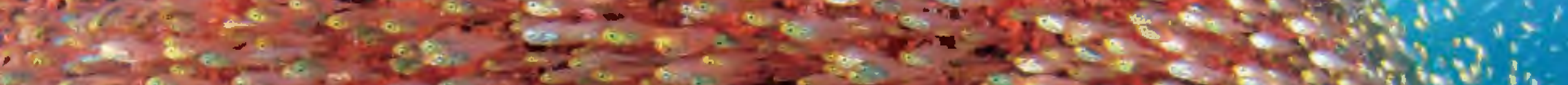

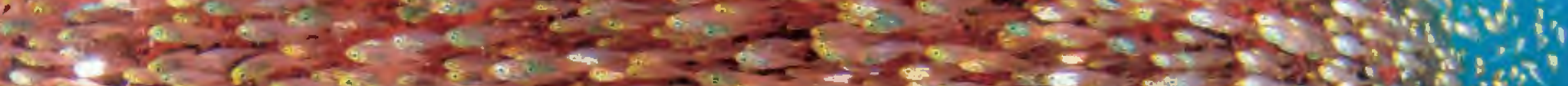

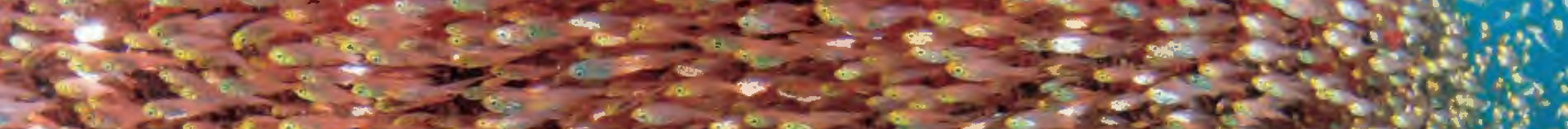

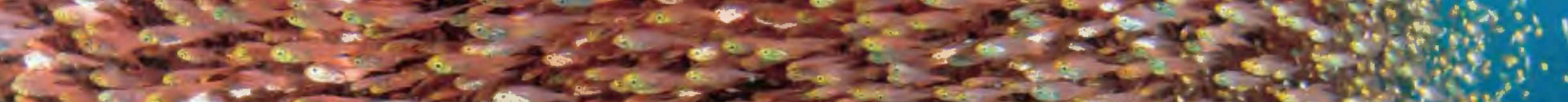

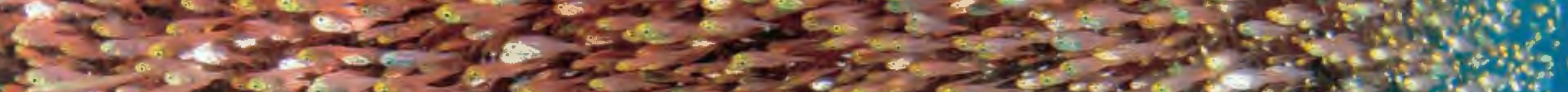

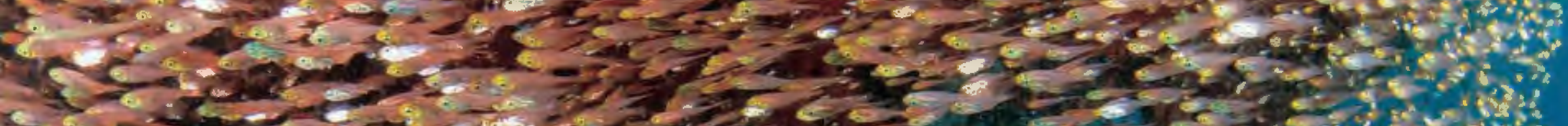

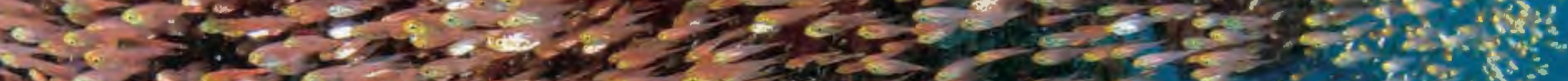

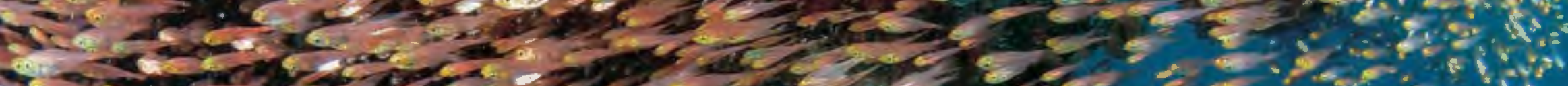

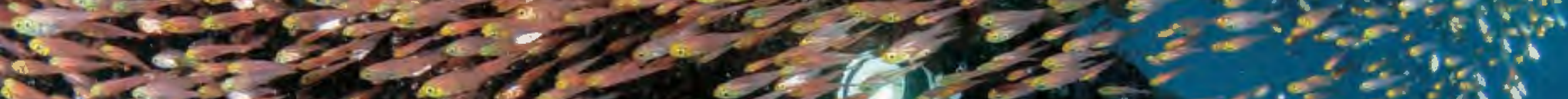

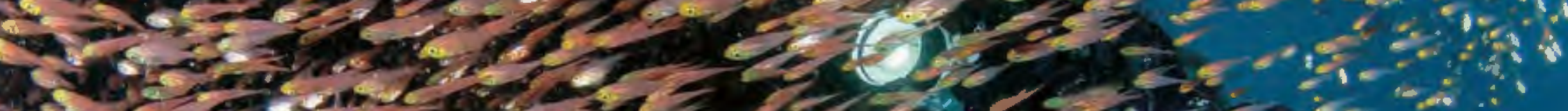

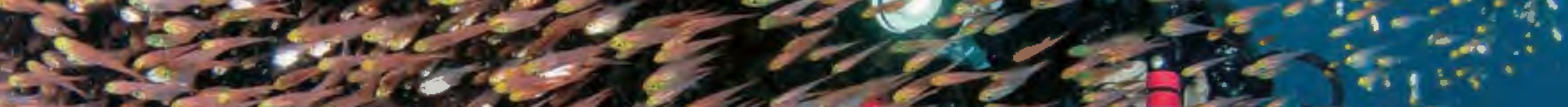

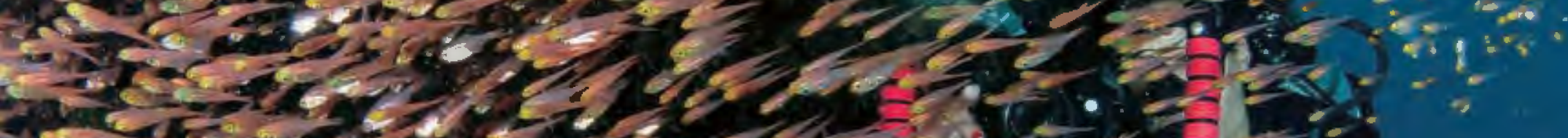

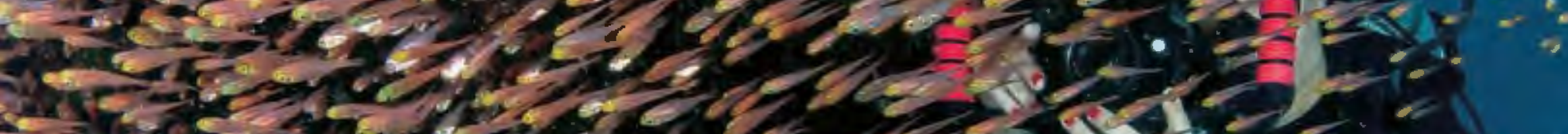

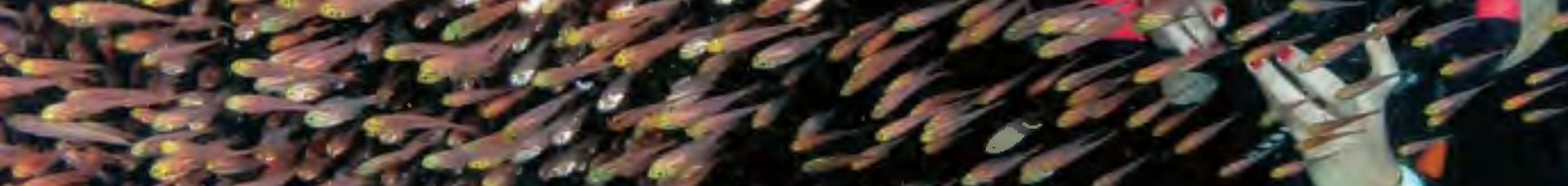

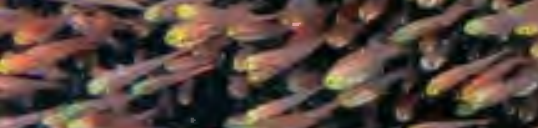

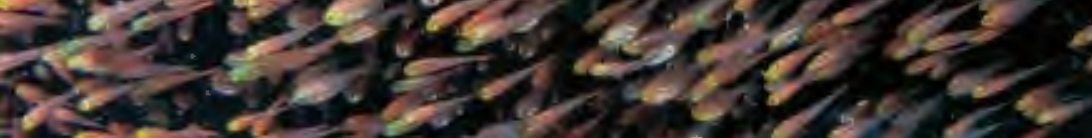

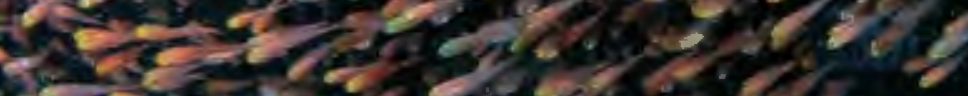

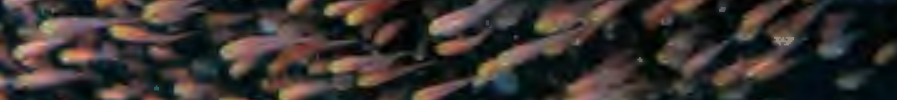
S.

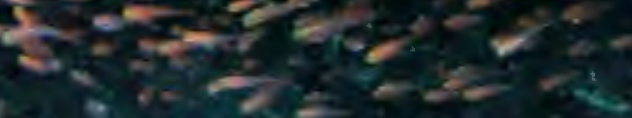

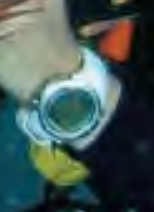

238
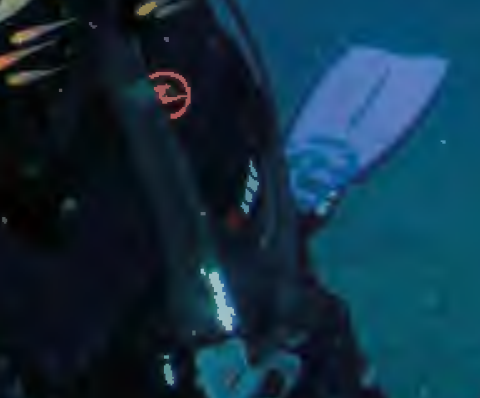

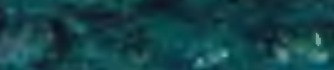




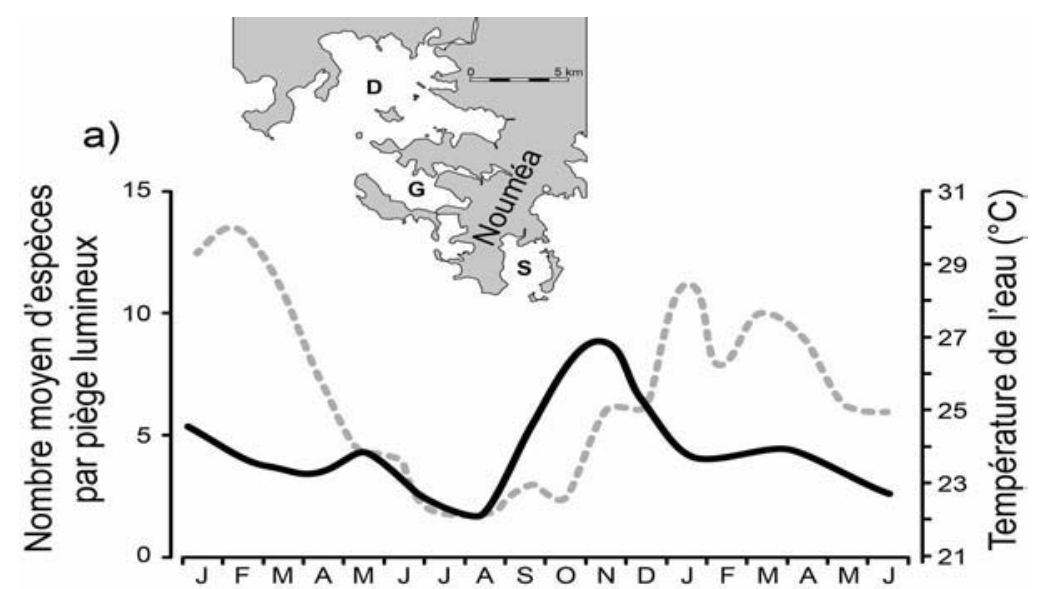

b)

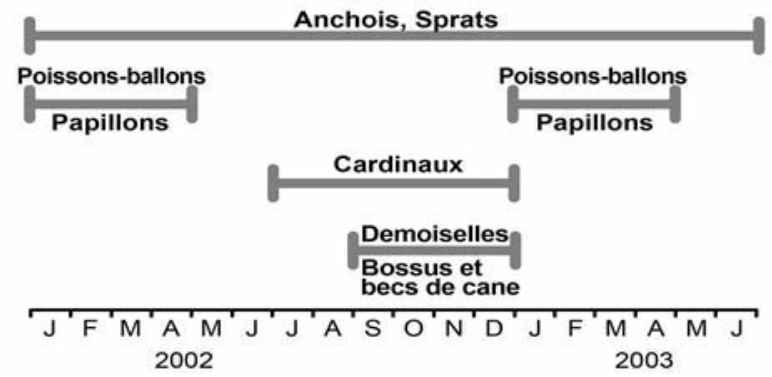

Figure 2 : Variations temporelles des captures de larves dans les pièges lumineux. A : nombre moyen d'espèces par piège dans la baie de Dumbéa (D), la Grande Rade (G) et la baie Sainte-Marie (S) (trait noir) et température de surface de l'eau (pointillés gris). $B$ : périodes auxquelles sont observées les principales familles. Source : CARASSOU, 2008

\section{Les larves et juvéniles : un moyen d'étudier la biodiversité ?}

Un résultat surprenant obtenu à l'occasion de nos analyses génétiques sur les larves de poissons récifaux de Nouvelle-Calédonie a été la présence, dans nos échantillons, d'espèces jusqu'alors inconnues. Parmi celles-ci : un bossu relativement rare, le bossu oblong Gymnocranius oblongus et une espèce cryptique du bec-de-cane malabar, qui reste à décrire. Cet exemple illustre, d'une part, la puissance des techniques moléculaires pour l'identification et la description des espèces; i et d'autre part, l'intérêt de travailler sur les larves pour échantillonner des espèces récifales passées jusque-là inaperçues.

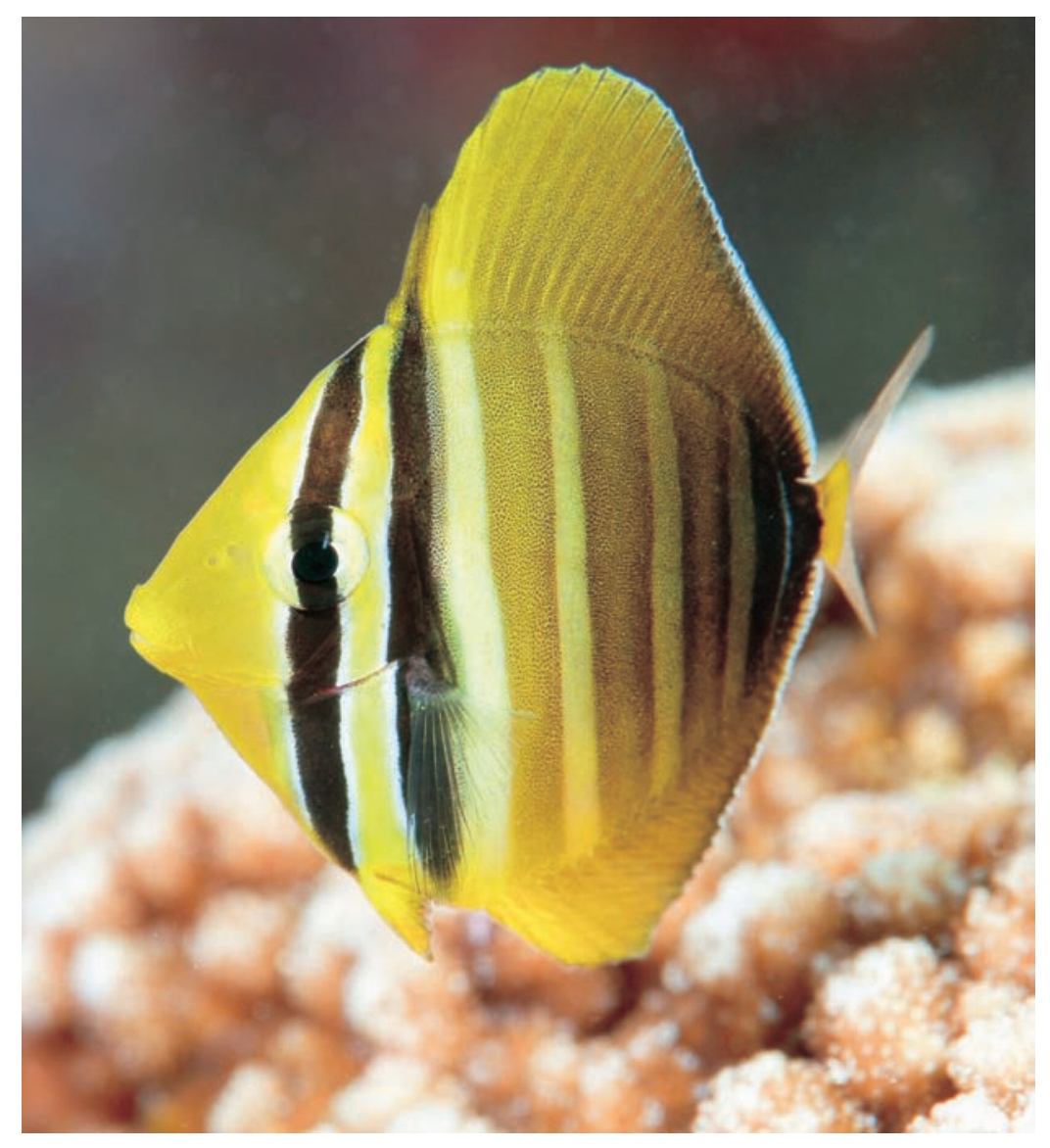

Juvénile de chirurgien à voile (Zebrasoma veliferum). @ G. Boussarie

\section{Références bibliographiques}

CARASSOU L., 2008 Les assemblages de larves de poissons dansle lagon de NouvelleCalédonie : structure spatio-temporelle et relations avec les facteurs abiotiques et biotiques de l'environnement. Thèse de doctorat, EPHE, $292 \mathrm{p}$.

HJORT J., 1914 Fluctuations in the great fisheries of Northern Europe viewed in the light of biological research. Rapports et procès-verbaux du conseil permanent pour l'exploration de la mer, 20 : 1-228.

MELLIN C. 2007 Sélection de l'habitat à l'installation et utilisation de l'habitat post-installation chez les poissons récifaux-lagonaires de NouvelleCalédonie. Thèse de doctorat de l'Université Pierre et Marie Curie et de l'École pratique des hautes études, Paris, 220 p. 


\section{Chapitre 16 \\ La biodiversité fonctionnelle dans le lagon}

Laurent Vigliola, Nicolas Guillemot, Laurent Wantiez et Michel Kulbicki

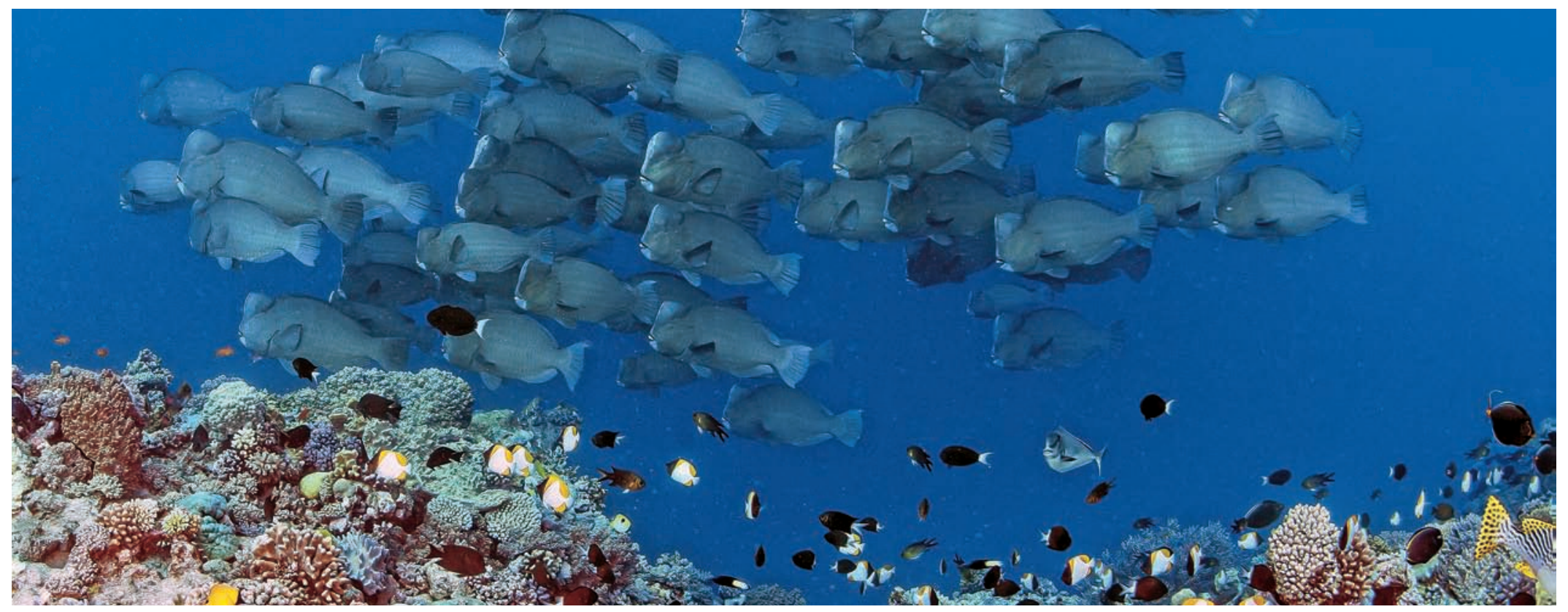

Le perroquet à bosse (Bolbometopon muricatum) est l'archétype des espèces réunissant plusieurs fonctions écologiques essentielles au bon fonctionnement des récifs.

(๑) National Geographic Society/E. Sala

\section{À chaque espèce sa fonction}

À Nouméa comme à Koné, à Moindou ou à Pouébo, en ville comme en tribu, partout en Nouvelle-Calédonie comme dans le reste du monde, les sociétés humaines fonctionnent suivant le même principe : le paysan plante, le boulanger fait du pain, le maçon construit, le professeur enseigne, l'artiste crée... Chaque personne a une fonction, un rôle plus ou moins important qui participe au bon fonctionnement de nos sociétés. Dans le lagon, comme partout ailleurs dans la nature, le même principe s'applique, les herbivores broutent, les carnivores chassent, les détritivores recyclent... Chaque espèce a une ou plusieurs fonctions dont l'importance est variable, avec cependant une règle d'or : le rôle joué par les espèces est la clef du fonctionnement et de l'existence même des écosystèmes. Pour que le récif et le lagon demeurent, il est essentiel que l'ensemble des fonctions soit assuré, que ce soit par une ou plusieurs espèces.

La diversité fonctionnelle se définit comme le décompte des rôles ou fonctions assurées par les espèces dans un écosystème. Ce décompte s'avère complexe pour de multiples raisons. En premier lieu chaque espèce peut remplir une multitude de rôles et, pour chacun d'eux, son importance peut être différente. Prenons le cas d'une espèce herbivore grégaire et de petite taille. Elle est utile à l'écosystème en tant que proie car elle nourrit ses prédateurs. Servir 
de proie est donc une des fonctions de cette espèce. Cette même espèce se nourrit également, et ainsi assure plusieurs autres fonctions. Par exemple, cet herbivore contrôle la croissance des algues et contribue ainsi à réguler la compétition entre les algues et les coraux constructeurs de récifs. Un exemple très étudié d'espèce cumulant plusieurs fonctions essentielles est le perroquet à bosse. En effet, cette espèce grignote le corail et les algues qui recouvrent les récifs, ce qui permet à de nouvelles espèces de venir coloniser la zone mise à nu, conduisant à un renouvellement de la faune et de la flore. Les petits morceaux de corail que le poisson n'aura pu digérer seront excrétés sous forme d'un nuage de sable fin qui s'ajoutera aux zones de sédiments abritant des espèces spécifiques. Les sédiments ainsi produits par un seul banc de ces poissons se chiffrent en tonnes chaque année. Par cet exemple sur l'alimentation, on peut concevoir le lien entre les caractéristiques - ou traits de vie -, ici alimentaires, des espèces et leurs fonctions dans l'écosystème.

\section{Des entités fonctionnelles complémentaires}

Les espèces ont un ensemble de traits de vie, pas seulement alimentaires, dont la combinaison est unique à chaque espèce. À l'heure actuelle notre niveau de connaissance est insuffisant pour définir les rôles précis de chaque espèce. En classant les traits de chaque espèce en catégories, il nous est cependant possible de ranger les espèces dans des groupes qui rassemblent les espèces ayant des caractéristiques similaires et donc a priori des fonctions écologiques très proches. Comme montré dans l'exemple précédent, le régime alimentaire est un trait de vie fonctionnel important. Pour les poissons, on distingue généralement les piscivores, les carnivores, les herbivores-détritivores, les omnivores et les planctonophages, chacune de ces catégories pouvant être déclinée de manière plus fine. Les autres traits de vie actuellement utilisés pour associer les poissons en groupes fonctionnels sont la taille de l'espèce, sa mobilité, sa position dans la colonne d'eau, sa période d'activité et son grégarisme. Bien d'autres traits, tels que ceux liés à la reproduction ou au comportement pourraient être ajoutés. Dans l'ensemble de ces traits, la taille a un rôle primordial. En effet, elle intervient de façon prépondérante sur la plupart des autres traits, dans les relations proies-prédateurs, et détermine l'énergie nécessaire au métabolisme des individus et donc la quantité de nourriture nécessaire à leur survie. La mobilité est également un trait de vie lié à des aspects énergétiques, les espèces mobiles puisant leurs ressources sur un territoire plus vaste que les espèces sédentaires. De plus, en se déplaçant, elles permettent un transfert d'énergie entre les différents habitats d'un écosystème. La période d'activité a des implications fonctionnelles puisque les espèces nocturnes et diurnes ne sont pas accessibles aux mêmes prédateurs et ne se nourrissent pas des mêmes proies. Le niveau dans la colonne d'eau est également un trait fonctionnel important qui participe aux flux énergétiques entre le fond du lagon et la surface et entre le large et le récif. Enfin, le grégarisme est lié à l'empreinte fonctionnelle des espèces, les individus vivant en larges bancs ayant un impact massif sur les transferts des nutriments au sein de l'écosystème.

Chacun de ces traits de vie peut être soit quantifié (par exemple une espèce pouvant atteindre une taille maximale de $48 \mathrm{~cm}$ à l'âge adulte) soit codifié en catégories (par exemple une espèce de taille moyenne). La combinaison de ces traits permet de définir des schémas de classification fonctionnelle plus ou moins complexes. Par exemple, un schéma simple est obtenu en combinant la taille et l'alimentation, avec des fonctions (ou entités fonctionnelles) du type « piscivore de grande taille », « herbivore de taille moyenne » ou encore «carnivore de petite taille », et un schéma complexe en combinant l'ensemble des traits de vie disponibles (par exemple « piscivore nocturne solitaire très mobile de grande taille chassant en pleine eau »). Ces classifications nous permettent d'estimer une diversité fonctionnelle, en comptant simplement le nombre de combinaisons existantes. Ces combinaisons, appelées entités fonctionnelles, restent une approximation de la vraie diversité fonctionnelle qui reste au-delà de nos moyens de mesure.

De nombreuses études basées sur cette approche montrent que, sur un récif, le nombre de fonctions reste inférieur au nombre d'espèces. En particulier, le nombre de fonctions n'augmente que très lentement au-delà d'un certain nombre d'espèces comme indiqué par une étude du lagon de Koné en Nouvelle-Calédonie (fig. 1). De nouvelles fonctions continuent d'apparaître lorsque la diversité spécifique est très élevée. Ces fonctions sont donc 


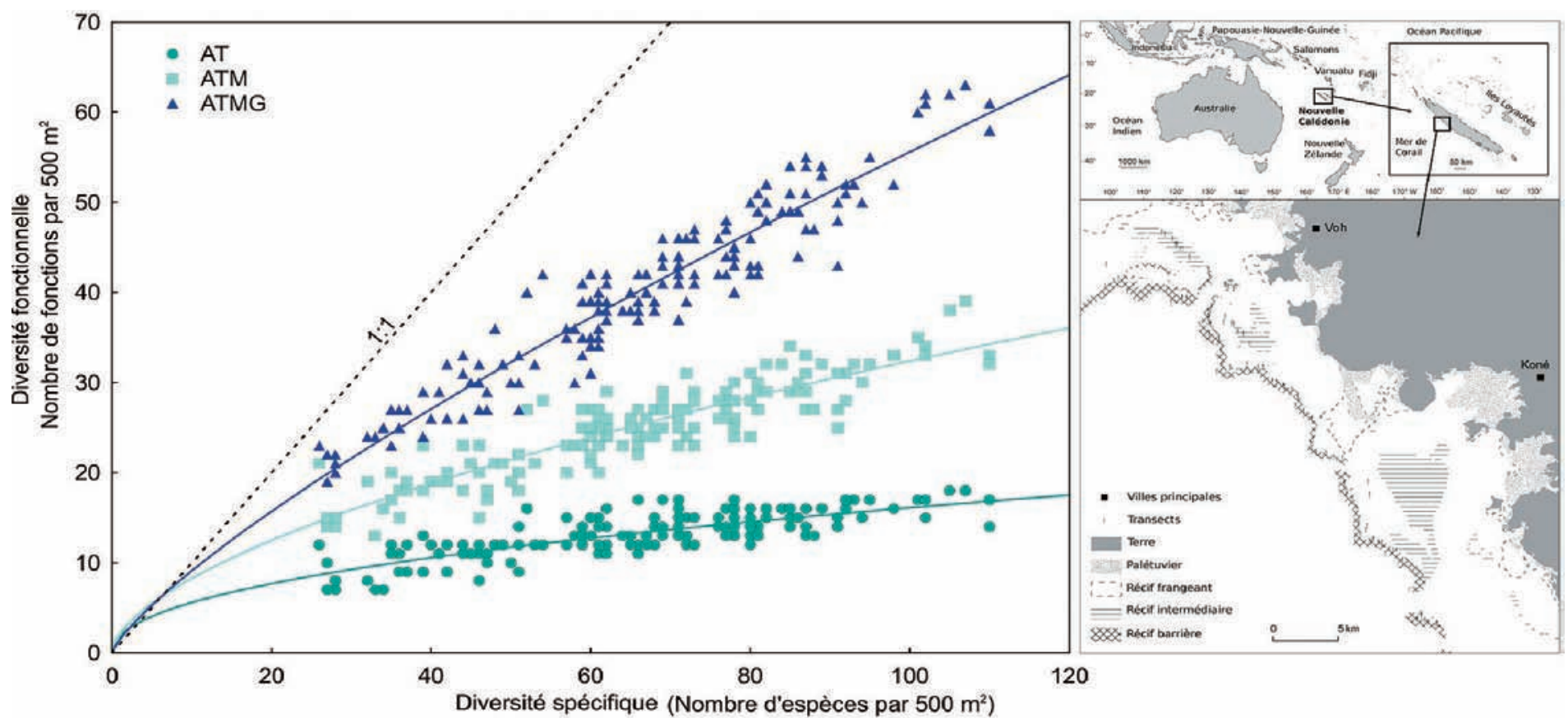

Figure 1 : Relation entre la diversité spécifique et la diversité fonctionnelle pour les poissons des récifs coralliens de Koné pour différents schémas de classification fonctionnelle. A : alimentation. T : taille. M : mobilité. G : grégarisme. Source : GUILLEMOT et al., 2011, modifié

représentées par peu d'espèces et, en général, peu d'individus, ce qui les rend très vulnérables, d'autant qu'elles n'apparaissent qu'à des niveaux exceptionnels de diversité. Ce résultat est très important car il a été démontré que, plus le nombre de fonctions au sein d'un écosystème sera élevé, plus cet écosystème sera productif, stable, résistant et résilient. Ceci est lié au concept des niches écologiques, qui stipule que chaque espèce a une place (habitat) et un rôle précis dans un écosystème, mais qu'en même temps chaque nouvelle espèce ajoute une nouvelle ressource sur laquelle de nouvelles espèces pourront s'établir. De nouvelles fonctions sont donc générées par les fonctions préexistantes dans un processus d'enrichissement et d'optimisation de l'écosystème.

\section{La diversité, un facteur de résistance aux perturbations}

Comme vu précédemment, plus un écosystème aura d'espèces, plus il contiendra de fonctions, et plus il sera susceptible de posséder la ou les fonctions lui permettant de résister à une perturbation. En d'autres termes, la diversité fonctionnelle procure aux écosystèmes une assurance. De même, lorsque plusieurs espèces occupent la même fonction, cela assure l'écosystème contre les conséquences de la disparition locale d'une espèce (suite à une maladie par exemple). Sur un récif donné, de nombreuses espèces apparaissent puis disparaissent au gré de variations dans le recrutement, de changements dans l'habitat ou les ressources. Tant que l'ensemble des fonctions est maintenu, quelle que soit l'identité précise des espèces composant l'assemblage, alors l'écosystème pourra se maintenir. La redondance fonctionnelle augmente ainsi la résilience d'un écosystème, c'est-àdire sa capacité à perdurer dans le temps, puisqu'il faudra impacter plusieurs espèces ayant la même fonction et donc « fonctionnellement interchangeables » pour impacter la fonction. À l'inverse, les fonctions peu redondantes sont vulnérables, les plus vulnérables étant les fonctions assurées par une seule espèce. Lorsque cela est le cas et que la fonction est essentielle au fonctionnement de l'écosystème, on parle d'espèce « clef de voute » dont la présence ou l'absence peut influencer l'ensemble de l'écosystème. 
Il y a donc deux forces opposées en action. D'un côté, avoir beaucoup de fonctions augmente l'assurance d'un système face aux perturbations. De l'autre côté, la redondance fonctionnelle rend chaque fonction moins vulnérable. L'augmentation du nombre d'espèces va permettre le renforcement de la redondance des fonctions existantes et l'apparition de fonctions nouvelles. L'étude réalisée à Koné montre ces deux forces en action. Dans les récifs de Nouvelle-Calédonie, le nombre de fonctions observées dans les assemblages de poissons est plus faible qu'attendu par chance, compte tenu du nombre d'espèces présentes par station sous un seuil d'environ 90 espèces pour $500 \mathrm{~m}^{2}$ (fig. 2).

En deçà de ce seuil, la diversité spécifique a plutôt tendance à renforcer la redondance fonctionnelle, et donc l'assurance de l'écosystème à résister au risque d'une perte locale d'espèces. Au-delà du seuil de 90 espèces, le nombre de fonctions observées dans les assemblages ne diffère pas de ce que l'on peut attendre par chance, compte tenu de la diversité spécifique. Par conséquent, audelà de ce seuil de 90 , la tendance est plutôt à l'augmentation de la diversité fonctionnelle avec l'arrivée de nouvelles fonctions, rares et vulnérables mais qui permettent un meilleur partitionnement des ressources et donc une plus grande efficience énergétique du système.

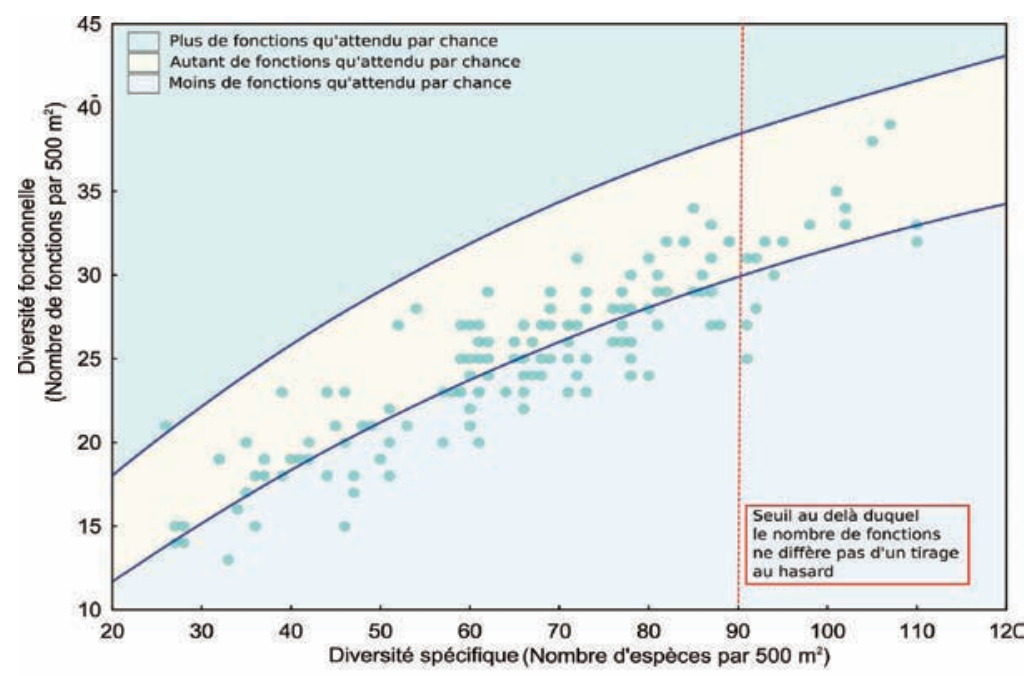

Figure 2 : Relation entre la diversité spécifique et la diversité fonctionnelle des poissons des récifs coralliens de la Nouvelle-Calédonie. Source : GUILLEMOT et al., 2011, modifié

\section{Les derniers récifs sauvages du monde}

L'archipel de Nouvelle-Calédonie possède une ZEE (Zone économique exclusive) de $1740000 \mathrm{~km}^{2}$. Dans cet espace maritime immense, certains récifs sont sous forte influence humaine, notamment ceux à proximité de la capitale, Nouméa, qui concentre les deux tiers de la population néo-calédonienne. $\mathrm{D}$ 'autres récifs sont extrêmement isolés au cœur de la mer de Corail, parfois à plus de $40 \mathrm{~h}$ de navigation de toute population humaine, comme les récifs de Chesterfield. Une étude récente a comparé la diversité fonctionnelle des poissons coralliens le long de ce gradient d'impact humain. Elle montre que la diversité fonctionnelle des poissons est maximale dans les récifs coralliens à plus de $20 \mathrm{~h}$ de trajet de Nouméa. Elle souligne également que cette diversité fonctionnelle a chuté de $60 \%$ dans les zones habitées de l'archipel (fig. 3).

Le lagon manque donc considérablement de main-d'œuvre pour fonctionner correctement, de nombreuses fonctions ayant été fortement impactées, par la pêche notamment. Les conséquences pour le lagon de cette érosion fonctionnelle sont graves car un écosystème qui fonctionne mal se dégrade. Dans le même temps, des solutions existent. Les provinces de Nouvelle-Calédonie ont créé de

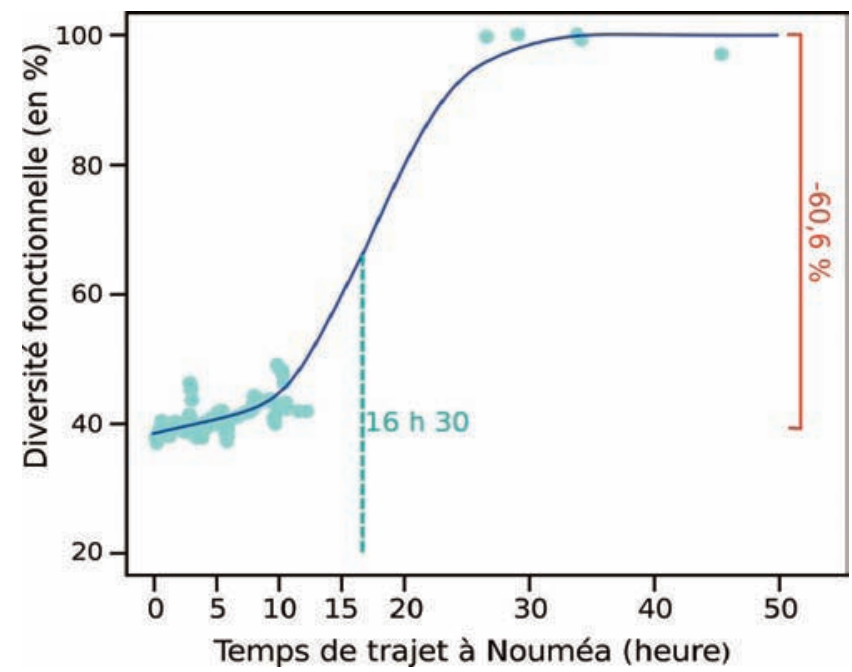

Figure 3 : Relation entre la diversité fonctionnelle (en \%) des poissons des récifs coralliens de la Nouvelle-Calédonie et le temps de trajet à Nouméa. Source : D'AGATA et al., 2016, modifié 


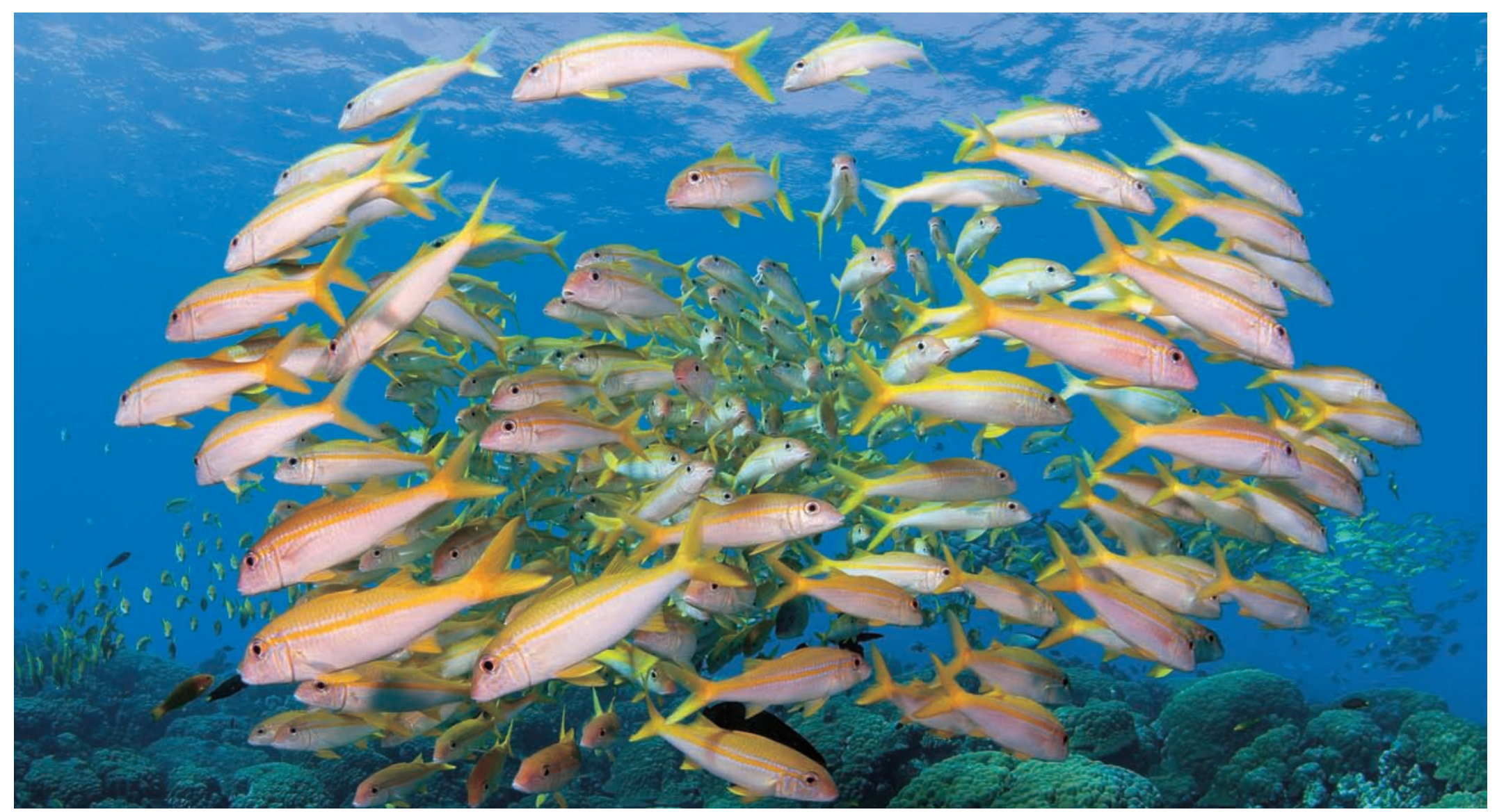

Banc de surmullets Mulloidichthys vanicolensis. Cette espèce occasionnellement grégaire vit dans les fonds sableux des récifs et lagons. Les adultes sont souvent solitaires et vivent sur les pentes sableuses où ils se nourrissent de petits invertébrés. $\odot$ M. Juncker

nombreuses réserves marines, un outil capable de restaurer en partie la diversité fonctionnelle. Plus récemment, le gouvernement de la Nouvelle-Calédonie a créé le parc naturel de la mer de Corail, qui inclut la plupart des récifs isolés de l'archipel. Protéger ces récifs est une responsabilité immense pour les Néo-Calédoniens. En effet, nos dernières estimations (MAIRE et al. 2016) indiquent qu'il ne reste sur la planète plus que $1,5 \%$ des récifs coralliens à plus de $20 \mathrm{~h}$ de trajet des populations humaines. La Nouvelle-Calédonie possède un tiers de ces derniers récifs fonctionnellement intacts. Protéger formellement ces derniers récifs sauvages de la planète, vierges de la plupart des impacts humains, serait un geste symbolique fort de la part des NéoCalédoniens en cette année 2018 des récifs coralliens.

\section{Références bibliographiques}

D'AGATA S. et al., 2016 Marine reserves lag behind wilderness in the conservation of key functional roles. Nature Communications. doi : 10.1038/ncomms 12000.

GUILLEMOT N. et al., 2011 Functional redundancy patterns reveal nonrandom assembly rules in a species-rich marine assemblage. Plos One 6 (10): e26735. doi : 10.1371/journal.pone.0026735.

MAIRE E. et al., 2016 How accessible are coral reefs to people? A global assessment based on travel time. Ecology Letters. doi : 10.1111/ele.12577. 



\section{Les serpents marins des récifs coralliens de Nouvelle-Calédonie}

François Brischoux, Xavier Bonnet, Richard Shine et Claire Goiran

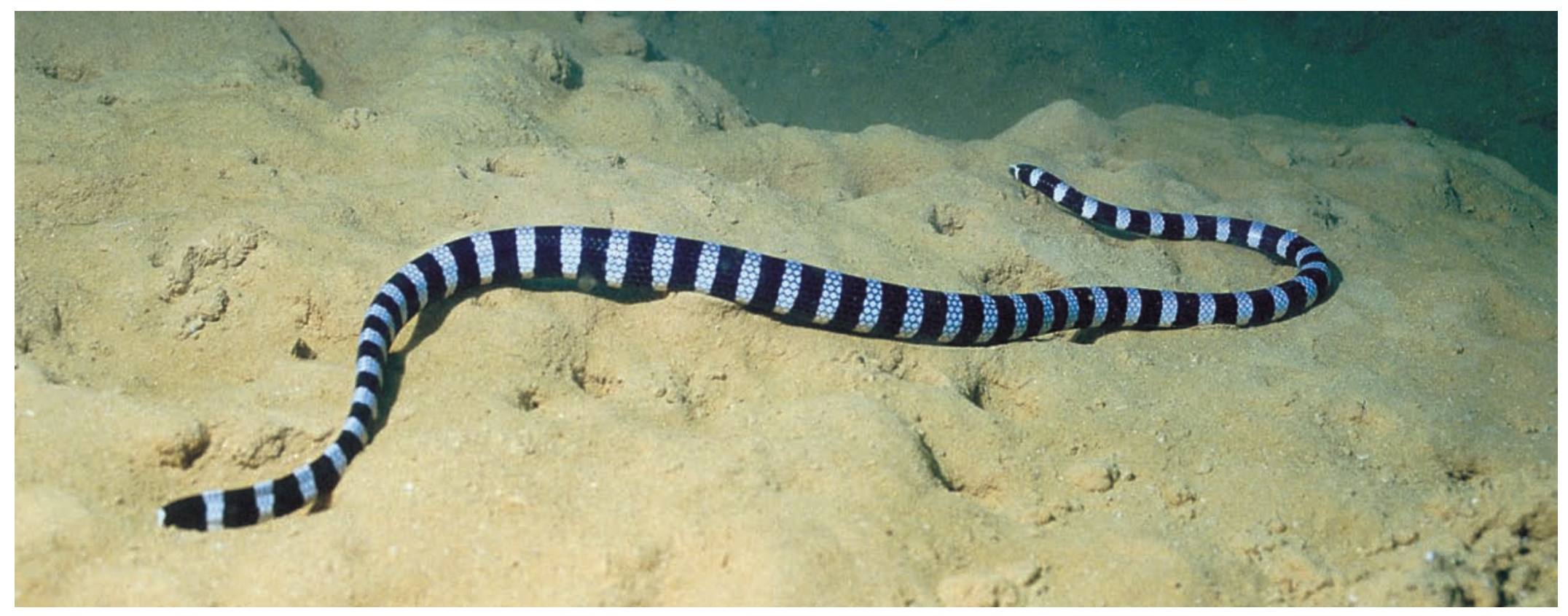

Laticauda laticaudata (tricot rayé bleu) évoluant sur un fond sableux avec de nombreux terriers, sans doute à la recherche d'une proie. (c) IRD/P. Laboute

\section{Généralités sur les serpents marins}

Au cours du Miocène, le clade des serpents a connu quatre événements indépendants de transition vers la vie marine, qui ont donné naissance à quatre groupes phylogénétiques utilisant de manière plus ou moins extensive le milieu marin. Seuls deux de ces groupes sont présents en Nouvelle-Calédonie, les Laticaudinae (tricots rayés) et les Hydrophiinae (« vrais » serpents marins). Ils font partie des Elapidae. Ces deux groupes phylogénétiques contiennent les serpents les mieux adaptés au milieu marin. Ils sont largement distribués dans les récifs coralliens des océans Indien et Pacifique, dont les récifs de Nouvelle-Calédonie. Les Laticaudinae sont amphibies et ovipares : ils s'alimentent en mer mais doivent revenir à terre pour toutes les autres activités (digestion, reproduction, dont la ponte des œufs, etc.). Sur les huit espèces de tricots rayés reconnues actuellement, deux sont présentes en NouvelleCalédonie, dont une est endémique. Il s'agit du tricot rayé jaune (Laticauda saintgironsi) et du tricot rayé bleu (Laticauda laticaudata, largement distribué). Les Hydrophiinae sont souvent qualifiés de serpents marins « vrais ». En effet, ce sont les espèces de ce groupe qui se sont émancipées de la plupart des liens avec l'environnement terrestre ancestral. Ils sont vivipares et passent l'entièreté de leur vie en mer sans jamais revenir à terre. Ce groupe phylogénétique est très riche : sur environ 70 espèces qui le composent, 12 sont présentes en Nouvelle-Calédonie. 


\section{Les Laticaudinae (tricots rayés)}

Les deux espèces de tricots rayés de Nouvelle-Calédonie sont largement réparties à travers le lagon : la plupart des îles et îlots du lagon néo-calédonien abritent des populations de l'une ou de l'autre espèce, le plus souvent des deux à la fois. À terre, comme la plupart des espèces de serpents, les tricots rayés vivent cachés dans des abris qui les protègent des températures excessives, de la déshydratation et des prédateurs. Si la plupart des îles et îlots du lagon offrent une diversité d'habitats suffisamment riche pour convenir aux deux espèces, certaines caractéristiques de l'environnement terrestre sont cruciales pour leur présence. En effet, le tricot rayé jaune est plus terrestre que le tricot rayé bleu. Il a de meilleures capacités locomotrices à terre et peut donc accéder plus facilement à des micro-habitats situés sur le littoral (chaos rocheux terriers d'oiseaux marins, entrelacs de racines, arbres tombés, etc.). Le tricot rayé bleu, moins terrestre, n'est présent que si ce type de micro-habitat est situé au plus près de la zone de balancement des marées. Contrairement au tricot rayé jaune, cette espèce utilise d'ailleurs très volontiers comme abri les rochers situés directement dans la zone de balancement des marées.

La physionomie des îlots et du littoral influence également la structure des populations de ces serpents. En effet, toutes les îles et

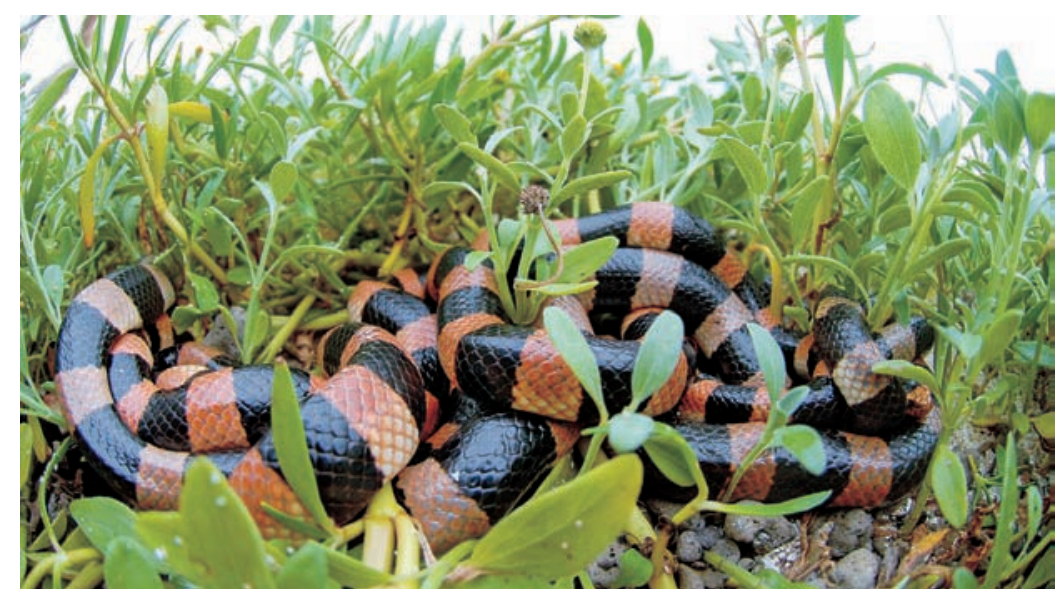

Accouplement de tricots rayés jaunes (Laticauda saintgironsi, endémique) sur l'îlot Améré (réserve intégrale Merlet). Une femelle est courtisée par plusieurs mâles. @ X. Bonnet îlots du lagon n'offrent pas les caractéristiques écologiques qui conviennent à toutes les étapes de leur vie. Par exemple, les œufs n'ont pas les mêmes besoins que des juvéniles en croissance ou que des adultes qui se reproduisent. Si certains sites sont favorables à tous ces stades de vie, la démographie des populations de tricots rayés néo-calédoniens peut également se structurer géographiquement. Certains sites jouent le rôle de nurserie en abritant principalement des sites de pontes et des nouveau-nés (par exemple, l'île Ouen), d'autres présentent des populations constituées essentiellement d'individus adultes (par exemple l'îlot Améré au sein de la réserve Merlet). Enfin, d'autres sites peuvent abriter tous ces stades de vie (par exemple, l'île Verte ou l'îlot Signal). Cette structuration des populations à large échelle spatiale à travers le lagon de Nouvelle-Calédonie a des conséquences importantes en termes de biologie de la conservation. En effet, des perturbations locales (par exemple sur un îlot clé assurant le rôle de nurserie, ou hébergeant une population de reproducteurs adultes) pourraient avoir des conséquences populationnelles à très large échelle et affecter d'autres populations relativement distantes.

Les tricots rayés utilisent le milieu marin pour se nourrir, principalement de poissons anguilliformes (congres, murènes et poissons-serpents). Collectivement, les deux espèces de tricots rayés de Nouvelle-Calédonie consomment un très grand nombre d'espèces (au moins 43 espèces différentes), dont la plupart sont des prédateurs benthiques, sédentaires et situées très haut dans la chaîne alimentaire. De fait, en s'alimentant sur ces prédateurs supérieurs, les tricots rayés jouent un rôle fondamental dans le fonctionnement des réseaux trophiques. La population d'un site comme l'îlot Signal (environ 4000 serpents) peut consommer plus de 45000 poissons anguilliformes par an, ce qui représente une biomasse de 1,5 t. En outre, ces serpents permettent d'échantillonner de manière efficace ce compartiment cryptique de l'ichthyofaune lagonaire. L'étude de leur régime alimentaire a permis de révéler la présence d'au moins 15 espèces de poissons anguilliformes qui n'avaient pas encore été observées en NouvelleCalédonie. Dans la plupart des cas, les densités estimées de ces poissons prédateurs ont été largement revues à la hausse, grâce à l'étude du régime alimentaire des tricots rayés. 
Il est important de noter que les deux espèces de tricots rayés de Nouvelle-Calédonie sont très complémentaires et permettent l'échantillonnage d'un grand nombre d'habitats. En effet, le tricot rayé jaune est plutôt spécialiste des espèces de poissons anguilliformes qui vivent dans les anfractuosités des récifs. Cette espèce consomme au moins 34 espèces différentes inféodées aux fonds durs. Le tricot rayé bleu consomme plutôt des espèces de fonds meubles (vasières, zones sableuses, herbiers) et, si son régime alimentaire est également essentiellement constitué de poissons anguilliformes, il intègre bien volontiers d'autres espèces de poissons comme les poissons-chats ou les poissons-fléchettes. Sur les fonds meubles, le tricot rayé bleu peut consommer jusqu'à 28 espèces différentes.

Leur caractère emblématique fait des tricots rayés des icônes de la Nouvelle-Calédonie. Mais plus que de simples animaux marins charismatiques, ils jouent un rôle clé dans le fonctionnement du lagon de Nouvelle-Calédonie. Ce sont également des modèles particulièrement pertinents pour examiner des questions de recherche fondamentale (par exemple le retour vers la vie marine), de fonctionnement des écosystèmes à large échelle (à travers le rôle dans les réseaux trophiques) ou en biologie de la conservation (par la structuration spatiale de leurs populations).

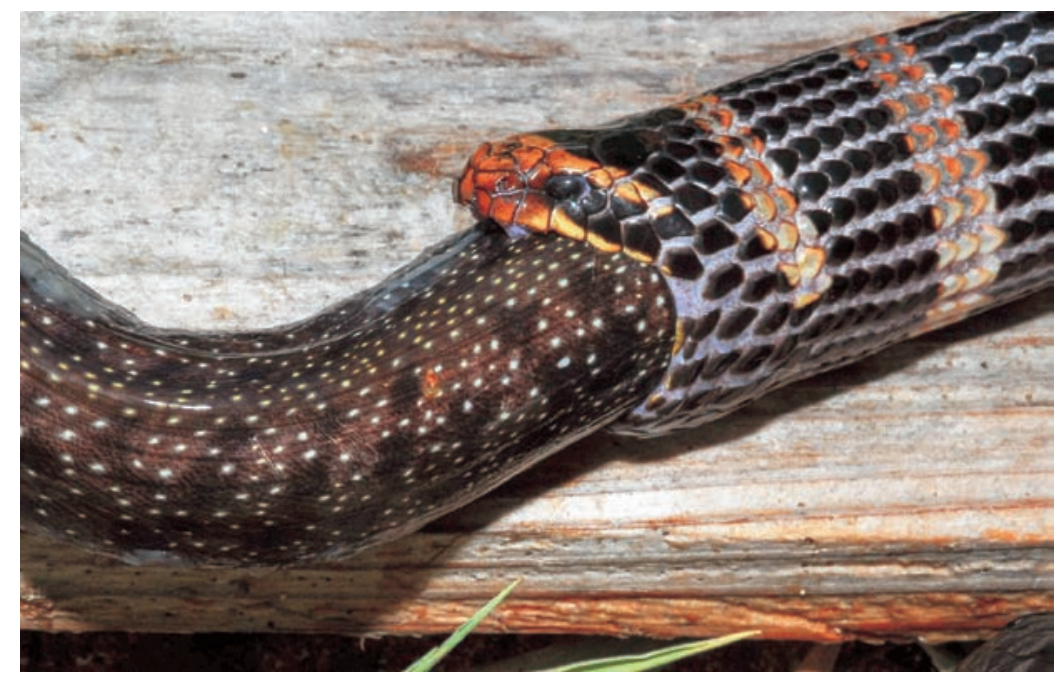

Régurgitation d'une murène (Gymnothorax eurostus) par un tricot rayé jaune (Laticauda saintgironsi). Cette technique a permis de révéler la richesse spécifique des poissons anguilliformes de Nouvelle-Calédonie. ( ) X. Bonnet

\section{Les Hydrophiinae (serpents marins « vrais »)}

Contrairement aux tricots rayés, les serpents marins faisant partie des Hydrophiinae sont vivipares et passent toute leur vie en mer. Ils sont très diversifiés à la fois d'un point de vue écologique et morphologique. Ils sont répartis en deux groupes. Les serpents du premier groupe consomment des œufs de poissons, principalement ou occasionnellement, alors que les serpents du second groupe capturent des poissons. En Nouvelle-Calédonie, ce premier groupe est représenté par trois espèces : l'aipysure de Dubois (Aipysurus duboisii), l'aipysure lisse ou serpent olive (A. laevis) et le serpent à tête de tortue, (Emydocephalus annulatus). Le second groupe est représenté en Nouvelle-Calédonie par neuf espèces, appartenant toutes au genre Hydrophis: $H$. coggeri, $H$. curtus, $H$. laboutei, $H$. macdowelli, $H$. major, $H$. ornatus, $H$. peronii, $H$. platurus et $H$. spiralis. D'une manière générale, les serpents du groupe AipysurusEmydocephalus fréquentent plutôt les habitats récifaux peu profonds. Le serpent à tête de tortue se nourrit exclusivement d'œufs de poissons (blennies, gobies et poissons demoiselles). Il n'est pas venimeux. Il est extrêmement sédentaire, au point que les populations vivant à l'anse Vata et à la baie des Citrons sont

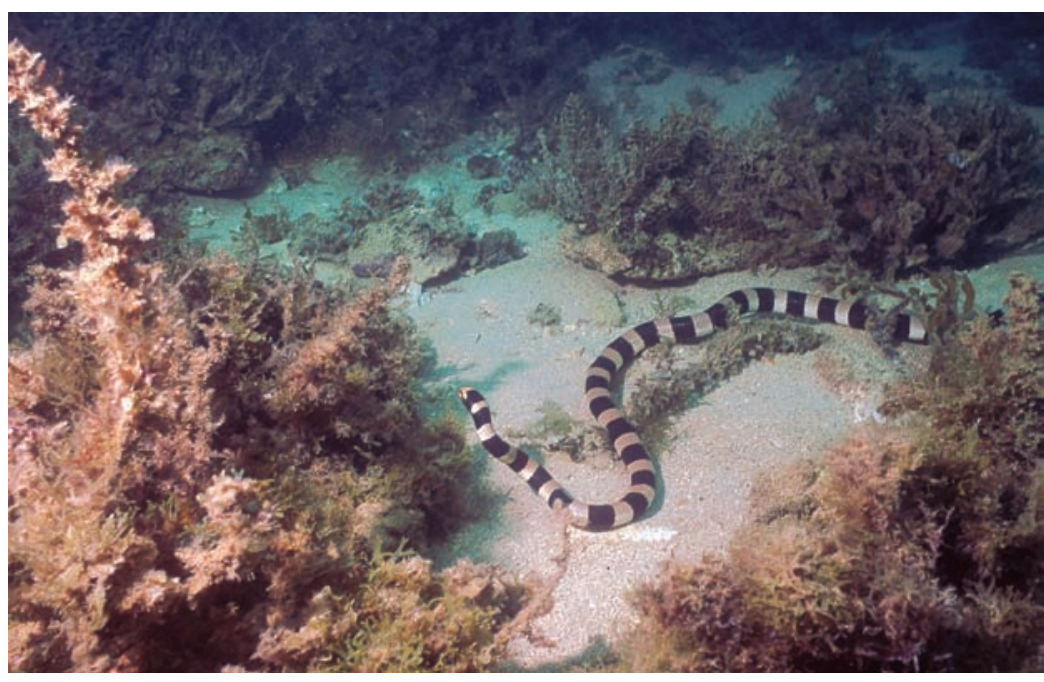

Tricot rayé jaune (Laticauda saintgironsi) évoluant dans une algueraie de l'îlot Amédée. (c) IRD/P. Laboute 


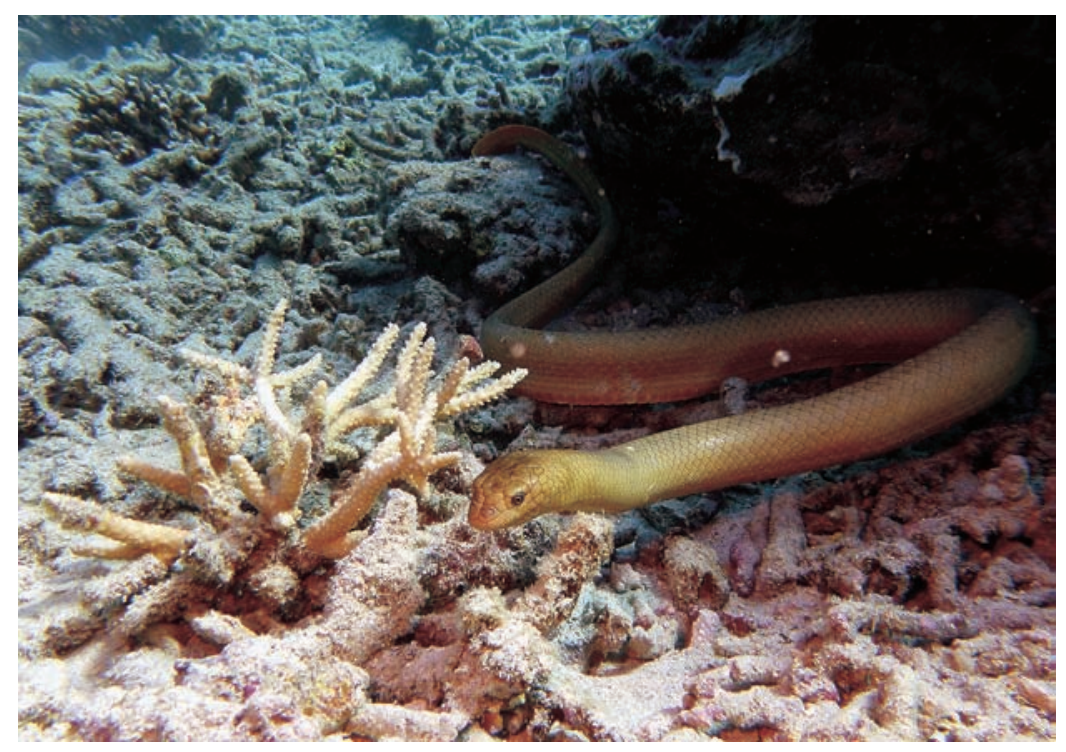

Aipysurus laevis. ๑ UNC/C. Goiran

différentes génétiquement. Les Aipysurus ont un régime alimentaire plus varié. Ils consomment des poissons de diverses espèces et éventuellement des œufs de poissons ou des crustacés. Le serpent olive (A. laevis) est le plus connu car il est très abondant en NouvelleCalédonie et il s'approche souvent des plongeurs.

Le genre Hydrophis s'est diversifié d'une manière exceptionnellement rapide depuis seulement quelques millions d'années. Il comporte environ 50 espèces qui exploitent des proies très différentes. Certaines sont très spécialisées et ne consomment qu'une espèce de proies, d'autres sont généralistes. Ces espèces peuvent vivre dans des écosystèmes plus profonds que les serpents du groupe Aipysurus-Emydocephalus, voire complètement au large en ce qui concerne $H$. platurus. Cela n'empêche pas certaines espèces comme $H$. major, $H$. peronii et $H$. coggeri de fréquenter aussi des baies peu profondes comme la baie des Citrons.

Certaines espèces, comme $H$. macdowelli et $H$. coggeri, possèdent une petite tête qu'ils peuvent enfoncer dans les terriers à la recherche de poissons anguilliformes, alors que d'autres, comme $H$. major, ont une grosse tête qui leur permet de capturer et

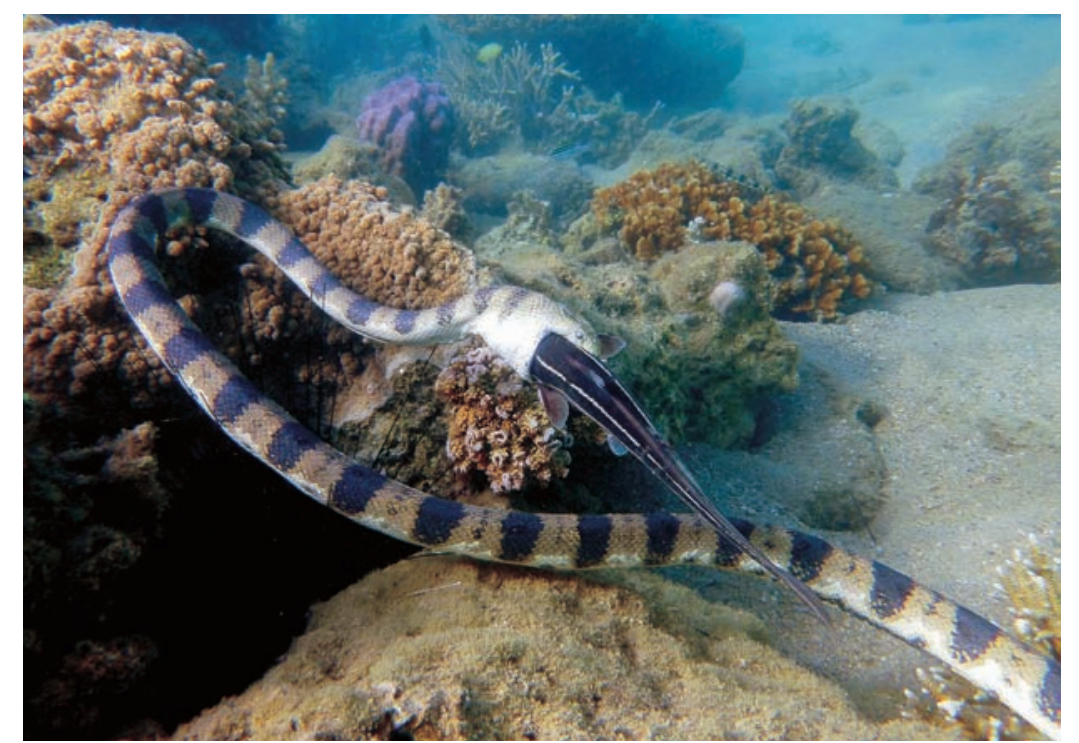

Hydrophis major avalant un poisson-chat (Plotosus lineatus). ๑ UNC/C. Goiran

d'ingérer des poissons d'un diamètre impressionnant par rapport à celui de leur corps. Le régime alimentaire $\mathrm{d}^{\prime} \mathrm{H}$. major est bien connu puisque cette espèce chasse de jour, dans les zones peu profondes, où il est facile à observer. En Nouvelle-Calédonie il se nourrit exclusivement de poissons-chats, Plotosus lineatus. L'effectif de la population d' $H$. major autour de la presqu'île de Nouméa est en cours d'étude. Il est probable qu'elle s'élève à quelques centaines $d$ 'individus. Cette population de prédateurs exerce une pression non négligeable sur la population de $P$. lineatus. Ce poisson-chat, qui possède un mucus toxique et des épines vénéneuses, est une espèce envahissante en Méditerranée où elle a un impact négatif sur la pêche.

Représentant l'extrême d'un mode de vie marin chez un serpent, $H$. platurus est une espèce de taille modeste (environ $70 \mathrm{~cm}$ ) complètement pélagique. Il se nourrit essentiellement de larves de poissons qui se concentrent à la surface océanique sous les débris flottants. Il occupe une aire de distribution remarquablement vaste, couvrant les océans Indien et Pacifique tropicaux. Bien qu'elle ne soit pas très commune en Nouvelle-Calédonie, cette espèce très particulière pénètre parfois dans le lagon néo-calédonien. 


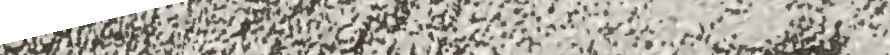

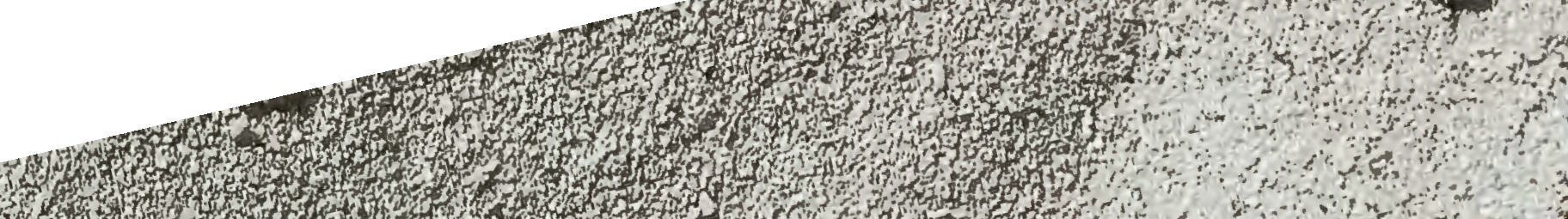

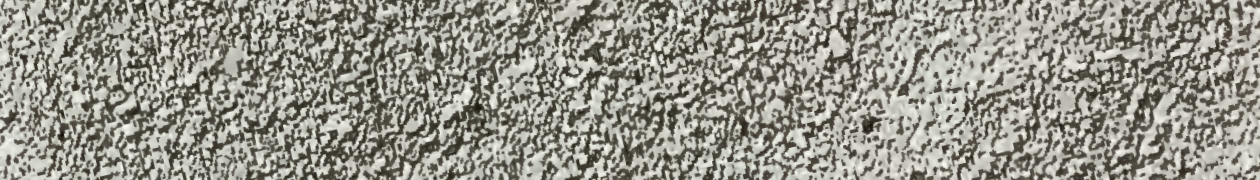

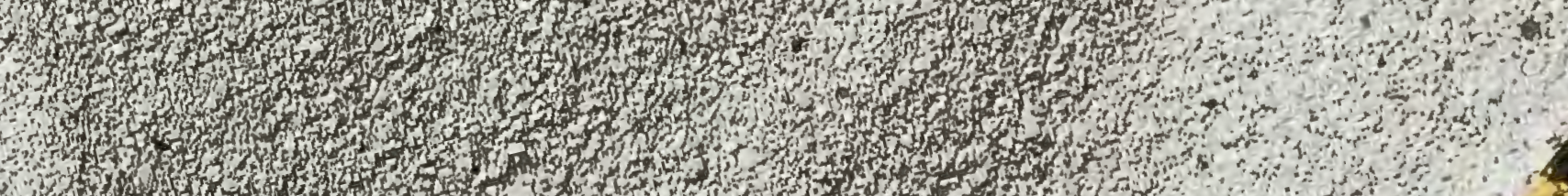

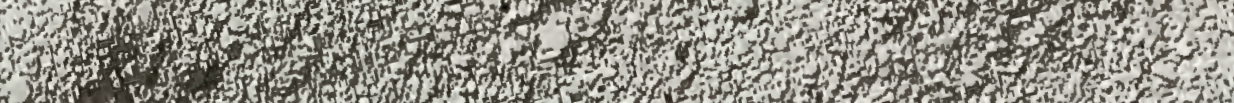

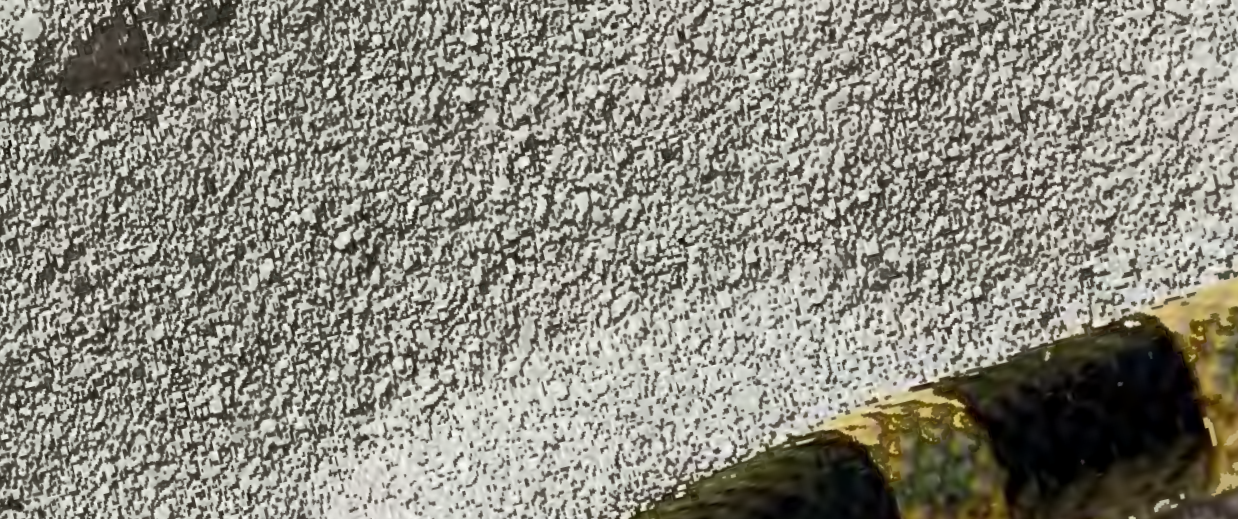
(2)

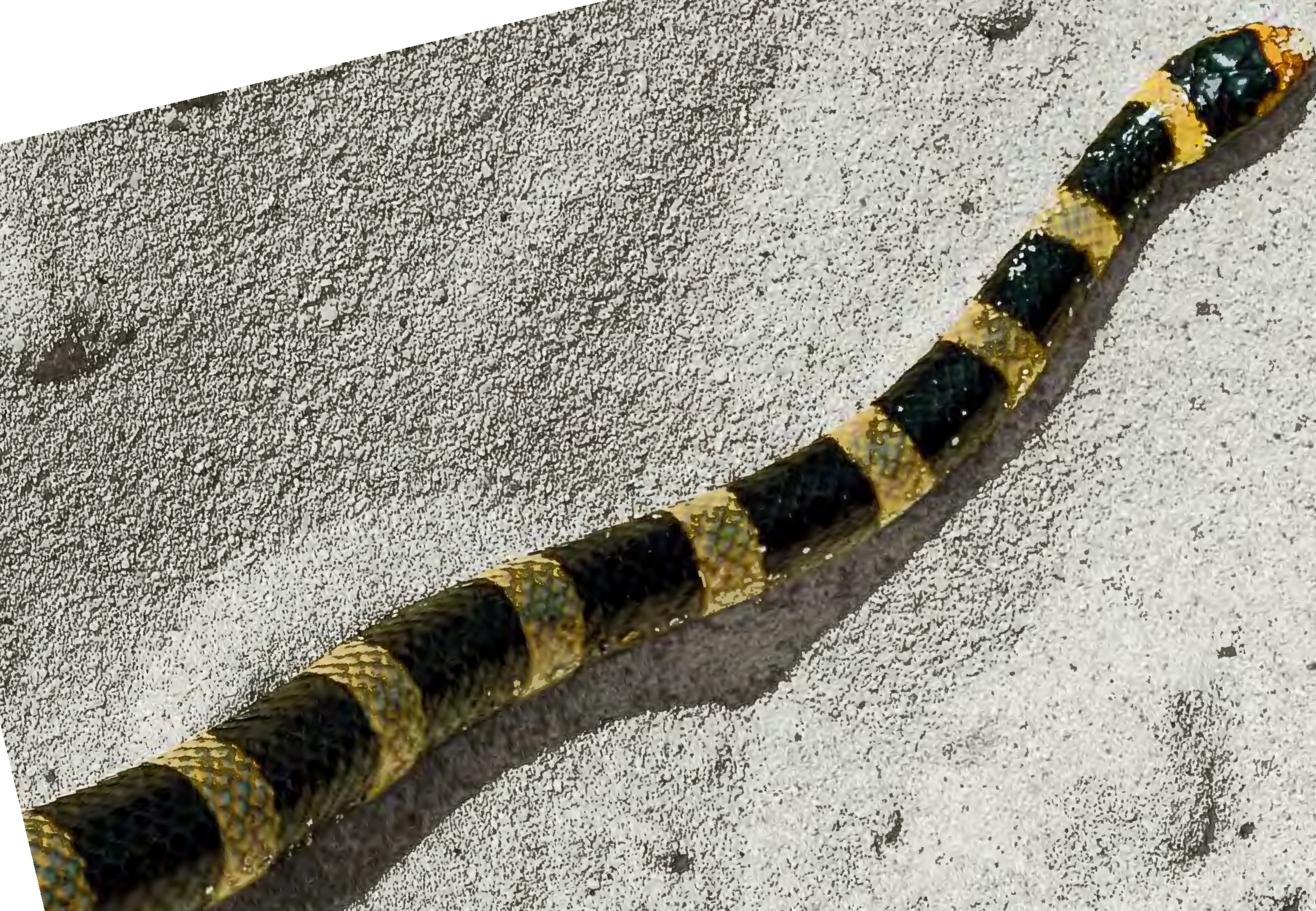
,
-
4
$+2$

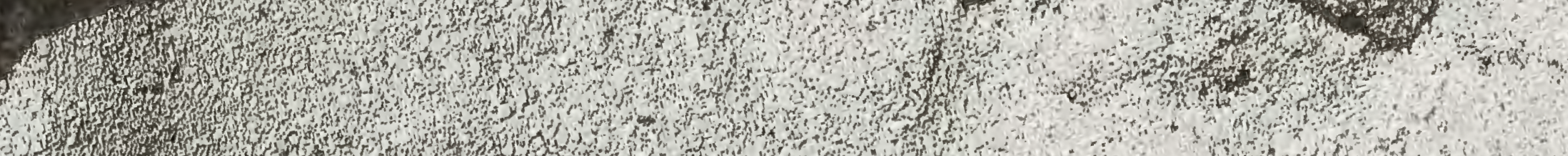

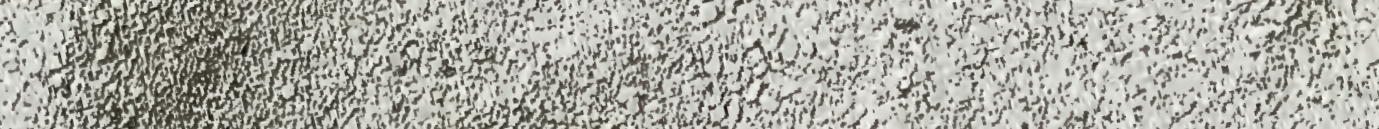

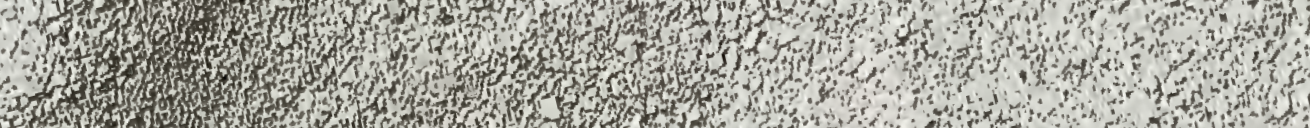
W

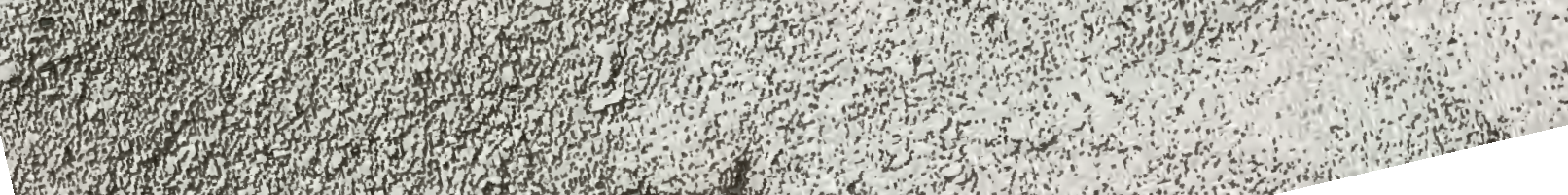

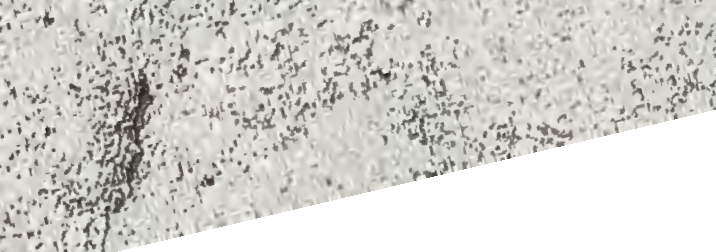
mow 


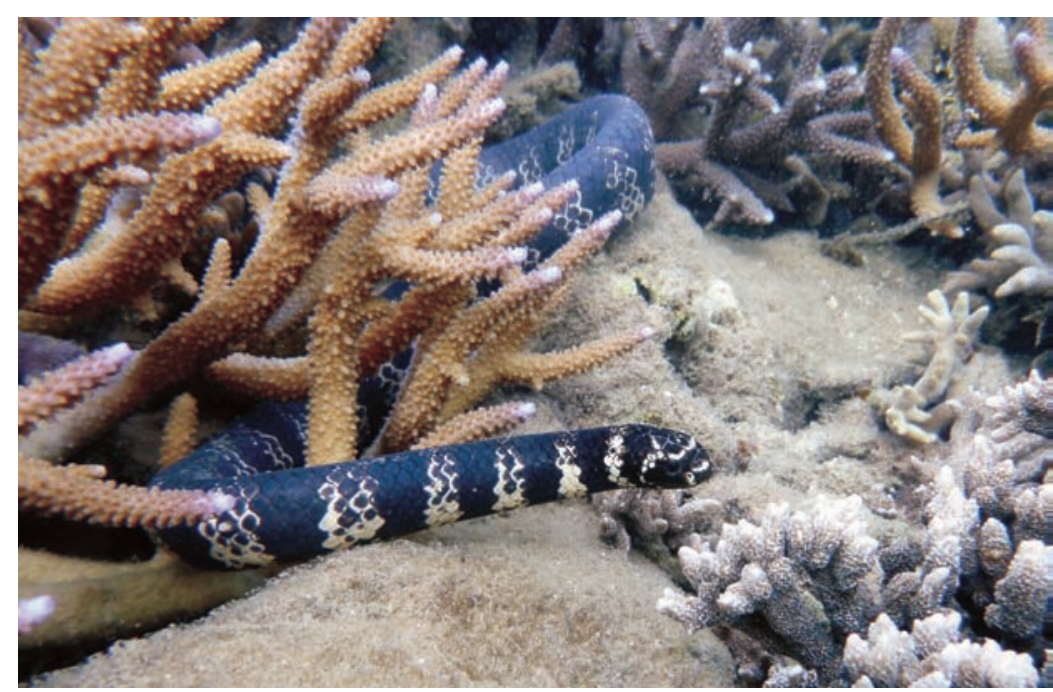

Emydocephalus annulatus. @ UNC/C. Goiran

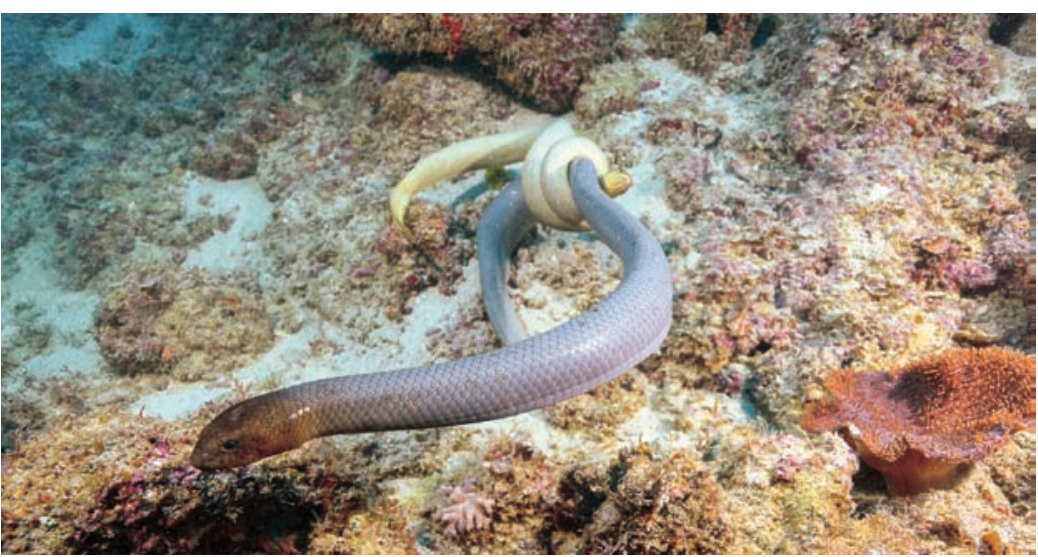

Accouplement Aipysurus laevis. @ IRD/E. Folcher

La Nouvelle-Calédonie présente un environnement très favorable à l'étude des serpents marins vrais. En effet, elle possède des écosystèmes récifaux et lagonaires riches et diversifiés qui hébergent de nombreux serpents. Parmi ces écosystèmes, certains, comme la baie des Citrons sont faciles d'accès, ce qui permet l'étude des populations de serpent sur le long terme. Deux espèces de serpents marins vrais font l'objet de recherche actuellement en Nouvelle-Calédonie : Emydocephalus annulatus et Hydrophis major. Ces recherches ont pour but la connaissance de l'écologie de ces espèces et la manière dont elles s'adaptent aux modifications de leur environnement.
Encadré 17

\section{Pourquoi les serpents marins viennent-ils voir les plongeurs?}

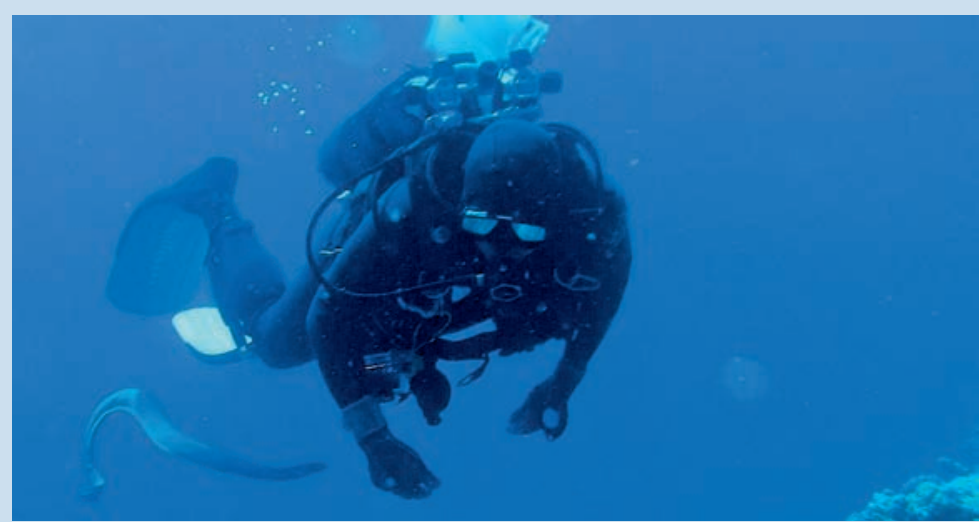

Curieux, ce serpent s'approche d'un scientifique (mission aux Chesterfield, CHEST 2015). (c IRD/C.E Payri

Les serpents terrestres ne viennent jamais observer les humains de près. Ils les fuient le plus souvent. Les serpents marins, au contraire, ne les évitent pas et ils viennent même parfois les examiner de près. À quoi est due cette différence de comportement?

Les serpents n'ont pas une vue très perçante. Pour identifier les autres animaux qu'ils rencontrent (proie, partenaire sexuel ou autre), ils collectent avec leur langue des molécules qu'ils ont émises dans le milieu et les analysent dans l'organe voméro-nasal situé dans leur palais. Les serpents terrestres peuvent ainsi recueillir des molécules dans l'air ou sur le sol pour connaître l'identité des autres animaux qui partagent leur milieu. Dans le milieu marin, les molécules émises par un animal sont trop rapidement dispersées dans l'eau pour que les serpents puissent les utiliser comme source d'information. Ils sont donc obligés de prélever directement les molécules avec leur langue sur l'animal qu'ils veulent identifier. Pendant la période de reproduction, généralement en hiver, les mâles inspectent très activement leur environnement à la recherche de femelles. Ils viennent souvent examiner les plongeurs, mais dès qu'ils ont constaté que ces derniers n'étaient pas des partenaires potentiels, ils s'en éloignent. Les humains interprètent parfois ce comportement comme une attaque, mais ce n'est que de la curiosité. 


\section{Chapitre 18 \\ Les réseaux trophiques en milieux coralliens}

Marine Julie Briand et Yves Letourneur

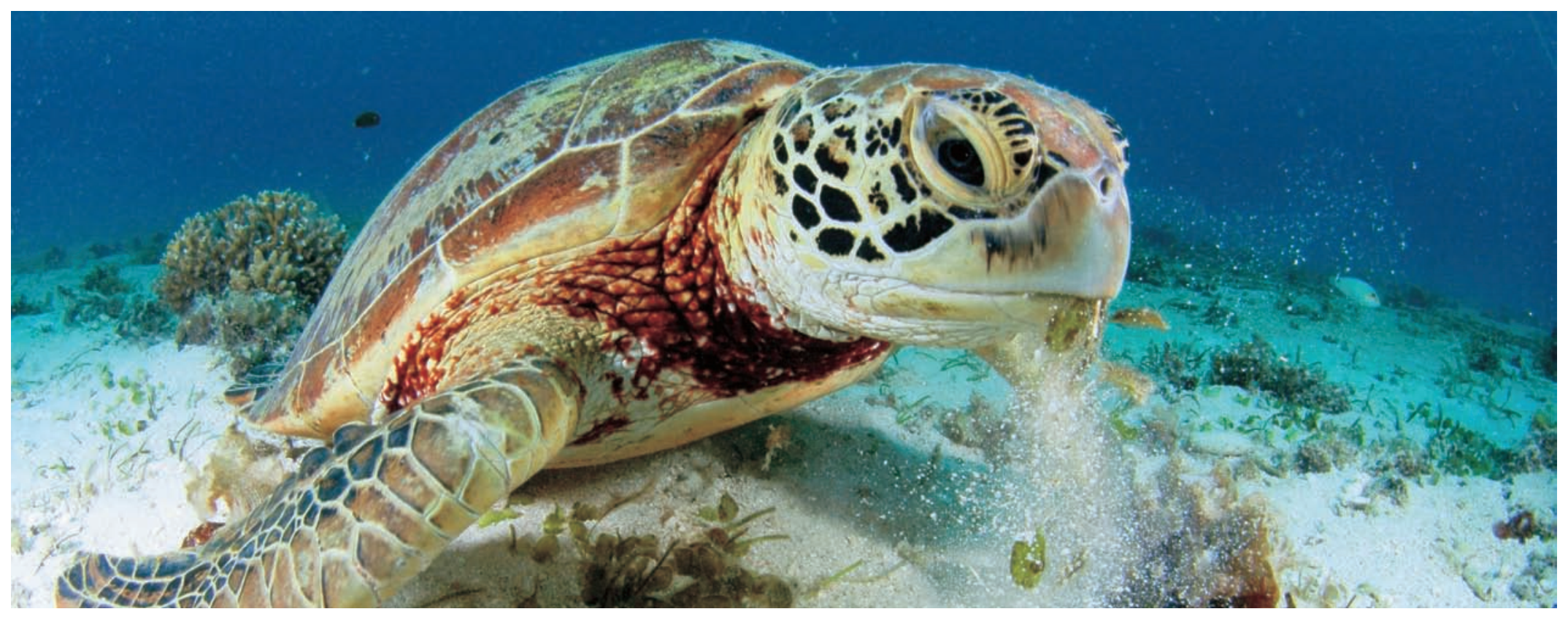

La tortue verte Chelonia mydas se nourrissant sur un herbier d'Halophila, côte ouest de la Grande Terre. @ M. Juncker

L'algue Sargassum spinulligerum absorbe les sels nutritifs présents dans l'eau ; le crabe Pilumnus vespertilio picore l'algue ; la murène Gymnothorax chilospilus attrape le crabe ; le tricot rayé Laticauda saintgironsi avale la murène et le requin-tigre Galeocerdo cuvier engloutit le serpent.

Ainsi va la vie dans les récifs coralliens de Nouvelle-Calédonie, où les relations alimentaires entre proies et prédateurs sont d'une très grande diversité et complexité. En effet, chaque organisme du récif joue un rôle précis et tient une place déterminée dans cette toile à l'équilibre fragile, où les espèces sont connectées.

\section{Une toile parfaitement tissée}

Un très grand nombre de chaînes alimentaires coexistent dans les récifs coralliens néo-calédoniens. Chacune se construit d'un premier maillon constituant une source alimentaire de « base », de multiples maillons intermédiaires regroupant des consommateurs très divers, et aboutit à un maillon terminal représenté par les grands prédateurs carnivores (fig. 1). L'ensemble de ces chaînes alimentaires forme un réseau étroitement interconnecté comparable à une immense toile d'araignée. Au sein de ce réseau, dit «trophique », d'importants échanges de matière et d'énergie se réalisent. 
Les principaux compartiments trophiques sont au nombre de cinq.

- I : Les sources alimentaires « de base », représentées par les producteurs primaires (phytoplancton, microphytobenthos, gazon algal, macroalgues benthiques, phanérogammes marines) et les réservoirs de matière organique (parties particulaires et dissoutes du sédiment et de l'eau de mer). Ces ressources de base sont nombreuses et parfois complexes, formées pour certaines de l'accumulation de matières d'origines diverses (marine ou terrestre, pélagique ou benthique, autochtone ou allochtone).

- II : Les consommateurs primaires, qui s'alimentent des producteurs primaires ou dans les réservoirs de matière organique, se composent principalement d'organismes du zooplancton, de filtreurs (par exemple les huitres), herbivores (par exemple les poissons-perroquets) ou détritivores (par exemple les holothuries et certains mollusques et crustacés).

- III : Les consommateurs secondaires, qui se nourrissent des consommateurs primaires, présentent des régimes alimentaires majoritairement omnivores ou à dominance carnivore.

- IV et $V$ : Les consommateurs tertiaires et quaternaires, qui sont les grands prédateurs des récifs coralliens et dont le régime alimentaire est strictement carnivore (par exemple les loches et les requins), voire exclusivement piscivore (par exemple les barracudas).

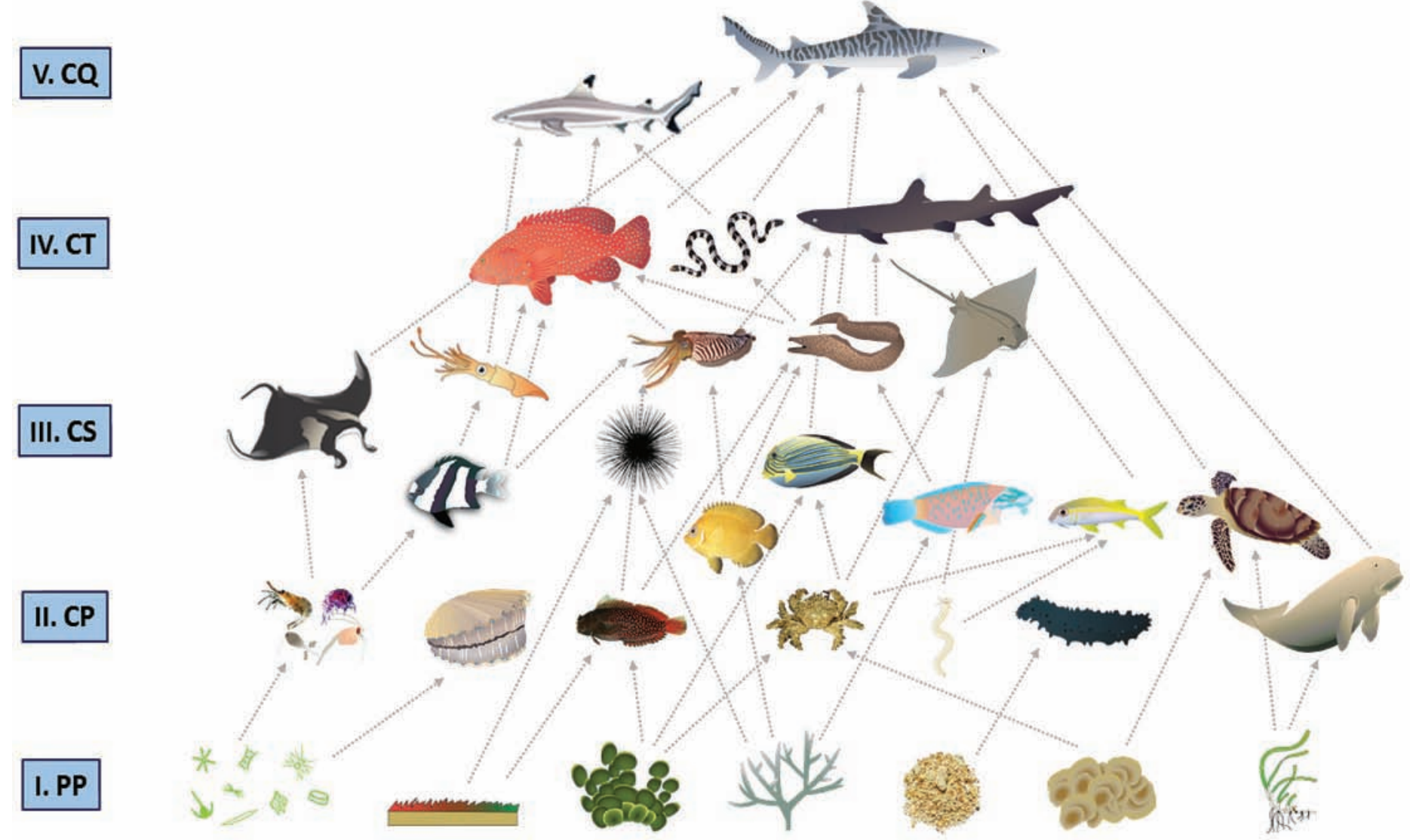

Figure 1 : Schéma simplifié des réseaux trophiques de l'écosystème récifo-lagonaire de Nouvelle-Calédonie. Les flèches indiquent les relations alimentaires existantes entre les organismes des cinq principaux compartiments. I : producteurs primaires (PP). II : consommateurs primaires (CP). III : consommateurs secondaires (CS). IV : consommateurs tertiaires (CT). $\mathrm{V}$ : consommateurs quaternaires (CQ). @ M.J. Briand, images http://ian.umces.edu 


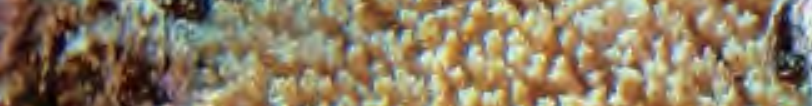
6.

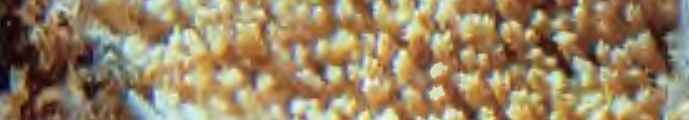
2. 20.

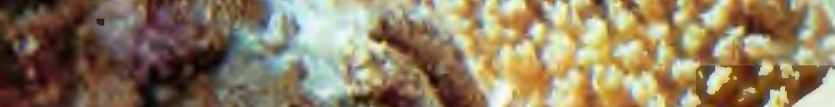

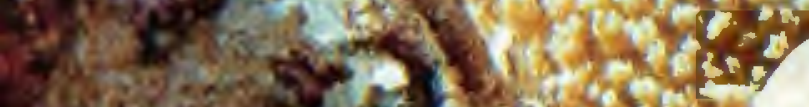

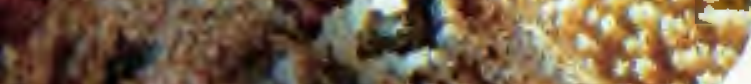

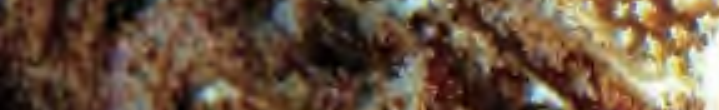
3. (7)

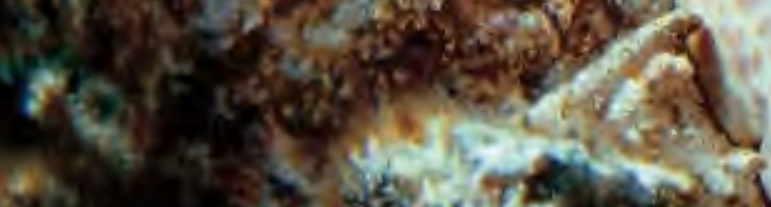
ts

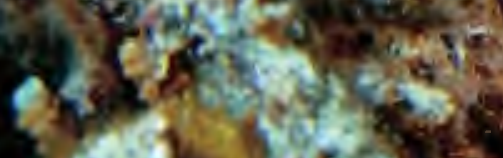

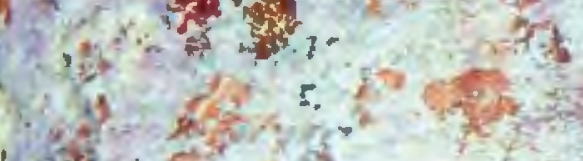

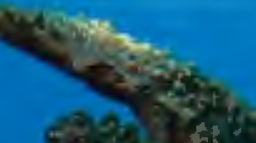

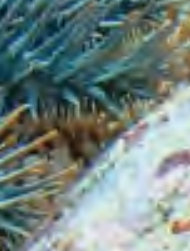

is

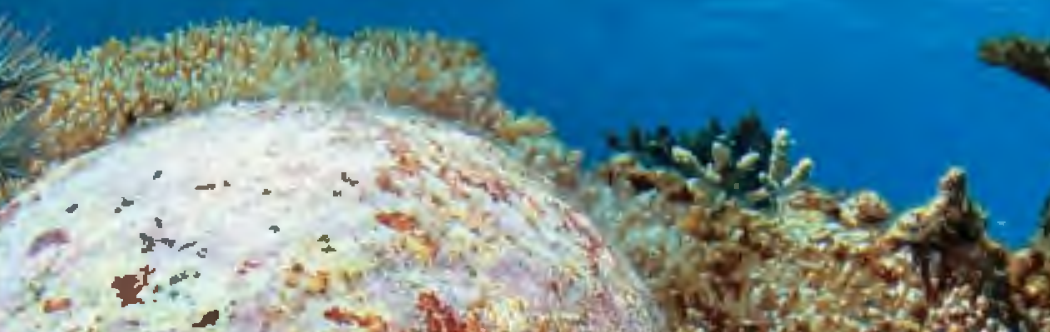
(3.2.

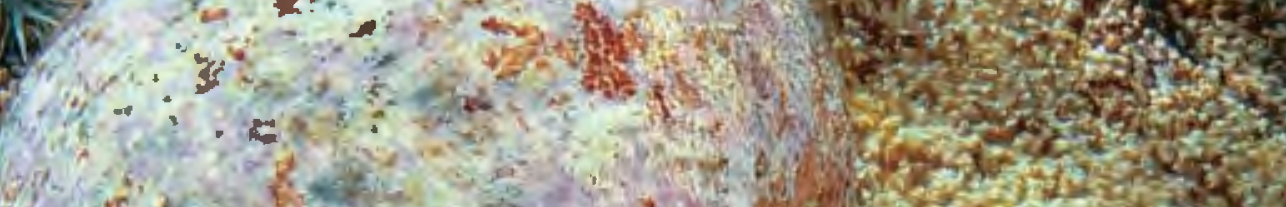

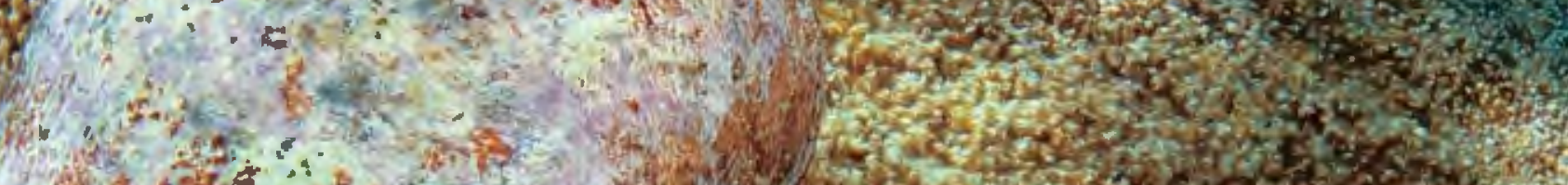

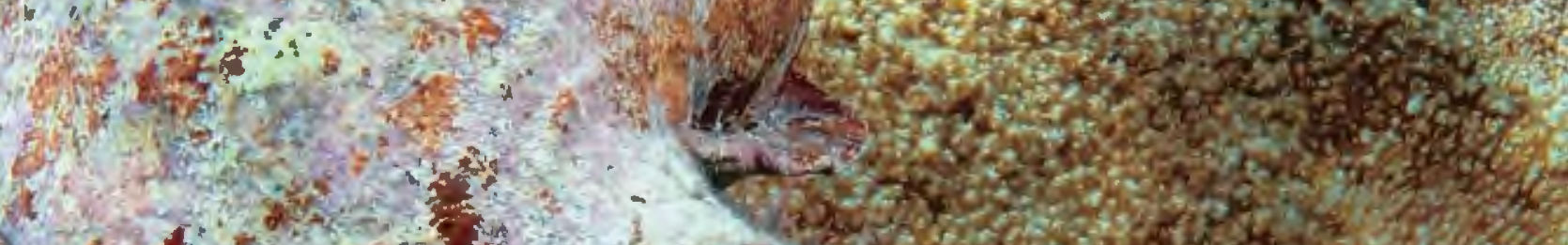

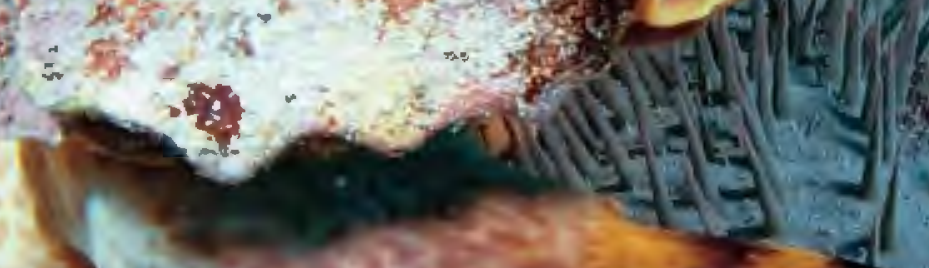

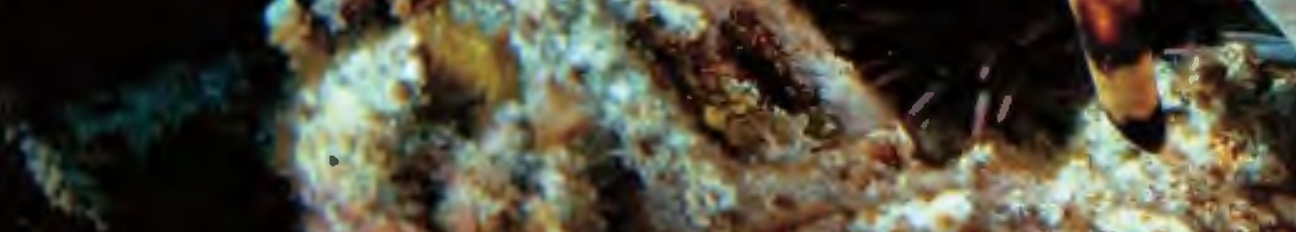

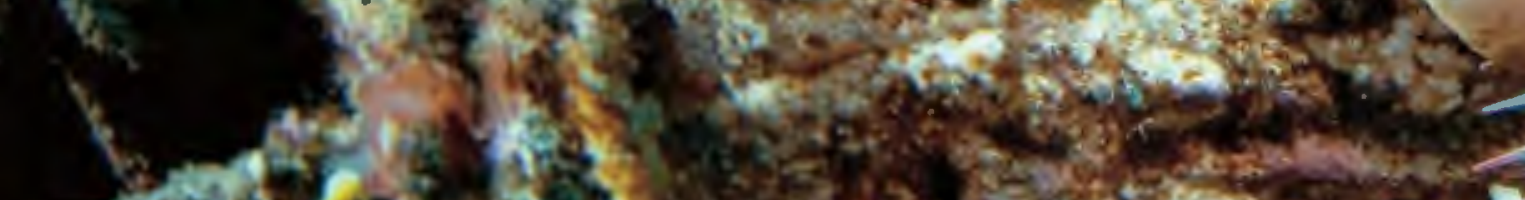

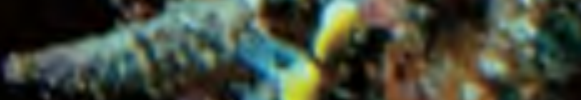

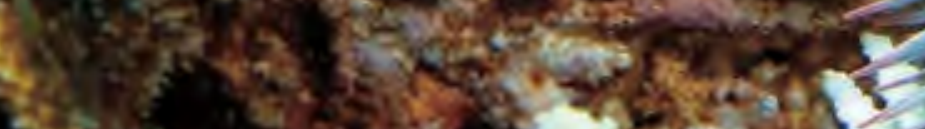


Plusieurs réseaux trophiques majeurs du lagon néo-calédonien sont déjà connus (BRIAND, 2014). Il y a les réseaux dits « sédimentaires » (dont la «base » est constituée de matière organique associée aux particules sédimentaires), «récifaux » (matière organique essentiellement liée au «gazon algal »), «lagonaire » (particules organiques et/ou phytoplancton présents dans l'eau de mer) et « détritique » (débris de phanérogames marines et d'algues non directement digestibles par la majorité des organismes herbivores). Les deux premiers réseaux sont les plus importants en termes de flux de matière au sein des récifs coralliens, tandis que les deux derniers participent de manière plus indirecte aux transferts de matière dans les récifs. Ces quatre réseaux trophiques sont alimentés par des sources de matière organique différentes mais sont étroitement liés, parce qu'ils se trouvent le plus souvent dans des habitats très voisins, mais aussi en raison de l'exploitation des sources de « base » et/ou des proies par des consommateurs communs.

De plus, l'importance d'écosystèmes associés aux récifs coralliens tels que les herbiers de phanérogames marines et les mangroves est clairement mise en évidence par les exportations de matière (débris divers, matière organique particulaire et dissoute) entre les différents habitats de l'espace récifo-lagonaire. Il est probable que d'autres réseaux trophiques restent encore à déterminer afin de mieux comprendre le fonctionnement des récifs coralliens de Nouvelle-Calédonie.

\section{Des relations complexes}

La grande complexité des relations existant entre ces compartiments réside dans la multitude de régimes alimentaires qui s'entrecroisent, associant des organismes spécialistes comme le poisson-papillon corallivore obligatoire Chaetodon trifascialis avec des opportunistes tels que la plupart des poissons carnivores de taille moyenne. Par ailleurs, chaque organisme peut voir son régime alimentaire modifié au cours de sa vie selon divers paramètres biologiques (en fonction de la taille, des périodes de reproduction) ou environnementaux (en fonction de la saison, des caractéristiques de l'habitat, de perturbations). Le nason à éperons bleus ou « dawa » (Naso unicornis) par exemple est un poisson zooplanctonophage au stade juvénile, qui devient herbivore au stage adulte. De même, les organismes herbivores tels que les mollusques gastéropodes broutent les espèces d'algues présentes sur le substrat à une saison donnée.

Par ailleurs, les connaissances disponibles sur le régime alimentaire des organismes récifaux sont régulièrement complétées, voire reconsidérées, grâce à l'évolution des techniques d'études. En effet, depuis quelques années s'ajoutent aux méthodes traditionnelles d'observation des contenus stomacaux des outils biochimiques qui permettent d'aller plus loin dans l'interprétation des régimes alimentaires et des relations trophiques. Il s'agit des méthodes d'analyses de la composition du tissu d'un organisme en isotopes stables du carbone et de l'azote, en acides gras, en acides aminés.

Ainsi, le régime alimentaire des oursins de récif Parasalenia gratiosa et Echinometra mathaei, habituellement qualifié d'herbivore suite à l'observation de leurs estomacs, semble être remis en question; de fortes signatures isotopiques en azote suggèrent un régime alimentaire davantage omnivore, parfois à dominance carnivore, induit par le «raclage» du substrat favorisant, outre la consommation d'algues, l'ingestion d'invertébrés fixés sur le substrat, comme des éponges, des bryozoaires et même des jeunes stades coralliens (BRIAND, 2014). Des modèles mathématiques relativement récents permettent de prédire la part relative de chaque proie dans le régime alimentaire d'un prédateur.

À partir des connaissances acquises sur l'alimentation et l'habitat d'un organisme, il est possible de définir la largeur de sa niche trophique et d'émettre des hypothèses sur ses interactions de compétition pour les ressources nutritives avec d'autres espèces de l'écosystème. Ces outils biochimiques sont également particulièrement utiles pour retracer l'origine des différentes sources alimentaires composant les réservoirs de matière organique qui supportent les réseaux trophiques dans les récifs coralliens. Comme dans le cas précédent, des modèles permettent d'estimer la contribution de chaque source alimentaire à la constitution du réservoir de matière organique. 


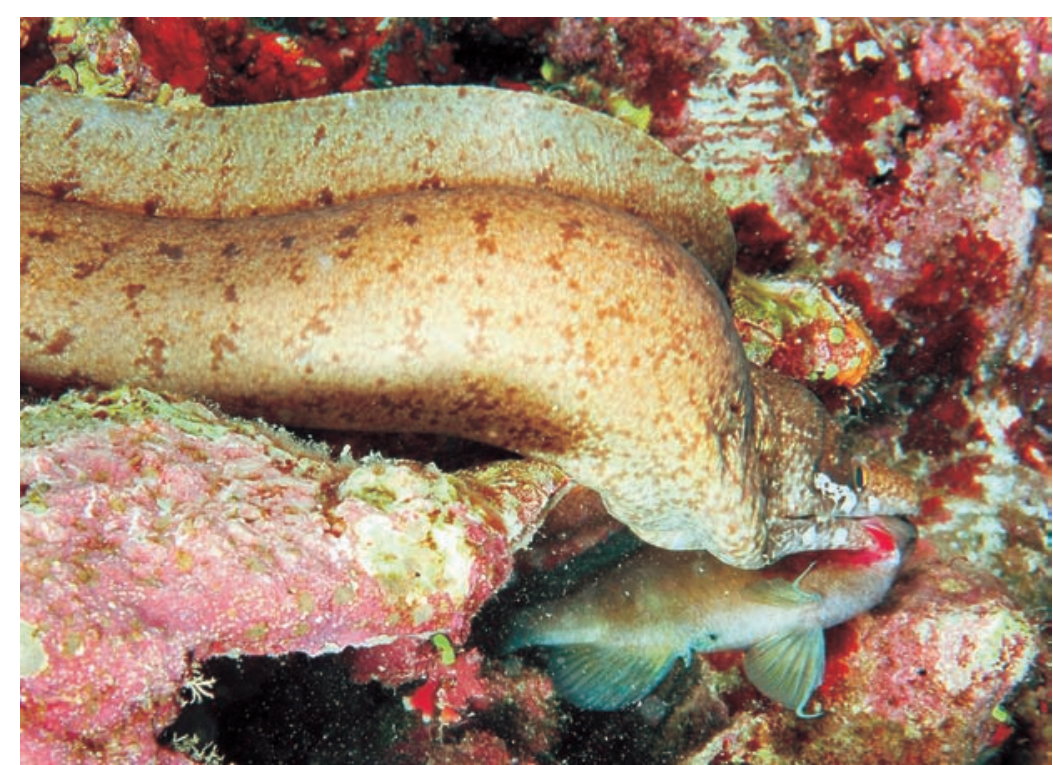

La murène Gymnothorax zonipectis attaquant un poisson. Lifou. @ M. Juncker

\section{Un équilibre fragile}

L'étude des réseaux trophiques permet de mettre en évidence le rôle écologique clé joué par les différents groupes ou guildes d'organismes récifaux de régimes alimentaires similaires, appelés «groupes trophiques ». Ainsi, certains organismes sont clairement identifiés comme étant des espèces clés des récifs néo-calédoniens. Par exemple, le rôle des herbivores au sens large est tout à fait fondamental dans les récifs coralliens car, en consommant les algues, ces organismes limitent fortement leur développement, permettant ainsi aux coraux dont la croissance est bien plus lente de rester compétitifs dans l'occupation de l'espace récifo-lagonaire. Il est alors possible d'anticiper les effets des perturbations sur ces réseaux trophiques à la structure fragile, pour lesquels un déséquilibre dans le fonctionnement des relations alimentaires peut avoir d'importantes conséquences. Bien que les effets en cascade dits «bottom-up » et «top-down », caractérisés par un déséquilibre respectivement par le bas (c'est-à-dire à partir des sources de base) ou par le haut (c'est-à-dire à partir des grands prédateurs) se répercutant sur l'ensemble du réseau, soient largement étudiés à l'échelle mondiale, ils ne sont pas encore précisément décrits au sein des récifs coralliens de Nouvelle-Calédonie.
La question de la pollution du lagon de Nouvelle-Calédonie par divers contaminants tels que les éléments traces métalliques et métalloïdes (arsenic, cobalt, mercure, nickel, etc.) ou les composés organiques (pesticides, polychlorobiphényles, etc.) peut être évaluée en relation avec les réseaux trophiques. En effet, l'ensemble des compartiments trophiques présente des niveaux détectables de contaminants, à des concentrations variables selon les composés et les organismes considérés. Une étude récente a mis en évidence le cheminement de certains éléments traces, notamment le mercure, le sélénium et, dans une moindre mesure, l'arsenic à travers la structure des réseaux trophiques; les réseaux « sédimentaires » et « récifaux » se sont révélés être des voies de transfert privilégiées (BRIAND, 2014). D'autres éléments en revanche sont présents dans différents organismes sans pour autant qu'existent des liens nets entre le niveau de contamination et le positionnement de l'organisme dans le réseau trophique.

Ces réseaux représentent donc un aspect essentiel de la mécanique fonctionnelle d'un écosystème. Leur étude dans les écosystèmes récifaux reste très complexe, mais cruciale, pour que de meilleurs plans de protection et de gestion soient mis en place. Les récifs coralliens de Nouvelle-Calédonie constituent en ce sens un formidable site d'étude par le patrimoine exceptionnel qu'ils représentent, mais également en raison des nombreuses menaces naturelles (cyclones, hypersédimentation, phénomènes de blanchissement) et anthropiques (rejets miniers, pollution urbaine, activités nautiques) auxquelles ils doivent faire face.

\section{Référence bibliographique}

BRIAND M., 2014 Place des poissons anguilliformes dans le fonctionnement des écosystèmes récifo-lagonaires de la Nouvelle-Calédonie : rôle trophique et impacts des contaminations. Thèse de doctorat, Université de la Nouvelle-Calédonie, $610 \mathrm{p}$. 


\title{
Le lagon, abri ou résidence des dauphins
}

\author{
Marc Oremus
}

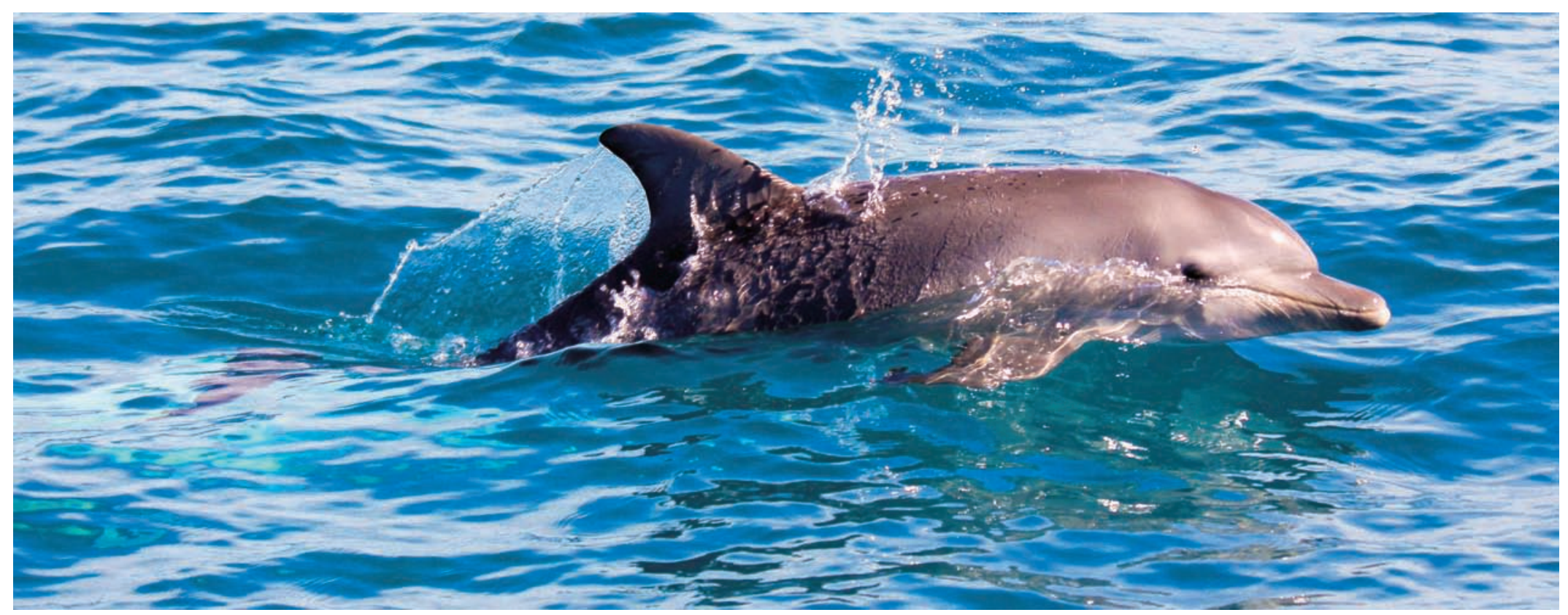

Le grand dauphin de l'Indo-Pacifique (Tursiops aduncus) présente une couleur assez uniforme, dans les tons gris ou marron clair selon la lumière. $\odot$ M. Oremus

Sur les 12 espèces de dauphins identifiées à ce jour dans les eaux de Nouvelle-Calédonie, deux en fréquentent quotidiennement les lagons : le dauphin à long bec (Stenella longirostris) et le grand dauphin de l'Indo-Pacifique (Tursiops aduncus).

\section{Un refuge à mi-temps pour certains}

La journée des dauphins à long bec est réglée comme du papier à musique. La nuit, ils arpentent les eaux du large à la recherche de petits poissons qui remontent des profondeurs. Au lever du jour, ils rejoignent les zones récifales où ils peuvent socialiser et se reposer à l'abri des grands prédateurs océaniques. Là, ils forment généralement de grands groupes de 15 à 60 dauphins. Le soir venu, ils entament un ballet acrobatique qui renforce les liens du groupe avant de regagner l'océan.

\section{Une résidence permanente pour d'autres}

La vie des grands dauphins de l'Indo-Pacifique est en revanche pleinement associée aux lagons car ils s'y nourrissent, s'y reproduisent et $s^{\prime} y$ reposent. Plusieurs petites populations résidentes, distinctes socialement et génétiquement, ont été décrites 


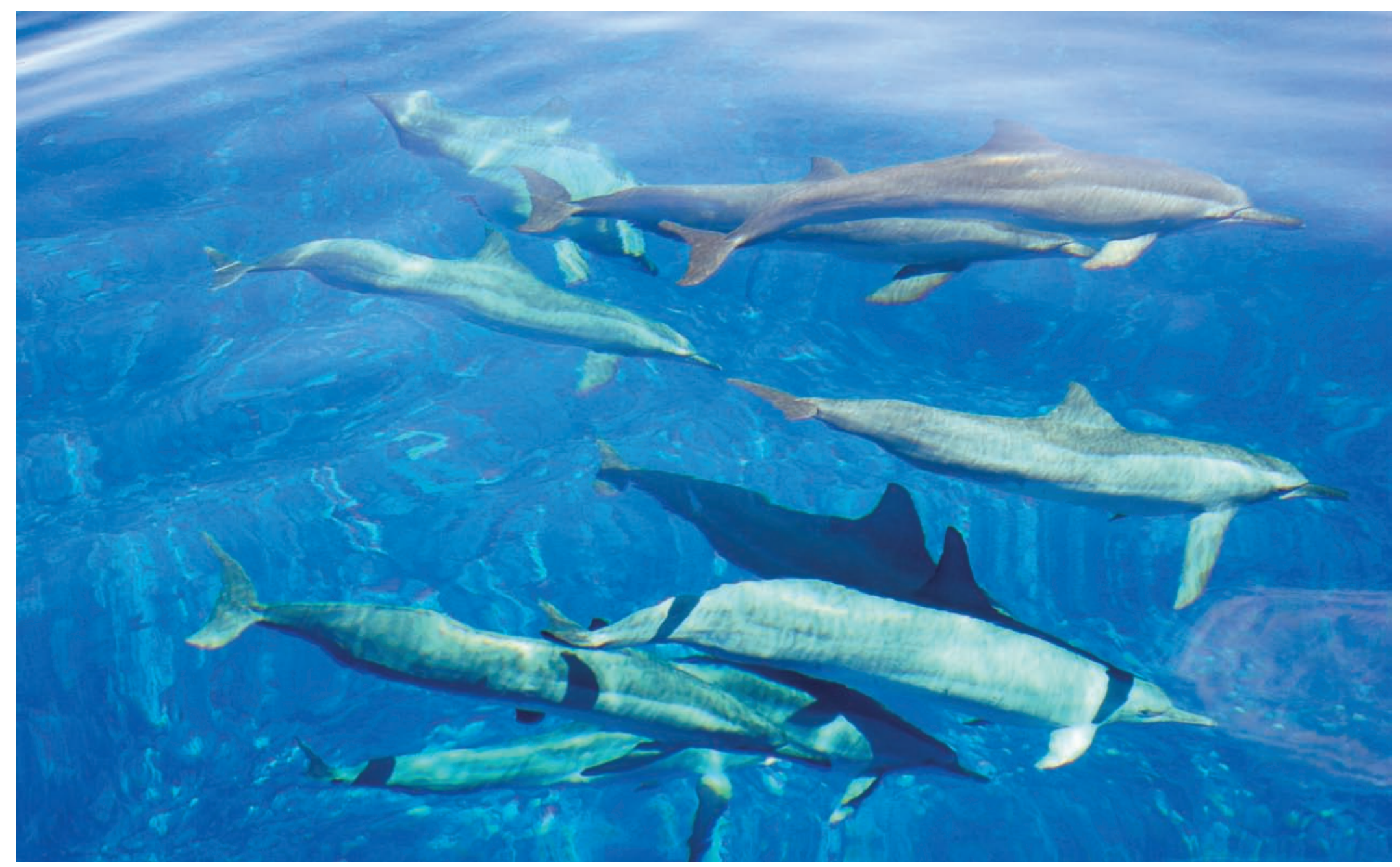

Groupe de dauphins à long bec (Stenella longirostris) se reposant en zone récifale peu profonde. ๑ M. Oremus

autour de la Grande Terre. Souvent en petits groupes de deux à dix dauphins, ils sont moins acrobates que leurs congénères à long bec mais ils peuvent être curieux ; il n'est d'ailleurs pas rare de les rencontrer aux étraves des bateaux.

\section{Des acteurs importants pour les récifs}

Le rôle joué par les dauphins en milieu corallien reste peu connu, mais il fait peu de doute que celui-ci est majeur. Les grands dauphins sont des prédateurs supérieurs des écosystèmes récifaux et participent donc activement à en réguler la chaîne alimentaire. Si les dauphins à long bec ne se nourrissent pas dans les lagons, ils transfèrent en revanche une quantité importante de matière organique en provenance du large via leurs déjections. L'ampleur de ce phénomène reste à préciser, mais il est établi que cette matière bénéficie aux poissons des récifs. 


\section{Fragiles et menacés : les oiseaux marins de la mer de Corail}

Philippe Borsa et Éric Vidal

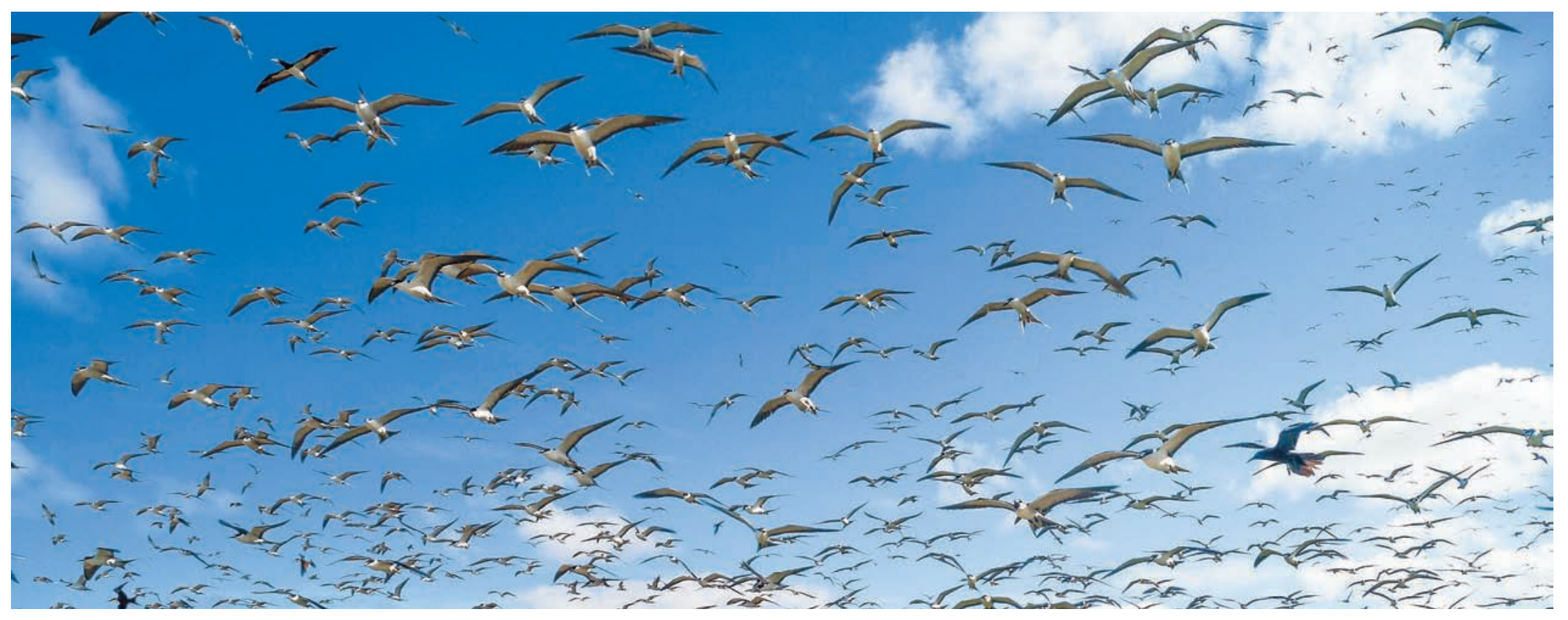

Sternes fuligineuses (Onychoprion fuscatus), îles Chesterfield. @ IRD/E. Vidal

\section{La mer de Corail, un sanctuaire tropical pour les oiseaux marins}

Le terme « oiseaux marins » se réfère à plusieurs familles d'oiseaux dont l'essentiel de la vie a lieu en mer ou sur le littoral et dont la nourriture consiste préférentiellement en des animaux marins : poissons, crustacés, calmars et autres invertébrés marins. Les puffins et les pétrels sont de remarquables voiliers, capables de migrations transocéaniques et de bons plongeurs : des oiseaux océaniques par excellence. Les oiseaux de deux autres familles, celles des frégates et des phaétons ou pailles-en-queue passent aussi l'essentiel de leur vie au large, survolant les océans sur de très grandes distances.
Les fous ont un rayon de prospection plus ou moins étendu au large. Ceux-ci pêchent en plongeant en piqué, mais sont aussi capables de happer des poissons volants en vol. Les sternes et noddis comprennent à la fois des espèces océaniques et des espèces côtières. Les mouettes se nourrissent sur le littoral ou dans le lagon. Tous séjournent à terre pour se reproduire car, comme la plupart des oiseaux, les oiseaux marins incubent leurs œufs puis élèvent leurs poussins au nid ou près du nid pendant plusieurs semaines à plusieurs mois.

La mer de Corail est une des dernières régions tropicales de la planète où l'impact des activités humaines peut être considéré comme relativement faible. En conséquence, les oiseaux marins, 
indicateurs sensibles de l'état de préservation des écosystèmes marins, y sont encore divers et abondants. Du fait de leur isolement et de leur proximité des zones de nourrissage en mer, les îlots coralliens sont des sites privilégiés pour la nidification des oiseaux marins. Les îlots peuvent aussi servir de reposoirs hors de la période de reproduction. Bien qu'étant de petite taille, les îlots récifaux constituent un habitat irremplaçable pour les oiseaux marins : pendant la période de reproduction, ils accueillent des populations entières qui, en temps ordinaire, occupent des centaines de milliers de kilomètres carrés dans l'océan.

Quatre ensembles récifaux concentrent l'essentiel des colonies d'oiseaux marins de la Nouvelle-Calédonie : l'archipel des Chesterfield-Bampton (au centre de la mer de Corail), les îlots des récifs d'Entrecasteaux (au nord de la Grande Terre) et les îlots des lagons nord et sud. Les îles coralliennes surélevées et inhabitées comme Beautemps-Beaupré et Walpole sont aussi des sites favorables à la reproduction des oiseaux marins. Ainsi, l'île Walpole abrite à elle seule au moins 11 espèces d'oiseaux marins nicheurs, dont une importante colonie de fous bruns et une des rares colonies de sternes blanches du Pacifique sud-ouest.

\section{Ingénieurs des cayes et îlots}

Les îlots à différents stades de végétalisation sont colonisés par différentes espèces d'oiseaux nicheurs. Par exemple, plusieurs espèces de sternes posent leurs œufs à même le sable ou les débris de corail. Certaines, comme la sterne de Dougall ou la sterne fuligineuse, nichent en colonies denses sur des cayes quasiment dépourvues de végétation. $D$ 'autres, comme la sterne blanche et le noddi noir nichent dans les arbres et, de ce fait, ne peuvent s'installer que sur les îlots déjà boisés. Le noddi brun peut se contenter de nids rudimentaires sur le sol ou bien de nids volumineux et extraordinairement élaborés, faits de fines brindilles entrelacées et construits bas dans les arbustes. De même, le fou brun et le fou masqué pondent leurs œufs à même le sol alors que le fou à pieds rouges et la grande frégate construisent leurs grands nids faits de branchages dans les arbres. Parmi les pétrels, le puffin fouquet et le pétrel de Tahiti creusent des terriers dans le sable, consolidés par la

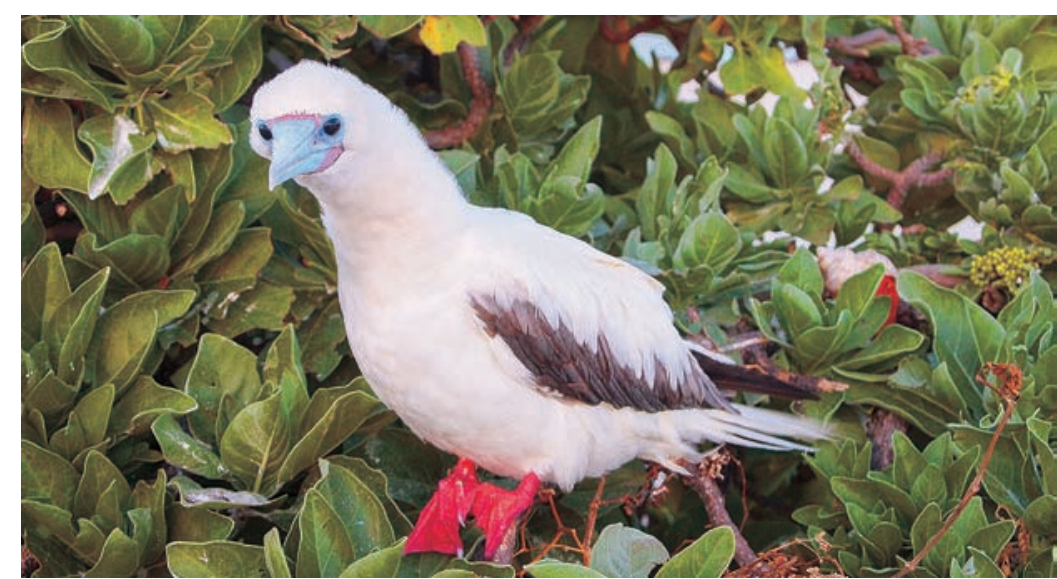

Fou à pieds rouges (Sula sula) dans les faux-tabacs, îles Chesterfield. @ IRD/P. Borsa

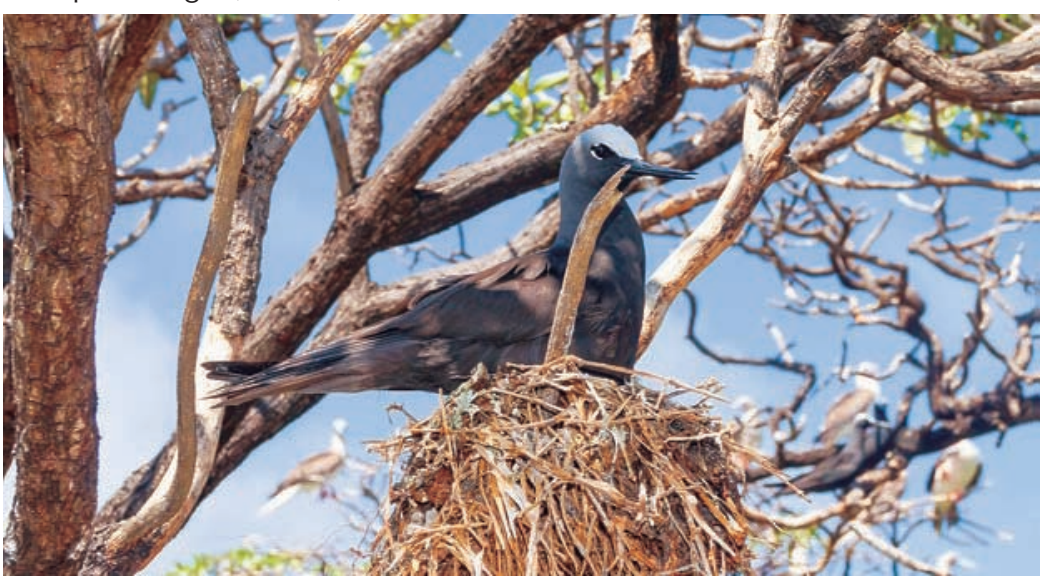

Noddi noir (Anous minutus), île Surprise. @ IRD/E. Vidal

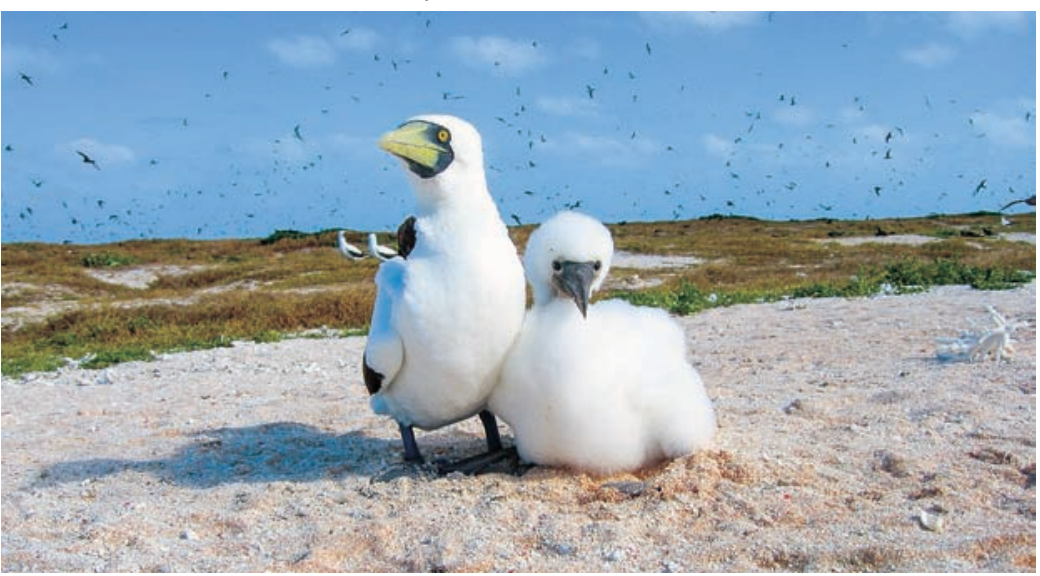

Fou masqué (Sula dactylatra) et son poussin, îlot Loop, Chesterfield. @ IRD/R. Proner 


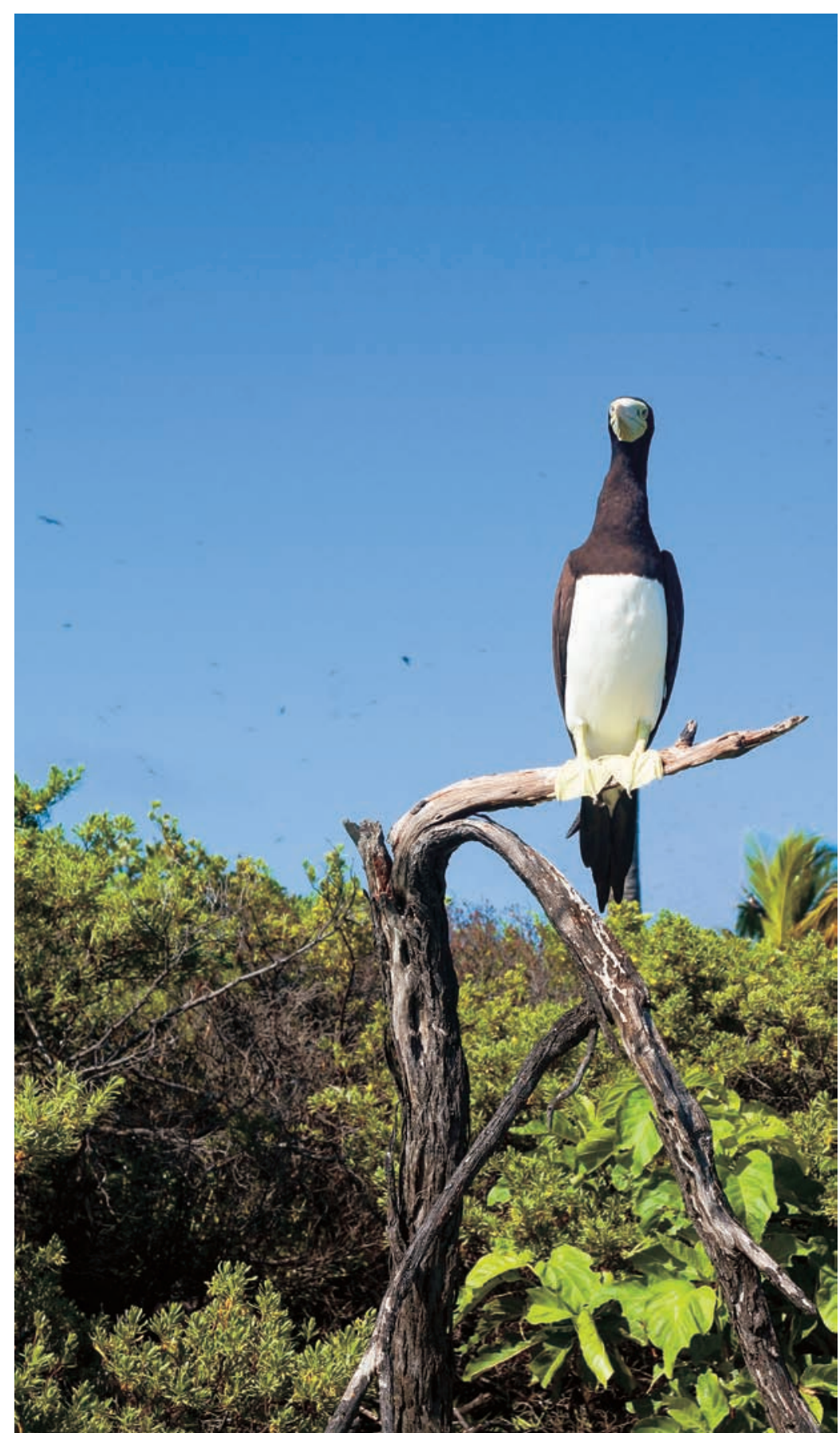

Fou brun (Sula leucogaster), île Surprise. @ IRD/E. Vidal végétation herbacée ou à l'abri des racines des arbres. Le pétrel à ailes noires niche lui aussi au fond d'un terrier, mais il choisit, de préférence, les îlots arborés.

Les colonies d'oiseaux installées sur les cayes dépourvues de végétation favorisent l'établissement de celle-ci par leurs déjections. En effet, ces déjections contiennent des ammoniates et des phosphates qui fertilisent l'îlot. C'est aussi tout un écosystème éphémère qui se met en place au moment de la reproduction des oiseaux et qui participe à la genèse du sol de l'îlot, du fait de l'apport de matière organique que constituent les œufs non éclos, les proies régurgitées qui échappent aux poussins, et les carcasses des oiseaux morts. La végétation participe à son tour à la stabilisation de l'îlot, l'aidant à résister aux cyclones et à ainsi maintenir l'habitat disponible pour la nidification des oiseaux.

Enfin, la croissance du sol due à la décomposition des végétaux terrestres et des algues et autres débris flottants utilisés pour la construction des nids, ainsi que l'accumulation des déjections d'oiseaux participent à la croissance en hauteur des îlots. Le lessivage des nutriments vers la mer et les déjections tombant directement à la mer contribuent aussi à la croissance des algues symbiotiques des coraux. Ainsi, les oiseaux marins jouent-ils un rôle-clé non seulement dans la croissance et la stabilisation des récifs et îlots coralliens, mais aussi possiblement dans la résilience de ces derniers face aux événements météorologiques extrêmes.

\section{Une biodiversité remarquable}

On recense 24 espèces d'oiseaux marins nicheurs dans les eaux néo-calédoniennes (tabl. 1). Une d'entre elles, le pétrel de la Chaîne, niche exclusivement dans les hauteurs de la Grande Terre. Toutes les autres espèces ont été signalées comme nicheuses sur les îles et îlots coralliens de la Nouvelle-Calédonie. Les populations néocalédoniennes de la sterne néréis, de la mouette argentée et du pétrel de Tahiti sont considérées comme des sous-espèces endémiques à l'échelle de la mer de Corail, mais, pour ces deux derniers cas, cela reste à confirmer par des études génétiques approfondies.

La sterne néréis niche aux îles Chesterfield-Bampton, dans le lagon nord et dans le lagon sud. Cette espèce avait autrefois une 
distribution plus large en Nouvelle-Calédonie, mais la population y est désormais réduite à quelques dizaines de couples nicheurs, ce qui en fait une des espèces les plus vulnérables du territoire. La sterne néréis pond ses œufs à même le sable des îlots. Elle est particulièrement sensible au dérangement par les plaisanciers, qui conduit à l'échec de la reproduction.

L'oiseau marin le plus abondant des îles et îlots coralliens de la Nouvelle-Calédonie est le puffin fouquet. Ses nombreuses colonies des îlots des lagons sud et nord et des Chesterfield-Bampton comprennent chacune de plusieurs centaines à plusieurs dizaines de milliers de couples nicheurs. Avec un effectif total de plus de 500000 couples reproducteurs, la Nouvelle-Calédonie héberge une partie importante de la population mondiale de cette espèce, estimée à environ 5 millions d'individus au total. La disponibilité de sites de nidification libres de prédateurs naturels, jointe à une densité suffisante, dans le rayon de prospection des oiseaux, de proies de taille et de qualité adéquates (calmars et petits poissons pélagiques), ainsi que la présence de prédateurs marins tels que les thons et les cétacés, qui rapprochent les bancs de poissons de la surface et les rendent ainsi plus accessibles aux oiseaux, expliquent en partie une telle abondance. Les puffins, comme d'autres pétrels, sont aussi capables d'adapter leur stratégie de prospection à la disponibilité spatiale de la ressource selon la phase de leur cycle reproductif. Lors de la période de reproduction, les oiseaux partent en mer pour des séjours d'une journée ou deux à proximité de la colonie, au retour desquels ils régurgitent leurs proies aux poussins, qu'ils alternent avec des séjours plus longs, jusqu'à une douzaine de jours plus au large, au cours desquels ils se réalimentent. Une fois libérés des contraintes de la reproduction à terre, les puffins effectuent une migration transocéanique pour aller exploiter les ressources des eaux tropicales du Pacifique nord, de la Micronésie aux îles de la Ligne.

Deux autres espèces quasi mythiques nichent, ou ont niché, sur les îlots coralliens des eaux néo-calédoniennes : le pétrel du Herald et l'océanite à gorge blanche. Le pétrel du Herald fut décrit à partir de trois spécimens présumément récoltés lors d'une visite du navire britannique Herald aux îles Chesterfield au milieu du XIXe siècle, soit avant l'intensification de la pêche baleinière dans la mer de Corail et avant l'extraction du guano. Ce pétrel n'a jamais été vu nichant, depuis, à cet endroit. L'océanite à gorge blanche a été observée sur un îlot du lagon nord dans les années 1990, mais elle semble bien avoir disparu depuis. Selon l'IUCN, cette espèce est en danger d'extinction du fait, principalement, des prédateurs introduits.

\section{Des populations mises en péril par les activités humaines}

Sur l'île Walpole et sur nombre d'îlots du pourtour de la Grande Terre et de la mer de Corail, les oiseaux marins sont exposés à la prédation par les rongeurs introduits par l'homme : le rat polynésien, le rat noir et la souris domestique. D'autres envahisseurs indésirables sont la fourmi électrique, qui harcèle les oiseaux au nid, et le figuier de barbarie, qui colonise les sites de nidification et obstrue l'accès aux terriers. Les changements environnementaux induits par les espèces envahissantes ont un impact direct sur les populations d'oiseaux et peuvent conduire, dans les cas extrêmes, à l'extinction des populations locales, comme c'est vraisemblablement le cas avec l'océanite à gorge blanche. Au cours des deux dernières décennies, des campagnes d'éradication des rongeurs ont été menées à d'Entrecasteaux, dans le lagon nord et dans le lagon sud, offrant un heureux répit aux oiseaux marins nicheurs de ces ensembles récifo-lagonaires.

L'extraction, par le passé, des ressources des îlots est une autre cause majeure de dégradation de l'habitat de nidification des oiseaux marins. Les îles Chesterfield servirent de base à terre pour les navires baleiniers de la mer de Corail. Les équipages coupaient le bois pour alimenter le feu des chaudrons et faisaient des razzias sur les œufs et les poussins d'oiseaux marins. De nos jours, l'homme reste un prédateur des oiseaux marins des îlots éloignés, puisque les équipages des navires de pêche qui s'aventurent aux Chesterfield-Bampton et à d'Entrecasteaux continuent à capturer des poussins de fous et de frégates pour la godaille du marin. L'activité d'extraction du guano, qui a eu lieu aux Chesterfield et à d'Entrecasteaux, a dévasté la végétation et le sol des îlots, les exposant davantage, par la même occasion, aux événements météorologiques extrêmes. C'est ainsi que le pétrel du Herald et le phaéton à brins rouges pourraient avoir disparu des îles Chesterfield et la mouette argentée, des îles d'Entrecasteaux. 
Le débarquement des plaisanciers sur les îlots est une autre menace trop souvent négligée. La seule approche d'un îlot par un bateau peut provoquer l'envol massif des oiseaux couveurs et ainsi exposer les œufs ou les poussins à l'ensoleillement et à la déshydratation, ce qui peut aller jusqu'à compromettre toute la saison de reproduction d'une colonie. Les plaisanciers, à terre, piétinent les œufs des sternes et les terriers des pétrels. Les chiens qui parfois les accompagnent capturent les poussins et les adultes. Le dérangement est maximal lors des fêtes de fin d'année sur les îlots. Les aménagements touristiques augmentent la fréquentation des îlots par les plaisanciers, tout en réduisant, par simple effet d'occupation du sol, l'habitat disponible pour la reproduction des oiseaux marins. Récemment, un croisiériste a jeté son dévolu sur un des îlots éloignés du lagon sud et sur les îles Chesterfield-Bampton, vantant un « véritable paradis pour les amoureux de la nature, offrant à ses rares visiteurs de longues plages immaculées, refuges de milliers d'oiseaux marins ». Dans les faits, la taille imposante d'un navire hôtel mouillant à proximité des îlots et les centaines de touristes débarqués en masse menacent la reproduction des oiseaux marins.

L'inventaire des perturbations ou déprédations sur les colonies ne serait pas complet si l'on ne mentionnait pas aussi les actions de recensement réalisées en dehors d'un encadrement scientifique adéquat et qui induisent un risque supplémentaire de dérangement et de piétinement, ou encore le programme de «veille sanitaire » conduit par les autorités vétérinaires dans les années 1990 et qui a conduit au sacrifice de nombreux oiseaux marins des îles Chesterfield et d'Entrecasteaux.

\section{Pistes pour les recherches futures sur les oiseaux marins de Nouvelle-Calédonie}

Avec la miniaturisation des instruments électroniques, il est maintenant possible d'équiper les oiseaux marins avec des balises Argos, des récepteurs GPS et d'autres instruments comme des enregistreurs de plongée et des capteurs de rythme cardiaque afin de mieux connaître leur biologie, leurs déplacements, ainsi que leur comportement entre deux passages au nid. Dans l'avenir, il devrait être possible d'automatiser le recueil de ce type de données en installant des récepteurs à proximité des nids, qui pourront interroger les instruments équipant les oiseaux à leur retour de mer, sans besoin d'intervention humaine et en minimisant, de ce fait, le risque de dérangement. Outre les connaissances qui seront ainsi acquises sur les oiseaux, il est désormais possible d'envisager $d$ 'utiliser les oiseaux comme auxiliaires de recherche. Ceux-ci seront susceptibles de nous renseigner, par exemple, sur la température de la mer, ou bien sur la nature, la profondeur et la densité des proies, soit autant d'informations qui nous permettront de mieux comprendre l'écologie de la mer de Corail et l'impact des changements subis par les écosystèmes océaniques.

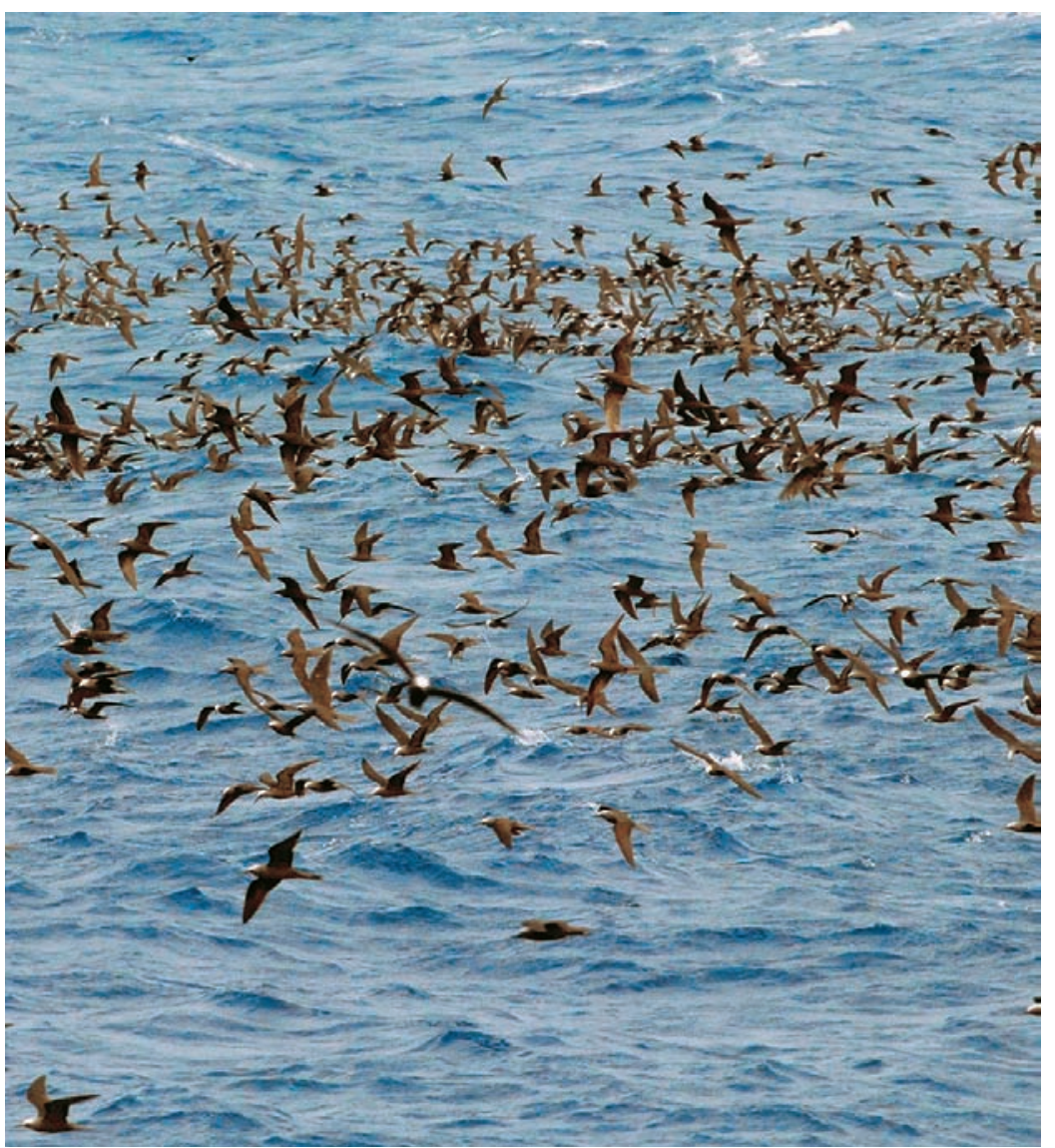

Noddis noirs (Anous minutus) en action de pêche au large de la passe de l'lle Longue, Chesterfield. @ IRD/P. Borsa 


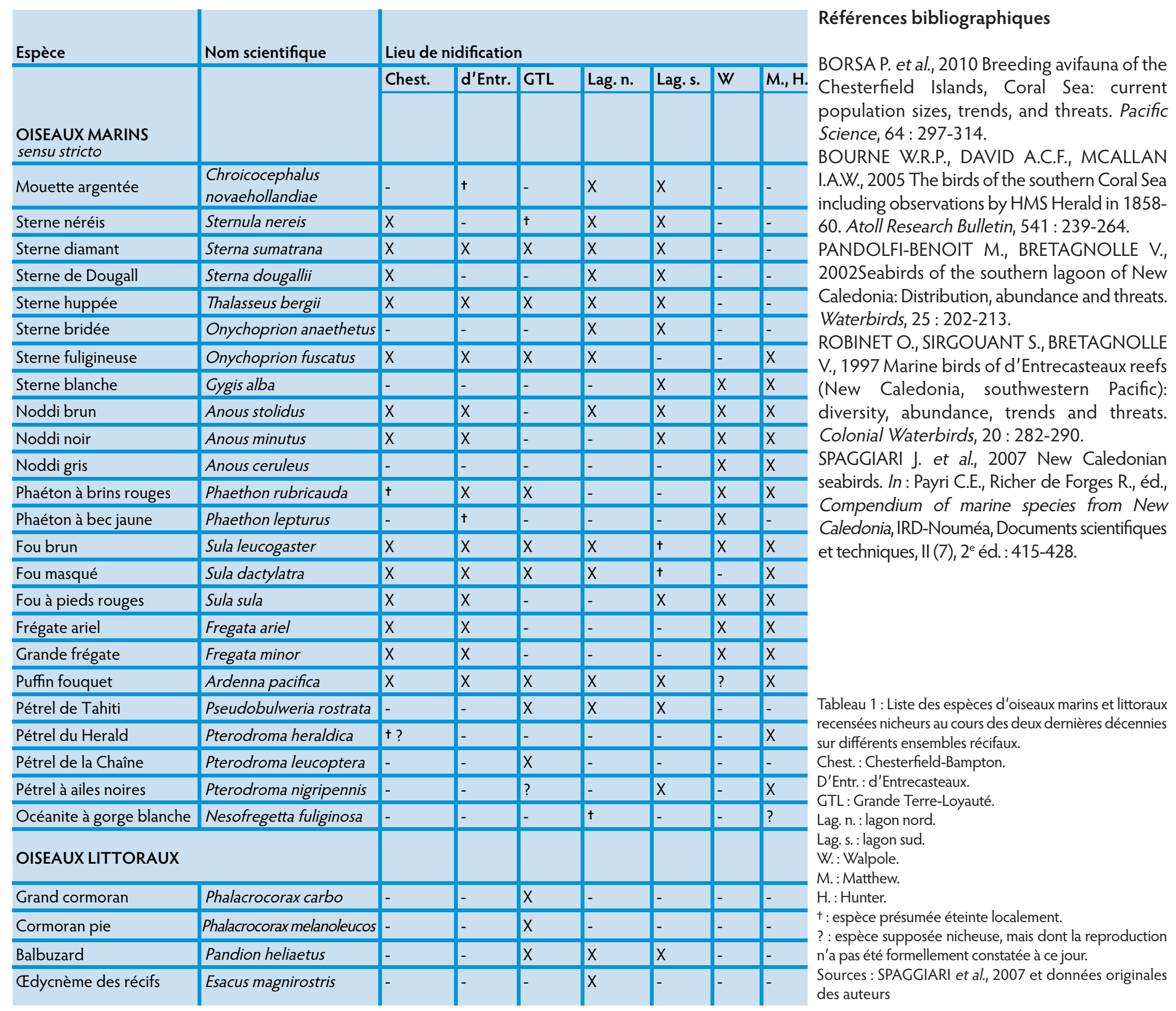




\section{Chapitre 21 \\ L'inventaire de la biodiversité récifale pour le partage des connaissances}

Éléonore Vandel, Sylvie Fiat, Jeanne de Mazières, Laurent Poncet et Pascale Joannot

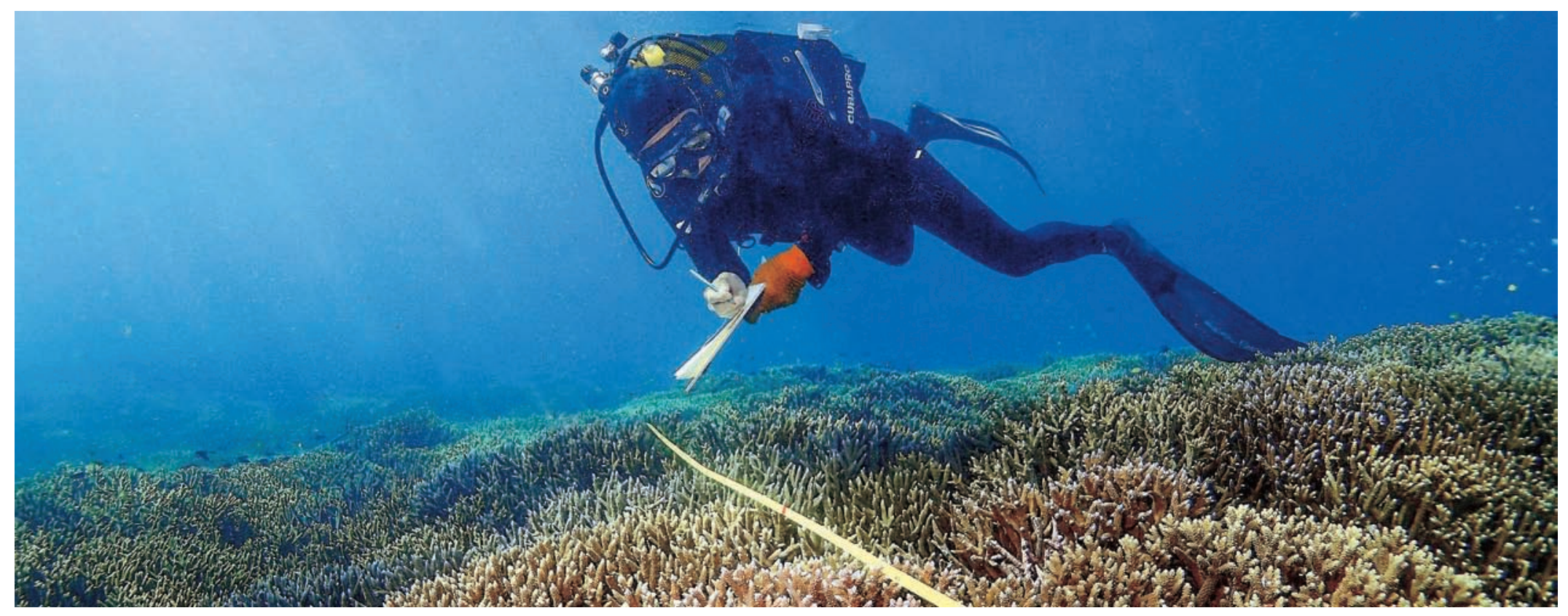

Relevé d'observation en plongée autonome sur le récif de Larégnère, mars 2017. ๑ IRD/S. Andréfouët

L'Ifrecor a lancé en 2006 un programme d'intérêt transversal sur la biodiversité des récifs coralliens des outre-mer. Ce projet piloté de 2008 à 2016 au Muséum national d'histoire naturelle par la délégation à l'outre-mer et mis en œuvre par le Service du patrimoine naturel (SPN) avait pour objectif la collecte de l'ensemble des données sur la biodiversité récifale des outre-mer et la mise à disposition du plus grand nombre sur le site de l'Inventaire national du patrimoine naturel (INPN ${ }^{3}$ ).

${ }^{3} \mathrm{http}: / /$ inpn.mnhn.fr

${ }^{4}$ https://inpn.mnhn.fr/telechargement/referentielEspece/referentielTaxo

\section{Une grande avancée sur l'inventaire de la biodiversité récifale}

En 2006, les informations sur la biodiversité récifale des outre-mer étaient très dispersées et aucune donnée relative à la biodiversité des récifs coralliens français n'était disponible. En 2016, au total plus de 24000 espèces marines pour l'ensemble des collectivités d'outre-mer possédant des récifs coralliens étaient intégrées au référentiel taxonomique national Taxref $\left(\mathrm{V} 10^{4}\right)$ mis en œuvre dans le cadre de l'INPN. 
Cet important travail réalisé grâce à l'action de l'Ifrecor n'est cependant qu'une faible partie du nombre d'espèces existantes. Grâce à ce programme, les cartes de répartition de nombreuses espèces ont pu être alimentées, et ainsi près de 300000 données d'occurrence ont été bancarisées dans les bases de données de l'INPN. Toutes ces données sont accessibles sur le site internet de l'INPN, et sont également reversées au GBIF (Global Biodiversity Information Facility ${ }^{5}$, système mondial d'information sur la biodiversité).

Le bilan réalisé dans le cadre de l'Ifrecor présente pour chaque collectivité d'outre-mer un résumé des résultats obtenus en 2015 (VANDEL et al., 2016). Ce travail n'a pu se faire que grâce aux nombreux partenariats avec les experts scientifiques et les gestionnaires de récifs coralliens, au travail des deux chargés d'études successifs de la délégation à l'outre-mer du Muséum (Julien Ringelstein et Éléonore Vandel), à l'implication de l'équipe du SPN qui l'a mis en œuvre, et notamment celle d'Olivier Gargominy (responsable de Taxref au SPN).

\section{Focus sur la Nouvelle-Calédonie}

Les récifs coralliens de Nouvelle-Calédonie constituent $50 \%$ de la superficie récifale nationale et présentent une diversité géomorphologique exceptionnelle.

Une partie des récifs et lagons est inscrite depuis 2008 au patrimoine mondial de l'Unesco. Le récif-barrière, long de 1500 km, est la deuxième plus grande barrière récifale au monde après la Grande Barrière australienne. On y observe à certains endroits un double, voire triple, récif-barrière. La Nouvelle-Calédonie possède $400 \mathrm{~km}^{2}$ d'herbiers de phanérogames et environ $260 \mathrm{~km}^{2}$ de mangroves.

\section{Listes d'espèces}

Les espèces marines de Nouvelle-Calédonie ont été recensées en 2007 dans un ouvrage collectif (PAYRI et RICHER DE FORGES (éd.), 2007). Plus de 50 taxonomistes ont été mis à contribution pour réaliser ${ }^{5}$ www.gbif.org

${ }^{6}$ https://inpn.mnhn.fr/espece/jeudonnees/37 ou http://lagplon.ird.nc ce travail qui porte sur environ 43 grands groupes. Les listes d'espèces de certains groupes ont pu être actualisées par la suite. Notamment, les travaux de l'IRD ont ainsi pu compléter les listes d'espèces d'algues (travaux de Claude E. Payri), de foraminifères, de scléractiniaires (travaux de Francesca Benzoni, en collaboration avec Michel Pichon), de crustacés (en collaboration avec l'IRENav, Institut de recherche de l'école navale), et de poissons (travaux de Michel Kulbicki, en collaboration avec l'université de la Nouvelle-Calédonie et le muséum $d$ 'histoire naturelle de Stuttgart). Le MNHN actualise régulièrement ses listes, notamment celle des mollusques (330 espèces nouvelles pour la science entre 2007 et 2015) et poursuit ses travaux sur les parasites de poissons.

\section{Zoom sur les algues}

Le compendium des espèces marines de Nouvelle-Calédonie recensait 443 espèces de macro-algues en 2007. Cette liste d'espèces a pu être complétée par la suite dans Taxref grâce à des publications récentes, ainsi qu'aux données de l'IRD (Lagplon $\left.{ }^{6}\right)$. On compte désormais plus de 500 espèces d'algues (Taxref, v10). Quelques espèces nouvelles ont été décrites, comme Sebdenia cerebriformis (N'YEURT et PAYRI, 2008), dans divers lieux du sudouest Pacifique, dont la Nouvelle-Calédonie.

\section{Répartition des espèces}

Lagplon, la collection des données de biodiversité marine de l'IndoPacifique de l'IRD de Nouméa, a été utilisé pour la diffusion sur l'INPN de près de 5000 données recensant près de 1000 espèces de la flore et de la faune benthique des eaux côtières de Nouvelle-Calédonie (encadré 17). Un partenariat avec l'IRD a également permis de bancariser et de diffuser toutes leurs données d'occurrence de poissons issues d'études réalisées entre 1984 et 2005 par Michel Kulbicki et son équipe. En tout, près de 160000 données concernant environ 1000 espèces de poissons sont en ligne. Plus de 25000 données d'occurrence provenant des collections du MNHN sont désormais diffusées (mollusques, échinodermes et crustacés). 


\section{0 ans de données de biodiversité marine géoréférencées}

Sylvie Fiat et Claude E. Payri

Dans les années 1970 débute la plongée hyperbare au centre Orstom de Nouméa. Mais c'est réellement avec la mise en place des programmes de pharmacochimie dès 1977 avec le Snom (Substances naturelles d'origine marine) suivi du Smib (Substances marines d'intérêt biologique) en 1982 et l'accroissement des moyens à la mer avec le Vauban et la Santa Maria en 1976 puis le Dawa en 1977 que les plongeurs biologistes de l'Orstom vont faire découvrir aux scientifiques l'incroyable biodiversité marine des récifs et lagons de la Nouvelle-Calédonie et de ses dépendances. Avec l'arrivée de l'Alis en 1987, les prospections vont s'intensifier et fournir de très nombreux spécimens qui constitueront les collections de références étudiées par un réseau international de taxonomistes, hébergées en partie au Muséum national d'histoire naturelle et au centre IRD de Nouméa. Les plongeurs, passionnés et très investis, consignent toutes leurs observations dans leurs cahiers et constitueront une banque $d^{\prime}$ 'images très riche sous divers formats, d'abord en argentique puis en numérique. Très tôt, ils créent une base de données qu'ils nomment « Lagplon ».

60 ans plus tard, les connaissances ont évolué et se sont accumulées. Les espèces ont été en grande partie identifiées par les taxonomistes et publiées dans divers ouvrages de la collection «Faune et flore » de l'IRD (ex-Orstom) et de très nombreux journaux scientifiques. Après un remarquable travail de mise à jour des données, passant par la numérisation de millier de photographies, et le développement du portail internet, les 20000 spécimens en collection et les 25000 observations sous-marines géoréférencées sont accessibles en quelques clics grâce à des cartes interactives et des moteurs de recherche modernes.
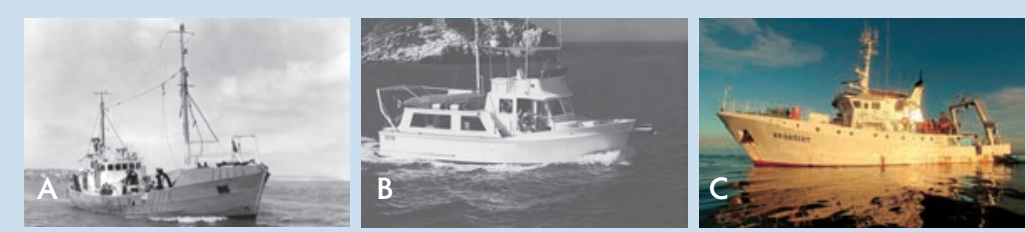

Les premières prospections biologiques en scaphandre autonome ont débuté à bord de l'embarcation la Santa Maria, mise en service en 1975, elles ont continué avec Le Vauban (A), chalutier de 24,5 m armé pour les programmes d'halieutique et d'hydrologie arrivé en 1976 à Nouméa. L'acquisition du Dawa (B), trawler de 11 m en 1977 faisait prendre un tournant particulier aux prospections en plongée dans les eaux lagonaires et récifales de la Grande Terre. L'Alis (C), bâtiment de $28,40 \mathrm{~m}$ prend le relais en 1987 jusqu'à ce jour en naviguant au-delà de la ZEE calédonienne.

(c) A et $\mathrm{B}:$ IRD/Base INDIGO, C:IRD/S. Andréfouët

\section{ESPÈcE Cantharellus Jebb/ Hoeksema, 1993}

Specimen de retetrence Lagplon: : HS29231

Classification : Noimalas

EWORMSINPN :

DEscription de L'EsptCE

Commentaire: Coralium artached. Each coral wen several movers. The corallum

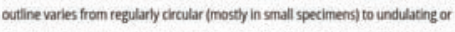

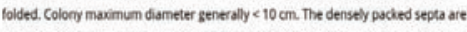

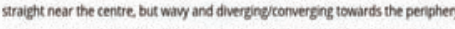
The septa of lower orderes are high and very thick, those of highere orders are low and thin. The septal margins are ectier trayed of finely denctated. Corallum wall solid and not grandisted Cossae are only usible where the corallum periphery extends begound the substratum. The costite sere poorly dertloped and neary of equal isie. They are ornumented by smple granular spines

Protection : basse

Bibliographie (RefeterencervRL):

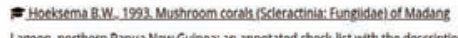
ated checkllistimith the description

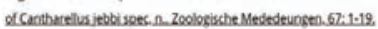
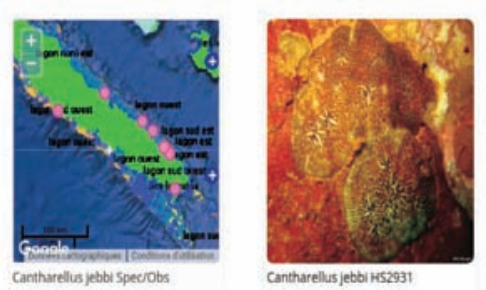

USTE DEs SPtCimens associts

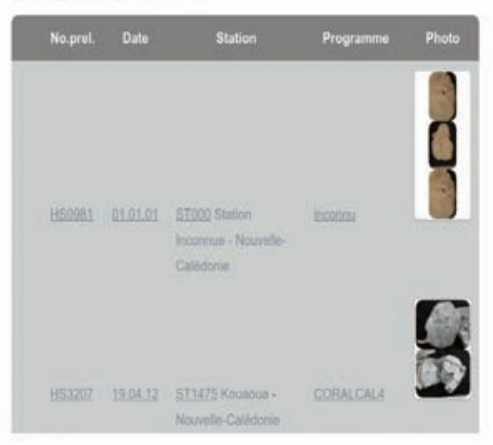

Les données bancarisées dans Lagplon renseignent sur les espèces et leur distribution. Ici, un exemple sur une espèce de corail dur. ๑ Lagplon 


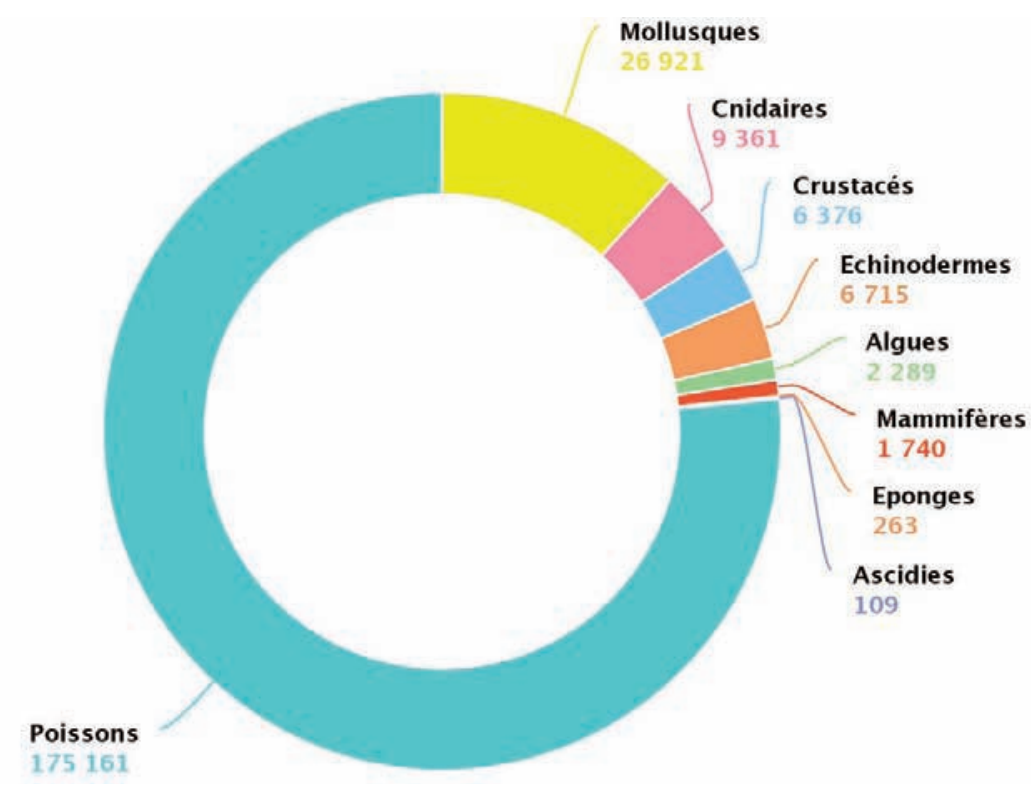

Nombre de données marines diffusées pour la Nouvelle-Calédonie par groupe taxonomique. Source : INPN, novembre 2017

Les données du programme régional de développement des pêches océaniques et côtières de la CPS (Communauté du Pacifique) ont ajouté 10800 observations de poissons et 7000 observations d'invertébrés marins à l'inventaire national.

Enfin, les données collectées en 2001 lors du Rapid Assessment Protocol de la région du Diahot (province Nord de la NouvelleCalédonie, WWF et EPHE) ont permis la mise à jour de plus de 700 cartes de répartition d'espèces de scléractiniaires et de poissons.

\section{Perspectives}

Certains groupes taxonomiques sont encore peu connus en Nouvelle-Calédonie, comme les annélides ou les hydraires. De plus, de nombreuses zones n'ont pas encore été prospectées, les connaissances sur les invertébrés marins restent à compléter. Dans cette perspective, le programme « La planète revisitée », mené par le MNHN, a permis de lancer depuis 2016 une série d'expéditions naturalistes afin de réaliser l'inventaire en Nouvelle-Calédonie de la biodiversité dite «négligée », impliquant de nombreux partenaires néo-calédoniens, nationaux et internationaux.

Par ailleurs des coopérations de plus en plus prononcées et opérationnelles entre l'UMS PAtriNat et la plupart des organismes producteurs de données français permettent de compléter l'inventaire national (INPN) avec un taux de plus de 5 millions d'occurrences par an comme le décrit l'indicateur de l'Observatoire national de la biodiversité $(O N B)^{7}$.

\footnotetext{
${ }^{7}$ http://indicateurs-biodiversite.naturefrance.fr/indicateurs/evolution-du-volume-de-donnees-disponibles-sur-la-biodiversite\#overlay-context =les-travaux-de-lonb-a-lechelle-locale
} 


\section{Partie 3 \\ Des récifs impactés mais résistants}

Coordination :Jérôme Aucan

Les récifs coralliens de Nouvelle-Calédonie subissent des pressions dues à l'activité humaine, et en particulier l'activité minière. À l'échelle globale, les émissions humaines de gaz à effet de serre ont pour conséquence un réchauffement et une acidification des océans, qui ont un impact à l'échelle locale sur les récifs coralliens (blanchissement). Les îlots coralliens de Nouvelle-Calédonie sont, de plus, soumis aux effets de la montée du niveau de la mer. Ces pressions humaines, directes ou indirectes, s'ajoutent aux pressions naturelles existantes, comme les invasions d'Acanthaster, l'étoile de mer dévoreuse de corail. Géographes, géologues, physiciens, chimistes et biologistes nous mettent en garde contre ces pressions et les risques que peuvent encourir les récifs, tout en maintenant un optimisme mesuré quant à la résilience des récifs coralliens de Nouvelle-Calédonie. 



\section{Les récifs et les pressions anthropiques, de la mine au lagon}

Gilbert David

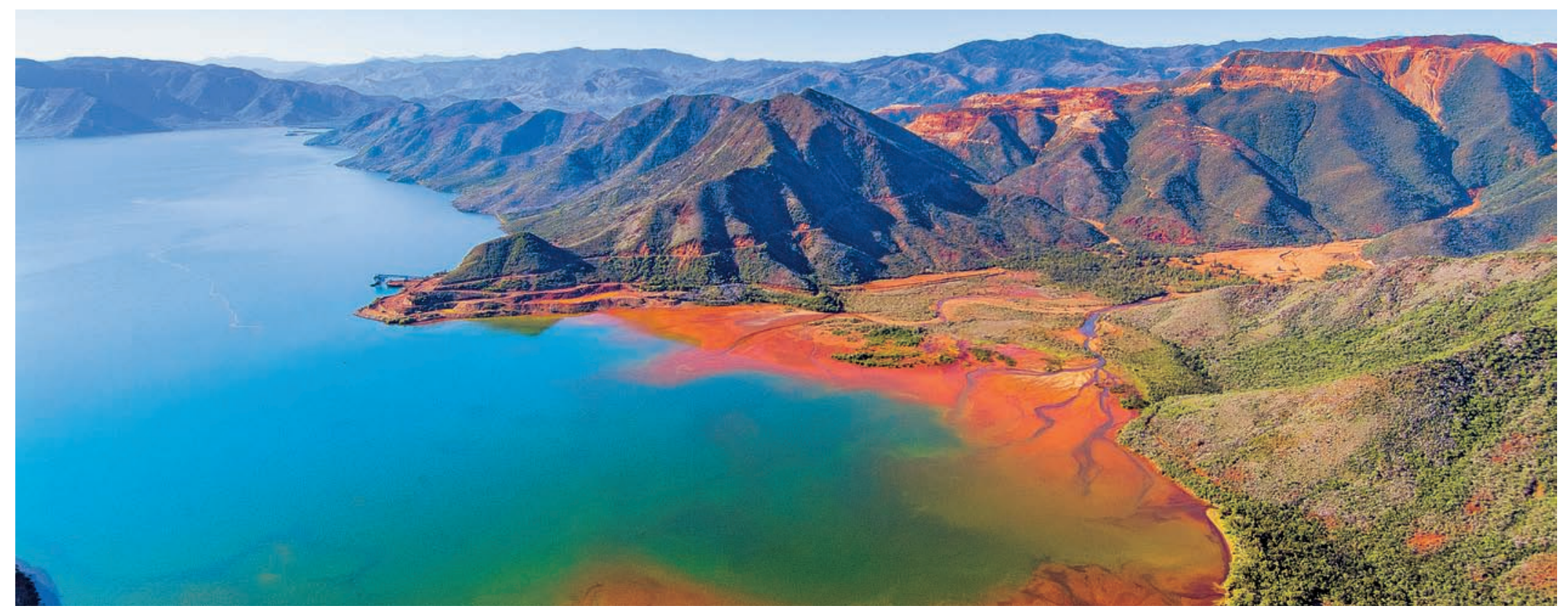

Vue du ciel du massif minier de Nakéty, côte Est, où le rouge tranche avec le vert de la végétation et le bleu de l'océan. @ P.-A. Pantz

\section{La Nouvelle-Calédonie vue du ciel, la dialectique rouge et bleue}

Vue du ciel, la grande terre de Nouvelle-Calédonie compose un ensemble coloré où dominent le vert des forêts de la chaîne centrale et des mangroves du bord de mer, le bleu du lagon et le rouge des massifs miniers. Ces couleurs peuvent être interprétées de deux manières différentes. Si la couleur dominante est le rouge, les mines de nickel à ciel ouvert sont les éléments structurants du paysage et le lagon néo-calédonien est perçu comme un écosystème menacé, réceptacle des pollutions terrigènes générées par l'activité minière. À l'opposé, on peut occulter la terre et se polariser sur le « plus grand lagon du monde » pour reprendre l'expression de LABOUTE et al. (1999). La Nouvelle-Calédonie est alors essentiellement parée de la couleur bleue de son milieu marin. Cette dialectique rouge et bleue est toujours structurante dans les débats sur l'avenir économique du pays. Chacun reconnaît aujourd'hui l'exceptionnel capital naturel que représentent les récifs et les lagons de NouvelleCalédonie qui couvrent une superficie d'environ $40000 \mathrm{~km}^{2}$. Le bilan des connaissances sur la biodiversité marine fait ainsi état de 15000 espèces et de nombreuses zones restent encore mal connues (PAYRI et RICHER DE FORGES, 2007). Mais, depuis plus d'un siècle, l'exploitation du nickel et le secteur métallurgique qui lui est associé dominent le secteur productif de la Nouvelle-Calédonie. Sur la décennie 2006-2016, ils représentent $90 \%$ de la valeur des 
exportations, soit 1,040 milliard d'euros en 2016 malgré un cours du nickel très bas sur le marché international (8 500 dollars la tonne en janvier 2016 quand il atteignait le double en 2011). Ce maintien de la valeur des exportations s'explique par les niveaux record de production de minerai et nickel métal en 2016. Jamais dans l'histoire de la NouvelleCalédonie, l'exploitation minière n'a été aussi intense. Chaque année la couleur rouge gagne ainsi en surface vue du ciel de Nouvelle-Calédonie.

\section{Des pressions dominées par l'action de l'homme : bassins-versants et centres urbains}

Bien que la Nouvelle-Calédonie soit affectée par le changement climatique, comme le reste de la région, le futur des récifs dépend également largement des activités que les humains déploient sur le littoral et les bassins-versants et qui génèrent des pressions dites anthropiques comme les pollutions urbaines ou agricoles et les perturbations induites par l'exploitation du nickel. Depuis l'ouverture de la première unité métallurgique en 1877 à Nouméa, les mines à ciel ouvert se sont multipliées, laissant des plaies béantes sur les flancs des montagnes. Or la Grande Terre de NouvelleCalédonie est l'une des régions du sud-ouest du Pacifique la plus touchée par les cyclones (8 à 9 cyclones et dépressions tropicales par an), les pluviométries journalières voisinent alors les records mondiaux et les bassins-versants sont souvent pentus. Dans ce contexte, réduire l'érodabilité des sites miniers est une priorité, ce qui passe par la gestion des eaux de ruissellement et la revégétalisation ${ }^{8}$ en plantant soit des espèces indigènes à croissance rapide comme Acacia Spirorbis et Casuarina collina, soit un cortège d'espèces de la flore locale des terrains miniers (L'HUILLIER et al., 2010). L'érosion des sols résultant de mauvaises pratiques agricoles, du surpâturage des animaux d'élevage (bovins), d'une surfréquentation des cerfs sauvages non endémiques ou de feux intempestifs ${ }^{9}$ peut également impacter localement les lagons. En période de pluies fréquentes et intenses, l'usage des engrais et des pesticides peut également poser des problèmes localement, notamment en province Sud, qui concentre la majeure partie des fermes de plus de 100 ha et les exploitations maraîchères.
En zone urbaine, le faible traitement des eaux usées est le problème majeur. En raison de la macrocéphalie du pays (DAVID et al., 1999 ; BOUARD et al., 2016) - plus de $70 \%$ de la population vit dans le Grand-Nouméa, formé de la capitale et de ses trois communes limitrophes (Paita, Dumbéa et le Mont-Dore) - et dans la conurbation urbaine de la province Nord qui se déploie sur la zone Voh-KonéPouembout, rares sont les chefs-lieux de communes qui dépassent les 1000 habitants en dehors de cet ensemble, en sorte que développer l'assainissement collectif est très coûteux.

\section{Les pressions provenant du lagon}

En raison de la taille de l'espace halieutique exploitable $\left(7280 \mathrm{~km}^{2}\right.$, dont $5490 \mathrm{~km}^{2}$ de récifs coralliens et $1800 \mathrm{~km}^{2}$ de fonds meubles de lagon), l'impact global de la pêche sur les formations récifales reste faible. Toutefois, localement, les risques de surexploitation existent, en particulier aux alentours des centres urbains, en raison notamment de l'importance de la pêche plaisancière et des quotas par embarcation qu'autorisent les pouvoirs publics. Les espèces prisées sur le marché international sont également très vulnérables à la surexploitation. Il s'agit principalement des trocas (coquillage nacrier utilisé dans l'industrie textile de haute gamme pour la fabrication de boutons) et des holothuries (concombres de mer). La pêche de cet invertébré marin, très prisé du marché chinois, est en forte progression depuis 2006. La demande internationale annuelle qui est de 70000 t de produit séché a du mal à être satisfaite. Les prix peuvent attendre 2000 euros le kilogramme sur le marché international. La pression s'accroît donc sur les pays qui disposent encore de ressources, ce qui explique les pêches illégales perpétrées par des navires vietnamiens en 2016 et 2017 dans le lagon néo-calédonien (chap. 31 ).

Dans beaucoup de pays du monde, l'aquaculture est une activité très impactante pour l'environnement. En Nouvelle-Calédonie, la petite taille et le faible nombre d'élevages de crevettes (18 entreprises pour une superficie moyenne de $40,2 \mathrm{ha}$ ), les densités réduites des crevettes (rendement moyen de 2,5 t/ha/an) et l'interdiction de l'utilisation de fertilisants chimiques et de pesticides, réduisent les

\footnotetext{
${ }^{8}$ Lorsque les sites sont antérieurs à 1975, leur réhabilitation est à la charge de l'État français et à celle du gouvernement de Nouvelle-Calédonie lorsqu'ils sont postérieurs à cette date.
} ${ }^{9}$ Selon les années, les feux peuvent détruire des dizaines de milliers d'hectares. 


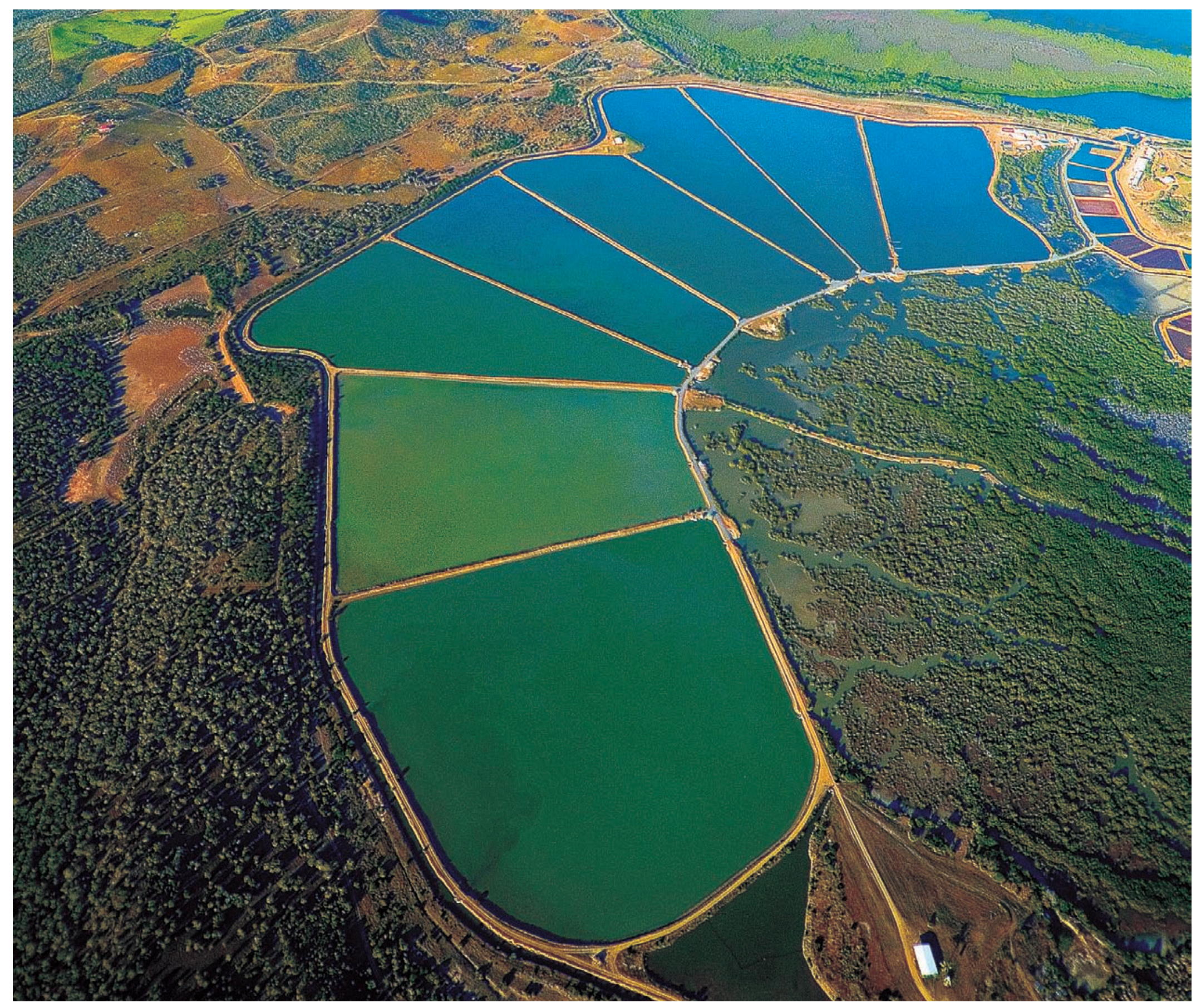

Ferme d'aquaculture de crevettes sur la côte ouest de la Grande Terre. ๑ P.-A. Pantz 
impacts des effluents sur les eaux du littoral. La localisation des bassins sur 723 ha de tannes (zones sursalées d'arrière-mangrove) limite la dégradation du couvert de mangrove, contrairement à ce qui est observé au niveau mondial pour les élevages de crevettes extensifs. La préservation de l'environnement naturel est par ailleurs une condition nécessaire à l'image de qualité du produit néo-calédonien et donc à l'exportation vers les marchés étrangers. Hormis l'élevage des crevettes, l'aquaculture reste peu développée. En 2017, elle se limite à deux élevages en cage, l'un concernant le pouate (Lutjanus sebae), l'autre le picot rayé (Siganus lineatus). En raison de la taille réduite de ces élevages, l'impact sur le lagon reste faible.

En dehors de la pêche et de l'aquaculture, la fréquentation des plans d'eau et des îlots, notamment à proximité de Nouméa, peut également impacter la qualité des écosystèmes (chap. 33). En zone rurale, les prélèvements de sable en zone peu profonde peuvent accroître de manière significative l'érosion côtière.

\section{L'inscription au patrimoine mondial et la réduction des pressions}

L'année 2008 constitue une date remarquable pour les récifs de Nouvelle-Calédonie avec l'inscription au patrimoine mondial de l'Unesco de $15808 \mathrm{~km}^{2}$ de barrière récifale et de lagon, soit un accroissement par 35 de la superficie protégée qui auparavant s'élevait à $446 \mathrm{~km}^{2}$. Six sites sont concernés, deux dans chacune des trois provinces. Deux espaces tampons sont associés à ce patrimoine. Le premier couvre $8206 \mathrm{~km}^{2}$ du Grand Lagon Sud et des eaux adjacentes; il inclut la zone côtière à proximité de l'usine métallurgique de Goro, dont les 26 km d'émissaire permettent l'évacuation vers le large d'eaux usées dont le niveau de toxicité ne doit pas dépasser un seuil maximal.

Le second couvre la plupart des bassins-versants des communes de La Foa, Moindou et Bourail et un tiers de l'espace terrestre au nord est de la Grande Terre, soit un total de $5146 \mathrm{~km}^{2}$. Hormis le Grand Nouméa, ces bassins-versants sont les espaces de la province Sud les plus impactés par l'homme. Leur classement comme espace tampon constitue une opportunité pour adopter une gestion intégrée des bassins-versants et du littoral. Au final, la mise en patrimoine des récifs de NouvelleCalédonie comme la création du parc naturel de la mer de Corail en 2014 constitue une réelle opportunité pour que des politiques publiques plus respectueuses de l'environnement, comme la généralisation du traitement des eaux usées, soient mises en place, et que les comportements individuels se modifient de manière à réduire les pressions sur le milieu récifal, l'ambition étant que d'ici 20 à 30 ans la Nouvelle-Calédonie se positionne comme un des rares endroits de la planète où l'écosystème récifal soit en bon état.

\section{Références bibliographiques}

BOUARD S. et al. (éd.), 2016 La Nouvelle-Calédonie face à son destin, quel bilan à la veille de la consultation sur la pleine souveraineté ? Paris, Karthala, 524 p. DAVID G., GUILLAUD D., PILLON P., 1999 La Nouvelle-Calédonie à la croisée des chemins (1989-1997). Paris, Société des Océanistes-Orstom, 324 p.

JOLLIT I. et al., 2010 The spatial structure of informal coastal fisheries in New Caledonia. Marine Pollution Bulletin, 61 (7-12):585-597.

L'HUILLIER L., JAFFRE T., WULFF A. 2010 Mines et environnement en Nouvelle-Calédonie : les milieux en substrats ultramafiques et leur restauration. Nouméa, IAC Édition, $412 \mathrm{p}$.

LABOUTE P., FEUGA M., GRANDPERRIN R. 1999 Le plus grand lagon du monde, Nouméa, Éditions C. Ledru, $273 \mathrm{p}$.

PAYRI C.E., RICHERDEFORGESB. (éd.), 2006 Compendium ofmarine species from New Caledonia, IRD-Nouméa, Documents scientifiques et techniques, II (7), 2 éd., 435 p. 


\section{Les métaux et leurs impacts sur les coraux}

Tom Biscéré, Anne Lorrain, Riccardo Rodolfo-Metalpa, Richard Farman, Antoine Gilbert, Andy Wright et Fanny Houlbrèque

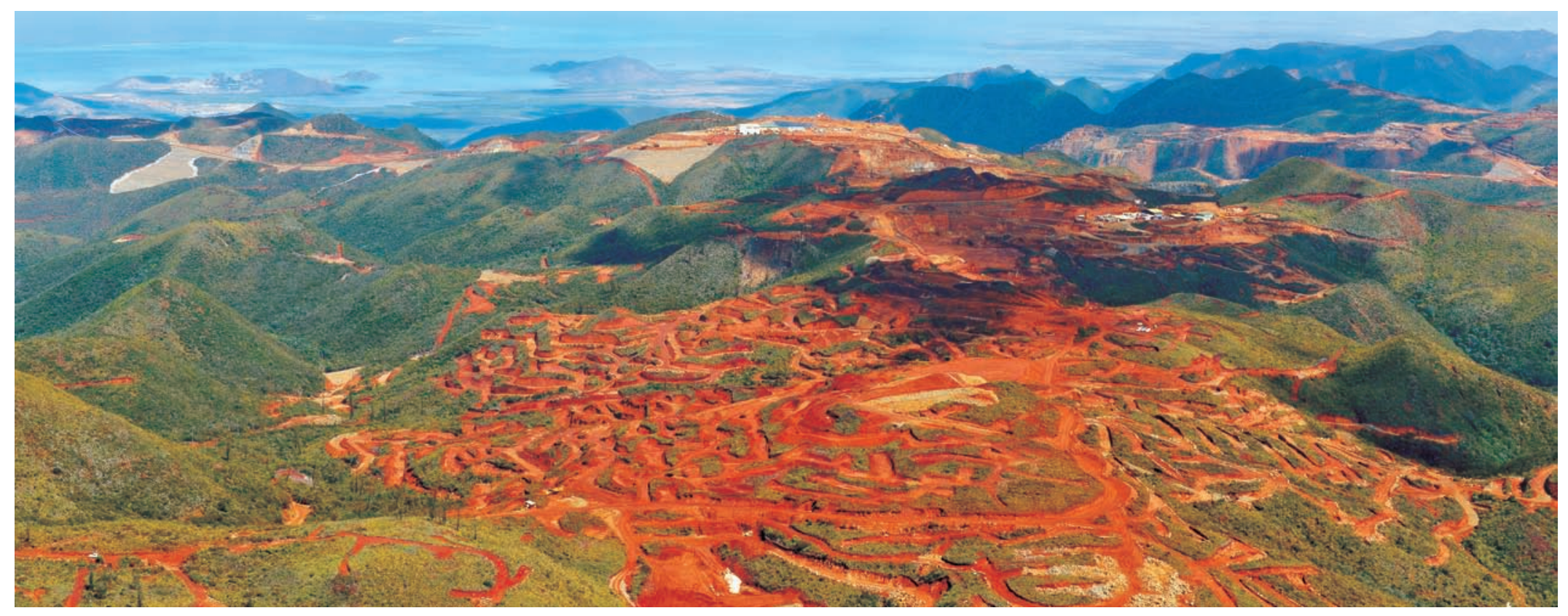

Sols mis à nu par une exploitation minière dans le nord de la Grande Terre (Nouvelle-Calédonie). @ Koniambo Nickel SAS/A. Wright

\section{La pollution métallique, un problème mondial}

Les récifs coralliens se sont largement dégradés à l'échelle globale au cours de la dernière décennie sous l'influence des activités anthropiques (HUGHES et al., 2003). Ils doivent faire face à de nombreuses menaces : maladie, surpêche, destruction des habitats et dégradation de la qualité des eaux. Cette dégradation des eaux est due à plusieurs facteurs : à la déforestation et aux opérations minières, qui augmentent l'érosion des sols; aux pollutions agricoles et domestiques ainsi qu'aux opérations de dragage, qui ne cessent de se multiplier le long du littoral. Les apports en métaux constituent également une forme de pollution; ils se font par l'intermédiaire du lessivage des sols, des effluents industriels, de la contamination atmosphérique sous forme particulaire et également principalement par l'exploitation minière. Par ailleurs, les émissions automobiles, les boues d'épuration, les déblais de dragage, les peintures antifouling apportent également des quantités conséquentes de métaux dans les océans. Cette pollution métallique affecte de nombreux récifs de par le monde (par exemple au Costa Rica, à Panama, en mer Rouge, en Thailande, à Tuvalu, à Puerto Rico). Parmi eux, les récifs de Nouvelle-Calédonie sont particulièrement concernés par ce problème. La Nouvelle-Calédonie se trouve en effet parmi les cinq producteurs majeurs de nickel dans le monde. Ses mines à ciel ouvert nécessitent d'importantes excavations qui mettent à nu les sols et augmentent considérablement leur érosion hydrique et 
éolienne. Tout ceci multiplie l'apport au lagon de particules riches en métaux via des eaux de ruissellement chargées de sédiments ou la pollution atmosphérique, avec le risque d'impacter le fonctionnement des récifs et leur biodiversité.

\section{Quand il y a trop de métaux dans l'eau...}

Les effets sur les coraux d'une forte sédimentation sont désormais bien connus. Une sédimentation élevée réduit tout d'abord la quantité de lumière disponible et diminue ainsi la capacité des Symbiodinium à réaliser leur photosynthèse et engendre généralement des taux de croissance plus faibles. Dans les cas extrêmes, une sédimentation élevée peut même être source de blanchissement des colonies et entraîner leur mort partielle ou totale (FABRICIUS, 2005).

Les effets des métaux dissous associés à ces fortes charges sédimentaires sont, eux, beaucoup moins étudiés. Même si l'on sait dorénavant que les coraux possèdent une exceptionnelle capacité de bioaccumulation des métaux, aussi bien dans leurs tissus que dans leur squelette, les études expérimentales sur les effets des métaux sur les coraux ont principalement porté sur leur reproduction et leurs jeunes stades de vie. Ces études ont démontré qu'un apport élevé en métaux entraînait une réduction du

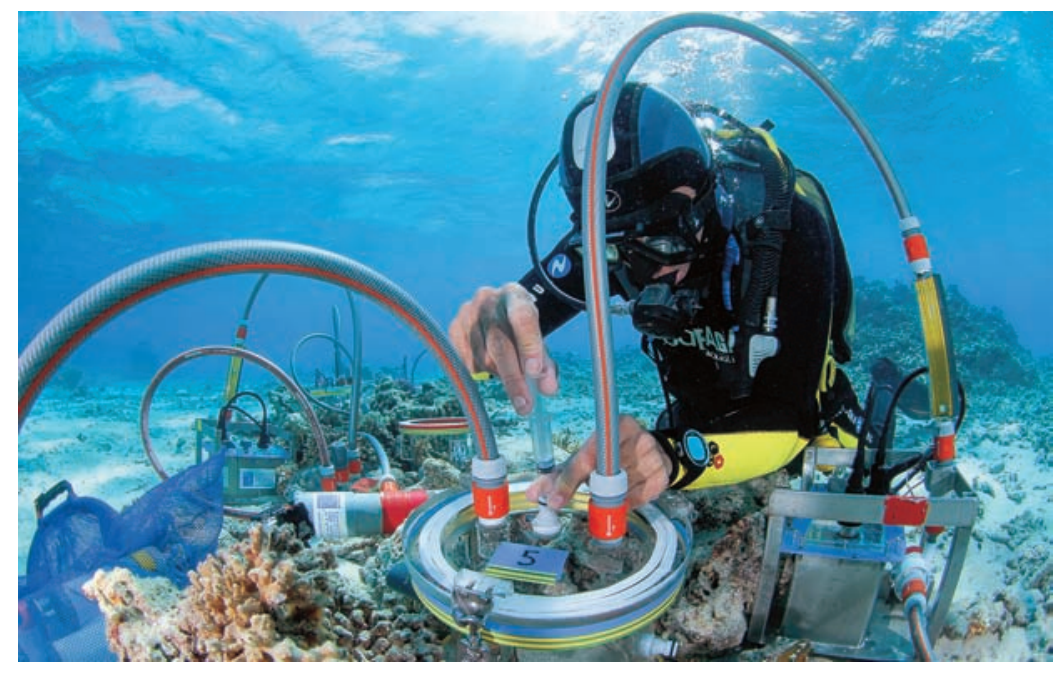

Incubations de colonies coralliennes dans des enceintes permettant de tester directement sur le récifl'effet d'un apport en nickel ou en cobalt sur la calcification et la photosynthèse des coraux. @ CNRS/E. Amice succès de la reproduction; une diminution de la fixation et du taux de survie des larves (REICHELT-BRUSHETT et HARRISON, 2005) ; une modification des taux de photosynthèse conduisant à une diminution de la calcification et de la croissance des coraux pendant leurs premiers stades de vie ; une perte des Symbiodinium dans les tissus coralliens et finalement une augmentation de la mortalité des coraux. Il est cependant très important de noter que toutes ces études expérimentales ont utilisé des niveaux exceptionnellement élevés de métaux : 100 voire 1000 fois supérieurs aux concentrations mesurées in situ, par exemple dans le lagon néo-calédonien.

\section{Qu'en est-il des coraux du lagon néo-calédonien ?}

Au niveau des récifs coralliens de Nouvelle-Calédonie, des études supplémentaires ont été menées pour comprendre les effets d'une exposition régulière des récifs proches des côtes, aux pollutions métalliques. Une série d'expériences sur le terrain et en laboratoire a permis de mettre en évidence les effets de concentrations « représentatives » de ce qui est mesuré dans le lagon, sur le métabolisme des coraux. Les effets de deux métaux, particulièrement abondants dans les eaux côtières en raison des activités minières de la Nouvelle-Calédonie : le nickel et le cobalt, ont ainsi été testés.

Concernant le nickel, bien que les concentrations dans l'eau soient généralement autour de 0,1 à $0,5 \mu \mathrm{g} \mathrm{L}^{-1}$, des concentrations excédant $20 \mu \mathrm{g} \mathrm{L}^{-1}$ peuvent être mesurées dans certaines zones le long du littoral néo-calédonien. De façon surprenante, l'exposition ponctuelle des colonies coralliennes, à des concentrations modérées de nickel $\left(3,5 \mu \mathrm{g} \mathrm{L}^{-1}\right)$ ne s'est pas révélée néfaste pour elles mais a stimulé au contraire leur métabolisme en augmentant leur calcification (BISCERE et al., 2017). C'est la première fois qu'un effet bénéfique du nickel sur les coraux est enregistré. Une des hypothèses pouvant expliquer le rôle positif du nickel serait liée à l'activité de l'uréase, une enzyme dont le site actif contient du nickel (fig. 1).

Cette enzyme est responsable de la transformation de l'urée en ammoniac et carbone, qui sont ensuite utilisés dans les processus de calcification des coraux. Ainsi, une exposition temporaire à un apport modéré en nickel aurait stimulé l'activité de cette enzyme, puis boosté la production de $\mathrm{CO}_{2}$ et donc la calcification corallienne. 


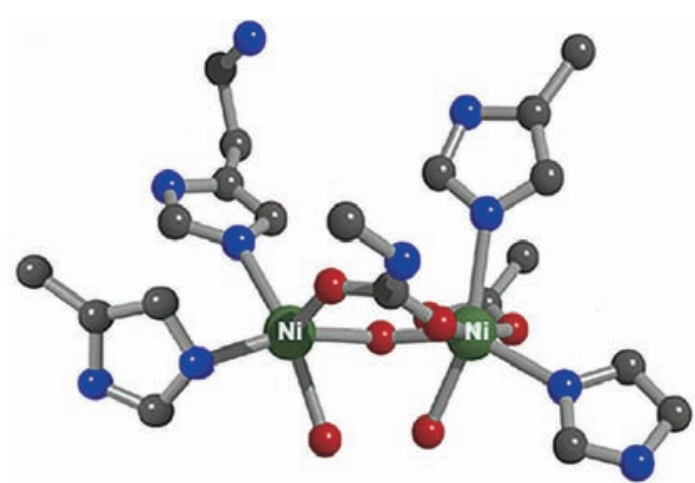

Figure 1 : Représentation chimique de l'uréase montrant le site actif contenant un double noyau de nickel. Source: www.rcsb.org

Concernant le cobalt, pour une augmentation très légère de sa teneur (dans la gamme des concentrations maximales rencontrées le long du littoral néo-calédonien, autour de $0,2 \mu \mathrm{g} \mathrm{L}^{-1}$ ), les taux de croissance des deux espèces de coraux testées ont été diminués d'un tiers et ont même chuté de $70 \%$ lorsque les teneurs en cobalt ont atteint $1 \mu \mathrm{g} \mathrm{L} \mathrm{L}^{-1}$ (BISCÉRÉ et al., 2015).

\section{Les métaux et les coraux, amis ou ennemis face au changement climatique?}

Aux stress locaux vient s'ajouter le changement climatique auquel les coraux devront désormais faire face. Les modèles climatiques prédisent un réchauffement atmosphérique de 2 à $4^{\circ} \mathrm{C}$ pour les 30 années à venir (IPCC, 2014). Ce réchauffement a déjà déclenché depuis ces 30 dernières années, des événements de blanchissement massif (c'est-à-dire la perte des algues symbiotiques dans les tissus coralliens, voir chap. 25) dans tous les récifs mondiaux. Par ailleurs, l'augmentation simultanée de la concentration en $\mathrm{CO}_{2}\left(\mathrm{pCO}_{2}\right)$ dans les océans altère la chimie des eaux en réduisant notamment le $\mathrm{pH}$ (de 0,1 unité $\mathrm{pH}$ au cours du XXe siècle) et les concentrations en carbonate (IPCC, 2014).

La communauté scientifique estime que les taux de calcification des récifs coralliens auront diminué de 17 à $37 \%$ d'ici la fin du siècle. Jusqu'à présent, les impacts des changements climatiques sur les coraux ont été étudiés de façon isolée (uniquement augmentation de $\mathrm{CO}_{2}$ et/ou de température), en supposant que les coraux se trouvaient dans des zones épargnées par les pollutions anthropiques. Cette hypothèse étant malheureusement loin de correspondre à la réalité, il est primordial d'étudier la synergie entre ces multiples facteurs et leurs effets de cascade de manière à pouvoir identifier et prévenir les risques qui pèsent sur l'état de santé des récifs coralliens.

À l'heure actuelle, par exemple, il s'avère difficile de déterminer si des apports réguliers en métaux, comme c'est le cas en Nouvelle-Calédonie avec l'activité minière, vont amplifier ou non les effets néfastes du changement climatique sur les coraux. Ainsi, des travaux ont été menés en laboratoire, afin de tester les effets combinés de l'acidification et du réchauffement des eaux sur plusieurs espèces de coraux, également soumis à des teneurs plus élevées en cobalt et en nickel.

Il a ainsi été mis en évidence que, même si à température « normale », le nickel stimulait la calcification des coraux, lorsque la température est augmentée, le nickel diminue la croissance des coraux jusqu'à $37 \%$, amplifiant ainsi les effets négatifs du réchauffement des eaux. À l'inverse, des colonies incubées pendant un mois à une plus forte $\mathrm{pCO}_{2}$ (et donc un $\mathrm{pH}$ plus faible) et à des concentrations plus élevées en cobalt se sont montrées peu sensibles à l'acidification du milieu et sont parvenues à maintenir des taux de calcification équivalents aux coraux contrôles (maintenus à pH et concentrations en cobalt normales).

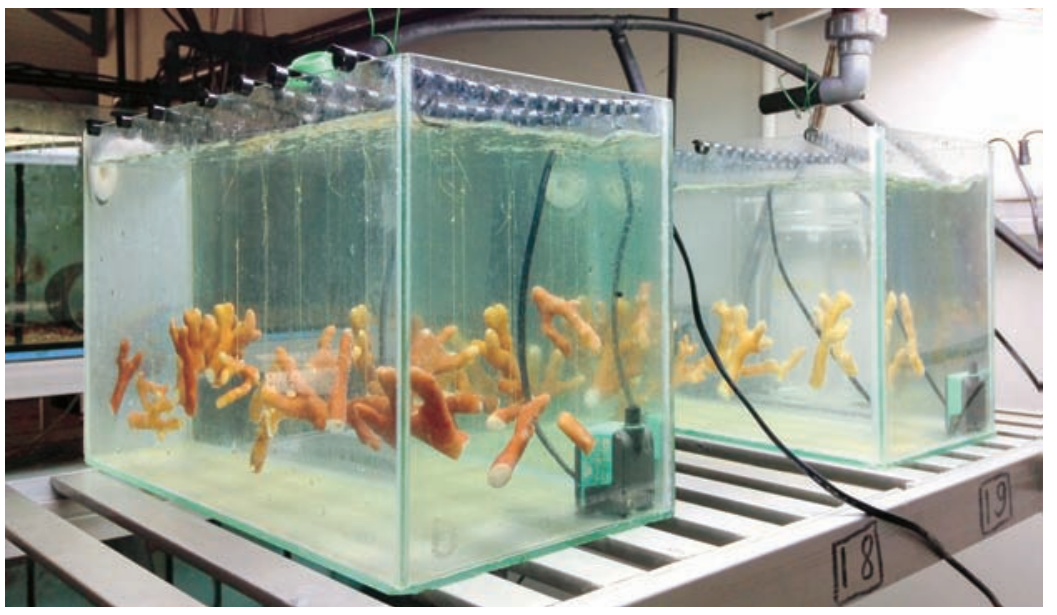

Dans les laboratoires de l'Aquarium des lagons à Nouméa, les colonies coralliennes sont soumises à différentes concentrations en cobalt et différentes températures. @ IRD/V. Meunier 


\section{Des réponses complexes face à des stress multiples}

Ces études mettent ainsi en évidence la complexité des réponses des coraux face à des stress multiples. Même si, en conditions «normales » de température, quelques métaux peuvent représenter une aide pour certains mécanismes physiologiques, ces effets se trouvent annulés voire inversés lorsque les coraux sont soumis simultanément à une élévation de la température des océans, comme cela est prévu d'ici la fin du siècle.

Ces travaux en laboratoire se sont focalisés sur les deux métaux les plus représentatifs du lagon néo-calédonien, mais il est bien connu que divers métaux sont déversés simultanément dans le milieu par les exploitations minières et les ruissellements vers le lagon. Très peu de données sont disponibles quant aux interactions entre les métaux. Un cocktail de métaux peut en effet augmenter ou réduire leur toxicité ou leur biodisponibilité pour les coraux. Il est également probable que des colonies coralliennes, pour lesquelles les taux de croissance diminuent déjà de $37 \%$ lorsqu'elles sont soumises à un apport chronique et modéré en nickel et à un stress de température, seront encore plus fragilisées si elles sont soumises à d'autres menaces telles que d'autres types de pollution ou une acidification des océans.

\section{Références bibliographiques}

BISCÉRÉ T. et al., 2015 Responses of two scleractinian corals to cobalt pollution and ocean acidification. Plos One, 10 (4), e0122898.

BISCÉRÉ T. et al., 2017 Nickel and ocean warming affect scleractinian coral growth. Marine Pollution Bulletin, 120 (1-2) : 250-258.

FABRICIUS K.E., 2005 Effects of terrestrial runoff on the ecology of corals and coral reefs: review and synthesis. Marine Pollution Bulletin, 50 (2) : 125-146. HUGHES T.P. et al., 2003 Climate change, human impacts and the resilience of coral reefs. Science, 301 : 929-933.

IPCC, 2014 Climate Change 2014: Synthesis Report. Contribution of Working Groups I, II and III to the Fifth Assessment Report of the Intergovernmental Panel on Climate Change [Core Writing Team, R.K. Pachauri and L.A. Meyer (eds)]. IPCC, Geneva, Switzerland, 151 p.

REICHELT-BRUSHETT A.J., HARRISON P.L., 2005 The effect of selected trace metals on the fertilization success of several scleractinian coral species. Coral reefs, 24 (4) : 524-534.

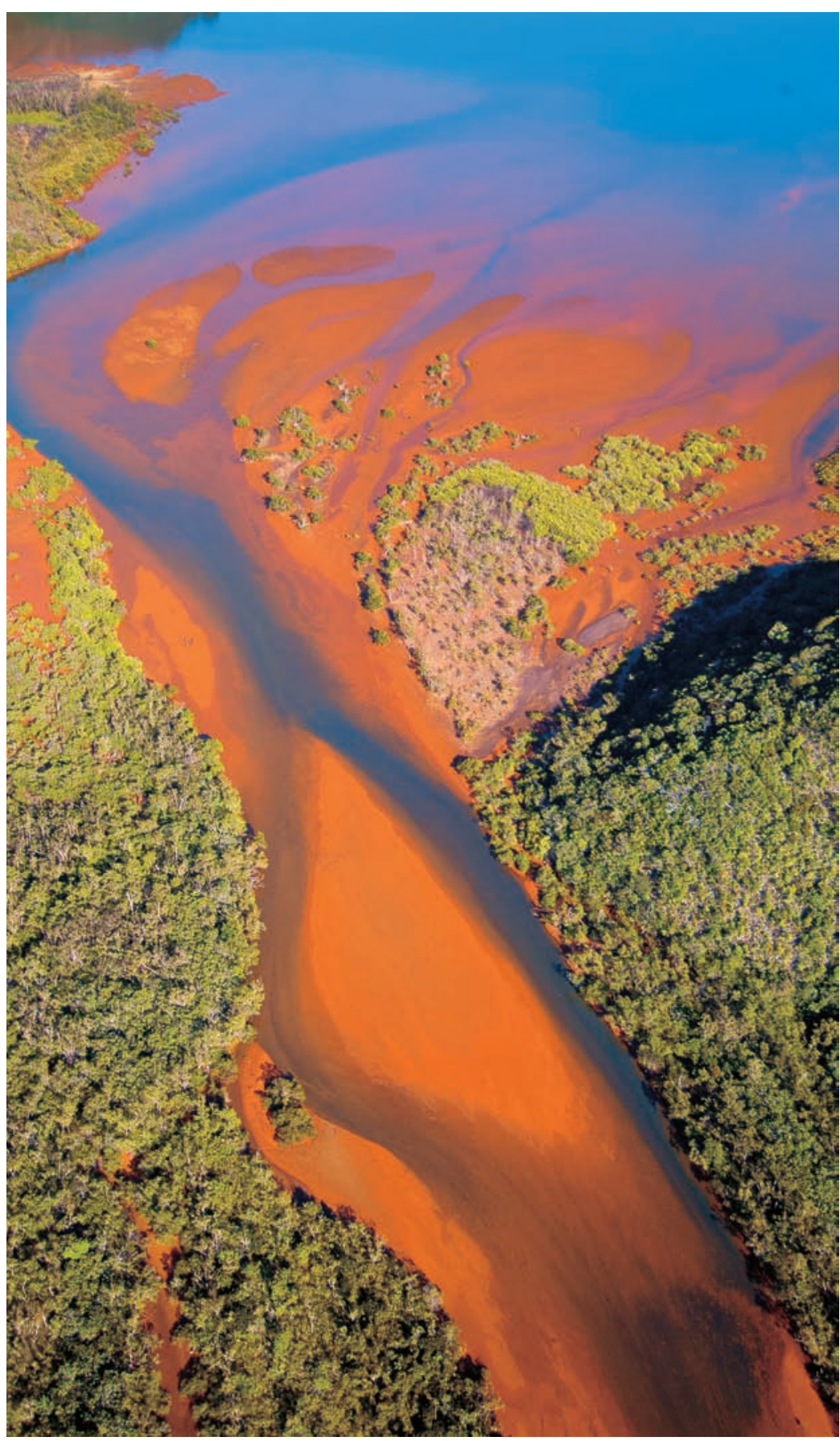

L'érosion des sols apporte au lagon des sédiments riches en métaux. @ P.-A. Pantz 


\section{Chapitre 24 \\ Des super-coraux en Nouvelle-Calédonie résistent au changement climatique}

Riccardo Rodolfo-Metalpa, Fanny Houlbrèque et Claude E. Payri

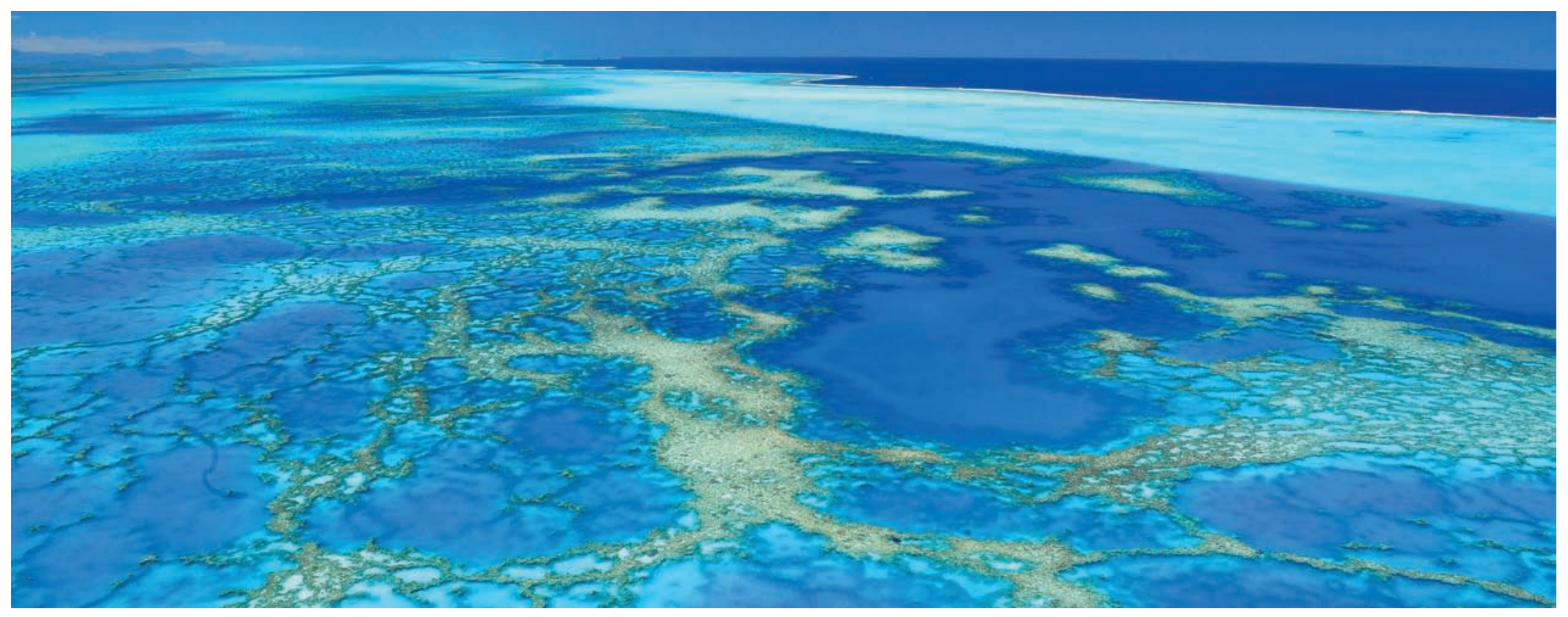

Lagon réticulé, Nessadiou. @ province Sud/M. Dosdane

\section{Les récifs coralliens sous la menace du changement climatique}

Les récifs coralliens sont déjà, à l'heure actuelle, largement impactés par les changements climatiques (GATTUSO et al., 2015). Depuis la révolution industrielle, les niveaux de $\mathrm{CO}_{2}$ atmosphériques ont quasiment doublé, entraînant un réchauffement global et une acidification des océans. Les effets des changements climatiques sur les organismes des récifs coralliens ont fait l'objet de nombreux travaux au cours des dernières décennies, travaux qui ont été essentiellement menés en aquarium.
Les espèces calcifiantes, telles que les coraux constructeurs de récifs, qui hébergent une grande partie de la biodiversité des océans mondiaux, seront vraisemblablement parmi les plus affectées par l'acidification des océans car leurs taux de calcification et de dissolution semblent être liés à la chimie des carbonates dans les océans (encadré 19). Plusieurs études montrent ainsi un déclin des taux de calcification des coraux lors d'une diminution du $\mathrm{pH}$ de l'eau de mer et parallèlement une augmentation des taux de dissolution des squelettes de carbonate. Le réchauffement des océans représente également une menace majeure pour la vie marine et les récifs coralliens en ont déjà largement souffert au cours des dernières décennies. Des températures de surface supérieures de seulement $1{ }^{\circ} \mathrm{C}$ par rapport 
aux maximales de température pendant la saison estivale, et ce pendant au moins deux à trois jours entraînent une perte de leurs algues symbiotiques pour les coraux (phénomène appelé blanchissement des coraux, chap. 25). Plusieurs études indiquent que la plupart des coraux sont capables de se remettre du blanchissement si les anomalies de température persistent moins d'un mois, mais le stress engendré par ces températures élevées peut entraîner des dommages irréversibles au niveau du métabolisme des coraux.

Des mortalités massives de coraux, suite à des épisodes de blanchissement, ont été rapportées partout dans le monde en 1998 et 2016. Bien que la majorité des études ait mis en évidence une diminution des taux de calcification des coraux avec la réduction du pH de l'eau des océans, et des mortalités massives suite au blanchissement lié aux températures plus élevées ; il semble que certains coraux soient au contraire capables de s'acclimater au réchauffement et à l'acidification des océans. Ces résultats apparemment divergents reflètent la difficulté à reproduire en laboratoire de façon adéquate et consistante des interactions environnementales et écologiques complexes. En dépit des efforts colossaux déployés par la communauté scientifique au cours des 15-20 dernières années pour comprendre l'impact de ces changements globaux sur les récifs coralliens et pour prédire de façon plus précise comment ces écosystèmes vont être modifiés dans le futur, la plupart des conclusions concernant les impacts des changements climatiques sur les coraux ainsi que les extrapolations à l'échelle de l'écosystème se basent sur des expériences menées à court terme en laboratoire sur des individus isolés, exposés à des conditions artificielles.

Ces expériences sont bien sûr informatives, car elles nous permettent d'identifier les effets d'un ou plusieurs paramètres de façon isolée, mais ces expériences sont incapables de prendre en compte la capacité d'acclimatation (et d'adaptation) des espèces dans un environnement naturel. Elles ne sont pas réalistes au niveau écologique car elles ne prennent pas en compte les effets des interactions entre espèces, les apports naturels en nourriture ainsi que les fluctuations des principaux paramètres environnementaux. De plus, la quasi-totalité de ces études ont négligé le rôle de l'adaptation puisqu'elles ont testé seulement les réponses aux changements globaux à l'intérieur d'une même génération d'individus et pendant des expositions très courtes au stress.
En outre, en parallèle de l'acidification des océans et du réchauffement, le taux de saturation en oxygène de l'eau de mer diminue, en raison de plus fortes températures et de l'eutrophisation des côtes, avec des conséquences méconnues, mais probablement négatives sur les organismes. La désoxygénation, désormais associée à l'acidification des océans et au réchauffement, forme « le trio mortel », qui pourrait affecter de manière irréversible les océans d'ici 2100.

Dans le but de mieux prédire le devenir des organismes marins face au changement climatique, il est temps de changer d'échelle et de s'intéresser aux effets au niveau de l'écosystème dans son ensemble. Pour réaliser cela, il est nécessaire de trouver des récifs coralliens qui sont déjà exposés aux conditions environnementales prévues d'ici la fin de ce siècle. On pourrait penser que cela est impossible mais il existe pourtant plusieurs exemples dans la nature : certains de ces endroits sont loin de nous, en Papouasie Nouvelle-Guinée, d'autres sont bien plus proches et se trouvent en Nouvelle-Calédonie !

\section{Prédire le futur des récifs coralliens grâce à l'étude des milieux extrêmes}

Les populations de coraux vivants actuellement en marge de leur environnement optimal et s'acclimatant à des conditions environnementales extrêmes sont devenues des modèles pour prédire la structure et le fonctionnement futurs des récifs coralliens. Les systèmes naturels tels que les résurgences sous-marines de $\mathrm{CO}_{2}$ (HALL-SPENCER et al., 2008, FABRICIUS et al., 2011) offrent des opportunités uniques pour étudier le devenir des communautés coralliennes face au changement global. Jusqu'à présent, aucun système naturel parfait n'a été découvert, mais les données provenant de tels systèmes sont d'une pertinence fondamentale au plan écologique car ils apportent un scénario réaliste et naturel. Par exemple, au niveau des sites de résurgence de $\mathrm{CO}_{2}$ en Papouasie Nouvelle-Guinée, le $\mathrm{pH}$ varie dans le temps, selon les conditions environnementales (par exemple des changements dans les courants dominants et les conditions atmosphériques) et son effet est habituellement limité dans l'espace (représentant une centaine de mètres carrés de récifs). De plus, seul l'effet de l'acidification des 
océans peut être observé jusqu'à présent car seules des résurgences «froides» de $\mathrm{CO}_{2}$ ont été découvertes et il est clair que le réchauffement sera probablement le facteur le plus influent dans le futur. L'IRD a commencé un programme de recherche sur le long terme utilisant des coraux vivants sur trois sites volcaniques de Papouasie Nouvelle-Guinée (projet Carioca). Une série d'analyses physiologiques et moléculaires, des transplantations coralliennes et des expériences multigénérationnelles ont permis de faire des prédictions plus fiables sur les réponses à l'échelle de l'organisme et des écosystèmes.

En février 2016, dans le contexte d'une collaboration entre l'IRD et l'université de Technologie de Sydney (Australie), les premiers travaux de terrain ont été menés sur un site exceptionnel situé à Bouraké, à 150 km de Nouméa (CAMP et al., 2017). Sur ce site, l'eau du lagon rentre dans la mangrove avec la marée montante, circule à l'intérieur du système pour sortir à marée descendante. La profondeur du système varie de quelques centimètres à plus de $6 \mathrm{~m}$. Le chenal, large de plus de $80 \mathrm{~m}$, pénètre à l'intérieur de la mangrove en formant de larges piscines sur une surface totale de plus de $60000 \mathrm{~m}^{2}$. Les premières mesures de variations du pH (fig. 1) au cours d'un cycle de $24 \mathrm{~h}$ ont montré la réelle valeur de ce site unique pour étudier la capacité des coraux à s'acclimater et à s'adapter aux conditions

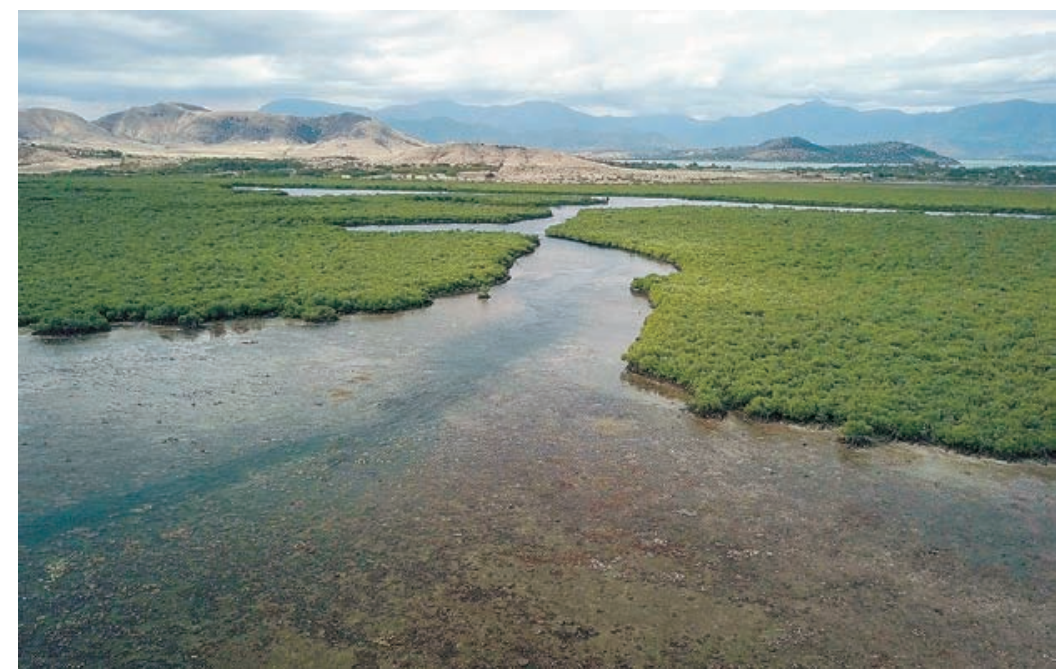

Site d'étude de Bouraké montrant le chenal principal permettant l'entrée de l'eau de mer du lagon, à l'intérieur de la mangrove. @ IRD/J.-M. Boré extrêmes. À chaque marée haute, de l'eau nouvelle du lagon entre par le chenal dans le large bassin interne à l'intérieur des mangroves. Pendant ce trajet, cette eau se mélange avec de l'eau de mer plus acide, chaude et désoxygénée. Ainsi même à marée haute, l'eau dans le système ne retourne jamais à des valeurs «normales ». Par exemple, les valeurs maximales de $\mathrm{pH}$ mesurées se situent autour de 7,9 (le pH normal de l'océan est actuellement de 8,05 alors qu'il est prévu qu'il diminue jusqu'à 7,7-7,8 en 2100). À marée basse, l'eau de mer devient plus acide et appauvrie en oxygène car le système commence à se vidanger et les larges volumes d'eau qui étaient à l'intérieur de la forêt de mangrove arrivent dans le système et sont ensuite évacués vers le lagon. À marée basse, le pH atteint la valeur extrême de 7,3 à proximité des coraux pour une concentration de $2 \mathrm{mg} \mathrm{L}^{-1}$ en $\mathrm{O}_{2}$ (la concentration normale d' $\mathrm{O}_{2}$ le long des côtes est de 4-6 $\mathrm{mg} \mathrm{L}^{-1}$ ).

De plus, l'ensemble de ces paramètres montre des fluctuations, clairement détectables, au cours d'un cycle de $24 \mathrm{~h}$, ce qui est extrêmement important pour évaluer la dose de stress reçue dans le temps par les coraux. Ceci rend ce site beaucoup plus intéressant que d'autres laboratoires naturels dans lesquels la durée et l'intensité du stress (par exemple les sites de résurgence volcanique) ne sont régulières ni dans le temps ni dans l'espace.

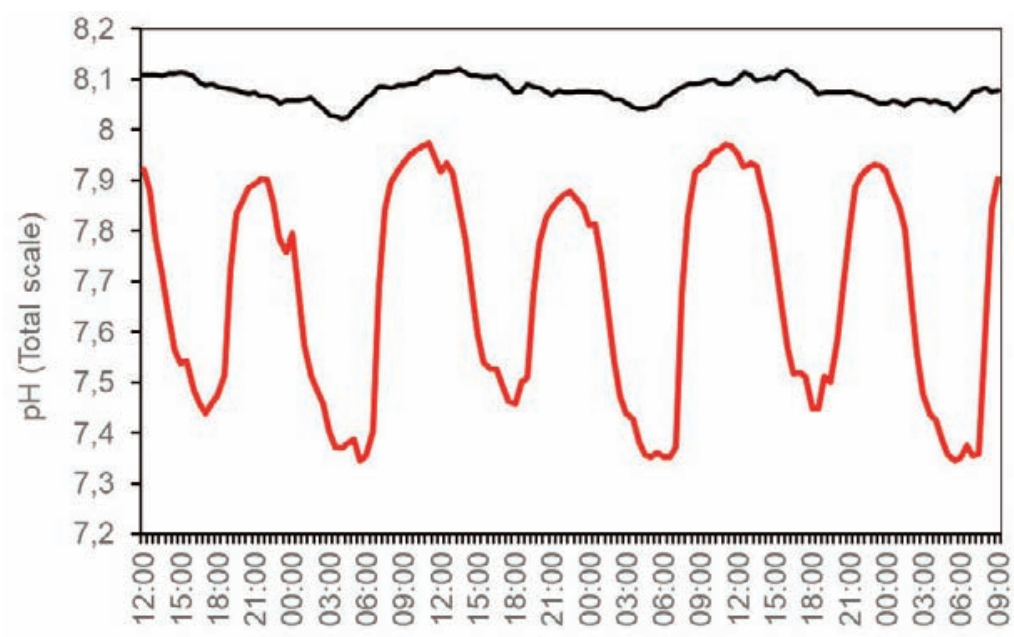

Figure 1 : Variations cycliques du pH sur le site d'étude (tracé rouge) et à l'extérieur, sur un site de contrôle (tracé noir). @ IRD/R. Metalpa 


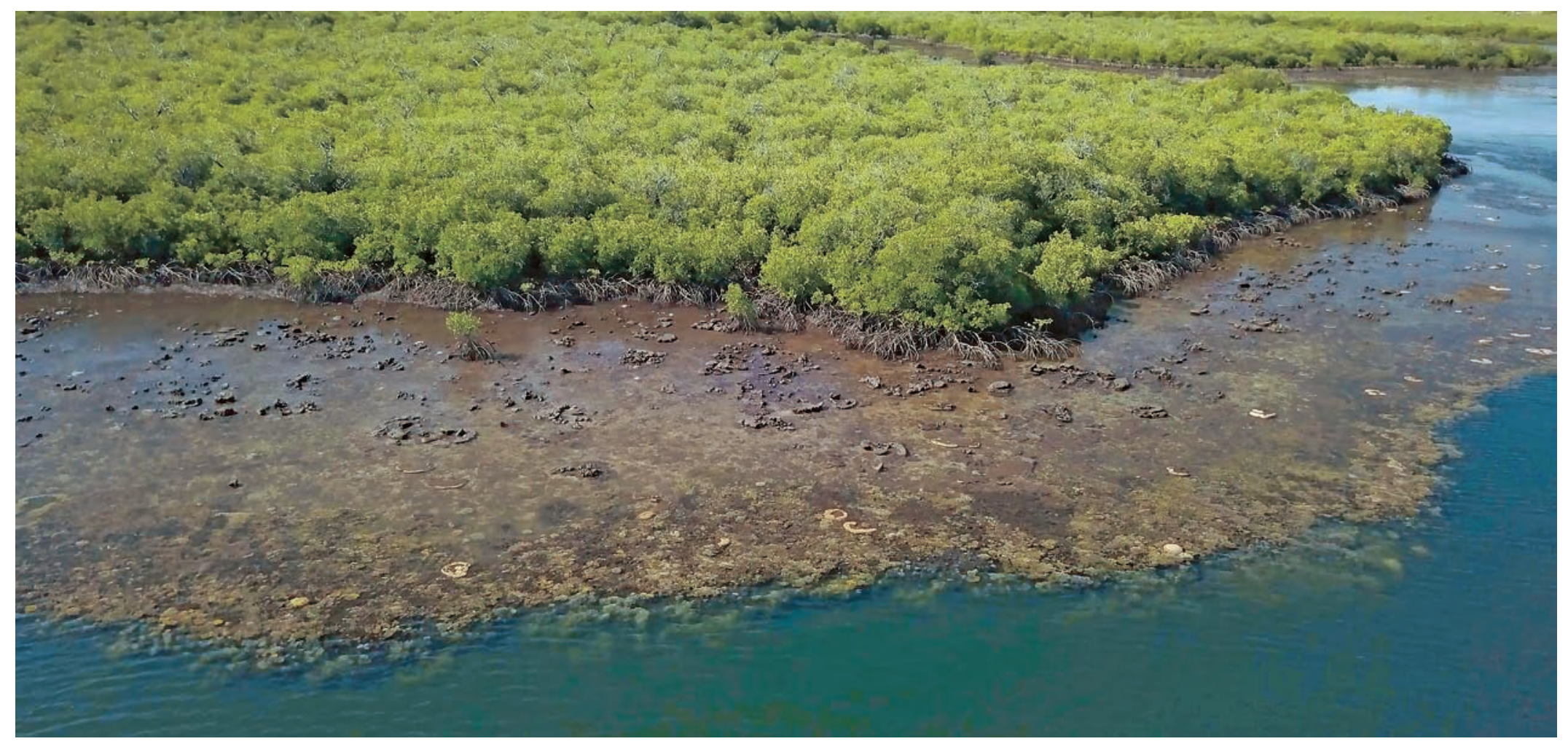

Vue aérienne du récif frangeant de Bouraké. @ IRD/J.-M. Boré

Selon la littérature, la persistance des coraux et des organismes calcifiants en général serait sérieusement compromise. Pourtant l'IRD a révélé à Bouraké, la présence de plus de 50 espèces différentes de coraux, formant des récifs très préservés, comparables aux autres récifs frangeants de Nouvelle-Calédonie.

Il est indéniable que ce site offre de nouvelles opportunités pour mieux comprendre le futur des récifs coralliens face au changement global. L'hypothèse principale, qui reste à vérifier, est que de nombreuses espèces marines, considérées par les études précédentes en laboratoire comme sensibles à l'acidification des océans, présentent en fait la capacité à s'acclimater, voire à s'adapter, aux conditions climatiques futures. L'élément central qui soutient cette hypothèse est la présence de nombreuses espèces de coraux dans ce système de mangrove, où les conditions de $\mathrm{pH}$, de température et de $\mathrm{pO}_{2}$ sont proches (ou au-delà) des valeurs prévues pour la fin du siècle.
Il s'agit de mieux comprendre quels sont les changements physiologiques utilisés par les coraux pour s'acclimater aux conditions extrêmes (plasticité phénotypique), ce qui constitue déjà une approche novatrice. Néanmoins, notre ambition est de vérifier si ces espèces, qui auront grandi dans ces conditions extrêmes, peuvent se reproduire et potentiellement s'adapter (par exemple avec une acclimatation transgénérationnelle).

Nous cherchons à comprendre comment les changements du métabolisme des coraux et de ses zooxanthelles permettent aux coraux de prospérer dans des milieux extrêmes. Les coraux vivent en association avec des zooxanthelles, mais également avec de nombreux microorganismes et on s'interroge également sur le rôle de ces microbes et des algues zooxanthelles dans la capacité des coraux à résister aux conditions extrêmes. 


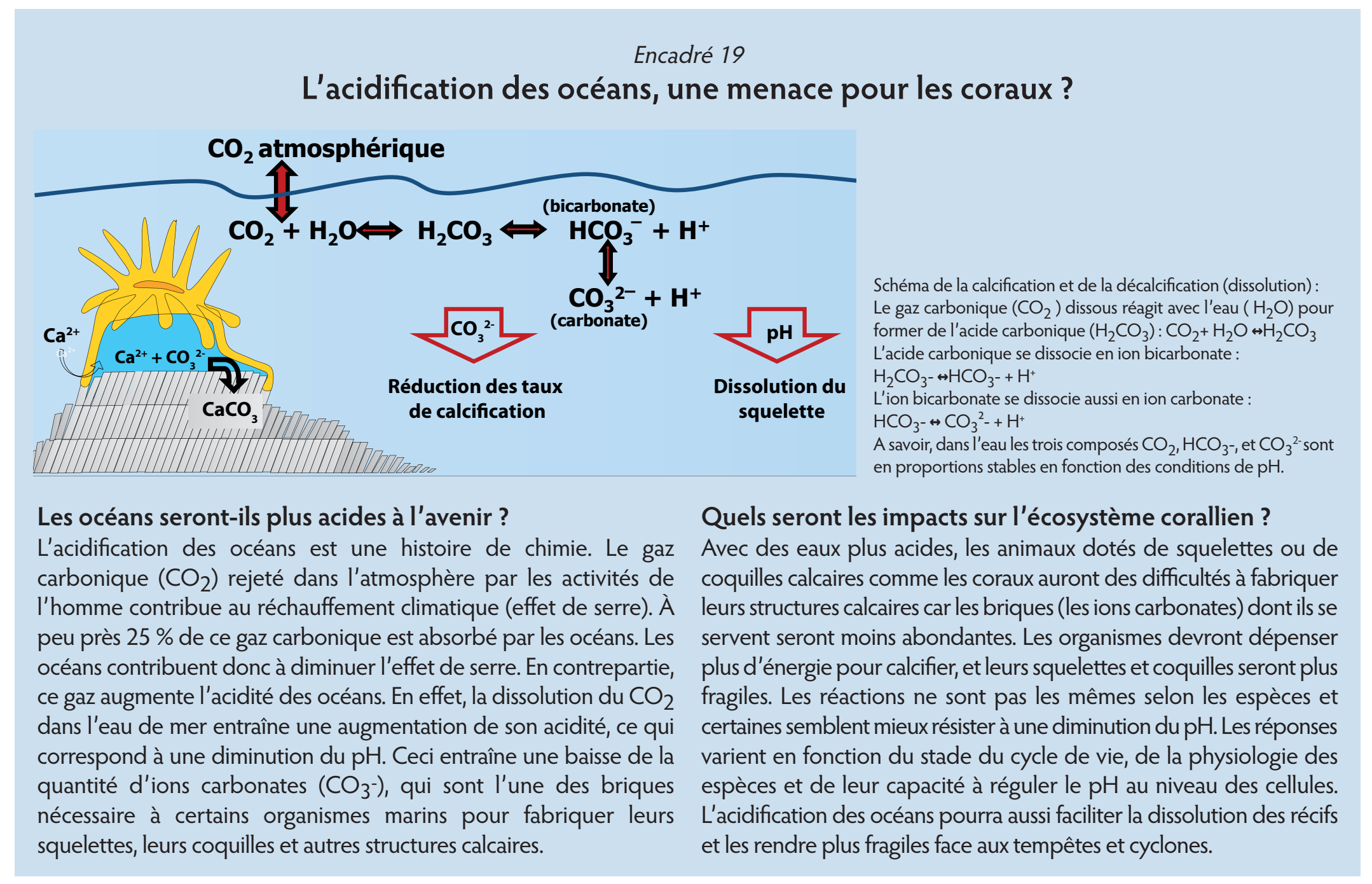

\section{Références bibliographiques}

CAMP E. et al., 2017 Reef-building corals thrive within hot-acidified and deoxygenated waters. Scientific Reports. Doi : 10.1038/s41598-017-02383-y. FABRICIUS K.F. et al., 2011 Losers and winners in coral reefs acclimatized to elevated carbon dioxide concentrations. Nature Climate Change. Doi : 101038/NCLIMATE1122.

GATTUSOJ.P. et al., 2015 Contrasting futures for ocean and society from different anthropogenic $\mathrm{CO}_{2}$ emissions scenarios. Science, 349 (6243) : aac4722-1. HALL-SPENCER J.M. et al., 2008 Volcanic carbon dioxide vents show ecosystem effects of ocean acidification. Nature, 454 : 96-99 



\section{Le blanchissement corallien de 2016}

Claude E. Payri, Francesca Benzoni, Laure. V. André et Fanny Houlbrèque

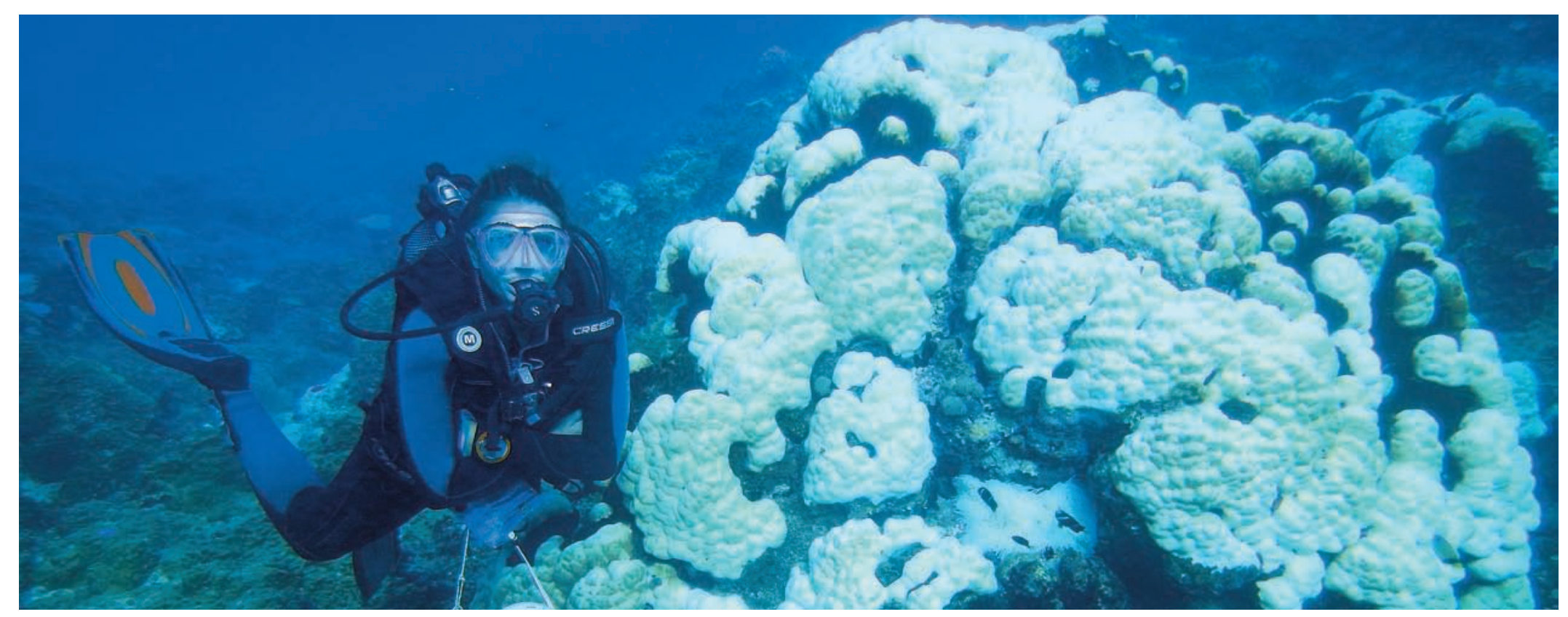

Colonie massive du genre Porites entièrement blanchie, récif d'Entrecasteaux, mars 2016. @ IRD/F. Benzoni

\section{Les récifs coralliens : un milieu fragile et menacé}

Les récifs coralliens sont parmi les écosystèmes les plus diversifiés en nombre d'espèces et les plus importants en termes économiques. Colorés, divers et riches, ils forment une interface protectrice entre la mer et la terre qui attire et concentre les activités humaines. Alors qu'ils occupent moins de $0,2 \%$ de la superficie des océans, ils abritent près de $30 \%$ de la biodiversité marine connue à ce jour et sont un réservoir de ressources dont dépendent directement ou indirectement 500 millions d'humains. Outre leur valeur écologique, les récifs coralliens fournissent des services écosystémiques, économiques et culturels essentiels pour les industries et les sociétés humaines, que ce soit par la pêche, la protection littorale, le tourisme ou l'accès à de nouvelles substances naturelles.

Structures naturelles, entièrement bioconstruites par des organismes biologiques tels que les coraux et les algues calcaires, les récifs coralliens sont particulièrement sensibles aux changements du milieu. Leur équilibre fragile est menacé par une combinaison de facteurs : la surexploitation du milieu et des ressources, et la dégradation globale du milieu physique (sédimentation, pollutions, etc.), exacerbées par l'accroissement démographique, l'émergence de maladies spécifiques des coraux et les changements climatiques. Leur déclin est observé à l'échelle mondiale. Le constat est sans appel avec à ce jour $20 \%$ des 
récifs dont les communautés ont totalement changé, $15 \%$ sérieusement affectés et risquant de disparaître d'ici une décennie, enfin $20 \%$ menacés de disparition dans moins de 40 ans. Les changements climatiques ont des répercussions sur la circulation, la température, le $\mathrm{pH}$, la salinité et les éléments nutritifs des mers. Le réchauffement des eaux de surface, progressif ou à la suite de fortes anomalies météorologiques ou climatiques a eu pour conséquence le blanchissement des coraux dans de nombreux récifs coralliens à travers le monde et ce, à plusieurs reprises au cours de ces dernières décennies.

\section{Le blanchissement corallien}

Les coraux bâtisseurs de récifs, ainsi que quelques autres taxons (anémones de mer, bénitiers.), vivent en symbiose avec des algues unicellulaires microscopiques appartenant au genre Symbiodinium et communément appelées « zooxanthelles ». Ces algues sont abritées dans les polypes, parties molles des coraux, et contribuent aux budgets énergétiques de leurs hôtes en leur permettant notamment d'accélérer la calcification du squelette. Les zooxanthelles contribuent également à la coloration des tissus vivants des coraux en raison de leurs pigments photosynthétiques verts et bruns. La perte substantielle ou complète des algues symbiotiques par les tissus animaux et/ou la diminution des concentrations de pigments photosynthétiques dans les algues se traduit par une perte de coloration de l'hôte. C'est ce phénomène de dépigmentation des polypes qui est appelé blanchissement corallien. Visuellement, le tissu animal devient translucide, laissant apparaître par transparence le squelette calcaire blanc. Ce processus n'est pas sans conséquence pour la vie des coraux même s'il peut être réversible, car il affecte leur croissance, leur fertilité et leur reproduction. Si la symbiose n'est pas restaurée, alors le blanchissement conduit à la mort du corail (fig. 1).

Le blanchissement des coraux est habituellement causé par des changements environnementaux abrupts auxquels le corail est incapable de s'adapter, tels que l'augmentation de température de l'eau de mer, un rayonnement UV élevé, une dessalure ou une infection bactérienne. Toutefois, la plupart des blanchissements massifs observés à grande échelle semblent avoir été causés par un dépassement des températures maximales moyennes de surface, d'un 1 ou $2^{\circ} \mathrm{C}$ seulement, pendant plusieurs semaines d'affilée.

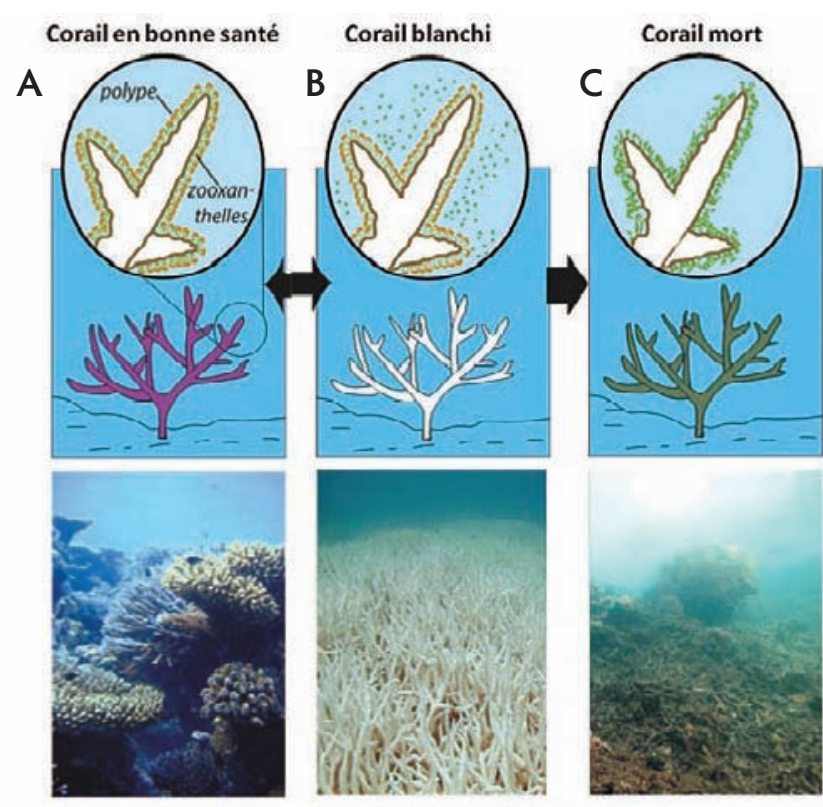

Figure 1 : Représentation schématique du blanchissement des coraux au niveau de la colonie (en haut) et de la communauté (en bas).

A : corail sain avec des zooxanthelles et coloration normale.

$B$ : corail blanchi après l'expulsion des zooxanthelles.

$C$ : gazon algal sur le squelette de corail mort.

Source : http://www.gbrmpa.gov.au/managing-the-reef/tareats-to-the-reef/climate-

change/what-does-this-mean-for-species/corals/what-is-coral-bleaching

\section{Un phénomène majeur en Nouvelle-Calédonie durant l'été 2016}

Jusqu'à l'été austral 2016, les récifs de la Nouvelle-Calédonie avaient été épargnés par les événements massifs de blanchissement. Un événement de blanchissement avait toutefois été signalé et documenté en janvier 1996, mais les données disponibles limitées ne concernaient que deux localités de la Grande Terre et ne permettaient pas de conclure à un événement majeur. En février 2016, un épisode de blanchissement massif sans précédent a été observé.

Les températures des eaux de surface baignant la Nouvelle-Calédonie ont été anormalement élevées pendant l'été austral 2016. Cette période a aussi été marquée par une augmentation du rayonnement $U V$ estimée à $10 \%$ en raison de l'absence de vent et de couvert nuageux. Les températures ont varié entre $27^{\circ} \mathrm{C}$ et $31^{\circ} \mathrm{C}$ de janvier à mai 2016, les 
plus chaudes étant enregistrées en février, de 1 à $2{ }^{\circ} \mathrm{C}$ supérieures au maximum climatique de la région (fig. 2). Les valeurs de $1{ }^{\circ} \mathrm{C}$ pour cet indice (Coral Bleaching Hotspot) et de $4{ }^{\circ} \mathrm{C}-$ Weeks (Degree Heating Week) pour son cumul au cours du temps sont considérées comme des seuils pouvant conduire au blanchissement des coraux et sont utilisés pour les prévisions des zones à risque. Le seuil de $4{ }^{\circ} \mathrm{C}$-Weeks a été franchi entre février et mi-mai 2016, les valeurs les plus élevées (au-delà de $8{ }^{\circ} \mathrm{C}$-Weeks) étant en mars et avril 2016 (fig. 2).

Cette anomalie météorologique, faisant de cette période la saison la plus chaude enregistrée en Nouvelle-Calédonie depuis les 30 dernières années, serait à l'origine du phénomène de blanchissement exceptionnel. Il est déjà établi par ailleurs que 2015 a été l'année la plus chaude jamais enregistrée à l'échelle mondiale. Dès lors, on imagine aisément que la conjugaison du réchauffement climatique global et du phénomène météorologique régional pouvait avoir des répercussions sur les récifs coralliens.
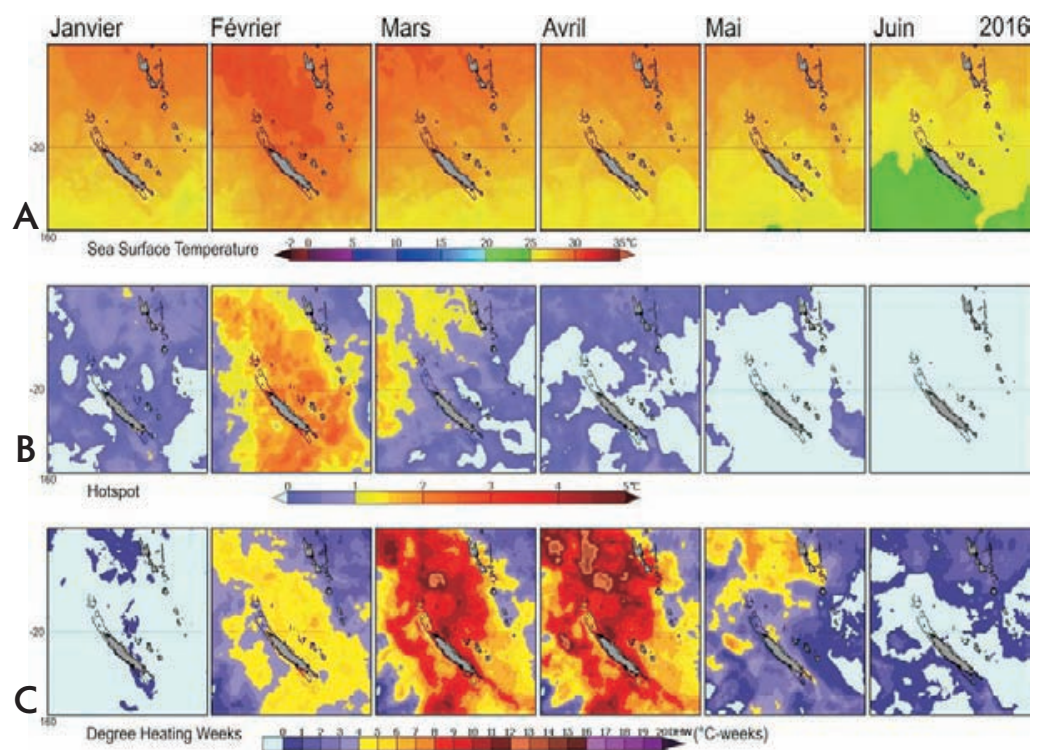

Figure 2 : Cartes de la température de surface de la mer. A : du Hotspot de blanchissement.

B : du Degree Heating Week autour de la Nouvelle-Calédonie au premier semestre 2016. $C$ : données pour le $15^{\mathrm{e}}$ jour de chaque mois.

Source : https://coralreefwatch.noaa.gov/satellite/bleaching $5 \mathrm{~km} / \mathrm{index} . \mathrm{php}$

${ }^{10}$ Le programme Blanco financé par le MOM, I'Ifrecor Nouvelle-Calédonie et l'IRD. Sur-Blanco, campagne océanographique à bord de l'Amborella, financée par le gouvernement de la Nouvelle-Calédonie.
De fait, de nombreuses observations obtenues, entre autres, par les chercheurs de l'IRD de Nouméa (programmes Blanco et SurBlanco ${ }^{10}$ ) et par un suivi participatif organisé par l'association Pala Dalik, ont indiqué que le phénomène avait affecté la quasi-totalité des récifs frangeants de la Grande Terre et des récifs intermédiaires du lagon et des îlots du lagon. Le blanchissement a également été observé aux îles Loyauté et aux récifs d'Entrecasteaux, mais aucune donnée n'est disponible pour les récifs éloignés des îles Chesterfield. Au total, plus de 300 observations ont été faites entre mars et avril 2016, soit par plongées soit par voie aérienne. La présence ou l'absence de blanchissement est globalement en bon accord avec la carte du Degree Heating Week (fig. 3).

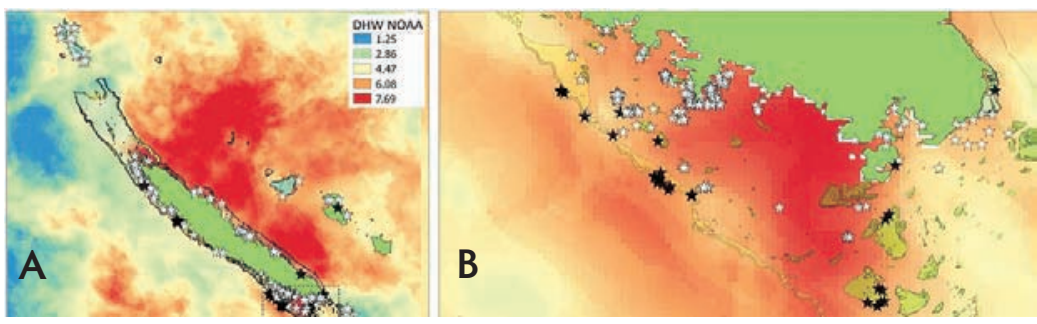

Figure 3 : Localisation des observations (étoiles) réalisées entre mars et avril 2016. A : autour de la Grande Terre.

$\mathrm{B}$ : dans le lagon sud et comparaison avec la carte du DHW en ${ }^{\circ} \mathrm{C}$-semaines, à la mi-février 2016 (NOAA 50-km SST Anomaly Product). La présence ou l'absence de blanchissement est marquée respectivement par des étoiles blanches (blanchissement observé) ou noires (pas de blanchissement). Source : BENZONI et al., 2017

\section{Un impact à des degrés divers}

Si la majeure partie des récifs a été impactée, l'atteinte a été variable (sévère, modérée ou légère) en fonction des espèces et des types de communautés coralliennes. Un corail blanchi n'est pas un corail mort, mais sans les algues symbiotiques ses apports énergétiques se voient fortement réduits. Dans le cas où les conditions de stress perdurent, les coraux finissent par mourir. Si les impacts modérés et légers permettent d'envisager un retour rapide à la normale, les atteintes sévères entraînent un risque de mortalité beaucoup plus important.

De manière générale, les récifs côtiers et lagonaires abritant majoritairement des coraux branchus ont été plus affectés que les 
récifs-barrières et les pentes externes, avec un taux de blanchissement atteignant $90 \%$ de la couverture corallienne. Pour les récifs d'Entrecasteaux, le blanchissement a concerné l'ensemble du complexe récifal, avec toutefois des atteintes plus sévères à l'intérieur des lagons des atolls qu'à l'extérieur. Les coraux massifs, en forme de boules et habituellement moins sensibles, ont été particulièrement affectés sur les récifs côtiers, donnant au phénomène un caractère particulièrement remarquable.

\section{Un phénomène dynamique}

Grâce à un suivi mensuel mené depuis février 2016 dans plusieurs sites du lagon de Nouvelle-Calédonie, les chercheurs ont pu montrer la dynamique du phénomène en établissant une cartographie de sensibilité des espèces à partir de plusieurs milliers de colonies observées et suivies durant un cycle annuel. Commencé en février 2016, le phénomène aura perduré jusqu'à fin mars 2016 pour s'atténuer progressivement avec l'arrivée de l'hiver austral et la chute de température, et disparaître totalement en août 2016. Deux mois après le début du blanchissement

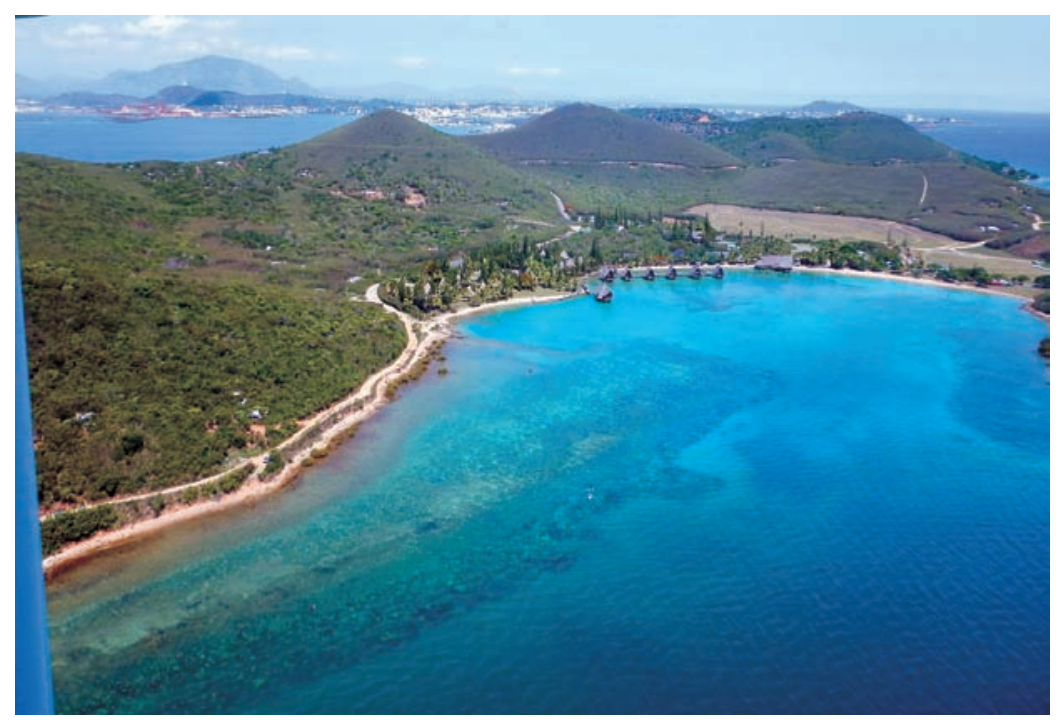

sur les sites du lagon de Nouméa, 70 à $80 \%$ des colonies blanchies avaient totalement récupéré leurs zooxanthelles et leur vitalité, 10-20\% étaient partiellement mortes et moins de $10 \%$ étaient totalement mortes.

\section{Les récifs sous surveillance après l'épisode de 2016}

Outre le phénomène remarqué durant l'été austral 1995-1996, d'autres événements, tels ceux de 1998 et 2002 qui ont fortement impacté la Grande Barrière de Corail australienne, n'ont pas concerné la Nouvelle-Calédonie. Quoi qu'il en soit, l'épisode de 2016 restera un phénomène massif et global, ayant touché de manière sévère différentes régions du monde.

Alors que plusieurs secteurs de la Grande Barrière australienne subissaient en janvier 2017 leur deuxième année consécutive de blanchissement corallien, les récifs de Nouvelle-Calédonie ont été dans leur grande majorité épargnés. Lors du suivi de février 2017 (campagne Post-Blanco ${ }^{11}$ ) les chercheurs ont observé pour les récifs d'Entrecasteaux et ceux de la côte est de la Grande Terre une mortalité

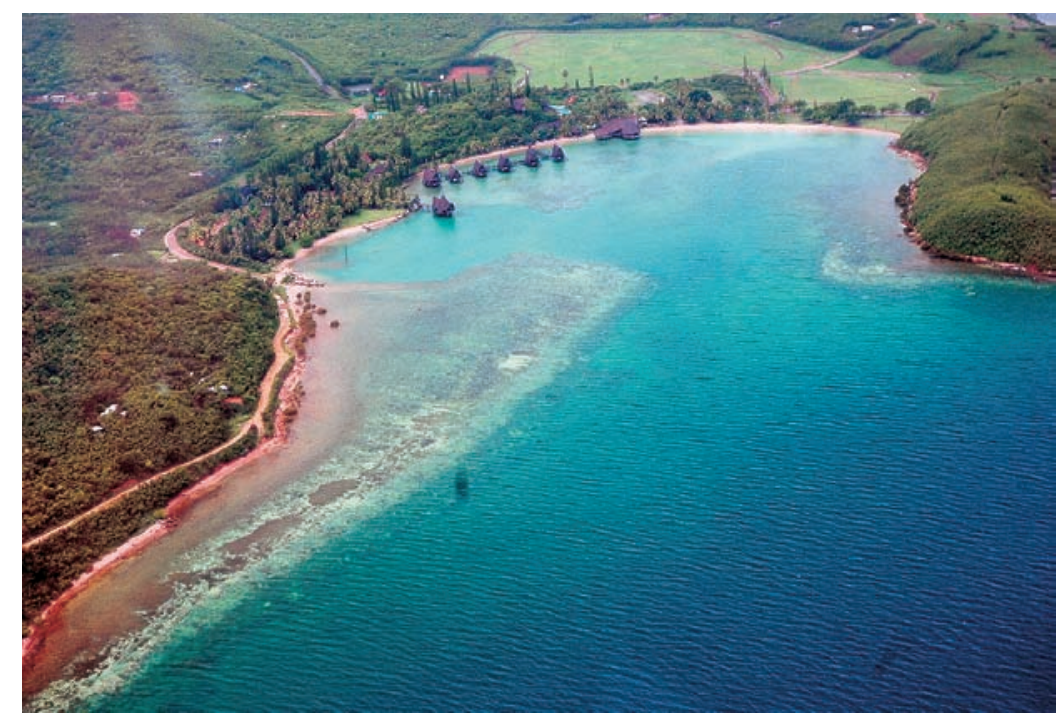

Comparaison des deux vues aériennes de la baie du Kuendu Beach à Nouville, Nouméa, prises fin janvier 2016 (à gauche) et fin février 2016 (à droite). Les taches blanches visibles sur la photographie de droite correspondent au blanchissement massif des coraux. @ IRD/F. Benzoni

11 http://umr-entropie.ird.nc/index.php/home/actualites/depart-imminent-de-la-campagne-post-blanco-suivi-de-letat-des-recifs-apres-lepisode-de-blanchissement-massif-de-2016 


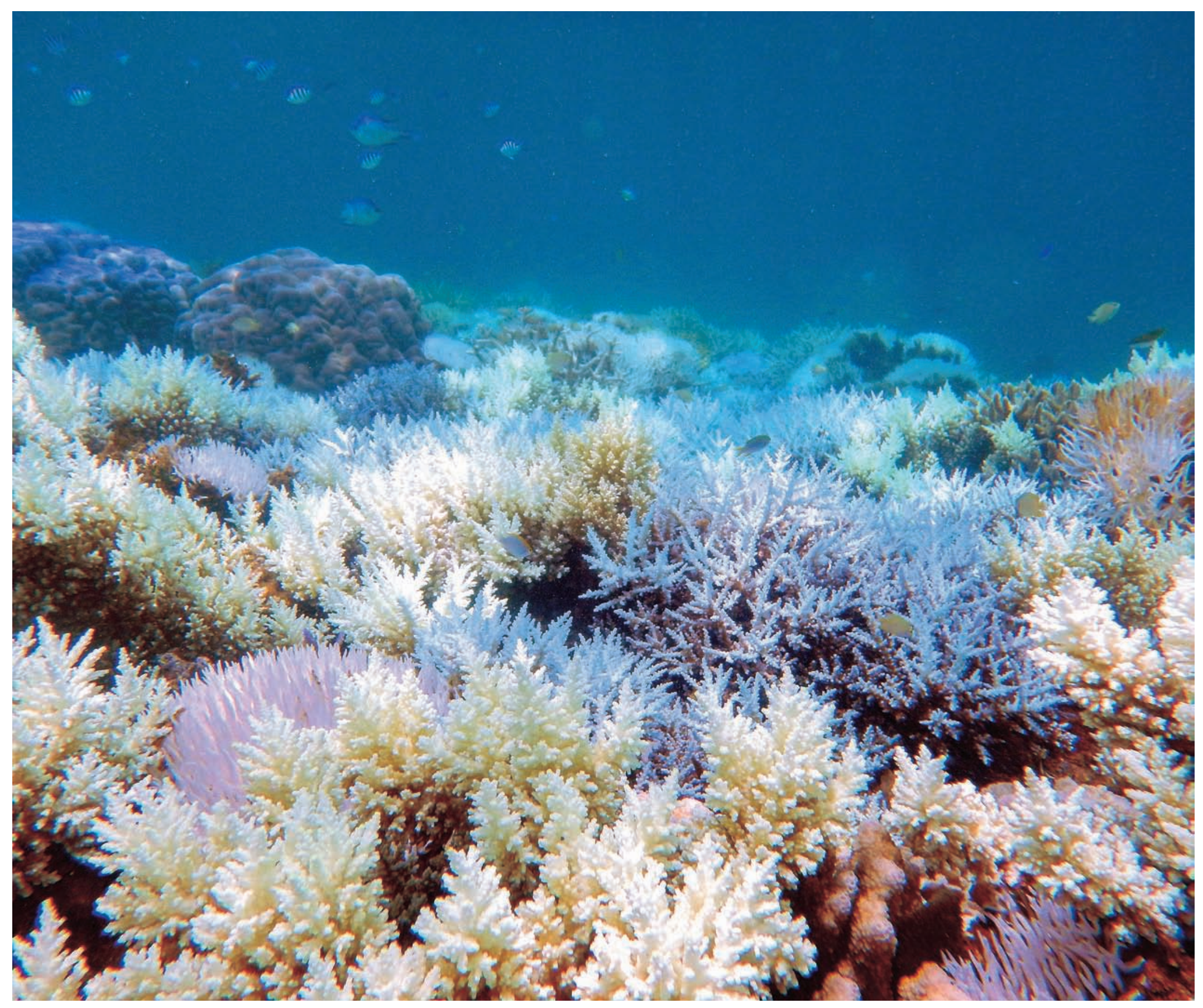

Communauté corallienne de coraux branchus entièrement blanchis. Récif de la Roche blanche, côte sud de la Grande Terre, février 2016. @ IRD/F. Benzoni 
plus importante des communautés coralliennes, attribuée au blanchissement de 2016 et à des eaux plus chaudes que celles du reste de la Grande Terre. En revanche, le suivi réalisé aux îles Chesterfield en avril 2017 (campagne Post-Blanco 2) a mis en évidence quelques signes de blanchissement récent, dont l'origine reste à établir.

\section{Quelles solutions?}

Le réchauffement climatique global et l'augmentation associée des températures de surface de la mer ne font plus aucun doute pour les prochaines décennies selon les prévisions du GIEC. Selon les travaux des chercheurs australiens il faut 10 ans à l'échelle du récif, pour que les coraux en souffrance récupèrent leur vitalité. Aussi, si l'on ne peut agir sur le dérèglement climatique, la mobilisation des chercheurs est cependant essentielle pour alerter sur la dégradation du milieu et pour documenter le phénomène sous divers aspects et étudier in fine la résistance, voire la résilience, des espèces concernées. Les scientifiques travaillent également à conjuguer les résultats obtenus durant l'observation du phénomène de 2016 avec ceux qu'ils détiennent déjà sur les communautés coralliennes de la région pour tenter de proposer des cartes de sensibilité des zones coralliennes qui pourraient être utiles aux gestionnaires dans le choix des zones à conserver en priorité.

\section{Références bibliographiques}

BAKER A.C., GLYNN P.W., RIEGL B., 2008 Climate change and coral reef bleaching: An ecological assessment of long-term impacts, recovery trends and future outlook. Estuarine, Coastal and Shelf Science, 80 : 435-471.

BENZONI F. et al., 2017 Plan d'action rapide et adaptatif, en cas de blanchissement corallien. Le cas de la Nouvelle-Calédonie, épisode 2016, synthèse. IRD Nouméa, Sciences de la Mer. Biologie Marine. Rapports scientifiques et techniques, 67, $90 \mathrm{p}$.

HERON S.F. et al., 2016 Warming trends and bleaching stress of the World's coral reefs 1985-2012. Scientific Report, $6: 38402$.

HUGHES T.P. et al.., 2017 Global warming and recurrent mass bleaching of corals. Nature, $543: 373-377$.

HUGHES T.P. et al., 2003 Climate Change, Human Impacts, and the Resilience of Coral Reefs. Science, 301 : 929-933.

RICHER DE FORGES B., GARRIGUE C., 1997 First observations of a major coral bleaching in New Caledonia. Marine Benthic Habitats Conference, Nouméa, Nouvelle Calédonie, 10-16 novembre (poster).

SPALDING M.D., BROWN B.E., 2015 Warm-water coral reefs and climate change. Science, $350: 769-771$. 


\title{
Chapitre 26 \\ La mobilité des îlots du lagon néo-calédonien : vulnérabilité ou résilience?
}

\author{
Myriam Vendé-Leclerc et Manuel Garcin
}

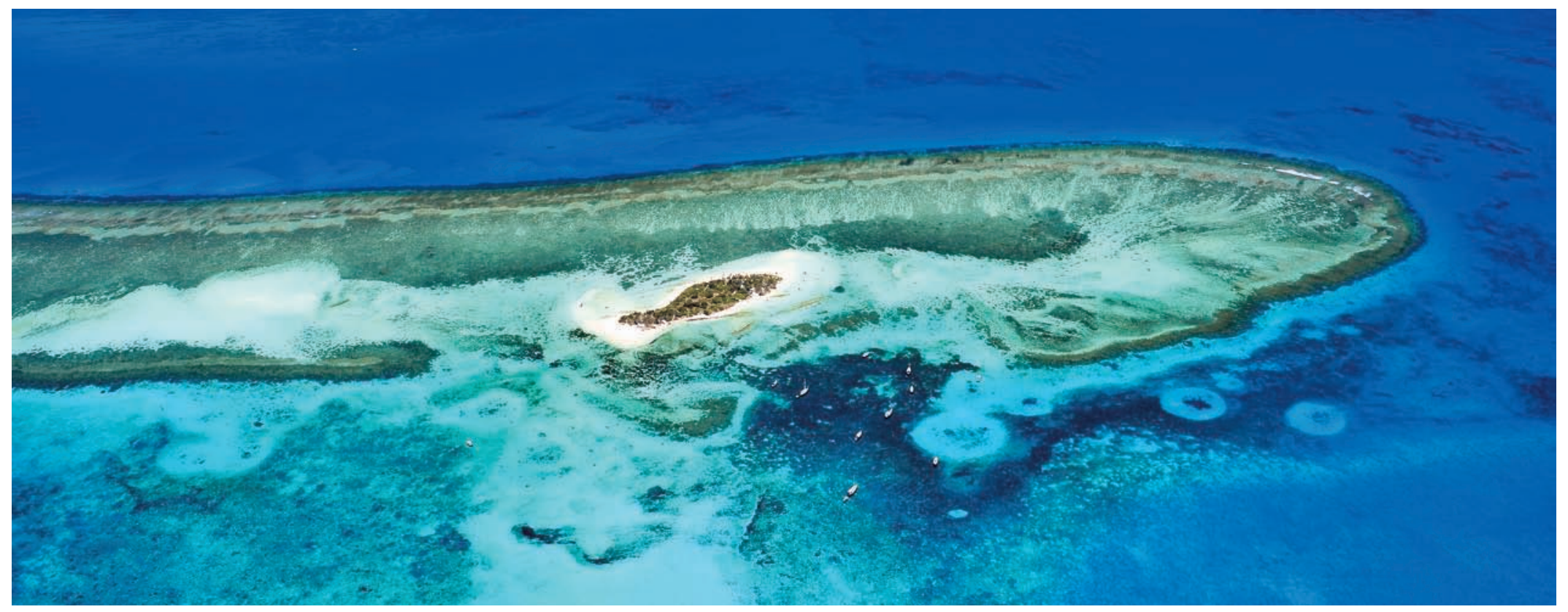

Îlot Larégnère vu du ciel, un îlot au milieu du lagon. @ province Sud/M. Dosdasne

\section{Des structures géomorphologiques singulières}

De nombreux îlots coralliens, de tailles diverses, allant de quelques mètres carrés à plusieurs hectares sont présents dans le lagon néocalédonien. Ces accumulations sableuses plus ou moins végétalisées, aussi nommées cayes, reposent sur de larges plates-formes récifales ou sur le récif-barrière. Ces îlots sont le résultat d'une accumulation de sédiments biodétritiques issus du démantèlement des édifices coralliens sous l'action des houles et des tempêtes.

Ces îlots constituent des espaces où les aspects environnementaux, culturels, sociétaux et économiques se mêlent. En effet, ils jouent un rôle capital dans les écosystèmes riches et spécifiques du lagon néocalédonien. Ils sont notamment des sites de nidification pour les tortues et les oiseaux marins. Certains bénéficient de mesures de protection environnementale grâce à un classement en réserve provinciale, voire gouvernementale, pour les îlots éloignés.

Ils ont également une grande importance dans la culture et le mode de vie néo-calédonien. Ils sont des lieux privilégiés pour la plaisance, la pêche ou encore les sports nautiques. La fréquentation n'a cessé de croître ces dernières années, ce qui a permis le développement d'une économie basée sur des activités récréatives avec la mise en place d'équipements et de services spécifiques. 
Les questions récurrentes posées par la population et les collectivités locales concernent d'une part leur évolution actuelle et d'autre part leur devenir, notamment dans la perspective du changement climatique et de l'élévation du niveau de la mer. La compréhension de la dynamique des îlots intéresse les décideurs et les organismes gestionnaires de ces espaces, mais aussi les scientifiques, particulièrement ceux travaillant sur les impacts du changement climatique sur les zones côtières.

\section{Une vingtaine d'îlots scrutés à la loupe}

Dans ce contexte, l'Observatoire du littoral de NouvelleCalédonie (Oblic) a commencé en 2013 une étude portant sur l'évolution récente et future de 21 îlots néo-calédoniens afin de fournir des clés de compréhension sur leur fonctionnement morphodynamique, les liens entre les facteurs de forçage (vents, vagues, niveau d'eau, etc.) et leur évolution, et enfin d'apporter des éléments de réponse sur leur avenir.

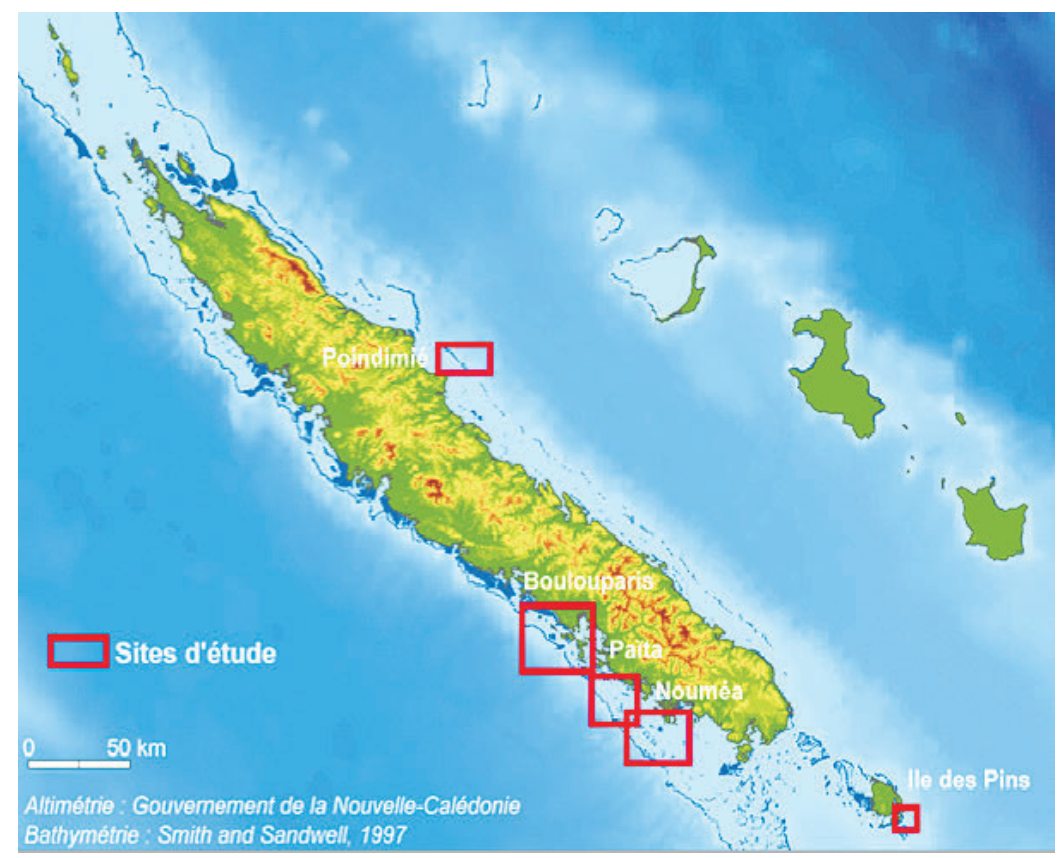

Figure 1 : Localisation des 21 îlots étudiés dans le lagon calédonien.

Altimétrie : gouvernement de la Nouvelle-Calédonie ; bathymétrie : SMITH et SANDWELL, 1997
La majorité de ces îlots est localisée dans le lagon ouest, quatre dans le lagon est et un au sud de l'île des Pins (fig. 1). Ces îlots sont situés dans des contextes différents et variés, notamment au regard de leur position par rapport au récif-barrière ou aux passes et de leur exposition aux vagues. La plupart sont peu ou pas aménagés et certains d'entre eux peuvent être très fréquentés. Seuls trois îlots sont modérément à très fortement anthropisés avec notamment des actions visant à lutter contre l'érosion de leur rivage.

Ces îlots ont fait l'objet d'observations géomorphologiques et sédimentologiques lors de campagnes de terrain sur une période allant de 2013 à 2016. Ces données recueillies sur le terrain ont permis d'identifier les caractéristiques géomorpohologiques des îlots, de cartographier les processus morpho-sédimentaires actifs affectant la côte de chaque îlot (érosion, accrétion, stabilité) pour finalement les comparer, voire les classer.

Ces observations ont été complétées par l'analyse de l'évolution temporelle des îlots à l'aide d'images satellite et de photographies aériennes anciennes. La durée couverte par les reconstitutions de chaque îlot est variable en fonction de la disponibilité de ces supports : les images satellite couvrent la dernière décennie, alors que les photographies aériennes historiques couvrent une période allant de 10 à 70 ans, pour quelques îlots seulement. Une approche classique consistant à utiliser la limite de végétation permanente comme ligne de référence et indicateur de la mobilité du trait de côte a été adoptée. À partir de la cartographie de cette limite, une analyse de la dynamique des îlots d'une échelle pluriannuelle à pluridécennale et une évaluation de leurs trajectoires évolutives ont pu être réalisées.

De plus, les facteurs de forçage ont été analysés afin de comprendre les interactions qu'ils peuvent avoir entre eux et leurs liens potentiels avec la dynamique géomorphologique des îlots. Les modifications de l'hydrodynamisme local et régional (climats de vagues, courants) et de la cyclogénèse (intensité et fréquence des événements extrêmes tels que les dépressions tropicales et les cyclones) constituent des facteurs possibles de dégradation ou au contraire de régénération de la morphologie des îlots. La variation de la hauteur moyenne de l'océan peut également agir sur leur évolution naturelle. Celle-ci est 
liée au phénomène de variation climatique interannuelle Enso (ElNiño-Southern Oscillation), à la remontée relative du niveau marin (sous l'influence du climat et des mouvements verticaux du sol), mais aussi aux changements d'origine anthropique.

\section{Des îlots aux caractéristiques variées}

Les analyses montrent une grande diversité des caractéristiques selon les îlots en termes de superficie (de 360000 à $180 \mathrm{~m}^{2}$ ) et de forme (ovoïdale, oblongue, triangulaire...). Des tendances d'évolution très différentes au cours des dernières décennies sont également mises en évidence, aussi pour des îlots situés dans la même zone géographique. La répartition des processus affectant la côte de chaque îlot (érosion, accrétion, stabilité) est la suivante : 54 \% de la longueur cumulée des côtes des îlots est actuellement en situation d'érosion, $30 \%$ est stable et $16 \%$ est en accrétion. Les situations sont donc très variables, certains îlots sont relativement stables dans le temps tandis que d'autres évoluent très vite et voient leurs surfaces diminuer significativement.

Tous les îlots montrent à l'heure actuelle qu'au moins 50 \% de leurs côtes sont affectées par l'érosion et pour plusieurs d'entre eux

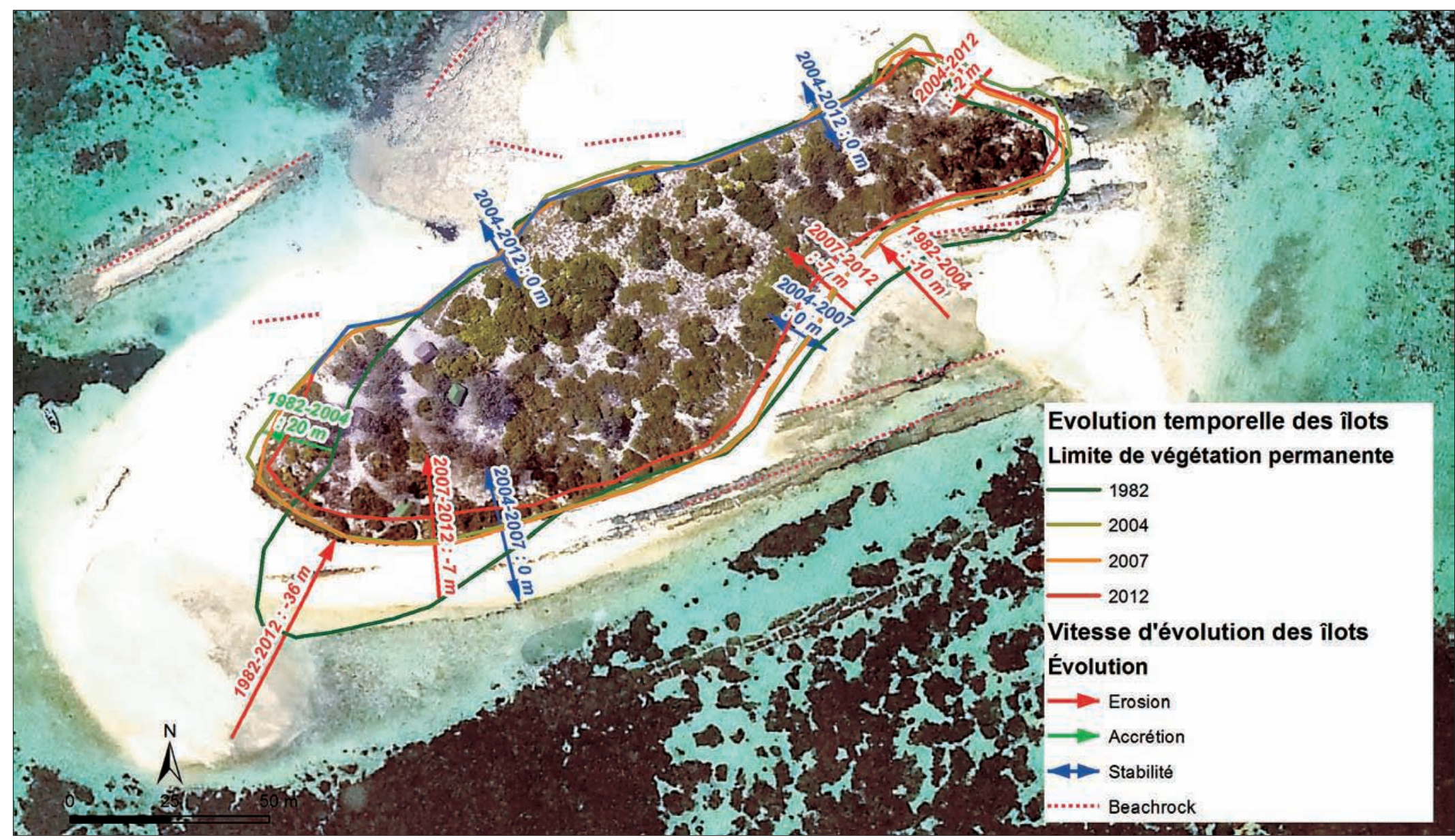

Évolution temporelle de l'îlot Larégnère de 1982 à 2012. Source : GARCIN et VENDE-LECLERC, 2015 
ce taux atteint $100 \%$. Toutefois, cette érosion peut aussi indiquer une migration de l'îlot ou une adaptation de sa géométrie. En effet, les îlots sont par nature beaucoup plus mobiles que les littoraux de la Grande Terre ou des îles Loyauté. Les îlots montrant une tendance significative à l'accrétion et à la croissance de leur surface au cours des dernières années sont très rares et ceux en situation de stabilité représentent moins d'un tiers de l'ensemble des îlots étudiés.

\section{Les beachrocks, composante essentielle de nombreux îlots}

Les beachrocks (encadré 20) ont également été cartographiés. Ils constituent une protection naturelle contre le recul du trait de côte notamment lorsque plusieurs générations sont présentes sous forme de bancs successifs. Les îlots dont les beachrocks ont une altitude supérieure à celle du niveau marin actuel (probablement formés lors du haut niveau marin de l'Holocène, entre 6000 et 2800 ans BP) sont souvent moins soumis au phénomène d'érosion de leur rivage. Ces îlots ont généralement des superficies et des altitudes moyennes sensiblement plus élevées que celles des autres. Néanmoins, dans quelques cas, la présence de beachrocks n'a pas empêché l'érosion de certains îlots ainsi que leur destruction partielle, voire totale. I s'agit le plus souvent d'îlots de surface relativement modeste, de faible altitude et donc probablement plus récents que ceux précédemment évoqués. Les variations du niveau marin rendent ces îlots beaucoup plus vulnérables à l'érosion.

\section{Le cycle de vie des îlots, de leur naissance à leur disparition}

Ces analyses conduisent à proposer un schéma du cycle de vie des îlots définit en plusieurs stades d'évolution. Ces stades sont contrôlés par différents paramètres environnementaux tels que les conditions hydrodynamiques locales, la variation des climats de vents et de vagues au cours du temps, ainsi que l'évolution du récif et du niveau marin relatif. Six stades constituent ce cycle de vie des îlots néocalédoniens : la nucléation, la croissance, la maturité, la décroissance, la relique et la disparition (fig. 2).

\section{Encadré 20}

\section{Ce que nous disent les beachrocks}

Les beachrocks (ou grès de plage) sont des roches sédimentaires formées au niveau de la zone intertidale par cimentation carbonatée des sables de plage et des sédiments bioclastiques et biodétritiques. Cette induration précoce se produit uniquement pendant les périodes de stabilité des plages et parallèlement au rivage ; les beachrocks ont donc, au cours du temps, fossilisé les lignes de rivage des îlots indiquant la localisation, l'orientation et la forme des anciennes plages ainsi que la paléo-morphologie de l'îlot. Ils permettent ainsi d'évaluer la surface passée de l'îlot, de détecter les secteurs où des reculs du trait de côte se sont produits et donnent donc des indications précieuses sur l'évolution de l'îlot dans le temps.

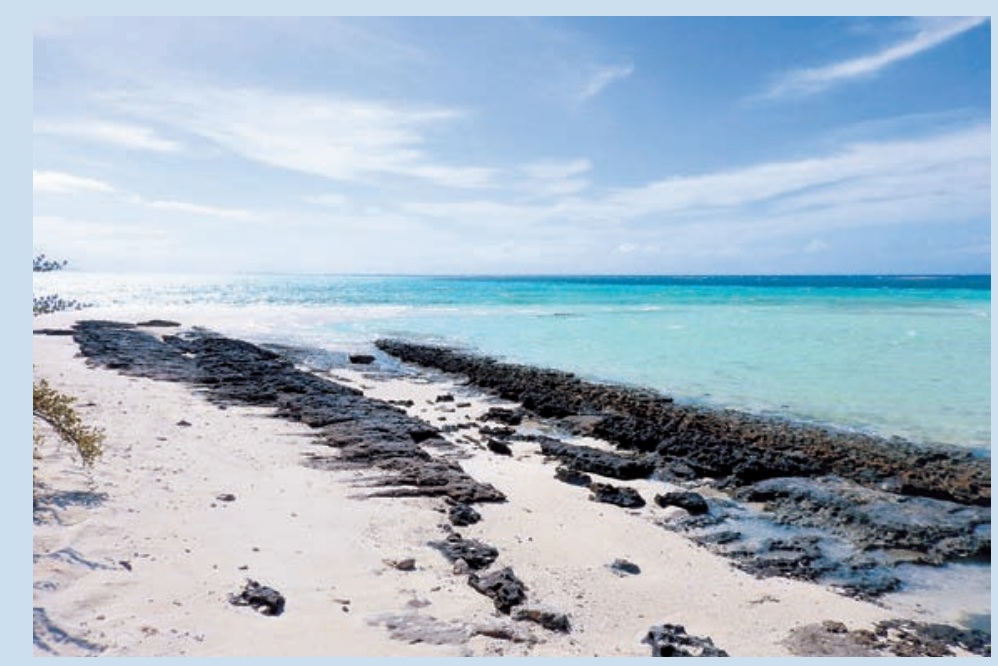

Plusieurs générations de beachrocks qui résultent de la fossilisation d'anciennes plages successives, sud-est de l'îlot Larégnère. ๑ M. Vendé-Leclerc

À chacun des îlots étudiés, un stade a ainsi pu être attribué. Les changements des facteurs de forçage ainsi que la géomorphologie actuelle ou héritée conduisent les îlots à évoluer d'une étape à l'autre. Mais ces phases ne s'enchaînent pas nécessairement de façon séquentielle et un retour à un stade antérieur est possible. 

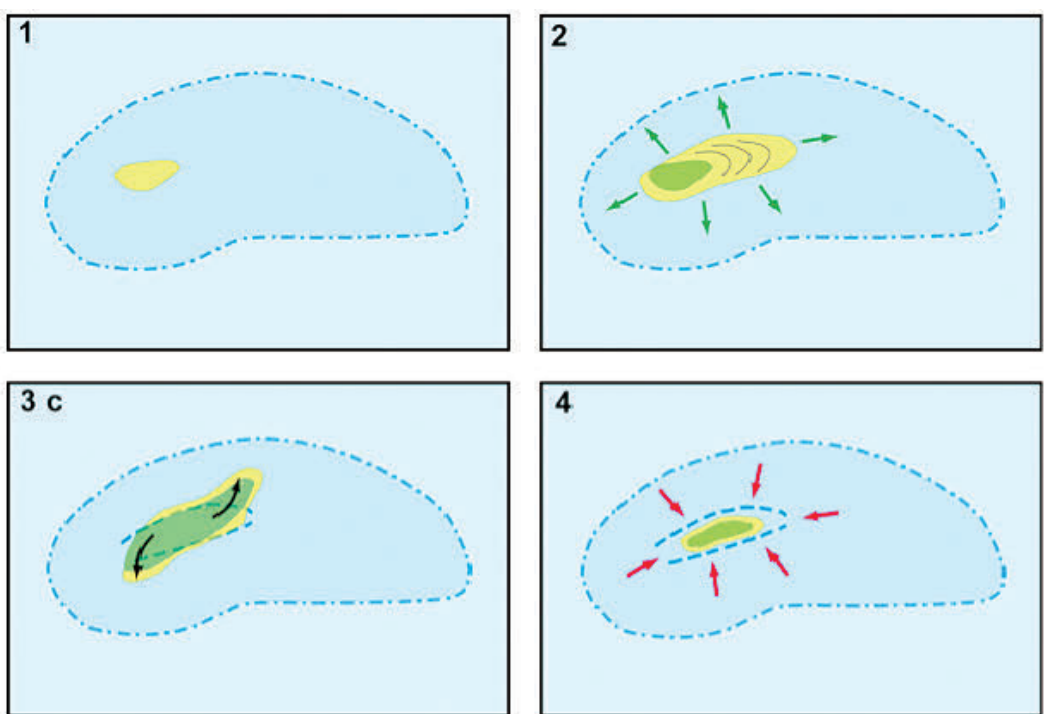

Figure 2 : Les différents stades évolutifs des îlots calédoniens.

Stade 1 : nucléation. Stade 2 : croissance. Stade 3a : mature stable. Stade 3b : mature migration. Stade 3c : mature adaptation. Stade 4 : décroissance. Stade 5 : relique. Stade 6 : disparition.

\section{Le futur des îlots : disparition ou adaptation?}

La question de l'avenir d'un îlot peut donc être abordée à travers différents critères qui constituent un facteur de résilience ou au contraire de fragilité : son évolution passée, son stade actuel, l'intensité des processus morpho-sédimentaires actuels et ses caractéristiques morphologiques. II convient également de prendre en compte l'évolution future des paramètres environnementaux comme les oscillations climatiques des

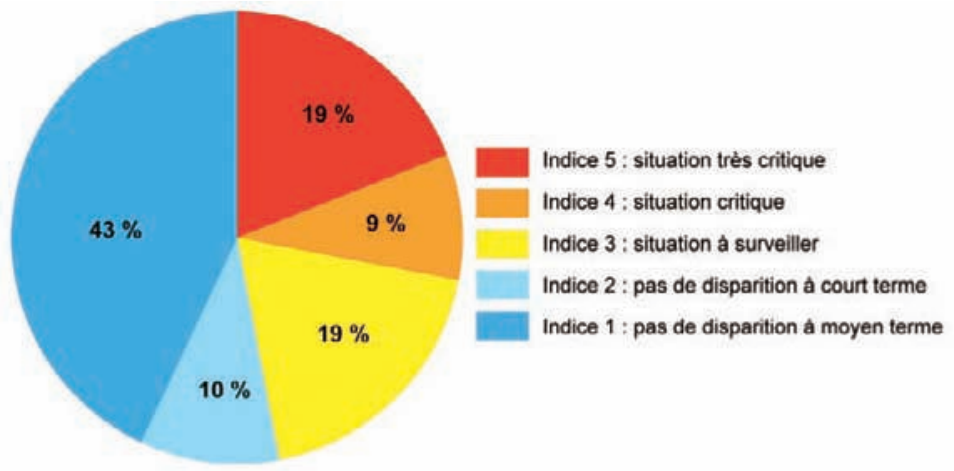

Figure 3 : Répartition des îlots en fonction de leurs évolutions futures plausibles (en \%). Source : GARCIN et al. 2016b
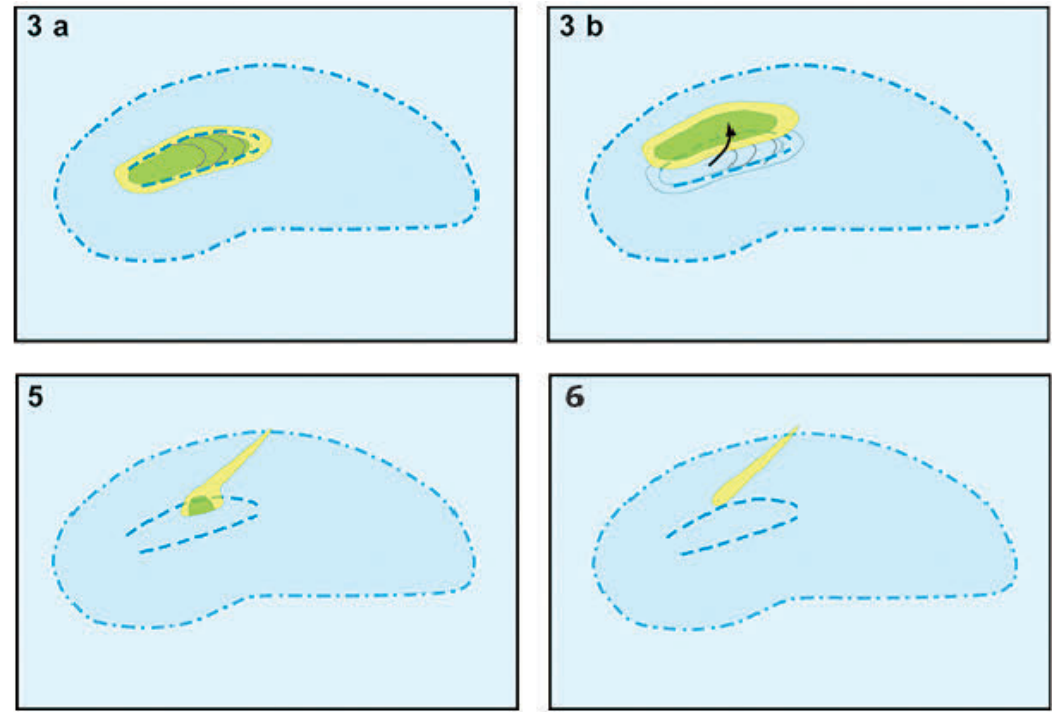
sud-ouest ou les événements extrêmes qui peuvent avoir un impact élevé sur la morphologie de l'îlot à très court terme avec parfois des effets irréversibles sur les îlots. De plus, à ces phénomènes naturels s'ajoutent le changement climatique et la montée progressive du niveau de la mer induits par les activités humaines. En utilisant ces données et informations, un indice d'espérance de vie indiquant le futur plausible de chaque îlot a été défini. Cet indice est classé sur une échelle de 1 à 5 , de la situation la plus stable à la situation la plus critique.

À partir de cette classification et en partant du postulat que la situation environnementale actuelle reste stable, il a été déterminé que, sur les 21 îlots étudiés, $19 \%$ sont dans une situation très critique qui peut conduire à leur disparition très probable dans un futur proche (quelques années) (indice 5) ; 9 \% des îlots sont dans une situation critique avec une disparition probable dans le futur proche et une disparition très probable à moyen terme (prochaines décennies) (indice 4); 19\% des îlots montrent des modifications rapides de leur morphologie qui pourraient les mettre en péril à moyen terme (sur une décennie) mais pas dans le futur proche (indice 3$) ; 10 \%$ des îlots ne sont pas menacés à l'échelle du temps court 
et moyen car de taille et altitude moyennes avec des surfaces qui augmentent ou décroissent de manière modérée (indice 2) et $43 \%$ ne sont pas menacés car stables ou en situation de croissance, avec de grandes surfaces et des altitudes relativement élevées (indice 1) (fig. 3) Ces résultats montrent que les situations sont contrastées d'un îlot à l'autre, voire, dans certains cas, pour des îlots proches.

Il convient également de souligner que les incertitudes sont plus grandes pour l'avenir à moyen et long terme en raison de la vitesse d'élévation future du niveau marin. Les incertitudes sont également liées à l'atteinte potentielle d'une valeur de seuil limite qui conduirait à une modification de la capacité de résilience des îlots. De plus, les changements de température des océans et de leur acidité influent de manière significative sur la santé et la croissance des récifs, entraînant ainsi une modification de leur rôle protecteur des zones côtières et de leur fonction de producteur de sédiments biodétritiques qui participent au budget sédimentaire des îlots.

À l'avenir, l'évolution des îlots du lagon néo-calédonien sera très variable en fonction de leur capacité de résilience face aux menaces que constituent les changements climatiques globaux.

\section{Les îlots, indicateurs des effets du changement climatique}

Les îlots sont caractérisés par une grande sensibilité face aux évolutions des conditions météo-marines et climatiques. Le nombre de facteurs de forçage jouant un rôle dans leur évolution y est plus réduit et leurs impacts sur la dynamique côtière y sont plus directs et plus facilement détectables. La compréhension de ces processus à l'échelle des îlots permet par conséquent d'acquérir une meilleure connaissance des phénomènes à une échelle plus large. Les îlots du lagon constituent ainsi des indicateurs des changements environnementaux pour la Nouvelle-Calédonie et peuvent servir de site de référence pour le suivi des impacts de l'élévation du niveau marin et du changement climatique.

\section{Références bibliographiques ${ }^{12}$}

GARCIN M. et al., 2016a Lagoon islets as indicators of recent environmental changes in the South Pacific. The New Caledonian example. Continental Shelf Research, $122: 120-140$.

GARCIN M., et al 2016b - Observatoire du littoral de Nouvelle-Calédonie Bilan des activités 2015, Typologie, méthodes et suivi des sites pilotes. BRGM/RP-65637-FR, 169 p., 148 fig., 14 tabl., 2 annexes.

GARCIN M., VENDE-LECLERC M., MENGIN M., 2017 Observatoire du littoral de Nouvelle-Calédonie. Bilan des activités 2016. Rapport BRGM/RP66941-FR, $130 \mathrm{p}$.

SMITH W. H. F. et SANDWELL T., 1997 Global seafloor topography from satellite altimetry and ship depth soundings, Science, 277 : 1957-1962.

${ }^{12}$ Références bibliographiques complètes disponibles à cette adresse : $\mathrm{https}: / /$ dimenc.gouv.nc/geologie-observatoire-du-littoral-de-nouvelle-caledonie-oblic/telechargement-oblic 


\section{Chapitre 27 \\ L'enjeu du «phénomène acanthaster » pour le Pacifique}

Pascal Dumas et Mehdi Adjeroud

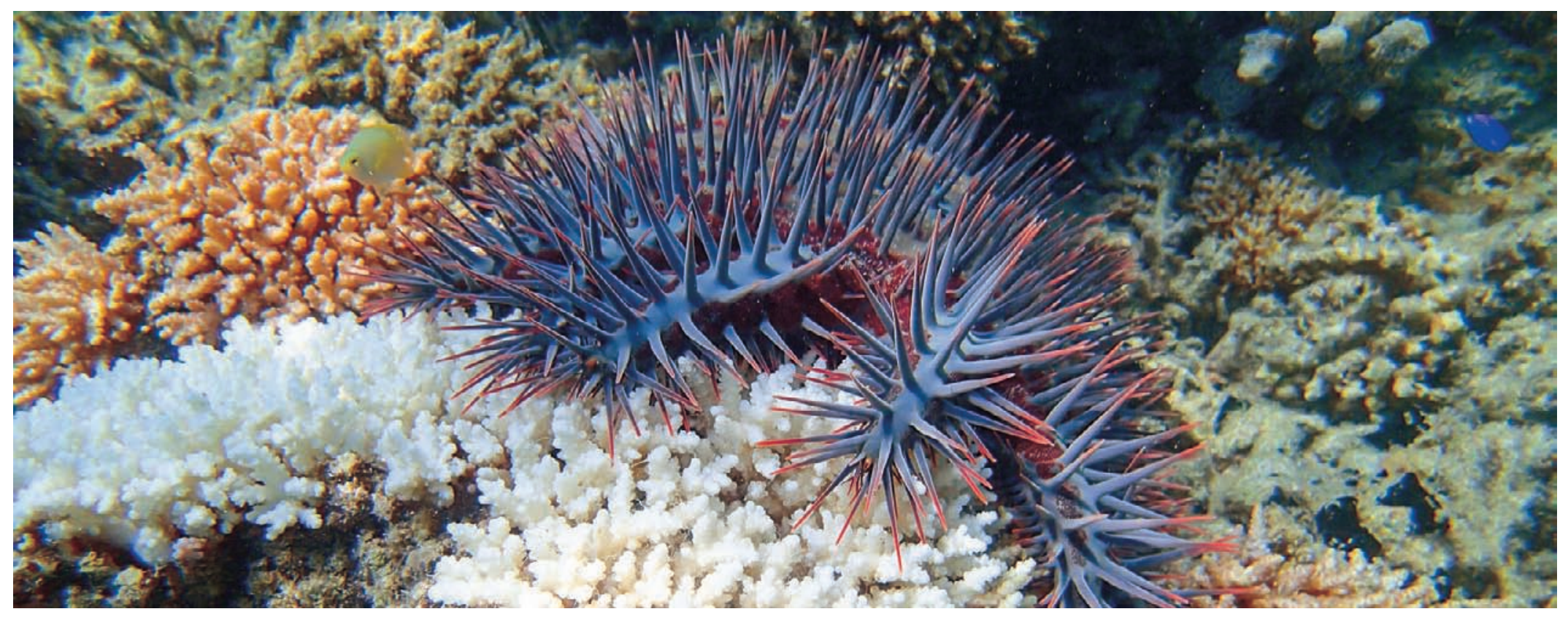

Acanthaster planci est une étoile de mer corallivore, qui se nourrit des polypes coralliens en dévaginant son estomac sur les coraux et laisse derrière elle uniquement le squelette calcaire blanc du corail. De grande taille à l'état adulte (30 à $40 \mathrm{~cm}$ de diamètre en moyenne), les acanthasters peuvent consommer jusqu'à $12 \mathrm{~m}{ }^{2}$ de corail par an. @ IRD/P. Dumas

\section{Un prédateur vorace}

Positionnées dans l'embranchement des échinodermes tout comme les oursins, les holothuries, les crinoïdes ou les ophiures, les étoiles de mer appartenant au genre Acanthaster sont généralement inféodées aux récifs coralliens de l'Indo-Pacifique. De couleur très variable selon les régions, elles possèdent généralement 10 à 20 bras et portent sur leur face supérieure de longues épines enduites d'un venin stéroïdien particulièrement douloureux et hautement toxique. Elles portent d'ailleurs le nom vernaculaire d'étoile de mer épineuse ou de couronne d'épines ( «Crown-of-thorns » chez nos voisins anglosaxons). En plus d'Acanthaster brevispinus, espèce plutôt rencontrée en profondeur, les résultats d'études génétiques récentes suggèrent l'existence d'au moins quatre espèces distinctes et séparées géographiquement au sein d'un continuum mer Rougeocéan Indien-océan Pacifique. Autrefois rattachées à l'espèce unique A. planci, les populations rencontrées sur les récifs du Pacifique relèvent désormais $\mathrm{d}$ ' $A$. cf. solaris, mais leur statut taxonomique (et notamment l'existence possible de plusieurs espèces distinctes au sein du Pacifique) fait encore l'objet de controverses. 
Outre leur taille imposante - certains spécimens dépassent les $70 \mathrm{~cm}$ de diamètre et peuvent atteindre $3 \mathrm{~kg}$-, la célébrité des acanthasters est essentiellement due aux conséquences de leur régime alimentaire sur les écosystèmes coralliens. Les acanthasters adultes sont en effet de redoutables prédateurs du corail, qu'elles consomment en dévaginant leur estomac sur les colonies. Une fois les polypes digérés sur place, l'acanthaster laisse derrière elle un squelette calcaire nettoyé et intact : facilement repérables, ces cicatrices alimentaires blanches constituent souvent un des premiers indicateurs de leur présence en nombre.

Présentes sur les récifs depuis les temps géologiques, les acanthasters constituent une composante naturelle des écosystèmes tropicaux. Dans un récif corallien en « bonne santé », elles sont relativement peu abondantes (de l'ordre de quelques individus par hectare) et la prédation qu'elles exercent n'a aucune incidence négative sur l'abondance, le recouvrement et la diversité des assemblages de coraux. Au contraire, elles contribuent au maintien de la diversité corallienne grâce à leurs préférences alimentaires marquées : en général, les coraux à croissance rapide comme les Acropora et les Montipora sont préférés aux coraux à croissance plus lente, tels que les Porites, ce qui laisse plus de place aux espèces moins opportunistes. Une acanthaster adulte consomme environ $10 \mathrm{~m}^{2} \mathrm{de}$ corail par an et n'a que peu de prédateurs réguliers. Sur près d'une trentaine d'espèces de poissons et d'invertébrés recensées, seules quelques-unes (le triton Charonia tritonis ou « toutoute », le poissonballon étoilé Arothron stellatus, le napoléon Cheilinus undilatus, certains balistes, empereurs ou poissons-coffres) sont connues pour s'attaquer aux adultes en bonne santé.

\section{Quand les populations d'acanthasters « explosent »}

Si en temps normal les acanthasters se font plutôt discrètes, leurs populations peuvent littéralement « exploser » à certains moments pour atteindre des valeurs extrêmes : jusqu'à plusieurs milliers, voire dizaines de milliers d'individus par hectare, pouvant persister pendant des mois ou des années sur de vastes étendues de récifs. Ces proliférations, largement imprévisibles, sont l'une des perturbations biotiques les plus graves pour les récifs coralliens, dont l'impact est quantitativement comparable à celui des cyclones. La mortalité corallienne peut dépasser $90 \%$ dans les zones récifales les plus sévèrement touchées, entraînant alors un profond remaniement de la structure et du fonctionnement de l'écosystème. Modification physique de l'habitat, raréfaction des proies, déplacement et remaniement d'espèces : les effets en cascade de la disparition des coraux peuvent se répercuter sur l'ensemble de la communauté récifale, allant parfois jusqu'au basculement vers un système totalement dominé par les algues.

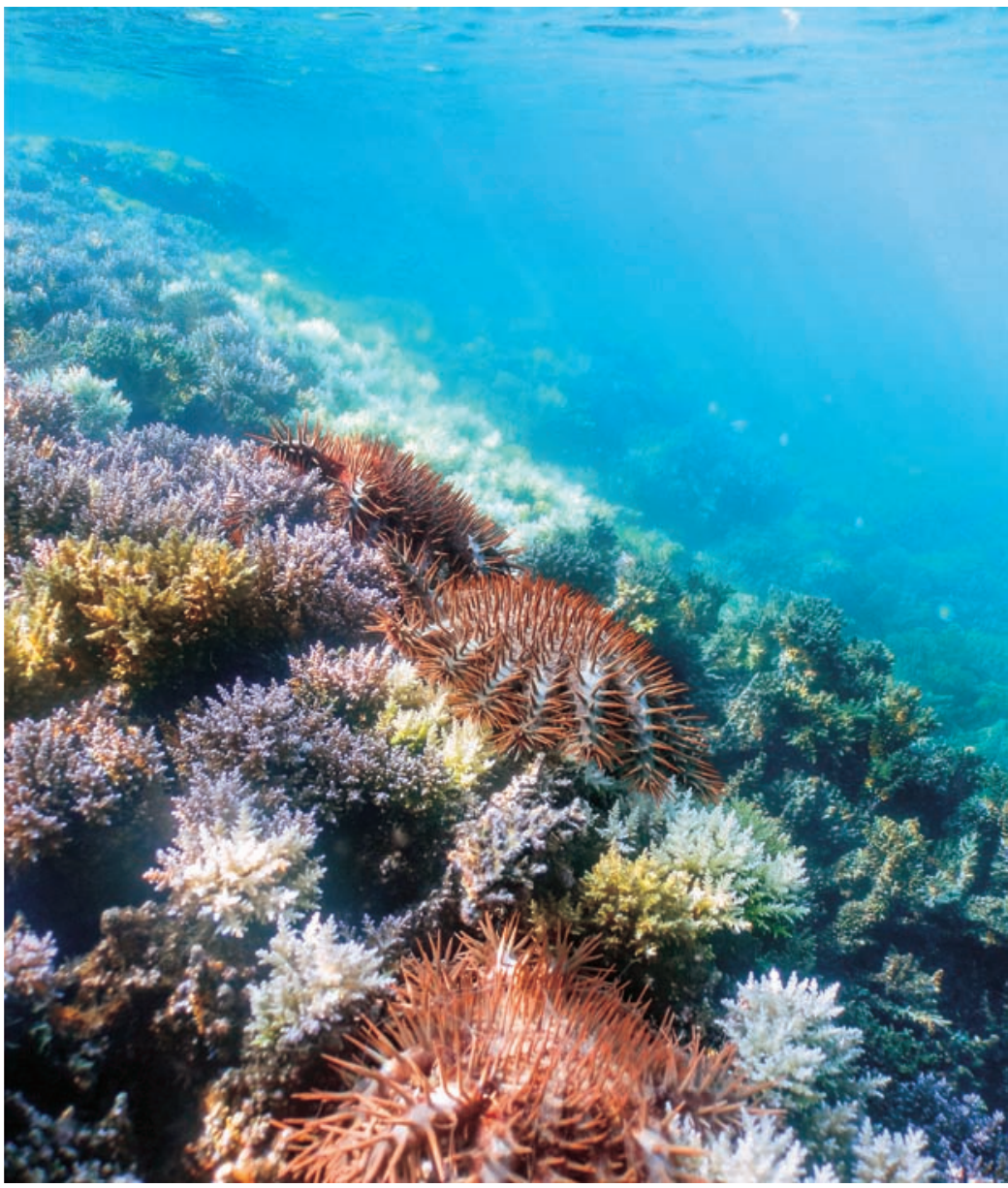

Certaines années, et pour des raisons encore mal connues, les acanthasters se mettent à pulluler, avec des densités atteignant plusieurs individus par mètre carré. Au bout de quelques mois, elles peuvent ainsi dévaster des portions importantes de récifs. La grande barrière de corail australienne, la Polynésie française, le sud du Japon, et plus récemment l'archipel du Vanuatu et la Nouvelle-Calédonie en ont fait la triste expérience ! (c) IRD/P.Dumas 
Même si des traces fossiles suggèrent une histoire beaucoup plus ancienne, les premières pullulations d'acanthasters et leurs conséquences n'ont été signalées et étudiées quantitativement qu'à partir des années 1960. Plus d'un tiers des récifs du Pacifique ont été concernés par ce phénomène : l'archipel des Ryukyus au sud du Japon, Palau, Guam, Samoa, la Grande Barrière de Corail, le Vanuatu, Fidji et Kiribati. Les récifs coralliens français n'ont pas été épargnés : les îles de la Société, en Polynésie française, ont connu un épisode très fort entre 2006 et 2009 ; la Nouvelle-Calédonie, jusque-là indemne de pullulations à grande échelle, a été affectée dans les années 2000, puis plus récemment à partir de 2012. En dépit d'efforts de recherche soutenus menés par la communauté scientifique, les causes de ces proliférations sont encore insuffisamment comprises. Pour certains chercheurs, la raréfaction des prédateurs naturels des acanthasters en particulier causée par la surpêche des espèces commerciales tels que tritons, napoléons, empereurs etc. - en serait une des causes. La dégradation globale de la qualité des eaux liée aux activités humaines est également pointée du doigt, mais cette hypothèse ne saurait à elle seule expliquer l'ensemble des invasions, a fortiori celles observées sur des récifs exempts de pollution. Pour d'autres auteurs, ces explosions démographiques seraient un phénomène naturel cyclique lié aux caractéristiques biologiques de l'espèce, naturellement prédisposée à de grandes fluctuations d'abondance par son extraordinaire fécondité : une seule femelle adulte peut pondre plus de 100 millions d'œufs en une seule saison de reproduction. Avec le recul et grâce aux avancées scientifiques récentes en génétique, biologie moléculaire et modélisation, le caractère hautement complexe, multifactoriel et multi-échelle des invasions s'affirme de manière de plus en plus évidente.

\section{« Risque acanthaster » et changements globaux}

À l'échelle de l'Indo-Pacifique, l'incidence des épisodes d'infestation semble augmenter en fréquence et en intensité - surtout au cours des dernières décennies, marquées par une prise de conscience croissante des changements globaux affectant la région. Avec un développement optimal dans des eaux chaudes $\left(26\right.$ à $\left.30^{\circ} \mathrm{C}\right)$ en présence de phytoplancton, les acanthasters seraient particulièrement sensibles aux effets du changement climatique : l'augmentation de la température des eaux de surface et l'enrichissement en nutriments en zone côtière sont actuellement considérés comme des facteurs majeurs favorisant la survie des larves, donc l'augmentation du nombre d'adultes atteignant potentiellement les récifs au terme de leur développement. Étant donné les grandes capacités de dispersion de l'espèce, dont les larves nageuses peuvent s'installer à plusieurs centaines de kilomètres de leur récif d'origine, l'aggravation du « risque acanthaster » à l'échelle régionale constitue un problème réel dans le contexte des scénarios de changement climatique actuels. Même s'il existe des preuves historiques montrant que les récifs coralliens peuvent se rétablir après coup, la récupération est généralement lente (plusieurs dizaines d'années) et n'est pas garantie : ces proliférations ne font qu'exercer davantage de pression sur des systèmes de plus en plus affaiblis par d'autres perturbations naturelles (blanchissement des coraux, cyclones, maladies coralliennes...) et anthropiques (pollutions, surpêche, aménagements littoraux, etc.). Pour la grande barrière australienne, une étude récente rapporte ainsi un recul de $50 \%$ de la couverture corallienne sur les 30 dernières années, la moitié de cette perte provient du seul fait des infestations récurrentes d'acanthasters.

En Nouvelle-Calédonie, notre connaissance des infestations et de leurs impacts quantitatifs sur les récifs est particulièrement limitée. Dans le prolongement d'études et d'observations ponctuelles remontant aux années 1980-1990, un bilan effectué en 2012 par les scientifiques de l'IRD sur 18 sites démontre l'existence d'infestations localisées, potentiellement mobiles, présentant des densités d'acanthasters parfois très élevées (jusqu'à 500 individus/ha). La zone la plus étudiée est le lagon sud-ouest, où les proliférations sont restreintes à quelques sites; souvent éphémères, elles passent généralement inaperçues des gestionnaires mais sont susceptibles de causer à moyen et long terme d'importants dégâts sur les coraux, notamment des genres Acropora et Pocillopora. Mais les informations relayées par les usagers du lagon laissent craindre l'existence de nombreuses infestations presque totalement ignorées, aussi bien en province Sud (par exemple la zone de Boulouparis, Ouaco, Corne Sud) qu'en province Nord (par exemple la zone de Hienghène, Poindimié, Poum), sur la côte Est (Côte oubliée...) ou dans les îles. 


\section{Gestion du « risque acanthaster »}

Dans la majorité des pays du Pacifique où les ressources coralliennes constituent la base de la pêche vivrière traditionnelle, les infestations $d$ 'acanthasters constituent une menace pour la sécurité alimentaire et le mode de vie des populations côtières. La question préoccupe également les professionnels du tourisme (clubs de plongée, hôtels...) dont l'activité peut être gravement impactée par des proliférations non maîtrisées, et les gestionnaires de l'environnement pour lesquels elle représente désormais un enjeu de conservation.

À l'heure actuelle, seule l'intervention humaine permet de lutter contre les proliférations d'acanthasters - avec plus ou moins d'efficacité selon l'ampleur du phénomène, les caractéristiques des récifs impactés (taille, isolement, vulnérabilité...), le contexte (socioéconomique, environnemental) et les moyens (humains, financiers) disponibles. Les approches les plus courantes visent généralement à limiter les pertes coralliennes en réduisant au maximum le nombre $d$ 'individus se nourrissant sur les récifs lors des vagues d'infestation. La méthode la plus ancienne consiste à prélever manuellement les acanthasters à l'aide d'outils variés - crochets, bâtons, fusils sousmarins, sacs etc. - pour les ramener et les détruire à terre. Nécessitant une main-d'œuvre importante et un engagement durable, cette approche montre ses limites en cas de proliférations massives, spatialement étendues et/ou récurrentes, d'autant qu'elle présuppose une bonne connaissance des spécificités biologiques et écologiques de l'espèce (en particulier de sa période de ponte locale). Plus rentables, les traitements par injection - qui consistent à inoculer en plongée une solution toxique entrainant la mort des acanthasters - remplacent de plus en plus souvent les méthodes de collecte. Toutefois, ces traitements ne sont pas sans inconvénients, et de nombreux composés chimiques autrefois utilisés (par exemple le sulfate de cuivre, le bisulfate de sodium, le formol, l'ammoniac, l'eau de javel...) ont dû être progressivement abandonnés en raison d'une toxicité avérée pour l'environnement et les autres espèces et/ou d'un coût élevé. Une nouvelle approche fondée sur l'injection de substances acides naturelles et bon marché a été récemment développée par l'IRD : des tests réalisés en conditions contrôlées et sur le terrain ont démontré l'efficacité létale du jus de certains fruits (différentes variétés de citron vert, fruit de la passion), du vinaigre blanc et de certains acides agroalimentaires en poudre. Induisant une mortalité élevée même à faible dose, ces substances constituent désormais une alternative écologique hautement crédible dans la lutte contre les proliférations d'acanthasters. Testée au Vanuatu depuis 2014, cette approche a été pour la première fois employée en Nouvelle-Calédonie en 2017. Réalisée sur l'îlot Vua avec la participation de plongeurs bénévoles et de moyens navigants mis à disposition par l'IRD, l'opération pilote a permis l'éradication de plus d'une tonne d'acanthasters sur deux jours et confirmé l'efficacité de la méthode en conditions réelles.

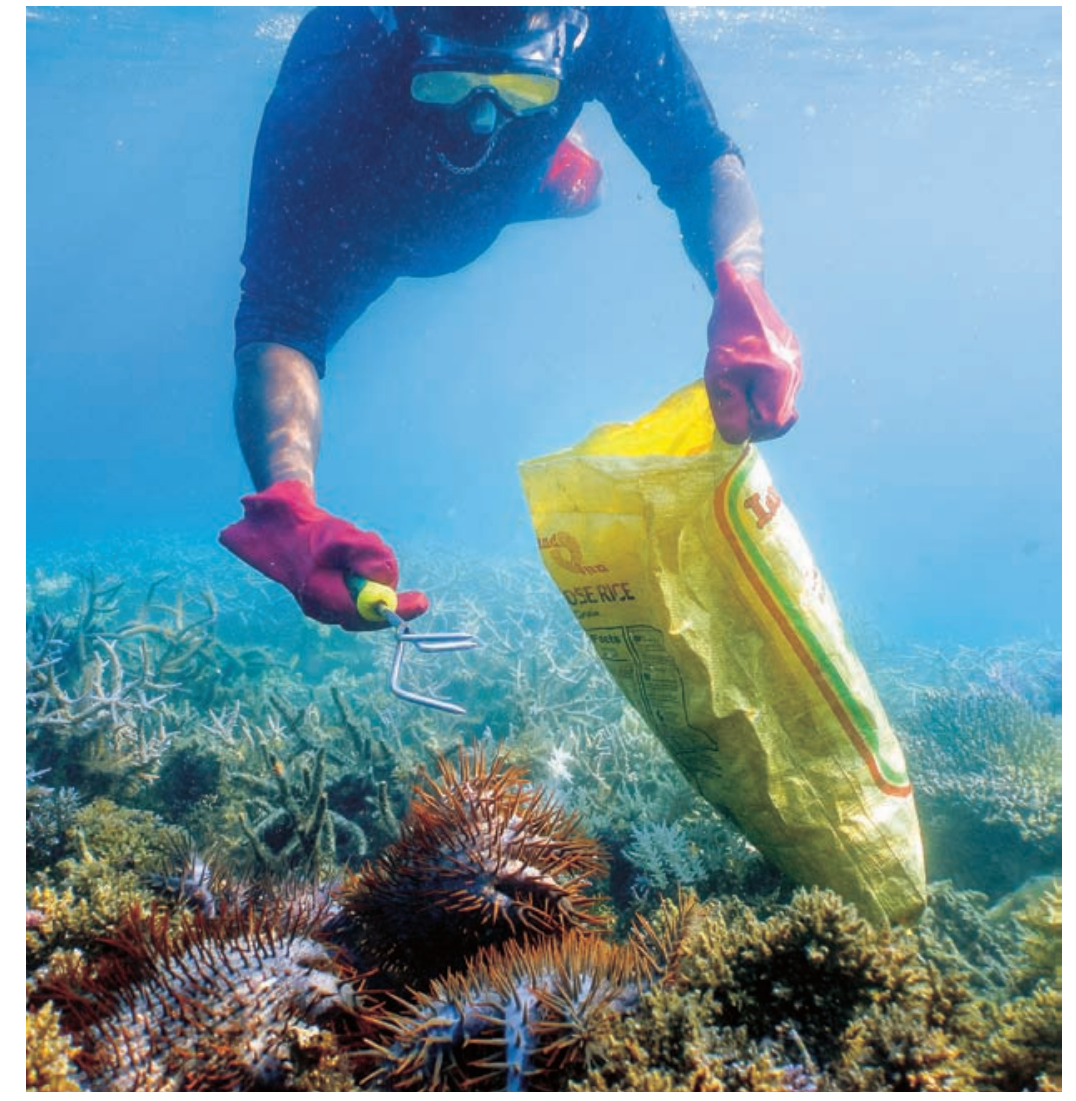

Les moyens pour lutter contre les pullulations d'acanthaster sont restreints. Dans certains états insulaires du Pacifique, les pêcheurs et plongeurs organisent des campagnes de ramassage, durant lesquelles les acanthasters sont prélevées manuellement. Mais elles sont souvent ponctuelles et limitées dans l'espace, et leur efficacité est loin d'être suffisante pour stopper une pullulation. Mais elles permettent de limiter les dégâts, et d'impliquer les populations locales dans la préservation de leur récif. @ IRD/P.Dumas 


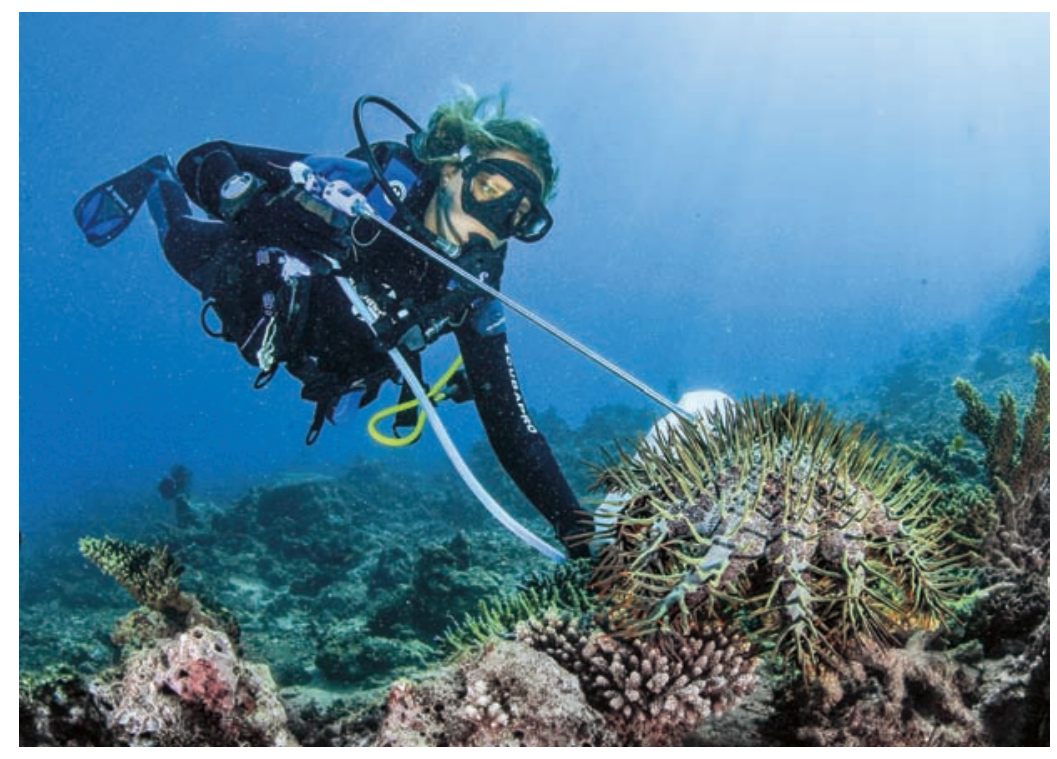

Récemment, des techniques plus élaborées ont été mises au point, qui tentent de concilier efficacité sur le terrain, faibles impacts sur l'environnement et coûts réduits. Par exemple, des kits d'injection létale de vinaigre ont été testés avec succès, comme ici autour de l'îlot Vua, dans le lagon sud-ouest de la Grande Terre. @ B. Preuss

Le caractère imprévisible des infestations rend leur gestion particulièrement complexe, surtout pour les récifs confrontés à une forte récurrence de ces épisodes, parfois année après année. Mais pour aussi efficace qu'elles puissent être, les méthodes de contrôle ne constituent pourtant qu'un traitement symptomatique du phénomène - un peu comme écoper l'eau d'un bateau percé. Et qui supposent au préalable la détection - la plus précoce possible - des populations en explosion. Une tâche pouvant sembler insurmontable pour les pays dotés de vastes formations récifales, dont le suivi à long terme nécessite des moyens conséquents. Face à la difficulté d'assurer le financement de suivis scientifiques pérennes couvrant l'ensemble du territoire, une alternative intéressante réside dans la création de réseaux de suivis « citoyens », ou la collecte de données est assurée par les usagers du lagon eux-mêmes. C'est l'objet du programme de suivi participatif Oreanet ${ }^{13}$ (Oceania Regional Acanthaster Network), mis en place en Nouvelle-Calédonie depuis 2015, qui s'appuie sur la participation volontaire des pêcheurs, plaisanciers, clubs de plongée, bureaux d'études, association et scientifiques pour surveiller le phénomène (encadré 21$)$.

${ }^{13} \mathrm{http}: / /$ oreanet.ird.nc
Encadré 21

Le programme Oreanet

Pascal Dumas et Sylvie Fiat

Lancé en juillet 2015 grâce au soutien financier du Fonds Pacifique, du gouvernement de Nouvelle-Calédonie et du GOPS (Grand observatoire de la biodiversité terrestre et marine du Pacifique sud et sud-ouest), le projet IRD Oreanet (Oceania Regional Acanthaster Network) a pour objectif de bâtir un réseau de surveillance opérationnel du risque acanthaster en Nouvelle-Calédonie, Vanuatu et Fidji. Le succès de ce réseau repose sur une approche participative où les observations sont relayées par les usagers du lagon, à l'aide d'outils conviviaux permettant un signalement rapide des acanthasters depuis un ordinateur, une tablette ou un smartphone. À ce jour le réseau Oreanet a permis le signalement de plus de 16000 acanthasters à travers près de 300 rapports participatifs émanant de pêcheurs, communautés côtières, plaisanciers, plongeurs, ONG, clubs et associations, organismes scientifiques etc. Des procédures standardisées de vérification du risque et d'action de contrôle sur le terrain ont également été développées et validées afin d'établir une cartographie du risque et de fournir un cadre d'intervention opérationnel lorsqu'une infestation est reportée via le réseau de surveillance.

Si le « phénomène acanthaster » est désormais reconnu comme porteur d'enjeux de conservation majeurs, une prise de conscience tardive de son ampleur et l'existence de controverses récurrentes quant à la pertinence de l'intervention humaine ont fortement contraint les capacités de réponse des pays affectés. En dépit de leur efficacité à court, voire moyen terme, les approches de gestion actuelles ne constituent finalement qu'une parade provisoire, un traitement des symptômes plutôt que de l'origine d'un phénomène complexe dont les causes profondes demeurent globalement méconnues. L'étape suivante requiert le développement d'une vision globale intégrant une meilleure compréhension des processus contrôlant l'initiation, le maintien et la diffusion des invasions d'acanthaster en lien avec les changements climatiques affectant les écosystèmes marins : un défi scientifique de taille. 



\title{
Partie 4 \\ Paroles, pratiques et représentations autour des récifs
}

\author{
Coordination : Catherine Sabinot
}

Depuis trois millénaires, les hommes sont liés aux récifs. Ils les ont aperçus de leurs pirogues à balancier, y ont découvert des passes qui leur ont permis de toucher terre et de s'installer aux abords des platiers et tombants récifaux pourvoyeurs de ressources halieutiques variées. Pour les Kanak, le lagon est un monde invisible habité par les Ancêtres et traversé par les « chemins des morts ». Pour tous, il est un lieu marqué par des histoires, des mémoires, et des « coups de pêche ». Des chercheurs en sciences humaines et sociales, aux côtés de leurs collègues des sciences de la nature, décryptent ce que représente le récif pour les Néo-Calédoniens. 



\section{Trois millénaires au vent des récifs}

Christophe Sand

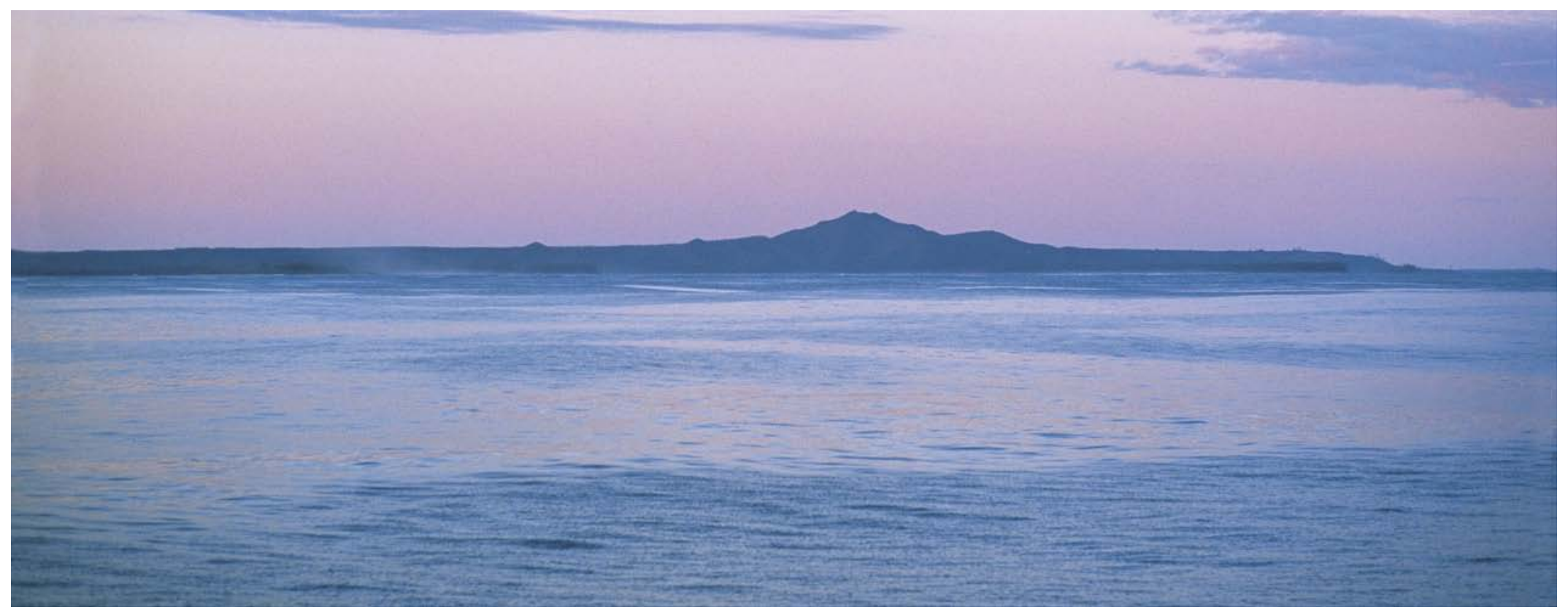

lle des Pins se détachant sur l'horizon. ( ) P.-A. Pantz

\section{La barre d'écume à l' horizon d'une nouvelle terre}

Dans le monde d'îles du pays néo-calédonien, les brisures d'un récif ne sont jamais loin du regard des clans côtiers. Approchant du ressac produit par les vagues s'enroulant sur le corail de surface, les premiers explorateurs de langues austronésiennes, qui s'approchèrent il y a environ 3000 ans de cette masse énigmatique et apparemment sans fin que constituait sur l'horizon la côte nord-est de la Grande Terre, ont recherché des passes. À ce moment unique et fugace d'histoire qu'est la première découverte d'une nouvelle terre, les marins n'étaient pas intéressés par les richesses potentielles de l'environnement marin, mais par la promesse de l'eau douce, là-bas, à terre, dans le prolongement de la passe que doublait leur pirogue à balancier. Ces découvreurs océaniens étaient originaires de la région du « grand triangle de corail » très loin dans le nord-ouest, entre Asie du Sud-Est insulaire et nord de la Mélanésie. La connaissance des récifs faisait partie de leur bagage culturel et de leur mémoire ancestrale depuis que l'homme est homme. Ils comprirent ainsi rapidement, lors de l'exploration de la Grande Terre néo-calédonienne, qu'ils étaient confrontés à l'un des ensembles coralliens les plus étendus qu'ils aient jamais observé, hors de proportions avec tout ce qu'ils avaient pu découvrir depuis qu'ils avaient quitté les côtes des îles Salomon, peuplées il y a plusieurs dizaines de milliers d'années, pour s'aventurer à travers des îles et des archipels qu'aucun homme n'avait explorés avant eux. 


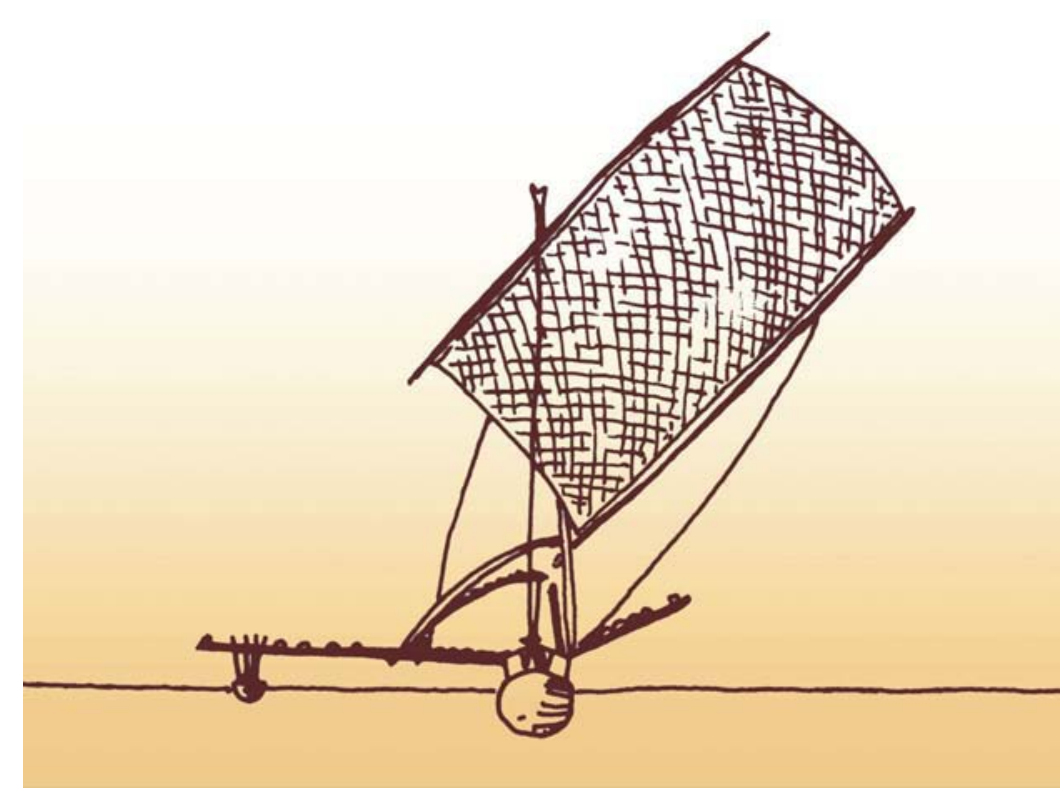

Figure 1 : Forme possible d'une pirogue ayant servi au premier peuplement de l'archipel néo-calédonien il y a 3000 ans. @ C. Sand

\section{Quand les récifs étaient vraiment « vierges » de tout impact anthropique}

Ces premiers groupes de navigateurs avaient un objectif principal en se lançant vers l'inconnu au-delà de l'horizon sur leurs pirogues (fig. 1) : découvrir une nouvelle terre et y fonder une implantation pérenne. Ceux qui abordèrent les côtes de l'archipel néo-calédonien constatèrent bien vite que les vents les avaient menés vers des latitudes plus froides que celles dont ils étaient originaires et que la géologie de la Grande Terre était bien différente de tout ce qu'ils avaient pu voir au cours de leurs voyages. Leur environnement terrestre familier était le bord de mer, avec un choix préférentiel clairement pensé pour implanter leurs sites de premier peuplement : une plage à proximité d'une source d'eau douce, proche d'un platier récifal côtier pour se nourrir, le tout situé face à un accès rapide vers la haute mer à travers une passe dans le récif. Les sites de Naïa, Nessadiou, Koné ou Koumac sur la côte ouest, Goro ou Pouebo sur la côte est, Keny ou Patho aux îles Loyauté comportent toutes ces spécificités.

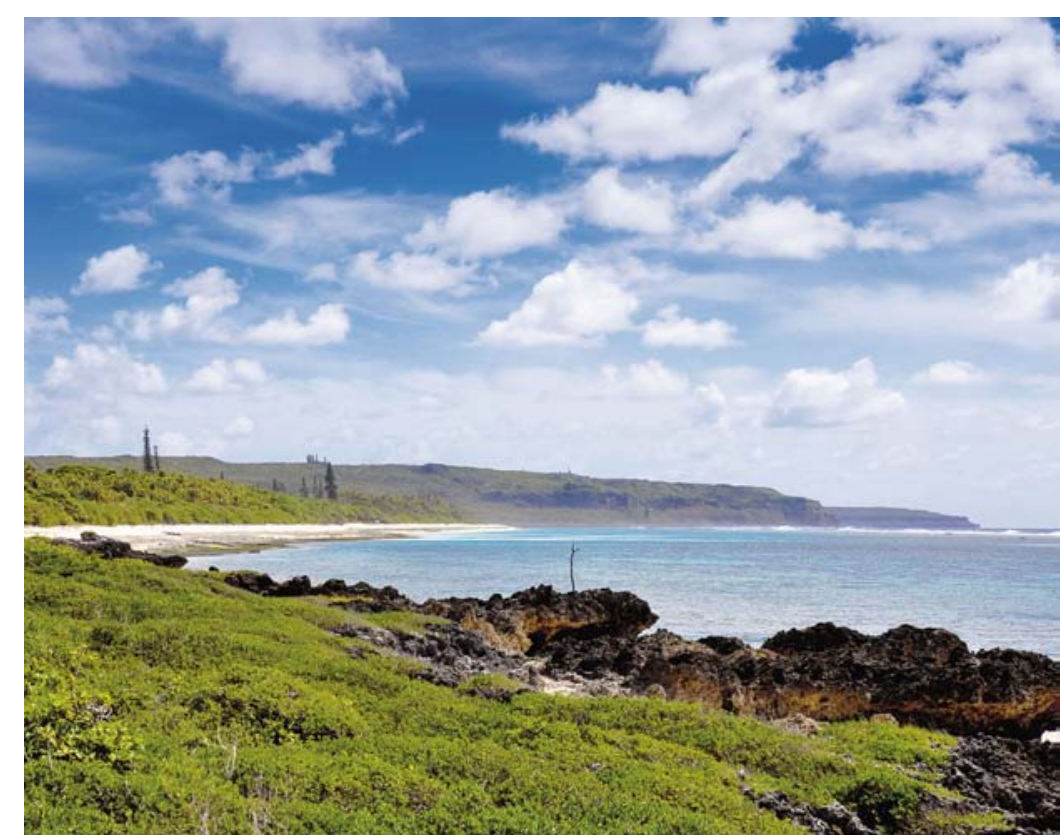

Vue de la dune de premier peuplement de Patho sur la côte orientale de Maré aux îles Loyauté. @ C. Sand

Si les fouilles archéologiques ont mis au jour avant tout des vestiges matériels liés à la terre dans ces sites de premier peuplement, comme des poteries décorées de la tradition Lapita et des haches en pierre, l'étude des vestiges de coquillages montre une tradition d'exploitation de tous les milieux marins disponibles. La présence de gastéropodes de type trocas et cônes est un signe qu'au moins une partie de la collecte se faisait sur un environnement récifal. De même, les ossements de poissons découverts dans les poubelles des sites Lapita aux îles Loyauté montrent la prédominance d'une pêche de Scaridae (poisson-perroquet), habitant dans un milieu de corail, probablement pêchés avant tout au filet, certains poissons carnivores de lagon étant pris grâce à des hameçons simples en coquillage.

Il est difficile d'imaginer aujourd'hui ce que devait être la richesse de ces environnements marins de l'archipel néo-calédonien lors du premier peuplement il y a 3000 ans, avant que les ramassages répétés de coquillages et le développement de la pêche par des groupes progressivement de plus en plus nombreux ne diminuent de façon significative les densités trophiques. Sur la côte centre ouest de la 
Grande Terre, où le lagon est peu étendu et le grand récif est d'un accès rapide à partir de la plage, les études archéologiques ont montré que l'économie des groupes côtiers de Deva a été pendant très longtemps fortement dépendante des produits de la mer. Afin d'éviter une surexploitation trop intense du milieu récifal, les familles ont, durant près de deux millénaires, vécu sur une organisation territoriale semi-nomade à faible densité de population, se déplaçant régulièrement d'une zone à une autre le long de la côte pour ne pas épuiser les ressources.

\section{De la terre sur le corail}

Mais ce serait une erreur de croire qu'à lui seul le prélèvement direct par l'homme a progressivement appauvri les récifs coralliens au cours des siècles et des millénaires qui ont suivi le premier peuplement. Un phénomène indirect massif a grandement contribué à changer les caractéristiques des lagons de la Grande Terre néo-calédonienne : l'érosion terrestre. En effet, les Océaniens sont des agriculteurs, planteurs de tubercules d'ignames et de taros, mais également de bananiers, des cannes à sucre etc. Pour étendre leurs champs, les descendants des premiers défricheurs Lapita ont progressivement brûlé les forêts sèches ou humides qui couvraient la grande majorité des environnements terrestres de la grande île.

Dans un milieu tropical où le feu naturel est extrêmement rare et où s'étaient développées au cours du temps des couches épaisses de sols humifères, la disparition des arbres a entraîné un processus répété d'érosion des sols de surface, qui se sont vus arrachés vers les bas de pentes lors des épisodes climatiques pluvieux de type cyclones, les alluvions étant entraînées par les creeks et les rivières jusqu'aux estuaires. Ceux-ci se sont progressivement retrouvés envasés, engendrant l'élargissement des plaines côtières parfois sur plusieurs kilomètres, avec le développement de mangroves au-dessus des anciennes plages de sable corallien (fig. 2).

Les particules fines de sédiment étaient, elles, entraînées en mer, venant se redéposer sur les spores de corail dans un processus que l'on qualifierait aujourd'hui de «pollution ». Ce déséquilibre infligé aux milieux récifaux proches des estuaires a impacté en cascade l'ensemble de la chaîne alimentaire, des poissons se nourrissant de corail jusqu'aux variétés de coquillages.

\section{Vivre dans un environnement de corail fossile}

Les traditions d'adaptation des groupes installés sur les îles Loyauté, à l'est de l'archipel néo-calédonien, formés de récifs coralliens fossiles surélevés, ont été profondément influencées par ce milieu naturel spécifique. Un des challenges de la vie sur des îles de karst est l'absence de cours d'eau, la porosité du sol ne permettant pas la formation de creeks. $\mathrm{Si}$, dans un premier temps, les groupes implantés en bord de mer ont prélevé toute une partie de leur eau douce à partir des écoulements de la lentille d'eau douce (lentille de Ghyben-Herzberg) sur les plages à marée basse, ceci n'a plus été possible lorsque certaines familles, attirées par des sols agricoles plus fertiles, ont commencé à

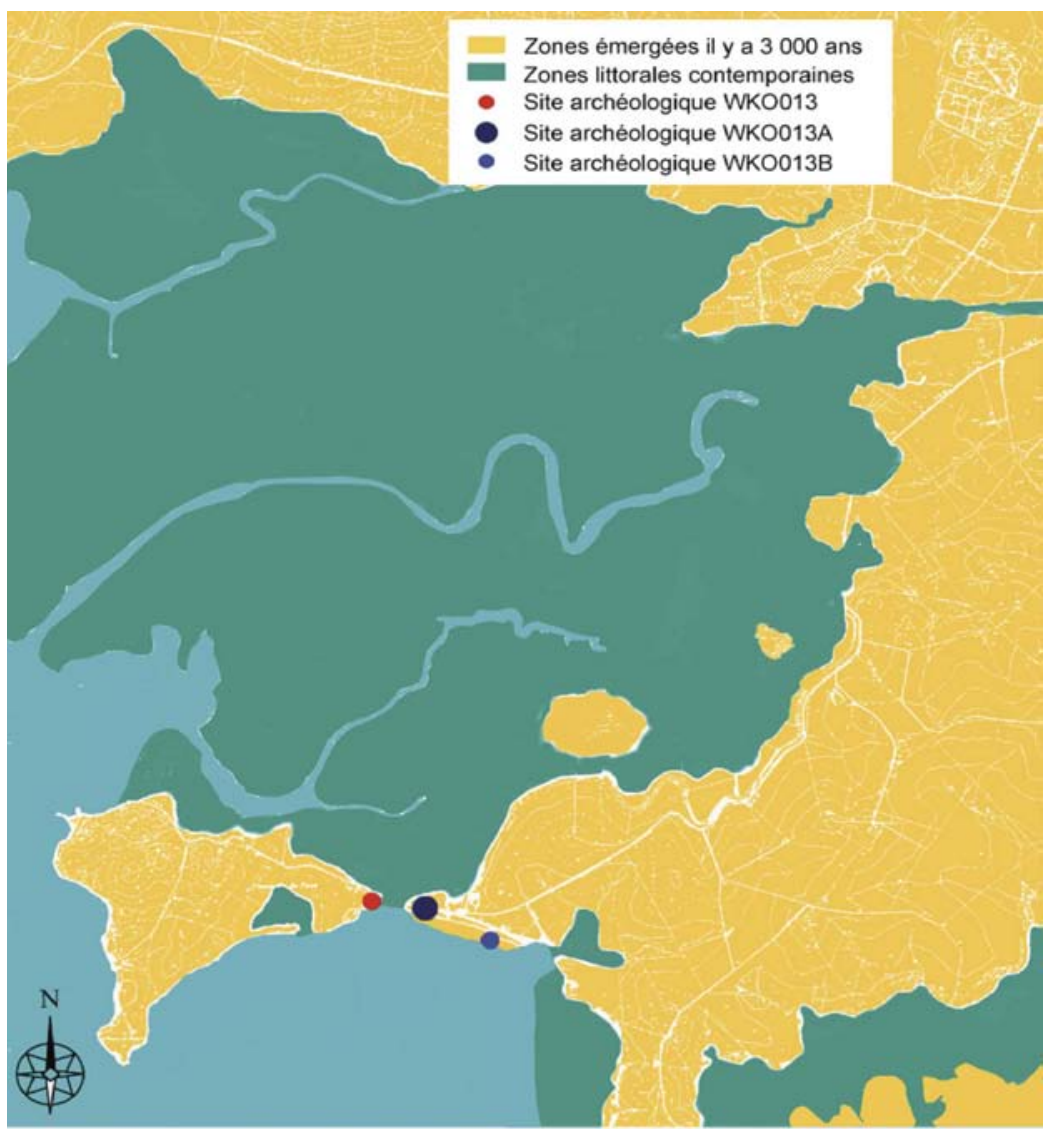

Figure 2 : Extension de l'estuaire de la rivière de la Koné au cours des derniers 3000 ans. Les codes correspondent aux différents sites Lapita de la plage de Foué, qui est le site éponyme de Lapita. @ C. Sand 


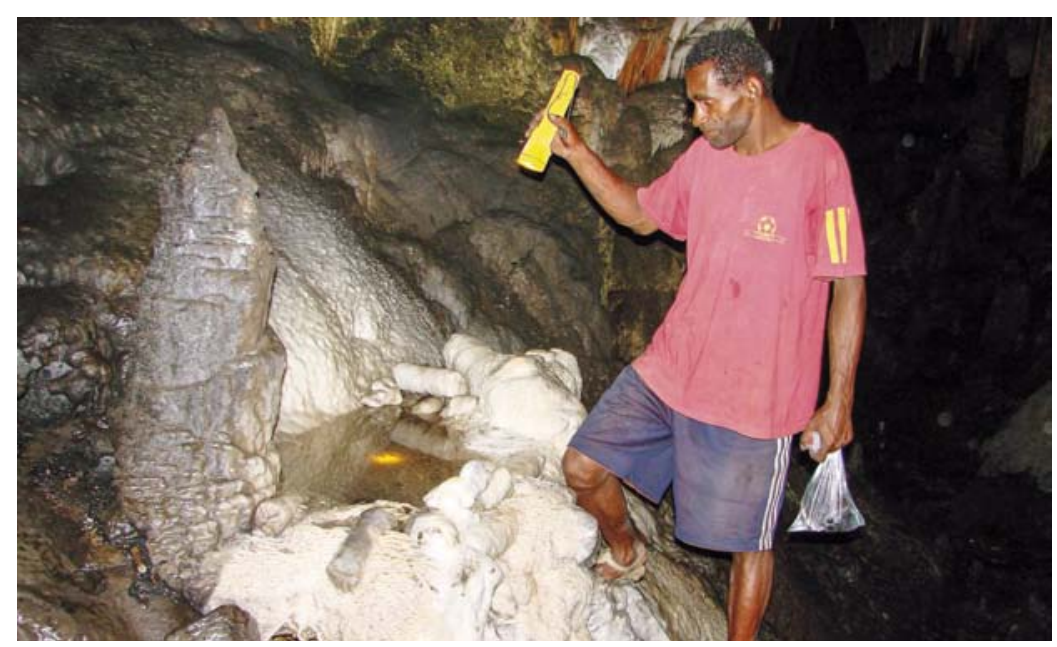

Vasque artificielle constituée de blocs de stalactites brisés, construite dans une grotte de l'île de Tiga pour récolter l'eau d'infiltration. @ C. Sand

s'installer sur les plateaux intérieurs. La présence d'écoulements côtiers signifiait que de l'eau était présente dans la masse calcaire et, pour le vérifier, des expéditions ont été organisées dans les grottes perçant les plateaux coralliens des îles Loyauté. Ces explorations difficiles et dangereuses, éclairées simplement par des torches en feuilles séchées, ont permis de découvrir des zones d'écoulement de l'eau par percolation en goutte à goutte à partir des plafonds, quand ce n'était pas de véritables vasques naturelles étanchéifiées par les dépôts millénaires de calcite qui étaient localisées. Les hommes ont alors rituellement organisé génération après génération des visites dans les entrailles de la Terre pour en rapporter de l'eau douce. Ils ont marqué leur passage en imprimant leurs mains au pochoir sur les parois des grottes, ont positionné de grandes coquilles de bénitier ou de nautile pour récolter les gouttes tombant du plafond, ont aménagé de véritables sentiers souterrains pour se guider dans la pénombre et sont parfois allés jusqu'à créer des vasques artificielles afin de faciliter l'accumulation d'eau.

\section{La nacre des monnaies kanak}

À partir de la fin du premier millénaire de notre ère, le développement de nouvelles traditions culturelles à travers l'archipel néo-calédonien a permis l'émergence d'un «ensemble culturel

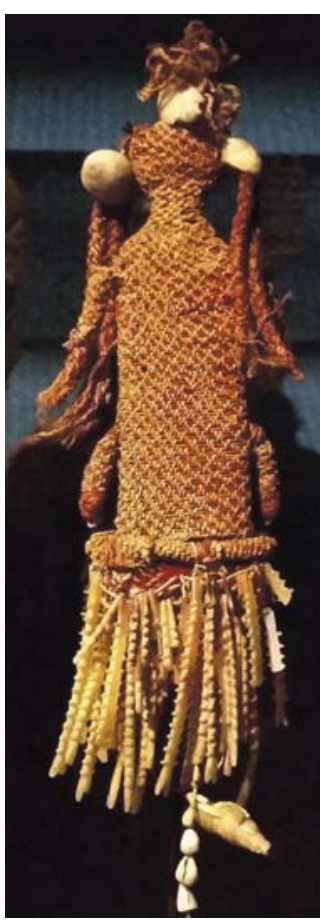

Monnaie kanak

à pendeloques en nacre. (c) C. Sand traditionnel kanak», caractérisé par une intensification massive de l'utilisation du milieu naturel. Ceci a engendré en particulier une sédentarisation des clans sur des terroirs et une plus grande attention portée à la protection de l'environnement insulaire. Cette évolution culturelle a été marquée également par l'apparition de nouveaux objets d'échanges entre groupes, avec en particulier la conceptualisation d'une forme unique de monnaie traditionnelle, spécifiquement kanak.

Celle-ci se caractérise par la présence de toutes petites pendeloques en nacre, taillées de façon minutieuse afin de pouvoir comporter des projections latérales perpendiculaires à l'axe central ainsi qu'un trou millimétrique d'attache au corps de la monnaie, fait à l'aide de fibres végétales et de poils de roussette tressés. Les coquilles de nacre utilisées pour la réalisation de ces objets de quelques centimètres de longueur étaient prélevées sur les environnements récifaux. Les traditions du centre de la Grande Terre racontent que les fabricants de monnaie kanak de la région de Houailou, sur la côte Est, traversaient la chaîne centrale en suivant des chemins coutumiers pour venir chercher cette matière première dans la région de Bourail sur la côte Ouest, où le grand récif a la particularité d'être à seulement $1,5 \mathrm{~km}$ du bord de mer.

Quand l'équipage de James Cook aborda la région de Balade, dans le nord-est de la Grande Terre, en septembre 1774, les marins anglais purent observer à plusieurs reprises au cours de leur rapide séjour le départ des pirogues allant à la pêche sur le grand récif. Ce lien immémorial des Kanak à la mer est matérialisé à travers l'archipel par la découverte de coquilles marines jusqu'au fond des vallées et des plateaux lors des inventaires archéologiques. Ces coquilles étaient transportées vivantes, en même temps que les paquets de sel séché indispensable à la cuisine, dans le cadre des échanges entre groupes côtiers et groupes de l'intérieur. 


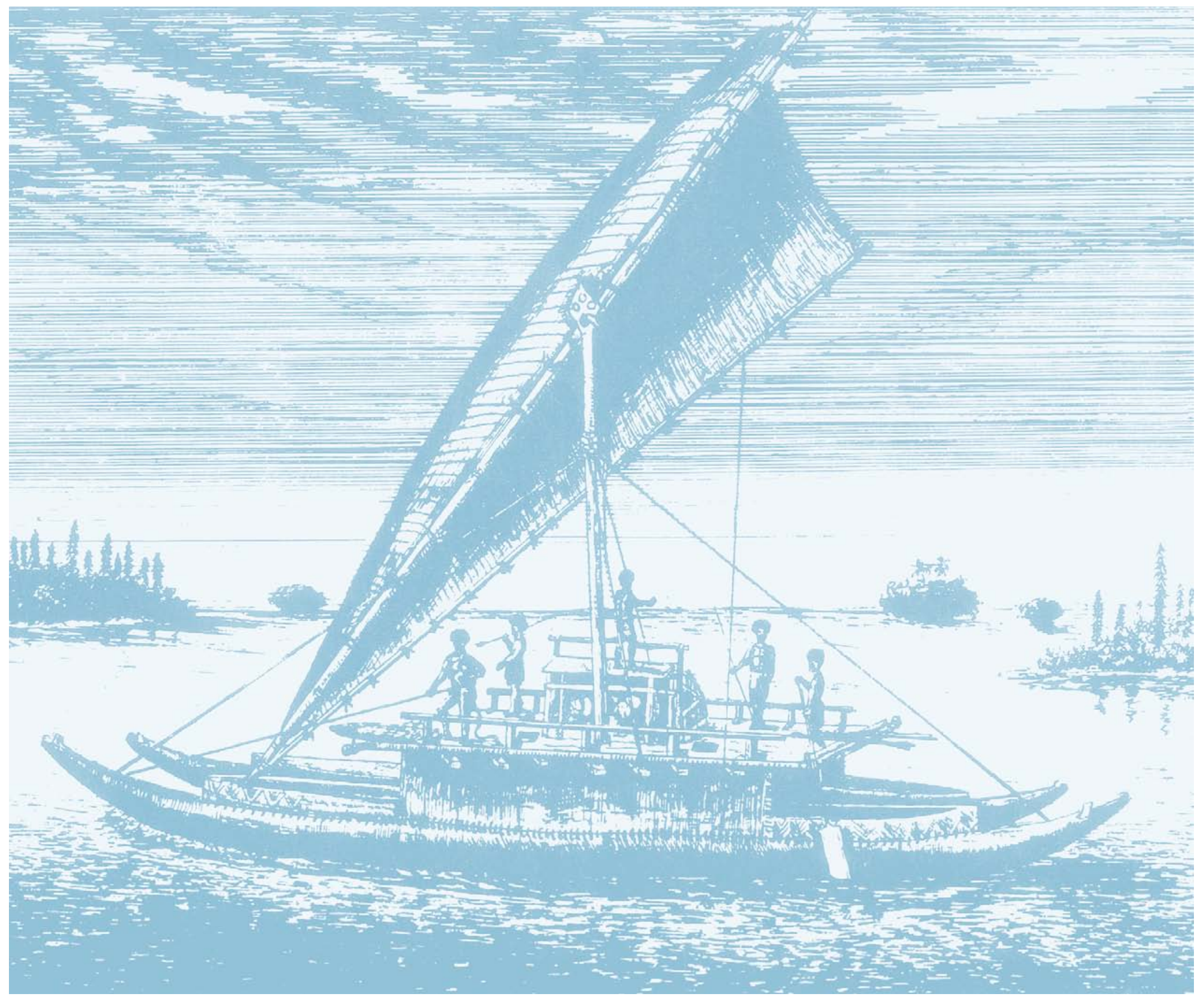

Grande pirogue double évoluant dans une baie de l'lle des Pins. @ Musée d'Océanie, la Neylière/dessin d'après nature de P. Bournigal 


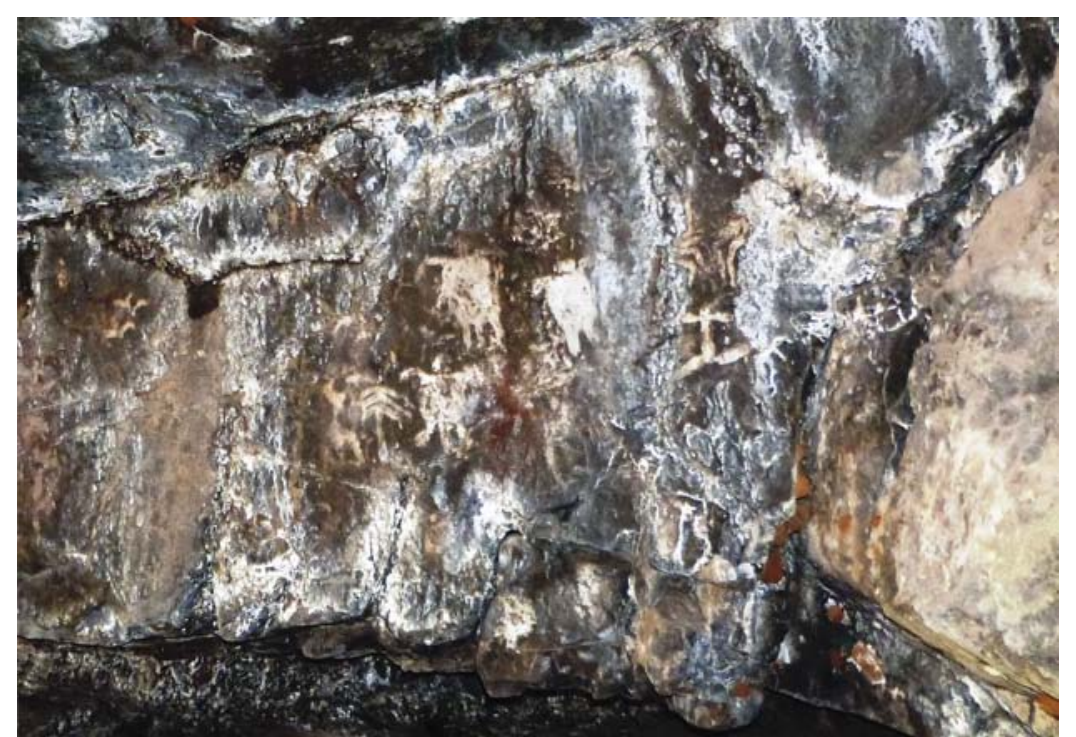

Représentations de tortues peintes sur la paroi d'une grotte du cap Bocage (Houailou). (c) C. Sand

Mais les études archéologiques montrent aussi que le monde marin était illustré dans l'art pariétal, à travers des représentations de tortues ou de poissons. Ces dessins et gravures sur les parois des grottes ou les dalles de sable cimenté des plages sont le témoignage laissé à la postérité par ces « hommes de la mer » au retour des pirogues lors des grandes pêches sur les récifs néo-calédoniens. Placée dans sa cavité protectrice en haut du piton de Faténaoué-Hwatenewe, la momie du chef Hmaè Kahouta, « homme de la terre » porte elle aussi son regard - au-delà de la plaine de Témala - vers la grande passe dans le récif de Voh, lieu de cheminement des âmes pour rejoindre le « pays des morts ».

\section{Références bibliographiques}

BOYER P. (éd.) 1997 La mer : espace, perception et imaginaire dans le Pacifique sud. Paris, L'Harmattan, 443 p.

SAND C., S. BEDFORD (éds), 2010 Lapita. Ancêtres océaniens, Oceanic Ancestors. Paris, Somegy Éditions d'Art/Musée du Quai Branly, $352 \mathrm{p}$.

SAND C., BOLEJ., OUETCHO A., 1998 «Traces ». 3000 ans de patrimoine archéologique calédonien. Nouméa, Les Cahiers de l'Archéologie en Nouvelle-Calédonie. (Nouméa), 8, 62 p.

SAND C. et al., 2008 Parcours archéologique. Deux décennies de recherches du département Archéologie de Nouvelle-Calédonie (1991-2007). Nouméa, Les Cahiers de l'Archéologie en Nouvelle-Calédonie, 17, 278 p.
Encadré 22

Fortifications mégalithiques en corail fossile

Si les cavités dans le corail fossile ont servi de façon originale de sources d'eau douce pour les habitants des îles Loyauté, le karst a aussi été exploité de façon régulière comme matériau de construction. Le cas le plus spectaculaire d'aménagement se trouve sur le plateau central de l'île de Maré, où les habitants ont construit au cours du premier millénaire de notre ère des fortifications mégalithiques. Celles-ci ont été édifiées en extrayant de carrières à ciel ouvert implantées au pied des pitons de karst de gros blocs monolithiques de corail fossile. Certains de ces blocs pouvaient peser plusieurs tonnes chacun et devaient être tirés à la force des bras jusqu'au chantier de construction, situé parfois à plusieurs kilomètres du lieu d'extraction. Là, ils étaient placés les uns au-dessus des autres jusqu'à plus de $4 \mathrm{~m}$ de hauteur, afin de former l'entourage de murs de $10 \mathrm{~m}$ de large sur plusieurs centaines de mètres de longueur. Ces forts comportaient des portes monumentales, où étaient placés certains des blocs les plus volumineux.

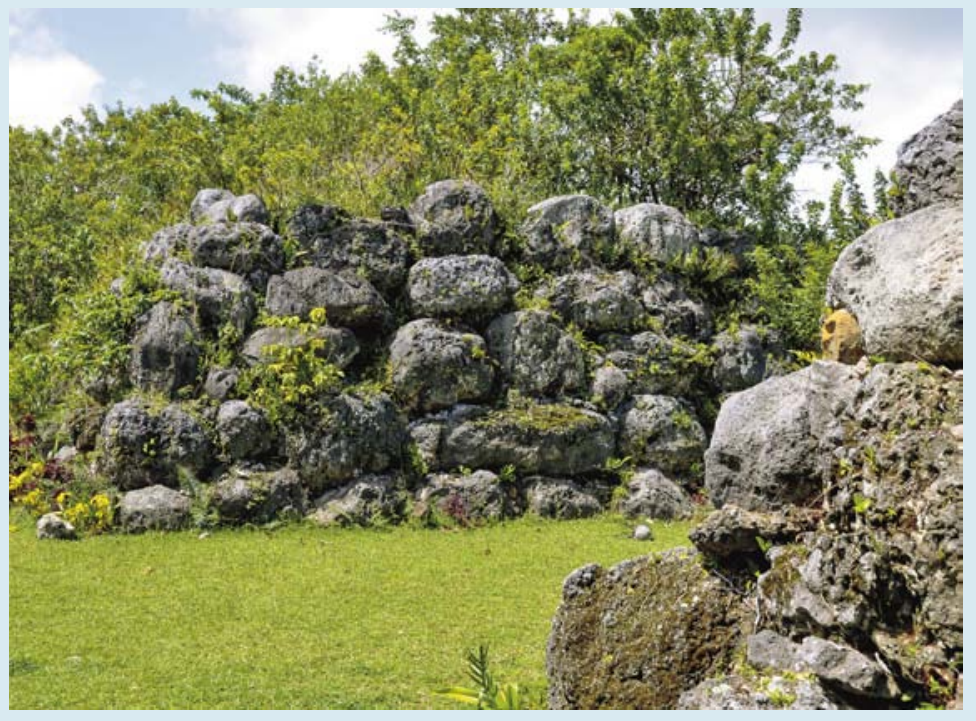

Entrée monumentale du fort mégalithique de Hnakudotit, construit sur le plateau de Maré avec des blocs de corail fossile. @ C C. Sand 


\title{
Des récifs, une parole et des hommes
}

\author{
Emmanuel Tjibaou
}

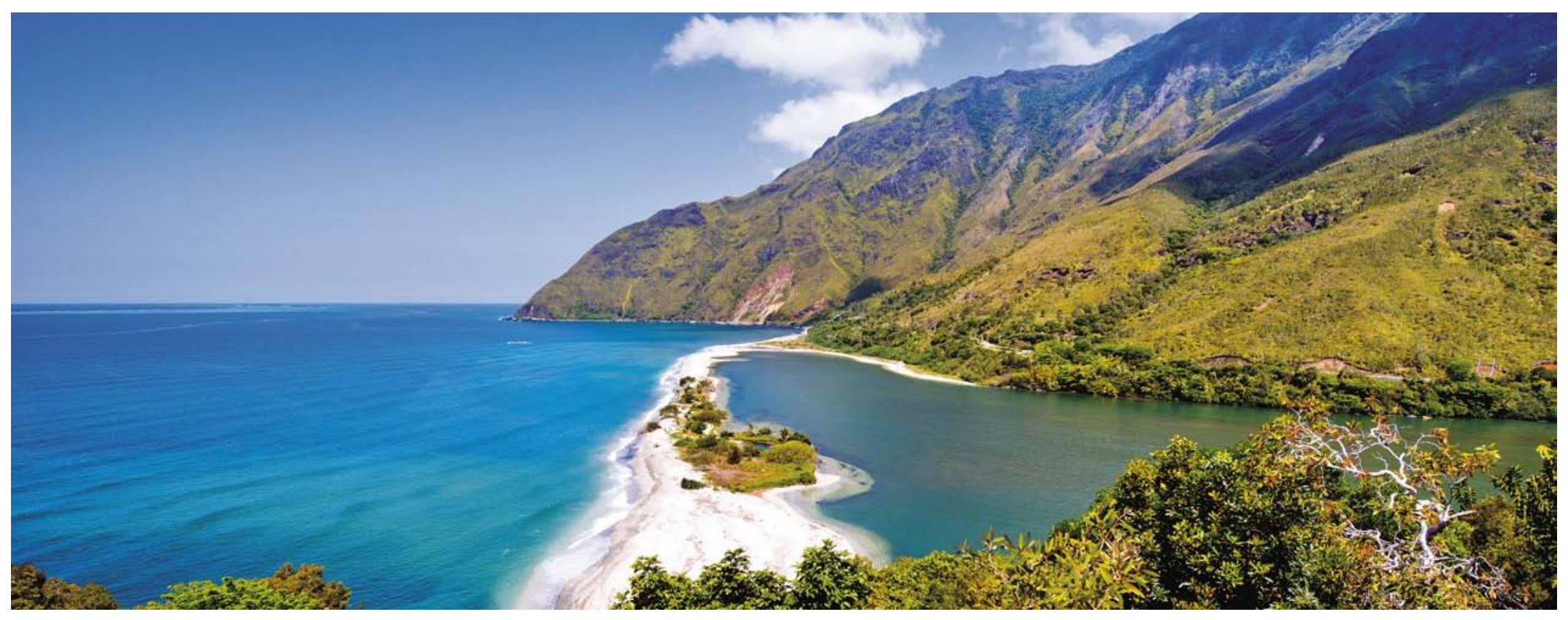

L'embouchure de la rivière Ouaième. @ P.-A. Pantz

En Nouvelle-Calédonie, comme dans de nombreuses sociétés insulaires du Pacifique, le rapport au monde marin et aux terres récifs qui en émergent est essentiel si l'on veut comprendre l'organisation politique et sociale des groupes humains de ces régions. Ici, la mer et les récifs sont le prolongement direct de la terre sur laquelle s'appliquent les devoirs, pratiques et obligations de la coutume kanak. Le parallèle entre les représentations rattachées à l'espace foncier et l'espace maritime peut s'expliquer de différentes raisons, d'une part les sociétés insulaires développent toutes des qualités de navigateurs connaisseurs de l'océan, d'autre part l'ensemble de ces groupes sociaux pensent leur origine mythologique comme issue de la mer.

\section{« Le chemin des morts »}

Une des clés de compréhension de ce rapport particulier entre homme, récif et mer émerge des représentations rattachées à ce qu'on appelle communément « le chemin des morts » dans le nordest de la Nouvelle-Calédonie. Ainsi sur l'ensemble de la région de Hienghène, dans l'intérieur des vallées comme sur l'ensemble du littoral, il est usuellement reconnu que, à la mort d'une personne, son esprit se détache de son enveloppe corporelle pour parcourir un sentier qui le mènera de l'intérieur des terres, lieu d'habitation du défunt (creek vers les vallées, cours d'eau vers les crêtes de 


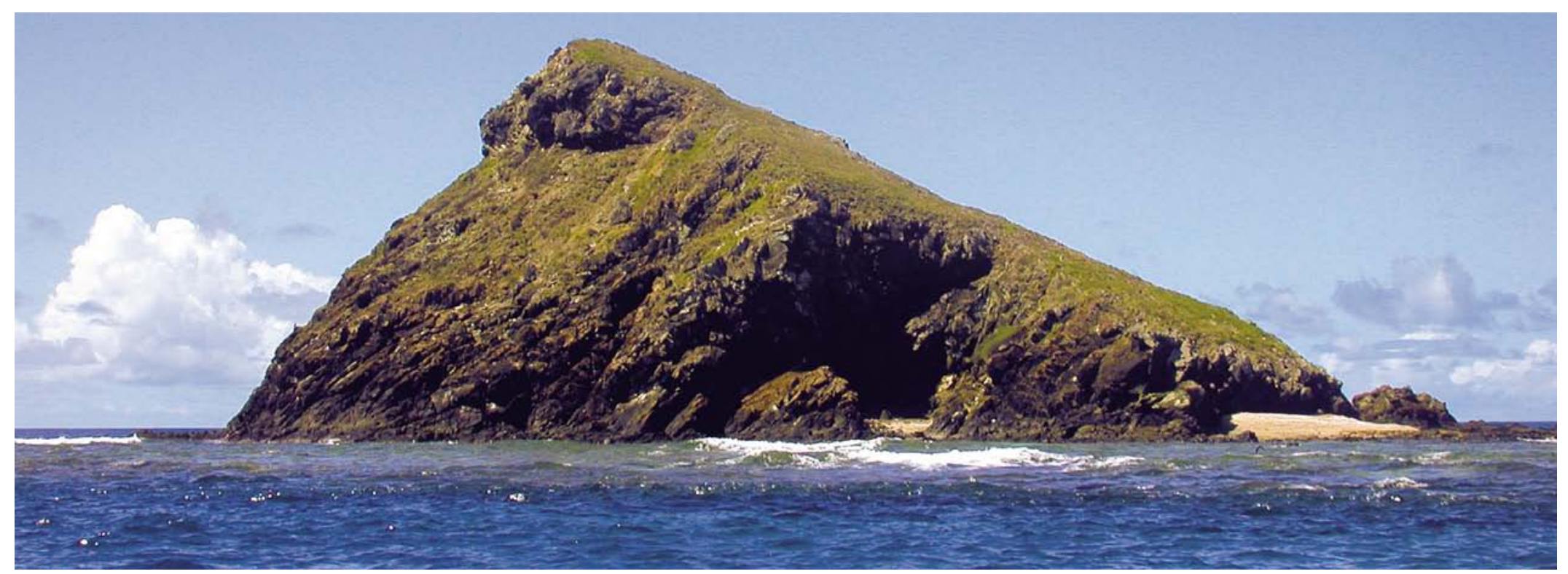

llot Kaavo marquant l'entrée du sentier des morts, Nord de Belep. ๑ E. Tjibaou

montagnes) jusqu'à l'entrée de la rivière Ouaième ${ }^{14}$. Ce sentier des esprits se prolonge dans le fond de la rivière auprès du gardien du passage nommé Hwaiwai vers le royaume des esprits situé face à la passe de Hienghène aux limites du récif de Tao. Il est nommé en langue fwâi de Hienghène sêêdan ne vi danu, signifiant littéralement le « chemin des esprits ». Ce cycle d'achèvement-dessèchement du processus vital chez l'homme kanak constitue une séquence initiatique qui rappelle son propre cheminement : l'individu émerge du flot de la matrice originelle où dansent les esprits au fond des océans, nommé Tiduuwon ${ }^{15}$. Toute sa vie, l'Homme imprime dans le sol un éloignement de cet océan des origines que son esprit retrouve à la mort. Paradoxalement, dans la région nord, les représentations associées tant au récif qu'au monde sous-marin témoignent autant de la légitimité de la mort que de la nécessité de la vie.

Deux personnages mythiques de cet espace du royaume des morts, Doibat et Hwaiwai, représentent cette toute-puissance originelle. Doibat, puissance spirituelle du monde sous-marin, a le corps recouvert de plantes, d'arbres, c'est lui qui garde l'entrée du royaume des morts sur l'archipel des Belep au nord de la Grande Terre ; il est d'une grandeur inégalée et son siège est à Lolon (Belep). Il malmène l'esprit des morts qui se présentent à lui avant de les faire rentrer par un passage sous-marin après l'île de Pott au nord des Belep. Hwaiwai est le gardien de l'entrée du royaume des morts dans la rivière Ouaième à Hienghène. Il attend avec une torche sous l'eau l'esprit du défunt qu'il jauge avec un pieu posé sur le lobe de l'oreille de celui qui arrive pour vérifier qu'il a les oreilles bien percées, signe de son initiation par les vivants. Les deux personnages mythiques se placent à l'entrée du monde sousmarin pour veiller que ces espaces ne soient pas déflorés par les vivants, Doibat est représenté avec des plantes sur tout le corps et Hwaihwai se transforme en requin ou dugong. Tous deux organisent le passage des esprits défunts du monde des vivants terrestres à celui des esprits surnaturels sous-marins selon des épreuves établies qui conforteront le bon fonctionnement du royaume des morts et permettront de signaler toute intrusion.

${ }^{14}$ Ouaième : rivière Weyem située sur le nord-est du littoral bordant la commune de Hienghène. Ce cours d'eau est relativement connu dans la région pour la place symbolique qu'il prend dans les traditions orales notamment comme porte vers le royaume des morts. Il s'agit du dernier cours d'eau traversé par un bac à moteur en Nouvelle-Calédonie.

${ }^{15}$ Tiduuwon : toponyme en langue fwâi de Hienghène, désignant un lieu-dit situé à l'embouchure de la rivière Ouaième, près de la passe. 


\section{Espèces marines et lieux de sens pour les hommes}

Certaines espèces de la faune sous-marine sont particulièrement associées à ce cheminement de l'esprit sous la mer telles que le requin, le requin-pèlerin, la baleine ou encore le cachalot et leurs apparitions à la surface dans ces zones sont interprétées comme la manifestation des esprits du royaume des morts. Ces animaux emblématiques des forces spirituelles marines se retrouvent également dans nombre de mythes d'origine de cette région du nord de la Nouvelle-Calédonie. La place de ces espèces mythiques au cœur du milieu marin et ses affleurements de surfaces que sont les récifs marquent non seulement l'emprise de la connaissance des Kanak de leur milieu, mais aussi la puissance évocatrice de l'imaginaire sur ces espaces. Ici les récifs, langues de sable, petits îlots, pentes sous-marines, passes sont autant de marqueurs mythiques ou historiques du savoir humain à un moment de son parcours de vie. La relation entre homme, récif et mer est perçue comme une entité particulière où l'individu se retrouve à naviguer au sein d'une communauté originelle densément peuplée et qui répond à des codes spécifiques. L'apprentissage de ces règles de cohabitation entre les espèces sous-marines et humaines s'apprend depuis le plus jeune âge à l'occasion de jeux, veillées contées et s'accompagne de rites à effectuer pour respecter les entités vivantes présentes sous les océans. À la connaissance du chemin des alliances coutumières pour quelqu'un originaire de l'intérieur des terres, celui du littoral devra répondre par la maîtrise des courants marins, passes et alizés pour devenir un homme accompli.

\section{Encadré 23}

\section{Discours de deuil à l'adresse des clans maternels}

Ce discours est dit en langue paicî par le chef d'Ometteux (Poindimié, nord-est de la Nouvelle-Calédonie) Umätu Michel Tiapi Gönô et recueilli par Dominique Paabu Oye en juillet 2005 à la tribu de Bayes Poindimié.

Le préposé à la parole (au discours) va dire, en substance : « Nous vous avons invité et appelé à accourir par ce chemin, à rentrer par cette allée et à venir vous présenter ici parce que l'os du pied (le tibia) de votre neveu a éclaté et s'est brisé, et le vital qui est en lui s'est aussi brisé, et il n'est plus au milieu de cette assemblée. Il n'a plus ce qui fait vivre et parler et marcher, il a tourné le dos au soleil et à la lune. Il a été aspiré par le tourbillon du diable, là-haut au milieu des airs, et emporté par le courant en bas dans l'étendue d'eau sans horizon, et il a été rejeté [comme épave] sur le platier [récif corallien frangeant, massif corallien contigu à la terre] à Wénégéi ${ }^{16}$. Et il est rentré dans la danse à Pijèpaa ${ }^{17}$ [la danse des morts]. Vous allez l'emmener là-haut sur la pierre dont il est issu, sur la pierre objet de ses respects et de ses interdits. Vous allez le confier à la tombe et au pays des ténèbres. Voici l'arbre, l'arbre sapin qui symbolise la disparition de votre neveu. Vous allez le prendre et l'amener à X [sont ici cités les noms du clan et des sous-clans de l'oncle maternel qui ne peuvent être révélés hors d'un cercle restreint de personnes]. Voilà c'est fini. »

«Pwi a popai â nä-é i nä pââ : "bë to mä paci pââ nä-guwë itë-mê nä-näigé bèè-nî nä guwë tö-mê nââ görö-igé bèèni nä guwë tö-mê nau coo-nî nä taö mä mä-biti i duru-â pwi nîa go-wë nä ta-biti $i$ jawé wâdo-é nä tiëu-é géé nââ pa-ba nä utê go-rë nî ba é-jè ningä mä cèkëé mä cö-mä-cö é nä-cëù tärä tötù mä parui â-jè cëù-é $i$ ukärä-duée dö gopaé-ré-näo â-jè dëti-é i duru-jawé wâ-boo nä-jawé tacîâ-jè tagötù-é nä-gö i paara kë wânâgëi â é-jè pärä nä i cäbu-këPijèpaa guwë mwâ popaé dö-nö-gö $i$ atù nyââ kêê nä-ia-é té-géé-goo i atù au-pi-too mä au-paa-pwicî kêê guwë töpwö-é nââ näcè oolaa mä cè pwaduu wëé-nî $i$ upwârâ cämù kärä nä-tiëu pwi nîaa go-wë guwë mwâ pa-dö nââ... wëé-nî â näbwé" ». Extrait du Rapport Paicî-Cèmùhî 2006. Enquêtes du département patrimoine et recherche, ADCK-CCT, Conseil coutumier Paicî-Cèmùhî (2006).

${ }^{16}$ Wénéguei : toponyme, nom de clan et chefferie du sud de l'atoll d'Ouvéa sur l'une des trois îles Loyauté (Nouvelle-Calédonie).

17 Pijèpaa : toponyme et nom de clan de la zone nord de la Nouvelle-Calédonie. Ce patronyme est associé généralement au statut de ceux qui effectuent les rites funéraires à l'intérieur d'une chefferie. 


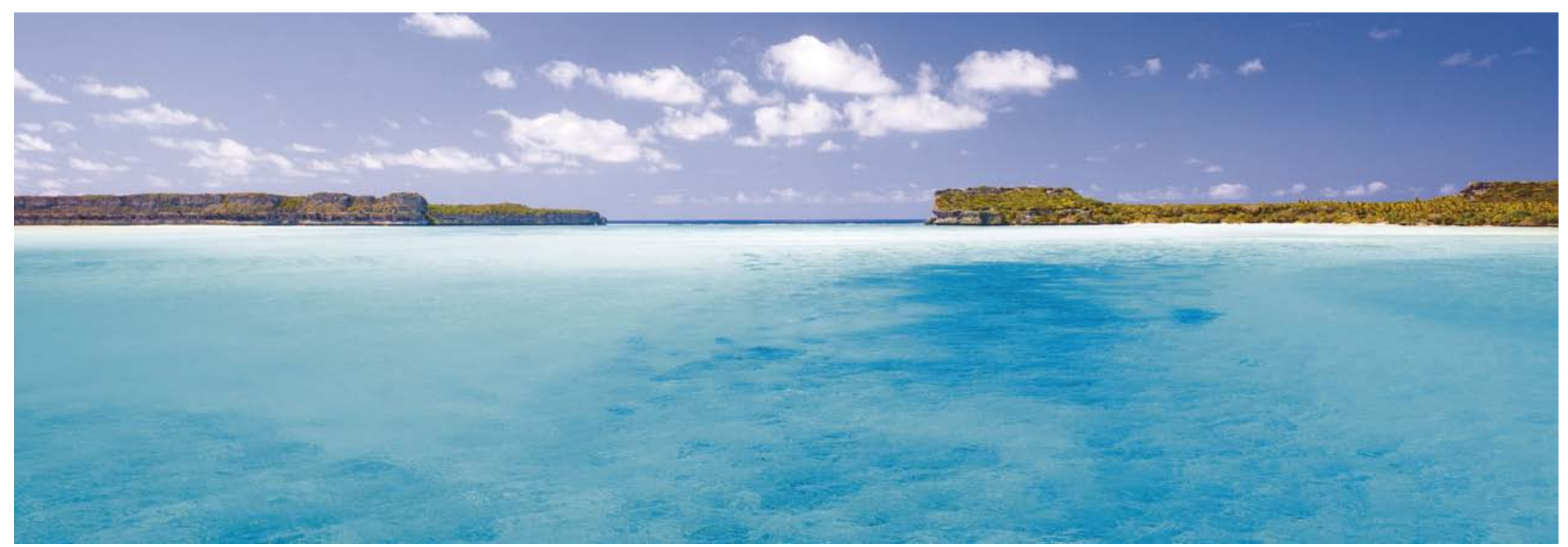

Vue de la passe de Fayawa depuis Mouli, Ouvéa. @ P.-A. Pantz

La thématique des récifs et de la mer dans les récits sacrés jahma ${ }^{18}$ de la région de Hienghène-Pouebo et sur le nord de la côte est inscrite la place de l'océan comme un continuum de l'espace terrestre. Il est assujetti à des autorités coutumières qui assument la gestion et l'entretien de ces zones immergées. Les traditions orales rattachées à ces thématiques rendent comptent d'une organisation politique spécifique propre aux espaces sous-marins auxquels les visiteurs doivent le respect (par exemple le geste coutumier de huremeno ${ }^{19}$ avant la pêche sur certaines zones; hiri ne buai ${ }^{20}$, ne pas crier lorsque l'on passe à certains endroits, etc.).

Il faut aussi rappeler que ces espaces, même sans indication de présence humaine peuvent relever de différents statuts:

- « mer coutumière » dépendant d'une chefferie à terre

(Hienghene-Pouebo);

- « mer coutumière » dépendant d'une chefferie mythique immergée issue d'une mythologie (Belep);

- point remarquable du relief (récif frangeant, affleurant, langue

de sable, patate corallienne...) relié à une tradition orale (histoire de Rat et Poulpe à Tiga) ;

- point remarquable du relief associé à une vague de migration ancienne (zone des Pléiades Héo à Ouvéa lié aux relations matrimoniales avec la chefferie Bouarate de Hienghène) ;

- point distinct du relief sous-marin associé à des rituels de pêche spécifique (passe de Mangalia et de Weyem pour les requins entre Hienghène et Touho). Ces zones sont sous l'autorité de clans identifiés et reconnus dans la société kanak.

Ces quelques exemples marquent définitivement l'emprise du monde kanak sur des zones que l'on pourrait considérer comme libres de toute emprise humaine. Les récifs près de la Grande Terre et des îlots comme le récif-barrière et les passes qui existent entre les récifs sont connus et marquent les chemins kanak, des vivants comme des morts. L'existence de la société kanak depuis près de 3000 ans sur la Grande Terre a inscrit aussi fortement dans la mémoire et sur les récifs tant les tragédies que les victoires de son peuple.

${ }^{18} \mathrm{Jahma}$ : genre de tradition orale dans les langues de Hienghène (fwâi, némi, pijé, jawé). Il est souvent traduit par « mythe » du fait des thématiques qu'il traite : peut être notamment évoquée l'origine des clans, d'une pharmacopée, d'une danse, etc. Ce genre peut aussi témoigner de la représentation d'une organisation politique, de règles à respecter.

${ }^{19}$ Huremeno : littéralement « bout de voyage » en langue fwâi de Hienghène. Ce rituel est réalisé à terre comme en mer lorsque l'on pénètre un espace habité par des hommes ou des esprits. Il est effectué par le visiteur qui, en déclinant son identité, présente une offrande à son hôte visible ou invisible.

${ }^{20}$ Hiri ne buai : littéralement « interdiction crier », en langue fwâi de Hienghène. 


\section{Pêches identitaires, nourricières et commerciales dans les écosystèmes récifaux}

Catherine Sabinot, Gilbert David, Matthieu Juncker, Séverine Bouard, Camille Fossier, Julie Mallet et Floriane Kombouare

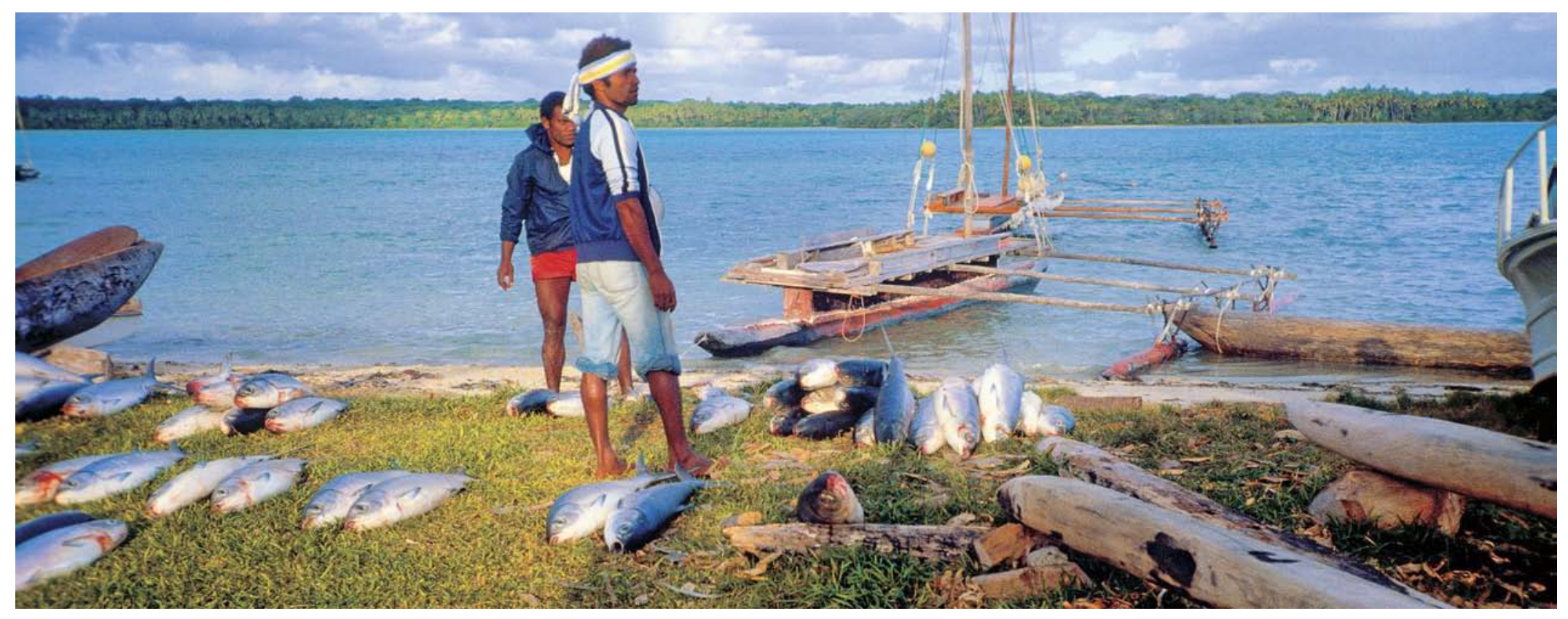

Retour de la pêche au mikwaa (Chanos chanos), lle des Pins. @ J. Tikouré

Pour les habitants de Nouvelle-Calédonie, le récif est bien plus qu'une colonie de corail, un platier ou une barrière récifale. Le récif, c'est le lagon et ses habitants, ce sont des passes, des êtres vivants, des âmes, des histoires, une mémoire. Pour les Kanak, cet espace est à la fois un monde invisible où vivent les ancêtres, où serpentent les chemins permettant de rejoindre le pays des morts, et un monde visible, expérimenté et connu entre autres par les pratiques de pêche qui font le quotidien de nombreux habitants du Caillou. En bord de mer il n'est de village ou de tribu dans lesquels la pêche n'occupe un fantastique espace. Ces pêcheurs sont des hommes et des femmes, des jeunes et des Vieux. Ils sont d'origines variées et pratiquent la pêche pour se nourrir, pour entretenir des liens avec un milieu qu'ils connaissent, pour renforcer et renouveler les liens entre les familles, entre les clans, entre les tribus ou tout simplement pour le plaisir. Beaucoup de Néo-Calédoniens ont « grandi dans la pêche », leurs parents étaient pêcheurs et ils leur ont transmis savoirs et techniques de pêche, mais surtout l'envie passionnée de passer du temps en mer.

Les pratiques de pêche et l'importance de cette activité pour les habitants de la Nouvelle-Calédonie amènent un tel foisonnement de questions qu'un ouvrage ne suffirait pas à épuiser le sujet : qui pêche 


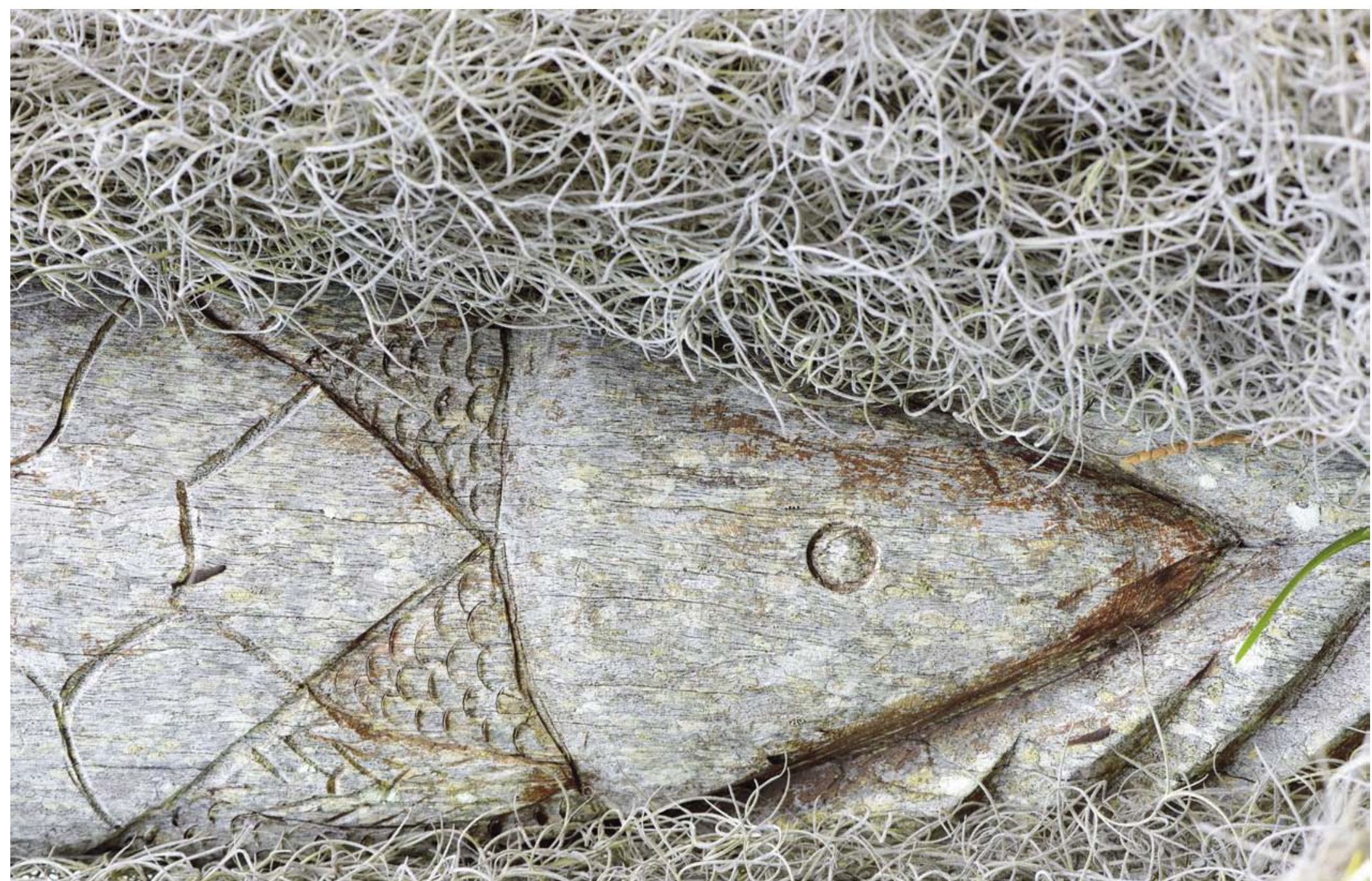

Sculpture sur bois représentant la tête du mikwaa à l'île des Pins. @ M. Juncker

et pour quoi ? Y a-t-il différentes techniques de pêche ? Quelles sont les espèces ciblées et les quantités prélevées ? Comment connaître les espèces qui habitent le récif et leurs comportements? Comment construit-on son expérience du récif ? Quels rôles jouent les récifs pour les pêcheurs de divers horizons ? Comment s'organisent les pêches sur chaque territoire ? Enfin, quelles valeurs sociales, culturelles, symboliques comme économiques portent les récifs néocalédoniens aux yeux de ses habitants?
Des chercheurs en anthropologie, ethno-écologie, et géographie travaillent sur ces questions et plusieurs projets de recherche ont contribué à mieux connaître comment les habitants de la NouvelleCalédonie se représentent cet environnement et comment ils I'utilisent. Ce développement apporte avec modestie l'éclairage des sciences humaines et sociales pour caractériser la pêche lagonaire et parler des pêcheurs qui la pratiquent, révélant l'importance des écosystèmes coralliens pour les Néo-Calédoniens. 


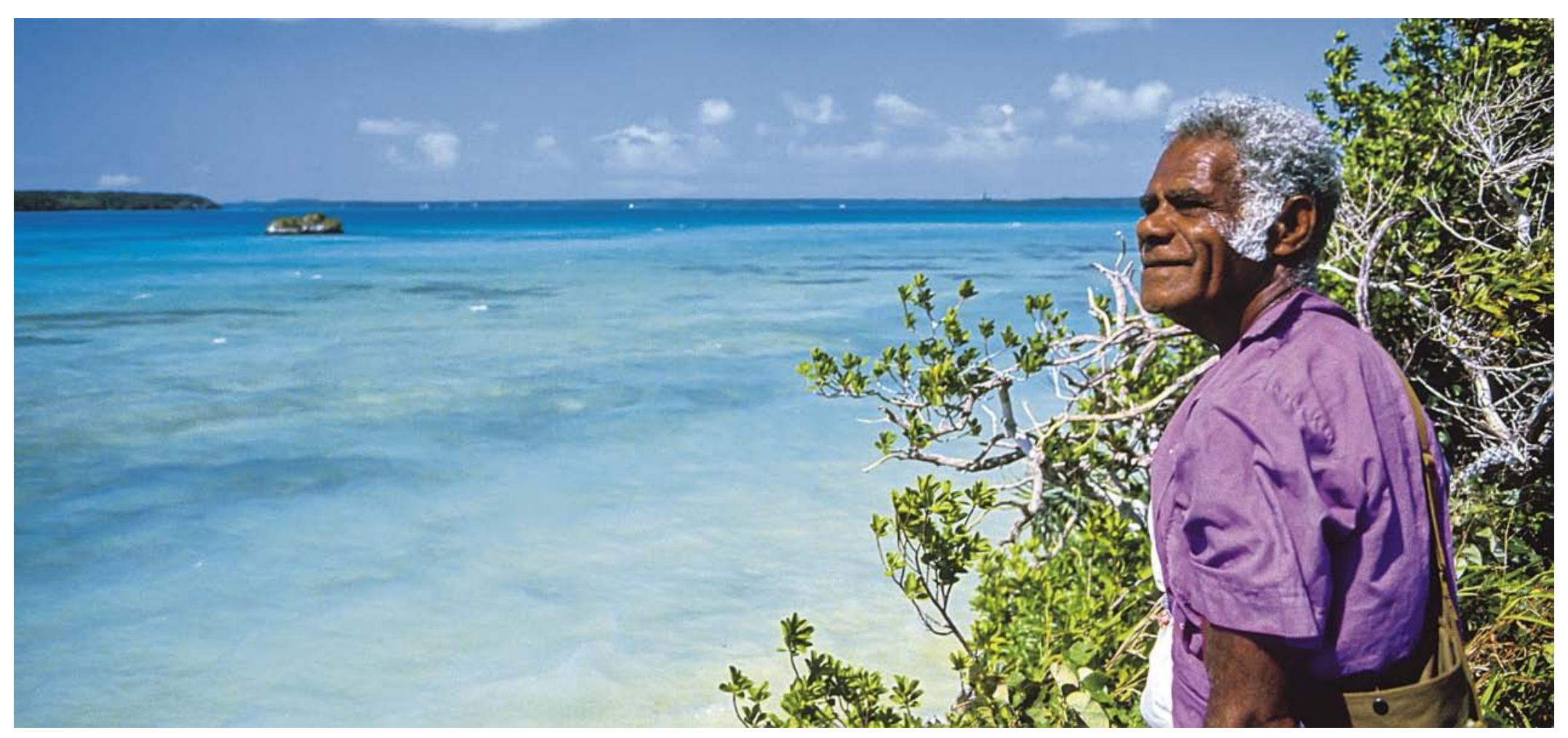

Le pêcheur scrute le lagon, lle des Pins - Baie d'Upi. @ P.-A. Pantz

\section{Connaître le récif et construire son expérience de pêcheur}

La pêche est pour beaucoup une pratique commune qui implique une observation attentive. L'expérience est quotidienne pour certains, régulière ou irrégulière pour d'autres. Les pêcheurs connaissent les récifs, ils les nomment, ils les classent. Ils savent aussi interpréter les signes de l'environnement et choisiront le coin de pêche en fonction de la marée, de la saison, de la météo... . Cette connaissance du terrain, ce savoir, ils l'ont acquis grâce à leurs observations personnelles, en accompagnant les Vieux: «C'est en allant en mer avec les Vieux qu'on apprend à pêcher. » Ils scrutent la surface du lagon depuis la plage, depuis leurs embarcations, voire depuis le haut d'un mât de pirogue pour repérer un banc de poissons ou une espèce particulière. L'observation est d'ailleurs ce dont tout pêcheur parle pour raconter son apprentissage de la pêche : « D'abord, je regarde. » Les pêcheurs connaissent très bien le récif et utilisent divers « repères » pour s'assurer une bonne pêche.

- Le tricot rayé nageant en surface est un signe informant de la présence d'un récif isolé où le poisson ne manquera pas.

- Des vols d'oiseaux marins indiquent l'emplacement d'un banc de poissons.

- La surface de l'eau qui se met à frétiller révèle la présence de poissons pélagiques.

- L'échouage massif de petits crustacés en baie du Prony annonce la présence de bancs de maquereaux.

- Après les cyclones, les bossus, les dawas et les becs-de-cane mordent à la ligne, tandis que les tazards sondent vers les grands fonds.

« En dessous des sternes il y a des anchois, et donc des tazards; en dessous des pétrels, il y a des grosses sardines. » (Koumac) 
Pour beaucoup de Calédoniens, les techniques de pêche sont apprises avec les Vieux. Les « coins » de pêche sont transmis par des proches et parfois découverts à force de recherches répétées : lieux de rassemblements de poissons récifaux, « cailloux de langouste », « trous de poulpes ».... Les pêcheurs savent où se situent les dawas, à quelle période ils sont gras. Ils constatent même l'évolution de leurs comportements sur des sites régulièrement visités par des pêcheurs. Leurs observations témoignent également de la diminution de ressource ou encore de la disparition des bancs de poissons de sites sur lesquels ils étaient par le passé toujours présents (picots, dawas, becs, loches...)

« Ily a moins de poissons. Moi, quand j'avais l'autre canote à moi, tout seul, je vais remplir la glacière. Maintenant, à cinq ou six, jamais on va la remplir la glacière. » (Pouébo)

Les observations des pêcheurs cumulées pendant des années (transmises ou apprises), des décennies et parfois même des
Encadré 24
Du savoir transmis par les Vieux aux GPS
«Je pêche par rapport à des endroits, pour le poisson, pour le crabe, pour tout. C'est avec le GPS maintenant... nous, avant, nos Vieux, ils nous ont pas appris avec le GPS, c'est avec les montagnes qu'on se repérait. » (Koné)
«Nous, les cailloux de nos vieux, avant, ils montrent, mais voilà, c'était secret. » (Koné)

Le GPS est un instrument de plus en plus répandu qui transforme l'apprentissage des lieux. Il est un appui apprécié par les pêcheurs, notamment pour les quelques-uns qui s'éloignent beaucoup des côtes. Par ailleurs, il redéfinit de nouveaux modes de transmission des lieux de pêche. À Bélep par exemple, pour les jeunes pêcheurs de bêches-de-mer, le GPS facilite l'exploration de nouveaux espaces qui n'avaient pas été visités depuis leurs grands-pères avec les voiliers. C'est un outil qui questionne aujourd'hui la production du savoir et sa transmission.
}

générations, permettent de construire un « savoir », une connaissance fine du récif, du comportement des organismes qui le peuplent... Aujourd'hui, ce savoir intéresse également les biologistes marins et les écologues car il les aide à localiser les couloirs de migrations, des zones de frai des poissons récifaux, les périodes de ponte, etc.

\section{Savoir où pêcher et respecter les territoires des uns et des autres}

« Ici on est plusieurs à faire la pêche. Chez nous ici les Kanak, c'est défendu de couper la route à l'autre qui vient devant ; ça fait qu'on va dans des petits endroits où il n'y a personne. » (Poum)

«Quand les pêcheurs professionnels sont arrivés dans les métiers de pêcheur, ça s'est fait tout naturellement. [...] On [les pêcheurs professionnels] ne vient pas sur le platier, d'abord parce que c'est assez dangereux de s'en approcher, mais aussi par respect pour ceux qui n'ont pas de bateau, qui vont poser les filets ou faire la pêche à pied. Ça s'est fait tout naturellement : il n'y a pas eu de réunions pour organiser des lieux de pêche, etc. » (Lifou)

Lorsqu'on est pêcheur, que l'on soit Kanak ou non, il existe un certain nombre de « règles » implicites à propos de l'usage des territoires. Celle du « premier sur les lieux » est l'une des mieux partagées. Par ailleurs, tandis que les récifs-barrières et les récifs isolés lointains sont des lieux de pêche privilégiés par les pêcheurs propriétaires de bateaux, en particulier les pêcheurs professionnels, les platiers et les zones proches des lieux d'habitation sont plutôt réservés aux pêcheurs vivriers.

Les pêcheurs nomment tant les espèces que les lieux où ils savent pouvoir les trouver. La toponymie habite ainsi le paysage marin. Certains îlots sont tabous; et peuvent être entourés de brumes rendant leur approche risquée. Les lieux où il convient de ne pas se rendre sont aussi nommés. L'exemple du petit récif « Peto » au sud de l'île Ouen, littéralement « oreiller » en langue numéé, est connu dans le grand lagon sud. Ce récif tabou, oreiller du requin Wakôdô gardien de l'île, doit être préservé de toute pêche. 


\section{Encadré 25}

Les tabous sur les lieux de pêche sont nombreux et variés en Nouvelle-Calédonie. Ils impliquent toujours une interdiction de passage ou de prélèvement. Ils peuvent concerner tous les habitants de l'île, seulement certaines tribus, ou certains individus. Un clan ou une personne, peut avoir pour rôle de lever ponctuellement ces interdits afin d'organiser par exemple une pêche collective pour un événement particulier : mariage, intronisation d'un chef, fête de l'igname, etc. Si ces interdits ont d'abord une fonction sociale, ils ont aussi un rôle bénéfique pour la préservation de la faune marine.

\section{Choisir ses outils en fonction des lieux et des pratiques}

Chacun choisit le type de pêche selon ses lieux de vie, ses moyens, ses savoirs, son métier, son rôle, etc. Il est fréquent que plusieurs outils soient embarqués à bord des plates (embarcation légère en aluminium) afin de s'adapter aux poissons présents sur le site de pêche voire à leur comportement.

La pêche à pied sur les platiers récifaux vise la collecte de coquillages et de poulpes. Si les hommes ne sont pas absents de cette pêche, elle est principalement réalisée par les femmes et les enfants.

La pêche à la ligne est souvent pratiquée sur des fonds meubles du lagon, au bord d'un platier récifal à marée montante, ou bien autour de récifs isolés afin de capturer des espèces vivant sur le fond ou proche du fond comme celles regroupées dans la famille des becs (Lethrinidae). Elle est pratiquée à la fois par les hommes et par les femmes. Le fusil harpon utilisé par les jeunes et les moins jeunes permet de cibler les poissons récifaux les plus communs (poissonsperroquets, loches...) partout dans le lagon, depuis le littoral jusqu'au récif-barrière, dans les passes et à l'extérieur. En plongée, se capturent aussi les langoustes et les cigales de mer, au fusil pour les langoustes les plus grosses.

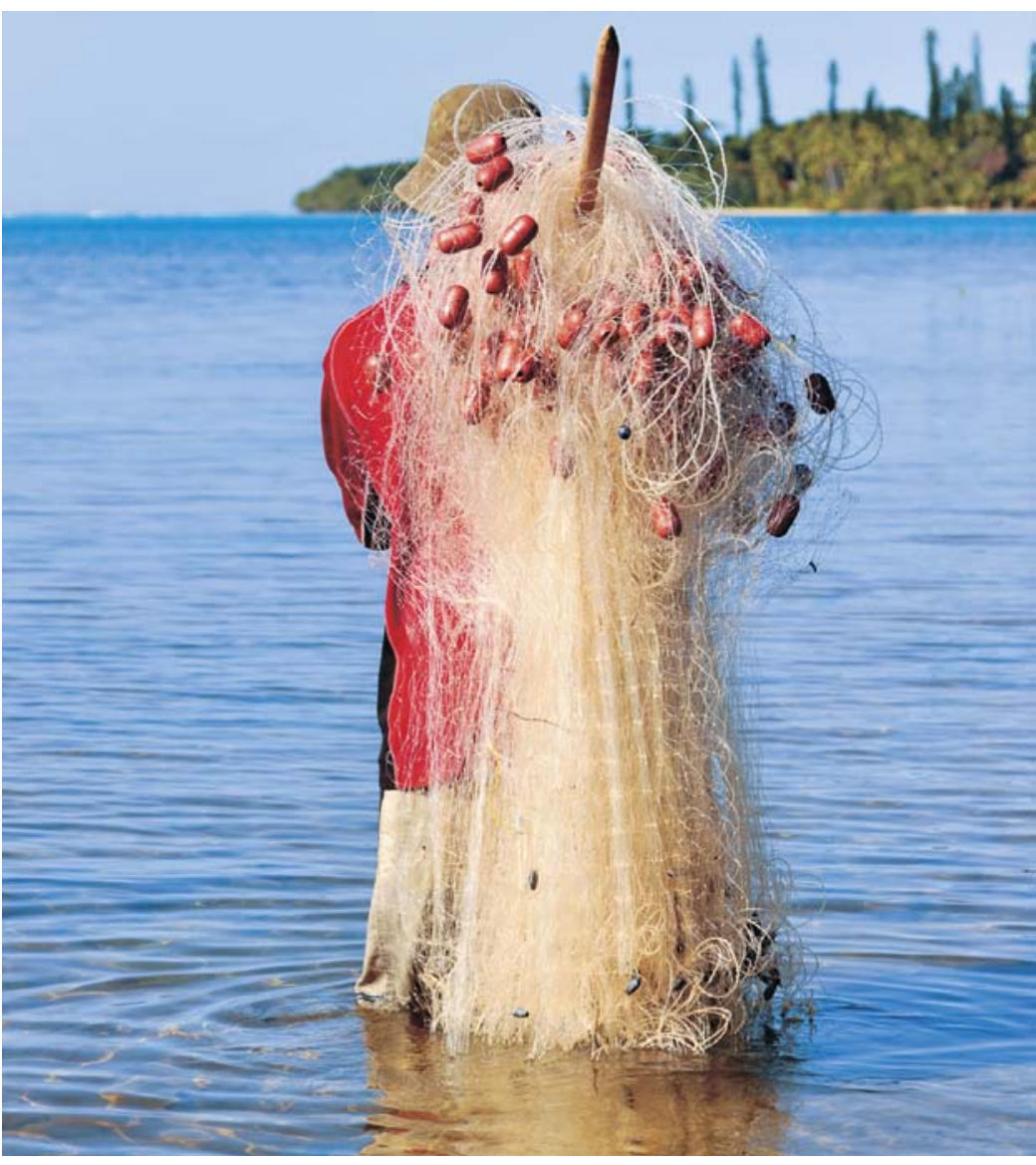

La marée est bonne, le filet est prêt à être posé. Le pêcheur scrute les picots sur le platier. Baie de Goro, Yaté, 2009. ๑ M. Juncker

La pêche en apnée à mains nues est aussi pratiquée pour collecter certains coquillages comme les trocas et les bénitiers, ainsi que les holothuries ou « bêches-de-mer » destinées au marché asiatique.

Le filet, en particulier la senne et l'épervier, est utilisé pour des poissons au comportement grégaire qui se déplacent sur des petits fonds (un à sept mètres le plus souvent) tels les dawas (Naso unicornis), les picots (Siganidae), les mulets (Mugilidae) ou encore les poissons blancs (balabio, poisson-lait ou Gerres longirostris). La senne est souvent considérée comme réservée aux pêcheurs « confirmés »; les Jeunes chassent plutôt au fusil sous-marin, à la traîne ou à la ligne et les enfants commencent très souvent par apprendre la pêche à pied sur le platier puis à la ligne depuis une embarcation. 


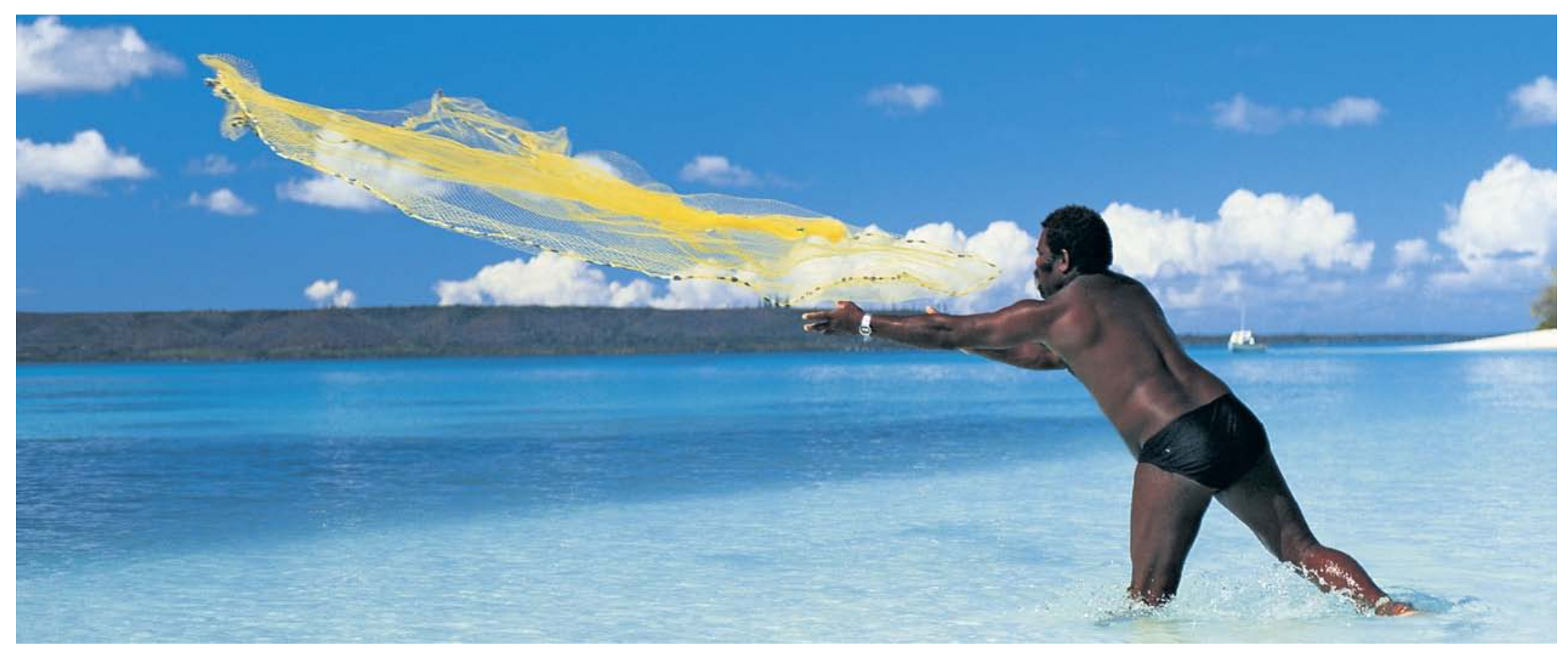

Pêche à l'épervier, lle des Pins - llot Brosse. @ P.-A. Pantz

\section{Pêcher pour exister, échanger, se nourrir et vendre}

« Notre champ, c'est sur les récifs. »

Ce témoignage a été entendu dans différents lieux de la NouvelleCalédonie : il se rapporte à des représentations actuelles comme anciennes de la place qu'occupent les récifs dans la vie des pêcheurs, en particulier des clans de la mer. Lorsqu'on connaît l'importance du champ et en particulier de l'igname pour les Mélanésiens, on comprend toute la valeur de ce témoignage.

La pêche joue un rôle essentiel dans l'organisation des sociétés kanak. Elle permet de renforcer les liens entre les clans au travers d'échanges. Pour les clans pêcheurs et les clans de la mer, elle est ce qui fait leur identité : ils ont un rôle à honorer vis-à-vis de leur chefferie et des autres clans et le produit de leur pêche est remis à la chefferie ou donné en partage lors de cérémonies coutumières. La pêche a aussi un rôle important dans les sociétés non-kanak mais se traduit de différentes manières. Pour bien recevoir son hôte, il est satisfaisant d'avoir des langoustes ou certaines espèces de grande taille. Pour les événements religieux, certains pêcheurs sont attendus avec le fruit de leur prise.

«J'essaye de garder du poisson dans le congélateur parce qu'on a des gens de la chaine qui viennent à n'importe quelle heure chercher du poisson pour des coutumes là-haut. » (Hienghène) «Avant, je faisais la pêche à pied, depuis petite avec mes parents. Pour améliorer les choses, $j$ 'ai pris un bateau pour pouvoir se déplacer un peu plus loin. Un premier truc c'était servir ceux qui étaient de la chaîne, faire la pêche et faire échange avec eux. Plutôt que de vendre, on fait échange. [... . Eux ils nous font [donnent] ce qu'on trouve [cultive] dans la chaîne : des taros, des maniocs... »(Gomen)

«lly a le xalaïa, les dons pour le pasteur tous les premiers lundis du mois. Si t'as pas de pièces, tu emmènes du poisson, si tu as pas du riz ou du poisson, tu emmènes des pièces. Ou des ignames, manioc, bananes. » (Poum) 


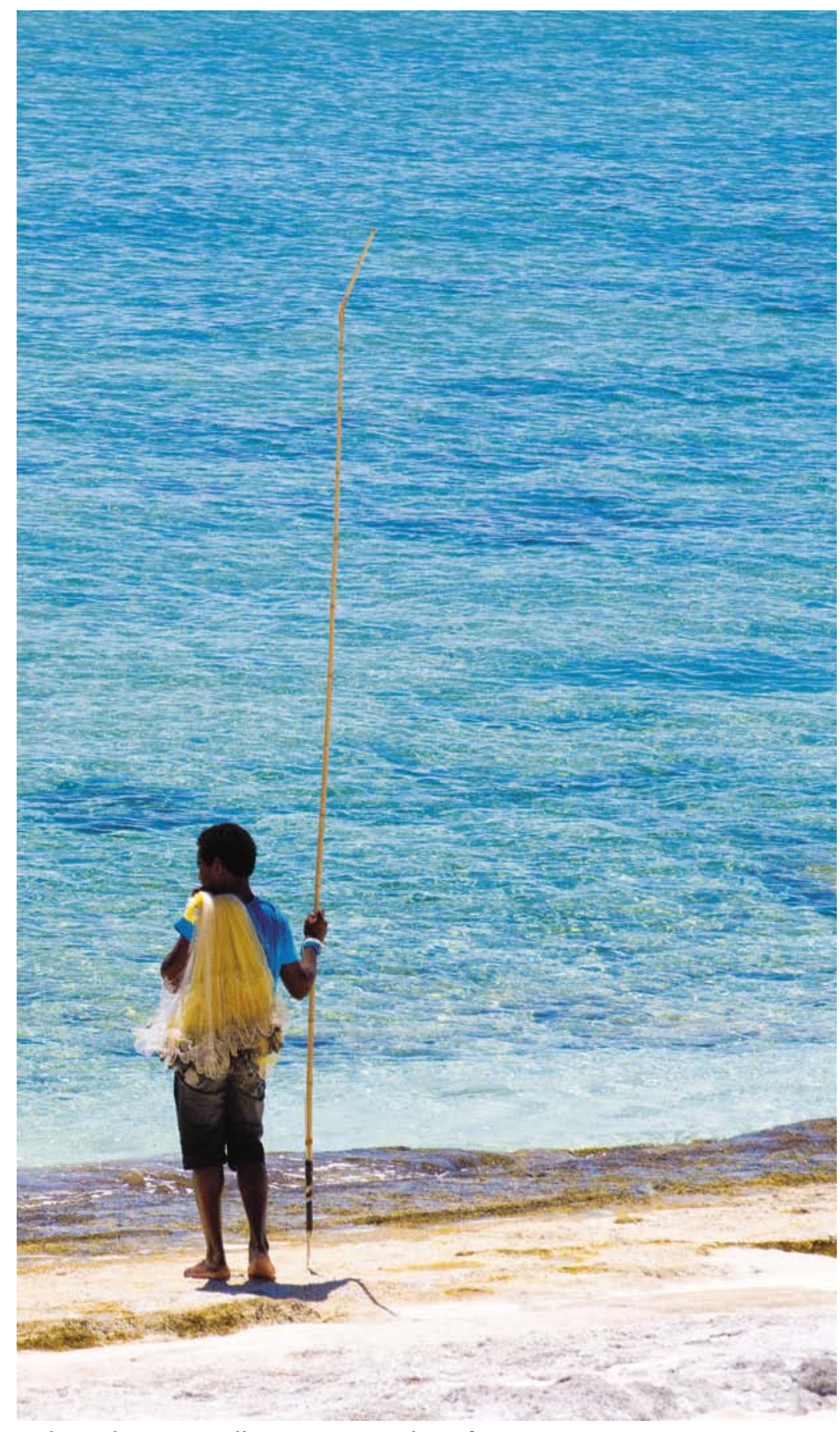

Pêcheur à la sagaie et à l'épervier. Doueoulou, Lifou. @ P.-A. Pantz
La pêche tient une place particulière dans l'alimentation et le quotidien des Calédoniens. Il est important de se rappeler que les seules sources de protéines animales avant l'introduction des cerfs et des cochons étaient les oiseaux (notou, cagou...), les roussettes et les ressources marines. Une enquête réalisée en $2011^{21}$ auprès des habitants des tribus montre que plus de la moitié des familles résidant sur terres coutumières pratiquent la pêche : $57 \%$ des ménages ont eu au moins une activité de pêche en 2010. Poissons du lagon, crabes, langoustes, coquillages, poulpes, bêches-de-mer : 2730 tonnes de produits issus de la mer ont été prélevés par les Kanak vivant en tribu. Cette pêche en mer représente, en moyenne, $370 \mathrm{~kg} / \mathrm{an} / \mathrm{foyer}$, avec des valeurs atteignant 586 et $572 \mathrm{~kg} / \mathrm{an} /$ foyer à Ouvéa et dans les tribus du Grand Nord respectivement (Belep, Pouebo, Ouégoa, Poum, Ouégoa et Kaala-Gomen).

Comme pour l'agriculture, les produits issus de la pêche en mer sont d'abord autoconsommés et donnés (60\% autoconsommés, 19\% donnés en 2010), et $21 \%$ sont commercialisés. La pêche en mer a ainsi permis de dégager $644 \mathrm{MF}$ CFP de recettes pour les populations des tribus en 2010. Les ménages des tribus du Grand Nord, des espaces de l'Ouest et du Sud-Est (Yaté, Thio et l'lle des Pins) ont tendance à beaucoup plus commercialiser leurs pêches que les habitants des autres tribus du reste du pays. Cette même année, aux côtés de cette pêche principalement vivrière, 656 tonnes de poissons du lagon (538 en 2018), 2860 tonnes de thonidés et associés (2 840 en 2015) ainsi que 253 tonnes de bêches-de mer et coquilles de troca (192 en 2015) ont été officiellement prélevés en Nouvelle-Calédonie par les pêcheurs professionnels (déclaration dans les cahiers de pêche déposés auprès des Provinces). Cela a permis de dégager 555MF de chiffres d'affaires en 2010 (447 en 2015) pour ce qui est des produits de la mer venant exclusivement du lagon et $1300 \mathrm{MF}$ pour ce qui est des produits de la pêche palangrière (1 200 en 2015).

${ }^{21}$ Enquête conduite par l'IAC auprès de 1786 ménages, soit environ 12,5\% des habitants des tribus (Guyard et al., 2013). 


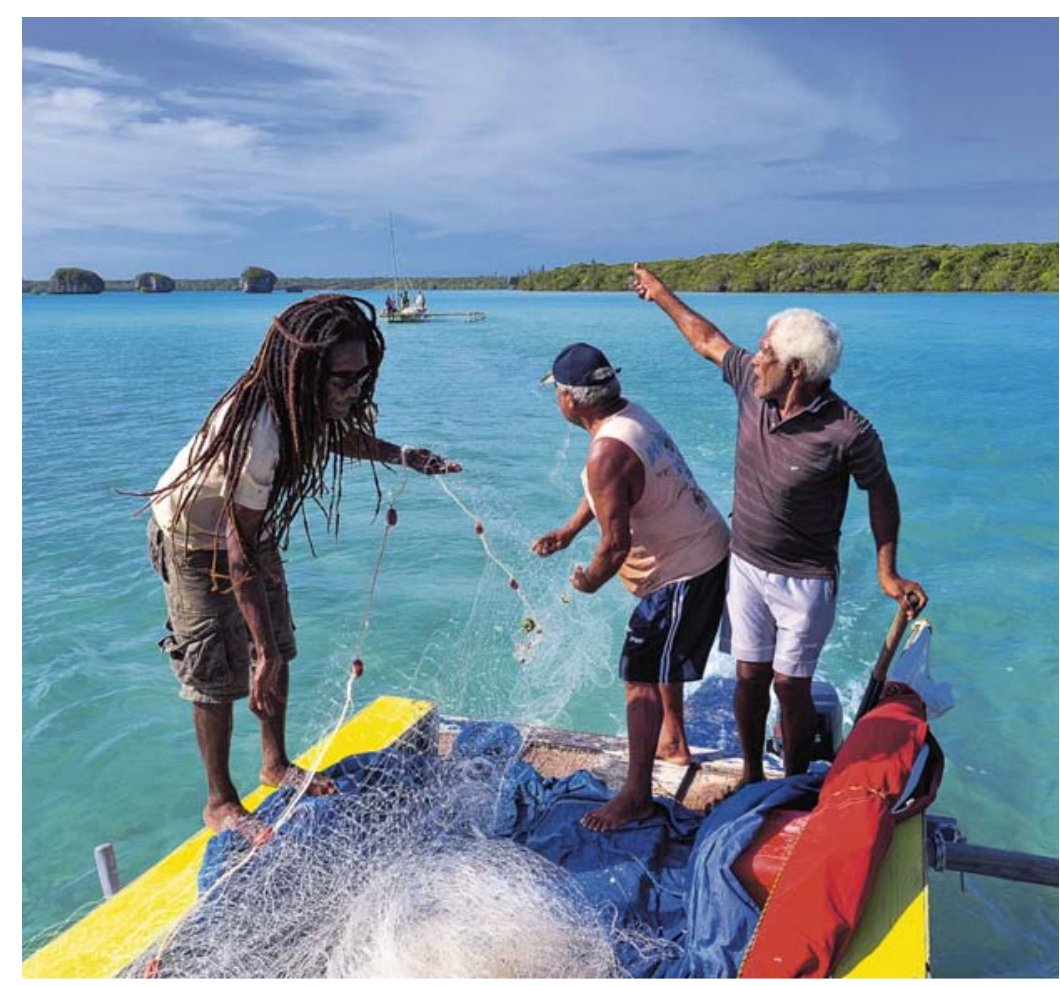

Chargement du filet à mïkwa sur une pirogue pontée, à Pwadèwia, baie de St-Joseph, île des Pins, 2017. @ M. Juncker

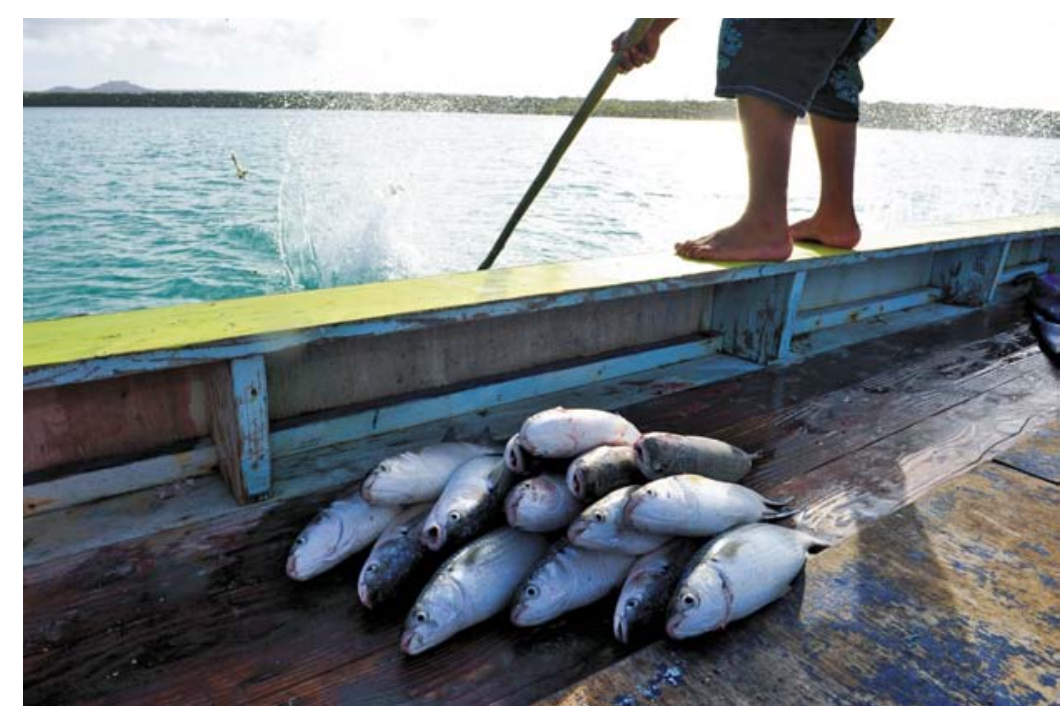

Encerclés au filet puis attrapés par de solides pêcheurs, les mikwaa sont remontés à bord de la pirogue, île des Pins, 2017. ๑ M. Juncker

\section{« Le lagon est notre garde-manger »}

«Il n'y a pas que le nickel sur le territoire... ça ne se mange pas la terre. » (Koumac)

«Iln'y a pas d'autres choix que valoriser la pêche ou le tourisme, si on ne le fait pas bientôt il n'y aura plus personne dans les îles, ils vont tous partir. Ça c'est un moyen de fixer les gens chez eux. »

Les « coups de pêche », expression consacrée et partagée par tous les Calédoniens tournés vers la mer servent à nourrir la famille, contribuer à des cérémonies, gagner quelques pièces, se constituer un revenu. Nous devons retenir qu'avant toute chose, le lagon est qualifié de « garde-manger » par nombre de femmes et d'hommes qui vivent aux côtés du lagon, aux abords des platiers. Cette expression traduit à la fois la valeur alimentaire, économique et symbolique accordée au récif et à ceux qui le parcourent, le connaissent et souhaitent en prendre soin et montre que pour de nombreuses raisons les récifs coralliens constituent un patrimoine naturel et culturel essentiel aux Calédoniens.

\section{Références bibliographiques}

GUYARD S. et al., 2013 L'agriculture des tribus en Nouvelle-Calédonie. Résultats d'une enquête de 2010 sur la place et les fonctions de l'agriculture, l'élevage, la pêche et la chasse pour les groupes domestiques résidant en tribu. Pouembout, IAC/CIRAD, 256 p.+ annexes.

JUNCKER M., JUNCKER B., 2018 Des récifs et des hommes. Histoires de pêcheurs de Nouvelle-Calédonie, Nouméa, Madrépores, 168 p.

LEBLIC I., 2008 Vivre de la mer, vivre avec la terre... en pays kanak. Savoirs et techniques des pêcheurs kanak du sud de la Nouvelle-Calédonie, Paris, Société des océanistes, Travaux et documents océanistes, 1, 288 p.

SABINOT C., LACOMBE S., 2015 La pêche en tribu face à l'industrie minière dans le sud-est de la Nouvelle-Calédonie. Revue de la société internationale d'ethnographie, 5, La mer et les Hommes: 120-137. 


\section{Chapitre 31 \\ Les récifs et leurs invertébrés, une manne durable pour les Calédoniens?}

Pascal Dumas, Marc Léopold et Loïc Bourgine

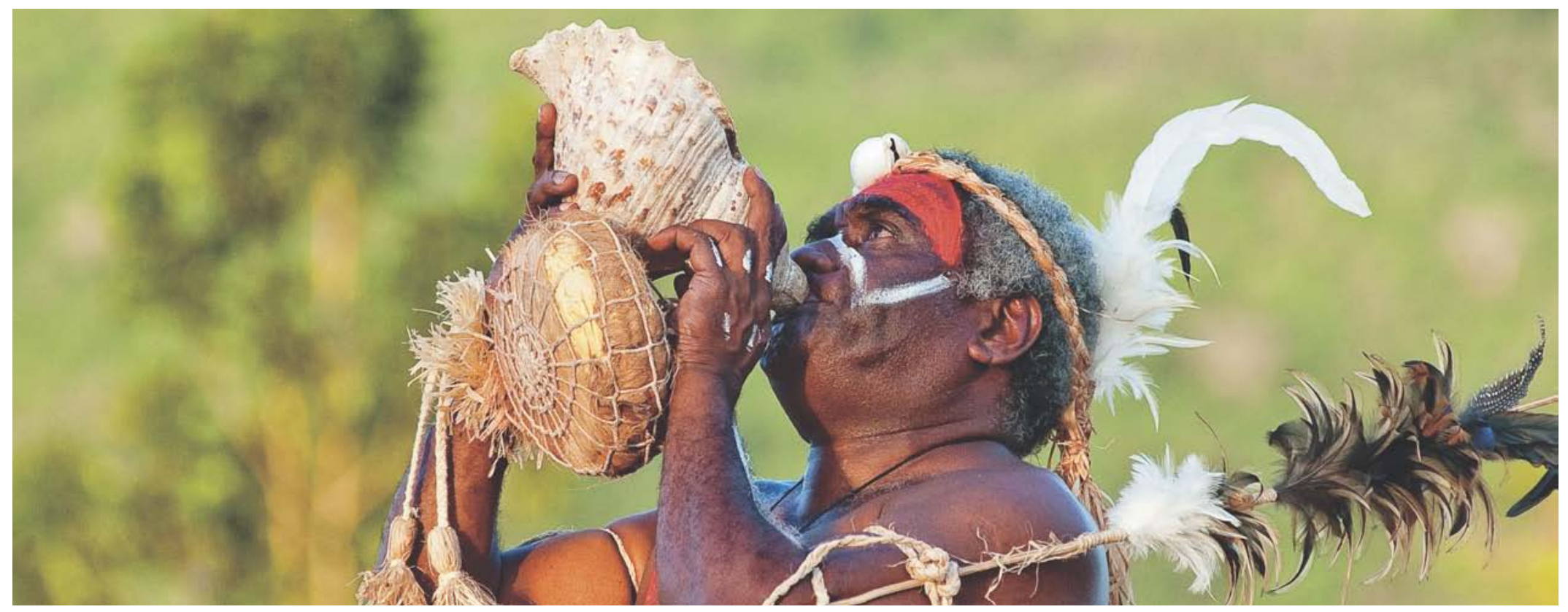

La « toutoute »(Charonia tritonis), instrument utilisé en Nouvelle-Calédonie pour rassembler ou avertir les habitants d'un village. @ ADCK/CCT/P.-A. Pantz

\section{Poulpes, coquillages et crustacés...} la grande diversité des ressources récifales

L'utilisation des espèces récifales par les populations insulaires du Pacifique n'est certes pas récente, comme l'attestent l'abondance et la variété des artefacts liés à la pêche (hameçons, pirogues, outils, coquillages, etc.) retrouvés dans les strates géologiques associées à l'installation des peuplades Lapita de la région. Bien que le régime alimentaire des populations côtières se soit considérablement diversifié depuis l'Antiquité, ces ressources demeurent une composante essentielle de la sécurité alimentaire des îles du Pacifique et un élément central de leurs traditions culturelles.
Si la diversité des espèces récifales potentiellement capturées est élevée - elle pouvait atteindre près d'une centaine d'espèces dans une île type du Pacifique sud il y a encore une trentaine d'années - , le spectre des espèces effectivement prélevées dans le milieu présente d'importantes variations selon les zones géographiques et leur contexte environnemental, économique et culturel. Les études réalisées montrent que les populations insulaires collectent généralement une grande variété d'invertébrés, ciblant tout particulièrement les mollusques bivalves (bénitiers, cardium, huitres, moules, clams...), les gastéropodes (trocas, burgaux, cônes, strombes, araignées...) et les céphalopodes (poulpes), les crustacés (crabes, crevettes, langoustes, cigales de mer, bernard-l'ermite, dont 
l'imposant crabe de cocotier Birgus latro) et les échinodermes (oursins et, plus récemment, holothuries). Il s'agit à l'origine de pratiques artisanales opérant à des échelles spatiales réduites (échelle d'un ou plusieurs récifs, d'une île, etc.), à caractère vivrier, et ayant progressivement évolué vers une orientation commerciale pour certaines espèces à forte valeur marchande.

La plupart des espèces récoltées le sont avant tout pour la consommation, après avoir éventuellement transité par divers circuits traditionnels d'échange ou de vente. Mais certaines ont conservé un caractère emblématique et jouent toujours un rôle dans les pratiques sociales et culturelles de la région : triton géant (Charonia tritonis, la « toutoute » en Nouvelle-Calédonie) utilisé comme instrument pour rassembler ou avertir les habitants d'un village, porcelaines ou cônes servant à confectionner des monnaies de coquillage, huitres perlières et bénitiers qui ornent certains objets de prestige utilisés lors de cérémonies d'échanges coutumières... sans oublier les nombreuses espèces utilisées en joaillerie ou qui finiront sur les marchés artisanaux à destination des visiteurs.

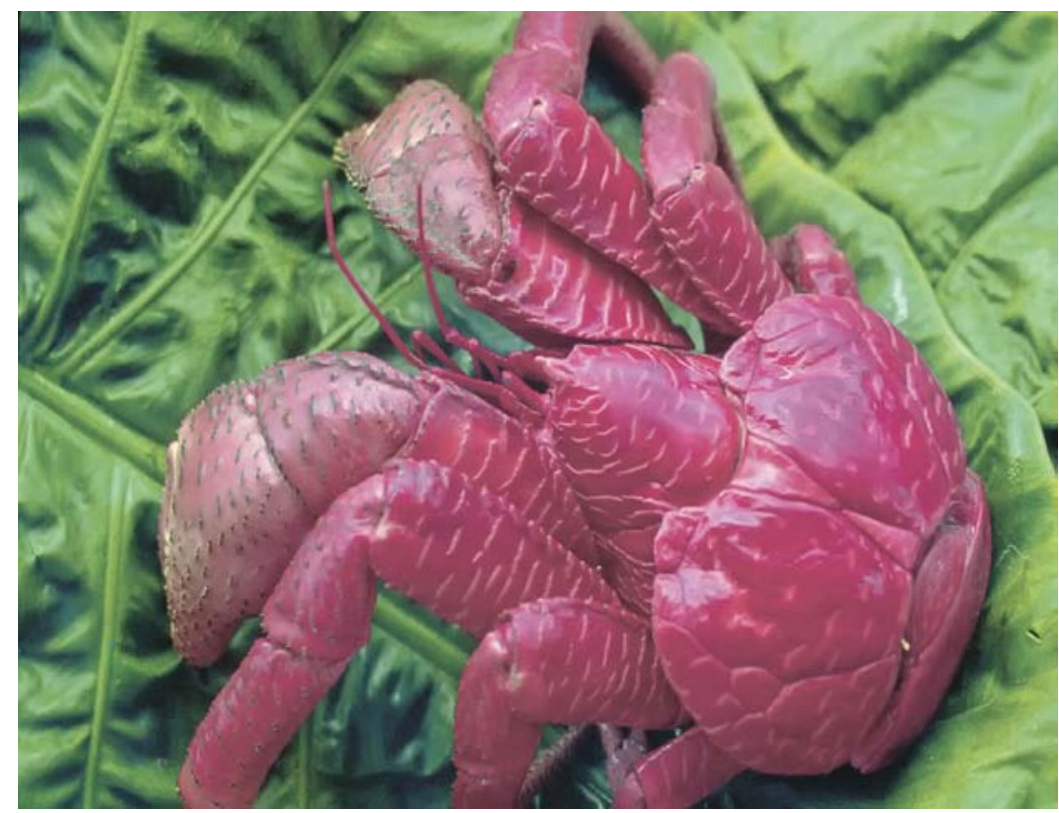

Crabe de cocotier (Birgus latro) cuit et prêt à être consommé. @ P.-A. Pantz

\section{Exploitation des ressources récifales en Nouvelle-Calédonie}

En Nouvelle-Calédonie comme dans de nombreuses autres îles de la région, les écosystèmes côtiers - y compris les récifs coralliens, les mangroves et les herbiers marins - contribuent à l'alimentation, aux revenus et, plus important encore, à l'autosuffisance des populations côtières et insulaires. Il est vrai que le territoire bénéficie à cet égard de conditions particulièrement favorables : plus de $4500 \mathrm{~km} 2$ de formations récifales présentant un haut niveau de variabilité structurale (récifs frangeants, intermédiaires, barrières - parfois double ou triple -, récifs d'atolls, etc.) et situées à l'interface entre les zones tropicale et tempérée sont à l'origine d'une grande variété de niches écologiques potentielles pour les espèces benthiques. Avec près de 10000 espèces marines d'invertébrés officiellement recensées dont plus de 2150 mollusques marins, 2000 arthropodes et 250 échinodermes, les écosystèmes coralliens de NouvelleCalédonie sont reconnus comme un «point chaud » de la biodiversité planétaire. Une étude réalisée par l'IRD révèle ainsi que

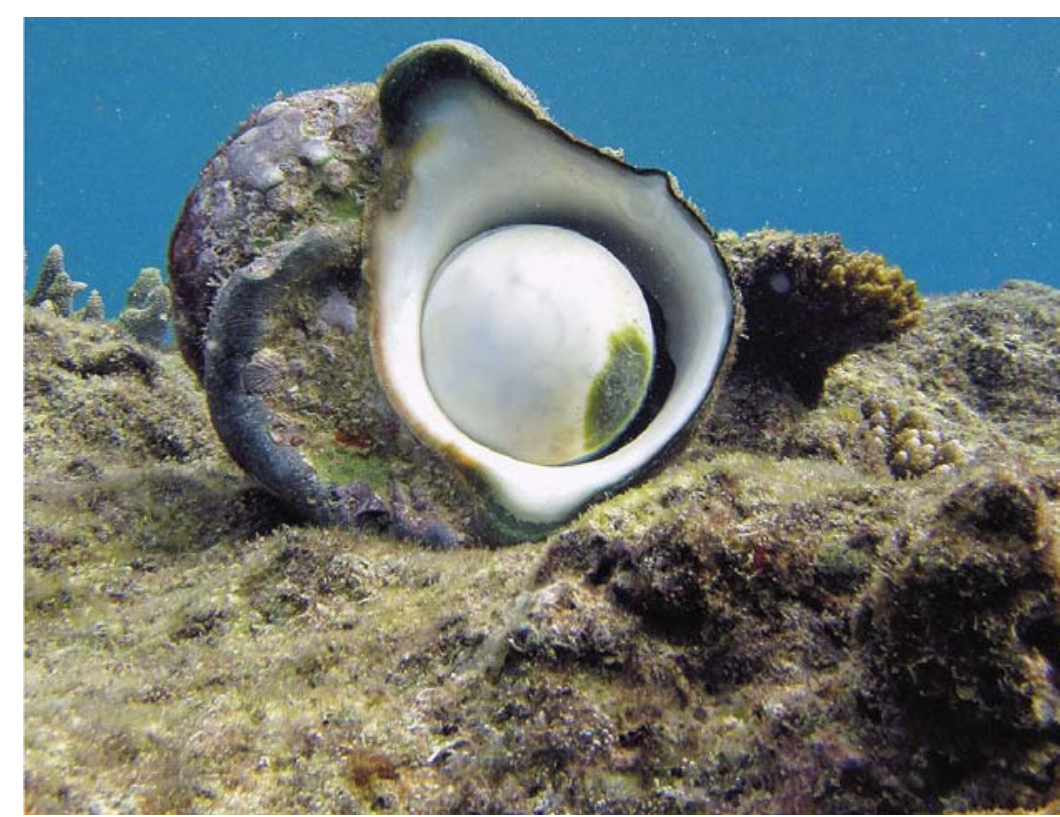

Burgau (Turbo marmoratus), Vanuatu. @ IRD/P. Dumas 
plus de 60 espèces de macro-invertébrés - pour l'essentiel des mollusques - sont récoltées par les pêcheurs à pied sur les platiers de la zone du grand Nouméa. À l'échelle du territoire, les captures d'invertébrés atteignent fréquemment des volumes élevés : entre 150 et 200 t/an (hors coquilles de trocas) d'après les chiffres disponibles. Mais ces valeurs sont très certainement sous-estimées car le caractère informel et dispersé de ces activités en rend l'évaluation difficile, particulièrement pour la pêche plaisancière et de subsistance.

Si la majorité des espèces restent traditionnellement dédiées à la consommation locale - par exemple le crabe de palétuvier, les langoustes, poulpes, bénitiers ou les nombreuses espèces de coquillages récoltées à marée basse tels que palourdes (Anadara scapha), grisettes (Gafrarium tumidum), moules (Modiolus auriculatus), sauteurs (Strombus luhuanus), et araignées (Lambis spp.) -, d'autres en revanche sont exportées. C'est en particulier le cas des holothuries et des trocas, dont la valeur cumulée à l'export oscille entre 400 et 500 millions de francs CFP par an ces dernières années. Et, très récemment, de la coquille Saint-Jacques (Ylistrum japonicum), très prisée pour la qualité et la saveur délicate de sa chair, dont 30 t de noix ont été exportées en 2016 sur les marchés asiatiques.

\section{La surexploitation opportuniste des holothuries : un enjeu majeur}

L'exploitation des holothuries s'est développée en NouvelleCalédonie exclusivement pour l'exportation de « bêche-de-mer » (nom du produit une fois l'animal éviscéré, bouilli et séché) vers les marchés asiatiques. Comme dans les pays voisins, la pêche des holothuries aurait commencé au début du XIXe siècle sous la forme d'expéditions commerciales, établissant des installations précaires et temporaires dans les zones de pêche isolées. Mais la mondialisation et l'essor de la demande du marché chinois depuis les années 1980 ont profondément et durablement marqué l'exploitation dans tous les pays du Pacifique. Nombre d'entre eux ont mis en place des moratoires nationaux suite à l'effondrement rapide des captures, après une courte période de développement des pêcheries. Se déplaçant peu, les holothuries se collectent en effet très facilement

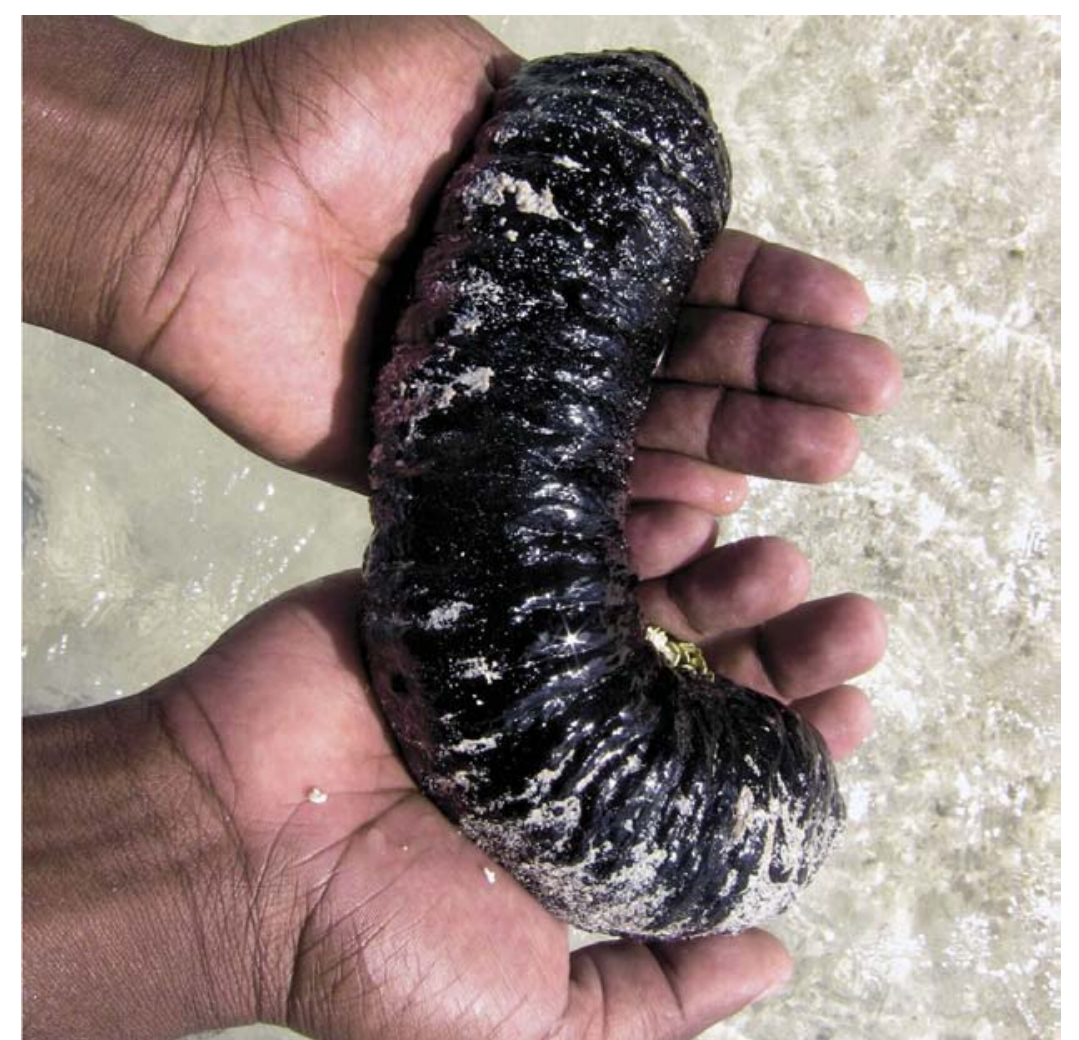

Holothurie (bêche-de-mer, Holothuria atra), Nouvelle-Calédonie. @ IRD/P. Dumas

à pied ou en plongée et sont donc très vulnérables à la pêche : en l'absence de restrictions effectives, l'exploitation intensive des géniteurs conduit généralement à un épuisement de la ressource en 10 ou 20 ans, voire moins pour les espèces à haute valeur comme l'holothurie grise (Holothuria scabra), l'holothurie à mamelles blanches ( $H$. fuscogilva) et à mamelles noires $(H$. whitmaei).

Contrairement à ses voisins, la Nouvelle-Calédonie a été relativement épargnée par la surexploitation jusque dans les années 2010. La pêche concerne moins d'une dizaine d'espèces et se concentre dans le lagon ouest et le lagon nord, au niveau des plateaux côtiers et du récif-barrière jusqu'à une vingtaine de mètres de profondeur (l'utilisation de scaphandre autonome ou de compresseur étant prohibée). La production oscille entre quelques dizaines et une centaine de tonnes de bêche-de-mer par an et 
constitue une source de revenus pour plus de 200 pêcheurs professionnels (valeur à l'export en 2016 : 425 millions de francs). Cependant, le pays fait aujourd'hui face à une pression majeure du marché, qui menace la durabilité des pêcheries et pousse les administrations à adapter rapidement la réglementation (en particulier la mise en œuvre effective de tailles minimales de captures et de licences de pêche). Un système de co-gestion par quotas a ainsi été développé avec succès entre les autorités provinciales et coutumières et les pêcheurs d'une zone pilote, mais sa transcription à grande échelle pose des difficultés. L'aquaculture de l'holothurie grise est une autre voie de développement expérimentée depuis une dizaine d'années. Des essais de repeuplement de cette espèce sont en cours depuis 2014, mais les résultats mitigés ne permettent pas encore d'envisager ces opérations - coûteuses et au succès incertain - comme remède à la surexploitation.

\section{L'exploitation stabilisée des trocas}

Comme les toutoutes, casques, sauteurs et autres porcelaines, le troca (Tectus niloticus) est un mollusque gastéropode marin fréquentant les récifs coralliens de la région Indo-Pacifique. De taille plutôt imposante (les plus gros spécimens dépassent $15 \mathrm{~cm}$ de diamètre), il est très recherché pour la qualité de sa nacre, exportée dès le début du XXe siècle vers l'Europe et l'Asie pour alimenter l'industrie des boutons de luxe et la joaillerie artisanale; sa valeur élevée et sa qualité non périssable (les coquilles peuvent être stockées plusieurs mois avant d'être vendues) en font une source de revenus intéressante pour les îles ou communautés isolées.

Suite à son extension géographique rapide dans le Pacifique à partir de transplantations effectuées dans les années 1930-1940, l'augmentation de la demande sur le marché mondial a rapidement suscité de sérieuses inquiétudes quant à sa préservation. Malgré des réglementations de pêche plus en plus restrictives et l'amélioration des mesures de réimplantation dérivées de l'aquaculture, les trocas sont surexploités dans la majorité des pays du Pacifique - avec pour conséquence une diminution généralisée des stocks pouvant aller jusqu'à l'extinction locale de l'espèce dans certaines régions.
En Nouvelle-Calédonie, l'exploitation de l'espèce débute dans les années 1900 et les exportations culminent rapidement autour de 1000 tonnes de coquilles par an entre 1910 et 1920 . Après une forte chute d'activité pendant la seconde guerre mondiale, les premières réglementations sont mises en place dans les années 1950 pour protéger une ressource dont la fragilité est rapidement pressentie par les scientifiques. Les trocas présentent en effet une distribution spatiale fortement hétérogène : les individus ne se répartissent pas au hasard sur les récifs, mais se concentrent dans des « microhabitats 》 bien spécifiques et relativement faciles d'accès (notamment les zones de dalle érodée au niveau des platiers et de la crête récifale, avec une faible complexité structurale et une faible couverture corallienne).

Même si sa croissance rapide et sa maturité sexuelle précoce lui confèrent une certaine résilience, le troca est ainsi particulièrement vulnérable à la surpêche, d'autant qu'il se déplace peu. En NouvelleCalédonie, la ressource de trocas ne semble cependant pas menacée à court terme. Avec un recul de la demande de nacre au profit de matières synthétiques, le troca n'est plus aussi recherché : les volumes exportés ces 10 dernières années varient entre 150 et 200 t/an pour un chiffre d'affaires oscillant entre 40 et 80 millions de francs CFP, bien loin derrière celui de la pêche des poissons récifo-lagonaires. Outre une limitation des tailles de capture fixée entre 9 et $12 \mathrm{~cm}$, destinée à protéger le potentiel reproductif de l'espèce, la gestion de cette ressource bénéficie de l'existence de nombreuses réserves marines, réparties sur l'ensemble du territoire.

De statuts variés (aires marines protégées, aires de gestion durable des ressources, réserves intégrales, réserves coutumières, etc.), ces espaces protégés constituent le cas échéant des refuges pour les géniteurs à même de favoriser la régénération de populations appauvries aux alentours. Une étude récente indique ainsi la présence de populations de trocas adultes deux fois plus denses au sein des aires marines protégées du lagon sud-ouest, et composées de spécimens 10 à $20 \%$ plus gros en moyenne que ceux observés dans les zones pêchées.

Des résultats très similaires sont observés chez nos voisins du Vanuatu, dont les réserves présentent pourtant des caractéristiques 
(taille, réglementation, gouvernance) très différentes. Car, au-delà des questions de protection et de statut, l'efficacité des réserves marines dépend avant tout de la présence de conditions propices à l'installation et au maintien des populations ciblées : pour les trocas comme pour d'autres espèces benthiques fortement dépendantes du substrat, la gestion des ressources ne peut se concevoir indépendamment de celle de l'habitat.

\section{L'exploitation du crabe de palétuvier pour le marché intérieur}

Sur le territoire comme dans le reste de la région, le crabe de palétuvier (Scylla serrata) constitue une ressource majeure pour de nombreuses populations riveraines des mangroves : de fait, les volumes de captures n'ont cessé d'augmenter depuis les dernières décennies, dépassant récemment les 40000 t pour l'ensemble du Pacifique. Sur la côte Ouest et nord de la Nouvelle-Calédonie, le crabe de palétuvier fait ainsi l'objet d'une pêche active dont le caractère vivrier et traditionnel a évolué progressivement vers un type commercial, suite à l'introduction de techniques de pêche plus sophistiquées (nasses pliantes) au début des années 2000. Autrefois exporté vers Tahiti, il constitue une source de revenus parfois essentielle pour certains ménages : la production a ainsi doublé au cours des 10 dernières années, passant d'une vingtaine de tonnes officiellement déclarées en 2006 à plus de $40 \mathrm{t}$ en 2015, avec un pic à près de $80 \mathrm{t}$ de crabes déclarées en 2010. Mais ces chiffres ne représentent qu'une partie de la réalité : une étude conduite par l'IRD fait notamment état de l'importance de la production vendue dans la commune de Voh, qui atteignait à elle seule près de 100 t de crabes en 2006.

En raison de son importance socioculturelle et économique, la gestion durable de cette ressource constitue un réel enjeu : la première réglementation concernant la pêche au crabe date de
1963, et fixait déjà une taille minimale de capture ainsi qu'une interdiction, à l'époque temporaire (deux ans), de capturer les crabes mous, c'est-à-dire en état de mue ${ }^{22}$. D'importants efforts de recherche sur la biologie, l'écologie et les perspectives pour l'aquaculture de l'espèce en Nouvelle-Calédonie ont, depuis, conduit à une évolution de la réglementation qui s'appuie actuellement sur quatre mesures principales:

- une fermeture annuelle de la pêche entre le $1^{\mathrm{er}}$ décembre et le 31 janvier pendant laquelle toute forme de capture est strictement interdite, destinée à protéger les individus pendant le pic de reproduction de l'espèce ;

- une taille légale de capture fixée à $14 \mathrm{~cm}$ (largeur totale de l'animal), destinée à limiter la pression de pêche sur les individus ne s'étant pas encore reproduits ;

- l'interdiction totale de consommer ou vendre des crabes mous, et de commercialiser des crabes autrement que vivant et entiers (la chair de crabes est interdite, sauf exceptions particulières) ${ }^{23}$;

- l'interdiction des nasses à crabes dont le maillage est inférieur à $65 \mathrm{~mm}$. Actuellement, la ressource ne présente pas de signes de surexploitation à l'échelle du territoire.

Si la biologie de l'espèce est désormais bien connue, certaines lacunes - par exemple la grande difficulté à observer et capturer les juvéniles de l'espèce dans leur milieu naturel - constituent cependant un obstacle à la compréhension fine de l'impact des prélèvements sur les stocks. Certaines études mettent également en évidence la variabilité marquée des rendements de capture à des échelles spatiales restreintes (de l'ordre du kilomètre), se traduisant par des densités de crabes capturables variant de plus d'un ordre de magnitude entre différents habitats. D'une mangrove à une autre, la pêche est ainsi moins productive dans les zones où les conditions sédimentaires, la salinité, la température, le couvert végétal, etc. seront naturellement moins favorables à l'espèce. Cette distribution hautement hétérogène de la ressource a de fortes implications socio-

${ }^{22}$ Arrêté du Journal officiel de la Nouvelle-Calédonie, 25 juin 1963.

${ }^{23}$ « La pêche, le transport, la commercialisation, l'exposition à la vente, la vente et l'achat des crabes de palétuvier, sont interdits du $1{ }^{\text {er }}$ décembre au 31 janvier. Demeurent interdits en tout temps, la pêche, le transport et la commercialisation, l'exposition à la vente, la vente, l'achat, la détention et la consommation des crabes mous et des crabes dont la taille est inférieure à $14 \mathrm{~cm}$ dans la plus grande dimension. Seule la commercialisation du crabe entier vivant est autorisée. La présentation à des fins commerciales de chair de crabe, sous quelque forme que ce soit, est interdite en tout temps, exception faite pour les seuls restaurateurs et traiteurs, et dans les seuls locaux où ils exercent leur activité et qui font l'objet d'une attestation de conformité ou d'un agrément d'hygiène » (Extrait de la réglementation de la pêche en province Nord, 2006). 


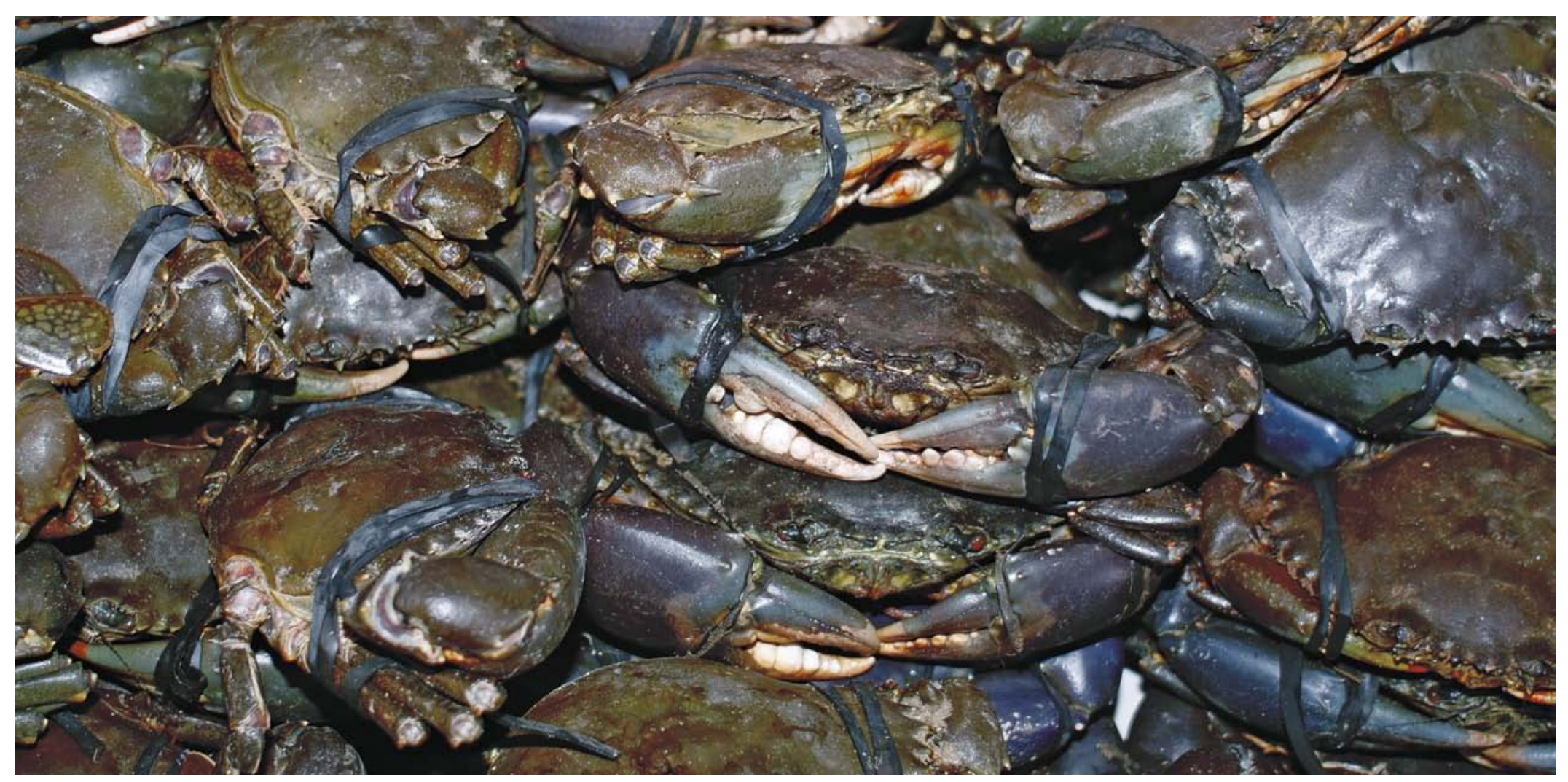

Crabes de palétuviers (Sylla serrata) prêts à la vente, Nouvelle-Calédonie. @ P.-A. Pantz

économiques en Nouvelle-Calédonie, où les systèmes traditionnels de propriété foncière empêchent généralement les pêcheurs de sélectionner librement leurs zones de pêche. Comme dans d'autres pays du Pacifique, celles-ci dépendent principalement de droits d'accès traditionnels plutôt que de la disponibilité réelle de la ressource : même si la situation se modifie avec la modernisation des techniques et le développement de la pêche embarquée, ces règles informelles déterminent en grande partie les zones accessibles aux pêcheurs. Ces résultats soulignent en particulier l'importance d'une approche de conservation qui prenne l'habitat en considération, en particulier aux petites échelles spatiales ; ils soulèvent également des questions sur la réglementation des pêches en vigueur en NouvelleCalédonie et la gestion optimale d'une ressource aussi spatialement hétérogène. La «compatibilité » des échelles écologiques (déterminant la structuration naturelle des populations) et d'exploitation (structurant les activités de pêche) constitue ainsi un argument fort en faveur d'une gestion spatialisée de la pêcherie.

Si le déclin des ressources récifales est un phénomène d'ampleur mondiale, il revêt une signification particulière dans le Pacifique insulaire. De fait, la grande majorité des espèces macrobenthiques récifales entrent dans le cadre de la pêche à un moment ou un autre de leur cycle biologique : leur raréfaction représente un risque majeur pour l'économie et l'organisation traditionnelle de sociétés, dont la dépendance aux produits de la mer est en général inversement proportionnelle au niveau de développement économique. La mise en place d'une politique de gestion durable des écosystèmes littoraux et de leurs ressources constitue un défi majeur pour la NouvelleCalédonie, spécialement dans un contexte économique profondément bouleversé par la crise du nickel et les enjeux politiques de demain. 


\title{
Chapitre 32 \\ Substances naturelles : des trésors cachés
}

\author{
Sylvain Petek
}

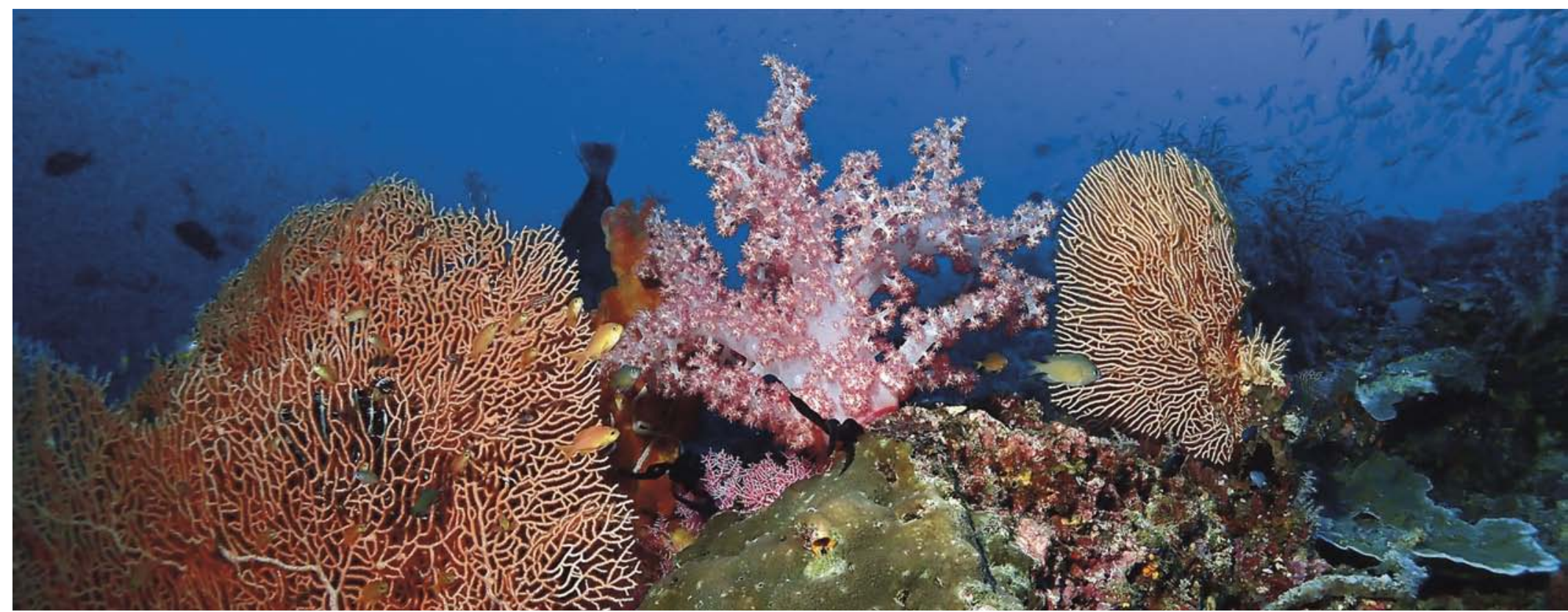

Les gorgones et les alcyonaires sont parmi les organismes testés pour la recherche d'activités biologiques. @ IRD/S. Andréfouët

Pour tout un chacun, le terme de « substances naturelles » est intimement lié aux médecines traditionnelles, l'ethnopharmacologie, l'herboristerie ou encore l'aromathérapie. Cette association d'idées provient des connaissances acquises et d'usages pluricentenaires, principalement des plantes terrestres, au sein des différentes communautés à travers le monde pour combattre différentes affections.

Plus généralement, derrière cette notion, on s'intéresse aux molécules synthétisées par les organismes, et plus particulièrement à celles ayant des activités biologiques et/ou thérapeutiques particulières.
Quel que soit l'organisme considéré, les molécules produites sont généralement classées en deux groupes, celles indispensables intrinsèquement à la vie, dits métabolites primaires (acides aminés, nucléotide [ADN, ARN...], acides gras à fonction membranaire...) que l'on va retrouver au sein d'organismes taxonomiquement très différents, et ceux dits secondaires, n'intervenant pas dans des fonctions physiologiques fondamentales, et généralement spécifiques au type d'organisme considéré (plantes, bactéries, champignons...). C'est à ces derniers que nous allons nous intéresser ici. 


\section{De l'écologie chimique aux applications inspirées de la nature}

Au cours de l'évolution, les organismes ont développé toute une panoplie de métabolites secondaires pour s'adapter aux variations physiques (luminosité, température, pression, salinité...) ou biologiques (prédation, colonisation, infestation...) de leur environnement, et pour communiquer. C'est au travers d'études transdisciplinaires d'écologie chimique, associant chimistes et biologistes, que l'on va être capable d'isoler, d'identifier et de comprendre le rôle joué par ces composés. Sur la base de ces travaux, des solutions innovantes inspirées de la nature, plus respectueuses de l'environnement, peuvent voir le jour, que ce soit en santé humaine et animale, en agronomie, en aquaculture, ou dans d'autres secteurs technologiques.

\section{Médicaments de la mer}

Si l'usage des plantes terrestres est très ancien et généralisé à travers le monde dans les différentes pharmacopées, l'utilisation historique d'organismes marins est surtout connue en Chine et en Extrême-Orient. Le Pen Ts'ao chinois, publié 2800 ans av. J.-C., comporte un chapitre entièrement consacré aux algues pour soigner les ulcères gastriques ou les goitres par exemple. Les Japonais utiliseront quant à eux bien plus tard, comme anthelminthique (antiparasitaire), une algue rouge, appelée kaïniso (Digenea simplex), contenant de l'acide kaïnique, conduisant à la préparation d'un véritable médicament contre les ascaris. En dehors de cette zone géographique, il n'existe quasiment pas de tradition orale ou de médecine traditionnelle qui fasse référence à l'utilisation d'organismes marins.

C'est à partir du milieu du XXe siècle, avec le développement de nouveaux moyens d'exploration sous-marine et d'analyse, et surtout à partir des années 1970, que vont réellement débuter les études méthodiques de la biodiversité marine pour des usages en santé humaine.
La vie étant apparue dans les océans, ils renferment encore aujourd'hui toutes les formes de vie existantes. Ainsi, sur les 33 embranchements principaux, 12 sont exclusivement marins et d'autres le sont essentiellement (cas des éponges ou des cnidiaires - méduses, etc. - dont il existe quelques espèces d'eau douce), autrement dit, toute une biodiversité marine sans équivalent dans les milieux terrestres et d'eau douce. Par ailleurs, l'eau de mer contient des éléments chimiques tels que des halogènes (chlore, brome, iode, fluor), du soufre et des métaux peu ou pas disponibles ailleurs. Cette diversité biologique combinée aux particularités chimiques du milieu marin et aux premières découvertes encourageantes nourrit de nombreux espoirs quant à l'émergence d'une nouvelle pharmacopée d'origine marine.

Ainsi, les premières céphalosporines, une famille d'antibiotiques très largement utilisée de nos jours, ont été découvertes en Italie en 1948, en cultivant Cephalosporium acremonium, un champignon microscopique présent dans des sédiments lagunaires. La famille des arabinosides, aux propriétés anticancéreuses et antivirales, a été inspirée de composés isolés d'une éponge des Caraïbes, Cryptotethya crypta, dans les années 1950.

Face à cette extraordinaire biodiversité et sans connaissances ethnopharmacologiques pour les guider, la tache des chercheurs est immense. Pour essayer de sélectionner les organismes les plus prometteurs, l'observation in situ de leurs comportements peut fournir certains renseignements. Ainsi des organismes sans protection physique, peu ou pas colonisés, ne subissant pas la prédation ou le broutage sont susceptibles d'avoir développé un cocktail chimique pour se protéger de ces agressions. Pour étudier ces organismes, différentes approches ont été utilisées, certaines plutôt « systématiques » (fig. 1), sans a priori quant à l'activité biologique de l'organisme, les mesures de bioactivité se faisant in fine sur les molécules isolées, et d'autres par bioguidage (fig. 2), permettant dans un premier temps de sélectionner les organismes actifs sur telle ou telle cible biologique (bactéries, enzymes, cellules cancéreuses...) et, de proche en proche, d'isoler le ou les principes actifs responsables de l'activité observée, chaque stratégie ayant ses avantages et ses inconvénients. 
Après plus de 50 ans de recherche, c'est une véritable chimiodiversité marine qui a été découverte, avec quelque 29600 molécules isolées, dont une grande partie est sans équivalent terrestre.

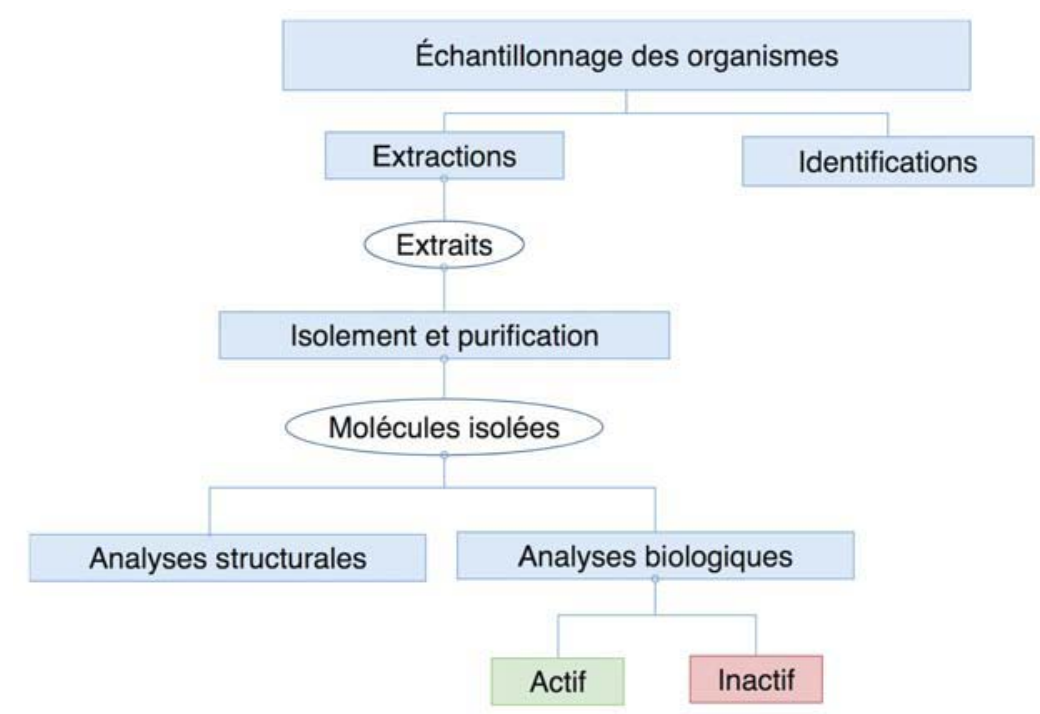

Figure 1 : Approche « systématique ». @ IRD/S. Petek

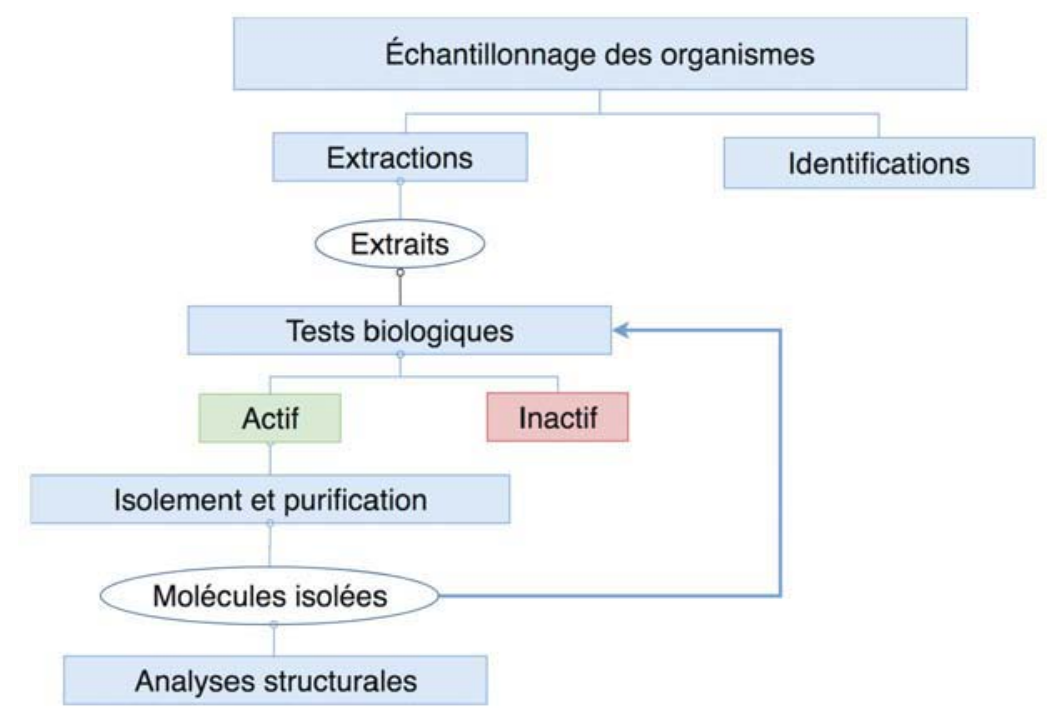

Figure 2 : Approche « bioguidée ». ๑ IRD/S. Petek
Comme le montre le graphique (fig. 3), un peu plus d'un tiers des composés proviennent d'éponges et/ou de leur microbiome associé. Ces animaux sessiles (chap. 13), ne pouvant fuir leurs prédateurs, ont développé tout un arsenal chimique pour se défendre, conquérir de nouveaux espaces et se prémunir des pathogènes. Par ailleurs, c'est également l'embranchement dont les composés offrent le plus large spectre d'activités biologiques : antibiotique/antibactérien, antifongique, anticancéreux, anti-inflammatoire, antiviral, antipaludique, immunostimulant, antispasmodique, etc.

À l'heure actuelle, en plus des céphalosporines (antibiotiques, $5^{\mathrm{e}}$ génération depuis 1964), ce sont 9 médicaments d'origine marine (ou dérivés) qui ont été mis sur le marché, pour des traitements anticancéreux, antiviraux, analgésiques et antiparasitaires. Une quinzaine d'autres molécules sont en phase d'essais cliniques. Au regard du nombre de molécules découvertes, ça peut paraître faible, mais quand on sait qu'en recherche pharmaceutique, seule une molécule sur 10000 deviendra un médicament et qu'il faut en moyenne une douzaine d'années entre la découverte de la molécule et sa mise sur le marché, le bilan est finalement très satisfaisant.

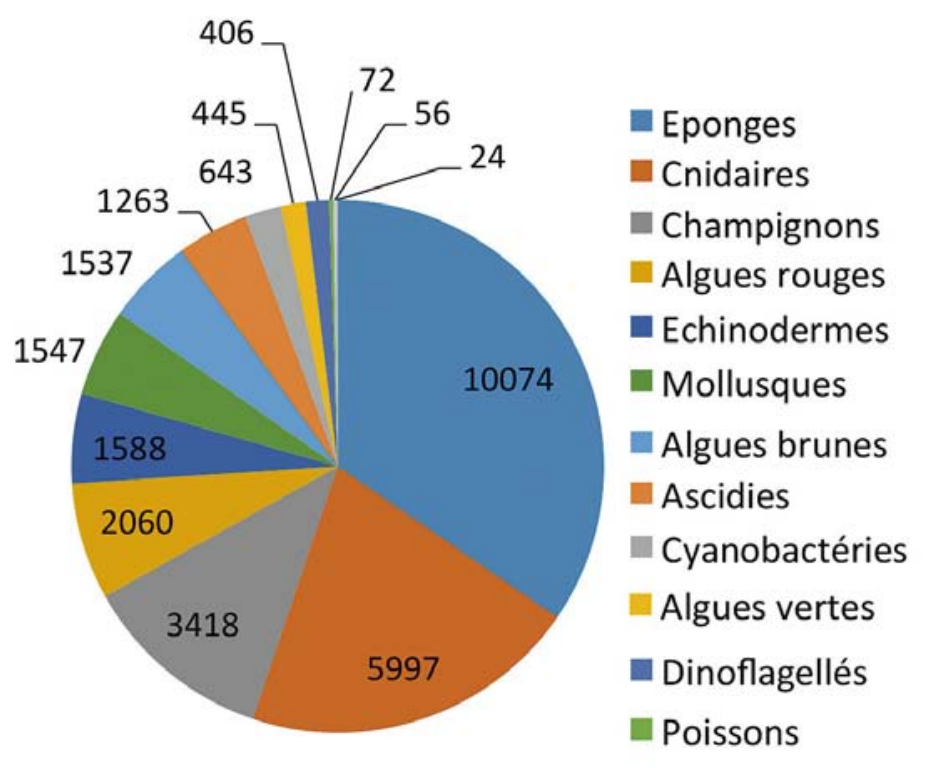

Figure 3 : Répartition des molécules découvertes par embranchement.@ IRD/S. Petek 


\title{
Encadré 26 \\ Cantharella, une base de données pour capitaliser les substances naturelles
}

\author{
Sylvain Petek et Adrien Cheype
}

Dès lors que l'on souhaite étudier les substances naturelles ${ }^{24}$, quelle qu'en soit l'origine, on se retrouve très rapidement confronté à gérer un important volume de données, de différentes natures et origines, concernant :

- les sites de prélèvement : pays, localité, point GPS, inventaire des espèces, information sur le milieu/biotope, etc. ;

- l'identification des organismes (taxonomie) échantillonnés, leur abondance, leurs caractéristiques physiques, génétiques, etc. ;

- les protocoles chimiques mis en œuvre, les molécules identifiées; - les tests d'activités biologiques réalisés.

De plus, ces travaux sont par nature pluridisciplinaires et nécessitent l'intervention de nombreux collaborateurs spécialisés, souvent géographiquement éloignés.

Au final, seule une partie de ces informations figureront dans des articles et seront ainsi pérennisées. À la longue, il y a par conséquent un risque que les données « brutes » deviennent inexploitables ou disparaissent alors qu'elles peuvent constituer un historique et ainsi servir de base à de nouveaux projets.

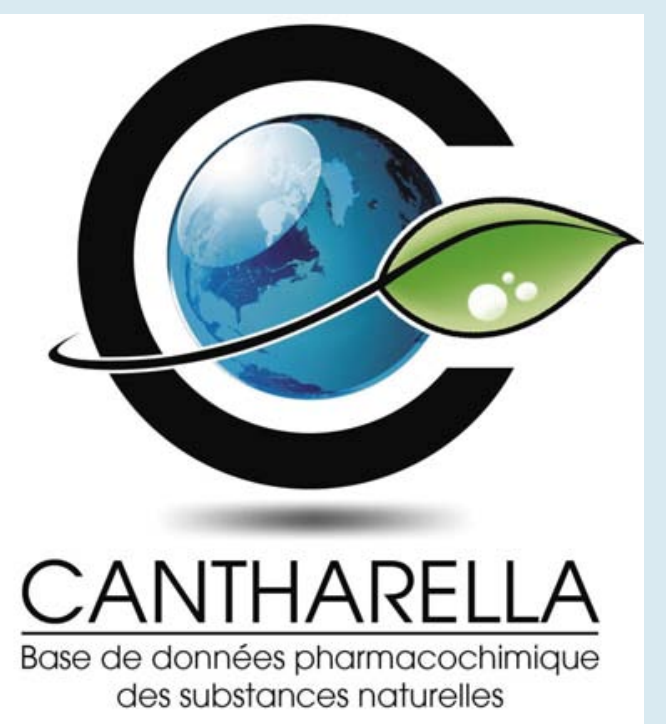

Pour finir, au fil du temps, l'hétérogénéité des supports papier ou informatiques, des formats de fichier, ou dans la manière de structurer les données compliquent très rapidement la réutilisation des informations.

Cantharella (PETEK et CHEYPE, s.d.), une base de données dédiée à l'étude des substances naturelles a été conçue pour apporter une solution aux différentes problématiques posées par ces données, en termes:

- d'accès et de partage entre collaborateurs ou de restitution auprès des collectivités ;

- d'analyse et d'actualisation;

- de pérennisation sur le long terme.

Cet outil de travail collaboratif, accessible en ligne, développé à partir de briques logicielles « libres », permet, au travers de quatre modules spécialisés, de capitaliser l'ensemble des données allant de la récolte des organismes en passant par les tests biologiques jusqu'aux molécules identifiées.

Par ailleurs, dans le cadre de la démarche APA (Accès et partage des avantages), l'outil permet également d'effectuer une restitution des travaux auprès des collectivités prospectées, et ainsi d'avoir un suivi des études menées sur leur biodiversité.

Pour les universités ou les laboratoires qui souhaiteraient l'utiliser, le logiciel est mis à disposition gratuitement sous licence libre .

Concernant l'instance de l'IRD, opérationnelle depuis 2010, elle capitalise les données de nombreux projets essentiellement dans le Pacifique (environ 700 stations de prélèvement, environ 950 espèces, plus de 700 résultats de tests biologiques).

\section{Référence bibliographique}

PETEK S., CHEYPE A. Cantharella : Base de données pharmacochimique des substances naturelles: (cantharella.ird.nc).

${ }^{24}$ Remerciements : financements IRD pour les programmes Spirales (DDUNI, Direction pour le développement des usages numériques innovants, IRD) et Maturation de projets innovants (SIV). 
La valorisation des substances naturelles d'origine marine se heurte souvent à certaines contraintes liées à l'accès, la disponibilité et l'impact environnemental d'une exploitation industrielle de la ressource. Par conséquent, leur utilisation passera souvent par la mise $\mathrm{au}$ point de leur synthèse par voies chimiques et/ou biotechnologiques, l'obtention de dérivés plus simples, où l'on cherchera à ne garder que les fragments de la molécule nécessaires à l'activité, et par l'ajout d'autres fonctions qui lui conféreront des qualités complémentaires, en termes d'assimilation, de stabilité, ou de ciblage, ce que l'on appelle de la pharmacomodulation. Ainsi, ces substances naturelles marines seront plutôt une source d'inspiration pour la découverte de structures chimiques bio-actives originales, qu'une ressource en tant que telle.

\section{Les explorations de la chimiodiversité marine néo-calédonienne}

En Nouvelle-Calédonie, les premiers travaux de bioprospection marine pour la recherche de nouvelles molécules d'intérêt thérapeutique, ont débuté en 1976 à l'Orstom avec le programme Snom (Substances naturelles d'origine marine), sous l'impulsion de Pierre Potier (Institut de chimie des substances naturelles, CNRS), impliquant des chercheurs et des plongeurs scientifiques de l'IRD (ex-Orstom) et l'expertise taxonomique du MNHN. Depuis, de nombreuses explorations et études se sont poursuivies jusqu'à maintenant, au travers de différents programmes et grâce au concours de diverses collaborations pluridisciplinaires françaises et internationales (fig. 4).

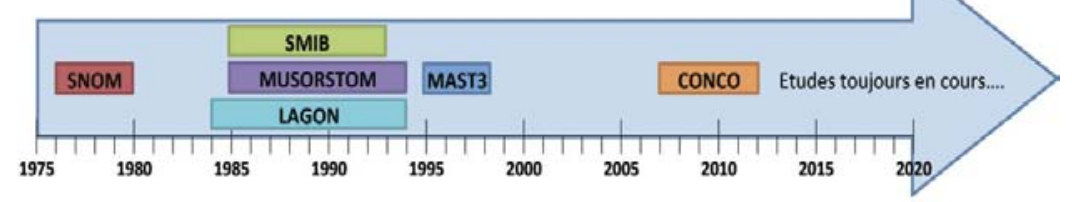

Figure 4 : Principaux programmes de bioprospection et de recherche à visées thérapeutiques. @ IRD/S. Petek
Une grande variété de zones géographiques et de milieux et d'habitats a été explorée, de la Grande Terre, en passant par les îles Loyautés, l'île des Pins, les atolls et récifs éloignés (Entrecasteaux et Chesterfield), des lagons aux pentes externes de la barrière récifale, jusqu'aux monts sous-marins (chap. 2).

À l'heure actuelle, tous embranchements confondus, des microaux macro-organismes, quelque 9372 espèces ont été inventoriées, sur lesquelles des analyses biologiques et/ou des tests d'activité ont été réalisés. Des études pharmacochimiques approfondies sur une cinquantaine d'organismes ont permis d'isoler et d'identifier plus de 350 nouvelles molécules bioactives aux structures originales, dont plus d'une centaine provenant d'éponges.

\section{Quelques exemples emblématiques}

La girolline, cette petite molécule extraite de l'éponge Cymbastella cantharella vivant sur la pente externe de la barrière récifale sud, s'est avérée particulièrement active in vitro et in vivo sur les cellules cancéreuses et tumorales. Sans toxicité majeure sur les souris et les chiens, les études cliniques ont pu être conduites jusqu'en phase II avec le groupe pharmaceutique Rhône-Poulenc Rorer (désormais Sanofi-Aventis), avant d'être malheureusement interrompues suite à des effets secondaires sur le système cardiovasculaire. La girolline a par ailleurs démontré des activités antiplasmodiales intéressantes in vitro sur quatre souches de Plasmodium falciparum, notamment en synergie avec la chloroquine, ouvrant ainsi la voie à de nouvelles stratégies antipaludiques.

L'arsenicin A produite par Echinochalina bargibanti, une éponge du lagon est de la Grande Terre, se distingue, d'une part, par sa formule polycyclique imbriquée, comportant quatre atomes d'arsenic, très originale pour une molécule organique d'origine naturelle et, d'autre part, par ses propriétés bactéricides, fongicides et antiprolifératives sur des lignées de cellules de leucémie aiguë promyélocytaire, contre les adénocarcinomes pancréatiques et les glioblastomes.

Le crinoïde, Gymnocrinus richeri, cet échinoderme, véritable fossile vivant, échantillonné par 520 m de fond sur la ride de Norfolk, 


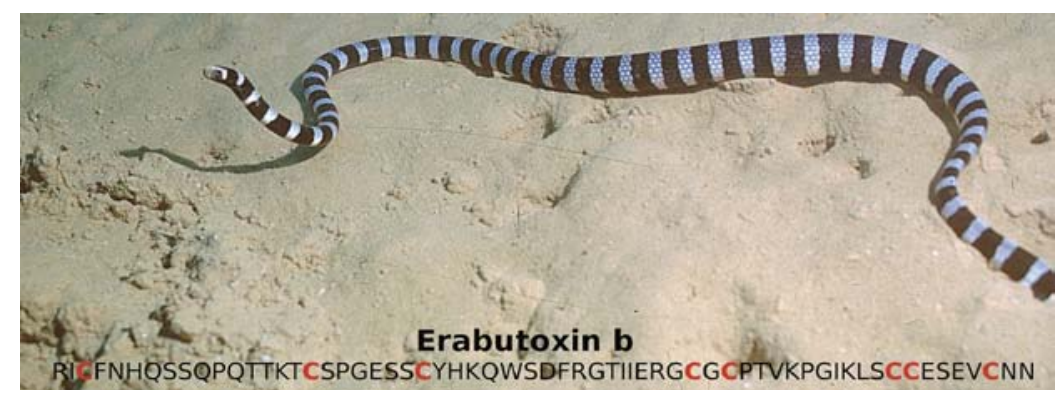

Laticauda Laticaudata et la formule de l'erabutoxin b. @ IRD/P. Laboute

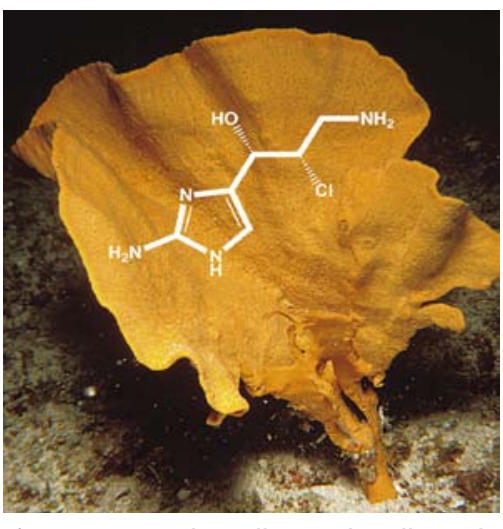

L'éponge Cymbastella cantharella et la formule de la girolline. ( IRD/J.-L. Menou

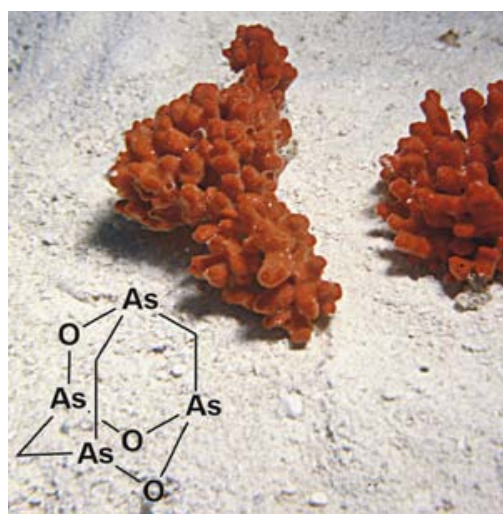

L'éponge Echinochalina bargibanti et la formule de l'arsenicin A. @ IRD/G.Bargibant

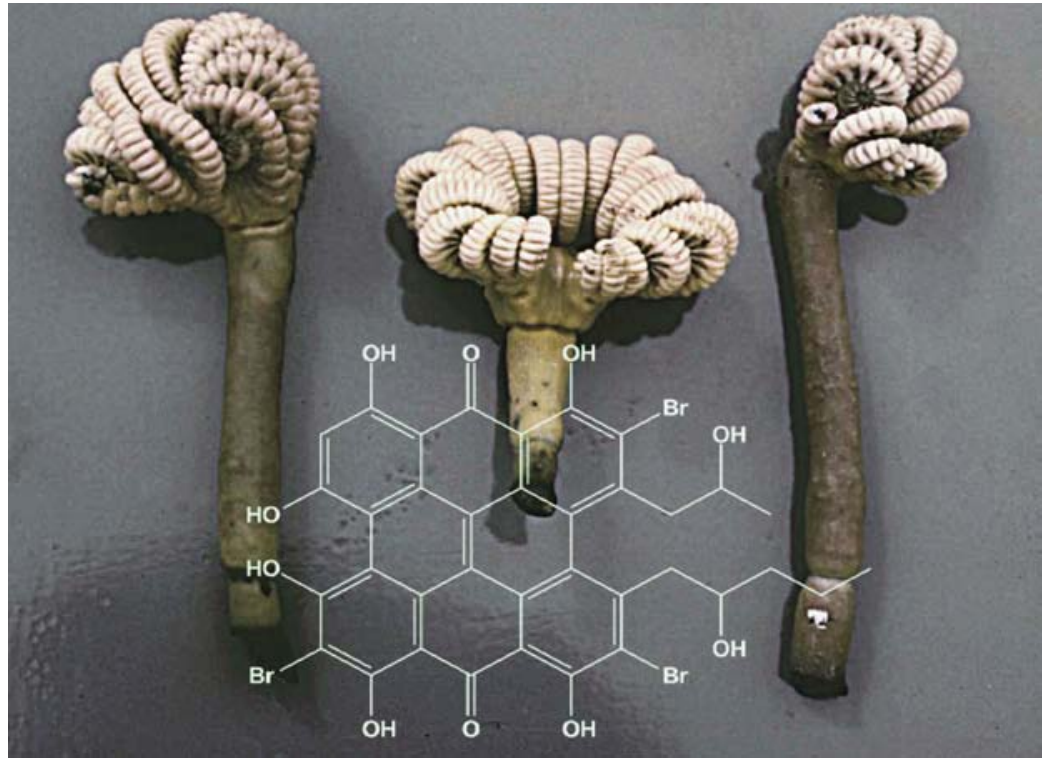

Le crinoïde Gymnocrinus richeri et la formule du gymnochrome B. @ IRD/P. Laboute a offert une nouvelle famille de pigments, les gymnochromes aux propriétés antivirales, anti-VIH et anti-dengue.

Enfin, les cônes, ces mollusques venimeux qui paralysent leurs proies en leur injectant un mélange de peptides neurotoxiques, sont particulièrement prometteurs pour la recherche d'analgésiques puissants, à l'instar du Prialt ${ }^{\oplus}$ (1 000 fois plus puissant que la morphine). Conus consors des Chesterfields par exemple, fait l'objet de tout un programme pour étudier son génome et la composition de son venin.

Les très emblématiques « tricots rayés », Laticauda colubrina et Laticauda laticaudata, de la même famille que les cobras ou les mambas (Elapidae) produisent un venin particulièrement puissant dont le polypeptide erabutoxin b, l'un de ses principaux composants, a été étudié pour ses propriétés sur le système neurologique.

Après toutes ces années, si certains pans de la biodiversité marine néo-calédonienne ont été particulièrement étudiés du point de vue pharmacochimique (éponges, cnidaires, ascidies...) du fait de leur potentiel en molécules bioactives d'intérêt, d'autres restent à explorer, à redécouvrir ou à valoriser à l'aune de nouvelles techniques biologiques et chimiques. Ainsi, les développements biotechnologiques autour des micro-organismes sont très prometteurs dans différents domaines, à l'instar des microalgues pour la production de biocarburants ou de composés à haute valeur ajoutée pour les cosmétiques ou la neutraceutique.

\section{Références bibliographiques}

CRAGG G.M., NEWMAN D.J., 2013 Natural products: A continuing source of novel drug leads. Biochimica et Biophysica Acta (BBA), General Subjects, $1830: 3670-3695$ et références citées.

HOSSAERT-MCKEY M., BAGNÈRES-URBANY A.G. (éd.), 2012 Écologie chimique : le langage de la nature. Paris, Cherche Midi, CNRS, 191 p.

KORNPROBST J.M., 2005 Substances naturelles d'origine marine. Chimiodiversité, pharmacodiversité, biotechnologie. Paris : Éditions Tec \& Doc, Lavoisier, $1830 \mathrm{p}$.

Les entreprises du médicament: http://www.leem.org (consulté le 16/10/2017). MarinLit: A database of the marine natural products literature : http://pubs.rsc.org/marinlit/ (consulté le 16/10/2017).

MOTUHI S.-E. et al., 2016 Marine Natural Products from New Caledonia. A Review. Marine Drugs, 14 (58). doi : 10.3390/md14030058 et références citées. 


\section{Chapitre 33 \\ Le lagon, un patrimoine naturel et un espace de loisirs}

Charles Gonson, Jocelyne Ferraris, Dominique Pelletier et Isabelle Jollit

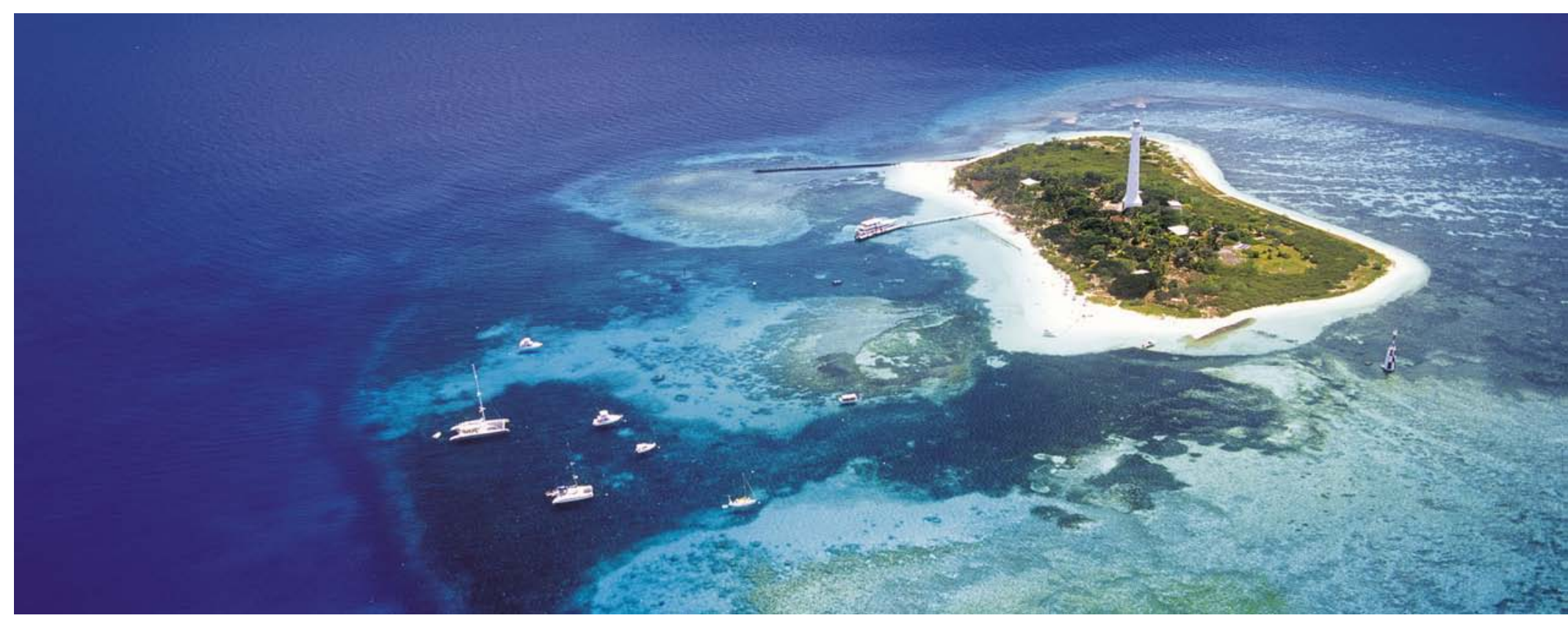

Ilot Amédée, haut lieu de tourisme lagonaire. @ P.-A. Pantz

\section{Les usages récréatifs, un enjeu de gestion des récifs coralliens}

On appelle « usagers récréatifs » un ensemble de personnes pratiquant une activité pour leur loisir, sans but de subsistance ou lucratif. Ces activités se caractérisent par une diversité de pratiques et, sous l'influence de la croissance démographique et de l'essor du tourisme, leur nombre dans les espaces naturels augmente fortement. Comme c'est le cas en Nouvelle-Calédonie, dans l'un des plus grands lagons du monde inscrit au patrimoine mondial de l'Unesco en 2008, les usages récréatifs s'intensifient et se diversifient dans tous les espaces côtiers.
Parallèlement, elles affectent les écosystèmes coralliens par ailleurs menacés par le changement global. Il apparaît donc indispensable de considérer les usages récréatifs dans le développement durable des zones côtières et tout particulièrement en milieu insulaire.

Les études scientifiques se sont véritablement intéressées à la diversité des activités de loisirs en milieu marin et côtier (plongée, plaisance, sports nautiques) depuis les années 2000. Ces recherches ont été motivées par la complexité grandissante des relations entre une société prolifique, dépendante d'une nature, bien commun épuisable, particulièrement fragile en milieu corallien. La recherche s'intéresse alors à mieux comprendre les socio-écosystèmes pour accompagner la gestion de ces espaces, notamment par la mise en 
place d'Aires marines protégées (AMP). Au sein de ces AMP, qui ont des objectifs aussi divers que la conservation de la biodiversité et le maintien d'usages durables, les activités de loisir sont largement pratiquées. Il est donc essentiel de mieux les connaître afin d'assurer la protection des écosystèmes et des ressources qui en dépendent, mais aussi pour anticiper l'émergence de conflits pour l'occupation de l'espace et l'exploitation des ressources.

Malheureusement, les usagers récréatifs sont encore mal connus du fait de la difficulté de disposer de méthodologies et outils adéquats pour obtenir des informations fiables, dans le temps, sur leur nombre, leur localisation ou encore leurs pratiques. Les recherches menées en Nouvelle-Calédonie ont ainsi permis de développer des méthodes d'évaluation des pressions et impacts de ces usages adaptées au contexte corallien et ainsi d'acquérir des connaissances utiles pour la préservation des écosystèmes lagonaires gérés par un réseau d'AMP.

\section{Les usages récréatifs, objet d'étude pour le développement durable}

La mise en valeur du patrimoine naturel des écosystèmes coralliens et leur conservation sont un véritable enjeu de développement durable pour la Nouvelle-Calédonie. L'augmentation de la

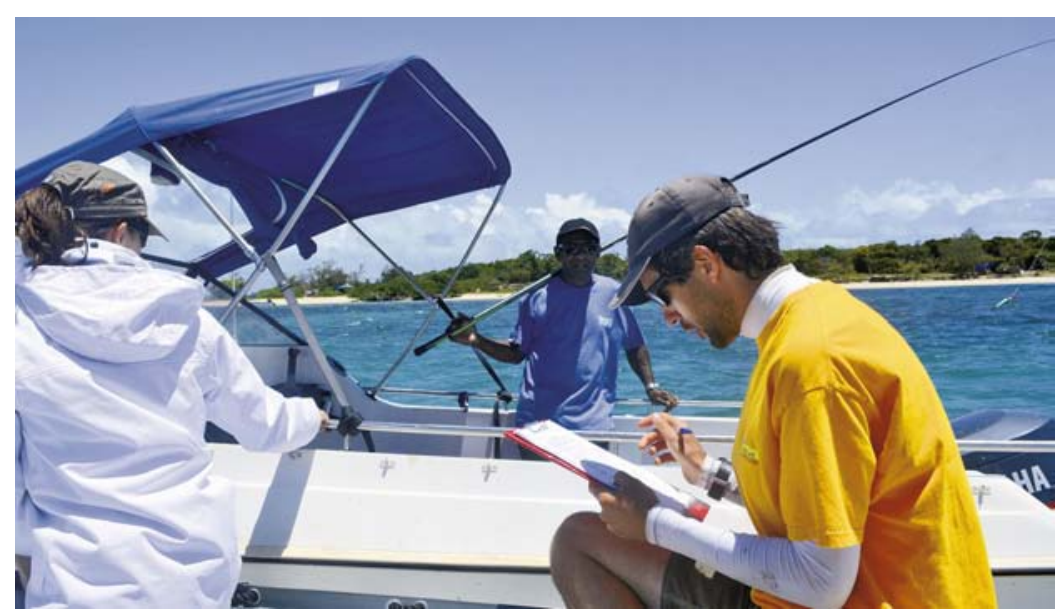

Enquête auprès d'un pêcheur récréatif à l'îlot Pandanus en 2014. @ Ifremer/C. Gonson démographie dans un premier temps, puis l'essor du nautisme et du tourisme amènent alors à considérer les activités récréatives comme une menace pour la gestion durable des ressources halieutiques et la conservation des récifs. Malheureusement, ces usages sont mal connus et difficilement quantifiables du fait de leur caractère diffus et informel. C'est pourquoi, depuis les années 1990, des programmes et projets de recherche impliquent acteurs locaux, gestionnaires de l'environnement néo-calédonien et scientifiques.

Les études scientifiques se sont d'abord attachées à mieux évaluer les pressions et impacts des petites pêcheries côtières (commerciales, de subsistance, récréatives). En 2005, les captures des pêcheurs plaisanciers à bord d'embarcations motorisées dans le lagon sudouest sont estimées à plus de 1100 t/an. Composées principalement $d$ 'espèces de poissons et de mollusques, ces captures se concentrent sur les récifs proches des centres urbains (Nouméa et Koné) ainsi que dans les lagons nord et sud de la Grande Terre. Les résultats obtenus mettent en exergue l'importance d'étudier la pêche récréative.

Par la suite, en raison des enjeux et coûts liés à la gestion complexe des usages lagonaires, le fort développement des autres activités, telles que la plaisance, la plongée ou les excursions sur les îlots n'a pas manqué d'interpeller les pouvoirs publics et les organismes de recherche. Avec le renforcement et l'acquisition des connaissances sur les usages récréatifs en milieu corallien, la complexité des

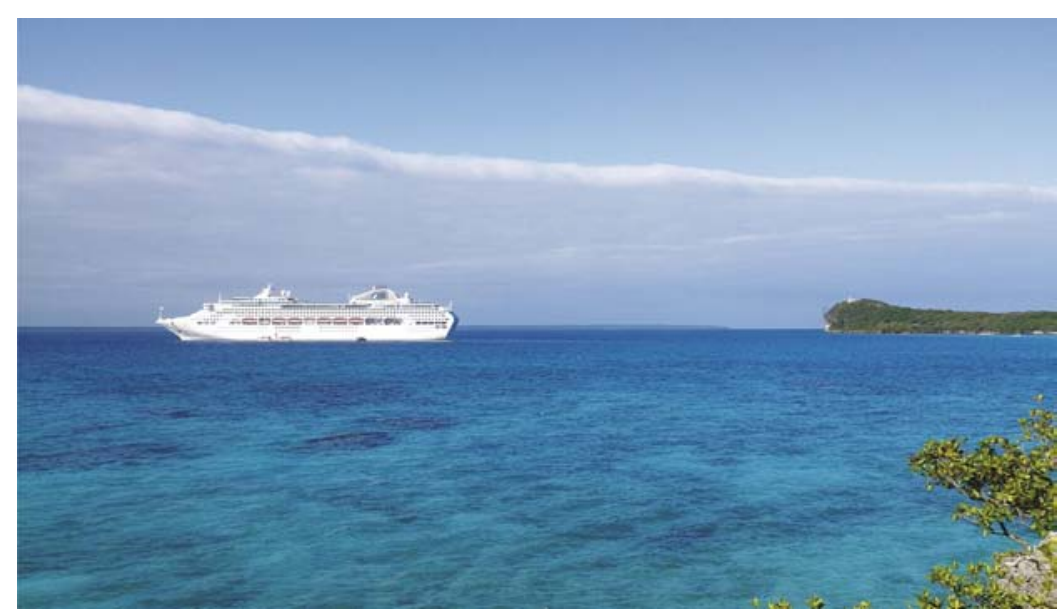

Paquebot au mouillage à Lifou. @ Ifremer/D. Pelletier 


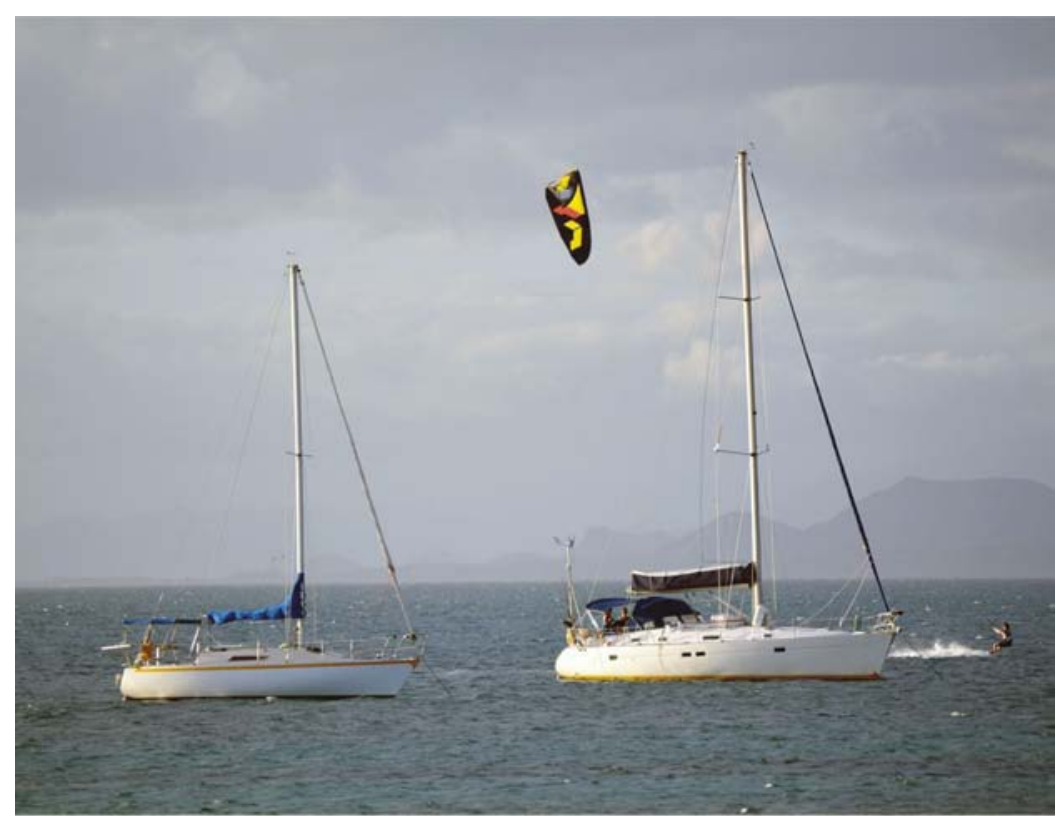

Cohabitation conflictuelle entre usagers dans la zone de mouillage d'un îlot. (c) Ifremer/C. Gonson

systèmes côtiers étudiés (diversité des activités récréatives, des écosystèmes et de leurs relations) est mieux intégrée dans les projets de recherche. Le concept de socio-écosystème s'impose alors de plus en plus avec le développement d'approches pluridisciplinaires et spatialement explicites.

Les activités récréatives liées aux récifs coralliens sont maintenant mieux connues. Ceci a permis de favoriser l'efficacité des stratégies de gestion mises en œuvre pour une diversité d'objectifs comme la gestion des ressources, la conservation de la biodiversité et la durabilité des usages. Dans le lagon néo-calédonien, notamment au sein des AMP et sites inscrits au patrimoine mondial de l'Unesco, de nombreuses recherches et mesures de gestion (par exemple la réglementation, la sensibilisation) ont ainsi concerné les usages récréatifs. Néanmoins le recul dans le temps sur la connaissance de ces usages est limité. De plus, les modifications rapides de ces usages (par exemple la diversification des activités, l'essor du tourisme), concomitantes aux changements globaux, menacent le développement durable de l'espace maritime néo-calédonien.

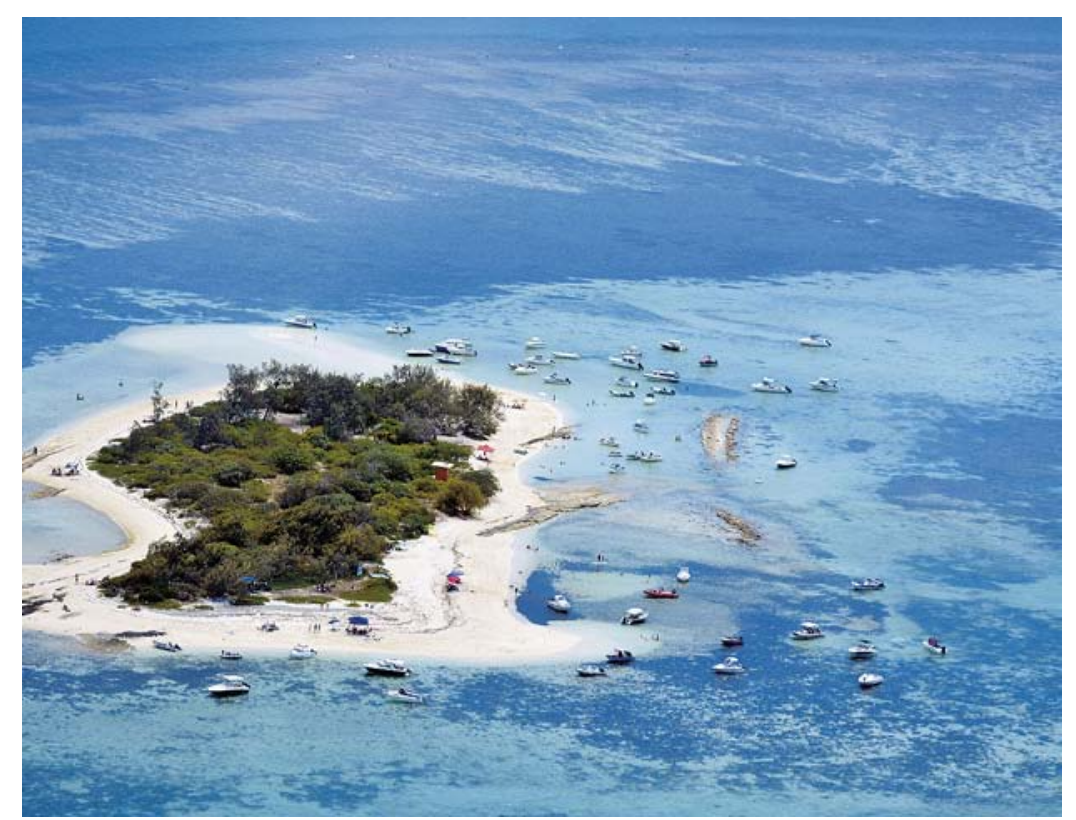

Îlot Larégnère sous la pression d'une forte fréquentation. @ Ifremer/C. Gonson

\section{Le lagon sous surveillance, une explosion du nombre de bateaux}

Le lagon sud-ouest, proche de Nouméa, concentre à la fois une population importante et des infrastructures nautiques nombreuses. Mettre en valeur ce patrimoine naturel lié aux récifs coralliens tout en protégeant les écosystèmes proches du centre urbain représente donc un enjeu de gestion fort pour la Nouvelle-Calédonie. C'est dans cette zone que des études associant chercheurs et gestionnaires de l'environnement ont permis de mettre au point des protocoles d'observation et d'indicateurs pertinents pour le suivi des usages, de leurs impacts et concernant les questions de gouvernance.

Entre 2005 et 2013, près de 700 sorties sur le terrain et plus de 2000 questionnaires ont été réalisés afin d'estimer la fréquentation et la répartition spatiale et temporelle des usagers récréatifs, ainsi que de caractériser leurs pratiques et opinions vis-à-vis de la gestion et de l'état écologique des écosystèmes. Aujourd'hui, les méthodes 
d'observation et de production d'indicateurs ont été optimisées. Pleinement opérationnelles, elles peuvent être mises en œuvre par les gestionnaires de l'environnement en Nouvelle-Calédonie comme les provinces et les comités de gestion locaux des sites inscrits au patrimoine mondial de l'Unesco.

Au cours de cette période de moins de 10 ans (2005 à 2013), le nombre de bateaux fréquentant les récifs et îlots de Nouméa a plus que doublé. Il s'agit essentiellement de résidents de l'agglomération du Grand Nouméa avec plus de 10 nouveaux bateaux chaque semaine qui se sont ajoutés à la flotte plaisancière. Par ailleurs la fréquentation accrue sur les îlots a été facilitée par le développement de l'activité de taxi-boats. À titre d'exemple, sur l'année 2013, on estime que plus de 10000 bateaux et 80000 personnes se sont rendus à l'îlot Maître, îlot très proche de Nouméa.

Les activités pratiquées sont diverses et ont un effet sur l'occupation de l'espace côtier par les usagers en lien avec les caractéristiques réglementaires, naturelles et sociales des espaces fréquentés. Ainsi, les espaces fortement aménagés (par exemple l'îlot Maître) canalisent une fréquentation importante, où se pratiquent des activités spécifiques (comme le kitesurf). Les espaces naturels protégés, visant à conserver les espèces et habitats naturels, et bénéficiant $d$ 'aménagements simples mais attractifs comme des corps-morts ou des farés, sont aussi plébiscités du fait de l'attente d'une bonne qualité environnementale (par exemple l'îlot Signal) À l'inverse, dans les espaces non réglementés et souvent plus éloignés, pratiquer la pêche et profiter d'une tranquillité associée à une faible fréquentation sont des activités recherchées.

À partir des connaissances acquises, un modèle de simulation visant à favoriser une gestion adaptative des espaces lagonaires a permis d'évaluer l'effet de mesures de gestion sur l'évolution de la biodiversité et des usages. Les résultats montrent que l'aménagement d'espaces récréatifs (comme le parking ou le balisage du plan d'eau) dans des zones littorales moins vulnérables face aux pressions associées aux activités de loisir, comme les plages de sable, serait une solution qui permettrait, en drainant une partie des usagers du lagon, de limiter les impacts sur les récifs et îlots.

\section{Des usages récréatifs durables pour un lagon sous pression}

La durabilité des écosystèmes coralliens et des usages récréatifs qui y sont pratiqués dépend de plusieurs facteurs, dont ceux de nature écologique et sociale. Écologique, car les écosystèmes subissent des impacts qui dépendent de leur vulnérabilité vis-à-vis des activités pratiquées et du comportement des usagers. Social, car la durabilité des usages concerne aussi la satisfaction que les personnes retirent de leur expérience du lagon. Cette satisfaction dépend notamment de leur capacité à tolérer la présence d'autres personnes en nombre sur un même espace afin de pratiquer leurs activités.

La distribution des usagers se répartit de manière de plus en plus hétérogène selon les zones et en fonction de la période de l'année ou de la semaine. Les pics de fréquentation sont dorénavant plus fréquents, les pressions associées aussi plus intenses impactent des espaces très localisés comme les îlots et récifs les plus proches des accès à la mer. Ces pressions résultent en des impacts écologiques qui altèrent l'équilibre des écosystèmes, par la raréfaction, voire la disparition des espèces et habitats les plus sensibles et la modification des peuplements de poissons et d'invertébrés. Or, la qualité écologique des écosystèmes récifaux participe au maintien des activités de loisirs, comme cela est le cas pour la plongée sous-marine ou la jouissance des paysages récifo-lagonaires. Les usagers sont d'ailleurs de plus en plus conscients de l'impact de l'augmentation des activités sur l'intégrité écologique des milieux fréquentés. Cette prise de conscience favorise la promotion de pratiques respectueuses de l'environnement et ainsi la pérennité des socio-écosystèmes récifaux. Malheureusement la biodiversité des récifs coralliens est particulièrement vulnérable à la simple présence humaine. L'état de santé des récifs coralliens est donc menacé par l'augmentation continuelle du nombre d'usagers récréatifs dans ces espaces.

Au-delà de la durabilité écologique, lorsque la fréquentation est intense, des conflits peuvent se produire, soit au sein d'une seule activité comme le « farniente » sur les plages très fréquentées, soit du fait de l'incompatibilité ressentie entre deux pratiques, en général, 
entre pêche et sports nautiques, ou entre plaisance et baignade, et jet-skis. Les pouvoirs publics jouent alors un rôle important afin de garantir la cohabitation des usagers pour qui la surfréquentation des sites visités est un facteur important de dérangement. Leurs actions peuvent se traduire par exemple par une répartition des différentes activités dans le temps et l'espace, ou bien par le fait de garantir la possibilité d'une expérience de « nature sauvage » malgré l'augmentation de la fréquentation.

\section{Les recherches à venir, liées aux enjeux de développement}

Dans les zones où il a pu être évalué en Nouvelle-Calédonie, le niveau des pressions dues aux usages récréatifs peut sembler relativement faible en comparaison avec d'autres régions de la planète. Il s'inscrit cependant dans un contexte démographique et touristique très évolutif et dans des écosystèmes particulièrement fragiles et soumis aux conséquences du changement climatique (cyclones plus intenses, réchauffement des eaux, blanchissement corallien...). Les menaces qui pèsent sur les écosystèmes coralliens et sur la durabilité des usages qui y sont pratiqués sont donc réelles et vont crescendo. Malheureusement, ces menaces sont mal évaluées du fait de la complexité d'estimer les effets du cumul de toutes ces pressions sur l'état et le fonctionnement des écosystèmes. C'est notamment le cas avec les effets liés aux changements climatiques ou dans les lagons faisant face aux zones anthropisées où l'accroissement des pressions associées aux activités de loisir est concomitant à celui des pressions d'origine terrestre.

Par ailleurs, il conviendrait de suivre les usages récréatifs dans des zones où de forts développements démographiques ou touristiques sont en cours ou sont attendus et ainsi mieux comprendre leurs impacts et leur évolution. Ceci est le cas à Koné avec le développement d'un bassin économique ou encore sur les îles Loyauté où le tourisme de croisière est en plein essor. L'évaluation de l'état de santé des écosystèmes doit être superposée à celle portant sur les activités afin d'identifier les zones les plus vulnérables. Il s'agira alors de déterminer des limites aux pratiques en fonction des vulnérabilités. Il faut aussi mieux connaître la nature et les motivations des usagers afin d'anticiper l'évolution de leurs comportements suivant la mise en place de mesures de gestion pouvant modifier leurs pratiques (par exemple le déplacement de l'effort de pêche hors des AMP).

Mieux comprendre les socio-écosystèmes lagonaires implique de raisonner à une échelle pertinente. En Nouvelle-Calédonie, de par la mobilité des usagers, leurs interactions, la connectivité des écosystèmes mais aussi la diversité des structures en charge de la gestion de l'environnement, c'est celle du territoire néo-calédonien. À cette échelle, exploiter les connaissances acquises dans une approche pluridisciplinaire mêlant sciences de l'environnement et sciences humaines et sociales, diffusées vers les décideurs et la société civile, devrait permettre de mieux anticiper les conséquences environnementales et économiques des politiques de développement.

\section{Référence bibliographiques}

JUNCKER M., 2006 Introduction à l'étude des pressions et des menaces sur les écosystèmes littoraux de Nouvelle-Calédonie. Rapport CRISP, 68 p. FERRARISJ., EMMANUELLI E., 2011 Guide pratique : Indicateurs d'évaluation et de suivi des écosystèmes coralliens. Rapport CRISP, IRD, 57p.http://www.spc.int/DigitalLibrary/Doc/FAME/Reports/CRISP/FR_2011_Ind icateurs_evaluation_suivi_systemes.pdf

GONSON C., 2017 Intégration des usages récréatifs et de la biodiversité marine pour la gestion et l'évaluation des espaces côtiers. Application aux Aires Marines Protégées de Nouvelle-Calédonie à partir de suivis de la fréquentation et la biodiversité et d'un modèle d'aide à la gestion.

Thèse de doctorat. Université Pierre et Marie Curie. 264 p. :

www.archimer.ifremer.fr/doc/00391/50261/50888.pdf

JOLLIT I., 2010 Spatialisation des activités humaines et aide à la décision pour une gestion durable des écosystèmes coralliens : la pêche plaisancière dans le lagon sud-ouest de la Nouvelle-Calédonie. Thèse de doctorat. Université de la Nouvelle-Calédonie, 588 p.

PELLETIER D. et al., 2011 Indicateurs de la Performance d'Aires Marines Protégées pour la gestion des écosystèmes côtiers, des ressources et de leurs usages (PAMPA). Rapport scientifique final du projet PAMPA. PAMPANWP1/Coord/5. 58 p. + Annexes et synthèse http://archimer.ifremer.fr/doc/00385/49601/ 



\title{
Partie 5
}

\section{Des espèces sensibles dans un espace fragile}

\section{Gestion, protection et conservation}

\author{
Coordination : Eric Vidal
}

Gérer, protéger ou conserver les récifs coralliens recouvre plusieurs réalités. S'agit-il de gérer un milieu, une ressource, un territoire ? Estce pour préserver une espèce rare ou menacée, ou maintenir des processus écologiques essentiels ? Est-ce plutôt pour garantir à tous de continuer à vivre et profiter des récifs, à y pêcher, à en admirer la vie marine ? Ou bien est-ce enfin pour sauvegarder les histoires et mythes qui y sont associés et participent à l'identité de chacun ? Les regards croisés de biologistes, d'anthropologues et de gestionnaires de l'environnement nous prouvent ici que gérer les récifs implique de considérer qu'il existe différents savoirs, différentes valeurs, différents usages, qu'il est essentiel de reconnaître, de concilier et de faire dialoguer afin de construire des règles partagées.

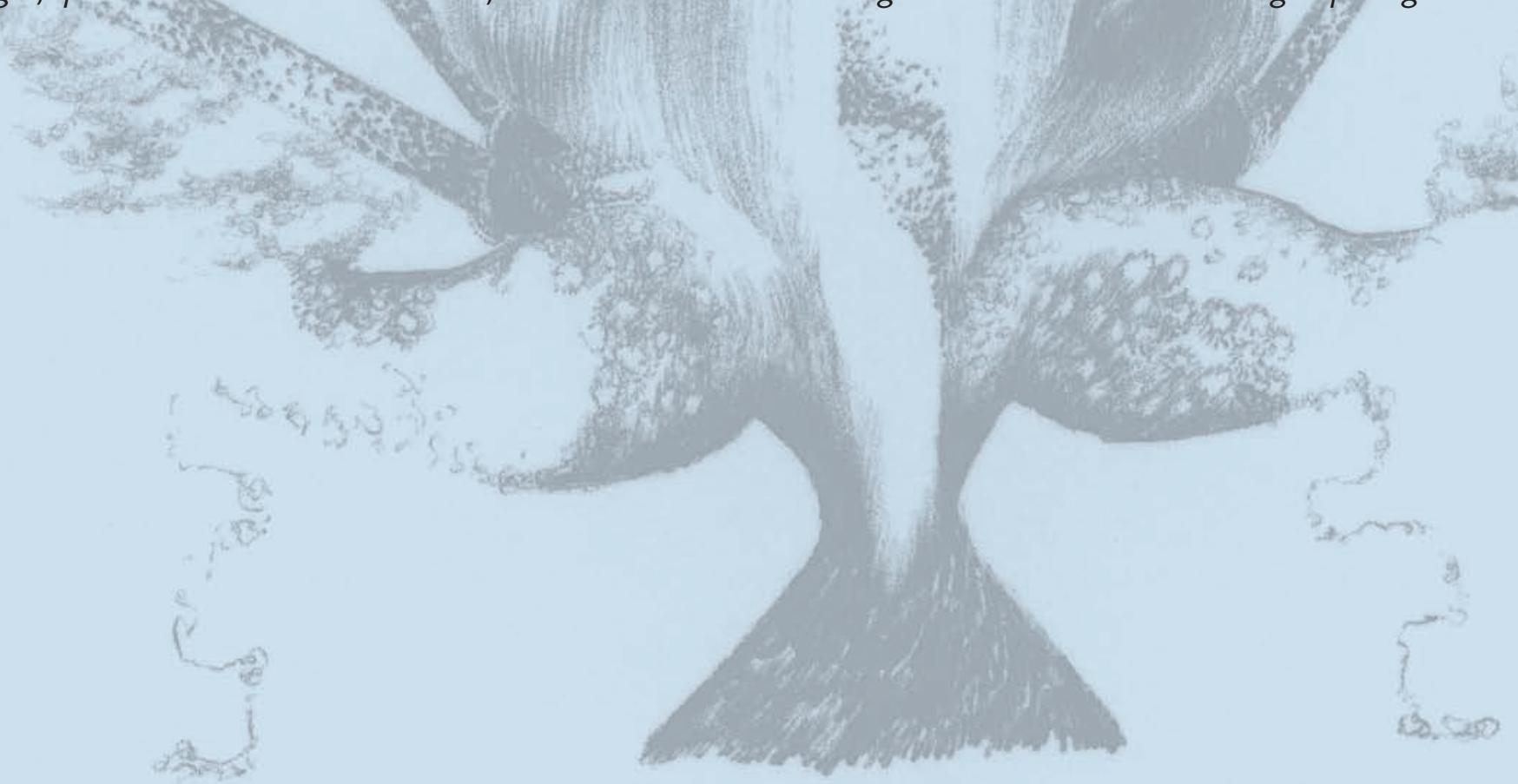





\title{
Gérer des espèces emblématiques et des écosystèmes récifaux
}

\author{
Catherine Sabinot et Éric Vidal
}

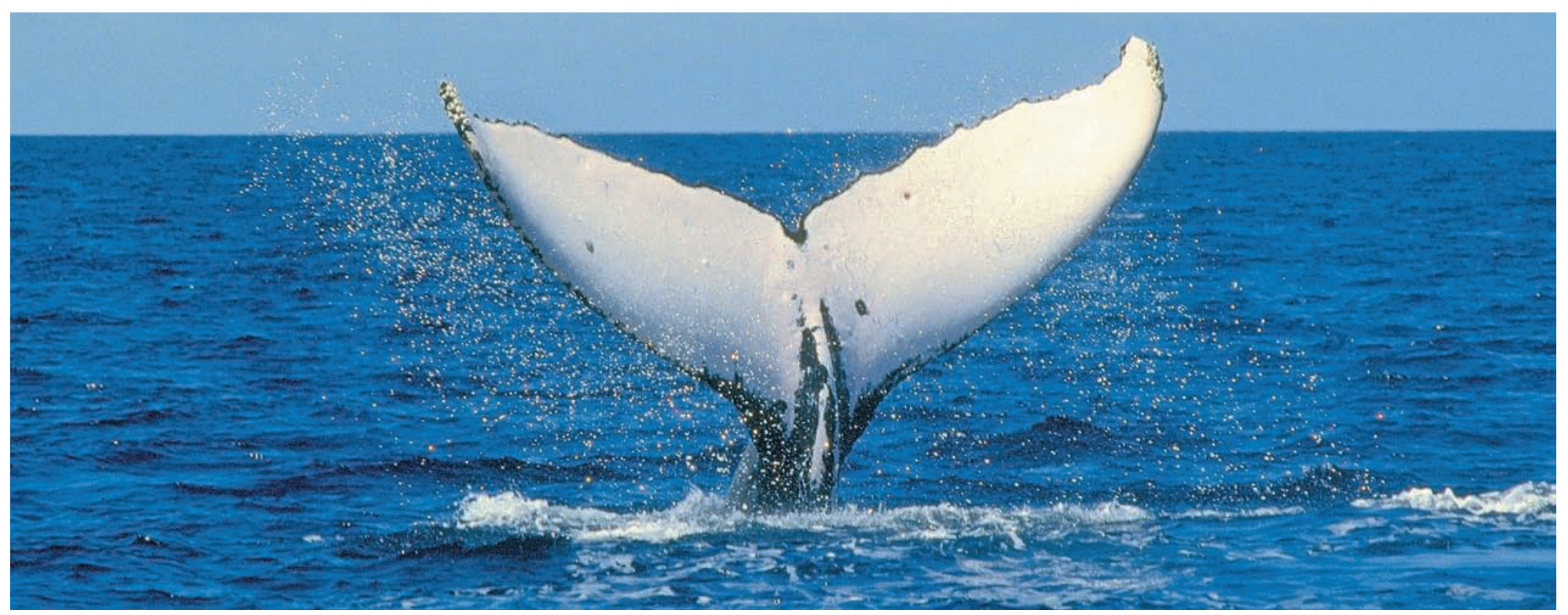

Caudale de baleine à bosse (Megaptera novaeangliae) appartenant à une population en danger qui vient se reproduire dans les eaux de Nouvelle-Calédonie. ๑ Opérations Cétacés/C. Garrigue

De nombreux biologistes travaillant en Nouvelle-Calédonie ont proposé de participer à ce livre sur les récifs coralliens de la Nouvelle-Calédonie en présentant la ou les espèces sur lesquelles ils concentrent leurs recherches et qui justifient selon eux des mesures de gestion particulières. Ces textes font donc la part belle à quelques espèces qui focalisent particulièrement l'attention des scientifiques en Nouvelle-Calédonie. Certains font état des connaissances que les scientifiques ont accumulées sur ces animaux et nous apprennent comment ces savoirs peuvent informer ou ont déjà orienté les politiques de gestion et de protection des récifs coralliens. Ces espèces ne sont pas uniquement étudiées parce qu'elles sont emblématiques ou charismatiques. Elles peuvent constituer des précieux bio-indicateurs de l'état de l'écosystème, ou encore représenter des espèces «sentinelles » qui sont en capacité de révéler très tôt des changements subtils dans l'environnement. D'autres jouent un rôle particulier dans l'écosystème et de nombreuses autres espèces et habitats en dépendent. Les oiseaux marins par exemple forment des colonies denses qui fertilisent les écosystèmes terrestres et marins avec leurs déjections. Enfin, certaines de ces espèces charismatiques peuvent être qualifiées d'espèces porte-drapeau («flagship species ») : le public et les usagers se révèlent plus enclins à accepter des restrictions et réglementations pour garantir les conditions de leur protection. Des recherches en sciences humaines et sociales visant entre autres à rendre compte du point de vue des Néo-Calédoniens à propos des animaux marins emblématiques ont débuté plus récemment. 
Quelques éléments sont partagés dans les encadrés : les espèces choisies par les biologistes s'y retrouvent ; toutefois, c'est l'importance sociale et symbolique qui domine pour justifier le caractère emblématique d'une espèce. Cela nous rappelle que tenir compte à la fois des valeurs sociales accordées aux espèces, des savoirs locaux et des savoirs scientifiques est toujours un enjeu majeur pour construire les politiques de gestion ajustées et respectées.
Dans les pages qui suivent, les auteurs privilégieront donc l'entrée « espèces », mais sans perdre de vue, comme le montrent d'autres chapitres de l'ouvrage, que les politiques de gestion et de conservation doivent aussi être pensées, structurées et organisées avec une vision écosystémique et spatialisée de l'espace lagonaire que l'on cherche à préserver. C'est aussi pour cela que cet ouvrage a accordé une place particulière aux collectivités en charge des différents types de réserves et d'aires protégées.

\section{Encadré 27 \\ Quelles sont les espèces emblématiques du récif pour les Néo-Calédoniens ? Camille Fossier, Estienne Rodary, Gilbert David, Espérance Cillauren, Ambre Piémontois et Catherine Sabinot}

Le programme Espam (Espèces emblématiques, acceptation sociale et durabilité des aires marines protégées) a commencé en 2017 un important travail sur les animaux marins emblématiques pour les Néo-Calédoniens. L'objectif est de connaître quelles sont les espèces les plus importantes pour les habitants de l'île en allant recueillir auprès des gens une liste de ces espèces et les raisons qui expliquent leurs choix. Un premier résultat marquant concerne la diversité des espèces évoquées : sur sept réunions publiques, 80 espèces ont été citées. Parmi elles, les tortues, les requins et le dugong sont les plus mentionnés, mais les espèces pêchées occupent également une place importante. Un second élément tout à fait remarquable touche aux raisons qui justifient que ces

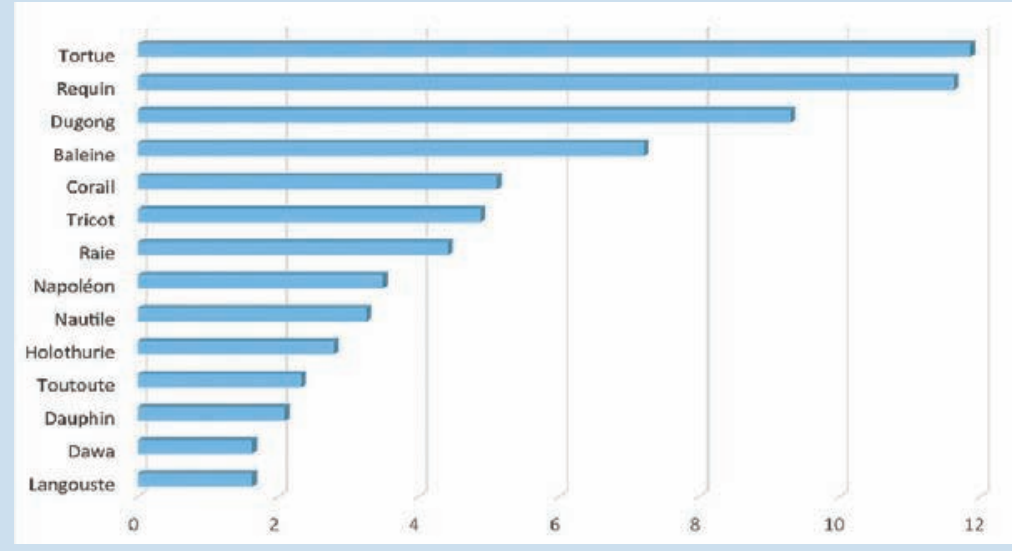

Figure 1 : Animaux cités par au moins $2 \%$ des personnes (nombre de mentions).

On notera l'importance du corail, qui apparaît pour son rôle de constructeur des récifs. Entretiens menés en 2017 par les auteurs animaux soient vus comme des emblèmes. L'importance sociale et symbolique des animaux (place dans la culture, totem kanak, etc.) est la raison la plus largement évoquée, suivie par le plaisir des observations directes. Les arguments écologiques sur l'importance d'une espèce, comme son rôle dans les écosystèmes ou les menaces qui pèsent sur elle arrivent en troisième position.

Ces résultats peuvent avoir un impact direct sur les politiques de conservation du lagon néo-calédonien, qui doivent prendre en compte les valeurs sociales attribuées aux espèces emblématiques. Des politiques uniquement basées sur des critères écologiques courent le risque de ne pas répondre aux attentes des habitants et, par là, de ne pas être efficaces dans la protection des récifs.

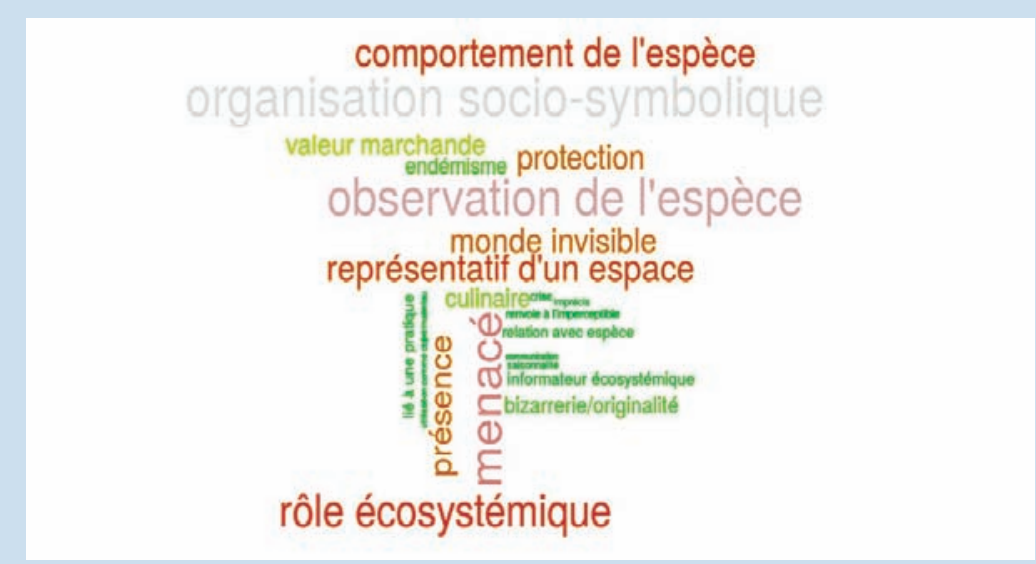

Figure 2 : Principales raisons évoquées pour justifier le classement en « espèce emblématique $\gg$ (taille des mots relative au nombre de mentions).des récifs. Entretiens menés en 2017 par les auteurs 


\title{
Chapitre 35 \\ Les bénitiers, une ressource à préserver
}

\author{
Cécile Fauvelot, Pascal Dumas et Josina Tiavouane
}

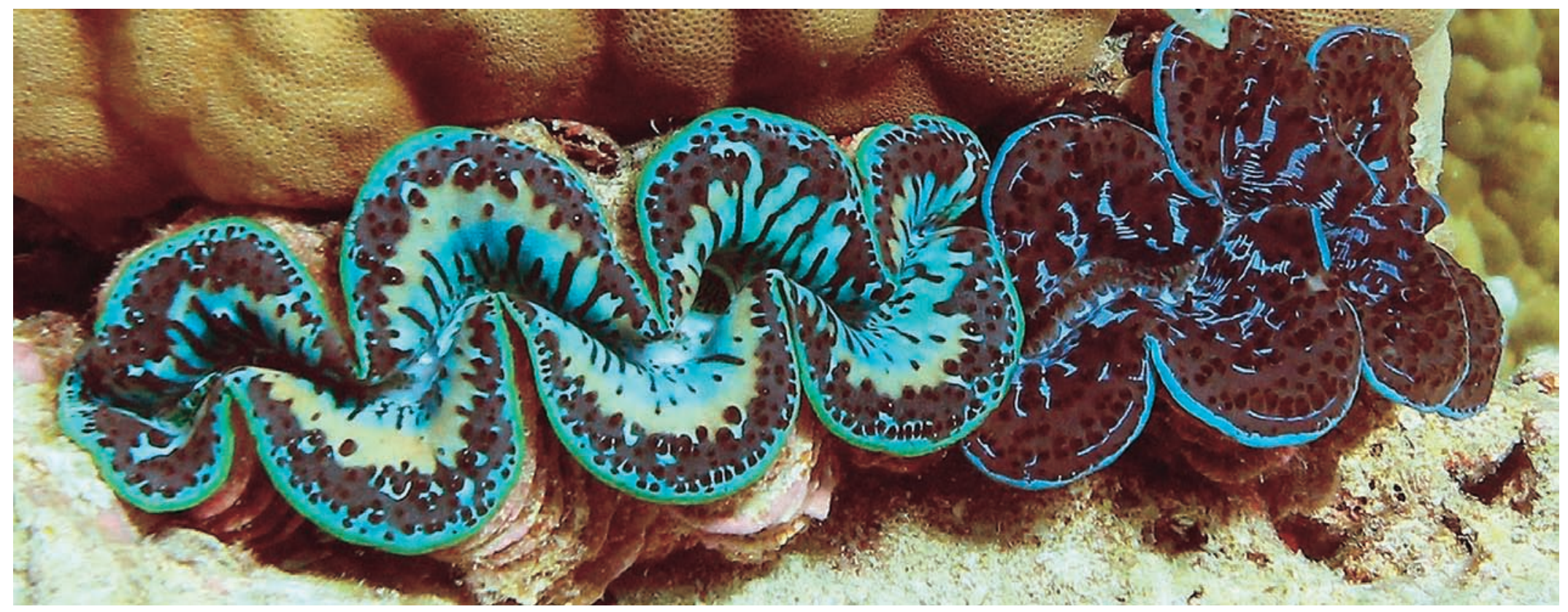

Tridacna maxima est la plus petite espèce de bénitier et la plus convoitée en aquariophilie en raison des couleurs éclatantes du manteau. @ IRD/S. Andréfouët

En Nouvelle-Calédonie, comme dans de nombreux pays du Pacifique, les bénitiers constituent une ressource très convoitée et cette exploitation peut menacer la disponibilité de cette ressource, pouvant même aller jusqu'à sa disparition. Il est à noter que Tridacna gigas, l'espèce la plus grande, autrefois présente sur les récifs de Nouvelle-Calédonie n'est maintenant plus visible qu'à l'état fossile. D'après les statistiques officielles de l'observatoire des pêches de Nouvelle-Calédonie, les volumes de captures annuels officiellement enregistrés entre 2000 et 2014 montrent des prélèvements importants, jusqu'à 9 t/an toutes espèces confondues. Depuis 2009, des mesures de protection ont été mises en place afin d'enrayer la diminution observée des stocks. Ainsi, la pêche des bénitiers est réglementée en province Nord (article 341-54 du Code de l'environnement) comme en province Sud (article 37 du Code de l'environnement): les prises sont limitées à deux bénitiers par bateau et par jour pour la pêche non professionnelle (plaisancière et vivrière) et à cinq bénitiers par bateau et par jour pour la pêche professionnelle. En province des îles, aucune loi sur la pêche de bénitier n'est appliquée, le droit coutumier kanak régulant seul cette activité. Cependant, l'absence de données statistiques au niveau spécifique empêche à l'heure actuelle toute tentative d'évaluation précise des prélèvements par espèce. C'est encore plus vrai dans le cas de la pêche de subsistance, non soumise à déclaration, et dont les impacts sur la ressource échappent à toute quantification. 


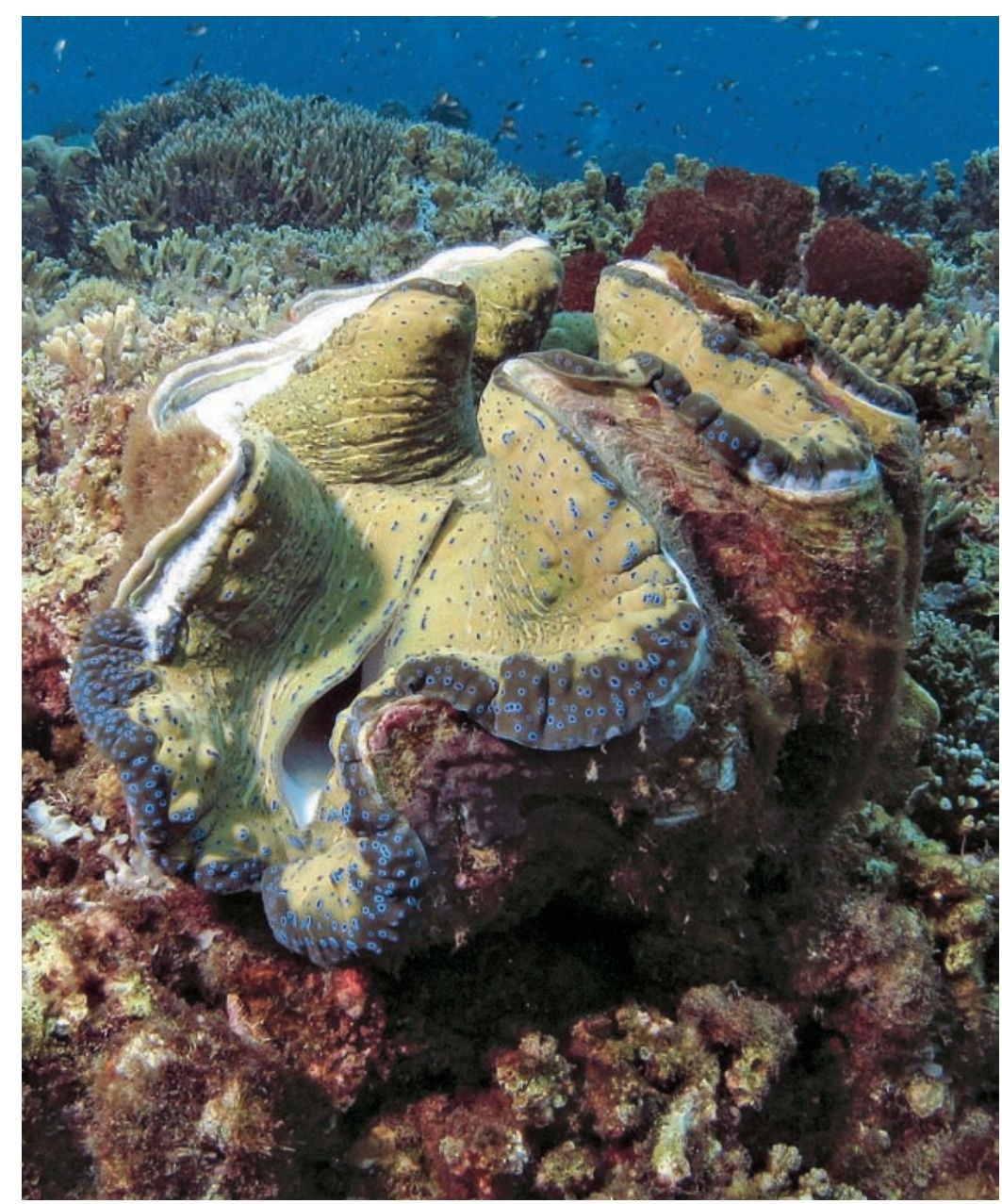

Tridacna gigas, présente dans tout le triangle de corail jusqu'aux Salomon, a disparu des récifs et lagons de Nouvelle-Calédonie, laissant des valves fossiles très recherchées par les lapidaires. @ IRD/S. Andréfouët

Malgré un effet positif (une diminution des captures) depuis la mise en place de ces réglementations, les données disponibles semblent indiquer que la ressource en bénitiers continue toujours à diminuer à cause de l'augmentation de la pression de pêche en lien avec le développement démographique du territoire.

Confrontés à l'état préoccupant de la ressource et au souhait des communautés locales de pouvoir continuer à consommer du bénitier, les gestionnaires, scientifiques et acteurs locaux doivent, plus que jamais, unir leurs efforts pour trouver des solutions innovantes. En septembre 2009, le WWF et le service des pêches et de l'aquaculture de la province Nord ont ainsi coordonné une opération de repeuplement en bénitiers rouleurs, Hippopus hippopus, dans les deux aires marines protégées (AMP) cogérées de Pouébo et Hienghène. En 2012, une étude génétique réalisée dans l'AMP de Hyabé/Léjao (Pouebo) a permis d'évaluer l'efficacité de ce repeuplement et d'estimer les échelles de dispersion des larves autour de l'AMP. Coordonné par l'IRD, ce travail a montré que non seulement $22 \%$ des bénitiers échantillonnés à l'intérieur de l'AMP sont issus de la reproduction de bénitiers de l'AMP, révélant ainsi un fort taux d'autorecrutement, mais également qu'environ un quart de ces autorecrues avaient pour parent au moins un bénitier réensemencé, démontrant l'efficacité certaine du repeuplement réalisé dans ce contexte.

Concernant l'exportation de larves, les résultats montrent que $18 \%$ des juvéniles échantillonnés sur les récifs frangeants de chaque côté de l'AMP sont issus de la reproduction d'adultes localisés dans l'AMP, et ce jusqu'à environ $35 \mathrm{~km}$. Les bénitiers réensemencés ont également participé aux exportations, avec une part de l'ordre de $30 \%$. Ainsi, les larves de bénitier rouleur issues des zones protégées où la pêche est réglementée s'exportent et contribuent à la résilience des populations situées dans les zones non protégées, soulignant le caractère important de ces aires marines protégées.

\section{Références bibliographiques}

TIAVOUANE J., DUMAS P., FAUVELOT C., 2014 Connectivité et dynamique des populations du bénitier rouleur Hippopus hippopus dans le lagon nord-est de Nouvelle-Calédonie. Rapport final d'opération (financement WWF), $31 \mathrm{p}$.

TIAVOUANEJ., 2016 Les bénitiers de Nouvelle-Calédonie : nouvelles espèces et échelles spatiales de connectivité chez Tridacna maxima et Hippopus hippopus. Thèse de doctorat Biologie Marine, Université Paris VI, 191 p. 
Chapitre 36

\section{Poissons rares ou endémiques, des acteurs méconnus qu'il faut préserver}

Michel Kulbicki, Philippe Borsa, Gérard Mou-Tham, LaurentVigliola et LaurentWantiez

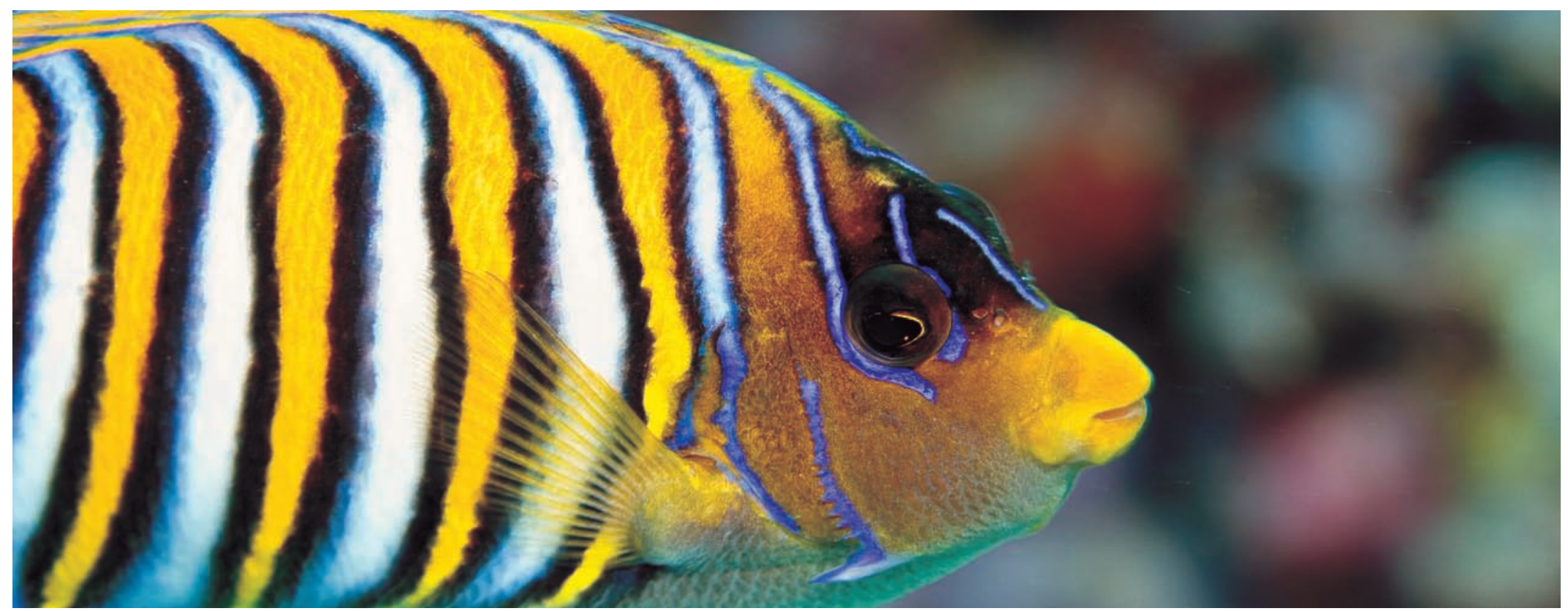

Ce poisson ange (Pygoplites diacanthus) est rare en Nouvelle-Calédonie à l'exception du lagon d'Ouvéa. Sa rareté s'explique peut-être par son alimentation, composée en grande partie d'éponges, toxiques pour la plupart des autres poissons. ๑ S. Floeter

Les espèces endémiques et les espèces rares sont souvent un sujet de curiosité, de la part tant du néophyte que des spécialistes (scientifiques ou gestionnaires). Cet intérêt est-il justifié en ce qui concerne nos poissons de récif?

En premier lieu, comment définir l'endémisme et la rareté ? L'endémisme est le fait de n'exister que dans une seule localité. En fonction de ce que l'on définit comme localité il peut y avoir de multiples échelles d'endémisme. Dans ce qui suit, nous parlerons d'endémisme local pour les espèces ayant une distribution géographique restreinte à un cercle d'environ $500 \mathrm{~km}$ de rayon, et d'endémisme régional pour celles dont l'aire de répartition atteint $1500 \mathrm{~km}$ de rayon. Ces échelles peuvent paraître grandes par rapport à l'endémisme terrestre qui porte souvent sur des aires de répartition très petites. Ce changement d'échelle découle des capacités de dispersion des poissons récifaux qui, sous forme larvaire, peuvent être entraînés par les courants marins océaniques sur des centaines de kilomètres. Il y a également plusieurs façons d'être rare :

- la rareté en abondance, pour laquelle il existe très peu d'individus de l'espèce sur l'ensemble de son aire de distribution ;

- la rareté de fréquence, où l'espèce ne se rencontre que rarement, avec cependant la possibilité d'être localement abondante. 
Il y a donc un lien entre rareté et endémisme, puisqu'une des définitions de la rareté porte sur la fréquence géographique et, par conséquent, sur l'aire de distribution.

\section{Intérêt de ces espèces}

Pour qu'une espèce soit endémique ou rare, il est probable qu'elle possède des caractéristiques biologiques, génétiques ou écologiques singulières et, dans ce cas, ces espèces ont une importance particulière dans la diversité des peuplements. Ainsi, on peut s'attendre à ce qu'une espèce endémique soit mieux adaptée aux conditions locales que les espèces non endémiques. De la même façon, une espèce peut être rare parce que ses caractéristiques biologiques ou écologiques lui interdisent d'être abondante - c'est le cas par exemple des grandes espèces -, cette rareté locale étant alors souvent compensée par une vaste distribution géographique. Dans tous les cas, les espèces rares apportent de la diversité aux peuplements et, comme démontré dans la partie consacrée aux fonctions écologiques des poissons, plus la diversité augmente et plus le peuplement utilise les ressources disponibles avec efficacité. Ceci a pour résultat davantage de stabilité, de résistance et de résilience aux changements environnementaux, mais aussi plus de services écosystémiques, dont notamment une production de biomasse supérieure.

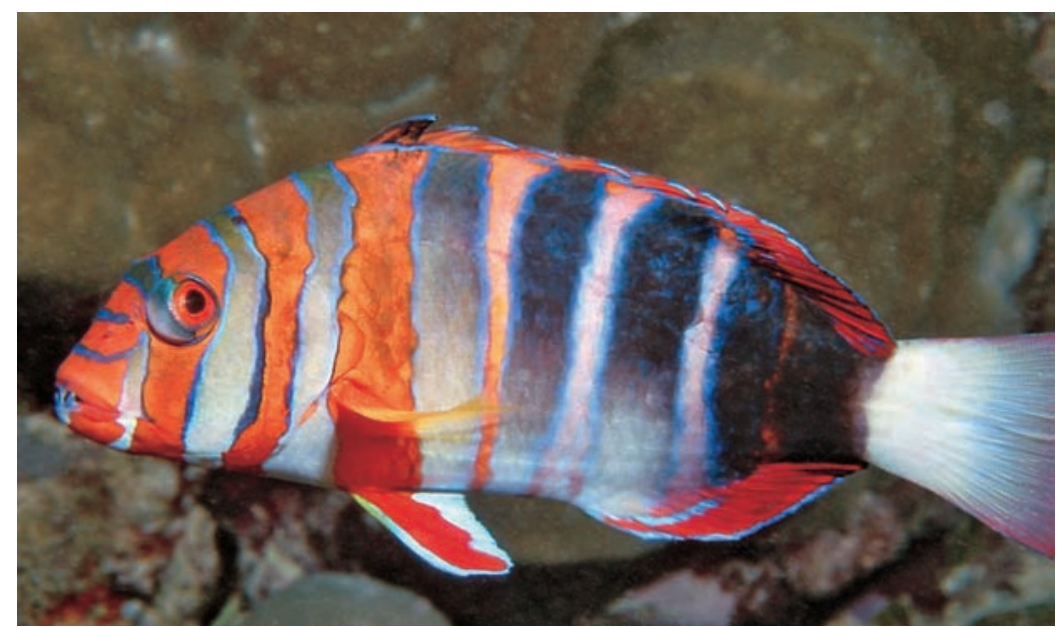

Le poisson arlequin (Choerodon fasciatus) se rencontre sur une grande partie du Pacifique mais reste rare partout. @ R.- F. Myers

\section{Des espèces difficiles à étudier}

Une espèce rare est, par définition, difficile à rencontrer, donc à étudier. Il existe cependant de la « fausse rareté », liée à l'échantillonnage. Ainsi, certaines espèces peuvent paraître rares du fait de leurs mœurs, par exemple les murènes, qui vivent dissimulées toute leur vie dans les anfractuosités du récif alors qu'elles sont en fait relativement abondantes. Par ailleurs, il convient de définir des seuils d'abondance à partir desquels une espèce est considérée comme rare. Dans ce qui suit, nous choisirons la limite d'un individu pour 10000.

Pour étudier les espèces endémiques, il faut surmonter deux difficultés :

- la définition de l'échelle concernée, déjà évoquée ;

- le niveau de connaissance et d'exploration des communautés de poissons.

Une espèce insulaire peut être longtemps considérée comme endémique pour la simple raison que les archipels des alentours n'ont pas été correctement explorés. Ainsi, aux îles Hawaï, la proportion d'espèces endémiques était estimée à environ $30 \%$ dans les années 1960. Elle est passée à $23 \%$ dans les années 1990 pour atteindre $17 \%$ à mesure que progressaient nos connaissances sur le reste du Pacifique. À l'inverse, ce que l'on croyait être une espèce unique peut se révéler être un complexe d'espèces. La raie à points bleus en est un bon exemple: on pensait jadis qu'il ne s'agissait que d'une seule espèce ; la génétique a permis de révéler 11 espèces distinctes, géographiquement séparées les unes des autres. Le statut de rareté ou d'endémisme pour un poisson de récif est donc instable, contrairement à ce qui s'observe pour le milieu terrestre. Ceci a des répercussions sur les politiques de gestion pour lesquelles une approche par biotope ou écosystème sera plus adaptée qu'une approche espèce par espèce.

\section{Les poissons récifaux endémiques, combien et qui sont-ils?}

Le nombre d'espèces de poissons récifaux endémiques à la Nouvelle-Calédonie est sujet à débat. Si l'on se restreint aux espèces correctement identifiées, il y a actuellement 27 espèces endémiques locales ou régionales connues, soit $1,8 \%$ des poissons récifaux. 
Les espèces endémiques néo-calédoniennes sont caractérisées, pour la plupart, par une vie sur le fond ; les individus sont solitaires et ils ne sont actifs que la journée. Elles appartiennent majoritairement au groupe des syngnathes (groupe comprenant les hippocampes), avec six espèces, aux gobies (cinq espèces), aux blennies (quatre espèces) et aux Tripterygiidae (quatre espèces). Ces trois dernières familles sont en général mal connues et il est probable que plusieurs des espèces reconnues actuellement comme endémiques ne le seront plus dans quelque temps, quand nos connaissances sur ces groupes auront évolué. Pour donner un exemple, une espèce récemment décrite de Nouvelle-Calédonie et alors supposée endémique, le bossu blanc Gymnocranius oblongus, a été depuis observée à Taïwan. Inversement, une des espèces du complexe de la raie à points bleus Neotrygon trigonoides pourrait se révéler unique à la région de la mer de Corail. À notre connaissance, aucune des espèces endémiques à la NouvelleCalédonie n'est abondante.

La question suivante est de savoir ce qui peut déterminer le nombre d'espèces endémiques. En particulier, le nombre ou la proportion d'espèces endémiques varient-ils d'une région à l'autre dans le Pacifique ? Et quelles sont les causes possibles des variations de l'endémisme des poissons récifaux ? L'endémisme des poissons récifaux du Pacifique est très inégalement réparti. Les régions à fort endémisme (seuil de 3,8\% et un maximum de $28 \%$ ) sont toutes situées sur le pourtour du Pacifique tropical. À l'opposé, la proportion d'espèces endémiques au centre du Pacifique tropical est bien moins importante, avec en moyenne 1,6\% des espèces identifiées. Les régions à fort endémisme, à l'exception du Japon, se caractérisent toutes par une faible richesse spécifique. En NouvelleCalédonie plus de la moitié des espèces endémiques sont considérées comme « endémiques locales ». Cette dominance de l'endémisme local sur l'endémisme régional s'observe sur toute la périphérie du Pacifique tropical, à l'exception de Hawaï et du Japon. En cela, la Nouvelle-Calédonie diffère des régions avoisinantes, comme la Grande Barrière, la mer de Corail, le Vanuatu ou les Salomon, où c'est l'endémisme régional qui domine.
Chez les poissons récifaux, les causes du niveau d'endémisme sont assez mal connues, si ce n'est que la proportion d'espèces endémiques augmente sur les archipels isolés, plus particulièrement si les îles sont petites. De façon très élémentaire, il est possible de distinguer deux grandes classes d'endémisme : l'endémisme par sympatrie et celui par allopatrie. Dans le premier cas, les espèces se « scindent » en deux ou plusieurs espèces suite à des phénomènes $\mathrm{d}$ 'isolement locaux souvent difficiles à démontrer (changements de l'environnement, acquisition de comportements dans un groupe d'individus...). Dans le second cas, des populations se retrouvent isolées les unes des autres et évoluent séparément jusqu'à accumuler des différences génétiques suffisantes pour en faire des espèces distinctes. L'analyse de la distribution des espèces endémiques sur l'ensemble de l'Indo-Pacifique suggère que l'endémisme par allopatrie serait le plus fréquent. Il est probable qu'avec la succession de glaciations puis de réchauffements avec, en corollaire, la rétractation puis l'expansion des régions comportant des récifs coralliens, nombre de populations se sont retrouvées isolées. Suivant leurs capacités de recolonisation à partir de zones refuges, ces populations auront pu ou non donner lieu à de nouvelles espèces, souvent endémiques.

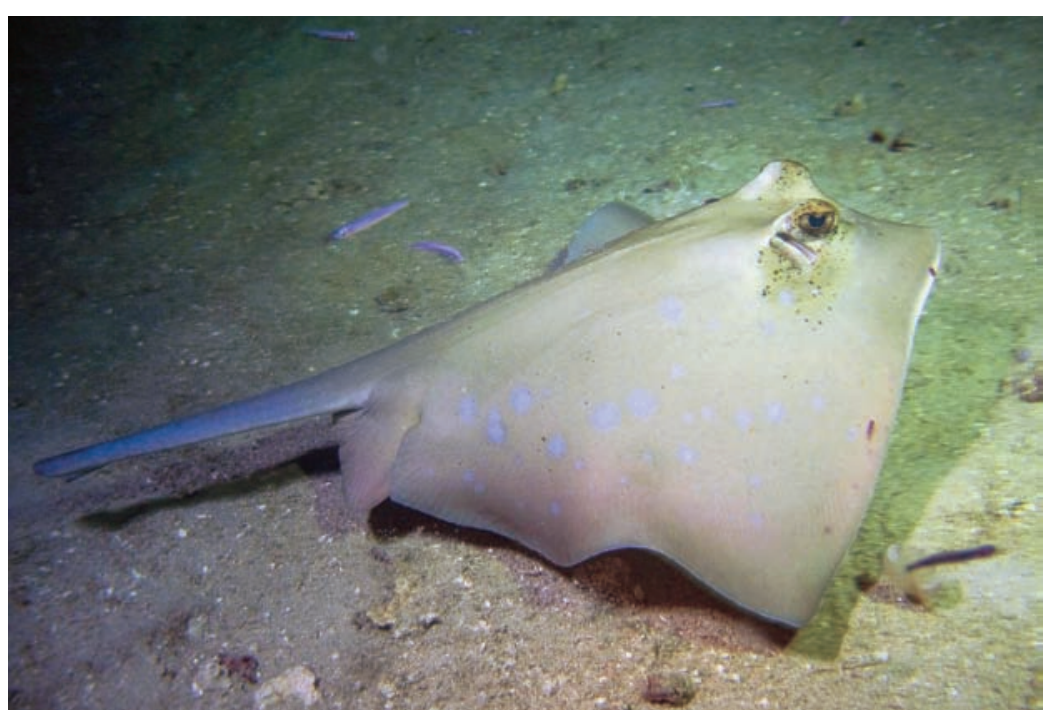

Raie à points bleus (Neotrygon trigonoides). @ J.-L Menou 


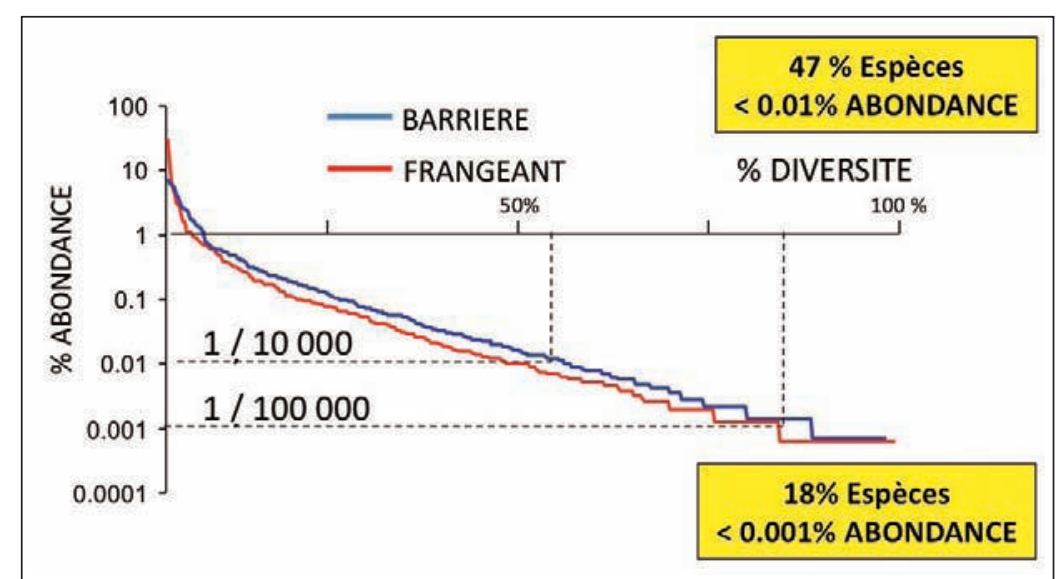

Figure 1 : Proportion d'espèces rares sur les récifs frangeants et les récifs-barrières de Nouvelle-Calédonie. Source : JONES, et al., 2002 et MOUILLOT et al., 2013

\section{Combien d'espèces rares ?}

Le nombre d'espèces rares dépend de la définition du niveau de rareté. La fig. 1 montre que la proportion d'espèces rares est très importante en Nouvelle-Calédonie : $47 \%$ des espèces pour une limite d'un individu pour 10000 et $18 \%$ pour une limite de $1 / 100000$. Cette proportion change légèrement en fonction du milieu, les récifs peu diversifiés ayant une moindre proportion d'espèces rares. La proportion d'espèces rares augmente avec la taille des îles : par exemple, elle est plus importante sur la Grande Terre qu'aux îles Loyauté. Cette proportion augmente aussi avec le nombre d'espèces de la région : la proportion d'espèces rares en Polynésie n'est que de $14 \%$ mais à Fidji elle atteint $29 \%$ (au taux de rareté 1/10 000).

\section{Caractéristiques des espèces endémiques et des espèces rares}

Les espèces endémiques sont en moyenne trois fois plus petites (fig. 2) que les autres espèces, les espèces endémiques locales étant légèrement plus petites que celles ayant un endémisme régional. De la même façon, les régions à fort endémisme ont des espèces endémiques plus grandes que les régions à faible endémisme. Ces différences de taille sont corrélées à l'éloignement et à la taille des îles : plus une île

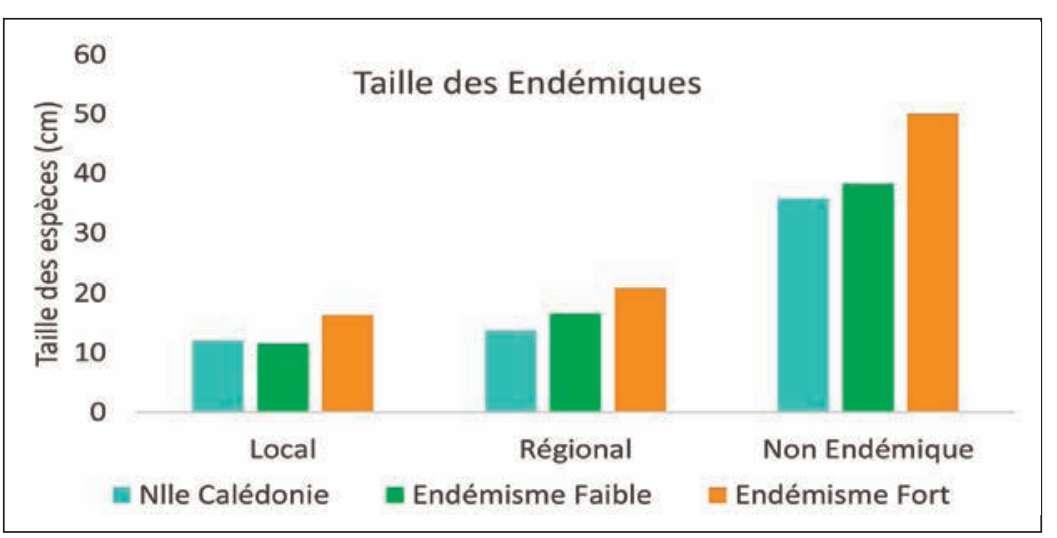

Figure 2 : Taille moyenne des espèces de poissons récifaux en fonction de leur degré d'endémisme (local, régional, non endémique) et suivant la proportion d'espèces endémiques. En Nouvelle-Calédonie, régions à endémisme faible : $<3,8 \%$; régions à endémisme fort : > 3,8\%. Source : JONES, et al., 2002 et MOUILLOT et al., 2013

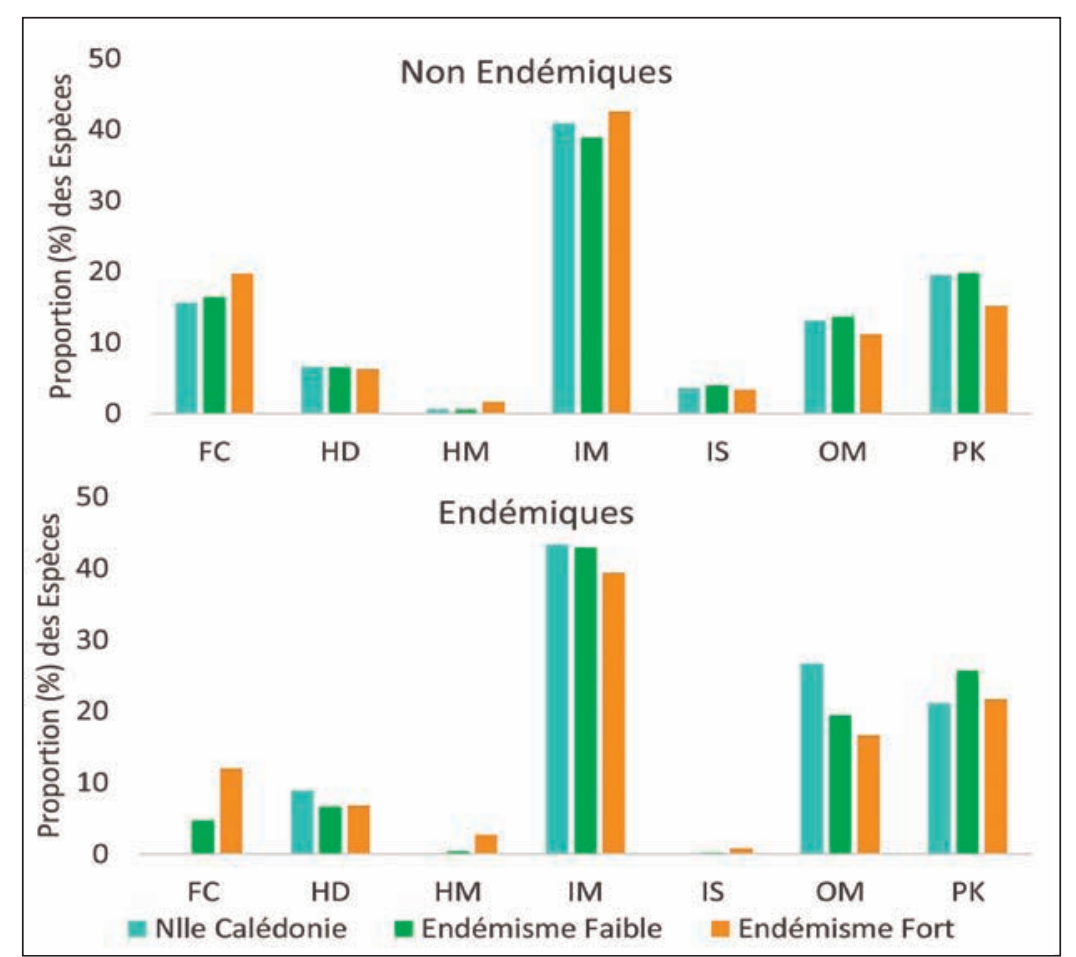

Figure 3 : Régime alimentaire des espèces de poissons récifaux en fonction de leur endémisme et du niveau d'endémisme régional.

$\mathrm{FC}$ : piscivores ; $\mathrm{HD}$ : herbivores de turf ; $\mathrm{HM}$ : herbivores de macro-algues ; IM : mangeurs d'invertébrés mobiles ; IS : mangeurs d'invertébrés sessiles (coraux) ; OM : omnivores ; PK : planctonophages. Source : JONES, et al., 2002 et MOUILLOT et al., 2013 
est petite et éloignée de la région centrale Indo-Pacifique, plus les poissons récifaux y sont représentés par de grandes espèces. Par exemple, à Hawaï, les espèces endémiques, nombreuses, comprennent une forte proportion (30\%) d'espèces de plus de $30 \mathrm{~cm}$, alors qu'il n'y en a que $8 \%$ en Nouvelle-Calédonie.

Les espèces endémiques ont des régimes alimentaires qui diffèrent de la moyenne (fig. 3). Elles sont moins souvent piscivores, ou mangeuses de macro-algues ou d'invertébrés sessiles, essentiellement des coraux, que les autres espèces. La Nouvelle-Calédonie se distingue par l'absence de ces trois types de régime alimentaire parmi ses espèces endémiques. En revanche, les espèces endémiques de Nouvelle-Calédonie sont plus fréquemment omnivores que dans les autres régions.

Les espèces rares sont en majorité carnivores (50 \% des espèces carnivores sont rares) ou piscivores (20\%) et sont pour la plupart (55\%) de taille moyenne $(8-30 \mathrm{~cm})$. Plus important, les espèces rares appartiennent pour la plupart à des fonctions écologiques qui ne comportent qu'une seule espèce. Autrement dit, chaque espèce rare a tendance à avoir une fonction écologique très spécifique. Sa disparition entraînerait de facto la disparition de la fonction qu'elle assure.

\section{Gestion et conservation}

Espèces rares et espèces endémiques sont souvent le cœur de cible de programmes de protection en milieu terrestre car ces espèces sont souvent menacées. Il en va de même de certaines espèces marines comme les coquillages endémiques, les dugongs ou la langouste de Bourail. Les poissons de récif actuellement menacés en NouvelleCalédonie sont dans l'ensemble des espèces emblématiques (chap. 38), alors que les poissons de récifs rares ou endémiques ne le sont pas ou peu. Alors comment et pourquoi les protéger?

Comment ? Les espèces rares ou endémiques occupent des habitats très divers en Nouvelle-Calédonie. Il y est donc difficile d'avoir une gestion spécifique de ces espèces. Il est en conséquence nécessaire de mener une politique de gestion globale qui s'intéresse davantage à la protection des habitats et à la préservation des conditions environnementales qu'à la protection d'espèces

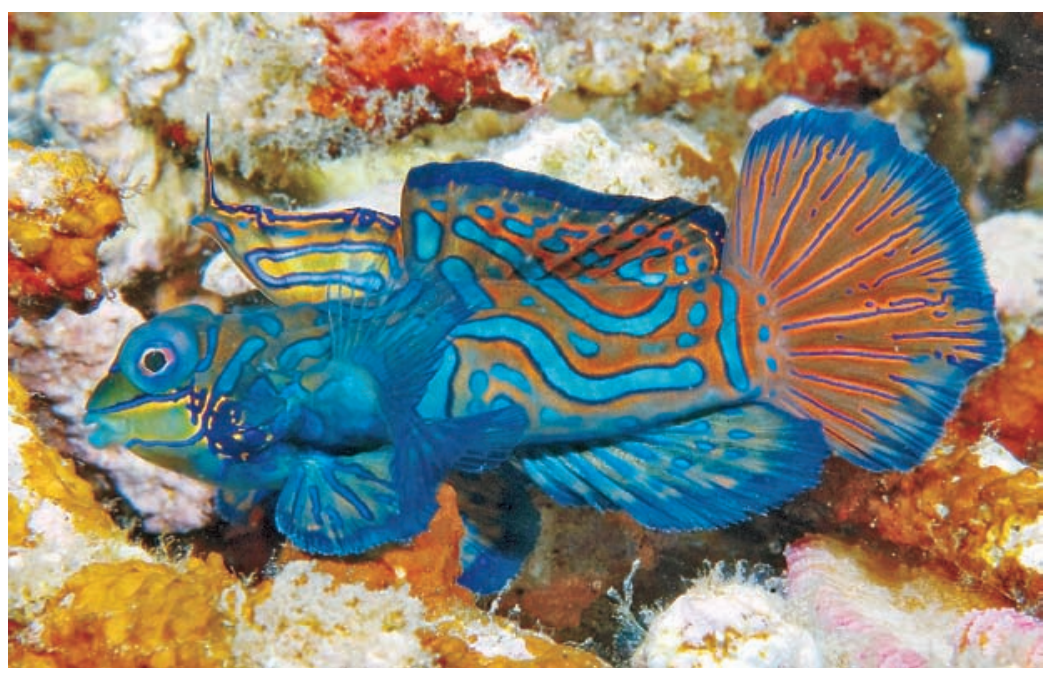

Le poisson mandarin (Synchiropus splendidus) est rare et difficile à observer, se cachant le plus souvent parmi les oursins diadèmes des zones littorales. @ R.- F. Myers

particulières. Ceci est donc très différent de ce qui peut être fait en milieu terrestre, où il sera possible de cibler la protection de certaines espèces comme le cagou, les perruches, le méliphage noir ou certaines plantes endémiques, même si la protection des habitats, par exemple la forêt sèche, est également un moyen de protéger un ensemble d'espèces, dont les espèces endémiques ou rares.

Pourquoi ? Ces espèces assurent souvent des fonctions écologiques spécifiques qui permettent un accroissement des services écosystémiques souvent bien supérieurs à ce que laisse présager leur rareté. Beaucoup de ces espèces sont particulièrement belles, les poissons anges sont l'archétype des espèces rares et belles. Une diminution de la diversité, à laquelle ces espèces participent fortement (fig. 1), est souvent un signal fort de perturbation. L'analyse des courbes diversité-abondance peut ainsi permettre de détecter par avance des dégradations dans leurs premières phases.

\section{Références bibliographiques}

JONES G. P., CALEY M. J. et MUNDAY P. L., 2002 Rarity in coral reef fish communities. In Coral Reef Fishes. Paris, Elsevier : 81-101.

MOUILLOT D.et al., 2013 Rare Species Support Vulnerable Functions in HighDiversity Ecosystems. PLoS Biol11 (5): e1001569. doi:10.1371/journal.pbio.1001569. 



\section{Les requins aux abonnés absents}

Laurent Vigliola, Jean-Baptiste Juhel, Laurent Wantiez et Michel Kulbicki

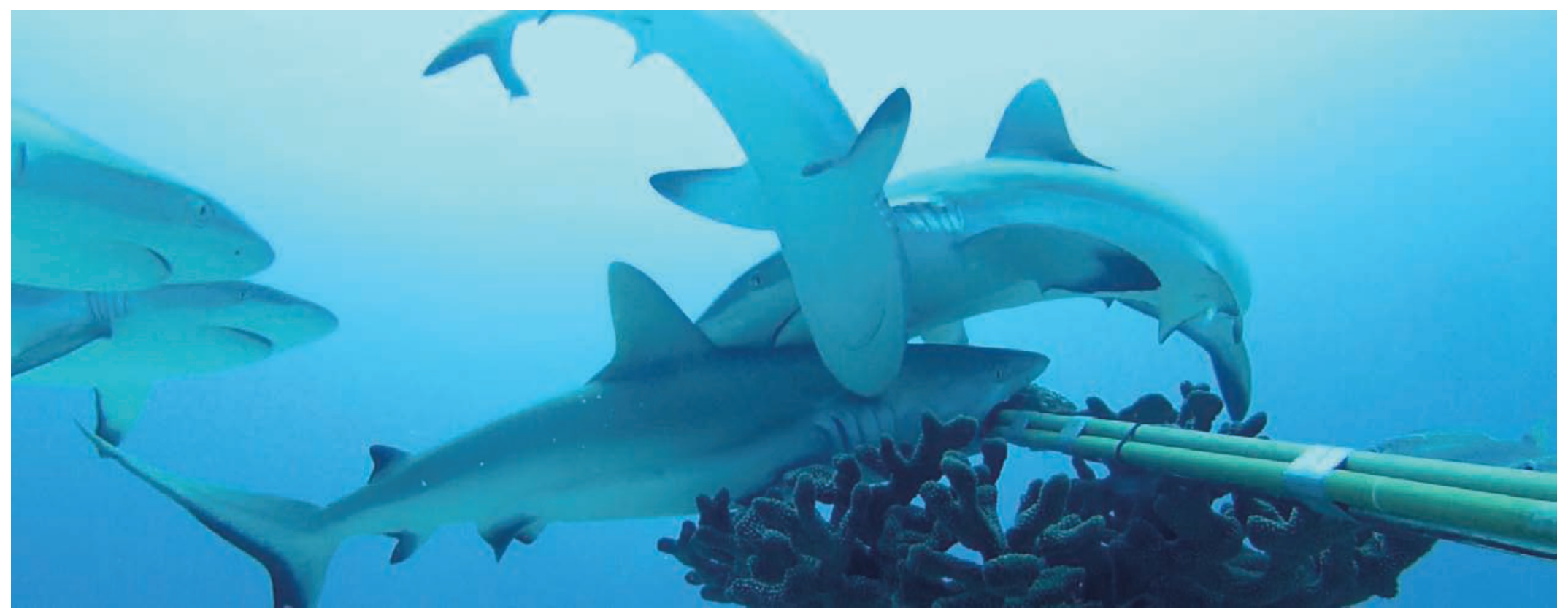

Requins gris de récif enregistrés par une stéréo-caméra appâtée au récif de l'Astrolabe. OIRD/ L. Vigliola

Bien qu'ils soient parmi les plus puissants prédateurs des océans, les requins sont en réalité très vulnérables et plusieurs espèces font face à un risque important d'extinction dans tous les océans du monde. Des études récentes révèlent que 97 millions de requins sont tués chaque année par la pêche et que certaines populations ont chuté de $99 \%$ (WORM et al., 2013). Contrairement aux autres poissons qui pondent des millions d'œufs chaque année, les requins ne peuvent mettre au monde que quelques nouveau-nés au cours de leur vie. Par exemple, le requin gris de récif, Carcharhinus amblyrhynchos, atteint la maturité sexuelle à 10 ans, âge à partir duquel les femelles pourront donner naissance de un

${ }^{25} \mathrm{http}: / /$ pristine.ird.nc

${ }^{26} \mathrm{http}: / /$ apex.ird.nc à cinq jeunes tous les deux ans, la période de gestation durant une année. Avec une reproduction aussi lente, il faudra des décennies pour que les populations décimées de requins se reconstituent.

Avec une population humaine relativement faible au regard de la taille du lagon, une pêche industrielle au requin historiquement absente et depuis peu formellement interdite, les requins de Nouvelle-Calédonie auraient dû être relativement épargnés. Ce n'est pas le cas. Dans le cadre des projets Pristine ${ }^{25}$ et Apex ${ }^{26}$, nous avons déployé 385 stations de caméras appâtées et réalisé 2790 plongées sous-marines pour échantillonner les communautés de requins de récifs sur l'ensemble de l'archipel de la Nouvelle-Calédonie. 


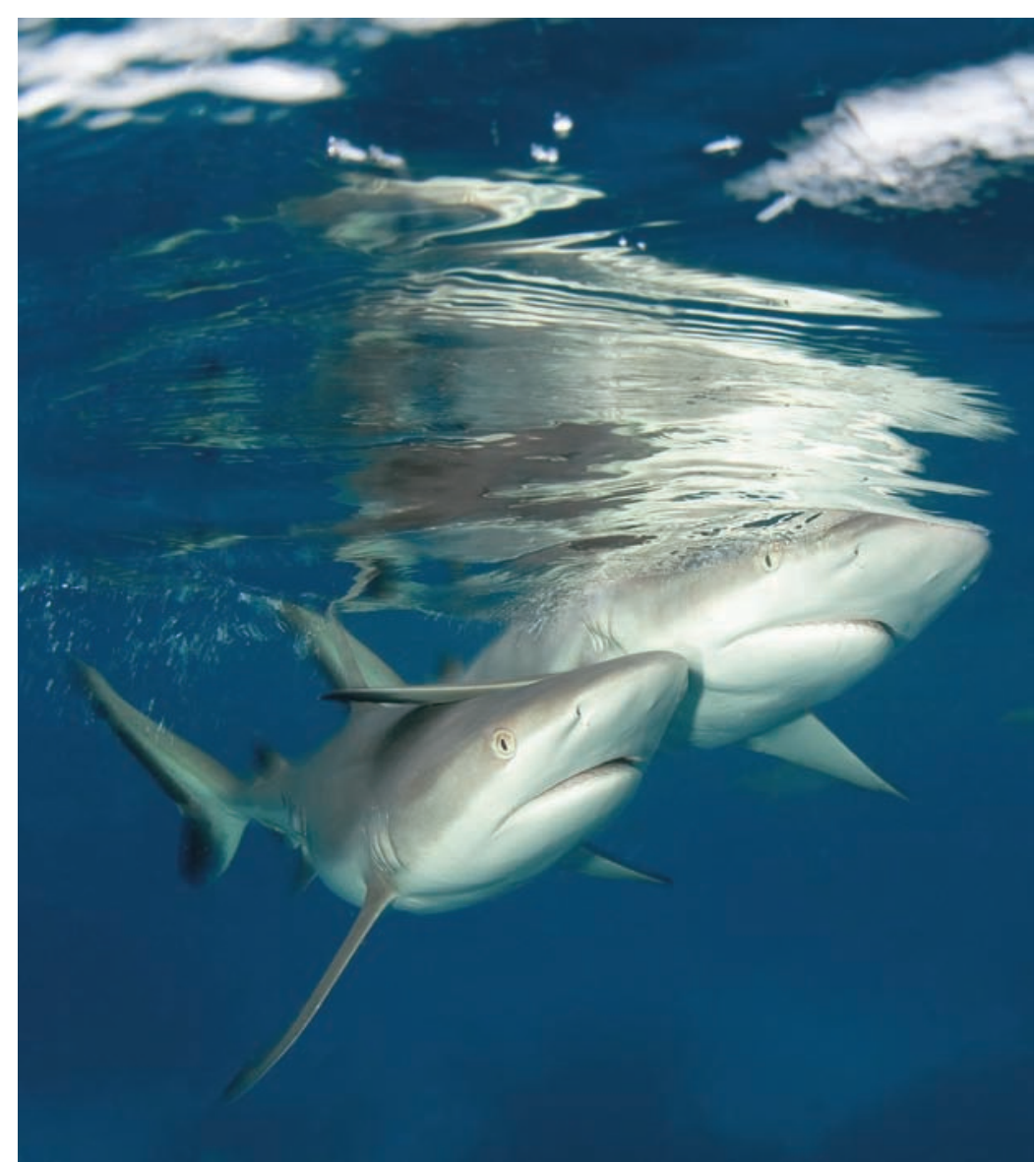

Carcharhinus amblyrhynchos (requin gris de récif); l'attitude des deux animaux évoque un rapprochement pour probablement s'accoupler. (c) M. Juncker

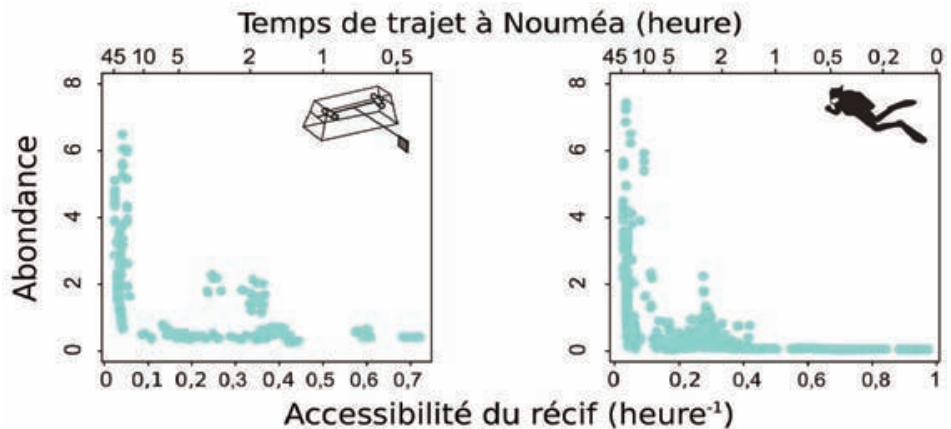

Figure 1: Abondance des requins en fonction de l'isolement des récifs de l'archipel de Nouvelle-Calédonie par stéréo-caméra appâtée (gauche) et par recensement visuel en scaphandre autonome (droite). Source : JUHEL et al., 2017
Nos résultats révèlent que la diversité et l'abondance des requins de récif sont maximales dans les récifs isolés de l'archipel, situés à plus de 25 h de trajet de la capitale Nouméa, à l'abri de la plupart des impacts humains, mais que ces animaux emblématiques ont quasiment disparu des récifs proches des populations humaines (JUHEL et al., 2018). L'impact est très sévère avec une abondance en requins qui chute de $97 \%$ et leur richesse spécifique de $94 \%$ dans les récifs à moins d'une heure de navigation de Nouméa par rapport aux récifs isolés (fig. 1).

De nombreuses hypothèses pourraient expliquer cette disparition dont les causes exactes ne sont pas identifiées. Par exemple les effets rémanents d'une pêche ancienne, la pêche illégale ou accidentelle, la surexploitation des proies, la dégradation de l'habitat, la pollution, ou le dérangement lors de la reproduction. Quelles qu'en soient les causes, la disparition des requins est inquiétante car, comme tous les grands prédateurs, les squales ont un rôle structurant majeur dans les écosystèmes naturels (RUPPERT et al., 2018). Néanmoins, des solutions existent. Les grandes réserves marines intégrales (supérieures à $200 \mathrm{~km}^{2}$ ), où la présence humaine est strictement interdite, ont des effets positifs sur l'abondance et la diversité des requins. La création de ce type de réserve implique de grands espaces et un certain isolement, conditions réunies dans les vastes lagons sud et nord notamment, mais aussi dans l'immense parc naturel de la mer de Corail, où les requins ont pour l'instant trouvé un dernier refuge. Les Néo-Calédoniens ont encore la possibilité de protéger efficacement et durablement les requins des récifs du Caillou.

\section{Références bibliographiques}

JUHEL J.B. et al., 2018 Reef accessibility impairs the protection of sharks. Journal of Applied Ecology, 55, 673-683.

RUPPERT J.L.W. et al., 2018 Human activities as a driver of spatial variation in the trophic structure of fish communities on Pacific coral reefs. Global Change Biology, 55 : 1-11.

WORM B. et al., 2013 Global catches, exploitation rates, and rebuilding options for sharks. Marine Policy, 40 : 194-204. 


\section{Les espèces emblématiques de poissons, porte-drapeaux de l'écologie participative?}

Michel Kulbicki, Philippe Borsa, Gérard Mou-Tham, Laurent Vigliola et Laurent Wantiez

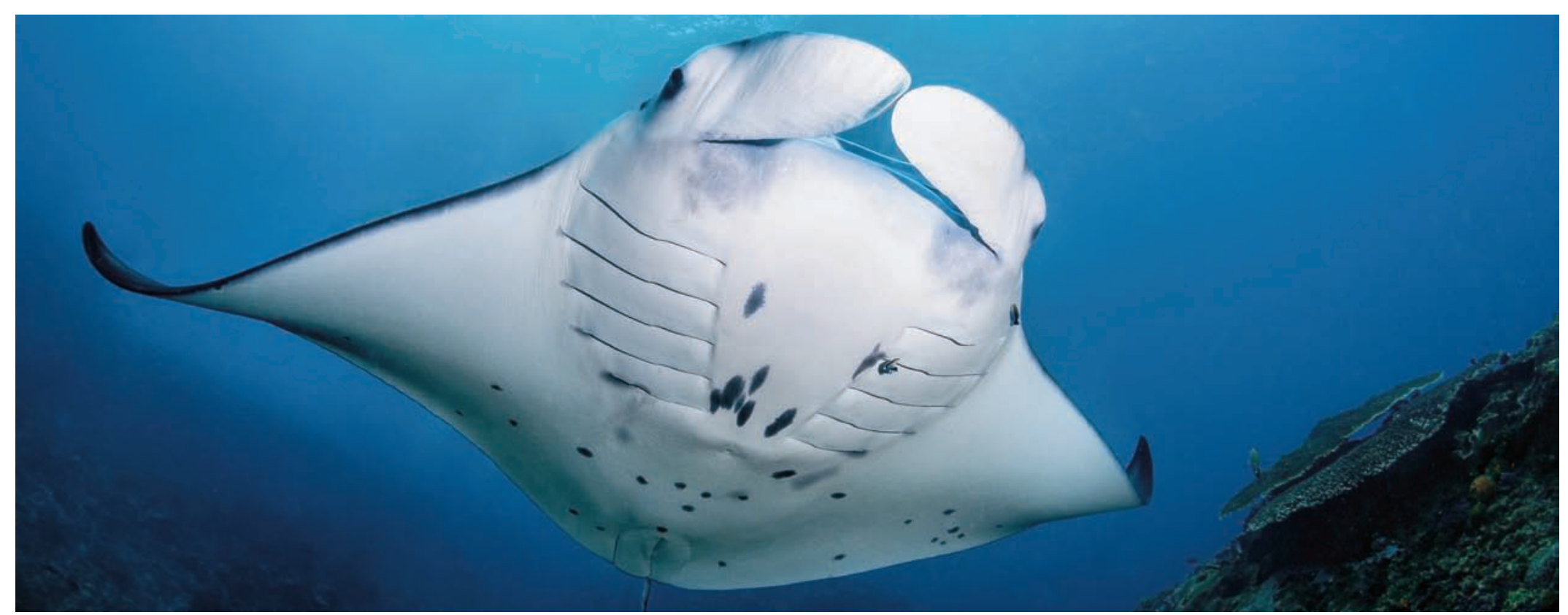

La raie manta (Manta alfredi) retient l'attention du public par sa taille (plusieurs mètres d'envergure), sa morphologie étrange et son comportement spectaculaire. Elle est le symbole même des espèces qui mettent en avant la préservation de l'environnement. @ IRD/G.Boussarie

La recherche scientifique est de plus en plus médiatisée. Cela permet de communiquer les dernières connaissances aux décideurs et à la population qui peuvent ainsi se forger une opinion informée. Pour intéresser le plus grand nombre, l'information doit être accessible et permettre la compréhension de systèmes complexes comme les récifs coralliens par des non-experts. Les espèces emblématiques permettent justement ce pont entre science, population et décision.

Pour être qualifiée d'emblématique, une espèce doit satisfaire une ou plusieurs des conditions suivantes : remplir une fonction écologique essentielle, être sensible aux perturbations, avoir une vaste répartition géographique et présenter un potentiel médiatique.

Chez les poissons récifaux, trois grands groupes d'espèces peuvent être classés comme emblématiques. En premier lieu les très grandes espèces comme les requins (chap. 37 ), les grandes raies, les mères loches, les napoléons ou les perroquets à bosse. Ces espèces, facilement identifiables, sont toutes très sensibles aux perturbations, en particulier la pêche, et plusieurs d'entre elles remplissent des fonctions écologiques clés. Le second groupe est constitué d'espèces de petite taille, colorées, facilement identifiables mais également sensibles aux changements de l'environnement. Citons les poissons-papillons, les 
poissons-anges ou encore les poissons-clowns. Le dernier groupe rassemble des espèces ayant une grande importance culturelle locale, comme, le dawa (Naso unicornis), le pouatte (Lutjanus sebae), le becde-cane (Lethrinus spp.), le mikwaa (Chanos chanos) ou le picot rayé (Siganus lineatus). Ces différents groupes ne jouent pas le même rôle dans notre relation à la préservation de l'environnement.

Le premier groupe est le plus médiatisé. En s'appuyant sur l'aspect spectaculaire de ces espèces il est possible de sensibiliser le public aux enjeux écologiques et sociétaux liés au maintien de ces espèces et, de facto, de contribuer à la santé de leur environnement. En Nouvelle-Calédonie des mesures ont été prises pour sauvegarder le napoléon (Cheilinus undulatus) suite à une campagne internationale de sensibilisation sur cette espèce dont les effectifs sont menacés dans les zones les plus peuplées. Une autre espèce, pour lesquels les enjeux économiques sont plus importants, le perroquet à bosse (Bolbometopon muricatum) continue à être pêché, malgré un rôle reconnu d'espèce clé dans le fonctionnement des récifs.

Le développement de l'écotourisme a permis également à une frange de plus en plus importante de la population de pouvoir observer in situ des espèces telles que les requins, les raies manta ou les mères loches non loin des zones les plus peuplées du territoire. Si ces espèces venaient à subir une chute de leurs effectifs il est probable que cela alerterait les populations et engendrerait des mesures de protection ou de gestion nouvelles. Il faut cependant noter que nombre de ces poissons se concentrent dans des zones protégées et leurs effectifs globaux pourraient diminuer sans changement notable de ces concentrations.

Le second groupe est plus accessible, les poissons-papillons par exemple pouvant s'observer sur tous les récifs du pays. Ces poissons sont très sensibles aux changements de leur habitat. Ainsi les poissonspapillons sont très fortement liés aux coraux et ils peuvent donc permettre de déceler des changements dans la qualité de la couverture corallienne sur le moyen et long terme. À ce titre, ils sont souvent proposés comme espèces indicatrices de la qualité environnementale. Par ailleurs, du fait de leur diversité (34 espèces en Nouvelle-Calédonie) et de la facilité à les reconnaitre, ils font partie de la plupart des programmes de science participative comme le GCRMN (Global Coral
Reef Monitoring Network) et le RORC (Réseau d'observation des récifs coralliens de Nouvelle-Calédonie). La science participative a amplement démontré son utilité en milieu terrestre, mais la complexité des écosystèmes récifaux rend son application plus délicate.

Le dernier groupe est assez difficile à définir car sa composition est plus variable. Il s'agit dans la plupart des cas d'espèces ayant une importance économique ou sociétale de longue date. En général ces espèces sont de taille moyenne à grande et sont une partie importante de la biomasse en poissons. La capture, la détention ou l'utilisation de ces espèces étaient souvent régies par des codes complexes avant l'arrivée des Européens. Citons par exemple le dawa (Naso unicornis) sur l'île de Tiga dont la pêche suivait un ensemble de règles coutumières ou encore le mikwaa (Chanos chanos) qui fait toujours l'objet de pêches communautaires très codifiées dans plusieurs tribus. La liste des espèces de ce groupe n'est définie nulle part, mais fait partie de la culture locale (chap. 30). Il est difficile d'imaginer que la population resterait insensible à une forte diminution dans le nombre ou la taille d'espèces telles que le picot rayé, le bec-de-cane, la saumonée ou le mulet. Bien qu'il existe des indicateurs écologiques basés sur la densité et la biomasse de certaines de ces espèces, ces poissons restent encore peu utilisés dans les approches de gestion. La réaction du public à des changements notables peut cependant générer des prises de décision. Ainsi, la raréfaction des mères loches (Epinephelus coioides et $E$. malabaricus), puis leur soudaine abondance suite à la découverte de leur lieu de ponte ont généré des réactions qui ont conduit à une réglementation les concernant. Autre exemple, la raréfaction du picot rayé a donné lieu à des essais d'aquaculture de cette espèce.

Jusqu'à présent il n'existait aucun statut spécifique pour les poissons récifaux emblématiques en Nouvelle-Calédonie, mais des concertations sont en cours. Dans ce cadre il pourrait être intéressant de mieux définir ces espèces et d'y associer des mesures visant soit à les protéger, soit à les utiliser comme indicateurs ou encore à en préserver spécifiquement le niveau et la qualité des populations. La plupart de ces espèces font partie du patrimoine culturel de ce pays, au même titre que le cagou, la perruche, les pins colonnaires, les kaoris ou les chevrettes. Au-delà de leur préservation ils restent un moyen important de communication et d'échange entre le public et les décideurs. 


\section{Chapitre 39 \\ Les tortues marines de Nouvelle-Calédonie}

Tyffen Read et Richard Farman

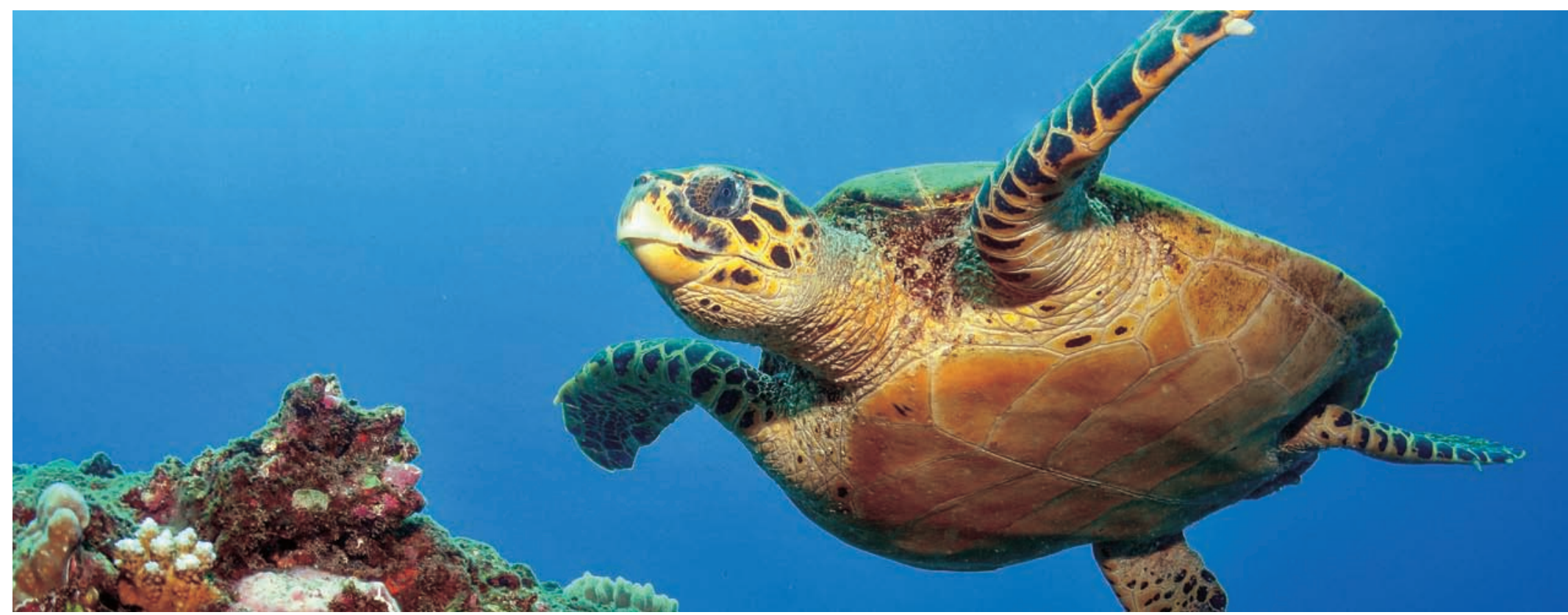

La tortue bonne écaille (Eretmochelys imbricata) est en danger critique d'extinction. Cette espèce est chassée pour la qualité des écailles de la carapace. @ G. Boussarie

Cinq des huit espèces de tortues marines recensées au niveau mondial fréquentent les eaux de Nouvelle-Calédonie. Leurs effectifs varient toutefois considérablement puisque l'observation de la tortue olivâtre Lepidochelys olivacea reste anecdotique et la conséquence sans doute d'animaux égarés, et celle de la tortue luth Dermochelys coriacea confidentielle car elle ne fait que transiter par la zone économique. Par contre, la tortue verte Chelonia mydas, la tortue grosse tête Caretta caretta et bonne écaille Eretmochelys imbricata sont fréquemment observées dans le lagon. Au niveau mondial, les tortues vertes et les tortues bonne écaille sont classées en danger et la grosse-tête comme vulnérable par l'IUCN (Union internationale pour la conservation de la nature).

\section{Deux sites majeurs de ponte}

La Nouvelle-Calédonie abrite deux sites de ponte majeurs pour les tortues vertes et les tortues grosses-têtes dans le Pacifique SudOuest, seconds en importance seulement après ceux de l'Australie et unique autre site de reproduction pour le reste du Pacifique insulaire pour les grosse-têtes.

Les tortues vertes de Nouvelle-Calédonie proviennent de différents groupes génétiques, principalement celui des récifs d'Entrecasteaux (indépendant), celui de la mer de Corail dont font partie les tortues qui pondent sur les atolls Chesterfield et ceux du 
nord et du sud de la grande barrière australienne. Il y a très peu d'échanges entre ces différents groupes. Les femelles montrent en effet un très fort taux de fidélité à leurs sites de pontes pendant une même saison (une femelle va pondre plusieurs fois pendant la saison) mais aussi entre les saisons successives. L'intersaison a été estimée à en moyenne à $8,35 \pm 3,30$ années.

$\mathrm{Si}$ on retrouve des sites de nourrissage des tortues vertes sur l'ensemble du lagon, notamment la côte Ouest, les sites de ponte sont principalement cantonnés au nord de la grande Terre et aux Loyauté. Les principaux échanges entre les sites de nourrissage et les sites de ponte ont été documentés entre l'Australie et la NouvelleCalédonie laissant présager l'existence de corridors de migration entre les deux pays, mais aussi «intra-muros ».

En effet, $61 \%$ des tortues vertes du Grand Lagon Sud (GLS) proviennent du site de ponte des récifs d'Entrecasteaux, $24 \%$ de ceux d'Australie et moins de $5 \%$ au groupe « Chesterfield/mer de Corail ». On ne connaît pas les effectifs des tortues vertes qui se nourrissent en Nouvelle-Calédonie. On estime à plusieurs milliers le nombre de femelles qui fréquentent le site de ponte aux récifs

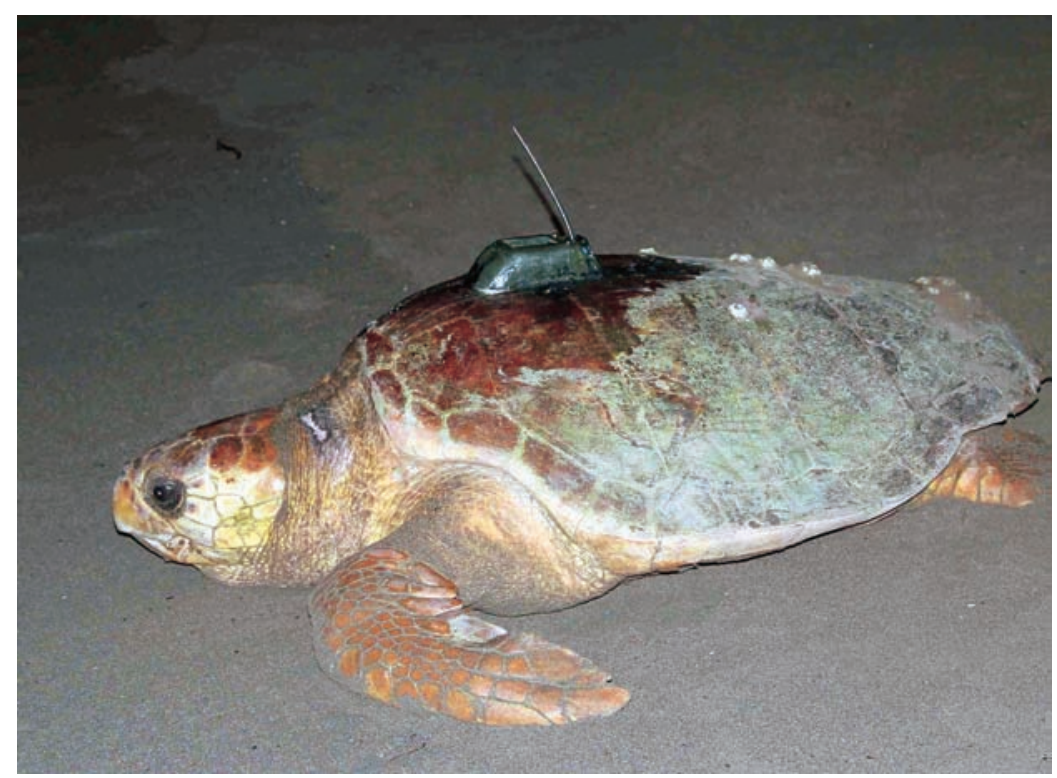

Tortue grosse tête équipée d'une balise émettrice pour étudier la migration de l'espèce entre les sites de ponte et de nourrissage. (c) Aquarium des Lagons
d'Entrecasteaux et quelques centaines supplémentaires pour le reste du lagon et autant pour les Chesterfield. La fréquence des tailles de la population du GLS est déséquilibrée avec une forte prédominance des juvéniles (88\%). Cela s'explique par un important recrutement de nouveaux animaux facilement identifiable à la couleur de leur plastron. Par contre l'absence d'adultes est préoccupante.

\section{Déplacements des populations de tortues et impact anthropique}

Dans cette zone, on a estimé que le domaine vital d'un animal est en moyenne de $54 \mathrm{~km}^{2}$ avec toutefois une importante variabilité d'une zone à l'autre et pas d'échange entre les zones.

La pêche professionnelle à la palangre a peu d'impact sur les populations de tortues vertes (une prise entre 2006 et 2008 et trois en 2016). Par contre les pêches autorisées par dérogation pour les cérémonies coutumières ont été estimées à 500 individus en 2014. Des animaux sont également prélevés illégalement sans qu'on puisse aujourd' hui en estimer l'importance.

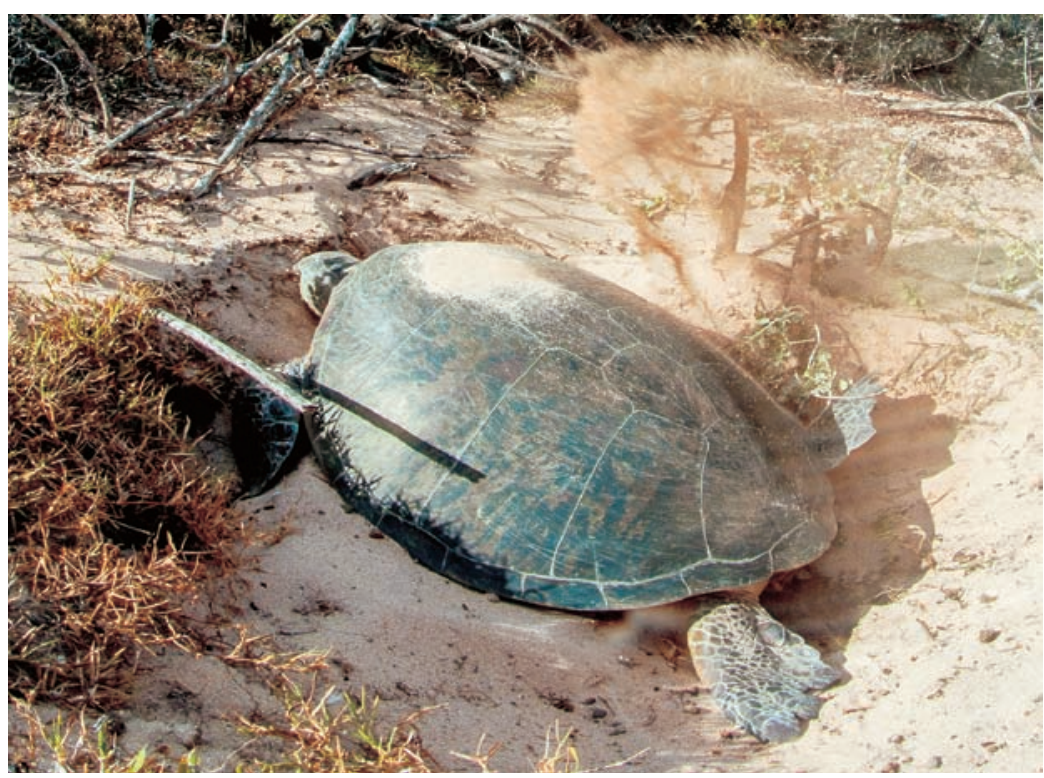

Ponte de Chelonia mydas. @ G. Boussarie 


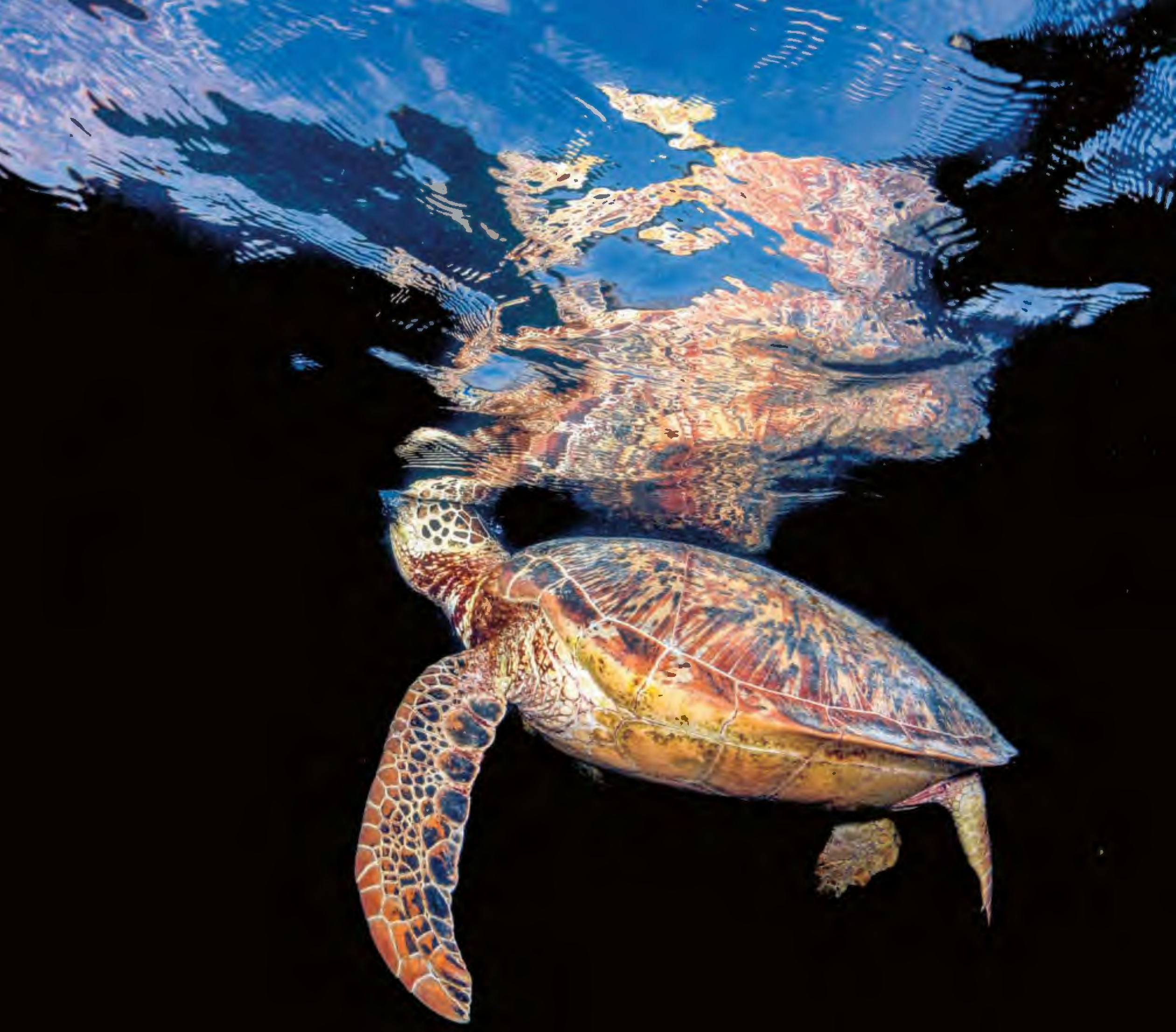


Les tortues grosses-têtes appartiennent au groupe génétique du Pacifique sud-ouest. Il y a très peu d'échanges entre les différents groupes génétiques de cette espèce (seulement cinq au niveau planétaire), ce qui constitue une contrainte importante au niveau de la gestion: l'effort de conservation devra s'appliquer sur l'ensemble des classes d'âge, notamment les plus jeunes, capturées dans les prises accessoires des pêcheries sud-américaines. Là encore, les échanges entre la Nouvelle-Calédonie et l'Australie ont été documentés, notamment à partir de femelles marquées sur le site de la roche percée qu'on a suivi jusqu'en Australie (Moreton Bay, le Cap York et dans le golfe de Carpentarie)... ou « bifurqué » vers la Papouasie Nouvelle-Guinée (les îles Trobirand). Quant aux juvéniles, leurs déplacements sont étroitement associés à l'isotherme $19{ }^{\circ} \mathrm{C}$ qu'ils vont suivre jusqu'en Nouvelle-Zélande où ils vont séjourner quelque temps avant de se lancer dans la traversée du Pacifique jusqu'aux côtes de l'Amérique du Sud... avant de revenir recruter dans les habitats côtiers de la région.

Comme pour la tortue verte, on ne connaît pas les effectifs des grosses-têtes se nourrissant dans le lagon néo-calédonien. On estime à une cinquantaine le nombre de femelles qui fréquente le principal site de ponte de la roche percée à Bourail et au moins autant disséminées sur les îlots du lagon du Grand Sud pour l'essentiel, mais aussi dans le nord. Les femelles montrent un très fort taux de fidélité à leurs sites de pontes pendant une même saison, mais aussi entre les saisons de pontes successives. L'intervalle intersaisons est de 2,84 $\pm 1,27$ années et l'intervalle entre les pontes d'une même saison est de 15,14 \pm 1,44 jours. Les tortues grossestêtes ne sont pas pêchées, mais le braconnage des œufs a été signalé à la roche percée (13\% des nids pillés). Il n'y a eu aucune prise accidentelle par la flottille palangrière de Nouvelle-Calédonie entre 2006 et 2008. Par contre, jusqu'à 3000 tortues sont capturées annuellement par les pêcheries péruviennes dont heureusement $92 \%$ sont réputées être relâchées vivantes. La ponte de tortues imbriquées n'a jamais été observée en Nouvelle-Calédonie à ce jour. C'est d'ailleurs l'espèce la moins connue et sans doute la moins abondante, même si on la rencontre souvent en plongée (zone de nourrissage). Toutefois, un groupe génétique non identifié a été répertorié dans plusieurs sites de la région, qui pourrait s'expliquer par l'existence d'un site de ponte dans les eaux néo-calédoniennes.

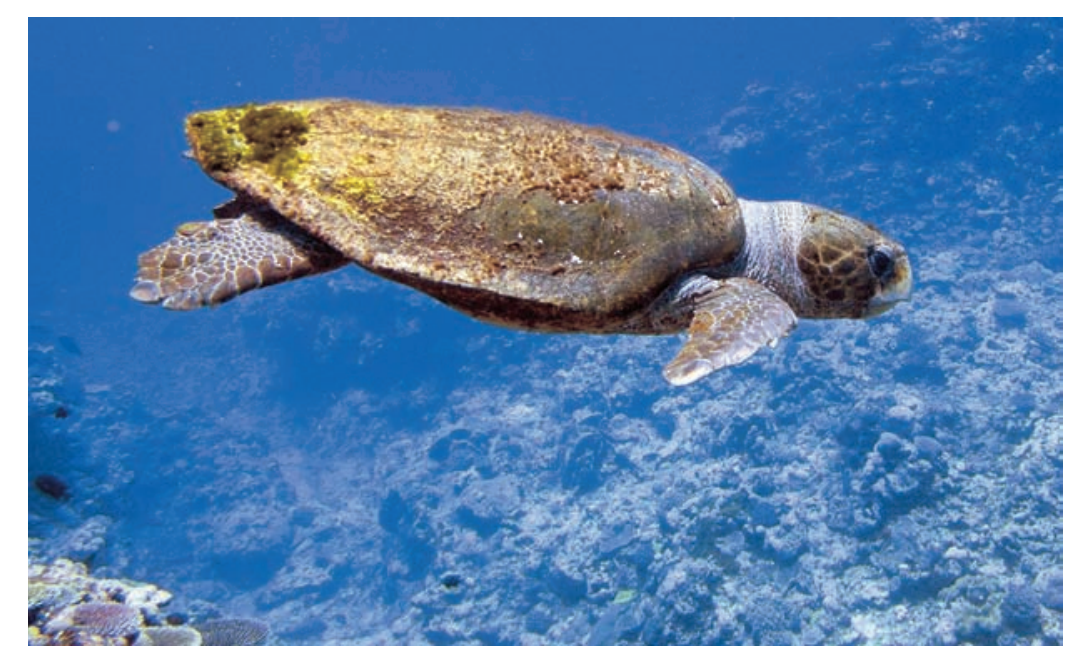

Tortue grosse tête (Caretta caretta) évoluant sur la pente externe du récif. ๑ J.-L. Menou

Toutes les espèces de tortue marine sont intégralement protégées à l'international par la Convention sur le commerce international des espèces de faune et de flore sauvages menacées d'extinction (CITES) et localement par les codes de l'environnement des provinces Nord et Sud et des textes réglementaires de la province des îles et de la Nouvelle-Calédonie. Outre la capture, la perturbation la détention et la destruction de toutes les espèces sont également interdites la destruction des nids et la vente des œufs ainsi que la commercialisation de quelque nature que ce soit. Compte tenu du statut de conservation de ces espèces (vulnérable ou en danger), de leur valeur patrimoniale, notamment pour les populations locales et de l'importance de la Nouvelle-Calédonie pour la conservation à l'échelon régional, un plan d'action local est en cours de réalisation pour établir les ordres de priorités et répartir les tâches, pour lutter notamment contre les effets du changement climatique qui impacteront les sites de ponte (érosion du littoral, élévation de la température des nids, modification du sexe ratio...). Comme la tortue, il faut savoir partir à point... la persévérance permet de réussir même sans les meilleurs atouts.

\section{Référence bibliographique}

BOYLE et al., 2009 Evidence for transoceanic migrations by loggerhead sea turtles in the southern Pacific Ocean. Proceedings of the Royal Society BBiological Sciences, 276 : 1993-1999. 


\section{Les oiseaux marins, sentinelles des eaux néo-calédoniennes}

Éric Vidal, Karen Bourgeois et Philippe Borsa

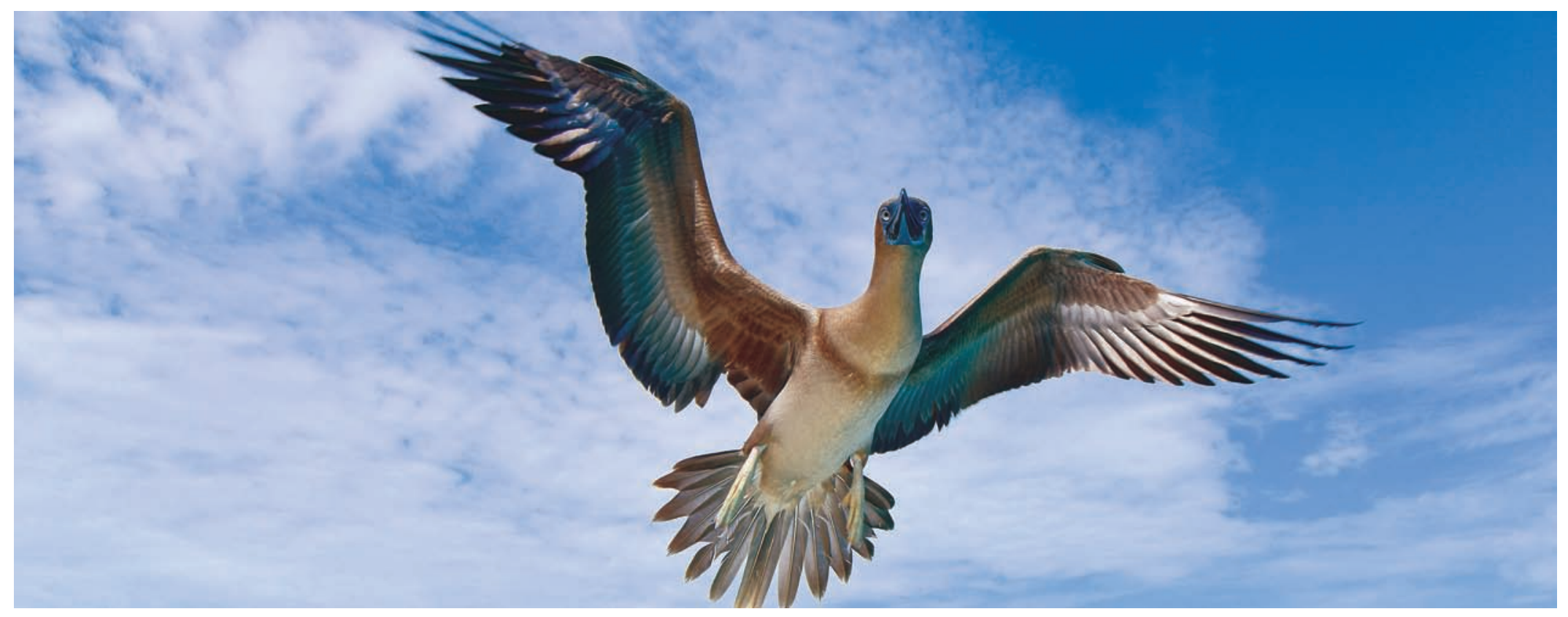

Juvénile de fou masqué (Sula dactylatra) en vol. @ M. Junker

Avec plusieurs centaines d'îlots disséminés comme autant de confettis sur une vaste surface océanique et lagonaire, les récifs coralliens de Nouvelle-Calédonie offrent un espace de nidification exceptionnel pour une communauté d'oiseaux marins diversifiée et abondante (chap. 20). Les oiseaux marins constituent l'un des groupes animaux les plus menacés à l'échelle mondiale et leur risque d'extinction augmente plus rapidement que pour tout autre groupe d'oiseaux. Les oiseaux marins représentent de précieux bio-indicateurs des impacts directs et indirects associés aux activités humaines tant à terre qu'en mer, parce que la plupart ces espèces sont longévives et partagent leur existence entre leurs colonies de reproduction à terre (notamment au niveau des îlots coralliens) et la mer (pour leur alimentation et lors des périodes inter- nuptiales). En particulier, leur position de prédateurs supérieurs, au sommet de la chaîne alimentaire marine et leur sensibilité aux modifications et perturbations environnementales, qui affectent les sites d'alimentation et de reproduction, en font des « espèces sentinelles » pour les gestionnaires des espaces naturels marins et insulaires.

Ces dernières représentent également d'intéressantes « espèces parapluies », en ce sens que leurs exigences écologiques élevées, notamment en termes de qualité et de superficie d'habitat, font que, si les conditions de leur conservation durable peuvent être réunies, par exemple dans le cadre d'aires marines protégées, celles-ci profitent en cascade à une large gamme d'autres espèces, de communautés et 
d'écosystèmes. En Nouvelle-Calédonie, l'importance et la variété des milieux littoraux et insulaires et la qualité et la superficie des écosystèmes lagonaires et océaniques font que la communauté d'oiseaux marins est à la fois numériquement très importante, diversifiée en espèces, mais également à forts enjeux de conservation du fait de la présence d'espèces menacées. Les oiseaux marins des îlots coralliens de NouvelleCalédonie doivent toutefois faire face à une variété d'impacts associés directement ou indirectement aux activités humaines.

Sur les sites de nidification, les oiseaux marins subissent l'impact d'espèces animales introduites, en particulier la prédation des œufs et des poussins par des rongeurs comme le rat noir, le rat polynésien ou la souris domestique, ou encore la piqûre vulnérante de certaines fourmis invasives comme la fourmi électrique. Ils subissent aussi la modification de leur habitat de reproduction par différentes espèces végétales introduites. La communauté d'oiseaux marins est également fortement sensible aux dérangements occasionnés par les visiteurs, et aux conséquences parfois dévastatrices des aménagements touristiques et des exploitations passées, comme l'exploitation industrielle du guano sur certains îlots des récifs d'Entrecasteaux ou des Chesterfield. Plus récemment, des questions nouvelles ont émergé sur les conséquences que pourraient avoir, dans un futur plus ou moins proche, la montée du niveau des océans et l'intensification des épisodes de submersion sur la disponibilité et la qualité des sites de reproduction des oiseaux marins sur les îles coralliennes basses. Ces questions sont complexes, car les îlots coralliens ne sont pas des entités géologiques «passives ». Leur évolution dans le temps dépend de phénomènes sédimentaires et physiques complexes.

En mer, les menaces peuvent sembler plus diffuses mais elles sont cependant bien réelles. Entre les modifications de l'environnement océanique y compris de la disponibilité alimentaire du fait des conséquences du changement climatique, les phénomènes de pollution et de biocontamination qui affectent particulièrement la physiologie des prédateurs supérieurs (métaux lourds, pesticides), ou encore l'ingestion de débris plastiques et les captures accidentelles dans les engins de pêche, les oiseaux marins ont à faire face à un faisceau dense de menaces récentes, dont l'acuité est encore trop peu documentée à ce jour dans les eaux néocalédoniennes et nécessite un approfondissement des actions de recherche.
Si les connaissances scientifiques de base sont acquises pour une partie des espèces d'oiseaux marins, d'importantes lacunes de connaissance subsistent encore, que plusieurs programmes de recherche récemment lancés devraient pouvoir contribuer à lever. C'est en particulier le cas du programme Biopelagos, porté par la CPS, I'IRD et le CNRS qui vise actuellement à mieux comprendre l'utilisation de l'espace océanique néo-calédonien par la communauté des oiseaux marins en combinant le suivi des déplacements des oiseaux au moyen de dispositifs électroniques miniaturisés, l'analyse des caractéristiques des habitats océaniques privilégiés pour l'alimentation et l'étude de leur régime alimentaire.

D'autres programmes scientifiques cherchent actuellement à combler les manques de connaissance sur les communautés, les effectifs, la reproduction et la démographie des oiseaux marins présents sur certains îlots éloignés, à mieux connaître la biologie de reproduction des différentes espèces, dont beaucoup ont encore été très peu étudiées, ou à préciser l'intensité des menaces subies à terre du fait des espèces invasives ou des changements de l'environnement. L'ensemble de ces données devrait rejoindre prochainement une base de données centralisée par l'IRD, qui sera ensuite mise à disposition des gestionnaires pour un meilleur partage des connaissances et des données. Ceci devrait contribuer à une gestion durable et éclairée de ce patrimoine biologique exceptionnel des eaux néo-calédoniennes.

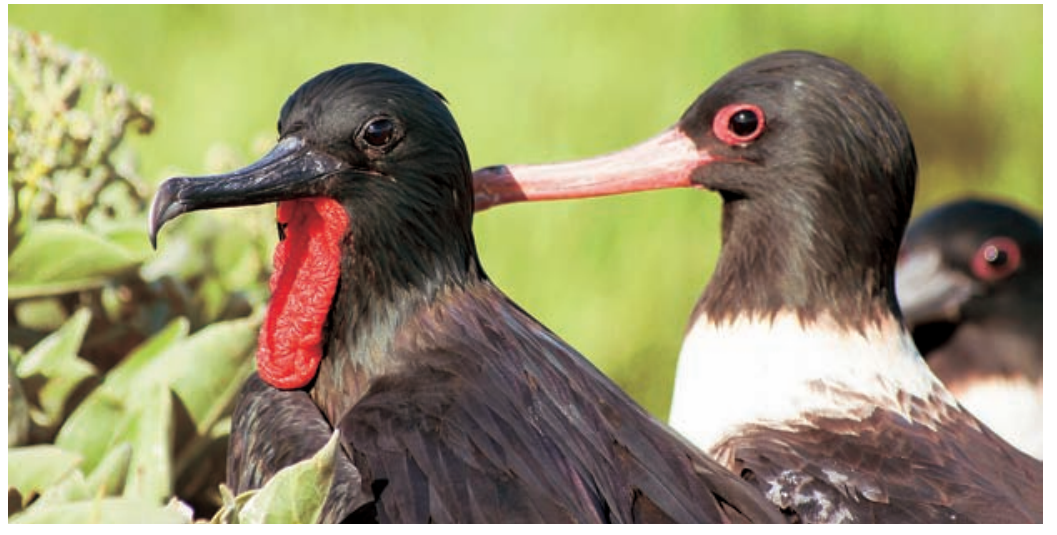

Couple de frégates ariel (Fregata ariel). Cette espèce est particulièrement sensible au dérangement humain ce qui explique qu'elle recherche les sites isolés. Îlots du Mouillage, Chesterfield, avril 2017. @ IRD/E. Vidal 


\section{Le dugong, sirène du lagon en danger}

Christophe Cleguer et Claire Garrigue

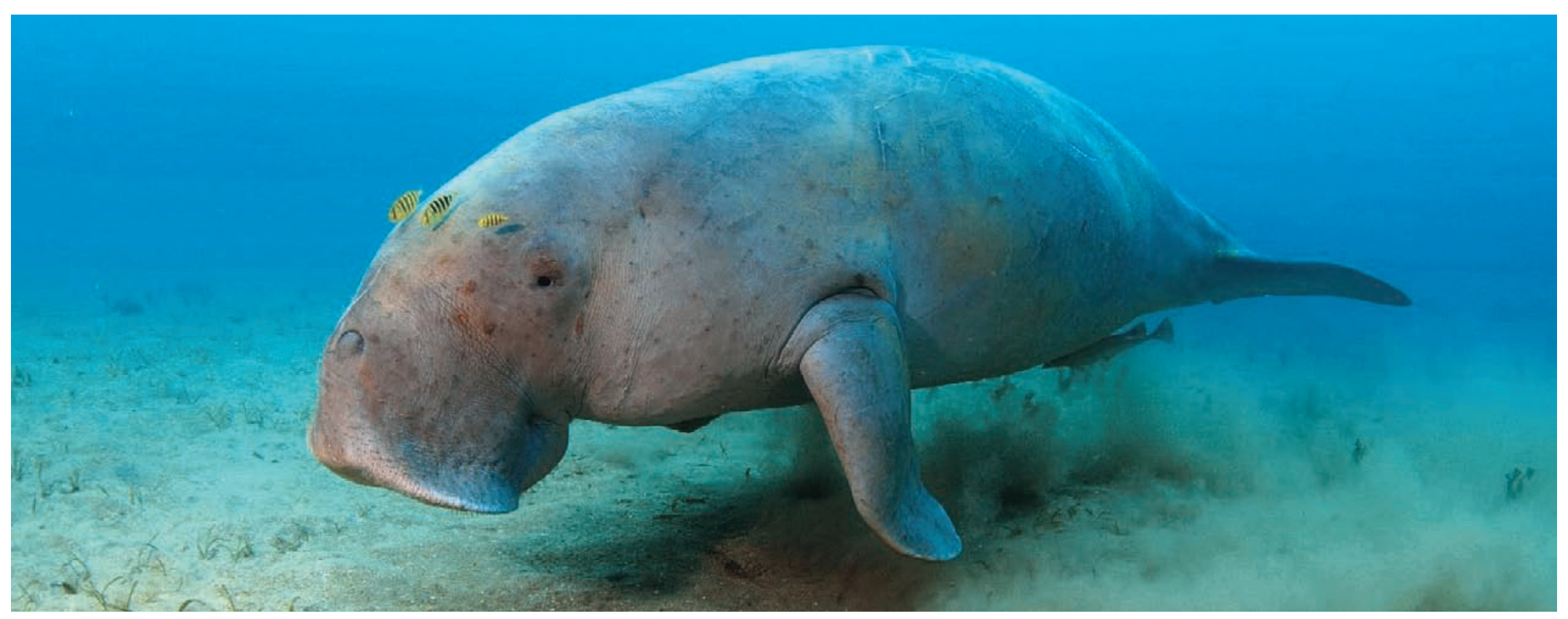

Un dugong (Dugong dugon) évoluant au-dessus d'un herbier diffus à la recherche de nourriture. ๑ M. Juncker

\section{Carte d'identité du dugong}

Avec son corps bronze massif et fusiforme de $3 \mathrm{~m}$ de long, ses petits yeux et son large sourire, son manque de nageoire dorsale, ses nageoires pectorales en forme de pagaies et sa nageoire caudale échancrée et aplatie qui rappelle celle des cétacés, le dugong ne passe pas inaperçu dans le lagon néo-calédonien. Aussi appelé «vache marine » le dugong est l'unique mammifère herbivore strictement marin. À partir de la fin du XVIII e siècle il est devenu le seul représentant de la famille des Dugongidae puisque son cousin, la Rhytine de Steller, a été exterminé par l'homme.
On trouve le dugong dans les zones côtières peu profondes de l'Afrique de l'Est jusqu'au Vanuatu, en passant par le Moyen-Orient, l'Asie du Sud-Est. Ce sont dans ces eaux qu'il trouve son garde-manger principal : les prairies de phanérogames.

Souvent concentré dans les baies protégées, les chenaux de mangroves ou les côtes sous le vent des îles côtières, le dugong donne l'impression d'être un animal très sédentaire. Il effectue pourtant des mouvements quotidiens, saisonniers, et même aléatoires, de quelques dizaines à quelques centaines de kilomètres. En Nouvelle-Calédonie, un suivi satellitaire d'une dizaine de dugongs a montré que ces derniers 
utilisaient aussi bien les lagons que les zones externes des récifsbarrières de la Grande Terre, parcourant pour certains une centaine de kilomètres et traversant les frontières administratives provinciales.

Le dugong atteint sa maturité sexuelle tardivement - entre 6 et 17 ans. Sa gestation et sa période d'allaitement sont longues puisqu'elles durent respectivement entre 13 et 15 mois et entre 14 et 18 mois. Son taux de reproduction, qui est faible (seulement un petit tous les 2 à 7 ans), est largement influencé par la disponibilité des ressources alimentaires. Toutes ces caractéristiques font du dugong une espèce très vulnérable aux perturbations naturelles et anthropiques qui l'entourent.

Protégé par plusieurs textes internationaux et inscrit comme espèce « vulnérable » sur la liste rouge de l'Union internationale pour la conservation de la nature (UICN), le dugong a déjà disparu dans de nombreux pays comme l'île Maurice, les Maldives, et le Cambodge, et son statut de conservation reste inconnu dans la moitié de son aire de répartition. Les causes d'une telle vulnérabilité sont multiples et leur intensité varie géographiquement. Dégradation des prairies de phanérogames, chasse, captures dans les filets de pêche et collisions avec les embarcations marines sont les actions directes ou indirectes de l'homme qui affecte les populations de dugongs dans la majeure partie de leur aire de répartition. Pour faire face à ces pressions, des initiatives de gestion et de conservations multiples et diverses sont mises en œuvre à l'échelle internationale, régionale et locale.

\section{Les dugongs des récifs néo-calédoniens}

En Nouvelle-Calédonie des campagnes de comptages aériens ont permis d'accroitre les connaissances sur l'abondance et la répartition des dugongs autour de la Grande Terre. Les dugongs sont majoritairement répartis sur la côte ouest et nord-est de la Grande Terre (fig. 1). Les zones à forte concentration sont distribuées de manière hétérogène. Des zones à fortes densités sont situées dans les régions de Nouméa, Ouano, Bourail-Poya, Koumac et Pouebo (fig. 2). Les dugongs sont peu présents au centre de la côte est ainsi que dans les grands lagons nord et sud, probablement du fait d'un habitat peu propice.

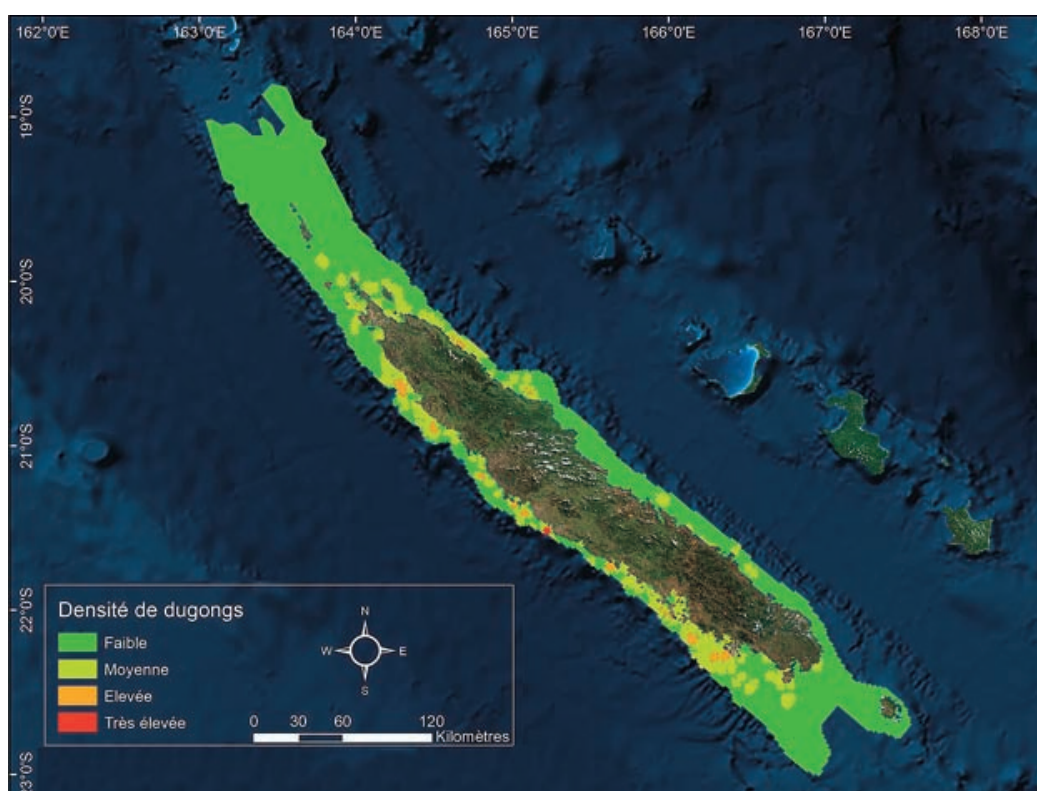

Figure 1 : Distribution et densité de dugongs autour de la Grande-Terre de Nouvelle-Calédonie basées sur les campagnes de comptages aériens menés entre 2003 et 2012. CLEGUER, 2015

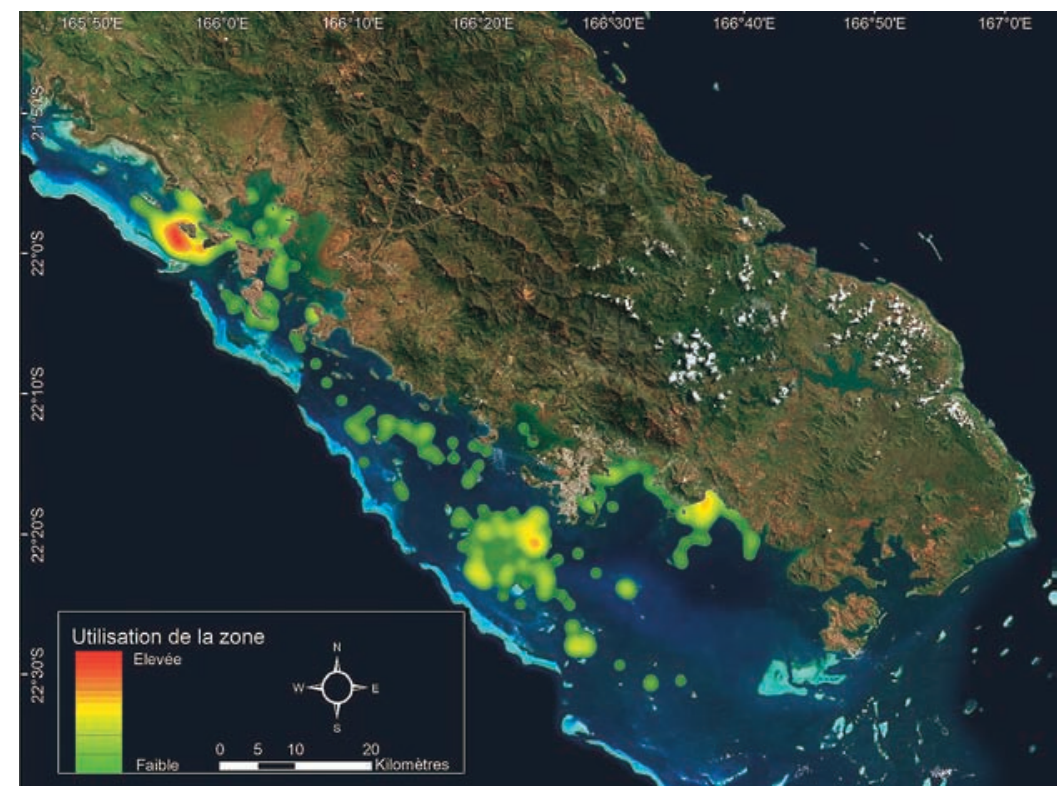

Figure 2 : Utilisation de la zone sud-ouest de la Grande-Terre par trois dugongs équipés de balises satellitaires. CLEGUER, 2015. Crédits fond de carte.@ Esri 


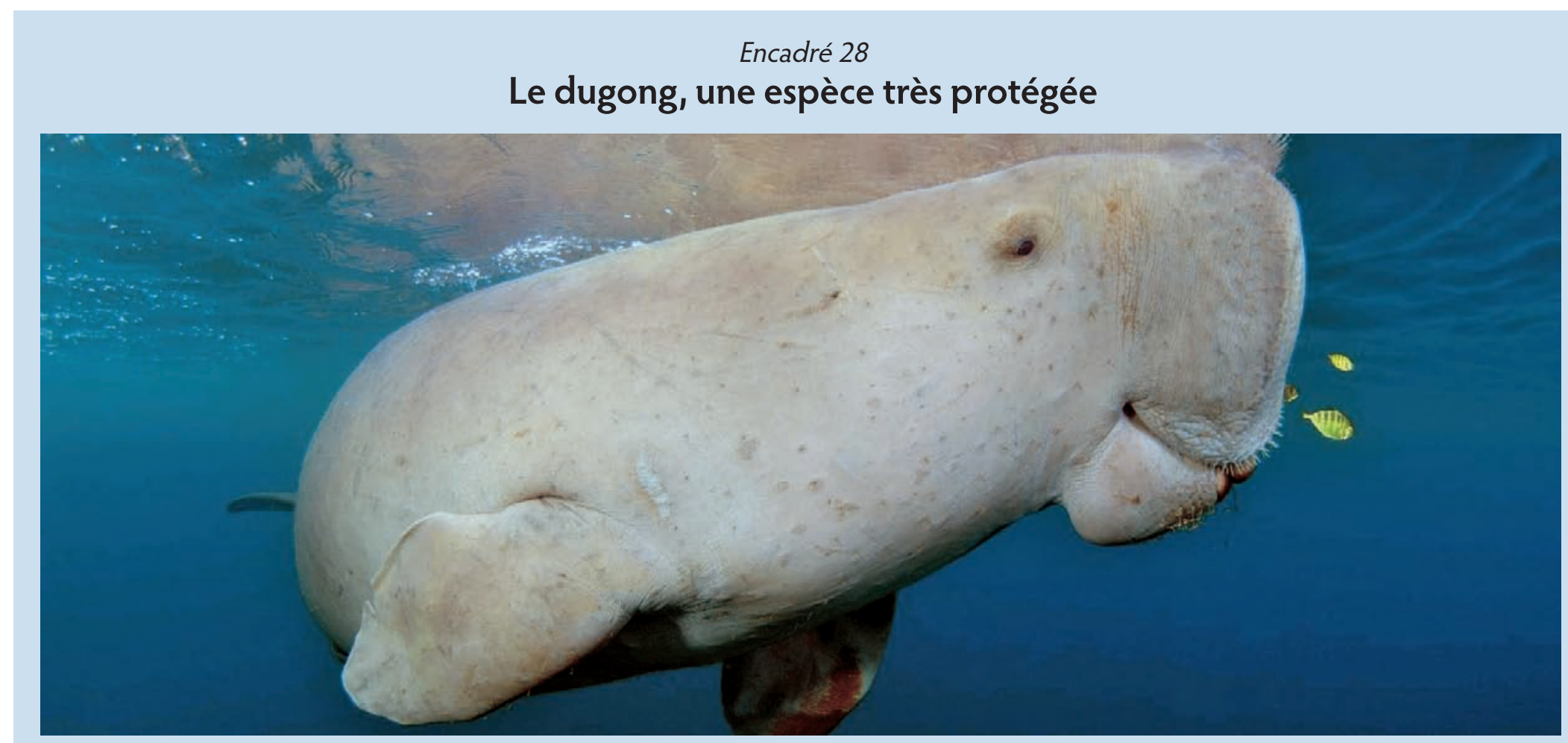

Un dugong entre deux eaux. Plusieurs cicatrices d'anciennes blessures sont apparentes à la surface du corps et témoignent des collisions avec des engins marins. @ M. Juncker

Le dugong est protégé par plusieurs textes internationaux. La Convention internationale sur le commerce des espèces menacées (CITES) de 1973 le répertorie dans son annexe I relative aux espèces les plus menacées. Elle en interdit « le commerce international de leurs spécimens ». Il est listé dans l'annexe II de la convention de Bonn de 1979 relative aux espèces migratrices appartenant à la faune sauvage (CEM), qui énumère les espèces ayant « un état de conservation défavorable ainsi que celles pouvant bénéficier d'une manière significative d'une coopération internationale » (CMS, 2009). Un mémorandum d'entente a été signé en 2007 et porte sur « la conservation et la gestion des dugongs et de leur habitat dans l'ensemble de leur aire de répartition ». L'espèce est également inscrite sur la liste rouge de l'Union internationale pour la conservation de la nature (UICN) dans laquelle il bénéficie du statut d'espèce vulnérable.
En Nouvelle-Calédonie, la chasse au dugong est interdite sur tout le territoire depuis 1963. Depuis 2004, la province Sud a totalement interdit la chasse, même pour un événement coutumier. En province Nord, des dérogations peuvent toujours être délivrées pour certaines fêtes coutumières. Cependant, le nombre de dérogations délivrées reste faible (15 entre 1995 et 2004, aucune depuis 2004). Un second plan d'action en cours (2015-2020) va permettre de garder cette dynamique et de s'atteler à d'autres problèmes majeurs tels que la lutte contre le braconnage et la capture dans les filets de pêche (intentionnelle ou non). D'autres actions suivront, comme le suivi du statut de conservation de l'espèce en Nouvelle-Calédonie, l'acquisition de nouvelles connaissances sur les dugongs de Nouvelle-Calédonie, et la poursuite de la préservation des dugongs par l'information, la sensibilisation et la mobilisation des Néo-Calédoniens. 
Aucun comptage aérien n'a pas été effectué aux îles Loyauté, mais tout porte à penser que très peu de dugongs y résident. Les dernières observations de dugongs aux îles Loyauté remontent à 2015 lorsqu'un dugong a été observé à Lifou puis à Ouvéa à un mois d'intervalle.

Les dernières estimations de la taille de la population, qui remontent à 2012, suggèrent qu'il reste moins d'un millier d'individus dans les lagons néo-calédoniens. Une estimation bien inférieure à la première mesure effectuée en 2003, qui s'élevait à 2000 dugongs. Bien qu'il soit impossible de confirmer une diminution de la population nous savons à présent que chaque individu compte pour la survie de la population. Ce statut précaire, confirmé par des analyses génétiques, se traduit par une fragilité des dugongs et sans doute une faible capacité de résilience. En d'autres mots, la mort de chaque animal par l'homme agit directement sur la survie de la population.

Les connaissances sur les causes de mortalité des dugongs en Nouvelle-Calédonie restent mal identifiées. Les échouages répertoriés ainsi que les diverses études menées sur les dugongs de NouvelleCalédonie depuis une dizaine d'années suggèrent que le braconnage, la capture accidentelle dans les filets de pêche et les collisions avec les embarcations marines constituent les principales menaces.

\section{Préservation}

Conscients de l'urgence à préserver la population de dugongs, un groupe technique réunissant les trois provinces, le gouvernement de la Nouvelle-Calédonie, le sénat coutumier, l'État, WWF-NC et Opération cétacés a lancé en 2010 un Plan d'actions dugong (PAD) pour une durée de cinq ans, animé par l'Agence française pour la biodiversité. Ce premier plan d'action dédié aux dugongs de Nouvelle-Calédonie visait avant tout à améliorer les connaissances sur l'espèce à l'échelle du territoire. Ainsi, un doctorat a permis d'étudier la variabilité temporelle de l'abondance et de la distribution des dugongs ainsi que leur utilisation des récifs néocalédoniens à différentes échelles spatio-temporelles (CLEGUER, 2015). Depuis septembre 2017 le CEN assure l'animation du PAD.
Cette étude a également permis de nourrir la réflexion engagée sur les stratégies de conservation du dugong sur le territoire. Une étude anthropologique mêlant savoirs traditionnels et pratiques actuelles est venue compléter ce projet en s'intéressant à la place du dugong dans la société néo-calédonienne (DUPONT, 2015). Enfin, deux études portant sur la génétique des populations de dugongs ont été menées afin d'établir la diversité génétique et d'explorer la connectivité de la population de dugongs de Nouvelle-Calédonie avec les populations voisines (OREMUS et al., 2015).

Les données acquises grâce à ces études scientifiques ont notamment permis de confirmer la fragilité de la population de dugongs de Nouvelle-Calédonie et de pointer les zones où les mesures de conservation et de gestion doivent être mises en place afin d'améliorer la protection de l'espèce. Des mesures ont déjà été prises comme la lutte contre les risques de collisions entre engins marins et dugongs.

\section{Références bibliographiques}

CLEGUER C., 2015 Informing dugong conservation at several spatial and temporal scales in New Caledonia. PhD. James Cook University, Townsville, Australia. $198 \mathrm{p}$.

CMS, 2009 Appendices I and II of the Convention on the Conservation of Migratory. Species of Wild Animals (CMS) :http://www.cms.int/en/legalinstrument/dugong DUPONT A., 2015 Évaluation de la place du dugong dans la société néocalédonienne. Plan d'action dugong Nouvelle-Calédonie 2010-2015. Rapport final, Agence des aires marines protégées (AAMP), $177 \mathrm{p}$. MARSH H., O'SHEA T.J., REYNOLDSJ.E., 2011 Ecology and conservation of the Sirenia: dugongs and manatees (no 18). Cambridge University Press, $521 \mathrm{p}$. OREMUS M., GARRIGUE C., CLEGUER C., 2015 Étude génétique complémentaire sur le statut de la population de dugong de NouvelleCalédonie. Rapport final, Opération Cétacés, 44 p. + annexes. 


\section{Des savoirs locaux pour gérer et réglementer les récifs}

Catherine Sabinot, Estienne Rodary, Marlène Dégremont, Victor David et Gilbert David

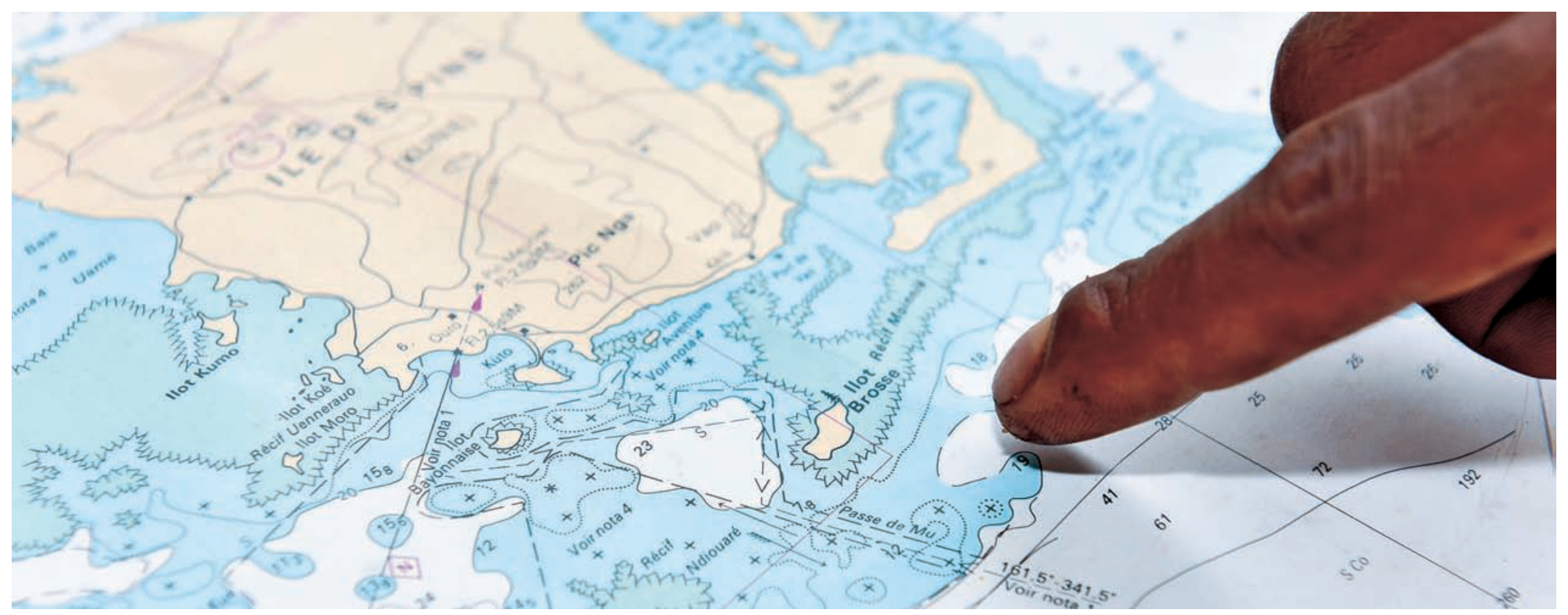

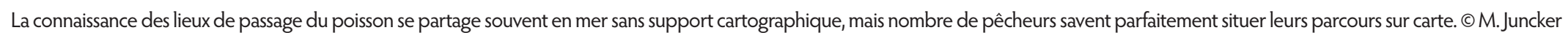

La Nouvelle-Calédonie est une terre peu peuplée, mais ses habitants sont des usagers passionnés des récifs et du lagon. Ceci oblige les autorités à mettre en place des mesures de gestion des espaces récifaux, c'est-à-dire d'organiser et de contrôler l'accès et les usages qui en sont faits. Cette gestion peut être faite par des professionnels, appuyés par un savoir technique et scientifique, avec des objectifs principalement fixés par l'écologie et la biologie, ainsi que par les engagements internationaux, impliquant eux-mêmes des enjeux à la fois écologiques et politiques. Dans la plupart des cas, ce sont les savoirs scientifiques qui sont mobilisés pour créer les règles visant à maintenir un « bon état » écologique. Toutefois, la gestion du lagon peut également être définie par d'autres types de savoirs, complémentaires des savoirs scientifiques, tels les savoirs locaux «vernaculaires ». Portant en eux des valeurs et des normes locales, parfois dites «traditionnelles », ils sont détenus par différents acteurs et différents groupes sociaux qui utilisent les récifs, et sont parfois liés à des pratiques de gestion durable. Connaître et prendre en compte les savoirs locaux peut informer les savoirs scientifiques comme directement guider les pratiques d'usage des écosystèmes. Enfin, intégrer les différents usagers dans l'élaboration de règles communes favorise l'efficacité de la gestion. Quand ces règles se traduisent en lois, gouvernementales ou provinciales, supposées être acceptées par tous, il y a davantage de chances que les réglementations soient respectées par les habitants de la NouvelleCalédonie si elles sont alimentées par ces savoirs locaux. Connaître, faire connaître et reconnaître les savoirs locaux constitue donc une étape essentielle des processus de construction et d'évolution des réglementations en matière environnementale. 


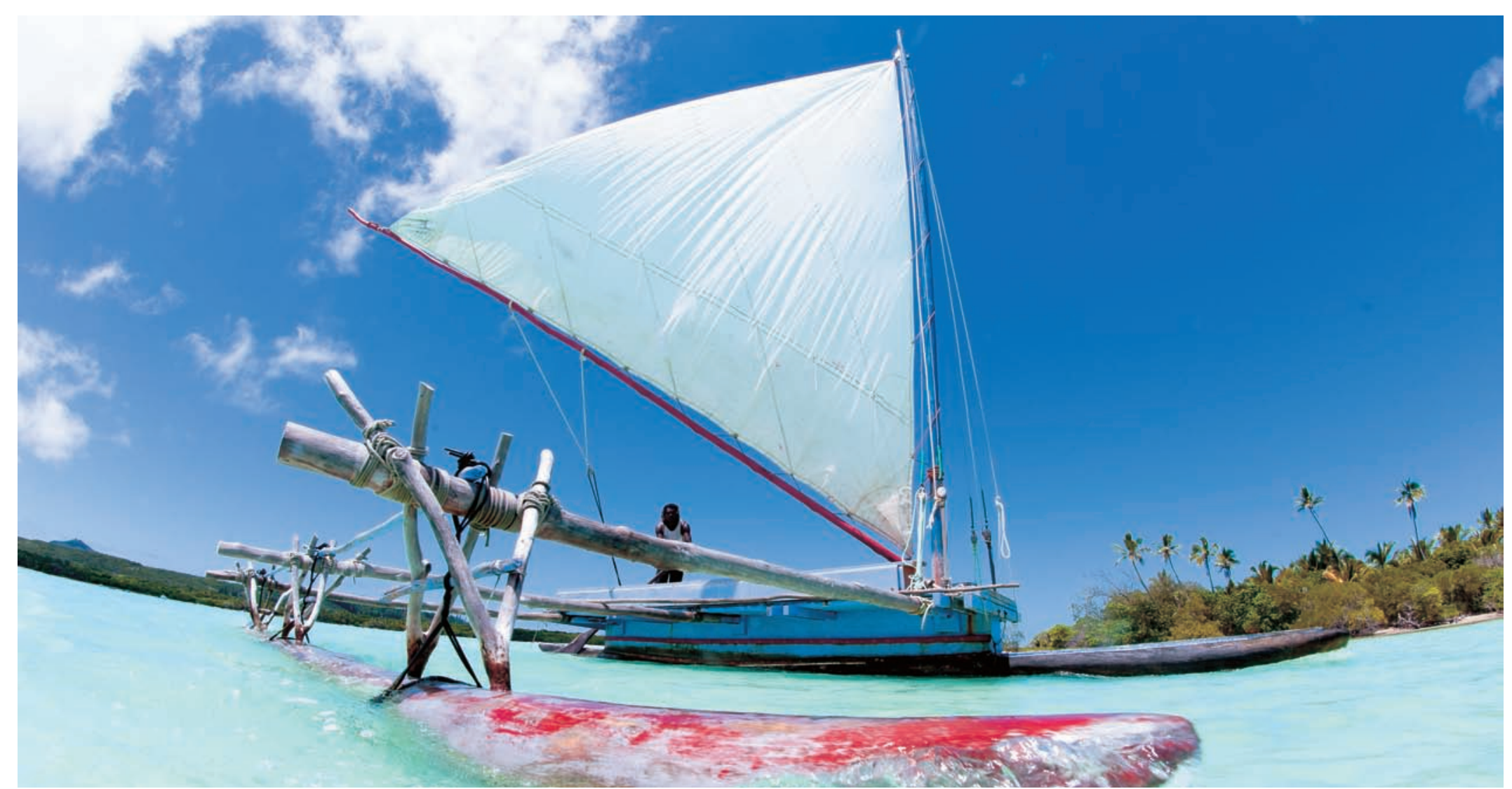

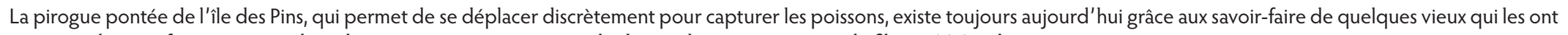
transmis à leurs enfants, tant pour bâtir la pirogue, que pour repérer les bancs de poissons et jeter le filet. @ M. Juncker

\section{Les savoirs écologiques locaux, fruits d'une expérience régulière du milieu}

« Lorsque les baleines arrivent, leur souffle ressemble à de la fumée. Cela rappelle la manière de brûler le champ pour le préparer. Elles tapent avec leurs nageoires, comme lorsque l'on plante l'igname » (Grand Sud). L'arrivée des baleines informe donc que le moment de planter l'igname est venu.

«Quand l'arbre iiletch est en fleur ou lorsque les roseaux oulek sont en fleurs, cela veut dire que les dawas (Naso unicornis) sont gras. Lorsque l'arbre wiitch fait des fruits cela signifie que les huitres sont pleines » (Hienghène). La floraison et la fructification de plantes terrestres informent ainsi que la saison est propice à la pêche et la collecte de certains poissons et fruits de la mer.

Les savoirs écologiques locaux sont des savoirs empiriques, liés à des pratiques, à un « engagement » avec les éléments de l'environnement. Les coraux, les passes, les poissons, les requins et bien d'autres animaux du lagon sont connus et racontés de génération en génération. Dans le monde kanak, ces savoirs se rapportent au monde des vieux. Ils sont aussi ressources alimentaires, sociales ou économiques. Ils s'acquièrent par l'expérience de chacun et sont donc sans cesse renouvelés au travers de relations régulières, $d^{\prime}$ interactions souvent quotidiennes, en particulier par des pratiques et des observations de l'environnement qui guident les pratiques de pêche et les déplacements sur le lagon. 


\section{Encadré 29}

\section{La gestion coutumière participative, ça marche !}

Luen lopué, Maël Imirizaldu et Sophie Katrawi

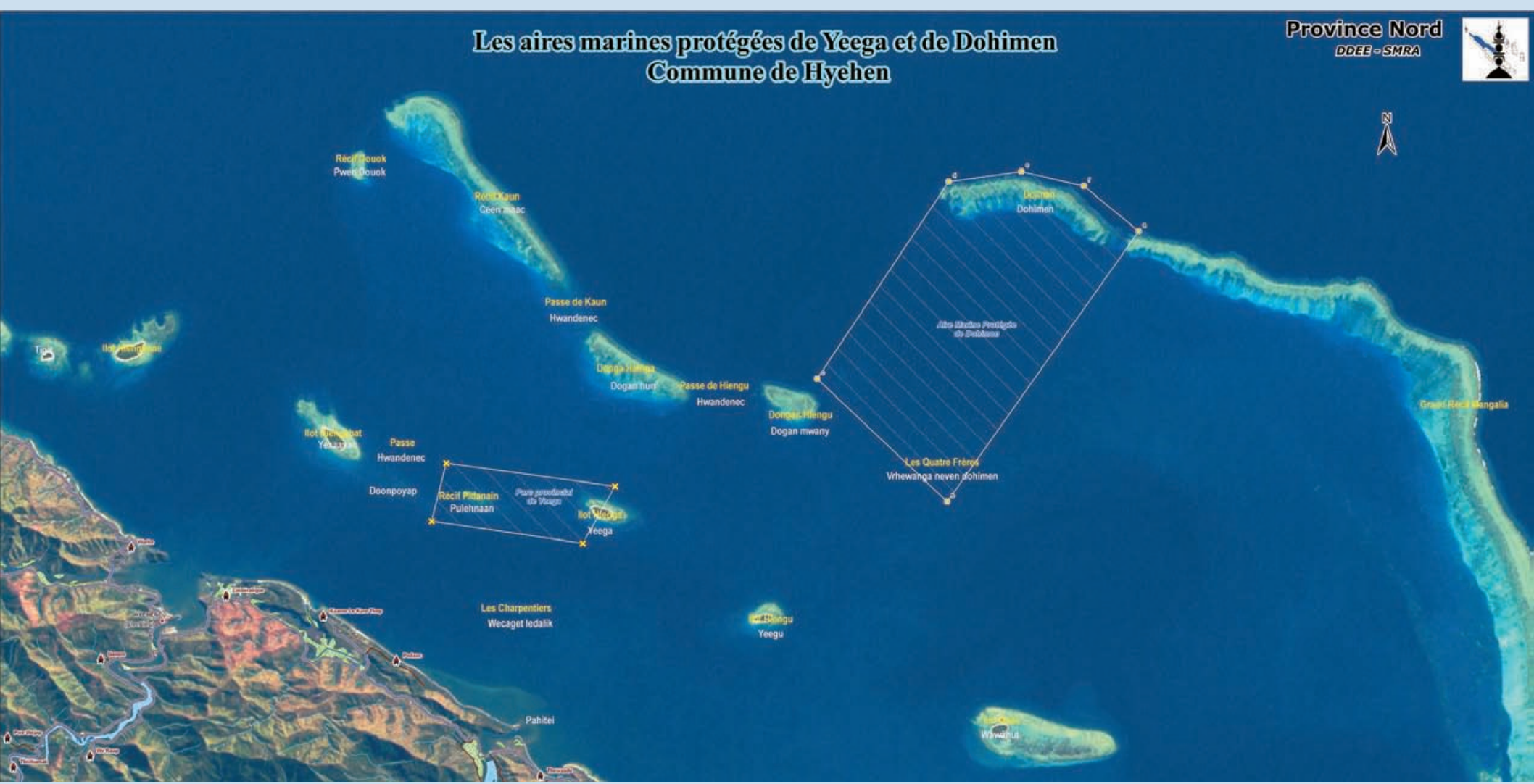

Aires marines protégées de Yeega et de Dohimen de la commune de Hyehen. Source : DDEE-SMRA, province Nord.

En Nouvelle-Calédonie, les quatre collectivités (gouvernement, province des îles, Nord et Sud) ont la compétence en matière de gestion de l'environnement ce qui les amène à travailler en étroite collaboration avec les coutumiers. En effet, ces acteurs ont souvent un rôle central dans la co-gestion des espaces maritimes. Même s'ils n'occupent pas physiquement l'ensemble de l'espace (qu'il soit marin ou terrestre), les coutumiers entretiennent avec lui un lien particulier. Ce lien peut être le fruit d'alliances, l'approvisionnement en ressources essentielles ou être tout simplement mythique. C'est un véritable attachement qui inspire la symbolique identitaire du peuple kanak et se traduit par une socialisation de l'espace, se décline en modes de vie et s'exprime par les légendes, les mythes et les pratiques. Les liens particuliers qu'ont les Kanak avec les territoires marin et terrestre ont été décrits de manière poussée par différentes études. Par conséquent, une attention toute particulière inscrite dans les accords de Nouméa et le préambule de la loi organique est accordée à l'intégration de ces caractéristiques culturelles dans le cadre de la gestion des espaces maritimes. 
Il en découle une gestion participative des sites néo-calédoniens. Par exemple, l'intégration des communautés locales dans la gestion des sites inscrits est une exigence de la part de l'Unesco dans le cadre du patrimoine mondial. Pour autant, dans le contexte néo-calédonien, la participation et l'implication des coutumiers a été centrale.

Cette gestion participative coutumière doit prendre en compte plusieurs aspects afin que la gestion se déroule au mieux sur le terrain, et pour paraphraser les coutumiers, que « les esprits des vieux veillent sur les hommes et la mise en œuvre des actions ».

Cela passe par le respect d'un certain nombre de pratiques liées à la culture kanak. « Faire la coutume », a-t-on l'habitude d'entendre. Mais cette expression recouvre plusieurs réalités. En effet, afin d'asseoir tous travaux dans un lieu donné, il faut commencer par l'introduire via un « geste coutumier ». Il s'agit de se présenter (montrer son visage), de s'abaisser pour demander de prendre la parole sans offenser les « vieux », d'exprimer sa demande ou de restituer des résultats et de faire un geste pour accompagner cette demande (igname, natte...). C'est le début de tout ce qui s'entreprend dans cette sphère.

La gestion participative coutumière intègre également un rapport à l'espace et au temps. En effet, au-delà des différences physiques (terre et mer, surface et contenu) le Kanak considère son foncier comme un tout (faune, flore, biotope), de la ligne de crête jusqu'aux récifs, voire au-delà de la ligne d'horizon (les récifs d'Entrecasteaux font partie de la chefferie de Dau Ar/Belep). D'ailleurs les récifs ont souvent des noms vernaculaires. Les collectivités doivent donc intégrer cette réalité dans leur politique de gestion. C'est ce que les trois provinces et le gouvernement de la Nouvelle-Calédonie s'efforcent de faire.

Le rapport au temps est souvent plus long. En effet, dans un cadre de gestion il faut souvent acter des orientations stratégiques, des actions à mettre en œuvre, ce qui requiert non pas l'adhésion de la majorité, mais le consensus de l'ensemble des familles et/ou clans

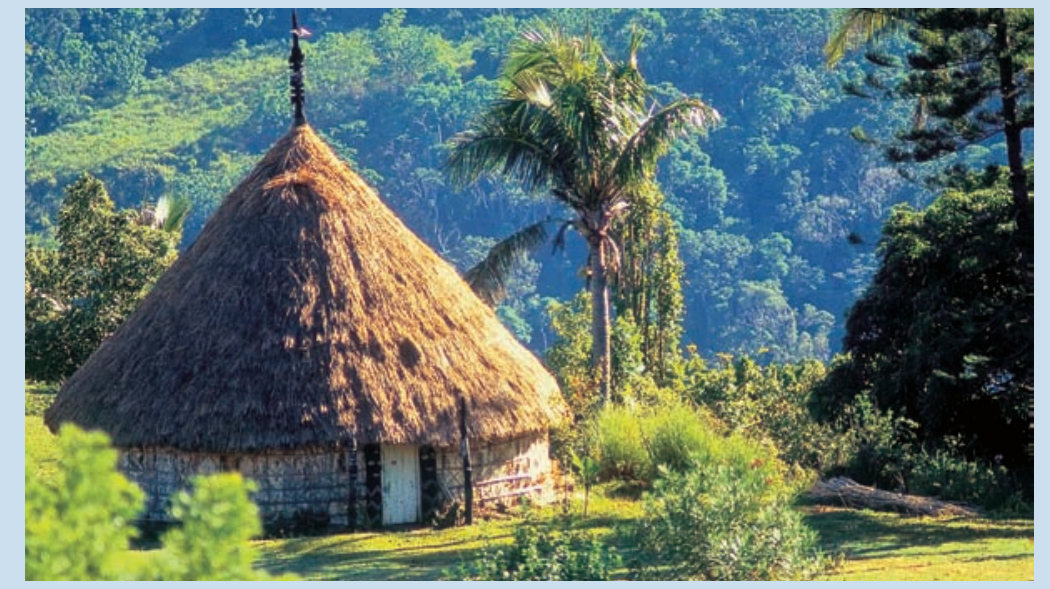

Case traditionnelle kanak, tribu de grand Atéou. @ P.-A. Pantz

concernés. Ce faisant la parole doit emprunter « les chemins de l'alliance » ou de sang pour que la décision soit actée. Ce cheminement de la parole est parfois long, mais nécessaire. Dans la pratique, des solutions sont trouvées afin de le faciliter.

Sur les sites néo-calédoniens, la gestion participative coutumière fonctionne bien. Les collectivités veillent à ce que les aspects coutumiers soient pris en compte dans la gestion et la mise en œuvre des actions, à l'instar de ce qui peut se faire en Australie, dans une certaine mesure. Les comités de gestion calédoniens, dans lesquels sont fortement représentés les coutumiers, constituent la formalisation de cette prise en compte. Ils en font des acteurs importants de la gestion et sont reconnus en tant que tel. Ainsi, des comités de gestion se rencontrent tous les deux ans sous l'égide du conservatoire d'espaces naturels (CEN) afin de faire le point sur la gestion des sites inscrits au patrimoine mondial de l'Unesco.

Enfin, le sénat coutumier possède un représentant au conseil d'administration du CEN, un représentant dans le comité de gestion du parc marin de la mer de Corail et dans d'autres structures devant se prononcer sur des questions environnementales : le conseil consultatif de l'environnement (CCE), le conseil économique, social et environnemental (CESE), les conseils d'aire, les conseils des jeunes. 


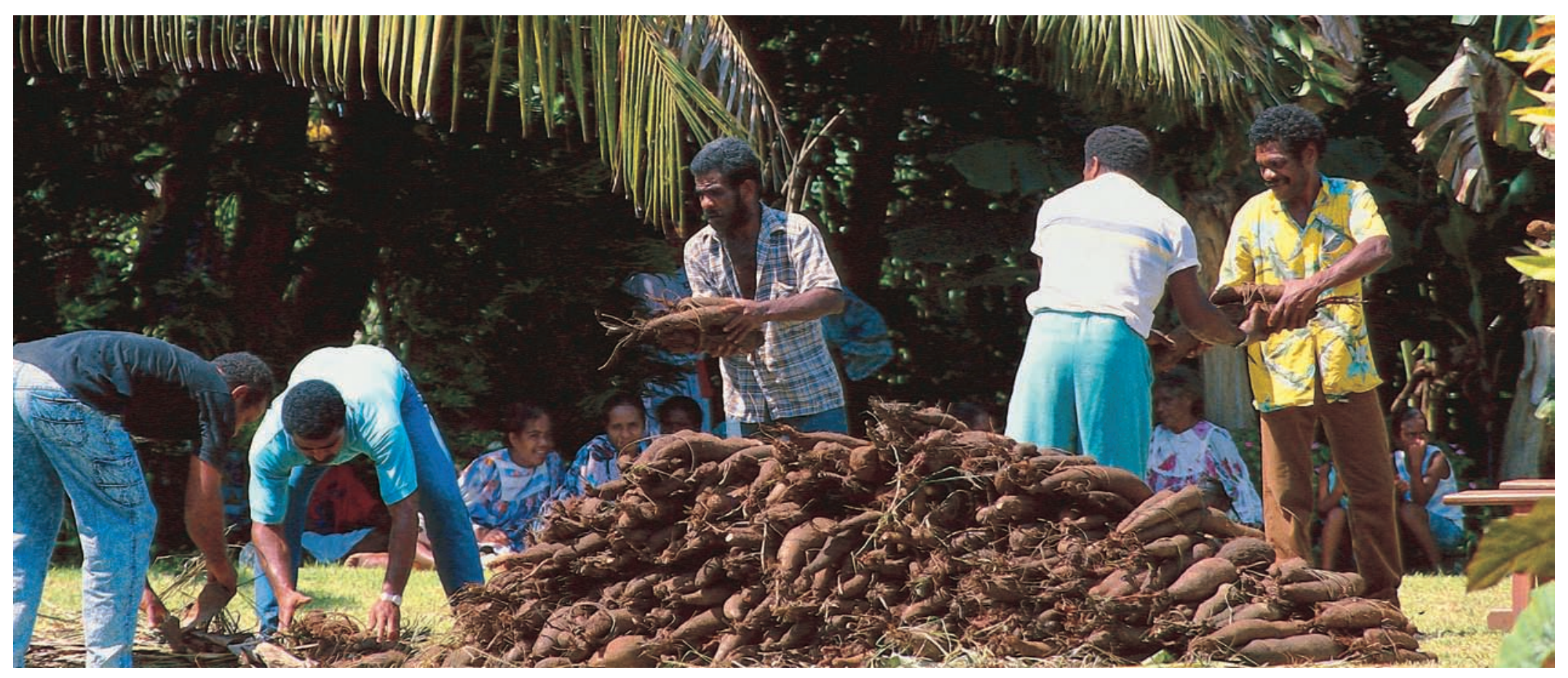

Préparation d'une coutume, île des Pins. @ P.-A. Pantz

\section{Des savoirs qui fondent une culture et des règles}

Une réserve coutumière constitue une zone fermée à la pêche de manière temporaire. Dotée de délimitations spatiales et temporelles flexibles, elle peut être ouverte occasionnellement à l'occasion d'événements coutumiers ou religieux. L'accès à la réserve peut relever de liens de parenté. Une réserve coutumière est généralement associée à une tribu, dans une logique de continuité territoriale entre la terre et la mer (encadré 29).

Contrairement à la réserve coutumière, un lieu tabou est permanent. L'accès à un site tabou implique un certain nombre de règles à observer telles que la demande d'autorisation à la tribu ou au clan associé, et la pratique d'un « geste » coutumier en signe de respect pour les ancêtres ou les entités qui peuplent les lieux. Ces lieux sont nommés et comportent une histoire connue par le « propriétaire » du savoir et donc du site.
Ceux qui habitent depuis longtemps à côté des récifs ont développé des savoirs particulièrement précis à son égard, savoirs qui font partie intégrante de leur histoire, de leur culture. Ces savoirs écologiques sont ainsi, pour les Kanak comme pour les autres communautés du territoire, à la fois le support et le ciment de leurs cultures. Ils sont les bases de relations sociales et de chemins, de liens, entre individus et entre groupes. Ils sont associés à des règles formelles et informelles de partage des territoires et des ressources. Ces règles, et les coutumes qui y sont associées, ont d'abord une fonction sociale et peuvent avoir des conséquences bénéfiques sur l'écosystème et assurer le maintien et la bonne santé $d$ 'un habitat ou de certaines espèces du lagon.

\section{Intégrer les savoirs locaux dans la gestion du lagon}

Dans le cadre de l'inscription des lagons néo-calédoniens au patrimoine mondial de l'Unesco, plusieurs comités de gestion ont été 
mis en place, regroupant l'ensemble des acteurs socio-économiques et institutionnels, ainsi que les représentants des populations riveraines.

Si la tortue verte Chelonia mydas est intégralement protégée en Nouvelle-Calédonie, il est possible d'obtenir des autorisations de chasse exceptionnelles pour des cérémonies coutumières. Ce système de dérogations a été mis en place pour tenir compte des spécificités de la culture kanak. Selon les provinces, il peut encore être aujourd'hui l'objet d'ajustements et de concertations avec le sénat coutumier, les aires coutumières et les populations afin d'affiner la norme lorsqu'elle produit localement des malentendus ou soulève des difficultés de mises en œuvre.

Le Code de l'environnement de la province des îles Loyauté, élaboré de manière participative, place la co-construction de règles relatives à l'environnement au cœur de la loi. Il s'agit de concilier les pratiques coutumières et les règles de droit issues de la « loi biodiversité » nationale de 2016 et d'objectifs internationaux. Les autorités provinciales peuvent désormais déléguer aux autorités coutumières le pouvoir de gérer les zones maritimes qui relèvent de leurs espaces d'influence, garantissant ainsi la prise en compte du droit endogène.

À travers ces exemples, on voit qu'il existe en Nouvelle-Calédonie de nombreuses expériences où se côtoient les savoirs locaux et les mesures officielles de gestion des espaces récifaux. Espaces de gestion « hybrides » où des aires marines protégées chevauchent des réserves coutumières ou des lieux tabous, prise en compte des usages de pêche pour définir le degré de protection des espèces socialement les plus emblématiques, etc. Cette pluralité assure le respect des mesures de gestion en officialisant certaines pratiques coutumières qui ne sont pas nécessairement connues par l'ensemble des usagers.

Ceci est d'autant plus important que, dans les sociétés kanak, l'organisation sociale et politique s'inscrit dans une relation au territoire qui comprend l'ensemble terre-mer. Les espaces coutumiers s'étendent de l'intérieur des terres (depuis les sommets de la chaîne sur la Grande Terre) jusqu'au récif et plus loin vers la haute mer. Les récifs, les îlots et les îles éloignées sont «marqués » par des toponymes qui témoignent d'une appropriation et de pratiques anciennes mais toujours présentes dans la tradition orale.
Face à l'hybridité des espaces et la pluralité des fonctions et des logiques coutumières évoquées ci-dessus, le droit doit donc s'adapter pour mieux protéger l'environnement comme on peut le voir en province des îles Loyauté.

\section{Faire dialoguer les savoirs}

En Nouvelle-Calédonie, les travaux des sciences sociales portant sur les relations entre les sociétés et leurs environnements, et donc sur leurs manières de « gérer » les espaces nommés « écosystèmes récifaux » par les scientifiques, sont souvent menés en interdisciplinarité (anthropologues, géographes, socioéconomistes, juristes mais aussi écologues et biologistes) et en relation directe avec les usagers et les détenteurs des savoirs locaux. Ce croisement entre différentes formes de savoirs rend possible la production de résultats utiles à la mise en œuvre de négociations éclairées entre habitants et décideurs, sans lesquelles il est difficile d'envisager des politiques de gouvernance des ressources naturelles appropriées, acceptées, acceptables, et durables.

\section{Références bibliographiques}

DAVID C., MEYER N. (éd.), 2012 L'intégration de la coutume dans l'élaboration de la norme environnementale : éléments d'ici et d'ailleurs, Bruxelles, Bruylant : 235-252.

LEOPOLD M. et al., 2013 La gestion d'un lagon en mutation : acteurs, enjeux et recherche-action en Nouvelle-Calédonie (Pacifique sud). VertigO, 13 (1): 1-18. SABINOT C., BERNARD S., 2016 « An emblematic marine species at a crossroads in New Caledonia: Green Turtle ». In : Fache E., Pauwels S., Resources, boundaries and governance: What future for fisheries in the Pacific? Pacific-credo Publications : 199-220.

TEULIÈRES-PRESTON M.-H., 2000 « Le droit maritime kanak et ses transformations ». In Bensa A., Leblic L., dir. En pays kanak. Ethnologie, linguistique, histoire, archéologie en Nouvelle-Calédonie Paris, Editions de la Maison des sciences de l'homme : 129-146.

WICKEL A. et al., 2016 « Valeur des lieux et gestion intégrée des zones côtières en Nouvelle-Calédonie ». In : Robert S., Melin H., Habiter le littoral. Enjeux contemporains, Presses universitaires d'Aix-Marseille, Coll. « Espaces et développement durable $»:$ 393-408. 


\title{
Chapitre 43 \\ Vers une gestion planifiée des réserves en Nouvelle-Calédonie
}

\author{
Laurent Wantiez, Emmanuel Coutures, Maël Imirizaldu, Michel Kulbicki et Laurent Vigliola
}

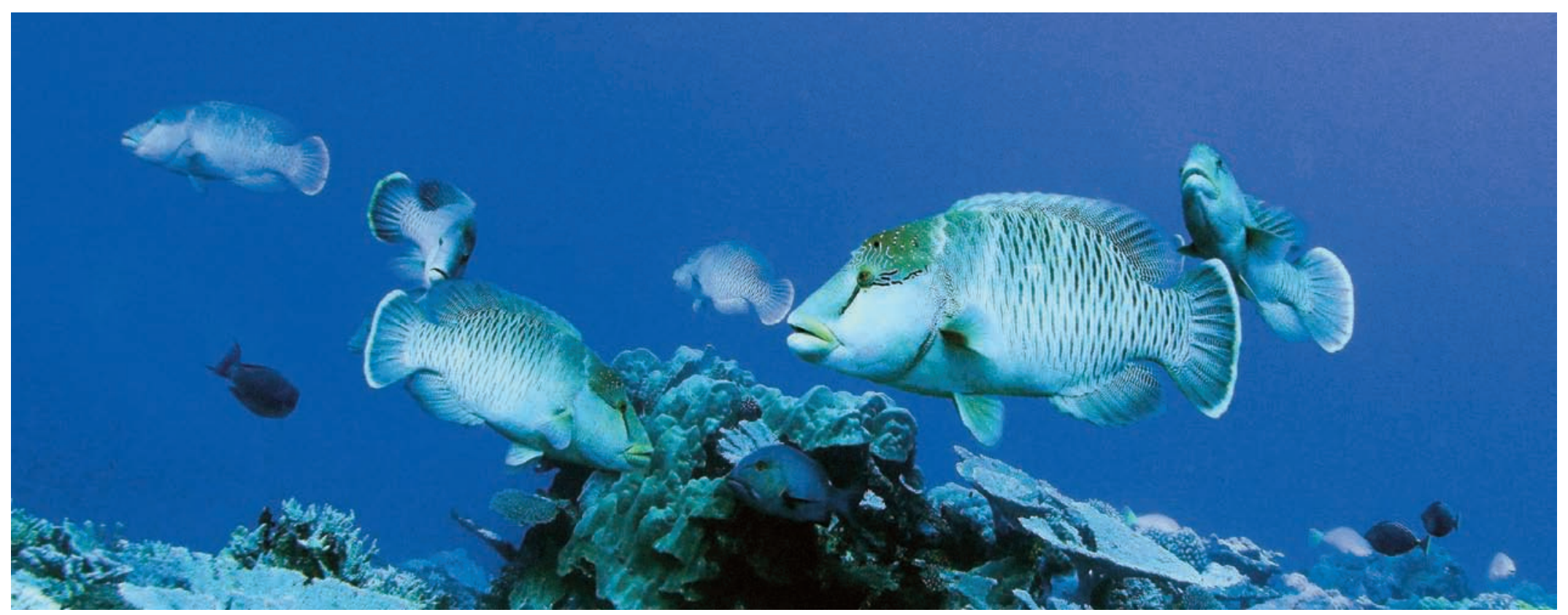

Napoléons juvéniles (Cheilinus undulatus). Cette espèce, classée en danger d'extinction par I'IUCN, s'observe dans les sites protégés. @ IRD/S. Andréfouët

Les récifs coralliens sont l'un des écosystèmes les plus menacés de la planète. Ils subissent de plein fouet l'impact combiné des changements climatiques globaux (réchauffement, élévation du niveau de la mer, acidification des océans) et des changements environnementaux locaux liés aux activités humaines locales (démographie galopante, pêche, pollution, dégradation des habitats). Ces pressions s'ajoutent aux perturbations naturelles (cyclones, acanthaster...), dont la dynamique destructrice est amplifiée par les changements environnementaux induits par les populations humaines. Conserver cet écosystème et préserver les ressources et les services qu'il fournit sont donc devenus des enjeux majeurs souvent traduits par un contrôle de l'extraction des ressources (sur les espèces, leur taille, les engins de pêche et la saison de capture) ou une protection des espaces (aires marines protégées).
Dans ce contexte, la Nouvelle-Calédonie a une position unique. Elle abrite le plus grand lagon du monde autour de la Grande Terre (19 385 km²), la seconde plus grande barrière récifale (1 600 km de long) après la Grande Barrière australienne et le tiers des récifs parmi les plus isolés et préservés de la planète. Par conséquent, les enjeux de protection y sont primordiaux à l'échelle locale mais aussi à l'échelle mondiale.

En Nouvelle-Calédonie, la mise en place de mesures de protection a été progressive et pragmatique. Elle s'est faite en parallèle à l'augmentation des pressions anthropiques et l'observation des premiers impacts, notamment de la diminution des ressources (pêche) et de la dégradation directe ou indirecte du paysage récifolagonaire (mine, urbanisation). La mise en place des premières 
mesures de protection dans les années 1970 s'est faite suivant une approche de «pragmatisme éclairé » répondant à une volonté d'agir malgré le déficit de connaissance. Aujourd'hui l'état de santé des écosystèmes coralliens néo-calédoniens ne serait probablement pas aussi satisfaisant si ce pragmatisme n'avait pas été le déclencheur et le carburant initial des politiques locales de conservation. Avec le temps et l'acquisition de connaissances sur la dynamique des systèmes, ces politiques évoluent progressivement vers une véritable stratégie de gestion planifiée.

Un des outils de protection les plus utilisés en Nouvelle-Calédonie cible la protection des espaces. Il vient en complément des réglementations sur les ressources en permettant de préserver la biodiversité et son environnement. Cette protection des espaces est familière au Néo-Calédonien, notamment avec l'utilisation historique de différentes formes de « réserves coutumières/traditionnelles » communes aux Océaniens, qui s'intègrent aujourd'hui progressivement dans la famille des aires marines protégées dites « contemporaines ». Le succès de cet outil réside dans sa simplicité relative de gestion et des effets avérés sur les ressources protégées, particulièrement les espèces exploitées.

\section{L'outil « réserve » en Nouvelle-Calédonie}

Les premières mesures de protection des espaces ont été prises en confrontant l'objectif de conservation (la réserve comme « gardemanger ») et l'analyse établie par les experts.

La première action significative a été la création de la réserve Merlet en 1970 (encadré 30). Cette initiative peut aujourd'hui être saluée pour plusieurs raisons. Elle a été prise à une époque où la conservation des récifs néo-calédoniens n'était pas un enjeu prioritaire. Elle est de grande taille $\left(173 \mathrm{~km}^{2}\right)$ et elle bénéficie du niveau de protection maximum (réserve intégrale). Ce statut de protection a été conservé jusqu'à aujourd'hui avec des moyens de surveillance accrus et un suivi régulier de son état de santé.

La seconde étape marquante a été la création des réserves du « parc du Grand Nouméa » (anciennement dénommé « parc du lagon sud »).
Ces espaces protégés sont des réserves marines réglementées où l'accès est autorisé, mais tout prélèvement interdit. C'est la prise de conscience de l'impact de la pêche sur les ressources des récifs coralliens proches de Nouméa, où la densité d'usagers et incidemment la pression plaisancière sont les plus fortes. Cette initiative s'est faite en deux étapes. Le phare Amédée et l'îlot Maître ont été protégés à partir de 1981 puis quatre autres îlots en 1989 (Bailly, Canard, Larégnère et Signal). Cependant, 1990 marque le début réel de la protection avec le déploiement du premier navire de surveillance, l'Isabelle. Parallèlement un suivi régulier (tous les 4 ans) de l'évolution de ces récifs a été engagé dès 1994 pour quantifier le succès de ces mesures. Leur statut a ensuite évolué en Aires de gestion durable des ressources (AGDR) ou en réserves naturelles selon les usages et éventuelles activités économiques qui s'y sont développées. À noter également, la mise en place de réserves saisonnières notamment pour la protection de sites de rassemblement de poissons pour le frai, tel que la passe de Dumbéa ou le Grand Port dans la baie du Prony. Par ailleurs, certaines initiatives ont été abandonnées par manque d'efficacité, notamment la réserve tournante des trois récifs-barrières situés face à Nouméa (Mbéré, Aboré et Kué), chaque récif étant successivement protégé pendant 3 ans.

Si la mise en place de ces premiers outils réglementaires de protection des espaces s'est faite autour de la capitale, ce mode de protection est utilisé depuis toujours par les populations autochtones au travers de ce que l'on appelle aujourd'hui les « réserves coutumières » (encadré 29). La conscience originelle de la propriété du lagon par les clans de la mer a conduit à la création de ces espaces communautaires protégés dont la vocation principale est de conserver «sa » ressource, notamment pour pouvoir en disposer lors de cérémonies coutumières majeures ou d'événements communautaires particuliers. Par exemple, cette situation a très probablement permis au Grand Lagon Nord d'être aujourd' hui une des formations récifales les plus exceptionnelles du territoire. Cette protection coutumière, qui a aussi un objectif de subsistance (pêches vivrière et artisanale), a évolué durant la dernière décennie vers une acceptation de la nécessité de s'adapter et d'intégrer ce mode de gestion aux règles de droits commun (protection réglementaire). Les objectifs associés ont continué d'évoluer de la seule protection des ressources («garde-manger ») à une volonté de conservation des 


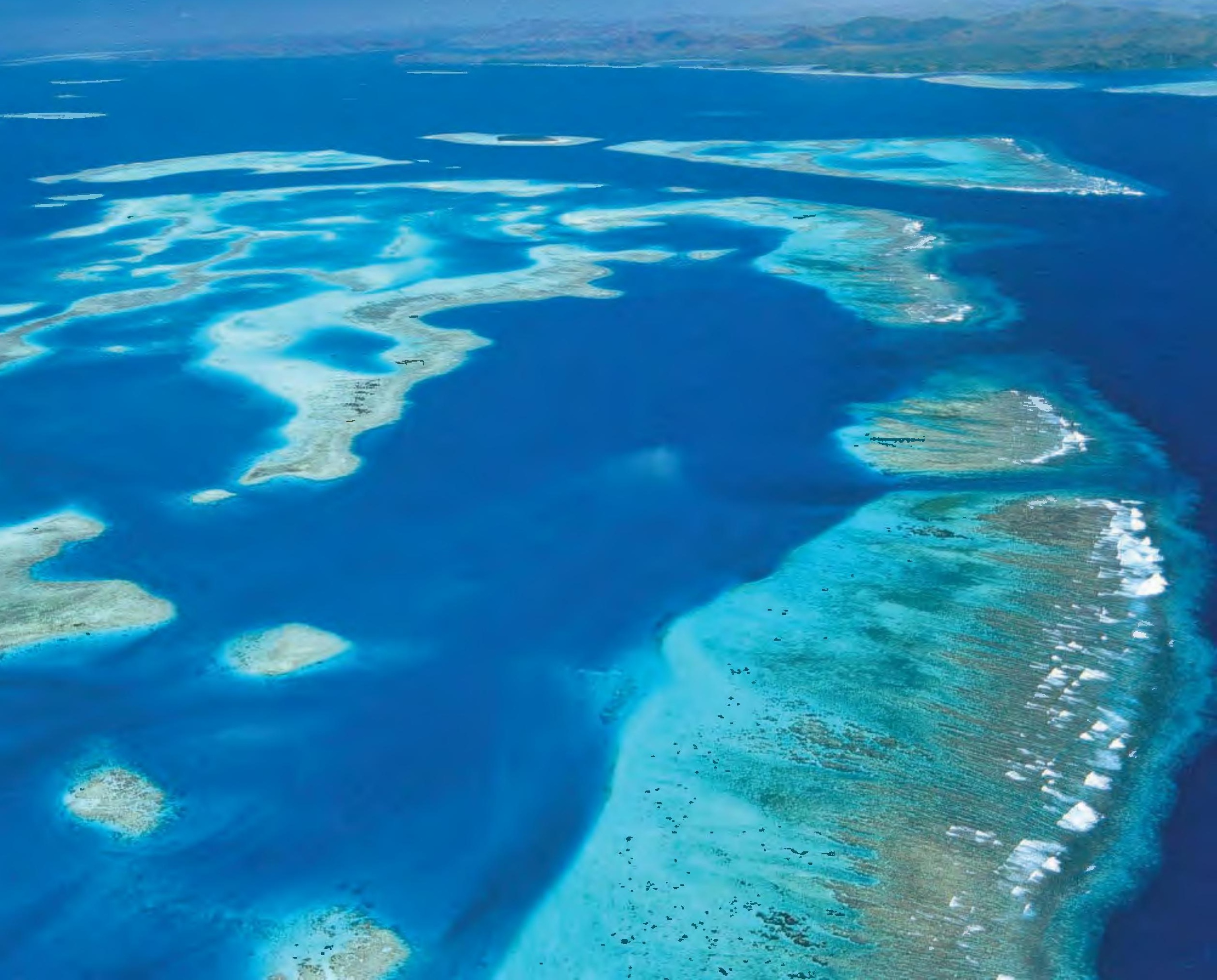




\section{La réserve Merlet, le joyau de la province Sud}

Emmanuel Coutures

Située entre les passes de la Sarcelle et de la Havannah, la réserve naturelle intégrale Yves Merlet, créée en 1970, constitue un sanctuaire pour la flore et la faune terrestre et marine du lagon sud. Cet espace maritime de 17200 ha, qui contient les îlots Améré et Kié, faisait déjà l'objet d'une gestion coutumière, officialisée par un procès-verbal de palabre entre la chefferie de Goro et le service territorial de la marine marchande. Désormais intégrée au parc provincial marin du Grand Lagon Sud (partie du bien inscrit sur la Liste du patrimoine mondial de l'Unesco), « la réserve Merlet » a pour objectif de conserver une zone récifo-lagonaire avec un minimum d'interactions anthropiques afin de maintenir son état sauvage. Cette sanctuarisation s'est accrue avec le temps ; les mesures dérogatoires pour l'organisation de pêches coutumières (mïkwaa, Chanos chanos, et tortues vertes), pourtant toujours prévues par le Code de l'environnement de la province Sud, ne sont plus mises en œuvre depuis près de 10 ans. La réserve fait l'objet de mesures de gestion spécifiques. Les autorisations à caractère scientifique de pénétrer dans « Merlet » et, a fortiori, d'y réaliser des prélèvements, sont de plus en plus rares et contraignantes.

Au regard de son statut et de la diversité de ses communautés coralliennes, la réserve Merlet constitue un site de suivi du Grand Lagon Sud. Entre 2008 (état initial) et 2013, le bilan de santé fait état d'un écosystème en très bonne santé sans impact anthropique significatif décelable (WANTIEZ et al., 2013). Elle abrite la diversité (plus de 100 espèces/station) et la densité (plus de 2,3 poissons $/ \mathrm{m}^{2}$ ) de poissons récifaux les plus importantes mesurées dans le cadre des suivis des récifs de Nouvelle-Calédonie. Les bénitiers y sont également très fréquents (95\% des stations), nombreux (4,9 individus/250 $\left.\mathrm{m}^{2}\right)$ et les trocas sont de grandes tailles $(9,7 \mathrm{~cm}$ en moyenne). Les espèces emblématiques sont fréquentes, notamment les tortues et les napoléons. Les gardes-nature réalisent entre une et cinq missions de surveillance de Merlet par mois, de jour comme de nuit, pour cinq à six infractions constatées par an. Avec le temps, la réserve Merlet est devenue la référence lorsqu'est évoquée l'importance environnementale et sociétale d'espaces de protection renforcée soustraits aux pressions humaines. C'est à la fois une fierté pour l'ensemble des Néo-Calédoniens et un joyau choyé et âprement protégé par la province Sud.

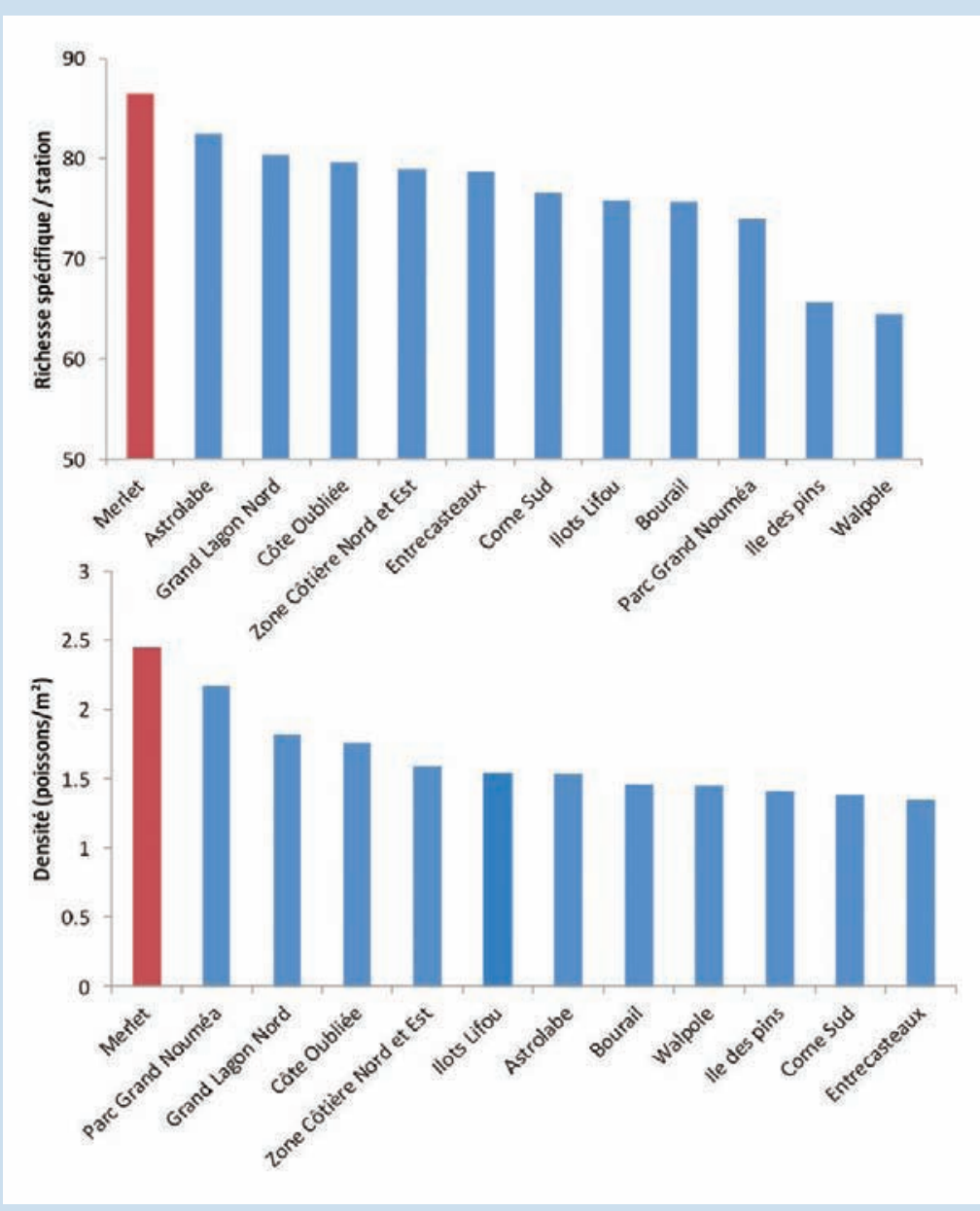

Nombre d'espèces par station et densité en poisson dans les principaux sites coralliens suivis en Nouvelle-Calédonie entre 2012 et 2014. @ UNC/L. Wantiez

\section{Référence bibliographique}

WANTIEZ L. et al., 2013 Communautés biologiques et habitats coralliens de la réserve Merlet. État des lieux 2013. Maintien de l'intégrité du bien. Province Sud de la Nouvelle-Calédonie, UNC, 86 p. 


\section{Encadré 31}

\section{Comment les enfants se représentent-ils le récif en Nouvelle-Calédonie?}

Jocelyne Ferraris, Georgeta Stoica, Catherine Sabinot, Pascale Chabanet,

Stéphanie M. Carrière, Claire Levacher et Marlène Dégremont

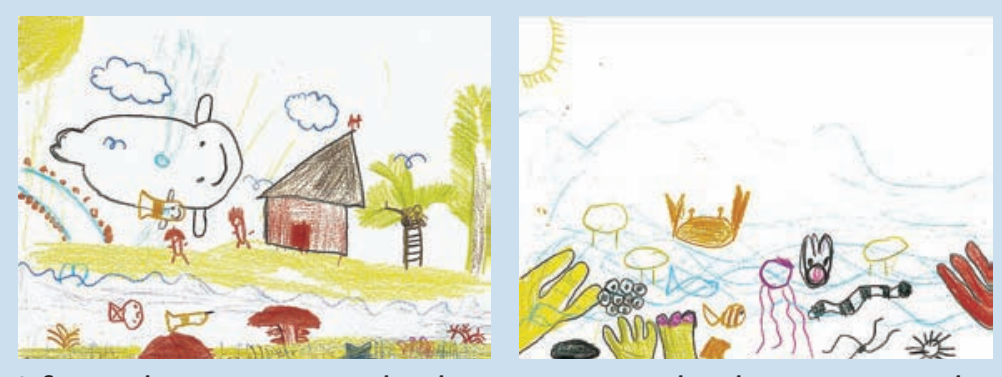

Influence du contexte socio-culturel et environnemental sur la représentation du récif corallien (après utilisation de la mallette MARECO).

A : Yaté, «La cascade de Wadiana » (c) J.-B. Agourere - B : Nouméa, « Le récif corallien ». ๑ M. Meray

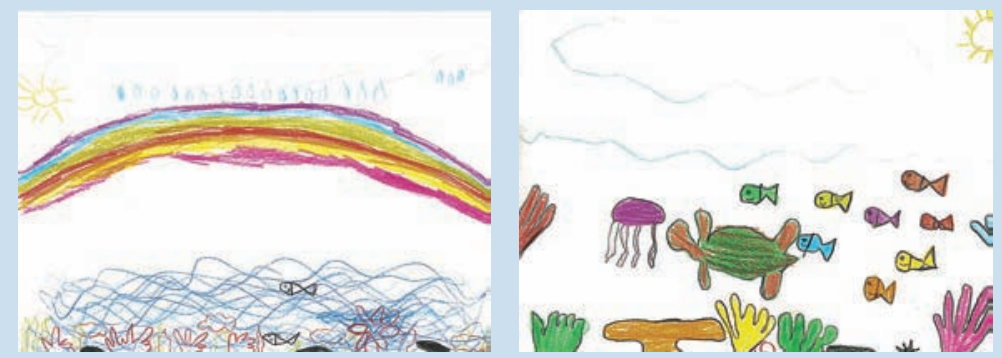

Dessins avant (gauche) et après (droite) l'utilisation de la mallette MARECO « Le récif entre nos mains » par Marie-Louise, 8 ans, école Isidore Noell. ๑ M. L. Xowi

Plus de 80 enfants de cinq écoles primaires de Nouméa (Boyer, Isidore Noell), la côte est (Thio et Yaté) et la chaîne (Coula) ont participé en 2016 à un programme de recherche interdisciplinaire sur les représentations des récifs coralliens . Ce programme, mené par une équipe de chercheurs en sciences naturelles et sciences sociales, visait à appréhender les savoirs, pratiques et perceptions liés aux récifs coralliens chez des enfants de 6-8 ans et à développer une méthode d'évaluation de l'impact d'une campagne de sensibilisation sur la vulnérabilité du récif dans quatre régions françaises (NouvelleCalédonie, Mayotte, Réunion et Pyrénées-Orientales).

\section{Découvrir l'écosystème corallien en s'amusant !}

Des dessins du récif corallien ont été collectés avant et après l'utilisation d'une mallette « Le récif entre nos mains » contenant trois jeux pédagogiques dont l'objectif est de transmettre des notions scientifiques sur la biodiversité, les perturbations, les usages et les modes de gestion de l'écosystème corallien. Les 1300 dessins, accompagnés des entretiens menés sur le terrain, sont analysés à l'aide d'une grille recensant et codant les éléments représentés, afin de comparer les représentations du récif corallien des 20 classes primaires impliquées dans le programme.

\section{Rencontre entre sciences et éducation}

L'analyse révèle une grande diversité des représentations chez les enfants aux profils socioculturels variés, mais également entre les milieux urbains, ruraux et côtiers, soulignant que les relations avec la nature ou l'environnement varient d'une école à l'autre en fonction des expériences directes et indirectes liées au récif. L'usage de la mallette MARECO se concrétise par un enrichissement de la connaissance de la biodiversité des récifs. L'immersion des scientifiques en milieu scolaire permet de mieux comprendre les savoirs académiques et empiriques et leur plasticité selon différents contextes, mais aussi leurs modes de transmission afin de contribuer à leur maintien, leur diffusion et leur amélioration. 
écosystèmes pouvant être valorisés économiquement (tourisme vert). Cette évolution a notamment conduit à la création des réserves de Pweevo et Hyehen sur la côte nord-est et des réflexions qui sont en cours sur l'île d'Ouvéa (Uvea/laai).

Les « temps modernes » sont marqués par le passage progressif du « pragmatisme éclairé » des débuts à une gestion planifiée, notamment par l'adoption d'un Code de l'environnement au niveau de chaque province. Deux initiatives majeures récentes illustrent également la prise de conscience des enjeux de protection et de conservation, l'inscription au patrimoine mondial de l'humanité des « Lagons de NouvelleCalédonie » en 2008 (15 $743 \mathrm{~km}^{2}$; chap. 46) et la création du parc naturel de la mer de Corail en 2014 (1 291000 km² ; encadré 5). Ces deux initiatives majeures engagent la responsabilité de la Nouvelle-Calédonie sur le long terme et seront couronnées de succès si elles s'accompagnent d'une politique de gestion forte et affirmée, d'une mise en œuvre des moyens adaptés aux enjeux et d'une cohésion de gouvernance.

\section{La réussite d'une gestion pragmatique}

L'utilisation pragmatique de l'outil « réserve » en NouvelleCalédonie est un succès qui s'appuie sur une chaîne de décisions : - la définition d'objectifs réalistes ;

- le choix d'une stratégie et d'un outil adapté à partir des connaissances disponibles;

- l'évaluation régulière des effets permettant une prise de décision informée et l'adaptation régulière des stratégies et objectifs de gestion.

Il est aujourd'hui admis que les réserves marines bien positionnées et surveillées ont de nombreux effets positifs sur les communautés protégées. Ces effets ont été vérifiés et démontrés à de nombreuses reprises en Nouvelle-Calédonie.

Les communautés de poissons des réserves du parc du Grand Nouméa se sont développées très rapidement après la mise en place des mesures de surveillance atteignant en 4 ans des niveaux spectaculaires. Le nombre d'espèces de poissons consommables a augmenté de $67 \%$, leur densité de $160 \%$ et leur biomasse de $246 \%$
(WANTIEZ et al., 1997) (fig. 1). Dans le même temps le nombre d'espèces et la biomasse des sites non protégés n'ont pas évolué et l'augmentation de densité y a été deux fois plus faible. Depuis 1994 les variations des populations protégées sont principalement naturelles (fig. 1). Elles sont notamment affectées par le passage de perturbations (cyclones) et se développent quand les conditions environnementales sont favorables. Les conditions océanographiques globales (El Niño/La Niña) semblent également affecter ces communautés.

Un second exemple type concerne les populations de langoustes dans la réserve de Ouano. Aucun spécimen n'a été observé dans la réserve et dans les zones non protégées adjacentes du réseau de suivi avant la création de la réserve et pendant 7 années après le début de sa surveillance. À partir de 2014, les langoustes sont devenues fréquentes dans la réserve de Ouano (plus de $50 \%$ des stations) alors qu'elles sont toujours absentes des observations dans les zones non protégées, bien que l'ensemble de la zone d'étude soit un habitat favorable pour ces espèces (WANTIEZ et al., 2015). Ce statut de protection a également permis le retour d'espèces emblématiques comme le napoléon.

La protection des espaces permet donc aux communautés protégées de se développer. À terme, elle a également un effet de « débordement » avec le déplacement de spécimens de la zone protégée vers les zones non protégées adjacentes, ce qui a également été montré dans le parc du Grand Nouméa pour des poissons commerciaux (saumonées, loches, perroquets) (CHATEAU et WANTIEZ, 2009). Ces différents effets se sont probablement produits dans tous les espaces protégés du territoire pour lesquels aucune donnée de suivi antérieure à la protection n'existe.

\section{Les limites des réserves néo-calédoniennes}

Les réserves marines sont un outil efficace. Néanmoins, comme tout outil, il a ses limites et ne peut régler l'ensemble des problèmes à lui seul. Il doit évoluer en fonction des connaissances et s'adapter aux enjeux environnementaux et sociétaux contemporains. 
Les suivis des récifs protégés de Nouvelle-Calédonie ont montré que les réserves ne pouvaient rien contre des phénomènes météorologiques majeurs (cyclones). En effet, de tels phénomènes ont un effet dévastateur immédiat et majeur sur l'habitat corallien et, par conséquent, sur les espèces qui y vivent. Un cyclone peut réduire à néant des années de protection. Par exemple, le cyclone Érica en 2003 a eu des effets destructeurs significatifs immédiats sur l'ensemble de l'écosystème du parc du Grand Nouméa avec pour conséquence une modification complète de la structure des peuplements qui était toujours significative à moyen terme (2 ans) (WANTIEZ et al., 2006), la restauration complète n'apparaissant qu'à long terme (10 ans) (WANTIEZ et al., 2014). Le temps nécessaire à la restauration est conditionné par l'absence de nouvelle perturbation pendant le processus, période pendant lequel l'écosystème est particulièrement vulnérable. Ainsi, les récifs se sont reconstitués à Nouméa, mais pas à Ouano où de fortes houles d'ouest en 2008 et 2009 ont anéanti les premiers signes de reconstitution de l'habitat corallien de cette région (WANTIEZ et al., 2015).

Par ailleurs, protéger un espace revient à augmenter l'effort de pêche sur les zones non protégées par simple transfert d'effort, dans un contexte où la pression qui s'exerce sur les récifs (pêche et usages non extractifs) augmente en Nouvelle-Calédonie. Par conséquent, si trop de récifs sont mis en réserve dans une zone où la population est importante, les effets pour l'ensemble des formations coralliennes pourront s'avérer plus négatifs que positifs. Il est donc nécessaire de trouver un optimum entre zones protégées et non protégées en fonction de la population et d'accompagner cette protection des espaces par des mesures de contrôle des prélèvements. Une alternative consisterait également à développer les activités économiques non extractives de manière à concilier développement économique et protection de l'environnement. Cependant, les usages non extractifs doivent également être régulés afin de minimiser leur impact environnemental. En effet, une réserve où tout prélèvement est interdit, mais où l'accès est autorisé est attractive pour la population qui vient y observer des communautés récifales en bonne santé (gros poissons par exemple). Ces espaces peuvent alors concentrer une population dépassant leur capacité de charge. Il suffit de dénombrer les bateaux présents dans les réserves du parc du Grand Nouméa les week-ends de beau temps pour s'en convaincre.
Les aires marines protégées sont souvent présentées comme l'outil idéal quand elles sont bien conçues et surveillées. Toutefois, malgré une protection efficace cet outil ne permet pas à l'écosystème corallien de retrouver des caractéristiques d'un système vierge de tout impact (D'AGATA et al., 2016). C'est le cas en NouvelleCalédonie, où les meilleurs résultats obtenus pour la réserve Merlet ne lui permettent pas d'atteindre la structure des récifs éloignés les plus préservés (Entrecasteaux, Astrolabe, Pétrie, Chesterfield...). Les différences sont les plus marquées pour les grands prédateurs comme les requins (JUHEL et al., 2018), mais aussi les espèces à forte valeur commerciale comme les bénitiers et les holothuries.
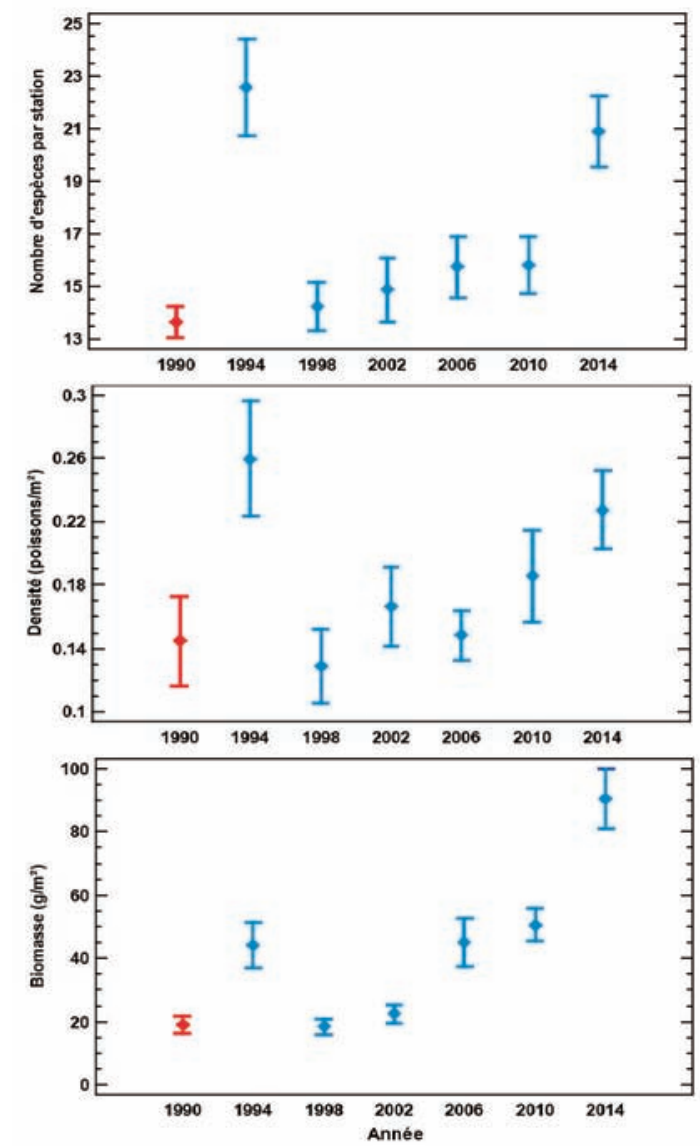

Figure 1 : Variations ( \pm erreur standard) de la richesse spécifique totale, la richesse spécifique par station, la densité et la biomasse des espèces de poissons commerciales dans les cinq réserves du parc du Grand Nouméa avant (en rouge) et après (en bleu) la mise en place des mesures de surveillance. Source : WANTIEZ et al., 2014 
Encadré 32

\section{Des récifs isolés bientôt sous haute protection}

Marie-Hélène Merlini et Julie-Anne Kerandel

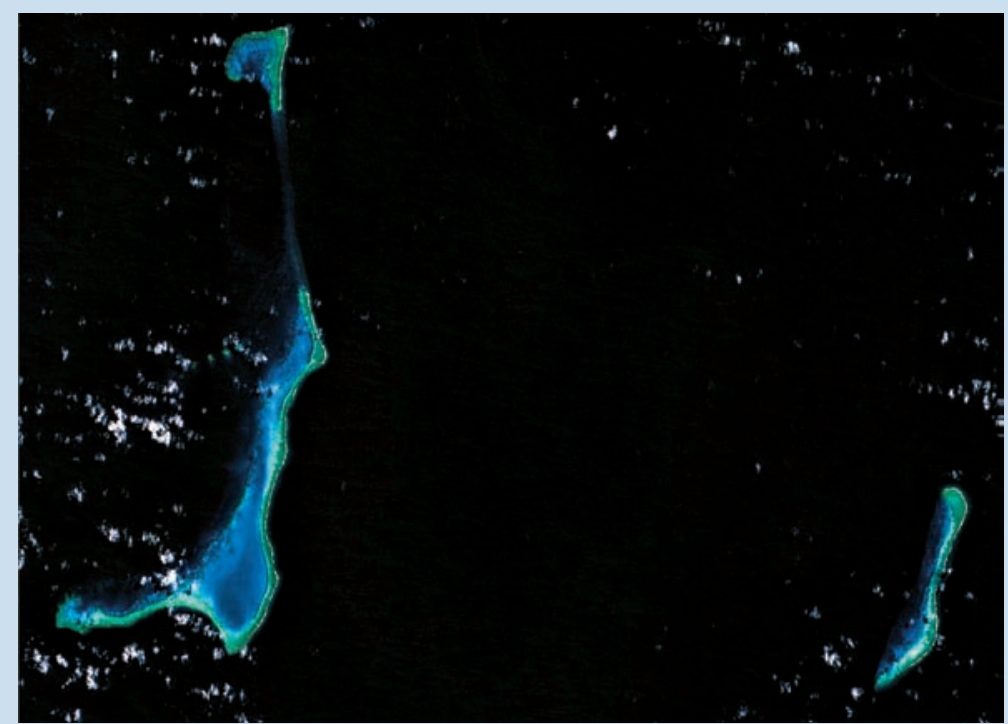

Récifs d'Astrolabe en image satellite. (image Sentinelle 2 du 15 mars 2018)

$1,5 \%$ des récifs dans le monde sont considérés « vierges » de tout impact humain. Le parc naturel de la mer de Corail abrite $30 \%$ des récifs les plus préservés.

\section{Pétrie et Astrolabe, des récifs exceptionnels}

Les récifs du parc naturel qui ont déjà été étudiés sont parmi les plus riches du monde et qualifiés par la communauté scientifique de Pristine. Les récifs Pétrie et Astrolabe, par exemple, abritent une des biomasses en poisson de récif parmi les plus élevées, se plaçant ainsi devant la plus grande réserve marine du monde aux Chagos (océan Indien). Chesterfield et Entrecasteaux devancent le récif de Kingman, jusqu'alors la référence mondiale des sites « vierges » du Pacifique. Ces études comparatives, menées en 2012 et 2013

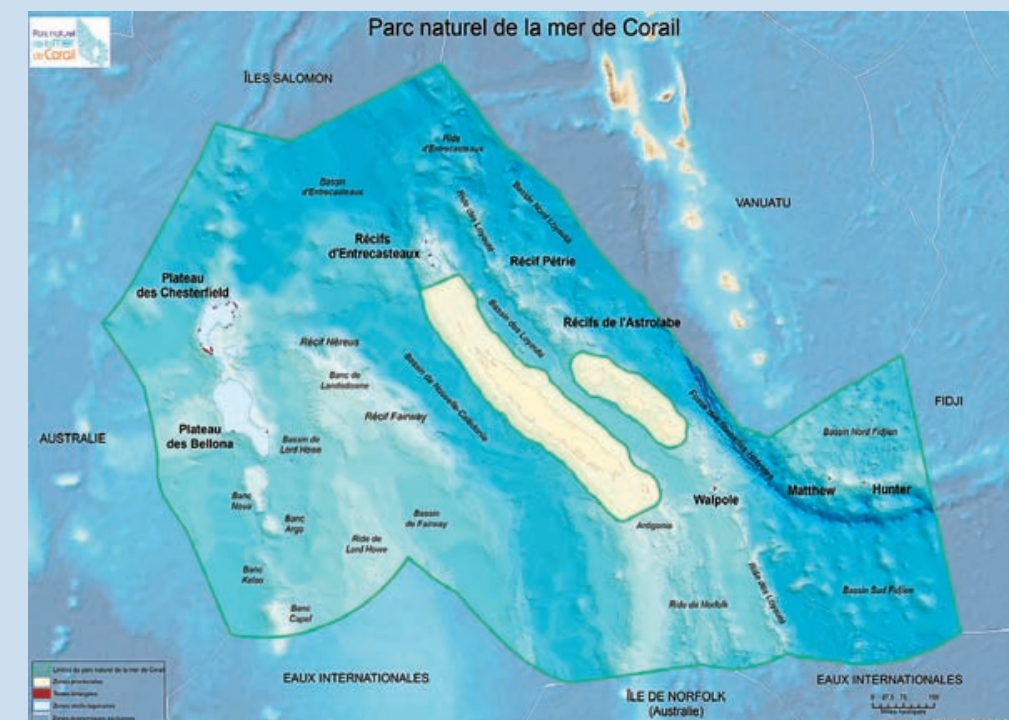

Parc naturel de la mer de Corail. @ Gouvernement de la N.C/DAM-NC/SPE

(projets «Pristine » et «Pristine Seas ») permettent de comprendre l'intérêt de réglementer l'accès aux zones d'intérêt écologique les plus éloignées de toute activité humaine.

\section{Entrecasteaux, un enjeu de préservation de la biodiversité}

Depuis le 23 avril 2013, le gouvernement de la Nouvelle-Calédonie a clairement affiché son intention de préserver les joyaux environnementaux de son espace maritime en instaurant par un arrêté une aire protégée aux atolls d'Entrecasteaux, la première réserve naturelle des eaux sous compétence du gouvernement. L'îlot Le Leizour et la partie végétalisée de l'îlot Surprise sont classés en réserve intégrale. L'ensemble des autres zones émergées, 
des eaux et des fonds marins compris à l'intérieur de l'aire protégée des atolls d'Entrecasteaux sont classés en réserve naturelle. Dans toute l'aire protégée, les activités liées à la pêche professionnelle sont interdites et l'accès à la zone est réglementé.

\section{Sanctuariser les récifs isolés, un des premiers axes de gestion}

Un an plus tard, le 23 avril 2014, le parc naturel de la mer de Corail est créé confirmant la dynamique de conservation et de préservation de tous les récifs éloignés de l'espace maritime néocalédonien. Même s'il est admis que l'éloignement des récifs coralliens est une protection naturelle, définir des mesures de gestion est aujourd'hui une nécessité absolue. Dans le plan de gestion du parc naturel de la mer de Corail, le premier objectif dédié au patrimoine naturel et culturel est de « protéger les écosystèmes et leur connectivité », notamment de « sanctuariser les récifs éloignés ». Cet objectif impose un haut niveau de protection pour les zones remarquables (récifs « Pristine »). D'ici à mi-2018, tous les récifs « pristine » (Chesterfield-Bellona et Pétrie-Astrolabe) seront classés par le gouvernement.

\section{Le maintien du cycle de la vie}

Un haut degré de protection contribuera à conserver les écosystèmes. Ces récifs servent par exemple de zones de reproduction et d'alimentation pour les requins de récif et les requins-tigres. Quant aux grands requins prédateurs, ils utiliseraient la zone Chesterfield-Bellona comme point de relais lors des migrations annuelles entre la Nouvelle-Zélande et la zone tropicale. Ainsi, les récifs coralliens sont des écosystèmes uniques d'une extrême importance pour le cycle de vie des espèces, et assurent la sauvegarde d'une vie sous-marine foisonnante et équilibrée. Instaurer une réglementation et y adjoindre les moyens nécessaires revient à faire un choix visionnaire et responsable à long terme.
Aujourd' hui les mesures de protection ciblent principalement les récifs coralliens qui représentent l'écosystème marin emblématique du pays. Cette approche a ses limites car elle ne prend pas en compte l'intégralité du paysage récifo-lagonaire qui fonctionne comme un patchwork d'écosystèmes fragmentés en relation. La conservation des récifs passe donc par celle, plus large, du paysage dans son ensemble. La « gestion réfléchie » qui se met progressivement en place en Nouvelle-Calédonie devra donc intégrer cette contrainte et des efforts significatifs devront être déployés pour préserver mangroves, herbiers et fonds meubles lagonaires qui sont aujourd' hui les parents pauvres de la protection. Il en est de même pour les montagnes sous-marines à la jonction entre les récifs isolés et ceux de la Grande Terre, les écosystèmes profonds et côtiers, pélagiques et récifaux.

\section{Références bibliographiques}

CHATEAU O., WANTIEZ L., 2009 Movement patterns of four coral reef fish species in a fragmented habitat in New Caledonia: implications for the design of marine protected area networks. ICES Journal of Marine Science, 66: 50-55.

D'AGATA S. et al., 2016 Marine reserves lag behind wilderness in the conservation of key functional roles. Nature Communications, $7: 12000$. doi : $10.1038 /$ ncomms 12000 .

JUHEL J.B. et al., 2018 Reef accessibility impairs the protection of sharks. Journal of Applied Ecology, 55, 673-683.

WANTIEZ L., THOLLOT P., KULBICKI M., 1997 Effects of marine reserves on coral reef fish communities from five islands in New Caledonian lagoon. Coral Reefs, $16: 215-224$.

WANTIEZ L., CHATEAU O., LE MOUELLIC S., 2006 Initial and mid-term impacts of cyclone Erica on coral reef fish communities and habitat in the South Lagoon Marine Park of New Caledonia. Journal of the Marine Biological Association of UK, 86 : 1229-1236.

WANTIEZ L. et al., 2014 Suivi du lagon du Grand Nouméa. Bilan de santé. Indicateurs de performance 2014. Province Sud de la Nouvelle-Calédonie, Université de la Nouvelle-Calédonie, 119 p. doi : 10.13140/RG.2.1.4067.4321. WANTIEZ L., FROLLA P., GOROPARAWA D., 2015 Communautés biologiques et habitats coralliens de Ouano (zone côtière ouest). État des lieux 2014. Maintien de l'intégrité du bien. Province Sud de la Nouvelle-Calédonie, Université de la Nouvelle-Calédonie, 78 p. doi : 10.13140/RG.2.1.2166.8888. 



\section{Les défis d'une modélisation de l'écosystème corallien}

Morgan Mangeas, Antoine Wickel, Jean-Brice Herrenschmidt, Catherine Sabinot, Pierre-Yves Le Meur, Laurent Vigliola et Gilbert David

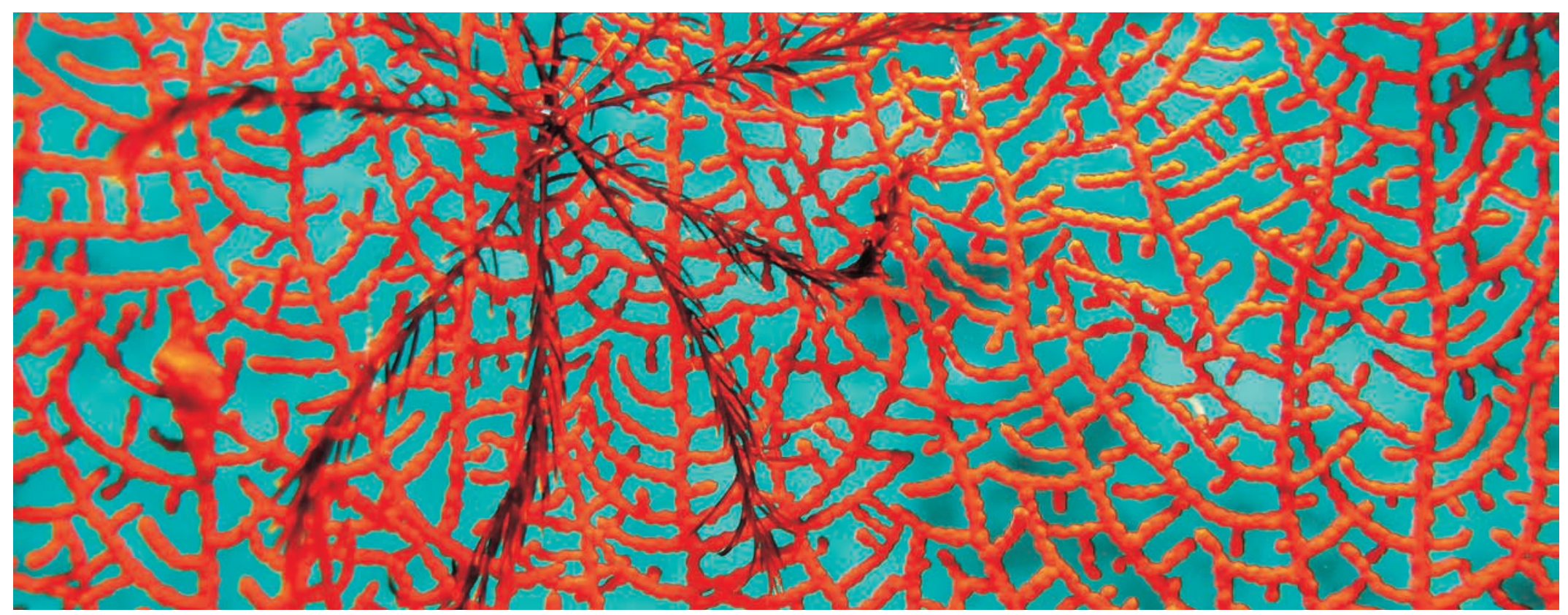

Gorgone et comatule, côte Est, 2012. @ IRD/J. L. Menou

L'écosystème corallien est complexe et sa santé dépend d'un équilibre entre les communautés biologiques qui y vivent et leur milieu. Lorsqu'ils sont en bonne santé, les récifs coralliens remplissent de nombreuses fonctions, traduites en termes de « services écosystémiques ». Ceux-ci contribuent au bien-être des communautés locales et participent au développement économique du littoral. Les récifs coralliens servent de support à des activités de loisirs et de tourisme, produisent de la biomasse qui participe au développement économique et à la sécurité alimentaire des populations via la pêche. Ils fournissent également d'autres services, comme la protection contre la houle et la séquestration du carbone. Les aspects culturels et patrimoniaux liés à cet écosystème à forte valeur symbolique et identitaire sont également essentiels aux niveaux local, national et international. La modélisation (encadré 33) de cet écosystème et des pressions auxquelles il est soumis, des interactions avec les acteurs humains et des liens avec les services écosystémiques représente un véritable défi. Les enjeux sont importants : modéliser l'écosystème corallien permet de mieux comprendre les règles internes et externes qui régissent ce système complexe et d'analyser finement les relations entre les briques élémentaires qui le constituent. La modélisation permet aussi d'estimer les réactions de l'écosystème corallien face à différents scénarios d'évolution des pressions environnementales et humaines. Enfin, en intégrant à la modélisation des variables de régulation, il est possible de déterminer quelle combinaison d'actions peut être efficace pour stabiliser cet écosystème et éviter une dégradation majeure. 


\section{Encadré 33 \\ Qu'est-ce que la modélisation?}

La modélisation consiste à définir un ensemble d'équations ou de règles destinées à décrire un phénomène et ses dépendances de façon reproductible et simulable. Le modèle ainsi généré sert à prédire le comportement d'un système en fonction de sollicitations connues. La modélisation nécessite généralement une phase de calibration qui consiste à estimer un jeu de paramètres afin que le comportement du modèle soit proche de celui attendu par des experts ou reproduise les observations passées.
Il existe plusieurs classes de modèle. On peut néanmoins faire la distinction entre une approche « mécaniste », qui met en équations les mécanismes biologiques, écologiques ou physiques induisant la dynamique du phénomène étudié, et une approche « statistique », qui se nourrit des données disponibles pour déterminer une fonction capable $\mathrm{d}^{\prime}$ ' « approximer » les interactions entre la variable à expliquer (le phénomène) et les variables explicatives (les facteurs qui influencent la dynamique).

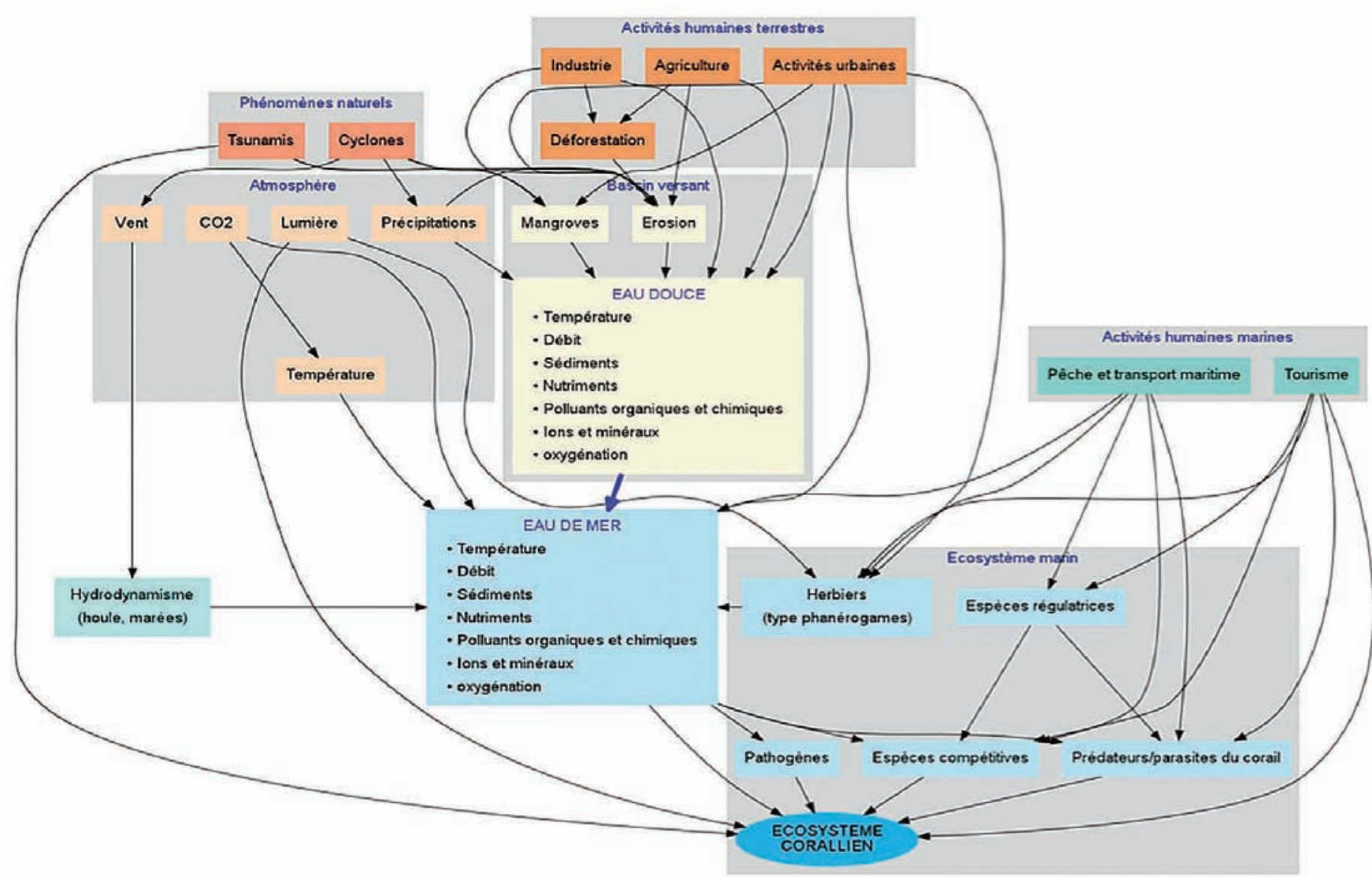

Figure 1 : Relations entre les principales causes génératrices de pressions sur l'écosystème corallien, les impacts potentiels et les différents indicateurs qui permettent d'évaluer l'état des milieux. Les flèches décrivent les relations connues entre ces différents éléments. Source : IRD/M. Mangeas 
Comme souvent avec les écosystèmes complexes, le modélisateur est confronté à des problèmes d'échelles spatiale et temporelle. Certaines pressions peuvent être ponctuelles comme un accident industriel qui rejette des pollutions chimiques dans le lagon perturbant massivement l'écosystème corallien à très court terme. $D$ 'autres peuvent agir sur plusieurs dizaines d'années comme la lente progression des températures de la mer $\left(+0,7^{\circ} \mathrm{C}\right.$ en moyenne depuis 1990), ce qui met à rude épreuve les capacités d'adaptation de la flore et la faune des récifs coralliens. De même, au niveau spatial cette fois-ci, la modélisation des processus agissant à l'échelle des colonies coralliennes nécessitera des informations détaillées et très localisées qui ne peuvent être disponibles à l'échelle d'un récif de plusieurs kilomètres carrés. La conception d'un modèle dépend donc de la nature du phénomène étudié et de la granularité spatiale et temporelle des données pertinentes disponibles. Enfin, un modèle adapté à une problématique représente toujours un compromis entre complexité, robustesse et capacité à simuler les observations.

\section{Pressions et impacts}

Le modèle de représentation des connaissances des pressions (ICRI, 2016) impactant la santé d'un écosystème corallien (fig. 1) constitue la première étape du processus conduisant à la mise au point d'une modélisation. Malheureusement, il reste encore de nombreuses zones d'ombre concernant les facteurs abiotiques (conditions physico-chimiques) et biotiques (interactions entre espèces) qui permettent aux systèmes coralliens de rester en bonne santé. Cela rend difficile leur traduction en équations. Il existe aussi peu de séries de données caractérisant simultanément l'état des milieux et la santé de l'écosystème corallien, qui permettraient d'estimer statistiquement les relations entre les différents éléments.

Le schéma devient encore plus complexe lorsque la santé de l'écosystème corallien est connectée aux acteurs socio-économiques et aux services induits par les récifs coralliens (fig. 2). On remarque en particulier que, si la santé de l'écosystème corallien se dégrade, certains acteurs sont susceptibles de réagir en constatant que les services écosystémiques sont impactés (moins de touristes, moins de poissons, activités de loisirs moins intéressantes...). Dans ce cas, ces acteurs feront pression sur les pouvoirs publics pour que des mesures de protection soient mises en place. D'où l'hypothèse d'un système dynamique, structuré par une boucle de rétroaction et d'autorégulation entre les acteurs et l'écosystème corallien.

Cette problématique complexe a été récemment abordée dans le cadre du projet de recherche Corail, financé par le programme européen Best et mené en Nouvelle-Calédonie et en Polynésie française entre 2013 et 2016. Les instituts de recherche, organismes et bureaux d'études impliqués dans ce projet ont travaillé en collaboration avec les décideurs et acteurs locaux pour appréhender et co-construire des développements méthodologiques et des outils de politiques publiques pour la gestion des écosystèmes coralliens. Les sites d'études étaient le Grand Sud et Hienghène pour la Nouvelle-Calédonie, et Opunohu et Moorea en Polynésie française.

\section{Réseaux bayésiens}

Un réseau bayésien (KJAERULFF et MADSEN, 2007) est un modèle graphique probabiliste représentant des variables aléatoires sous la forme d'un graphe orienté acyclique. Son architecture en réseau permet de retranscrire quasi directement les modèles de représentation des connaissances tels que ceux décrits dans les fig. 1 et 2. Les relations de cause à effet entre les variables ne sont pas déterministes dans ce type de modélisation, mais probabilistes. Ainsi, l'observation d'une cause ou de plusieurs causes n'entraîne pas systématiquement l'effet ou les effets qui en dépendent, mais modifie seulement la probabilité de les observer. L'intérêt particulier des réseaux bayésiens est de tenir compte simultanément de connaissances a priori d'experts et de l'information contenue dans les données. Les réseaux bayésiens sont surtout utilisés pour l'analyse des risques et pour l'aide à la décision. Mathématiquement, les états des variables représentant les nœuds dans le réseau bayésien s'évaluent à partir de techniques de calcul de probabilités conditionnelles et du théorème de Bayes (encadré 34). Un réseau bayésien simplifié peut par exemple modéliser les interactions entre écosystème corallien, services écosystémiques induits, pressions 


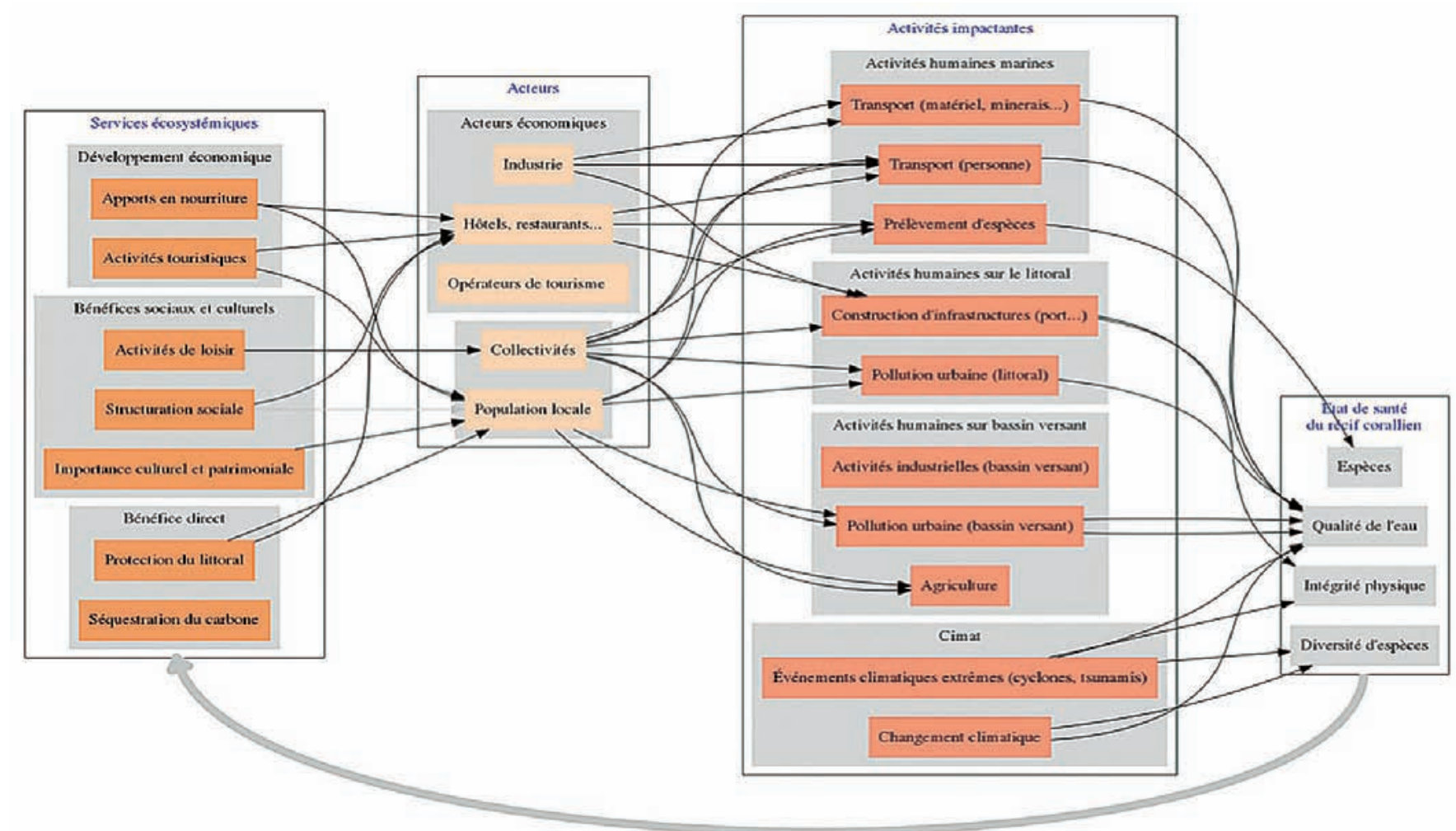

Figure 2 : Interactions entre acteurs, services écosystèmiques, pressions sur l'écosystème corallien et impacts potentiels. Les flèches décrivent les relations connues entre ces différents éléments. Source : IRD/M. Mangeas

humaines et perturbations naturelles (fig. 3). Ce modèle a été testé avec succès dans d'autres régions du monde, mais le manque de données rend son application difficile en Nouvelle-Calédonie. L'un des avantages des réseaux bayésiens est toutefois de pouvoir construire un modèle sur la base de connaissances expertes. Un modèle a été ainsi calibré sur certaines zones de Nouvelle-Calédonie sur la base des connaissances des chercheurs, habitants et praticiens du lagon et acteurs de la gestion de l'environnement.

La modélisation des rétroactions nécessiterait l'utilisation d'un modèle plus complexe comme un modèle bayésien dynamique (DBN). Cette approche simplifiée nous a permis cependant de déterminer les grandes tendances et de proposer des scénarios susceptibles de servir de guide pour la gestion des écosystèmes coralliens dans la zone étudiée.

\section{Site étudié}

Yaté est une commune de Nouvelle-Calédonie située au sud de la Grande Terre, à $80 \mathrm{~km}$ de Nouméa (fig. 4). Sa superficie est importante $\left(15^{\mathrm{e}}\right.$ commune la plus vaste de France) pour un faible nombre d'habitants (moins de 2 000). La population, résidant essentiellement sur une étroite bande littorale, pratique une activité de pêche traditionnelle sur les récifs faisant face à la commune. Or, depuis 2009, une des plus importantes usines de nickel au monde a été construite et est exploitée par l'opérateur minier brésilien Vale. Si le lagon et les récifs coralliens connexes à la commune sont toujours florissants, bien que soumis à plusieurs formes de pressions, la population a en grande partie délaissé la pêche pour des emplois dans l'activité minière. Le territoire offre un exemple type d'arènes de négociation multi-acteurs avec des enjeux très variés (risques 


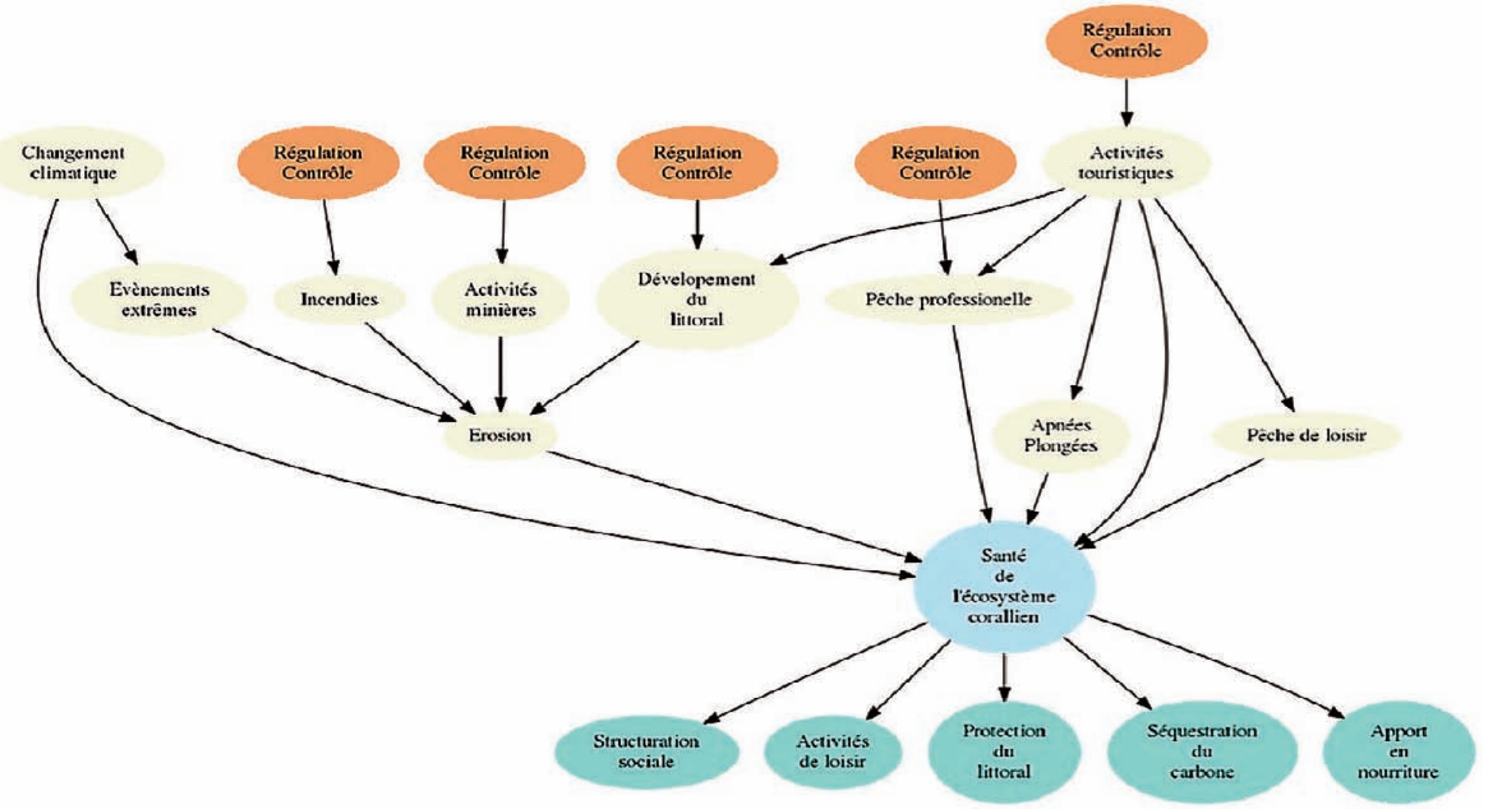

Figure 3 : Réseau bayésien simplifié. Source : IRD/ M. Mangeas.

\begin{tabular}{|c|c|}
\hline \multicolumn{2}{|c|}{$\begin{array}{c}\text { Encadré } 34 \\
\text { Le théorème de Bayes }\end{array}$} \\
\hline 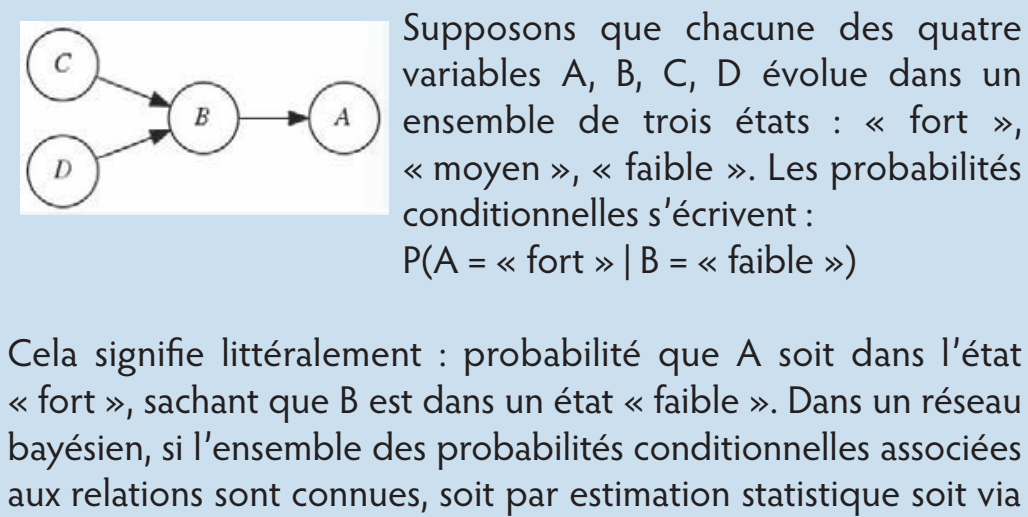 & 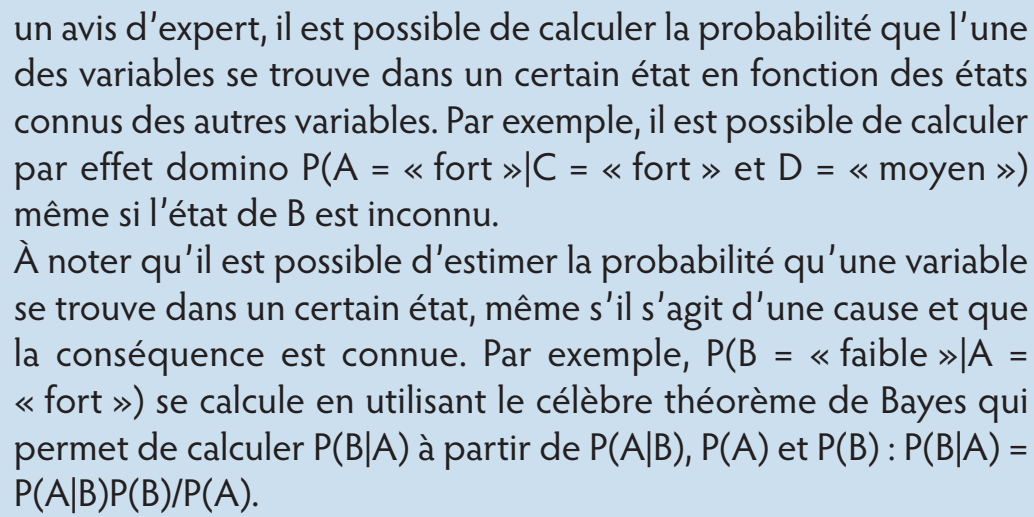 \\
\hline
\end{tabular}




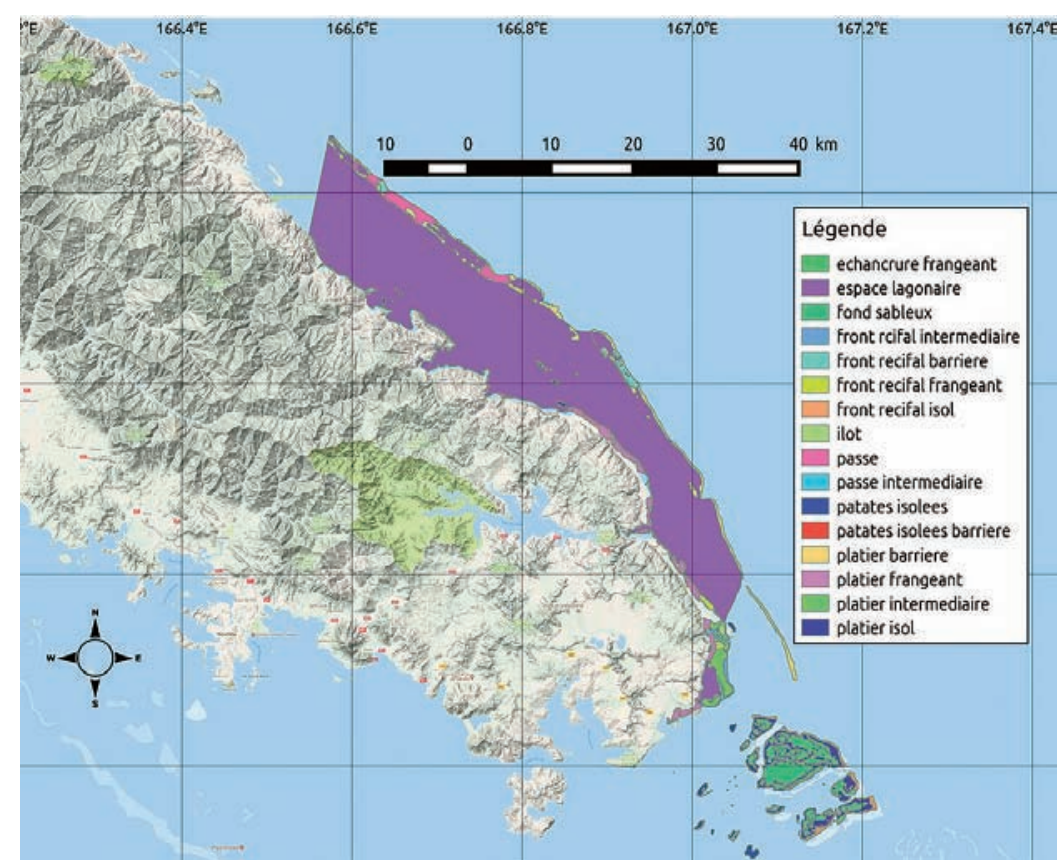

Figure 4 : Sites étudiés dans le sud de la Grande Terre de Nouvelle-Calédonie. Source : IRD/M. Mangeas

environnementaux, industriels miniers, usages vivriers...). Les négociations autour de la gestion de l'environnement et de la compensation des impacts miniers y sont d'ailleurs très actives, parfois conflictuelles et souvent médiatisées. Les données disponibles proviennent de l'ISEE (Institut de la statistique et des études économiques Nouvelle-Calédonie) pour les données socioéconomiques, du portail géographique de la Nouvelle-Calédonie pour ce qui concerne les données spatialisées et des données de I'OEIL (Observatoire de l'environnement en Nouvelle-Calédonie), pour ce qui concerne les données biologiques.

\section{Scénarios étudiés via la modélisation}

Le réseau bayésien simplifié a été calibré pour fournir des réponses satisfaisantes concernant les besoins et l'état de santé actuel des récifs coralliens de la commune de Yaté. Les différentes pressions ont aussi été évaluées et les impacts estimés par connaissances expertes. Il s'agit à présent d'exploiter la modélisation élaborée afin de fournir les tendances sur quatre configurations particulières. Les quatre scénarios, qui correspondent à des situations contrastées, mais possibles dans cette région, sont:

- 1 : Situation actuelle : état du récif et des services écosystémiques soumis aux pressions humaines et naturelles de ces dernières années ;

- 2 : Mise en place d'une réserve naturelle intégrale sur la zone intertidale et subtidale du lagon de la commune de Yaté correspondant au niveau de protection l.a de l'UICN ;

- 3 : Fermeture de l'usine de Vale : l'activité minière est interrompue entraînant le licenciement des employés qui doivent se reconvertir ;

- 4 : Accroissement de la population des villages alentour (forte urbanisation) : afflux massif d'une population dans la zone.

Les récifs coralliens de la commune de Yaté sont actuellement considérés en bonne santé (scénario 1), particulièrement dans les zones peu fréquentées, éloignées des lieux d'habitation. Cet état observé indique que les activités humaines et industrielles régulières impactent peu l'écosystème jusqu'à présent. Cet état observé ne tient pas compte des pollutions ponctuelles éventuelles engendrées par un accident industriel comme un dysfonctionnement de l'émissaire marin à proximité, qui évacue l'eau du complexe métallurgique du port de Prony jusque dans le chenal de la Havannah, et qui concentre une majeure partie des craintes en matière d'impacts sur les écosystèmes du lagon de Yaté.

Les résultats de projection du modèle concernant la santé de l'écosystème corallien et les activités de loisirs sont fournis sur la fig.5. Dans le cas du scénario 2, la protection la de l'UICN impose que tout prélèvement soit interdit dans la zone et le modèle prévoit que la santé de l'écosystème s'améliorera. En cas de fermeture de l'usine (scénario 3) le modèle prévoit une dégradation de l'écosystème en raison d'un retour des habitants à un mode de vie plus orienté sur l'exploitation des ressources marines. Enfin, dans une perspective d'urbanisation accélérée de la zone (scénario 4), la forte fréquentation plaisancière du lagon, l'aménagement du littoral et les rejets polluants liés à une forte concentration d'habitants pourraient engendrer des impacts importants sur les récifs de la zone. Sur la base des données disponibles le modèle semble donc indiquer qu'un accroissement important de la fréquentation aurait un impact plus important que 

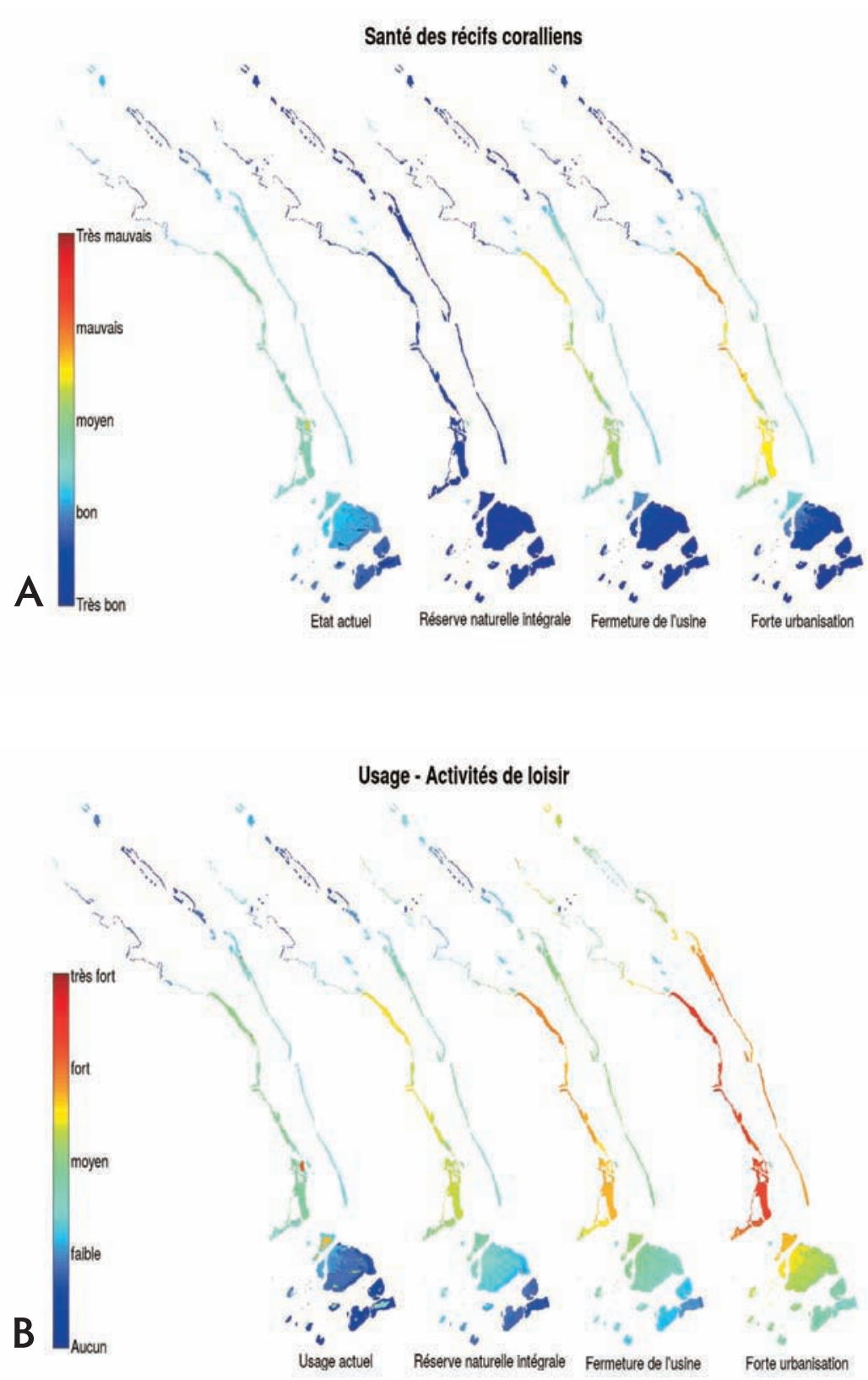

Figure 5 : Commune de Yaté, estimation spatialisée et évolution dans le cadre des trois scénarios étudiés.

A : Estimation spatialisée de la santé de l'écosytème corallien. B : Estimation spatialisée des activités de loisirs dans le lagon. Source : IRD/M. Mangeas

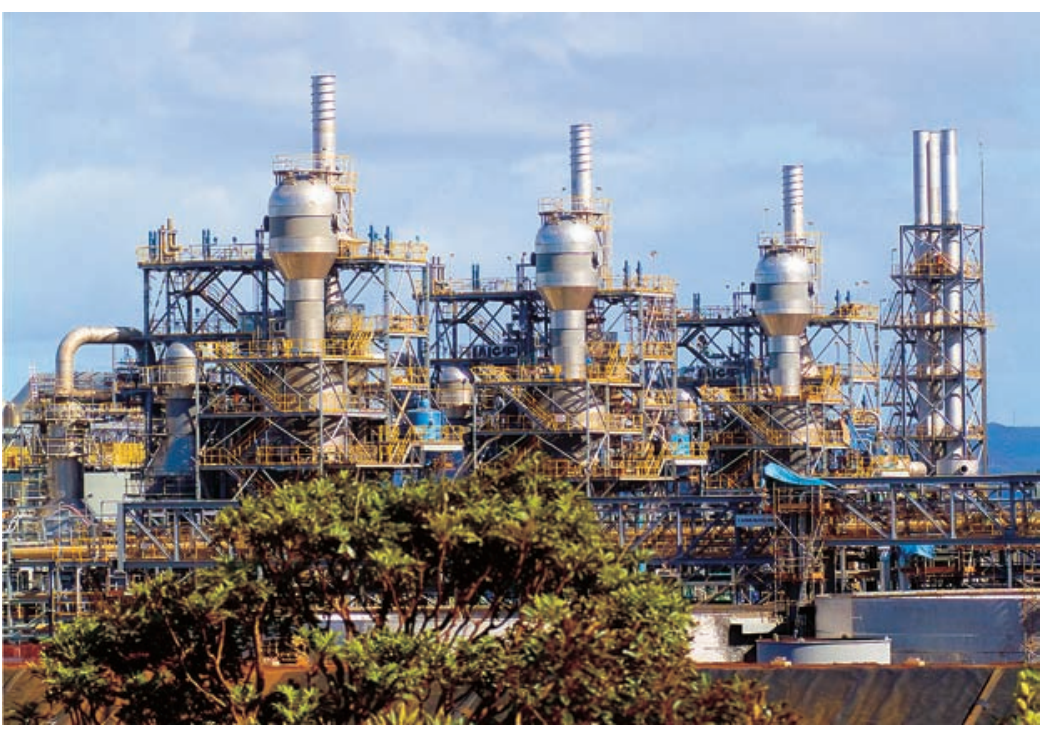

Usine Vale, Prony. @ P.-A. Pantz

celui des activités minières « courantes » (hors pollutions engendrées par un accident industriel). Néanmoins, ce modèle a été ajusté sur des données très parcellaires, notamment concernant les impacts environnementaux indirects et à long terme de la mine et de l'usine sur l'ensemble des composantes de l'écosystème corallien.

L'un des grands avantages de la modélisation réside dans la possibilité d'analyser toutes les situations qui résultent d'influences prises en compte dans le modèle. Ainsi, il est tout à fait possible de tester des scénarios combinant «mise en réserve » et «fermeture de l'usine » ou « fermeture de l'usine » et «forte urbanisation ». L'approche par réseau bayésien permet aussi d'identifier la cause la plus probable si une amélioration ou une dégradation de l'écosystème corallien est constatée en fonction de la zone concernée et de l'intensité du phénomène.

La modélisation de l'écosystème corallien et des pressions auxquelles il est soumis reste d'une grande complexité. Les changements sociétaux notamment restent difficiles à appréhender, beaucoup plus que les impacts directs quantifiables, mais tout autant que les impacts indirects avec des multitudes d'interactions entre espèces et variables environnementales. En l'absence de séries 
d'observations suffisamment longues et précises, la modélisation est fortement dépendante de connaissances expertes et nécessite une approche multidisciplinaire pour déterminer les intrications biologiques, sociétales et environnementales qui influencent l'état des récifs coralliens et déterminent leur capacité à produire des services écosystémiques. Dans le cas de la commune de Yaté, du fait des incertitudes autour des résultats, la modélisation représente plus un outil de concertation et d'analyse que de prédiction. La modélisation n'est d'ailleurs pas un but en soi ; pour qu'elle soit utile il faut en faire un outil convivial et performant de gestion afin que les acteurs et décideurs puissent l'exploiter dans des processus concertés de prise de décision.

\section{Références bibliographiques}

ICRI, 2016 Case studies: from ridge to reef, Implemented coaral reef conservation and management through a community-based approach emphasing land-sea connectivity, ICRI, Ministry of the environment, décembre 2015, $16 \mathrm{p}$.

KJAERULFF U.B., MADSEN A.L., 2007 Bayesian Networks and Influence Diagrams: A Guide to Construction and Analysis, New York, Springer-Verlag, 303 p. 


\section{Droit applicable aux récifs coralliens de Nouvelle-Calédonie}

Victor David

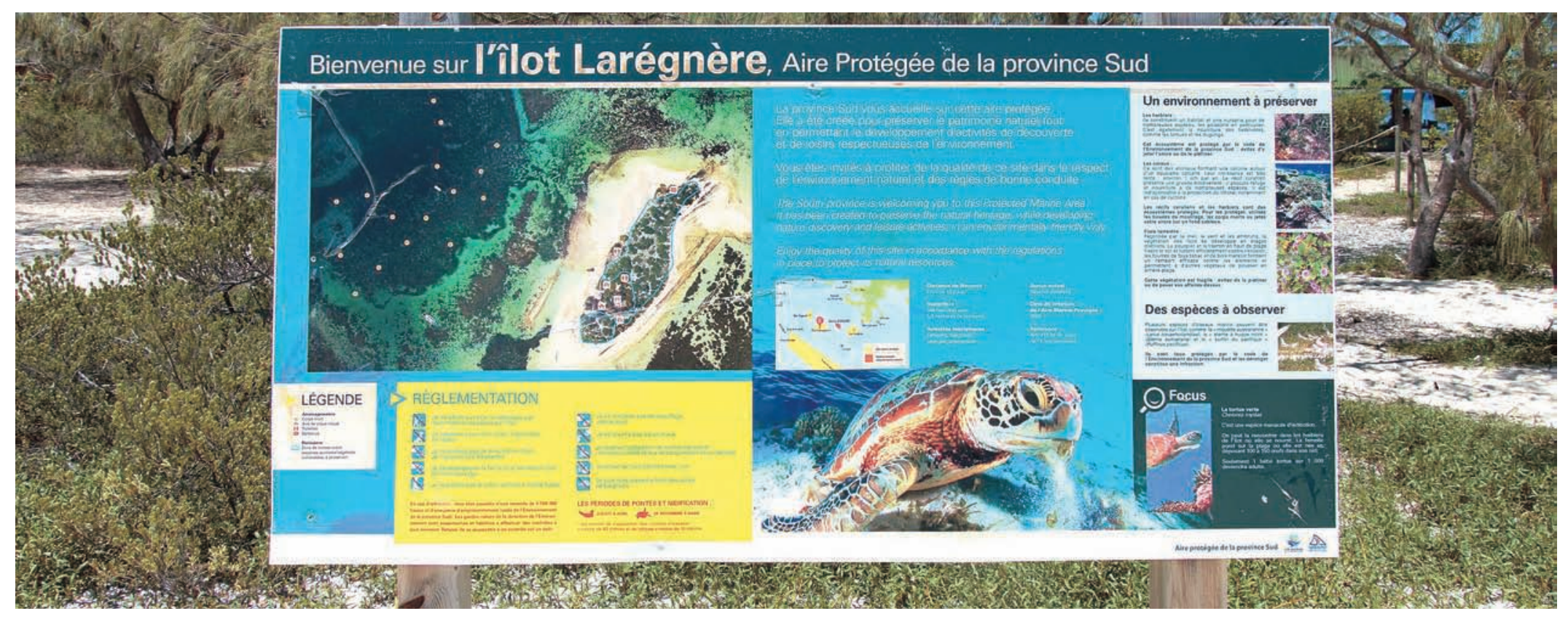

Aire protégée de la province Sud, îlot Larégnère. @ IRD-ENS/T. Berr

Quitte à surprendre le lecteur, on pourrait dire qu'il n'existe pas à proprement parler de droit applicable aux récifs coralliens de Nouvelle-Calédonie ! En effet, à la différence d'autres écosystèmes, force est de se rendre compte que, malgré l'importance des récifs coralliens à différents points de vue, largement développés dans cet ouvrage, malgré leur extrême vulnérabilité face aux aléas naturels et les dangers encourus d'origine anthropiques, il n'y a pas, à quelques exceptions près, de textes juridiques contraignants au niveau international, national, régional ni en Nouvelle-Calédonie dédiés aux récifs coralliens, véritables forêts tropicales des mers (sea rainforests). Il est important, avant de continuer, de clarifier les notions de droit contraignant (hard law) et de soft law.
Le « hard law » se réfère à des textes juridiques contraignants. Dans le contexte du droit international, le droit dur comprend des traités ou accords internationaux, ainsi que le droit coutumier international, qui créent des obligations exécutoires et des droits pour les parties (les États) et d'autres entités internationales. Le nonrespect de ces obligations peut entraîner la poursuite de la partie devant des juridictions internationales.

Le « soft law » se réfère à des règles qui ne sont ni strictement obligatoires par nature, ni complètement dépourvus de signification juridique. Dans le contexte du droit international, le «droit mou » 
se réfère à des accords qui consacrent des lignes directrices, des déclarations politiques, des plans d'actions, des stratégies, des guides de bonnes pratiques ou des codes de conduite qui fixent des normes. Cependant, ils ne sont pas directement applicables et leur non-respect ne peut donner lieu à aucune poursuite ou sanction

\section{Les règles juridiques relevant du soft law}

Depuis une cinquantaine d'années, de multiples programmes et actions concrètes ont pourtant été mis en avant en faveur de la conservation et de la gestion directe ou indirecte des récifs coralliens. Toutefois, ces initiatives, sur le plan juridique, relèvent du soft law. Elles ont été mises en œuvre, en termes de droit contraignant, par les recours suivants :

- le plus souvent, la technique juridique des espaces protégés et particulièrement les aires marines protégées (AMP);

- les règles juridiques relatives aux espèces protégées et la protection de la « biodiversité marine » en général ;

- les règles juridiques relatives à la gestion de la pêche et de prévention de la surpêche ;

- les règles destinées à la prévention, à la lutte contre et la réparation des pollutions marines;

- les règles destinées à la lutte contre les espèces exotiques envahissantes;

- les règles de protection du «patrimoine commun » ou « patrimoine mondial »;

- les règles destinées à la promotion du tourisme.

Depuis l'accord de Paris sur le climat et compte tenu des impacts du réchauffement global et de l'acidification des océans, des mesures juridiques de lutte et d'atténuation de ces impacts pourront être utilisées en faveur de la protection des coraux.

\section{Les textes internationaux de soft law mobilisables}

Plusieurs textes de soft law sont applicables en NouvelleCalédonie et mobilisables pour la protection des récifs coralliens. Au niveau international, c'est la France qui signe et ratifie les traités, accords et conventions. Toutes les conventions signées par la France ne sont pas automatiquement applicables en Nouvelle-Calédonie. La protection de la biodiversité étant une matière transférée à la Nouvelle-Calédonie et ses provinces depuis 1988, il faut s'assurer que les accords internationaux y sont bien applicables. C'est le cas notamment des accords suivants, qui peuvent être utilisés pour la protection et la gestion des récifs coralliens :

- le programme MAB, Réserves de biosphère (Unesco, 1971);

- la convention de Ramsar sur les zones humides (1971);

- la convention sur la Protection du patrimoine mondial, culturel et naturel (Unesco, 1972);

- la convention des Nations unies sur le droit de la mer (Unclos, 1982);

- la convention sur la biodiversité (1992);

- la convention internationale pour le contrôle et la gestion des eaux de ballast et sédiments des navires (2004);

- Les objectifs d'Aichi (2010);

- L'Initiative internationale pour les récifs coralliens (ICRI). L'ICRI se définit comme « un partenariat informel entre les Nations et les organisations qui s'efforce de préserver les récifs coralliens et les écosystèmes connexes à travers le monde.

Bien que l'Initiative soit un groupe informel dont les décisions ne lient pas ses membres, ses actions ont été déterminantes pour continuer à souligner globalement l'importance des récifs coralliens et des écosystèmes associés pour la durabilité environnementale, la sécurité alimentaire et le bien-être social et culturel. » ;

- L'agenda 2030 des Nations unies et, en particulier, l'objectif 14 et ses sept sous-objectifs ;

- L'accord de Paris sur le climat (2015).

\section{Les textes nationaux favorables aux récifs coralliens}

Au niveau national, pour ne mentionner que les textes les plus récents, signalons la loi n 2016-1087 pour la reconquête de la biodiversité, de la nature et des paysages. Celle-ci précise, dans son article 113 , que « [p]our stopper la perte de biodiversité en outremer et préserver son rôle en faveur de l'adaptation des territoires 
au changement climatique, l'État se fixe comme objectifs, avec l'appui de ses établissements publics sous tutelle et en concertation avec les collectivités territoriales concernées :

1/ D'élaborer et de mettre en œuvre un programme d'actions territorialisé de protection de 55000 hectares de mangroves d'ici à 2020 ;

2/ D'élaborer, dans le cadre de l'initiative française pour les récifs coralliens et sur la base d'un bilan de l'état de santé des récifs coralliens et des écosystèmes associés réalisé tous les cinq ans, un plan d'action contribuant à protéger $75 \%$ des récifs coralliens dans les outre-mer français d'ici à 2021. »

Si l'article 113, qui relève du soft law, n'a pas été rendu directement applicable en Nouvelle-Calédonie, l'État pourra néanmoins agir - par le biais de ses établissements de recherche, l'Ifrecor ainsi que l'Agence française pour la biodiversité - notamment avec la Nouvelle-Calédonie et ses provinces. Mais on peut également penser que des demandes de financement adressées par les collectivités calédoniennes à l'État pour la protection des mangroves et récifs coralliens de l'archipel recevront, en vertu de cet article 113, une suite favorable.

\section{Les accords régionaux exploitables en Nouvelle-Calédonie}

Au niveau régional, la Nouvelle-Calédonie étant membre à part entière du Programme régional océanien pour l'environnement (PROE) et du forum des îles du Pacifique, les accords et programmes d'action propres à ces organisations régionales peuvent être mis en œuvre en Nouvelle-Calédonie.

À ce jour, au niveau régional, il n'existe aucun texte juridique contraignant en matière de récifs coralliens. À l'occasion du lancement de la $3^{\mathrm{e}}$ année de IYOR (Année internationale des récifs coralliens), les îles Fidji ont fait le choix en janvier 2018, d'appliquer la convention de Ramsar sur les zones humides pour protéger leur grande barrière de corail (Cakaulevu). En effet, dans cette convention, les zones humides bénéficient d'une définition assez large et peuvent donc inclure des sites tels que les récifs coralliens.
En revanche, des documents de soft law existent depuis longtemps et permettent l'adoption de plans d'action en faveur des récifs. Il s'agit d'abord de la convention d'Apia sur la protection de la nature dans le Pacifique Sud (1976) approuvée par la France en 1988 et entrée en vigueur depuis 1990. Il s'agit d'une protection large de l'environnement avec l'incitation à la création d'aires protégées pour la sauvegarde « d'échantillons représentatifs des écosystèmes naturels ».

Ensuite, la convention de Nouméa pour la protection des ressources naturelles et de l'environnement dans la région du Pacifique sud (1986), dite « convention du PROE », inscrit le Pacifique Sud dans le programme des mers régionales du Programme des Nations unies pour l'environnement (PNUE), lancé au début des années 1970. Les mesures de lutte - contre différentes sources de pollution notamment - permettent de prendre des mesures favorables aux récifs coralliens, même s'ils ne sont pas cités dans la convention. Il est intéressant de noter que le PROE a déclaré une année double des récifs (2018-2019) pour promouvoir la protection des récifs coralliens auprès de ses États membres.

\section{Les textes juridiques de Nouvelle-Calédonie}

Dans l'ordre juridique de la Nouvelle-Calédonie, on trouve un certain nombre de textes qui concernent indirectement ou directement les récifs coralliens de l'archipel.

Dans les dispositions générales, il convient de mentionner la loi organique 99-209 modifiée, qui répartit les compétences entre l'État, la Nouvelle-Calédonie et ses provinces. La protection de la biodiversité relève de la compétence normative de chacune des trois provinces, d'où l'existence de trois codes de l'environnement s'appliquant dans la limite de leur périmètre géographique. L'espace maritime ne relevant pas de l'une des provinces et se trouvant dans la limite de la Zone économique exclusive (ZEE) relève de la Nouvelle-Calédonie. Ainsi, les récifs coralliens situés dans le domaine public maritime d'une province relèvent de cette province. Ceux qui sont situés dans la ZEE aujourd' hui relèvent des règles de protection et de gestion adoptées par la Nouvelle-Calédonie. Cela signifie qu'il peut y avoir quatre régimes de protection différents (même s'il existe des mécanismes et espaces de concertation et d'harmonisation 
informels ou formels comme le conservatoire des espaces naturels). À ces différents régimes de droit formel, il convient de mentionner l'existence du droit endogène (règles coutumières) relatif à la gestion des espaces maritimes, faisant partie du foncier coutumier, et qui peut inclure des aires protégées de droit endogène. Leur prise en compte effective par l'ensemble de la population nécessite une formalisation que seule la province des îles Loyauté a expressément acceptée, dans un premier temps sous la forme de la « déclaration commune d'Ouvéa » cosignée par les autorités coutumières et provinciales en 2007 puis dans son Code de l'environnement en 2016.

Au niveau des espaces maritimes relevant de la Nouvelle-Calédonie, la protection des récifs peut s'effectuer dans le cadre des catégories d'aires marines protégées prévues par la délibération 51/CP de 2011. En application de cette délibération a été adopté l'arrêté du 23 avril 2014 pour la création du parc naturel marin dénommé parc naturel de la mer de Corail. Début février 2018, aucune règle concrète de protection spécifique des récifs coralliens n'avait été adoptée.

La Nouvelle-Calédonie intervient également dans la protection des coraux dans le cadre de sa compétence en matière de commerce extérieur avec l'interdiction, depuis 2009, de l'exportation de coraux. Enfin, il faut rappeler que la compétence (partagée avec l'État) sur les relations extérieures à l'échelle de la région Pacifique donne la possibilité de conclure des accords bilatéraux et multilatéraux en matière de protection des récifs coralliens. Les provinces quant à elles interviennent dans la protection juridique des récifs coralliens au travers des différentes dispositions de leurs Codes de l'environnement respectifs (aires protégées, espèces protégées, luttes contre les pollutions...).

Parmi les mesures qui concernent spécifiquement les coraux et qui relèvent du droit contraignant, il faut mentionner les dispositions du titre III du livre 2 du Code de l'environnement de la province Sud consacrées à la conservation des «écosystèmes d'intérêt patrimonial », parmi lesquels les récifs coralliens de plus $100 \mathrm{~m}^{2}$.

On le voit, les textes juridiques contraignants imposant des droits et obligations exécutoires spécifiques aux récifs coralliens n'existent pas ou sont rares. Il faut d'autant plus s'en émouvoir lorsque l'on sait que la protection, notamment par le mécanisme des aires protégées, n'est pas toujours satisfaisante (chap. 43) ni par celui des luttes contre les pollutions.

La $3^{e}$ année internationale des récifs doit servir à étudier la possibilité d'une convention internationale sur les récifs coralliens incluant ses déclinaisons régionales, nationales et locales, avec des dispositions contraignantes pour les protéger efficacement. La reconnaissance de la personnalité juridique de l'océan et des éléments de la biodiversité marine - tels que les récifs coralliens, qui bénéficieraient alors de droits propres - serait un véritable progrès.

\section{Références bibliographiques}

BEURIER J.-P., 1994 Le droit de la protection des coraux et des espèces menacées de disparition en zone tropicale, Revue Juridique de l'Environnement, numéro spécial « Droit de l'environnement en Amérique tropicale $\gg: 57-77$.

BEURIER J.-P., 2007 «La protection juridique de la biodiversité marine ». In Pour un droit commun de l'environnement : mélanges en l'honneur de Michel Prieur. Paris, Dalloz : 803-815.

BURKE L. et al., 2012 Récifs coralliens en péril revisité. Synthèse à l'intention des décideurs. World Resources Institute. Washington D.C. https://www.wri.org/sites/default/files/recifs_coralliens_en_peril_revisite.pdf LEFEBVRE C., 2010 Protection et préservation du milieu marin : « Les apports des conventions régionales sur les mers aux dispositions de la convention des Nations unies sur le droit de la mer », VertigO, hors-série, 8 :

http://journals.openedition.org/vertigo/10288;

PAIVA TOLEDO A. (de), 2016 La protection juridique internationale de la biodiversité marine. Veredas do Direito, Belo Horizonte, 13 (27) : 31-62. http://dx.doi.org/10.18623/rvd.v13i27.924

SALVAT B. et WILKINSON C., 2008 L'initiative récifs coralliens pour le Pacifique (programme Crisp) : bilan des connaissances acquises, Le Journal de la Société des Océanistes, 126-127 :

http://journals.openedition.org/jso/4792; DOI : 10.4000/jso.4792 (mis en ligne le 15 déc. 2011, consulté le 15 fév. 2018).

STAHL L., 2017 L'outre-mer et la loi pour la reconquête de la biodiversité, de la nature et des paysages, Revue juridique de l'environnement, 42 (1): 95-109 : https://www.cairn.info/revue-revue-juridique-de-l-environnement2017-1-page-95.htm 


\section{Chapitre 46 \\ Les récifs et lagons néo-calédoniens au patrimoine mondial de l'Unesco}

Myriam Marcon

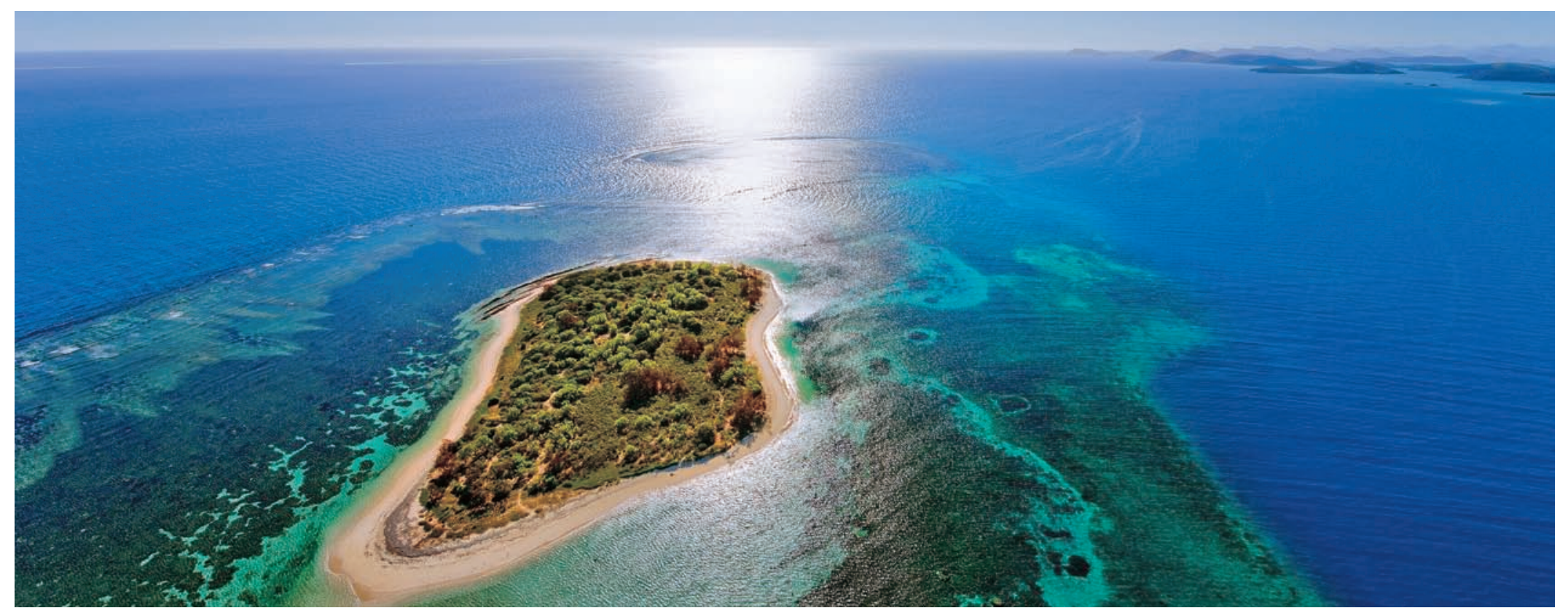

Ilot N'dué, lagon Sud. ๑ P.-A. Pantz

\section{Une reconnaissance internationale vectrice d'actions et de cohésion}

« Les lagons de Nouvelle-Calédonie : diversité récifale et écosystèmes associés » ont rejoint la prestigieuse Liste du patrimoine mondial en 2008. Grâce à un important soutien de l'Initiative française pour les récifs coralliens (Ifrecor), les acteurs néo-calédoniens se sont fédérés et ont présenté une candidature collégiale.

Depuis, les efforts et engagements autour de la protection des récifs, élément majeur du bien inscrit, n'ont cessé de se multiplier. Alors qu'on ne comptait qu'un comité de gestion au moment de l'inscription, ce sont aujourd'hui 13 comités de gestion qui sont au chevet des zones composant le bien. Représentatifs des populations locales (secteurs coutumier, institutionnel, économique, touristique, de l'enseignement, associatif, etc.), ils élaborent et mettent en œuvre les plans de gestion des différentes zones composant le bien, dont la finalité principale est le maintien de l'intégrité de ce dernier. En 10 ans, dix plans de gestion ont ainsi vu le jour.

\section{Un travail en réseaux pour plus d'efficacité}

L'existence du Conservatoire d'espaces naturels (CEN), structure notamment en charge de la coordination pour la gestion du bien 


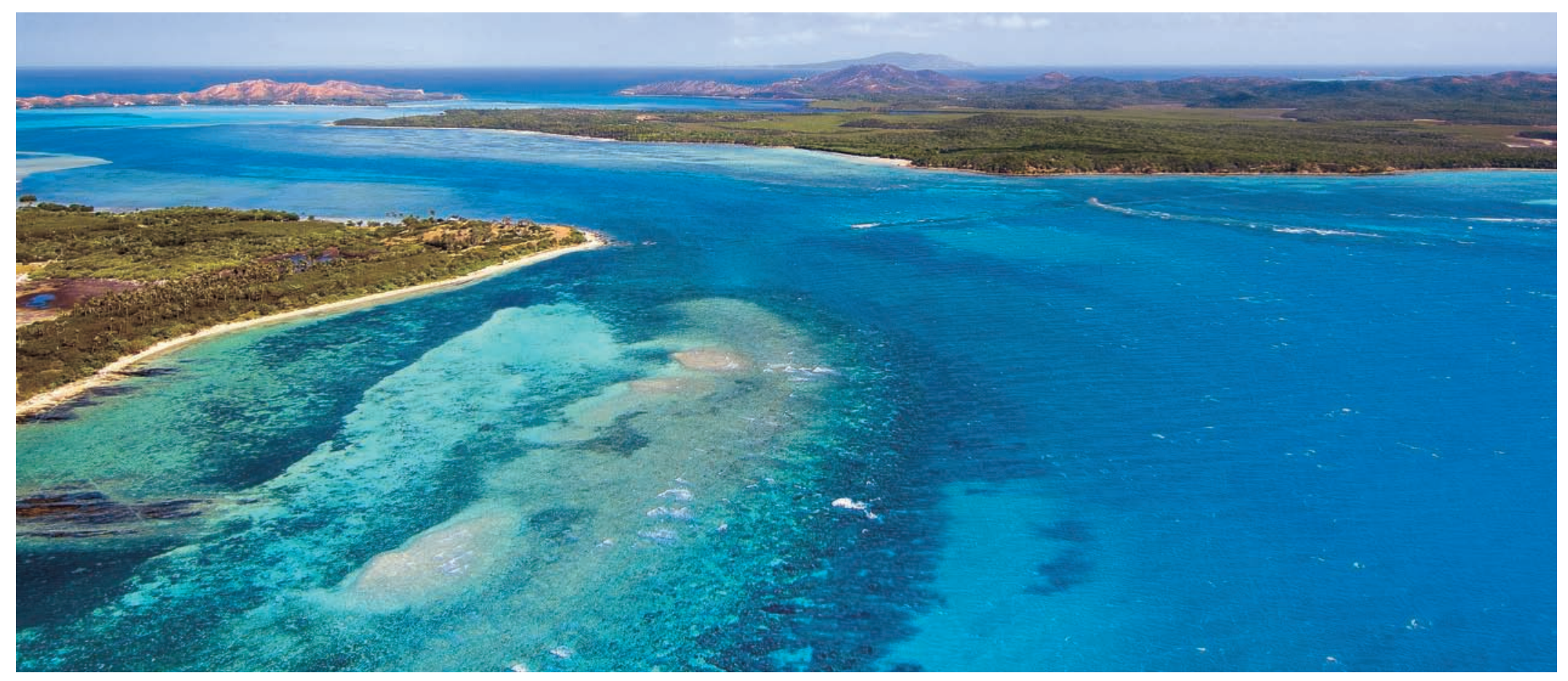

Boat Pass, lagon Nord. ๑ P.A. Pantz

néo-calédonien inscrit au patrimoine mondial, permet d'offrir une plateforme d'échanges entre les gestionnaires. Depuis sa création, le CEN s'attache à produire des outils d'animation de réseau : le forum des comités de gestion, les formations, l'organisation d'échanges d'expériences sont autant de moyens de renforcer les compétences des comités de gestion et d'accroître l'efficacité des actions.

Des supports de communication et de sensibilisation variés, élaborés par le CEN, permettent de promouvoir la convention du patrimoine mondial et $d$ 'inciter à de bonnes pratiques. On citera par exemple « Mon nom est lagons », une vidéo visant à sensibiliser les touristes, ou l'exposition « Les gardiens du trésor », autant d'outils mis à disposition des acteurs néo-calédoniens impliqués dans la gestion de ce patrimoine.

L'inscription sur la Liste du patrimoine mondial permet également aux parties prenantes de Nouvelle-Calédonie de bénéficier des expériences d'autres gestionnaires de sites marins dans le monde. Les conférences organisées par le Centre du patrimoine mondial sont des opportunités d'échanges très riches, notamment sur les problématiques d'échelle mondiale, comme le changement climatique, le tourisme de croisières, etc.

L'Ifrecor, coordonnée localement par le CEN depuis 2016, est une plateforme supplémentaire pour engager des réflexions et des actions en faveur de la protection des récifs et des écosystèmes associés.

\section{Attention les yeux !}

Avec cette inscription au patrimoine mondial, une attention accrue est prêtée aux lagons et récifs de Nouvelle-Calédonie. Les populations, les institutions, les associations, les chercheurs, accordent aujourd'hui plus que jamais une vigilance renforcée à ce joyau reconnu de tous. 


\section{Épilogue}

\section{En Nouvelle-Calédonie, la mer ne sépare pas les hommes, elle les lie}

Didier Poidyaliwane, membre du gouvernement en charge des affaires coutumières, de l'écologie, du développement durable, des relations avec le Sénat coutumier et des conseils coutumiers, des terres coutumières

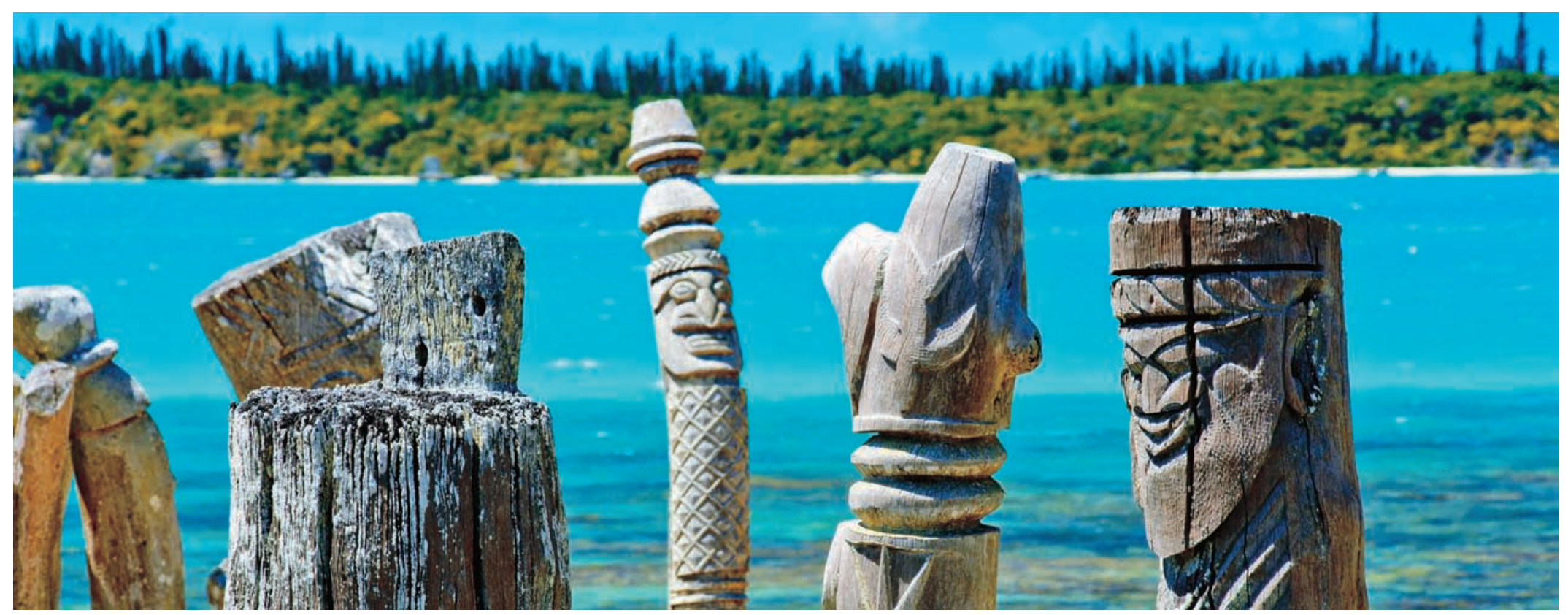

Totems de St. Maurice, île des Pins. @ P.A. Pantz

Cet ouvrage nous rappelle que la Nouvelle-Calédonie représente un espace maritime exceptionnel et comprend un littoral développé, de grands lagons et des récifs coralliens d'une biodiversité de premier ordre. Il nous montre aussi que l'écosystème corallien résulte d'interactions permanentes entre la mer et la terre et que l'accroissement démographique et le développement des activités humaines ont engendré au fil du temps des transformations qui ont laissé quelques stigmates. En dépit d'un environnement globalement encore bien préservé, la Nouvelle-Calédonie n'échappe pas à l'évolution sociale et économique du monde avec ce qu'elle a de positif mais aussi de négatif pour l'environnement marin.
Comme indiqué au long des chapitres, cet écosystème extraordinaire de richesses et de diversités est, du fait de sa nature complexe, fragile et vulnérable. Les processus d'adaptation et de résilience sont eux aussi complexes et les recherches sur la résistance des communautés coralliennes aux modifications de l'environnement et aux changements climatiques en sont encore à leurs balbutiements. L'ouvrage met en particulier en lumière le site unique de Bouraké où coraux et mangroves parviennent à vivre dans des conditions proches de celles prédites pour la fin de ce siècle. Cet exceptionnel observatoire naturel devrait permettre à l'avenir aux scientifiques de mieux comprendre les capacités d'adaptation des 
coraux et alimenter cette fois avec des données grandeur nature, les modèles prédictifs qui ne se basent pour l'heure que sur des mesures en laboratoire, réduisant ainsi les incertitudes sur les projections et les scénarios futurs.

L'écosystème corallien représente pour les Calédoniens un patrimoine naturel et culturel fondamental et vital, il nourrit les hommes dans tous les sens et participe pleinement à la construction des codes de fonctionnement des sociétés et de leurs identités. Le continuun écologique mis en avant par les scientifiques tout le long de l'ouvrage connu dans la culture Kanak a été façonné pendant des millénaires d'une manière équilibrée entre la nature et les Hommes. L'approche n'est pas rompue par la mort puisque des nombreuses zones «tabou » ou « cimetières » des esprits des morts sont fréquentes dans le lagon autour de la Grande Terre et les Îles loyauté.

Edifiées, codifiées et cartographiées depuis longtemps, des règles de partage, de protection des territoires par les groupes claniques et tribaux coexistent et parfois se chevauchent avec les règles institutionnelles de gestion des espaces.

Les savoirs des populations en lien avec la nature et ceux des scientifiques doivent relever les défis à venir de coproduire des normes mieux ajustées aux enjeux écologiques et socio-culturels.

Les paysages marins offrent par leur beauté et leur diversité un terreau fertile à de nouvelles initiatives porteuses d'avenir pour le développement harmonieux de la Nouvelle-Calédonie. Aussi leur maintien en bon état écologique conditionne-t-il cette réussite. Conscients de cet enjeu, les services en charge de la gestion de l'environnement ont mis en place depuis deux décennies un réseau d'aires marines protégées, accompagné de textes réglementant les espèces iconiques et menacées ainsi que les activités dans ces espaces protégés. L'accession au label patrimoine mondial de plus de la moitié des surfaces de récifs et lagons ceinturant la Grande Terre a marqué un virage dans les actions de conservation avec la mise en place de comités de gestion dans chacune des aires protégées. Après dix ans d'existence, 13 comités de gestion et plusieurs associations fédérés autour des collectivités, du Gouvernement et du Conservatoire des Espaces Naturels agissent pour la protection de ces lagons et récifs. Le gouvernement de la
Nouvelle-Calédonie a souhaité aller plus loin en créant en avril 2014 le parc naturel de la mer de Corail, qui englobe toute la zone économique exclusive calédonienne et représente une des aires marines protégées les plus étendues de la Planète. La récente validation d'un plan de gestion et les divers arrêtés qui en découleront réglementeront les activités au sein de cet espace. La sanctuarisation des récifs isolés du très grand plateau des Chesterfield-Bellona à l'ouest de la Grande Terre et des récifs de Pétrie et de L'Astrolabe à l'est devrait limiter les impacts des activités humaines sur ces milieux exceptionnels et préservés.

Mais le défi le plus difficile à relever sera sans doute celui d'un développement d'usages durables, responsables et respectueux à la fois de la nature et des hommes. Certains chapitres de cet ouvrage ont montré que les activités touristiques et de loisirs, essentielles pour l'économie du pays et son ouverture au monde, ne sont pas exemptes d'implications dans la dégradation des écosystèmes récifolagonaires, que ce soit par la construction d'infrastructures ou par les activités déployées dans le lagon.

La diversité biologique en général et celle associée aux récifs coralliens en particulier représentent un atout majeur pour le développement de la Nouvelle-Calédonie. Beaucoup reste encore à découvrir et à comprendre de cet espace qui s'étend depuis les abysses colonisés par des coraux profonds jusqu'aux eaux claires des lagons qui abritent une multitude de coraux constructeurs de récifs. Cet écosystème, qui constitue également un patrimoine immatériel, source de savoirs, de mythes, de légendes et de rites, nécessite un recensement précis des savoirs traditionnels avant qu'ils ne s'éteignent avec les Anciens.

Les écrits rassemblés dans cet ouvrage témoignent à la fois des efforts de recherche et des échanges entre disciplines différentes que le lagon a su faire dialoguer dans le souci de mieux comprendre pour mieux préserver ce bien commun. Le parc naturel de la mer de Corail, condensé de vie, source de bio-inspiration et enjeu de territoire et de liens, inscrit désormais la Nouvelle-Calédonie dans une politique ambitieuse de préservation et d'utilisation durable de l'espace océanique et place notre petit archipel du Pacifique dans le grand concert mondial des nations maritimes. 


\section{Glossaire}

Accrétion : constitution et accroissement d'un organisme en général calcaire (coraux, algues) ou d'une structure (récif).

ADN : acide désoxyribonucléique, support universel de l'information génétique chez les êtres vivants, transmis d'une génération à la suivante par la reproduction.

Aire marine protégée (AMP) : espace maritime et/ou littoral délimité dans l'espace et le temps, visant la protection de l'environnement naturel, et où les pratiques sont spécifiquement réglementées.

Allochtone : originaire d'un autre endroit.

Anthropique : qualifie toute forme provoquée directement ou indirectement par l'action de l'homme.

Autochtone : originaire de cet endroit.

Beachrocks : ce grès de plage est une roche sédimentaire qui se forme dans la zone littorale par cimentation rapide du sable ou des débris coquillers ou coralliens sur une plage, parallèlement au rivage, au niveau de la zone de déferlement des vagues ou de balancement des marées.

Benthique : qualifie les organismes et les processus qui ont un lien avec le fond des océans.

Bioaccumulation des métaux : capacité des coraux à absorber et à concentrer les métaux dans leurs différents compartiments (tissu animal, Symbiodinium et squelette).

Biocénose : aussi appelée « communauté », elle correspond à l'ensemble des êtres vivants (animaux, végétaux, microorganismes, etc.) établis dans un même milieu, ou biotope.
Biodétritique : qualifie des sédiments constitués de bioclastes, débris d'organismes vivants tels que les squelettes de coraux et de coquillages, et apportés mécaniquement sur un lieu.

Biome : vaste région biogéographique s'étendant sous un même climat, comme le récif corallien.

Biote : ensemble des organismes vivants (flore, faune et champignons ainsi que les micro-organismes...) présents dans un habitat (naturel, semi-naturel), biotope particulier, lieu ou région précise.

Bloom : terme anglais pour « efflorescence », qui correspond à une augmentaiton relativement rapide de l'abondance d'une ou plusieurs espèces.

Bold : Barcoding of life datasystems, base de données et d'analyse des barcodes ADN de tous les êtres vivants, hébergée par l'université de Guelph au Canada.

Cambrien : plus ancienne des six périodes géologiques du Paléozoïque qui s'étend de 541 à 485,4 millions d'années.

Cayes : petits ilots de sable ou de corail.

Chaîne alimentaire : suite de relations alimentaires existant entre les organismes (chaque consommateur mange une proie ou une ressource non vivante qui le précède).

Creek : petit cours d'eau à sec en période de sécheresse.

Diazotrophe : organisme capable de produire (indirectement) des substances protéiques à partir de l'azote gazeux (N2) présent dans l'atmosphère et l'environnement. 
Échinoderme : embranchement d'animaux marins présents à toutes les profondeurs océaniques, qui regroupent les étoiles de mer (astérides), les oursins (échinides), les concombres de mer (holothuries), les crinoides et les ophiures.

Enzyme : protéine dotée de propriétés catalytiques, capable d'accélérer une transformation de composés.

Éocène : période géologique d'il y a 56,0 à 33,9 millions d'années marquée par l'émergence des premiers mammifères modernes et une extinction massive d'espèces.

Eutrophisation : déséquilibre du milieu provoqué par l'augmentation de la concentration d'azote et de phosphore.

Fréquentation : niveau d'usage mesuré sous la forme d'un nombre ou d'une densité d'usagers.

Géomorphologie : étude de l'évolution des formes et des reliefs de la surface de la terre et des causes de celle-ci.

Gestion participative : mode de gestion impliquant l'ensemble des parties concernées.

Grand Nouméa : agglomération regroupant les communes de Nouméa, Dumbéa, Païta et du Mont-Dore.

Hétérotrophie : nécessité d'un organisme de se nourrir uniquement de matière organique constituant ou ayant constitué d'autres organismes.

Holocène : époque géologique s'étendant sur les 10000 dernières années et dernière période du Quaternaire.

Ichthyofaune : partie de la faune rassemblant les poissons.

Indicateur : mesure d'un phénomène ou d'un effet, qui dépend du protocole d'observation et du mode de calcul mis en œuvre.
Inventaire de la biodiversité : établissement de la liste des espèces rencontrées dans un milieu donné.

Isotope : atome d'un même élément qui contient un nombre identique de protons mais un nombre différent de neutrons.

Klippe : partie d'une nappe de charriage isolée du reste de celle-ci par l'effet de l'érosion.

Longévive: se dit d'un animal dont la durée de vie persiste de façon durable.

Manteau : partie du globe terrestre située entre la croûte et le noyau.

Mésozoïque : ère géologique, anciennement appelée ère secondaire, qui s'étend de 252 à 66 millions d'années.

Miocène : époque géologique qui s'étend de 23 à 5,3 millions d'années.

Mitochondrie : organelle présente dans toutes les cellules des êtres vivants appelés eucaryotes, qui possèdent un noyau cellulaire.

Neutraceutique : se dit d'un produit alimentaire vendu sous forme de comprimé ou autre présentation pharmaceutique et ayant des effets positifs sur la santé.

Nudibranches : animaux marins appartenant aux mollusques, sans coquille, dont les branchies sont à nu.

Oligocène : époque géologique qui s'étend de 33,9 à 23,03 millions d'années, caractérisée par la rareté d'apparition de nouveaux mammifères.

Paléozoïque : ère géologique, appelée aussi ère primaire qui a duré près de 300 millions d'années et qui s'étend de 542 à 251 millions d'années. Pédivéligère : stade de développement larvaire qui voit l'apparition d'un pied grâce auquel la larve se fixera. 
Pélagique : qualifie les organismes et les processus qui ont un lien avec la colonne d'eau sans relation avec le fond.

Péridotite : roche magmatique composée essentiellement de cristaux d'olivines et de pyroxènes et qui constitue la majeure partie du manteau supérieur de la terre.

Phanérogame : végétal possédant des fleurs et des graines.

Pinacle : édifice corallien qui s'élève du fond du lagon jusqu'à la surface.

Plaisance : activité pratiquée pour des loisirs avec des embarcations nautiques (voiliers, bateaux à moteurs, barques).

Protocole d'observation : méthode d'acquisition de données sur le terrain.

Quaternaire : période géologique la plus récente sur l'échelle des temps géologiques, qui a débuté il y a 2,6 millions d'années.

Réseau trophique : ensemble de chaînes alimentaires qui relient les organismes et par lequel est assurée la circulation de matière et d'énergie dans un écosystème. De nombreux êtres vivants peuvent appartenir à plusieurs chaînes alimentaires et à plusieurs niveaux dans la chaîne alimentaire.

Réserve intégrale : territoire naturel intégralement protégé, où aucune activité n'est autorisée pour préserver et gérer des ressources naturelles remarquables ou menacées.

Résilience : capacité d'un écosystème, d'un habitat, d'une population ou d'une espèce à retrouver un fonctionnement et un développement normal après avoir subi une perturbation environnementale importante.

Senne : très long filet à maille simple.
Socio-écosystème : système intégrant les sphères sociales et environnementales ainsi que leurs interrelations.

Symbiodinium : microalgue vivant au sein des tissus coralliens et capable de réaliser la photosynthèse, appelée communément zooxanthelle.

Symbiote : organisme vivant avec un autre d'une espèce différente et dont chacun tire un avantage souvent vital.

Tanne : zone herbacée ou inondable se développant aux abords de la mangrove.

Trochophore : phase larvaire chez certains invertébrés (mollusques) caractérisée par une forme de toupie.

Typologie : méthode de classement en groupes relativement homogènes se distinguant les uns des autres par leurs caractéristiques.

Ultramafique (ou ultrabasique) : se dit de roches magmatiques très pauvres en silice (moins de $45 \%$ ) et contenant plus de $90 \%$ de minéraux riches en fer et magnésium.

Usages récréatifs : activités pratiquées pour le seul plaisir des usagers, sans but lucratif ni de subsistance.

Véligère : stade larvaire des mollusques issus de la larve trochophore.

Zooplanctonophage : organisme se nourrissant de migroorganismes constituant le zooplancton.

Zooxanthelle : algue unicellulaire, appartenant au genre Symbiodinium, vivant en symbiose avec différents invertébrés marins comme les coraux, les bénitiers, ainsi qu'avec de nombreuses espèces d'anémones de mer, de méduses. 


\section{Sigles et acronymes}

ACNC : Alis Current of New Caledonia

AGDR : Aire de gestion durable des ressources

AMP : Aires marines protégées

APA : Accès et partage des avantages

Bold : Barcoding of life datasystems

CEM : Convention espèces migratrices

CEN : Conservatoire d'espaces naturels

CITES : Convention internationale sur le commerce des espèces menacées

CPS : Communauté du Pacifique

DBN : Dynamic Bayesian Network (RBD en français, pour Réseau bayésien dynamique)

DDUNI : Direction pour le développement des usages numériques innovants (de l'IRD)

DENV : Direction de l'ENV (province Sud de la Nouvelle-Calédonie)

DFA : Direction du foncier et de l'aménagement

Dimenc : Direction de l'industrie, des mines et de l'énergie de la Nouvelle-Calédonie

DITTT : Direction des infrastructures, de la topographie et des transports terrestres

DTSI : Direction des technologies et des services de l'information

EAC : Courant est australien

ECC : Courant est calédonien

Enso : El Niño-Southern Oscillation

Espam : Espèces emblématiques, acceptation sociale et durabilité des aires marines protégées (projet de recherche financé par la Fondation de France coordonné par C. Sabinot)

GBIF : Global Biodiversity Information Facility

GCRMN : Global Coral Reef Monitoring Network

GIEC : Groupe d'experts intergouvernemental sur l'évolution du climat GOPS : Grand observatoire de la biodiversité terrestre et marine du Pacifique sud et sud-ouest
Ifrecor : Initiative française pour les récifs coralliens

INPN : Inventaire national du patrimoine naturel

IRD : Institut de recherche pour le développement

IRENav : Institut de recherche de l'école navale

ISEE : Institut de la statistique et des études économiques de la Nouvelle-Calédonie

IUCN : Union internationale pour la conservation de la nature

JAXA : Agence spatiale exploration japonaise

MNHN : Muséum national d'histoire naturelle

MODC : Matière organistique dissoute colorée

Modis : Spectroradiomètre imageur à résolution modérée

Nasa : Agence spatiale nationale américaine

$\mathrm{NCJ}$ : Jet nord calédonien

Oblic : Observatoire du littoral de Nouvelle-Calédonie

OEIL : Observatoire de l'environnement en Nouvelle-Calédonie

ONB : Observatoire national de la biodiversité

Oreanet : Oceania Regional Acanthaster Network

PAD : Plan d'actions dugong

PNUE : Programme des Nations unies pour l'environnement

PROE : Programme régional océanien pour l'environnement

RORC : Réseau d'observation des récifs coralliens de Nouvelle-

Calédonie

SCJ : Jet sud calédonien

SEC : Courant sud équatorial

SIV : Service innovation et valorisation

Snom : Substances naturelles d'origine marine

SPN : Service du patrimoine naturel

STCC : Contre courant subtropical

UICN : Union internationale pour la conservation de la nature

Vahine : Variability of Vertical and Trophic Transfer of Diazotrophderived Nitrogen in the South West Pacific

ZEE : Zone économique exclusive 


\section{Auteurs}

\section{Mehdi Adjeroud}

Biologie des coraux

IRD

UMR Entropie (Université de La Réunion, CNRS, IRD),

Université de Perpignan

52, avenue Paul Alduy

66860 Perpignan, France

\section{Laure André}

Biologie marine

UMR Entropie (Université de La Réunion, CNRS, IRD)

98848 Nouméa, Nouvelle-Calédonie

\section{Serge Andréfouët}

Ecologie récifale, dynamiques spatiales

\section{IRD}

UMR Entropie (Université de La Réunion, CNRS, IRD)

BP A5

98848 Nouméa, Nouvelle-Calédonie

\section{Rémi Andreoli}

Télédetection

Bluecham SAS

BP A5

98800 Nouméa, Nouvelle-Calédonie

\section{Jérôme Aucan}

Physique océanographique

IRD

UMR LEGOS (Université Paul Sabatier-Toulouse III, CNES, CNRS, IRD)

BP A5

98848 Nouméa, Nouvelle-Calédonie

\section{Mar Benavides}

Biologie océanographique

IRD

UMR MIO (IRD, CNRS, Aix-Marseille Université)

98848 Nouméa, Nouvelle-Calédonie

\section{Francesca Benzoni}

Taxonomie des coraux, écologie récifale

UMR Entropie (Université de La Réunion, CNRS, IRD)

BP A5

98848 Nouméa, Nouvelle-Calédonie

Department of Biotechnologies and Biosciences

University of Milano-Bicocca

Piazza della Scienza 2

20126 Milan, Italie

\section{Tom Biscéré}

Biologie marine

IRD

UMR Entropie (Université de La Réunion, CNRS, IRD)

BP A5

98848 Nouméa, Nouvelle-Calédonie

\section{Sophie Bonnet}

Biologie océanographique

IRD

UMR MIO (IRD/CNRS/Aix-Marseille Université)

Campus de Luminy, Case 901,

13288 Marseille 9, France 


\section{Xavier Bonnet}

Biologie de la conservation des reptiles

Centre d'études biologiques de Chizé

CNRS UMR 7372-Université de La Rochelle

405, Route de La Canauderie

79360 Villiers-en-Bois, France

\section{Philippe Borsa}

Génétique des populations

IRD

UMR Entropie (Université de La Réunion, CNRS, IRD)

911, avenue Agropolis

34394 Montpellier, France

\section{Séverine Bouard}

Géographie et agro-économie

IAC

Équipe TerAU «Territoires, acteurs et usages »

Institut agronomique néocalédonien, Centre de recherches nord Thierry Mennesson

BP 6

98825 Pouembout, Nouvelle-Calédonie

\section{Philippe Bouchet}

Malacologie

MNHN

UMR ISYEB (CNRS, MNHN, UPMC, EPHE)

Muséum national d'histoire naturelle CP 50

45, rue Buffon

75005 Paris, France

\section{Karen Bourgeois}

Écologie, oiseaux marins

IRD

IMBE, UMR CNRS 7263/IRD 237/AMU/UAPV

BP A5

98848 Noumea, Nouvelle-Calédonie

\section{Loïc Bourgine}

Filière pêche

Direction du développement économique et de l'environnement de la province Nord

BP 41

98860 Koné , Nouvelle-Calédonie

\section{Marine Julie Briand}

Écologie marine

UMR MIO (IRD, CNRS, Aix-Marseille Université)

Aix-Marseille Université

163 avenue de Luminy

13009, Marseille, France

\section{François Brischoux}

Biologie évolutive des squamates

Centre d'études biologiques de Chizé

CNRS UMR 7372-Université de La Rochelle

405 , route de Prissé-la-Charrière

79360 Villiers-en-Bois, France

\section{Mercedes Camps}

Biologie océanographique

IRD

UMR MIO (IRD, CNRS, Aix-Marseille Université)

BP A5

98848 Nouméa, Nouvelle-Calédonie

\section{Laure Carassou}

Biologie marine, écologie intégrative

Unité de recherche «Écosystèmes aquatiques et changements globaux » (EABX), Irstea Bordeaux

50, avenue de Verdun

33612 Cestas, France

\section{Stéphanie M. Carrière}

Ethnoécologie

IRD

UMR GRED (IRD, UM3)

911, avenue Agropolis

34394 Montpellier, France 


\section{Pascale Chabanet}

Écologie des poissons récifaux

IRD

UMR Entropie (Université de La Réunion, CNRS, IRD)

Université de La Réunion

15, avenue René Cassin

97744 Saint-Denis 9, La Réunion

\section{Adrien Cheype}

Développement logiciels

IRD

BP A5

98848 Nouméa, Nouvelle-Calédonie

\section{Espérance Cillauren \\ Géographie}

IRD

UMR Espace pour le Développement (IRD/Université Montpellier/Université de La Réunion/Université des Antilles et de la Guyane) Maison de la télédétection 500 , rue J.-F. Breton

34093 Montpellier, France

\section{Christophe Cleguer}

Biologie des mammifères marins

Cetacean Research Unit, School of Veterinary and Life Sciences

Murdoch University

South Street, Murdoch WA

\section{Emmanuel Coutures}

Direction de l'environnement

Centre administratif de la province Sud (CAPS) Artillerie

6 , route des Artifices,

98800 Nouméa, Nouvelle-Calédonie

\section{Gilbert David}

Géographie

IRD

UMR Espace pour le Développement (IRD/Université

Montpellier/Université de La Réunion/Université des Antilles et de la Guyane)

Maison de la télédétection

500 , rue J.-F. Breton

34093 Montpellier, France

\author{
Victor David \\ Juriste \\ IRD \\ UMR GRED (IRD, UPMV Montpellier) \\ BP A5 \\ 98848 Nouméa - Nouvelle-Calédonie
}

\section{Marlène Dégremont}

Anthropologie

IRD

UMR GRED (IRD, UPMV Montpellier)

BP A5

98848 Nouméa, Nouvelle-Calédonie

\section{Térence Desclaux}

Physique océanographique

Ifremer,

Unité de Recherche «Lagons, écosystèmes et aquaculture durable » BP A5

98848 Nouméa, Nouvelle-Calédonie

\section{Pascal Douillet}

Physique océanographique

IRD

UMR MIO (IRD, CNRS, Aix-Marseille Université)

BP A5

98848 Nouméa, Nouvelle-Calédonie

\section{Marion Drouzy}

Physique océanographique

Analytical and Environmetal Laboratory (AEL)

BP A5

98800 Nouméa, Nouvelle-Calédonie

\section{Pascal Dumas}

Biologie marine

IRD

UMR Entropie (Université de La Réunion, CNRS, IRD)

BP A5

98848 Nouméa, Nouvelle-Calédonie 


\section{Cécile Dupouy}

Biologie océanographique

IRD

UMR MIO (IRD, CNRS, Aix-Marseille Université)

BP A5

98848 Nouméa - Nouvelle-Calédonie

\section{Richard Farman}

Aquarium des Lagons

BP 8185

98807 Nouméa, Nouvelle-Calédonie

\section{Cécile Fauvelot}

Génétique des populations

IRD

UMR Entropie (Université de La Réunion, CNRS, IRD)

Laboratoire d'océanographie de Villefranche

181, chemin du Lazaret

06230 Villefranche-sur-Mer, France

\section{Jocelyne Ferraris}

Biostatistique

IRD

UMR Entropie (Université de La Réunion, CNRS, IRD)

Université de Perpignan

52, avenue Paul Alduy

66860 Perpignan, France

\section{Sylvie Fiat}

Ingéniérie bases de données

IRD

UMR Entropie (Université de La Réunion, CNRS, IRD)

BP A5

98848 Nouméa, Nouvelle-Calédonie

\section{Renaud Fichez}

Biogéochimie marine

IRD

UMR MIO (IRD, CNRS, Aix-Marseille Université)

Campus de Luminy

Oceanomed

13288 Marseille, France

\section{Camille Fossier}

Ethnoécologie et anthropologie

IRD

UMR Espace pour le développement (IRD/Université

Montpellier/Université de La Réunion/Université des

Antilles/Université de la Guyane)

BP A5

98848 Nouméa, Nouvelle-Calédonie

\section{Manuel Garcin}

Géologie

BRGM/Direction risques et prévention/Unité Risques côtiers et changement climatique

3, avenue Claude Guillemin

BP 6009, 45060 Orléans, France

\section{Claire Garrigue}

Étude des mammifères marins

IRD

UMR Entropie (Université de La Réunion, CNRS, IRD)

BP A5

98848, Nouméa, Nouvelle-Calédonie

\section{Julie Gaubert}

Écologie marine

IRD

UMR Entropie (Université de La Réunion, CNRS, IRD)

BP A5

98848, Nouméa, Nouvelle-Calédonie

\section{Antoine Gilbert}

Biologie marine et halieutique

Ginger Soproner

BP 3583

98846 Nouméa, Nouvelle-Calédonie

\section{Claire Goiran}

Biologie marine

UNC

ISEA Université de la Nouvelle-Calédonie

BP R4

98851 Nouméa, Nouvelle-Calédonie 


\section{Charles Gonson}

Écologie statistique, conservation de la biodiversité

LEAD, Ifremer Nouvelle-Calédonie

UMR Entropie (Université de La Réunion, CNRS, IRD)

\section{BP A5}

98848 Nouméa, Nouvelle-Calédonie

\section{Olivier Grosso}

Ingénieur en géochimie

CNRS

UMR MIO (IRD, CNRS, Aix-Marseille Université)

Campus de Luminy, Oceanomed

13288 Marseille, France

\section{Nicolas Guillemot}

Halieutique

Dexen

BP 32401

98897 Nouméa, Nouvelle-Calédonie

\section{Jean-Brice Herrenschmidt}

Géographie, développement durable

GIE Océanide

IRD

BP A5

98848 Nouméa, Nouvelle-Calédonie

\section{Fanny Houlbrèque}

Écophysiologie des coraux

IRD

UMR Entropie (Université de La Réunion, CNRS, IRD) BP A5

98848 Nouméa, Nouvelle-Calédonie

\section{Maël Imirizaldu}

Conservation du milieu marin et conservation internationale Tours de Magenta, Bâtiment P2

BP 14124

Nouméa, Nouvelle-Calédonie

\section{Luen lopué}

Étude de la biodiversité

Province des îles Loyauté

BP 50 Wé

98820 Lifou, Nouvelle-Calédonie

\section{Pascale Joannot}

Biologie marine

MNHN

57, rue Cuvier

75005 Paris, France

Isabelle Jollit

Géographie

IRD

UMR Entropie (Université de La Réunion, CNRS, IRD)

BP A5

98848 Nouméa, Nouvelle-Calédonie

\section{Jean-Baptiste Juhel}

Écologie marine, fonctionnement des communautés

Université de Montpellier

UMR Marbec (IRD, UM, Ifremer, CNRS)

Place Eugène Bataillon

34095 Montpellier, France

\section{Matthieu Juncker}

Écologie marine

Observatoire de l'Environnement

31 rue Kervistin

98800 Nouméa, Nouvelle-Calédonie

\section{Sophie Katrawi}

Service des milieux et ressources aquatiques (SMRA)

Hôtel de la province Nord

41, avenue Jimmy Welepane

98860 Koné, Nouvelle-Calédonie 


\section{Julie-Anne Kerandel}

Direction des affaires maritimes de la Nouvelle-Calédonie Service pêche et environnement marin (DAM-NC/SPE)

2 bis, rue Félix Russeil

BP 36

Nouméa, Nouvelle-Calédonie

\section{Floriane Kombouare}

Enquête culturelle

Département Patrimoine et recherche

ADCK-Centre culturel Tjibaou

Rue des accords de Matignon

BP 378

98845 Nouméa, Nouvelle-Calédonie

\section{Michel Kulbicki}

Écologie des poissons

IRD

UMR Entropie (Université de La Réunion, CNRS, IRD)

\section{UPVD}

52, avenue Paul Alduy

66860 Perpignan, France

\section{Laura Lagourgue}

Phycologie

IRD

UMR Entropie (Université de La Réunion, CNRS, IRD)

BP A5

98848 Nouméa, Nouvelle-Calédonie

\section{Jérôme Lefèvre}

Physique océanographique

IRD

UMR Legos (Université Paul Sabatier Toulouse III, CNES, CNRS, IRD)

BP A5

98848 Nouméa, Nouvelle-Calédonie

\section{Romain Le Gendre}

Physique océanographique

Ifremer,

Unité de Recherche «Lagons, écosystèmes et aquaculture durable » BP A5

98848 Nouméa, Nouvelle-Calédonie

\section{Pierre-Yves Le Meur}

Anthropologie

IRD

UMR GRED (IRD, UM3)

911, avenue Agropolis

BP 64501

34394 Montpellier, France

\section{Marc Léopold}

Halieutique

IRD

UMR Entropie (Université de La Réunion, CNRS, IRD)

Institut halieutique et des sciences marines

Université de Toliara

Madagascar

\section{Yves Letourneur}

Écologie marine

Institut Isea

Université de la Nouvelle-Calédonie,

BP R4

Avenue James Cook

98851 Nouméa, Nouvelle-Calédonie

\section{Claire Levacher}

Anthropologie

IAC

Équipe TerAU «Territoires, acteurs et usages » Institut agronomique néocalédonien, Centre de recherches nord Thierry Mennesson

BP 6

98825 Pouembout, Nouvelle-Calédonie 


\section{Didier Lille}

Télédetection

Bluecham SAS

BP A5

98800 Nouméa, Nouvelle-Calédonie

\section{Anne Lorrain}

Écologie marine

IRD

UMR Lemar (IRD/CNRS/Ifremer

Technopole Brest Iroise

29280 Plouzané, France

\section{Julie Mallet}

Entrepreunariat

IAC

Équipe TerAU «Territoires, acteurs et usages » Institut agronomique néocalédonien

Centre de Recherches Nord Thierry Mennesson

BP 6

98825 Pouembout, Nouvelle-Calédonie

\section{Morgan Mangeas}

Mathématicien

IRD

UMR Espace pour le Développement (IRD/Université Montpellier/Université de La Réunion/Université des Antilles/Université de la Guyane)

Centre IRD

BP A5

98848 Nouméa, Nouvelle-Calédonie

\section{Myriam Marcon}

Gestion du bien inscrit au patrimoine mondial Conservatoire d'espaces naturels BP 10

98860 Koné, Nouvelle-Calédonie

\section{Chloé Martias}

Biogéochimie marine

IRD

UMR MIO (IRD, CNRS, Aix-Marseille Université)

BP A5

98848 Nouméa, Nouvelle-Calédonie

\section{Lydiane Mattio}

Phycologie,

CSIRO,

Indian Ocean Marine Research Center (IOMRC)

WA6009 Crawley (Perth) - Australia

\section{Jeanne de Mazières}

Projet «Connaissance biodiversité marine » UMS PAtriNat (ex SPN) MNHN/CNRS/AFB

36, rue Geoffroy Saint-Hilaire

75005 Paris, France

\section{Christophe Menkès}

Physique océanographique

IRD

URM LOCEAN (Université Pierre et Marie Curie, CNRS, IRD, MNHN) BP A5

98848 Nouméa, Nouvelle-Calédonie

\section{Marie-Hélène Merlini}

Communication

Direction des affaires maritimes de la Nouvelle-Calédonie

Service pêche et environnement marin (DAM-NC/SPE)

BP 36

98845 Nouméa, Nouvelle-Calédonie

\section{Valentine Meunier}

Biologie marine

IRD

UMR Entropie (Université de La Réunion, CNRS, IRD)

BP A5

98848 Nouméa, Nouvelle-Calédonie 


\section{Gérard Mou-Tham}

Étude des poissons

IRD

UMR Entropie (Université de La Réunion, CNRS, IRD) BP A5

98848 Nouméa, Nouvelle-Calédonie

\section{Marc Oremus}

Génétique (spécialité mammifères marins)

WWF-France en Nouvelle-Calédonie

Rue du Mont-Té

BP 692

98845 Nouméa, Nouvelle-Calédonie

\section{Gustav Paulay \\ Biologie marine \\ Florida Museum of Natural History \\ Université de Floride \\ Gainesville FL32611-7800, USA}

\section{Claude E. Payri}

Biologie marine, phycologie

IRD

UMR Entropie (Université de La Réunion, CNRS, IRD) BP A5

98848 Nouméa, Nouvelle-Calédonie

\section{Christophe Peignon}

Biologie marine,

IRD

UMR Entropie (Université de La Réunion, CNRS, IRD) BP A5

98848 Nouméa, Nouvelle-Calédonie

\section{Ambre Piémontois}

Anthropologie

UMR Espace pour le développement (IRD/Université de Montpellier/Université de La Réunion/Université des Antilles/Université de la Guyane)

BP A5

98848 Nouméa, Nouvelle-Calédonie

\section{Bernard Pelletier}

Géologie

IRD

UMR Géoazur (Université de Nice-Sophia Antipolis, CNRS, IRD, OCA) BP A5

98848 Nouméa, Nouvelle-Calédonie

\section{Dominique Pelletier}

Biostatistique et biodiversité

Ifremer

BP 2059

98846 Nouméa, Nouvelle-Calédonie

\section{Sylvain Petek}

Chimie des substances naturelles marines

IRD

UMR LEMAR (IRD, CNRS, UBO, Ifremer)

Institut Universitaire Européen de la Mer

Rue Dumont d'Urville - 29280 Plouzané, France

\section{Ambre Piémontois}

Anthropologie

UMR Espace pour le développement (IRD/Université de Montpellier/Université de La Réunion/Université des Antilles/Université de la Guyane)

BP A5

98848 Nouméa, Nouvelle-Calédonie

\section{Laurent Poncet}

Pilotage centre de données

UMS PAtriNat MNHN/CNRS/AFB

CP 41

36 rue Geoffroy Saint-Hilaire, 75005 Paris

\section{Dominique Ponton}

Biologie marine (spécialité poissons)

UMR Entropie (Université de La Réunion, CNRS, IRD)

97420 Le Port, La Réunion 


\section{Tyffen Read}

Biologie marine (spécialité tortues)

Aquarium des Lagons

BP 8185

98807 Nouméa, Nouvelle-Calédonie

\section{Estienne Rodary}

Géographe

IRD

UMR Gouvernance Risque Environnement Développement

(IRD/UPMV Montpellier)

BP A5

98848 Nouméa, Nouvelle-Calédonie

\section{Martine Rodier}

Océanographie et chimie

UMR EIO (UPF, Ifremer, IRD, ITLM)

Université de la Polynésie française

BP 6570

98702 Faa'a Tahiti, Polynésie française

\section{Riccardo Rodolfo-Metalpa}

Changement climatique

IRD

UMR Entropie (Université de La Réunion, CNRS, IRD)

BP A5

98848 Nouméa, Nouvelle-Calédonie

\section{Catherine Sabinot}

Ethnoécologie et anthropologie

UMR Espace pour le développement (IRD/Université de Montpellier/Université de La Réunion/Université des

Antilles/Université de la Guyane)

BP A5

98848 Nouméa, Nouvelle-Calédonie

\section{Christophe Sand}

Archéologie

Institut d'archéologie de la Nouvelle-Calédonie et du Pacifique 65, rue Teyssandier de Laubarède 98800 Nouméa, Nouvelle-Calédonie

\section{Richard Shine}

Biologie de l'évolution (spécialité reptiles)

School of Biological Sciences

A 08

Université de Sydney

NSW 2006, Australie

\section{Georgeta Stoica}

Anthropologie

IRD

UMR Entropie (Université de La Réunion, CNRS, IRD)

Université de Perpignan

52, avenue Paul Alduy

66860 Perpignan, France

\section{Josina Tiavouane}

Écologie marine

IRD

UMR Entropie (Université de La Réunion, CNRS, IRD)

BP A5

98848 Nouméa, Nouvelle-Calédonie

\section{Emmanuel Tjibaou}

Patrimoine et recherche

Agence de développement de la culture kanak (ADCK)

Rue des Accords de Matignon

BP 378

98845 Nouméa, Nouvelle-Calédonie

\author{
Laura Tremblay-Boyer \\ Halieutique \\ CPS \\ BP D5 \\ 98848 Nouméa, Nouvelle-Calédonie
}




\section{Éléonore Vandel}

Délégation à l'outre-mer

MNHN

Espèces exotiques envahissantes

Muséum départemental du Var

737, chemin du Jonquet

83200 Toulon, France

\section{Myriam Vendé-Leclerc}

Géomatique et géologie

Dimenc

Service de la géologie de la Nouvelle-Calédonie BP N2

98849 Nouméa, Nouvelle-Calédonie

\section{Éric Vidal}

Invasions biologiques et conservation

IRD

IMBE, UMR CNRS 7263/IRD 237/AMU/APV

BP A5

98848 Nouméa, Nouvelle-Calédonie

\section{Christophe Vieira}

Phylogénétique et phycologie

Université de Gand

Groupe de recherche en Phycologie

UMR Entropie (Université de La Réunion, CNRS, IRD)

BP A5

98848 Nouméa, Nouvelle-Calédonie

\section{Laurent Vigliola}

Ecologie des poissons récifaux

IRD

UMR Entropie (Université de La Réunion, CNRS, IRD)

BP A5

98848 Nouméa, Nouvelle-Calédonie

\section{Laurent Wantiez}

Biologie marine

Université de la Nouvelle-Calédonie BP R4

98851 Nouméa, Nouvelle-Calédonie

\section{Guillaume Wattelez}

Mathématique et informatique

Université de la Nouvelle-Calédonie

BP R4

98851 Nouméa, Nouvelle-Calédonie

\section{Antoine Wickel}

Géographie

GIE Océanide

IRD

BP A5

98848 Nouméa, Nouvelle-Calédonie

\section{Simon van Wynsberge}

Biologie des populations et écologie IRD

UMR Entropie

BP A5

98848 Nouméa, Nouvelle-Calédonie 